Biological Report 90(12)

December 1990

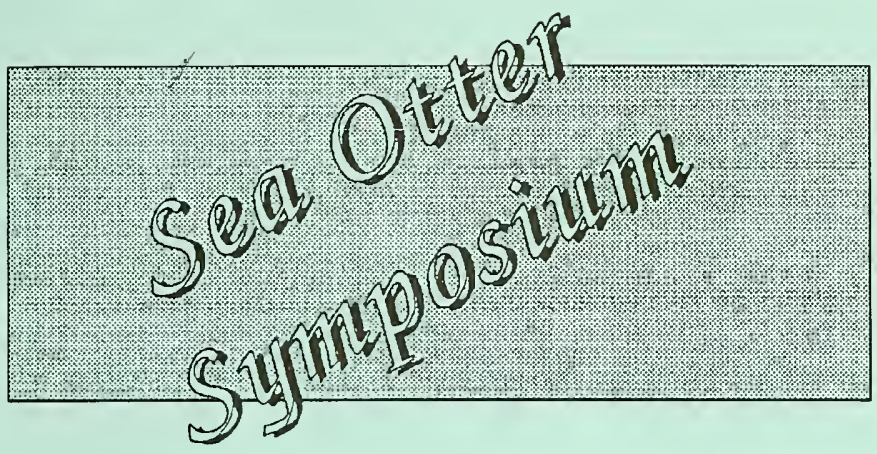

Sea Otter Symposium: Proceedings of a Symposium to Evaluate the Response Effort on Behalf of Sea Otters After the T/N Exxon Valdez Oil Spill Into Prince William Sound, Anchorage, Alaska, 17-19 April 1990

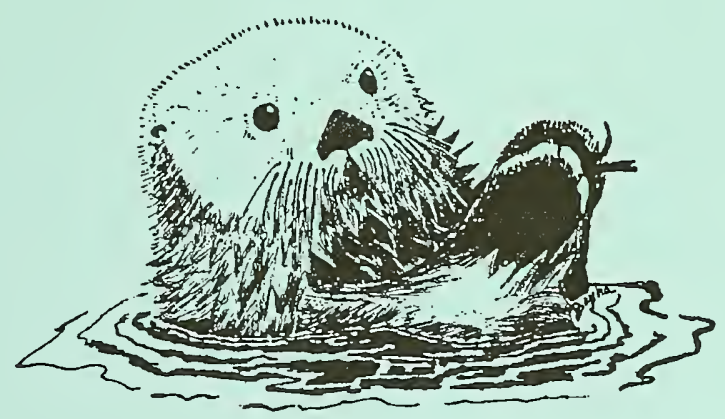

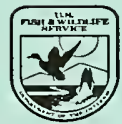

U.S. Department of the Interior Fish and Wildlife Service Washington, D.C. 20240

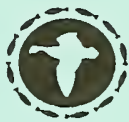

National Fish and Wildlife Foundation 18 th and C Streets, N.W. Washington, D.C. 20240 


\section{Biological Report}

This publication series of the Fish and Wildlife Service comprises reports on the results of research, developments in technology, and ecological surveys and inventories of effects of land-use changes on fishery and wildlife resources. They may include proceedings of workshops, technical conferences, or symposia; and interpretive bibliographies.

Copies of this publication may be obtained from the Publications Unit, U.S. Fish and Wildlife Service, 1849 C Street, N.W., Mail Stop 130-ARLSQ, Washington, DC 20240, or may be purchased from the National Technical Information Service (NTIS), 5285 Port Royal Road, Springfield, VA 22161.

\section{Sea Otter Symposium Steering Committee}

\author{
Keith Bayha, Symposium Chair \\ Mark Bartholomew \\ Pamela Bergmann \\ Amy Christiansen \\ Randall Davis \\ Anthony DeGange \\ Ramona Haebler \\ Robert Hardy \\ Mary Hogan
}

\author{
Jennifer Kormendy \\ Calvin Lensink \\ Lloyd Lowry \\ Rosa Meehan \\ Nancy Michaelson \\ James Styers \\ Jon Thomas \\ John Watts \\ Terrie M. Williams
}

\section{ISSN 0895-1926}

\section{This publication may be cited as:}

Bayha, Keith, and Jennifer Kormendy, Technical Coordinators. 1990. Sea Otter Symposium: Proceedings of a symposium to evaluate the response effort on behalf of sea otters after the T/V Exxon Valdez oil spill into Prince William Sound, Anchorage, Alaska, 17-19 April 1990. U.S. Fish Wildl. Serv., Biol. Rep. 90(12). 485 pp. 


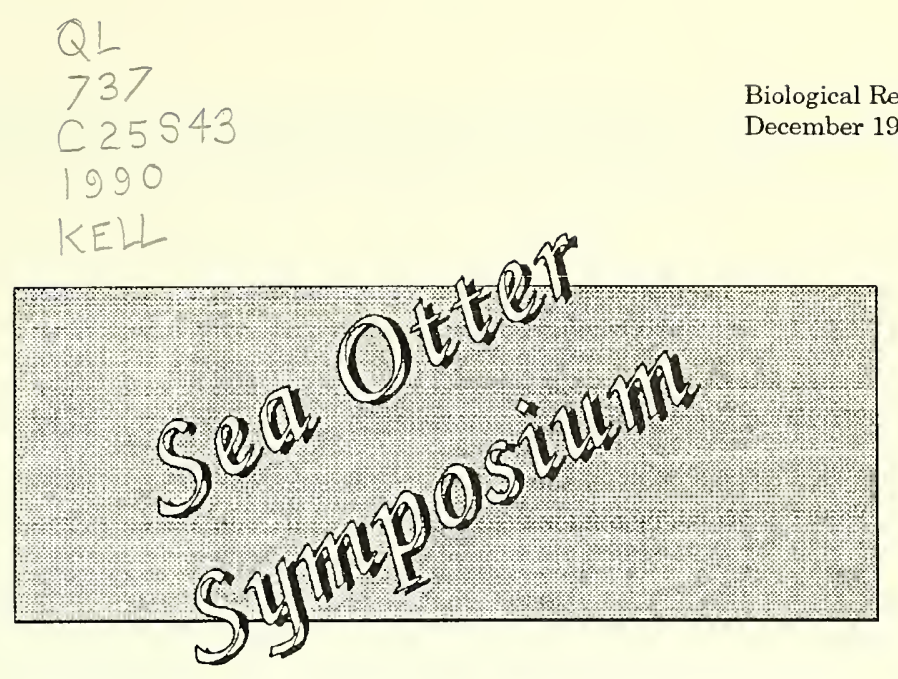

\title{
Sea Otter Symposium: Proceedings of a Symposium to Evaluate the Response Effort on Behalf of Sea Otters After the T/V Exxon Valdez Oil Spill Into Prince William Sound, Anchorage, Alaska, 17-19 April 1990
}

\author{
by
}

Keith Bayha and Jennifer Kormendy, Technical Coordinators and Editors

U.S. Fish and Wildlife Service

1011 East Tudor Road

Anchorage, Alaska 99503

U.S. Department of the Interior

Fish and Wildlife Service Washington, D.C. 20240
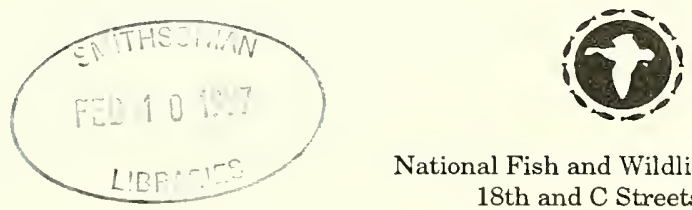

National Fish and Wildlife Foundation 18 th and C Streets, N.W. Washington, D.C. 20240 


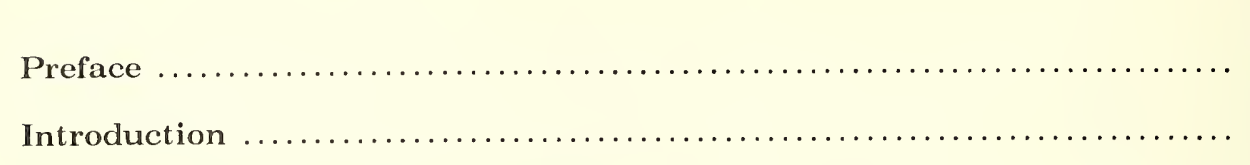

\section{Summary of Sea Otter Rescue Inventory}

\section{Opening Address}

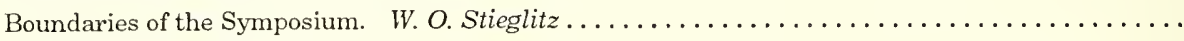

\section{Introductory Session}

Movement of Oil Spilled From the T/V Exxon Valdez. J. A. Galt and D. L. Payton ..............

Distribution and Relative Abundance of Sea Otters in South-central and Southwestern Alaska Before or at the Time of the T/V Exxon Valdez Oil Spill. A. R. DeGange, D. H. Monson,

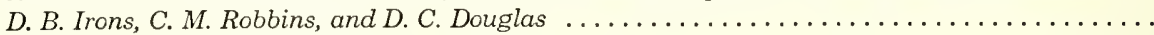

Role of the U.S. Fish and Wildlife Service in the Sea Otter Rescue. K. Bayha ..............

Alaska's Role in Mitigating the Effects of the T/N Exxon Valdez Oil Spill on Sea Otters. L. F.

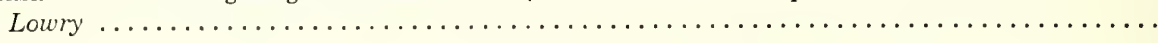

Press Interest in Sea Otters Affected by the T/V Exxon Valdez Oil Spill: A Star is Born. B. T.

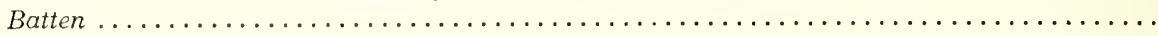

\section{Capture Session}

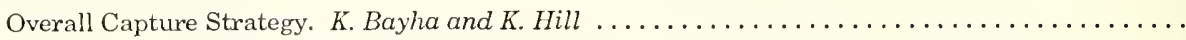

Evaluation of Sea Otter Capture After the T/V Exxon Valdez Oil Spill, Prince William

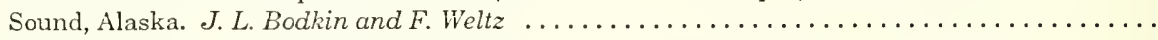

Sea Otter Capture Along the Kenai Peninsula. R. L. Britton, C. T. Benz, and J. J. Foster .........

Sea Otter Survey and Capture Effort, Kodiak Island Archipelago and Alaska

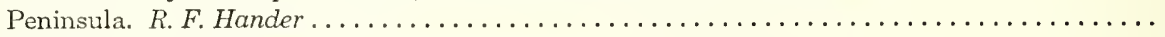

Transportation of Sea Otters to Rehabilitation Centers. D. W. Cramer .................

Field Test for Detecting Crude Oil on the Fur of Sea Otters. K. Hill and P. A. Tuomi ..........

Analysis of Sea Otter Fur for Crude Oil Contamination. D. C. Perrollaz and J. A. Rash (abstract) .

Distribution, Age, and Sex Composition of Sea Otter Carcasses Recovered During the Response to the T/V Exxon Valdez Oil Spill. A. R. DeGange and C. J. Lensink ...............

Capture of Lightly Oiled Sea Otters for Rehabilitation: A Review of Decisions and

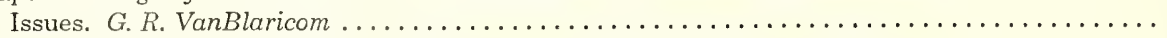

mpetus for Capturing, Cleaning, and Rehabilitating Oiled or Potentially Oiled Sea

Otters After the T/V Exxon Valdez Oil Spill. J. Ames ........................... 


\section{Rehabilitation Session A: Facilities and Records}

History of the Sea Otter Rehabilitation Centers. R. W. Davis and J. Styers . . . . . . . . . 142

Valdez Otter Rehabilitation Center. R. W. Davis and T. M. Williams . . . . . . . . . . . 158

Seward Otter Rehabilitation Center. J. Styers and T. McCloskey . . . . . . . . . . . . 167

Homer Temporary Care Facility and Jakolof Pre-Release Facility. L. Redman . . . . . . . . . . . 172

Record Keeping for an Otter Rehabilitation Center. S. F. Loshbaugh . . . . . . . . . . . . . . 182

Animal Rehabilitation Center Data Base. D. J. Swarthout . . . . . . . . . . . . . . . . . . . . 224

\section{Rehabilitation Session B: Husbandry}

Clinical Evaluation and Cleaning of Sea Otters Affected by the T/V Exxon Valdez Oil Spill. T. M. Williams, J. McBain, R. K. Wilson, and R. W. Davis . . . . . . . . . . ... 236

Coat Gradation and Conditioning of Sea Otters at the Seward Otter Rehabilitation Center. J. A. Rash, C. R. McCormick, R. Alexander, S. J. Nichol, and D. C. Perrollaz . . . . . . . 258

Husbandry at the Valdez Otter Rehabilitation Center. P. A. Tuomi . . . . . . . . . . . . . . 274

Husbandry at the Seward Otter Rehabilitation Center. J. Otten . . . . . . . . . . . . . 285

Pup Nursery at the Seward Otter Rehabilitation Center. D. Styers and C. R. McCormick ...... 301

Behavioral Observations of Rehabilitating Sea Otters in Prerelease Holding Pens. N. E.

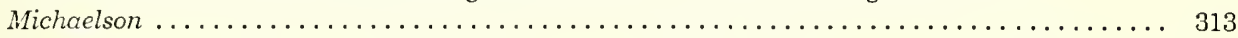

Food Procurement and Feeding of Sea Otters During the T/N Exxon Valdez Oil Spill. P. Ferrante . 321

\section{Veterinary Procedures Session}

Postcapture Supportive Care of Oil-contaminated Sea Otters. J. F. Thomas .............

Clinical Treatment and Rehabilition of Sea Otters. R. K. Wilson, C. R. McCormick, T. D.

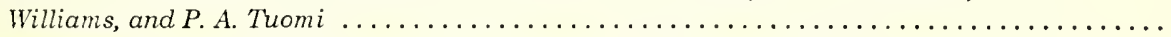

Perspectives of Veterinary Technicians. L. L. Kelly, A. M. Green, and B. W. Miller .............

Chemical Restraint and Anesthesia of Sea Otters Affected by the Oil Spill in Prince

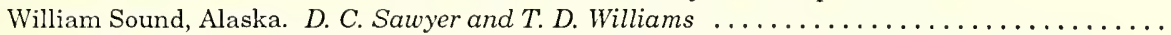

Blood Collection and Analysis During the T/V Exxon Valdez Oil Spill. T. D. Williams and R. K.

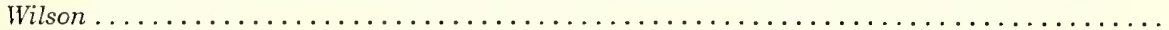

Identification of a Herpes-like Virus in Sea Otters During Rehabilitation After the T/V Exxon Valdez Oil Spill. R. K. Harris, R. B. Moeller, T. P. Lipscomb, R. J. Haebler, P. A. Tuomi, C. R. McCormick, A. R. DeGange, D. Mulcahy, T. D. Williams, and J. M. Pletcher . . . . . . . .

Pathological Examination and Collection of Toxicological Samples From Sea Otters. R. J. Haebler, R. K. Harris, J. M. Pletcher, R. B. Moeller, T. P. Lipscomb, M. Bates, and C. Armitstead

\section{Release Session}

Development of the Release Strategy for Rehabilitated Sea Otters. A. G. Rappoport, M. E. Hogan,

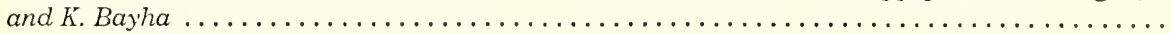

Hazards of Releasing Rehabilitated Animals With Emphasis on Sea Otters and the

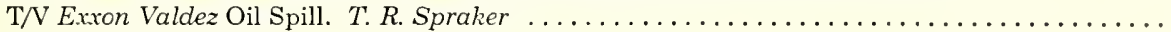

Determining Health of Rehabilitated Sea Otters Before Release. R. J. Haebler, R. K. Wilson, and

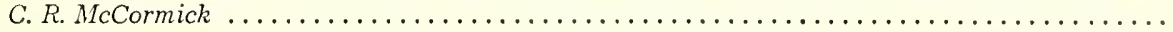

Procedures and Rationale for Marking Sea Otters Captured and Treated During the T/V Exxon Valdez Oil Spill. A. R. DeGange and T. D. Williams ..................... 
Postrelease Monitoring of Radio-instrumented Sea Otters in Prince William Sound, C. W.

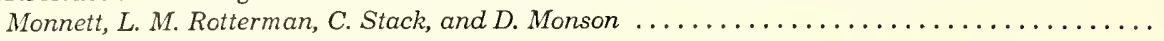

Sea Otter Release Site Selection and Postrelease Activities Along the Kenai Peninsula, Alaska. E. Sharpe . . . . . . . . . . . . . . . . . . . . . . . . . . .

Transfer and Placement of Nonreleasable Sea Otters in Aquariums Outside Alaska. J. A. Gruber and M. E. Hogan

Protecting Sea Otters From Oil Spills: Recommendations Based on the Alaska

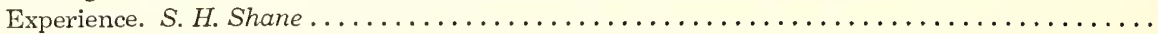

\section{Introduction to Workshops}

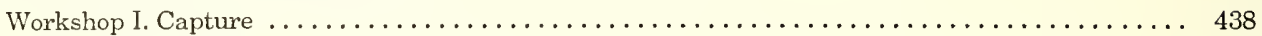

Workshop II. Facilities $\ldots \ldots \ldots \ldots \ldots \ldots \ldots \ldots \ldots \ldots \ldots \ldots \ldots \ldots \ldots \ldots \ldots \ldots \ldots \ldots \ldots \ldots \ldots \ldots$

Workshop III. Husbandry $\ldots \ldots \ldots \ldots \ldots \ldots \ldots \ldots \ldots \ldots \ldots \ldots \ldots \ldots \ldots \ldots \ldots \ldots \ldots \ldots \ldots \ldots$

Workshop IV. Veterinary Procedures $\ldots \ldots \ldots \ldots \ldots \ldots \ldots \ldots \ldots \ldots \ldots \ldots \ldots \ldots \ldots \ldots \ldots \ldots \ldots$

Workshop V. Release .................................... 457

Acknowledgments . . . . . . . . . . . . . . . . . . . . . . . 467

Appendix A. Sea Otter Response: Chronology of Events, 1989 . . . . . . . . . . . 469

Appendix B. Index to Authors $\ldots \ldots \ldots \ldots \ldots \ldots \ldots \ldots \ldots \ldots \ldots \ldots \ldots \ldots \ldots \ldots \ldots$

Appendix C. List of Peer Reviewers $\ldots \ldots \ldots \ldots \ldots \ldots \ldots \ldots \ldots \ldots \ldots \ldots \ldots \ldots$

Appendix D. Registered Participants .......................... 480 
The T/V Exxon Valdez grounded on Bligh Reef in Prince William Sound, Alaska, in the early morning of 24 March 1989, spilling 11 million gallons of toxic crude oil into pristine Prince William Sound.

As part of the response effort, a sea otter (Enhydra lutris) rescue was begun. The effort continued until 11 September 1989 at a cost reported to be in excess of $\$ 8$ million. The rescue was precedent setting in several ways: the magnitude of the effort-as many as 14 capture crews at one time were spread over 400 nautical miles from the spill site to the Shelikof Strait, the number of animals handled (454) and people involved (more than 430), the techniques and equipment tested, and the apparent success-197 sea otters released into the wild.

The U.S. Fish and Wildlife Service, with assistance from nearly every sector that participated in the response, evaluated the rescue effort in a symposium in April 1990. The papers presented and the five concurrent workshop syntheses serve to document the effort, evaluate what was learned, and offer recommendations.

The summary table included here is intended to provide the reader ready access to the number of sea otters handled. 
SUMMARY OF SEA OTTER RESCUE INVENTORY

Captured from Wild

Released/Escaped from Boats

Died on Boats

Sent to shore alive

Died in Seward or Kodiak w/o entry

Released from Kodiak Temp. Care Fac.

Snipped to SORC but not logged in!

Born in Captivity

Total in Bio-Data Base

In VORC Bio-Data Base (assigned VA非s)

In SORC Bio-Data Base (assigned SWłs)

In Bio-Data Base retaining H作

Total in Bio-Data Base
Zone of Origin

\begin{tabular}{|c|c|c|c|}
\hline PWS & Kenai & Kodiak & Total \\
\hline Zone & Zone & Zone & \\
\hline$\overline{158}$ & $\overline{219}$ & 59 & $\overline{436}$ \\
\hline-14 & -42 & -31 & -87 \\
\hline-3 & -2 & 0 & -5 \\
\hline \multirow[t]{4}{*}{$\overline{141}$} & $\overline{175}$ & $\overline{28}$ & $\overline{344}$ \\
\hline & -1 & -2 & -3 \\
\hline & & -1 & -1 \\
\hline & & -1 & -1 \\
\hline+2 & +16 & +0 & +18 \\
\hline$\overline{143}$ & $\overline{190}$ & $\overline{24}$ & $\overline{357}$ \\
\hline \multirow[t]{3}{*}{143} & 13 & & 156 \\
\hline & 163 & 24 & 187 \\
\hline & 14 & & 14 \\
\hline$\overline{143}$ & $\overline{190}$ & $\overline{24}$ & $\overline{357}$ \\
\hline
\end{tabular}

Balancing the Temporary Care Facilities (TCF) Inventory

In Kodiak Inventory (assigned K非s)

In Homer PRF inventory (assigned H非)

Total arrived from field to TCF

Tnru Homer to VORC w/o H非 (VA非s)

Thru Homer Assigned H非

To VORC from Homer PRF (VA非s)

Plus one died in route ( $H$ 非)

To SORC from Homer PRF (SWls)

Died at TCF (H非) (K非s)

To Jakolof directly ( H非s)

Born at Homer TCF to Homer mothers(H非)

Total given H位 at Homer TCF

Total assigned H非 at Jakolof PRF

Born at Jakolof to Homer mothers

Born at Jakolof to Seward mothers

Rogues at Jakolof in Inventory

Released from Kodiak Temp. Care Fac.

Shipped to SORC but not logged in!
28

26

18

$\frac{-2}{16}$

$-4$

$-1$

$-7$

$-1$

$\frac{+1}{18}$

28

$-2$

$-3$

$$
\begin{array}{ll}
\frac{8}{+1} & \\
+2 & \\
+5 & \\
& -1 \\
& -1
\end{array}
$$


SUMMARY OF SFA OTTER RESCUE INVENTORY (page 2)

To SORC from Homer TCF, given SW" s To SORC from Kodiak TCF, given SW $\mathrm{s}$ From field direct to SORC, given SW"s Born in captivity, given SWP \#s In SORC Bio-Data Base (assigned SWks)

To VORC from Homer TCF given VA非

To VORC via Seward pre-SORC given VA非

To VORC from PWS capture boats

To VORC from Cordova citizen (VA非)

Rogue volunteer at VORC (VA非)

Births at VOKC given VA非
In VORC Bio-Data Base (assigned VA非)

\begin{tabular}{|c|c|c|c|}
\hline $\begin{array}{l}\text { PWS } \\
\text { Zone }\end{array}$ & $\begin{array}{l}\text { Kenai } \\
\text { Zone }\end{array}$ & $\begin{array}{l}\text { Kodiak } \\
\text { Zone }\end{array}$ & Total \\
\hline \multirow{7}{*}{ Zone } & 8 & & 8 \\
\hline & & 24 & 24 \\
\hline & 143 & & 143 \\
\hline & 12 & & 12 \\
\hline & $\overline{163}$ & $\overline{24}$ & 187 \\
\hline & 6 & & 6 \\
\hline & 7 & & 7 \\
\hline 139 & & & 139 \\
\hline 1 & & & 1 \\
\hline 1 & & & 1 \\
\hline 2 & & & 2 \\
\hline$\overline{143}$ & $\overline{13}$ & & $\overline{156}$ \\
\hline 21 & $\begin{array}{l}-19 \\
99\end{array}$ & -2 & \\
\hline
\end{tabular}

Transferred from SORC to VORC(kept S
Transferred from SORC to Jalolof PRF

\section{Summary of Births in Captivity}

Born at:

Seward ORC

Valdez

Homer Temp. Care Facility

Jakolof Pre-Release Facility

Totals

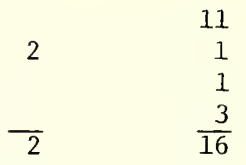

11

1

$\frac{3}{16}$
11

3

1

$\frac{3}{18}$

\section{Summary of Deaths in Captivity}

\author{
Died at: Valdez ORC \\ Seward ORC \\ Died at Jakolof PRF \\ Died at Homer TCF \\ Died enroute Homer to VORC
}

Total

\begin{tabular}{rr}
81 & 3 \\
0 & 29 \\
& 2 \\
& 1 \\
81 & 1 \\
\hline 36
\end{tabular}

0

84

635

2

2

$\begin{array}{r}1 \\ 1 \\ \hline 123\end{array}$ 
SUMMARY OF SEA OTTER RESCUE INVENTORY (page 3)

Zone of Origin

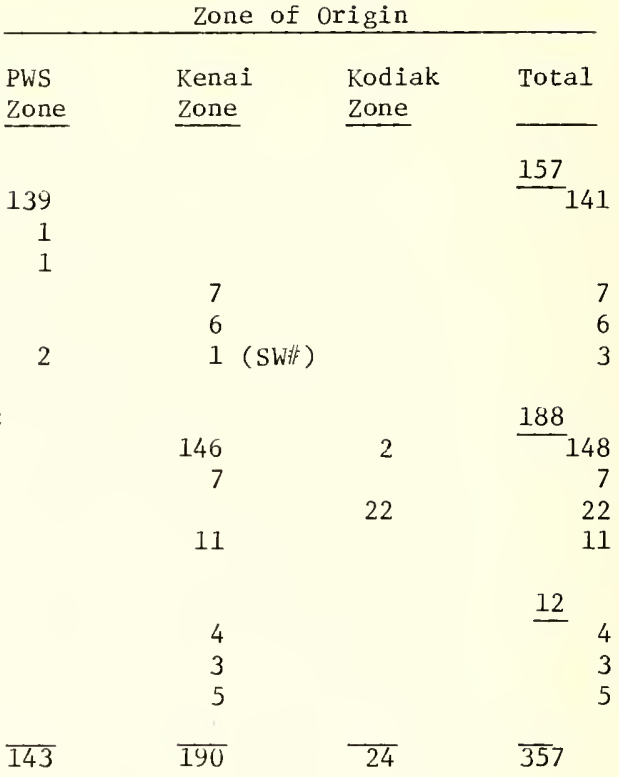

Died at facilities:

Valdez ORC

81

Seward ORC

0

Died at Jakolof PRF

Died at Homer TCF

Died enroute Hower to VORC

Total

orca Inlet non-spill otter

Valdez Harbor "volunteer"

Thru Seward pre-SORC

Arrived from Homer TCF

Born at VORC to mothers from

Arrived directly from field

pup):

Arrived from Hower TCF

Arrived from Kodiak TCF

from

Direct from Homer TCF

Born at Jakolof PRF

TOTAL "arrived alive inventory"

143

$\overline{8 I}$

$\frac{-81}{62}$

$\frac{-36}{154}$

$\frac{-6}{18}$

$\frac{-123}{234}$

\section{4}

35

2

1

$\frac{1}{123}$

Less deaths at facilities

Available for release or aquaria

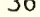

$\overline{6}$

Shipped to Aquaria:

Died in Anchorage

Died at Aquaria thru 2/01/90

Total

Alive at Aquaria 2/02/90

Less aquaria candidates

Available for release/escape

$\frac{-24}{38}$

3

5


SUMMARY OF SEA OTTER RESCUE INVENTORY (page 4)

Zone of Origin

\begin{tabular}{llll}
\hline PWS & Kenai & Kodiak & Total \\
Zone & Zone & Zone & \\
\hline
\end{tabular}

Escaped/Released into Wild from:

SORC TOTAL

Implant transmitters to PWS

Not-implants to Harris Bay

Not-implants to Taylor Bay

Non-implants to Picnic Harbor

VORC Octagon Pre-release Fac. TOTAL 38

Escaped into Valdez Harbor

Flipper radios to Simpson Bay

Implant radios to PWS

Non-implant radios to PWS

Jakolof Pre-Release Facility TOTAL

Implant radios to PWS

Non-implants to PWS

Non-implant to Harris Bay

Non-implants to James Lagoon

Non-implants to Nuka Bay

Escaped/Rel. in L. Jakolof Bay

Rogues released to Kachemak Bay

2 re-released in Dog Fish Bay (not in Bio-data base)
1

32

4

6

$10 *$

18

38

146

$\frac{96}{6}$

24

21

7

20

13
1

19

$7 *$
4
7
1

70

10

7

23 *

30

108

$\underline{12} 2 *$

$15 *$

6

125

324

6

7

26

Totals Available for release/escape

197

* Indicated sea otters with implant radios. 


\section{SUMMARY OF SEA OTTER RESCUE INVENTORY (page 5)}

\section{SUMMARY OF DEAD OTTER INVENTORY}

\begin{tabular}{|c|c|c|c|c|}
\hline & & Zone of or & gin & \\
\hline & $\begin{array}{l}\text { PWS } \\
\text { Zone } \\
\end{array}$ & $\begin{array}{l}\text { Kenai } \\
\text { Zone } \\
\end{array}$ & $\begin{array}{l}\text { Kodiak } \\
\text { Zone }\end{array}$ & Total \\
\hline Dead from Field * & 490 & 188 & 198 & 876 \\
\hline Est. to have died before spill & 69 & 15 & 7 & 91 \\
\hline Rated for degree of oiling & 238 & 108 & 33 & 379 \\
\hline Number judged oiled & 235 & 75 & 30 & 340 \\
\hline Oiled Status Unknown & 183 & 65 & 158 & 406 \\
\hline $\begin{array}{l}\text { Died at renabilitation facilities } * * \\
\text { Valdez ORC }\end{array}$ & 81 & 36 & 6 & 12384 \\
\hline Seward ORC & & 29 & 6 & 35 \\
\hline Died at Jakolof PRF & & 2 & & 2 \\
\hline Died at Homer TCF & & 1 & & 1 \\
\hline Died enroute Homer to VORC & & 1 & & 1 \\
\hline Died at aquaria by $2 / 1 / 90 * *$ & y & 1 & 2 & 12 \\
\hline Died in Anchorage in transit & 1 & & & 1 \\
\hline Died at Sea World, San Diago & 4 & & & 4 \\
\hline Died at Pt. Defiance, Tacoina & 2 & 1 & 2 & 5 \\
\hline Died at Vancouver & 2 & & & 2 \\
\hline Cummulative Dead Recovered & $\overline{580}$ & $\overline{225}$ & $\overline{206}$ & $\overline{011}$ \\
\hline
\end{tabular}

Note: These data supersede previously released data. * Data quality controlled by Calvin Lensink. ** Data quality controlled by Keith Bayha. 


\title{
Opening Address
}

\section{Boundaries of the Symposium}

\author{
by
}

\author{
W. O. Stieglitz \\ U.S. Fish and Wildlife Service \\ 1011 East Tudor Road \\ Anchorage, Alaska 99503
}

The 24 March 1989 grounding of the T/V Exxon Valdez on Bligh Reef in Prince William Sound, Alaska, resulted in the largest oil spill in United States history and the first one to affect a large number of sea otters (Enhydra lutris). For most of us assembled here today, that event triggered a period of intense and stressful activity. For some, this period was also a significant emotional event that changed our lives.

While everyone who participated in the response effort has some special insight into what happened, what was done right, and what might have been done better, none of us had the vantage point to gain an accurate perspective of the entire response effort. Because this symposium is limited to examining the response effort on behalf of sea otters, even after its conclusion we still will not have acquired a complete understanding of everything that transpired. However, I hope the next 3 days will provide each of you an opportunity to expand your understanding of the rationale for decisions made, strategies employed, and events that occurred both where you worked and elsewhere in the large and sometimes complicated bureaucracy that characterized the response effort.

To help you understand the big picture a little better, the symposium's steering committee asked that I discuss some of the legal constraints that affected the response and must, of necessity, shape this symposium.

\section{Whose Spill Was It?}

First, there is the question of a Federal versus a non-Federal spill. The Comprehensive Environmental Response, Compensation, and Liability Act (CERCLA), as amended by the Superfund Amendment and Re-authorization Act and the Clean Water Act provide the legal basis for who is responsible for what. All oil spills are "non-Federal" until they are officially declared to be "federalized." The T/V Exxon Valdez spill was never federalized because Exxon Company U.S.A. accepted responsibility from the outset and was judged to be financially capable and competent to respond. This meant that many of the management decisions were Exxon's to make.

The referenced acts also authorize the Federal Government to assist and to assume certain responsibilities in support of a non-Federal spill. Additionally, Executive Order 12580 names the members of, and delegates certain responsibilities to, the National Response Team, of which the Department of Interior (DOI) is a member. The $\mathrm{Na}$ tional Response Team oversees the Nation's effec- 
tive and efficient response to oil and hazardous substance spills.

As a member of the Alaska Regional Response Team, DOI works with other Federal departments and the State of Alaska to provide guidance and assistance to the U.S. Coast Guard (the Federal on-scene coordinator for spills in marine waters) and the U.S. Environmental Protection Agency (the Federal on-scene coordinator for spills on land and in fresh water) in a manner described in the National Contingency Plan and in the Regional Contingency Plan. The National Contingency Plan is the major rule covering DOI's response; this plan ensures that the resources and expertise of the Federal Government are immediately available for oil and hazardous substance incidents that require a national or regional response. The Department of Interior also responds to a spill in compliance with Superfund and Clean Water Act provisions for Federal facilities; these provisions address spill incidents on or affecting Federal lands.

Thus, as will be reported in papers that follow, Exxon and its contractors initiated many of the response actions. Federal agencies, such as the U.S. Fish and Wildlife Service, provided advice, monitoring, and when requested, technical assistance.

\section{Trustee Responsibilities}

Under its trusteeship, DOI is authorized to seek compensation and restoration of natural resources that have been injured by a spill. U.S. Fish and Wildlife Service trust resources affected by this spill include sea otters, raptors and other migratory birds, and shorelines of the Alaska Maritime, Kodiak, Becharof, and Alaska Peninsula national wildlife refuges. The National Park Service trust resources affected by this oil spill include the shorelines and coastal resources of Kenai Fjords National Park, Katmai National Park and Preserve, and Aniakchak National Monument and Preserve.

Trustee agencies (i.e., State of Alaska and the Departments of Agriculture, Commerce, and Interior) generally are following the procedures of the Natural Resource Damage Assessment regulations (43 CFR, Part 11). A trustee council (consisting of Alaska Department of Fish and Game Commissioner D. Collinsworth, Regional Forester M. Barton, National Marine Fisheries Service Regional Director S. Pennoyer, and me, the Alaska Regional Director of the Service) was formed to direct the damage assessment of the T/V Exxon Valdez oil spill.

The damage assessment process consists of a series of studies and analyses that are intended to determine injuries and culminate in the compensation for and restoration of the trustee resources. Because these studies are still underway and because of the possibility of litigation, presentation of certain data and information at this symposium is premature and inappropriate. The symposium steering committee and the authors and editors of the papers to be presented have each had to grapple with distinguishing between what is response and what is damage assessment. So that all participants and readers of this proceedings have the same understanding, let me state here the guidance I have given on this point.

Response, in the instance of sea otters and their habitat, includes all the rescue efforts (which in turn include surveys to locate and assess otters in stress, capture, transport, veterinary treatment, rehabilitation, and release), certain procedures necessary to prepare animals for release (blooddrawing, retagging, and radio-implant surgery), recovery of dead otters, gross necropsy of dead otters, collection of tissues and data, analysis of tissues and data to assist in treatment of otters, and observations of distribution and condition of oil as it affected the behavior, distribution, and reproduction of sea otters. In short, any activity whose purpose is to minimize adverse effects on the trust resources is considered response.

Damage assessment includes such questionstimulating topics as comparison of before- and after-spill sea otter census data, extrapolation of histopathic and toxicologic data to sea otters not captured, radio-tracking data from released otters beyond 15 August 1989 used to bring about the release strategy, as well as the studies outlined in the State and Federal Natural Resource Damage Assessment Plan for the T/N Exxon Valdez Oil Spill, August 1989, Public Review Draft.

Evaluation of response activities and data related to sea otters is the subject of this symposium. Damage assessment activities and data will be addressed in other forums as the process evolves. As noted in the first page of the compendium of abstracts you received this morning, we obtained permission from the Justice Department to allow one exception. You will hear tomorrow about the results of the radio-tagging study this past fall and winter. 
On behalf of the U. S. Fish and Wildlife Service, I welcome you to Anchorage and to this symposium. I urge your close attention to the speakers and your candid participation in the workshops as we search for greater understanding and consensus on the issues and recommendations. 


\title{
Introductory Session
}

\author{
Editor and Chair: Pamela A. Bergmann, U.S. Department of the Interior, \\ Office of Environmental Affairs, Anchorage, Alaska.
}

\section{Movement of Oil Spilled From the T/V Exxon Valdez}

\author{
by \\ J. A. Galt and D. L. Payton \\ National Oceanic and Atmospheric Administration \\ Hazardous Materials Response Branch \\ 7600 Sand Point Way, N.E. \\ Seattle, Washington 98115
}

\begin{abstract}
The task of tracking and estimating the movement of oil spilled from the T/V Exxon Valdez resulted in a considerable expenditure of effort by industry as well as Federal and State agencies. These efforts resulted in hundreds of overflight reports, hours of remote-sensing data, a greatly expanded weather observation network, satellite-tracked current drifters, and significant computer analysis or modeling techniques-all providing fragments of information.

Modeling techniques, combined with observational data, have been used to hindcast the surface movement of the spilled oil. Preliminary results indicate that, by the end of the second week of the spill, about $30 \%$ of the spilled oil may have been lost to weathering processes, $40 \%$ beached within Prince William Sound, 25\% exited Prince William Sound, and about 5\% remained floating within Prince William Sound. Of the oil leaving the Prince William Sound system, it is estimated that about $10 \%$ traveled beyond Gore Point, and only about $2 \%$ reached as far as Shelikof Strait.
\end{abstract}

When the T/V Exxon Valdez grounded early in the morning of 24 March 1989, a large amount of crude oil was released almost instantaneously. From that moment on, the task of estimating how the spilled oil would move and spread through the Prince William Sound (Fig. 1) and the Gulf of Alaska coastal areas (Fig. 2) became a major concern. During the next few months considerable resources were directed at this problem by industry and private, Federal, and State agencies. This resulted in hundreds of overflight reports, hours of remote-sensing data, a greatly expanded weather observation network, satellite-tracked current drifters, and significant computer analysis or modeling techniques-all providing fragments of information. These data were analyzed as they were generated and have been the subject of continual reexamination. We discuss our present estimate of where the oil went and the processes that were responsible for its movement. 


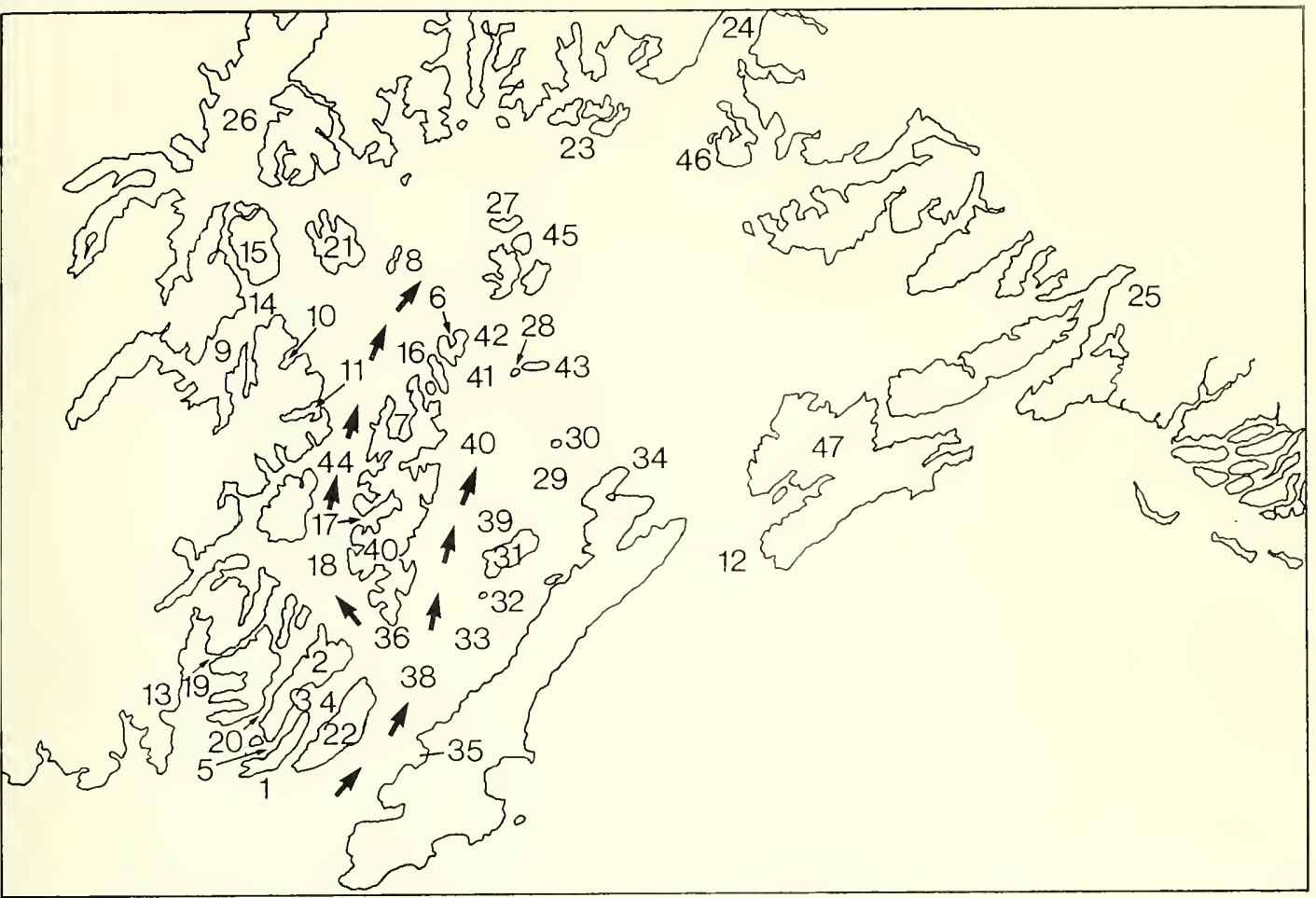

1 Erlington Is.

2 Evans Is.

3 Sawmill Bay

4 Latouche Passage

5 Elrington Passage

6 N.W. Bay

7 Herring Bay

8 Lone Island

9 Port Nellie Juan

10 Main Bay

11 Eshamy Bay

12 Hinchinbrook Entrance

13 Port Bainbridge

14 Applegate Is.

15 Culross Is.

16 Ingot Is.
17 Lower Herring Bay

18 Pleiades Is.

19 Bainbridge Passage

20 Prince of Wales Passage

21 Perry Is.

22 Latouche Is.

23 Glacier Is.

24 Valdez Arm

25 Orca

26 Port Wells

27 Story Is.

28 Little Smith Is.

29 Applegate Rock

30 Seal Is.

31 Gibbon Anchorage

32 Little Green Is.
33 The Needle

34 Montague Pt.

35 Hanning Bay

36 Pt. Hellen

37 Montague Is.

38 Montague Strait

39 Green Is.

40 Knight Is.

41 Ingot Is.

42 Eleanor Is.

43 Smith Is.

44 Knight Is. Passage

45 Naked Is. Group

46 Bligh Reef

47 Hinchinbrook Is.

Fig. 1. Map of Prince William Sound with major place names.

\section{Initial Phase of the Spill}

When the T/V Exxon Valdez grounded, the weather in Prince William Sound was calm and relatively clear. Under these conditions, there was very little wind or wave activity to affect the movement of the spilled oil. These conditions persisted throughout Friday, $24 \mathrm{March}$, and Satur- 


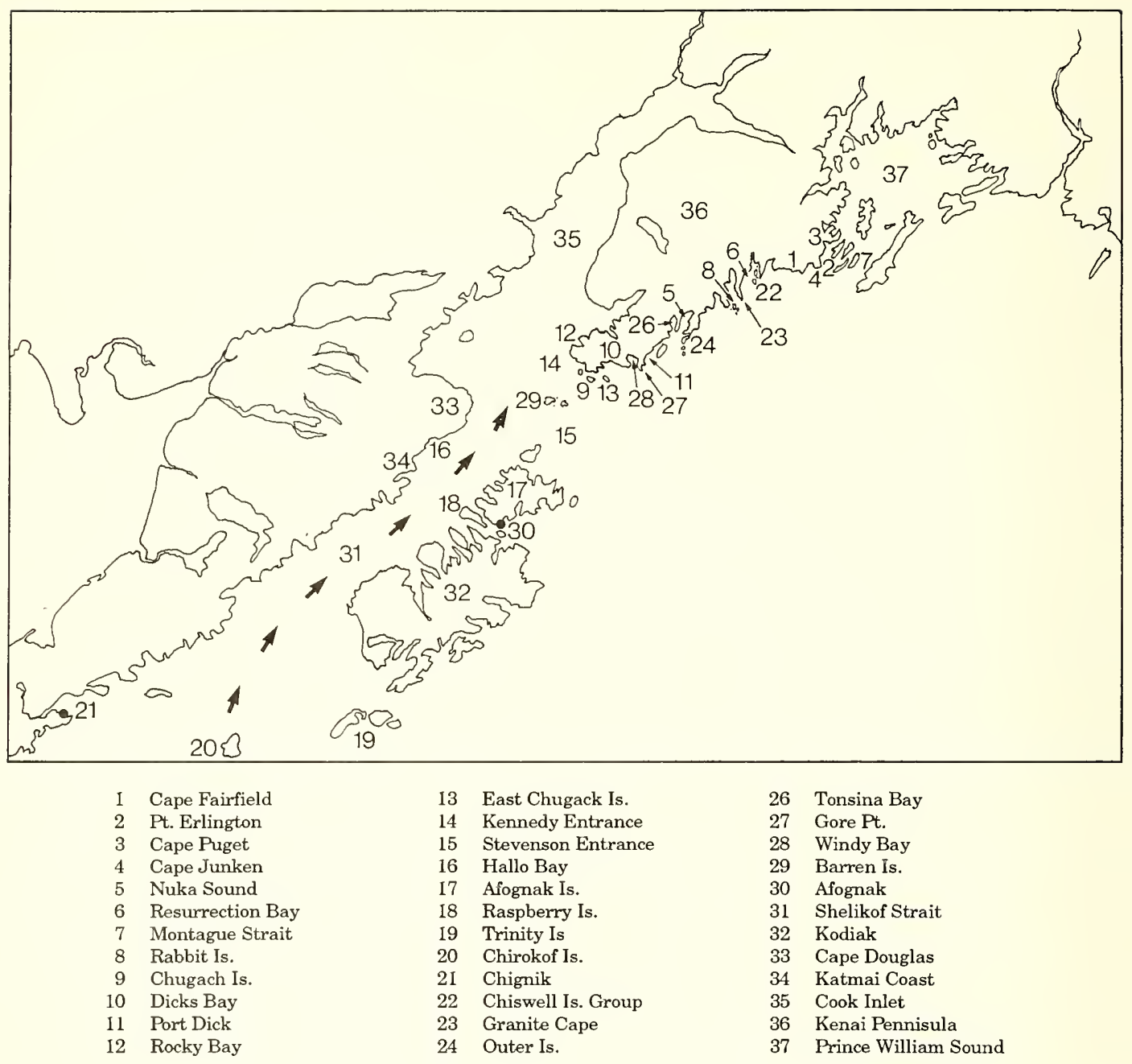

Fig. 2. Map of the south-central Gulf of Alaska coast.

day, 25 March. During this time, the oil spread into a large, more or less contiguous pool that moved slowly to the west and southwest. As can be seen from Fig. 3, the center of the oil pool was generally south of Glacier Island, between Bligh Reef and Naked Island. During this quiescent period, the oil showed no tendency to form a mousse (water-in-oil emulsion) and, although evaporation of the lighter weight hydrocarbon components took place rapidly, the evaporation process was most likely limited by the surface transfer processes because there was virtually no stirring or rupturing of the oil surface by wave action. 


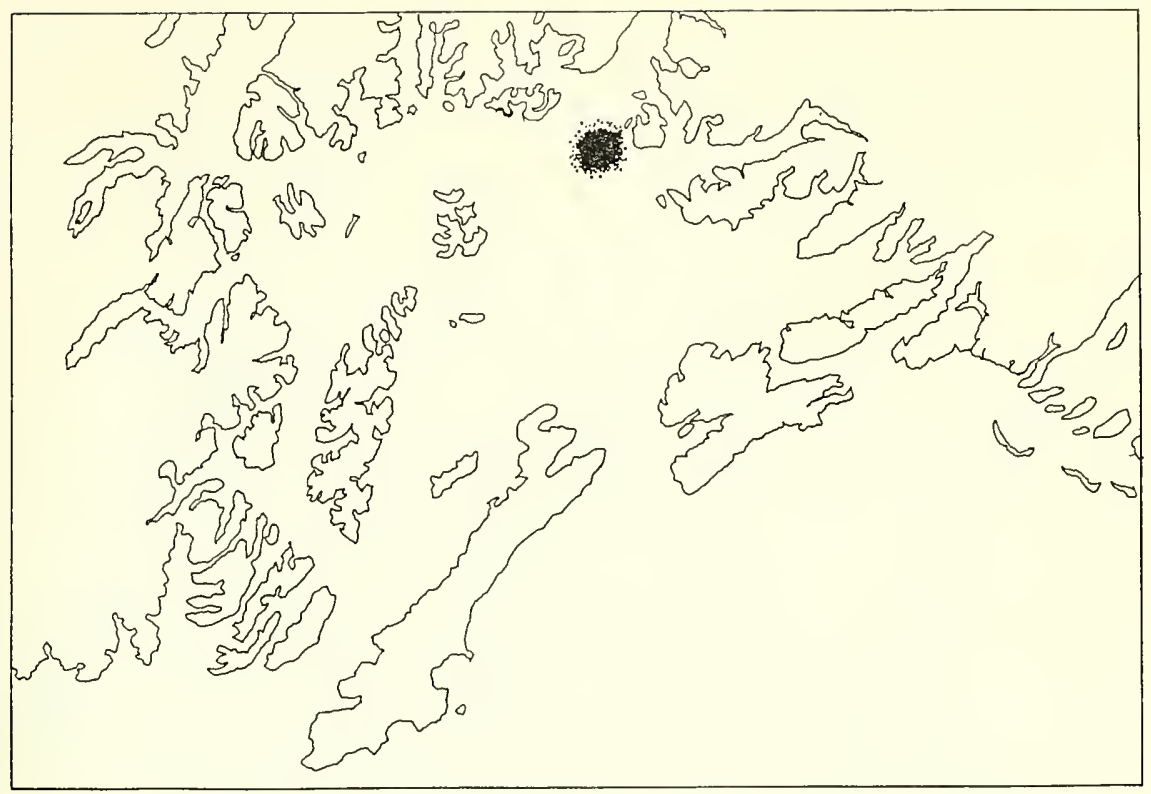

Fig. 3. Approximate distribution of the floating oil on 24 March 1989.

The major movement of the oil during this period was controlled by currents and was consistent with the simple circulation pattern shown in Fig. 4. This pattern is a reasonable representation of the mean surface flow in Prince William Sound and indicated that the future movement of the oil would be west and south through Montague Strait. In addition, the predominant tendency for drainage winds to flow out of major bays or fjord arms (e.g., Valdez, Orca, and Port Wells) seemed to indicate that, even at this stage in the spill, the possibility of oil traveling into the eastern or southeastern segments of Prince William Sound was minimal.

During this early phase of the spill an additional process, which was related to the freshwater runoff from major glaciers and streams, was first noticed and appeared in many places throughout Prince William Sound and along the Kenai Peninsula. In this process, relatively fresh water spread as a lens, pushing out from boundary fjords. As the lens spread, it formed a convergence line along its leading edge that tended to trap flotsam (or oil) and inhibit its movement into the fjord or nearshore region. This process was clearly effective around and south of Glacier Island on 25 March. The freshwater interface controlled the northern edge of the oil from Glacier Island along a line extending to the northern edge of Storey Island.

\section{Major Storm}

During the third day of the spill, Sunday, 26 March, the Prince William Sound area experienced a major windstorm. This had a profound effect on the spilled oil, dramatically changing its appearance, character, and distribution. The dominant wind direction during the storm was east to northeast; however, drainage winds from the northern fjord arms and Port Wells translated into a northeast to north-northeast wind over the central area of the spill. As a result, oil moved rapidly between Naked Island and Smith Island toward Montague Strait.

In addition to simply moving the oil, the storm supplied a tremendous amount of mixing energy that affected the spilled oil in three important ways. The first effect was that the more or less contiguous slick was ruptured into bands and streaks and spread over a significantly larger area. This meant that the oil was no longer of uniform thickness. Typically under such conditions, slicks will cover 


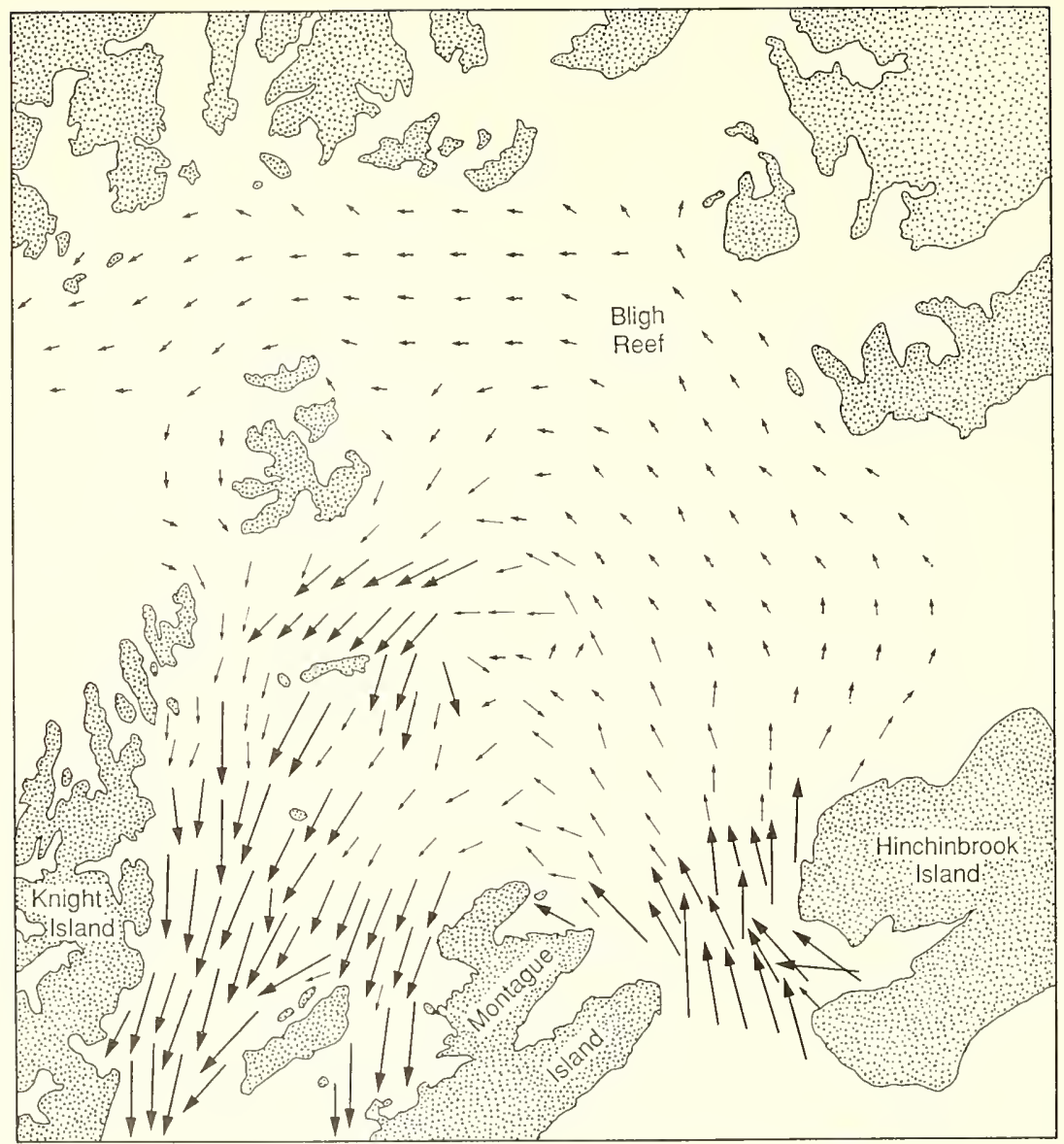

Fig. 4. Approximate mean current pattern used for trajectory analysis in central Prince William Sound during the initial period of the spill.

large areas, with $90 \%$ or more being on the order of microns thick and leaving most of the product in relatively small, narrow bands that are associated with vertical movement in the water column (convergence zones). Under heavy wind conditions, these convergence zones are typically associated with Langmuir cells, which are depicted in Fig. 5. This explains the banded or streaked appearance that shows up in most overflight pictures taken during this period of the spill.

The second effect of the storm was that mixing processes were dramatically increased. Evaporation of the lighter (and more toxic) fractions of the oil was enhanced, with estimates of about 15-20\% of the total being lost by the end of the storm. In addition, breaking waves caused by the wind led to the dissolution of oil into the water column. Natural surfactants enhance this process, acting somewhat like a dispersant, so that small droplets appear to be in solution and rapidly mix to extremely low concentrations. This may have accounted for another 15-20\% loss of total oil by the end of the storm.

The third effect of the storm was that a significant fraction of the remaining oil formed a waterin-oil emulsion (mousse). The water content of the 


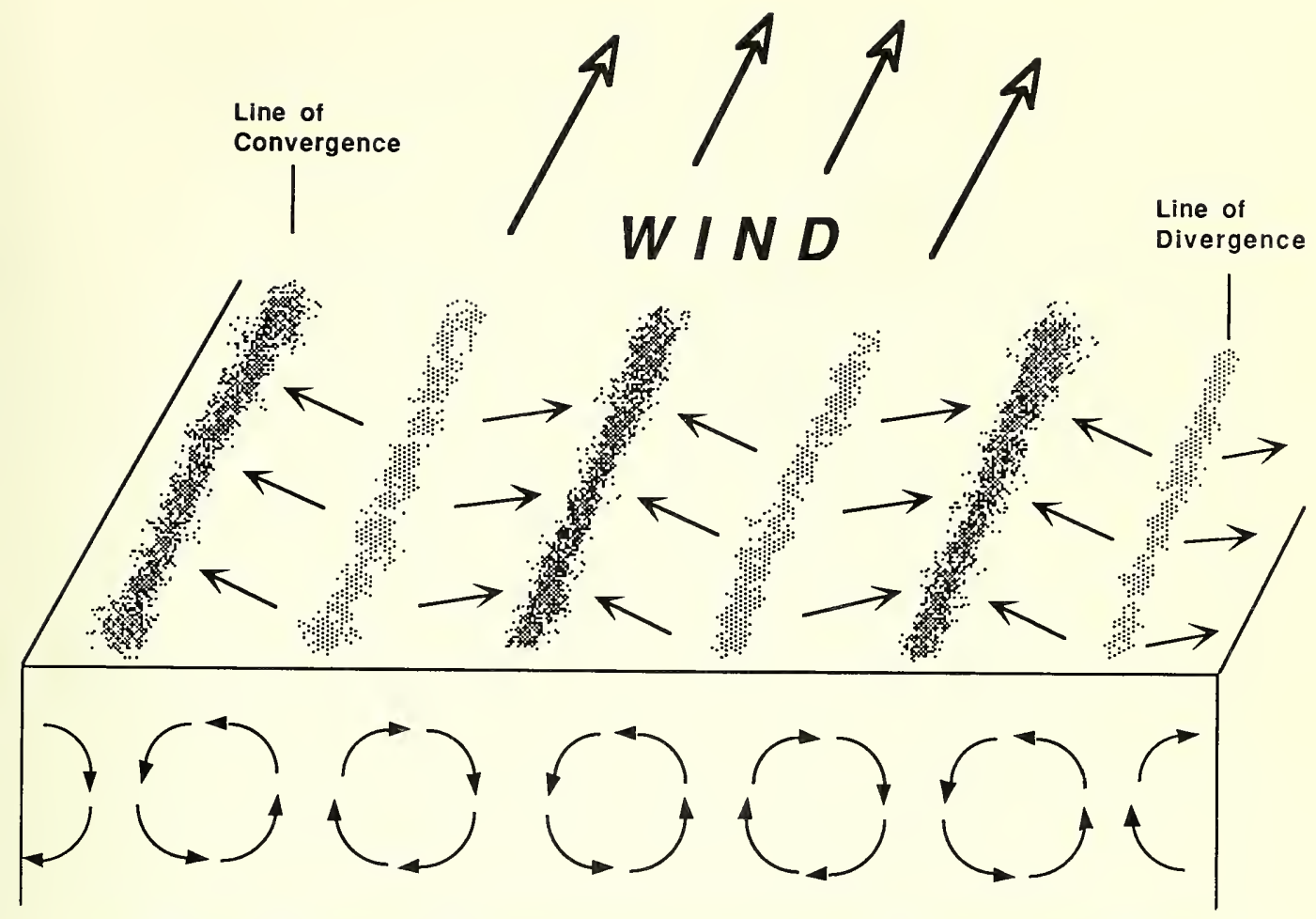

Fig. 5. Schematic representation of wind-induced Langmuir cell development. Convergence lines act as collection zones for floating materials such as popweed (Utricularia vulgaris), oil, or pollen.

mousse was tested and found to be about $70 \%$. This more than tripled the volume of the slick for that fraction of the oil spilled and remaining that formed a mousse. The mousse also had different physical properties than the original oil, most notably, a higher viscosity, which made it "sticky" and slower to weather or degrade.

As the storm progressed, the oil slick arched southwest and then south-southwest, first affecting beaches along the southwest coast of Naked Island and then grounding large quantities of oil on Smith Island, Little Smith Island, and Eleanor Island. Figure 6 illustrates the location of the oil near the end of the storm. By the end of the storm, the oil had weathered, mixed, emulsified, and moved so that a distinct new phase of the spill was at hand. Scattered, but heavy, concentrations of floating oil were centered in the area between Naked Island, Smith Island, and Eleanor Island. From this junction, channels lead in all directions but, because of persistent current and wind patterns, the oil was expected to move south or west. The areas of special interest then became Montague Strait and Knight Island Passage. Oil quickly moved though both of these passages. This major bifurcation continued throughout the spill, giving two branches to the trajectory problem, each of which acted somewhat differently.

At this time, the spill had become significantly more difficult to deal with and, somewhat ironically, it became easier to understand and predict future movement. With the slick's center of mass near the northern end of Montague Strait, it had moved close to the influence of the most dominant and persistent current in Prince William Sound. 


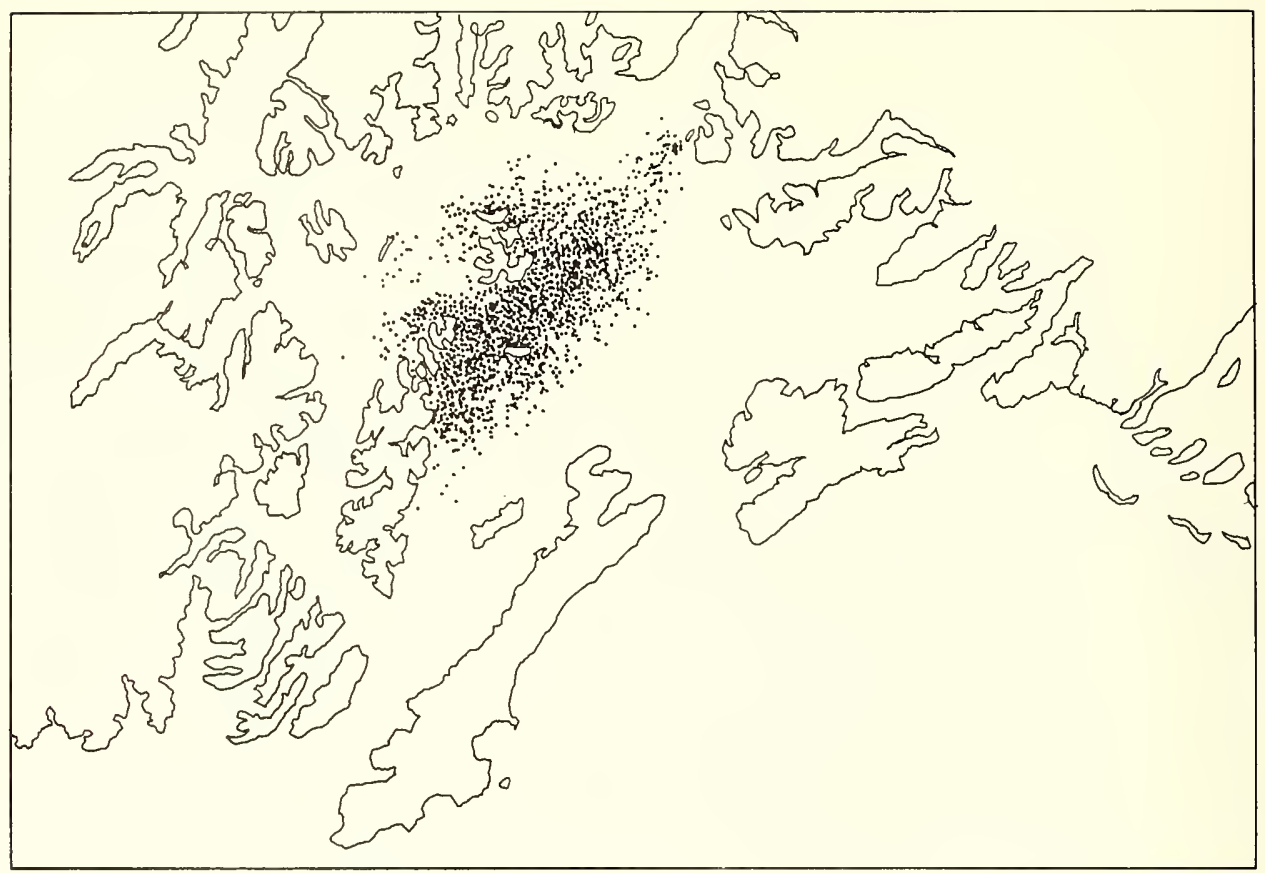

Fig. 6. Approximate distribution of the floating oil on the afternoon of $26 \mathrm{March} 1989$.

\section{Montague Strait}

The major current in Prince William Sound is the flow that enters it through Hinchinbrook Entrance and exits through Montague Strait. This current is concentrated along the eastern shore of Knight Island, with most of the flow traveling between Knight and Seal islands. Observations of the oil movement revealed that the maximum speed along the axis of this current has a net displacement of 16 to $24 \mathrm{~km}$ per day. A rough computer simulation of this current is shown in Fig. 7. In addition to this net current, there are tidal currents; however, throughout Montague Strait the tidal currents are usually not strong enough to reverse the flow. During the first few weeks of the spill, when floating oil concentrations were high, no up-strait flows were evident. As oil entered the northern end of Montague Strait between Smith and Eleanor islands during the fourth and fifth days of the spill (27 and $28 \mathrm{March}$ ), the oil quickly spread out, thereby affecting the coast of Eleanor, Ingot, and Knight islands, with lesser concentrations beaching on Seal Island and Applegate Rock. By the end of 28 March, the leading edge of the oil was between Latouche Island and the southern end of Montague Island; by 29 March (day 6 of the spill), it had moved beyond Montague Strait into the Gulf of Alaska. This relatively fast movement through Montague Strait, with shoreline oiling primarily along the eastern shore of the Knight Island group, is typical of the movement of most of the oil that entered the northern end of Montague Strait. During the first few weeks of the spill there were several exceptions to this typical flow. Two of those exceptions were of particular significance.

The first exception occurred on 29 March, when there were northwest winds in the triangle formed by Smith, Naked, and Knight islands and through- 


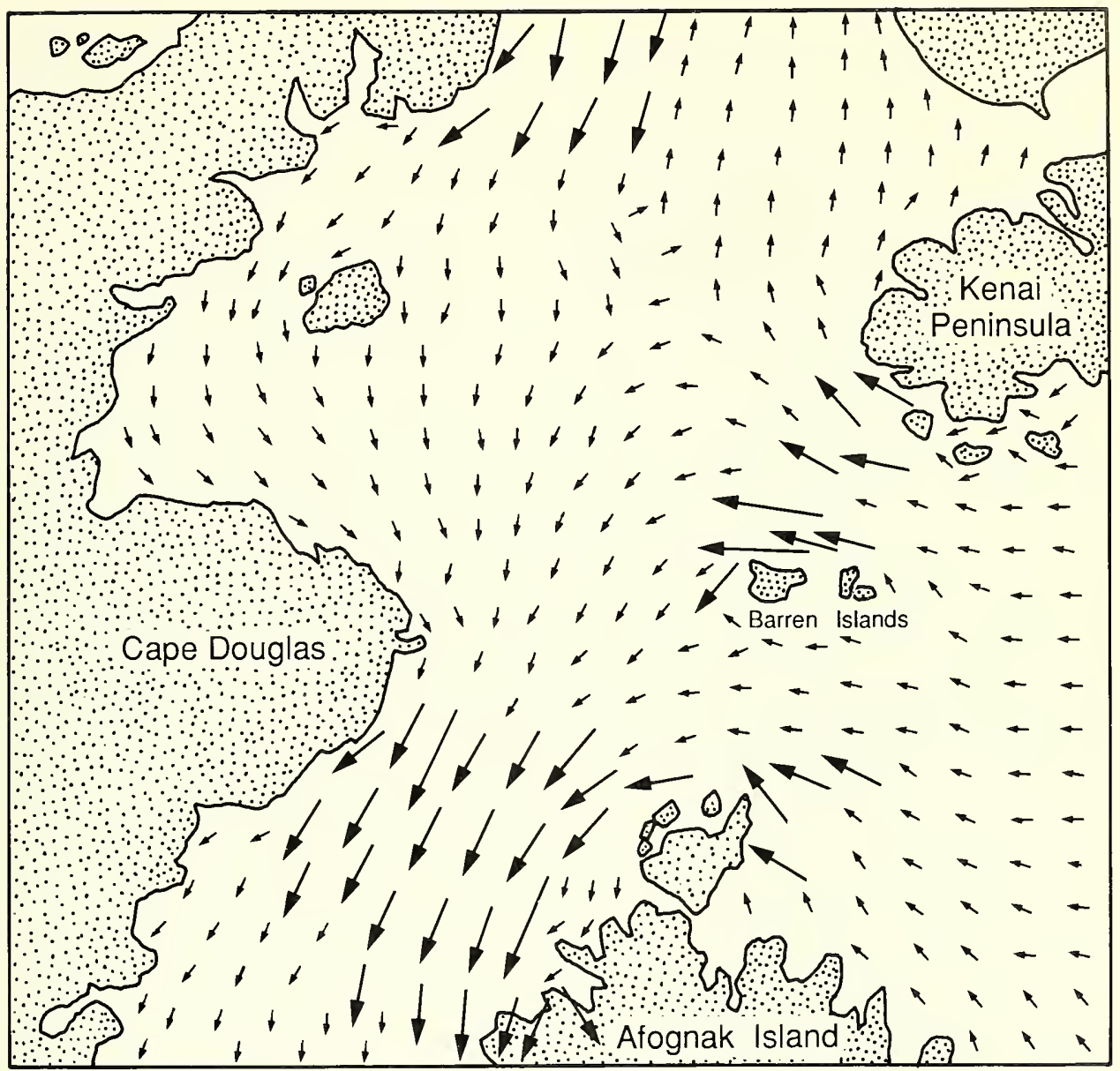

Fig. 7. Approximate mean current pattern used for trajectory analysis in southwest Prince William Sound during the initial period of the spill.

out the northern end of Montague Strait. As a result, some of the oil moving between Smith and Eleanor islands moved away from the strong current region along the western side of Montague Strait. This oil, which moved south around Applegate Rock, resulted in relatively heavy concentrations of oil on beaches along the northern coast of Green Island, with initial effects concentrating along the northeast coves of the island around Gibbon Anchorage. As shown in Fig. 7, the currents east and south of Green Island are much weaker than those on the western side of Monta- gue Strait. As a result, this oil remained in the area for some days, reoiling Applegate Rock, the northern shore of Green Island, and eventually spreading lighter concentrations on to Little Green Island and The Needles. This eastward extension of the oil was responsible for the initial and major oiling of Green Island and generally represented the eastern limit of significant oiling in Montague Strait. Later in the spill, however, minor amounts of oiling occurred at a few places along the west coast of Montague Island, in particular, along the northern shore centered around Montague Point, 
and later far to the south around Hanning Bay. Both of these events were associated with northwest wind episodes.

The second exception to the typical current occurred at the southern end of Knight Island, where Knight Island Passage meets Montague Strait. The flow along the western side of Knight Island is predominantly south, but is much weaker than the flow along the eastern side of Knight Island. In Knight Island Passage this flow is sufficiently weak that, during some phases of the spring-neap tidal cycle, the currents during the flood tide are strong enough to reverse the direction of the flow in the southern part of Knight Island Passage, which means that as oil drifted south past Point Helen, it entered an area where the current flooded west into Knight Island Passage. Thus the oil was deflected, so that when the tides ebbed, the trajectory led along the western side of Latouche Island, threatening Elrington Island, Latouche Passage, Evans Island, and the Sawmill Bay hatchery. This phenomenon was first noticed on $30 \mathrm{March}$, which was about halfway between neap tides (weakest period) and spring tides (strongest period). Over the next week, these tides increased each day and subsequently sent larger and larger pulses of oil into the passage between Latouche and Evans islands.
During the first week of April major oil concentrations threatened Latouche and Elrington passages. Lesser amounts of oil continued to threaten this area, but never to the extent as was seen during this period. Figure 8 shows the general distribution of the oil by 30 March.

\section{Knight Island Passage}

As oil moved west between Naked Island and Eleanor Island it entered an area that has virtually no steady current patterns, and winds dominate the trajectories. By the end of the first major storm, oil had entered this area in relatively high concentrations. During the next two days (days 4 and 5 of the spill), the oil moved south under the influence of northerly winds, and heavy concentrations went ashore on Eleanor Island, particularly in Northwest Bay. Heavy oil also moved past Ingot Island and onto the northwest parts of Knight Island, with large concentrations entering Herring Bay.

For the next few days widely scattered bands of heavy oil seemed to mill around in the area between Lone Island, southwest Naked Island, and the northern end of Knight Island. Some patches moved west nearly to Port Nellie Juan, and light

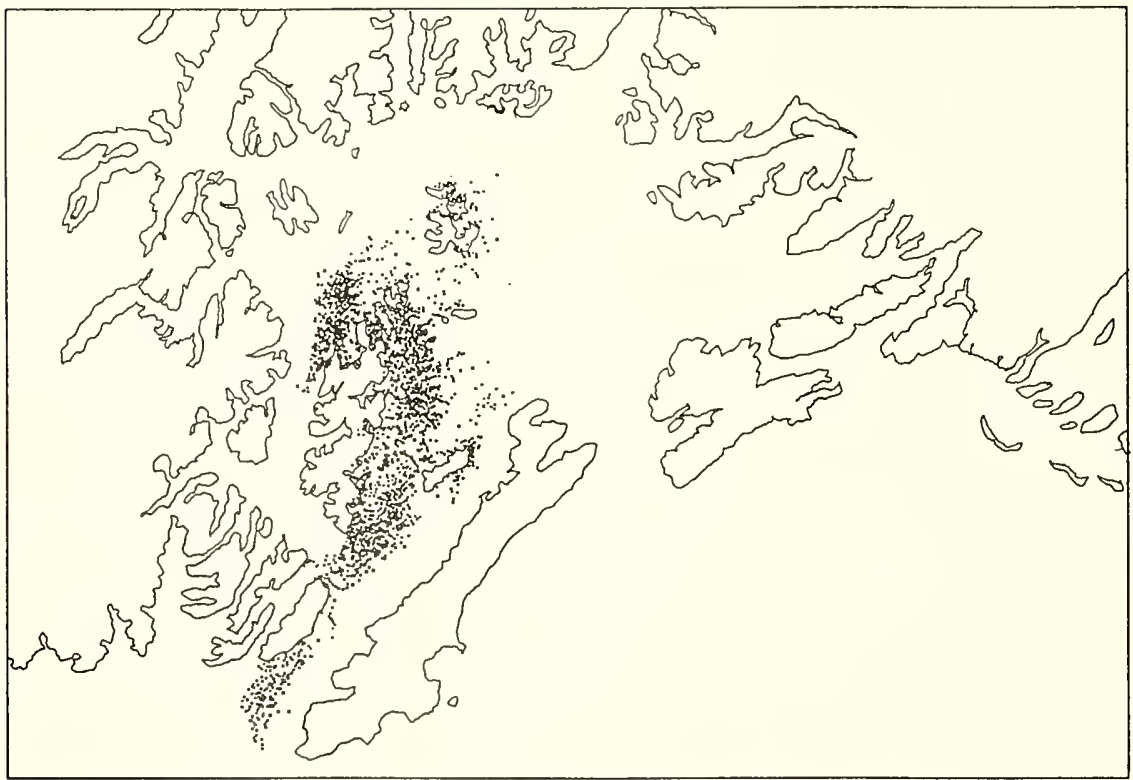

Fig. 8. Approximate distribution of the floating oil, midday 30 March 1989, 6.5 days into the spill. 
shoreline effects were observed between Main Bay and Eshamy Bay. As patches and bands of oil reached the southern part of this area, they entered Knight Island Passage and came under the influence of a weak current system that carried them south at a speed of 5 to $8 \mathrm{~km}$ per day. As this slow drift continued, day-to-day variations in the wind pushed the oil back and forth, but the dominant direction was such that most shoreline effects were from Northwest Bay to Herring Bay, with some oil actually passing through the channels north and south of Ingot Island and back into the current system of Montague Strait.

Over the next 2 weeks, most of the oil that moved west between Naked Island and Eleanor Island followed this general pattern; however, relatively small amounts of oil moved down Knight Island Passage, with moderate shoreline effects in Little Herring Bay; and past the Pleiades Island group, with scattered shoreline effects. Eventually, some of the oil following this path was seen to pass through Bainbridge Passage and Prince of Wales Passage into Port Bainbridge and then into the Gulf of Alaska.

The steep shorelines along much of the coasts of Smith, Eleanor, Ingot, and Naked islands provided a special physical process caused by reflected or standing wave patterns. These wave patterns have a convergence node just offshore that trapped oil close to shore, without having the oil actually beach. Then, after a sudden change in the wind (and wave patterns), this oil floated away from shore and appeared as a secondary source or new patch of oil. This phenomenon occurred on 1011 April, when a large (compared with what was left floating in the area) patch of oil moved away from Smith Island and, under the influence of a strong easterly wind, moved between Naked and Eleanor islands to form a large patch between Northwest Bay and Lone Island. In the next week, this patch moved back and forth. When more-easterly winds developed, moderate amounts of the oil went ashore on Lone Island, southwestern Perry Island, Culross Island, and Applegate Island.

Lighter concentrations of oil also moved up Perry Channel and down into Port Nellie Juan. As the winds returned to a northerly and northwesterly direction, the movement of the remnants of this oil was more typical of movements seen in the early part of the spill and led to additional shoreline oiling between Main and Eshamy bays to the west and Herring Bay to the east.

\section{Gulf of Alaska}

Floating oil first exited Prince William Sound through Montague Strait about 30 March (day 7 of the spill) after which a more or less continuous passage of oil flowed into the Gulf of Alaska. This passage of oil probably reached its maximum sometime within the next week. By the second week of April (more than 2 weeks into the spill), between 20 and $25 \%$ of the oil had moved into the Gulf of Alaska, primarily through Montague and Latouche straits, with lesser amounts passing through Port Bainbridge. In the second week of April, although the Prince William Sound system continued to act as a source of oil for the Gulf of Alaska, the amount of oil coming from Prince William Sound was greatly reduced. By mid- to late April, this source, which consisted of small, isolated patches of lightto-moderate oil, diminished further.

The major current systems that affect the flow over the Alaska Continental Shelf are the result of two components. The first component is the large-scale Gulf of Alaska Gyre, which leads to a westerly flow over the shelf. This current generally flows at less than a knot, but reaches a maximum (typically about a knot) near the shelf break region. The second component is a relatively strong nearshore current (the Alaska Coastal Current) that has been studied in detail by Johnson et al. (1988). This current is caused by a pressure gradient set up by freshwater runoff from the coast, and is typically 10 to $24 \mathrm{~km}$ wide in the region between Montague Island and the western end of the Kenai Peninsula. Although this current varies in speed, depending on the amount of fresh water that enters the system, speeds as high as 3.4 knots have been observed (Johnson and Royer 1986). In the first week of April, the Alaska Coastal Current was considerably below its maximum; typical speeds were between onequarter and one-third knots. Even at this reduced level, the Alaska Coastal Current was the dominant transport process affecting oil leaving Prince William Sound. Virtually all of that oil moved west and then southwest along the coast, with the highest concentrations generally within $24 \mathrm{~km}$ of the various headlands.

As mentioned previously, oil first entered the Alaska Coastal Current about 30 March. By 2 April, the leading edge of the oil was west of Cape Fairfield, centered about $16 \mathrm{~km}$ offshore. Although most of the oil did not reach the coast, light oiling was reported on Point Elrington, Cape Puget, and Cape Junken. By 4 April, the leading edge of the oil was south of the Chiswell Island group, from 
just off the headlands and extending a little more than $18 \mathrm{~km}$ across the width of the coastal current. This movement in the coastal current progressed at a rate of about 10 to $13 \mathrm{~km}$ per day. Just west of the Chiswell Island group, the bathymetric contours become more complex, with a fairly large bank extending south of the islands. In this area, the coastal current is deflected offshore, and large eddies tend to spin off between the current axis and the shore (typically somewhere south of Granite Cape). Floating oil followed these patterns, with the majority deflected south and away from shore, while a smaller portion tended to get caught up in the eddies and mill around west of the Chiswell Islands. By 7 April (day 15 of the spill), the leading edge was about $32 \mathrm{~km}$ offshore, between Outer Island and the Chiswell Islands, with widely scattered oil patches and streamers occurring nearer to the shore, west of the Chiswell Islands and south of Granite Cape.

By 9 April, the oil's leading edge, which had continued to move southwest, was about $56 \mathrm{~km}$ south of Nuka Sound. From here, the oil could be traced in a more or less continuous series of streaks, streamers, and patches to Montague Strait, a distance of about $161 \mathrm{~km}$. Beyond that point, the leading edge feathered out into broken patches of scattered sheen. On windy days, this process was exaggerated and the slick would actually appear to shrink; on calm days it would extend, but never beyond Montague Strait as a single, connected series of oil patches. Despite the more or less continuous appearance of the oil up to this time, over the segment of the Alaska Coastal Current that contained floating oil, the actual fraction of the surface covered was very small (a few percent). Thus, there were many thin lines of floating oil separated by large areas of clear water.

Beyond Nuka Sound, the oil was in individual patches or streaks. A simple line could no longer be followed out from Prince William Sound, and reconnaissance became more difficult. Nonetheless, the amount of oil remaining in these scattered patches, although often difficult to see from the air, still represented significant hazards to offshore birds, floating sea otters, and shorelines in the event that it was blown ashore. The resulting bits of oil were patchy and generally widely scattered, with many relatively clear areas in between.

The coast between Prince William Sound and the Barren Islands is composed of rugged headlands separated by large fjords. The coastal mountains are sufficiently high to interact with largescale weather patterns, causing local variations in the wind fields, which strongly affected the movement and beaching of the oil. The most pronounced of these small-scale weather patterns was the down-fjord winds that developed routinely as winds off the coast came from the south or southeast. Under these conditions, the south or southeast winds moved oil closer to shore and threatened beaches. At the same time, winds blowing down the larger bays (such as Resurrection Bay) tended to keep oil out. In addition to wind effects, fresh water that entered most fjords near their heads set up a two-layer circulation system, where surface waters moved seaward and deeper waters exhibited return flows into fjords. This reinforced the tendency for oil to remain offshore and not penetrate deeply into fjords.

Considering the nature of the Alaska Coastal Current and the drainage, or offshore, winds and currents within fjords, it was likely that oil beaching would be concentrated along offshore islands, coastal headlands, and eastward-facing spits or promontories. Relatively few coastal effects would be expected within fjords. This was generally what occurred-all of the major fjords showed little or no oil moving into them, and offshore islands were moderately to heavily oiled at some time (including the Chiswell Island group south of Resurrection Bay in the first week of April; then Hagget Island, Rabbit Island, and Outer Island, south of Nuka Bay; and the Chugach Islands near the western end of the Kenai Peninsula in the second week in April). Although most of the headlands were oiled to some extent, many rewashed relatively quickly because they were often subject to high-energy wave action. A major patch or concentration of oil was blown toward shore slightly west of Nuka Sound around 11 April. The eastward-facing spits and promontories showed heavy oiling in several instances; Gore Point was one that acted like a scoop in the westward drift and was heavily oiled. Under the influence of southeast winds, oil was also driven into Tonsina Bay. In addition, Dicks Bay and Port Dick, which are just west of Gore Point, received light-tomoderate oiling during this period. These fjords are not large enough to develop much protective drainage winds and circulation. During the next few days, oil patches continued to move west and come ashore. By 13 April, some of the western bays, such as Rocky Bay and Windy Bay (north of East Chugach Island), also received light-to-moderate amounts of oiling. 


\section{Barren Islands and Beyond}

By the time oil from the T/V Exxon Valdez reached the Chugach Islands, it was in the form of widely scattered patches and lines of sheen.
Typically these patches were composed of tarballs, which are small pieces of mousse that vary in size from less than $2.5 \mathrm{~cm}$ to nearly $1 \mathrm{~m}$ in diameter. In some instances, strong surface convergence patterns in the currents (caused by

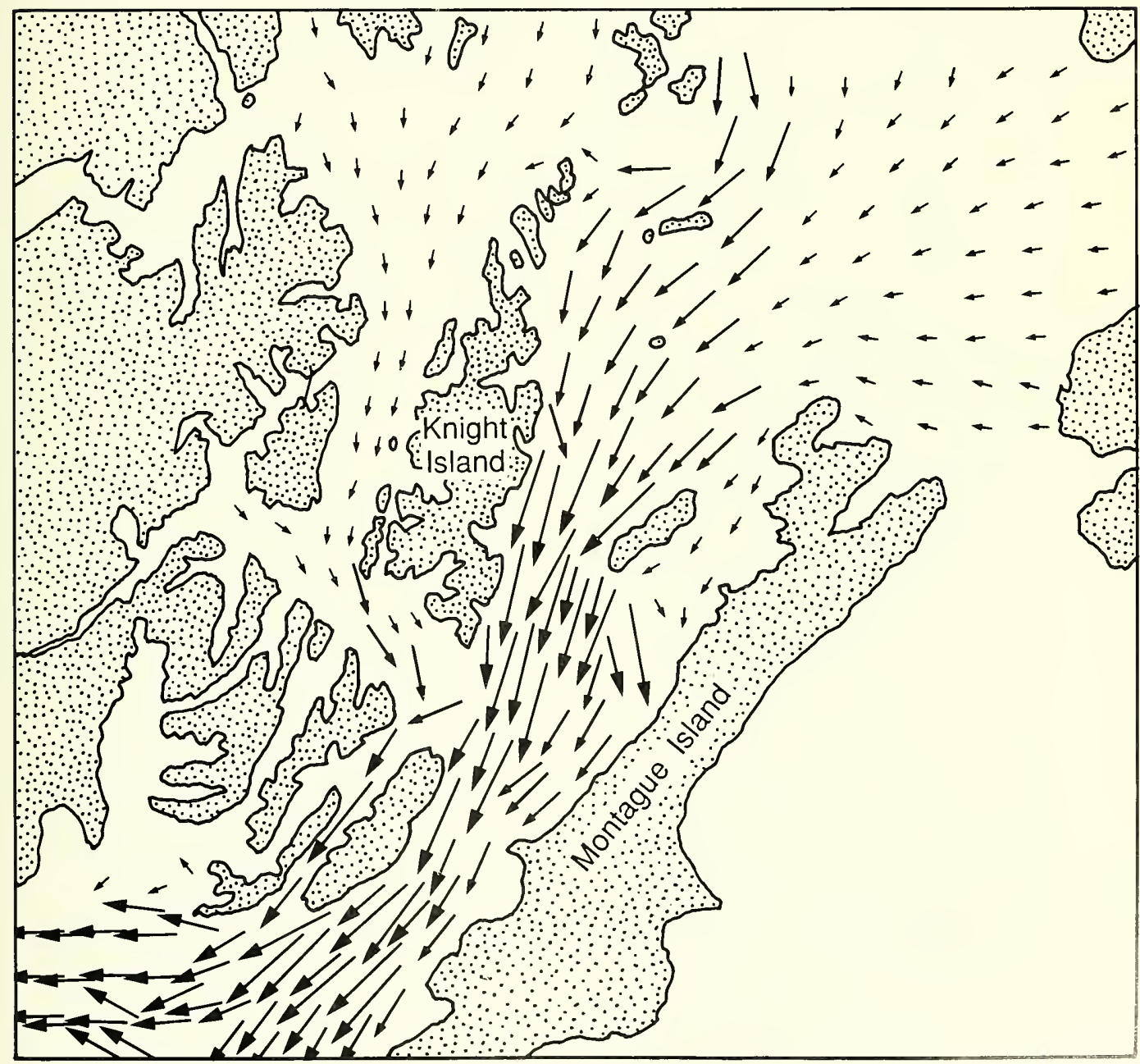

Fig. 9. Approximate mean current pattern used for trajectory analysis in Lower Cook Inlet and Upper Shelikof Strait. 
freshwater mixing or wind shear) collected tarballs into streaks, where they coalesced and mixed with other debris and flotsam to form a continuous line of mousse. Widely scattered tarballs can also coalesce along a beach and yield a continuous band of mousse in the intertidal zone. By the third week in April, scattered patches of oil were moving between Afognak Island and the western end of the Kenai Peninsula. This path includes the Barren Islands, with the Kennedy Entrance to the north and the Stevenson Entrance to the south.

As the Alaska Coastal Current moves beyond the Barren Islands, it is deflected north, around the end of the Kenai Peninsula, where it then flows west, turns south of Cape Douglas, and then enters Shelikof Strait (Fig. 9). A small part of the current closest to the Kenai Peninsula shoreline actually moves north along the coast and enters lower Cook Inlet. In addition to this current structure, the wind patterns in lower Cook Inlet tend to show fjord-like behavior, and strong northerly winds are common. Therefore, most of the oil passing the Barren Islands moved along the Alaska Coastal Current across the mouth of lower Cook Inlet and into Shelikof Strait. Only a small fraction of the oil could move north along the eastern side of lower Cook Inlet.

As scattered oil patches moved across lower Cook Inlet and into Shelikof Strait, another physical process affected the oil and caused behavior that is of interest. This process was due to the relatively large amounts of fresh water flowing out of Cook Inlet which, in turn, cause a strong convergence band that wraps around Cape Douglas and extends down the northern side of Shelikof Strait. This convergence zone was able to coalesce a good deal of scattered oil, thereby appearing to reconstitute the spill. More serious than the visual appearance of a large band of oil was the fact that many birds that raft up and sleep on the water during the night were also drawn into convergence lines and mixed with the oil. This explains the sudden appearance of large numbers of oiled birds along the Katmai coast, particularly around Hallo Bay.

During the oil movement across lower Cook Inlet and down Shelikof Strait, individual wind patterns grounded a number of patches, resulting in widely scattered light-to-moderate coastal effects. Once again, the heaviest shoreline effects were seen on beach segments that faced the predominant currents and winds. This led to scattered oil along the Katmai coast and a moderate concentration at Cape Douglas. In April, however, spotty shoreline oiling also took place on Afognak,
Raspberry, and Kodiak islands because of northerly winds.

By the time the remnants of the oil reached the end of Shelikof Strait, they were so widely scattered that only isolated tarballs could be found. Currents generally turn south around the western end of Kodiak Island, and some tarball spatter was seen on the Trinity Islands and eventually on Chirikof Island. Along the coast of the Alaskan Peninsula a small number of tarballs (about six) were discovered in the Chignik area.

All of the oil that came to Kodiak Island did not necessarily come in the Alaska Coastal Current and pass by lower Cook Inlet and Shelikof Strait. Oil that moved offshore south of Nuka Sound was seen to scatter and spread out in a number of offshore eddies. These eddies generally mill around over Portlock Bank; however, some mixing takes place with water of the Alaska Stream that runs offshore along the shelf break south of Kodiak. It is estimated that a small fraction of the oil followed this route and may have been responsible for the widely scattered tarball spatter that was reported along the southern coast of Kodiak Island.

\section{Summary and Conclusions}

No oil spill in recent U.S. history has been studied as much as that of the T/N Exxon Valdez. Moreover, these investigations and studies will undoubtedly continue, and response personnel and environmental scientists will be able to broaden their knowledge about oil spills from these efforts. It is also true that no oil spill in recent history captured the attention of the press and public as much as that of the T/N Exxon Valdez. As a result, hundreds of reporters looking for stories and many naive observers were seeing a major oil spill for the first time. Unfortunately, information management during the height of a spill response has little quality control. Thus, many misconceptions were passed on, which left millions of readers and viewers overwhelmed with information that tended to be more sensational than true. Although this happened in all areas of spill response, the greatest problem for trajectory analysis and understanding of the movement and spreading of the oil was the false-positive sightings. On a daily basis, reports of floating oil came in from dozens of sources. Hundreds of overflight maps were prepared. During the course of the spill, ice, internal waves, kelp beds, natural organics coming from kelp beds, pollen, plankton blooms, cloud shadows, and guano washing off rocks were all reported at one time or 
another as oil. These, of course, were in addition to the hundreds of reports of actual oil sightings, of which there were a great deal. Press, television, and news magazine accounts typically treated all reports the same; the most common representation of the spill that was presented to the public was a continuous black blob extending from Prince William Sound to somewhere in the Aleutian Islands. It is easy to understand why the several hundred million people who were interested in the spill and had no other sources of information thought that the spill looked like a 600-mile-long parking lot.

Faced with this kind of confusion, it is difficult to get an accurate picture of where the oil spill moved and what it was like. There are several techniques, however, that help. The first technique is to concentrate on trained observers (as the spill went on their numbers increased). The second technique is to use computers and trajectory analysis routines that account for the oil movement due to winds and currents. During a spill, such models are used for actual forecasts, but after the fact, they become very useful in a hindcast mode. This technique uses both the observations and the computer, neither of which is totally reliable. The model is run forward from the initial spill. Once or several times each day it is checked against observations. If sighted oil patches are required to swim upstream (or move against strong winds), then they are treated as false positives. If, on the other hand, the leading edge of the slick or individual patches of oil are seen to outrun or lag behind the computer projections, then the hydrodynamic current estimates are suspect and the model is adjusted accordingly and rerun. The chronology and coverage of the spill can be reconstructed in a fairly reliable way with these methods.

A second advantage of using hindcast techniques is that the computer models are quantitative and will provide estimates of the actual amounts of oil that moved to various locations throughout the spill history, which allow something like an oil budget to be approximated. Preliminary results of such a process indicated that, by 7 April or the end of the second week of the spill, about $30 \%$ of the spill had evaporated within Prince William Sound. An additional $40 \%$ was on the beaches or in the intertidal zone, mostly on Smith, Eleanor, Ingot, and Knight islands, with secondary amounts on Green and Latouche islands. About $25 \%$ of the oil had passed through Prince William Sound and extended in the Alaska Coastal Current to south of the Chiswell Islands. This left about $5 \%$ of the oil floating in Prince William Sound. Beyond this time decreasing amounts of floating oil were seen, primarily due to the rewashing of the oiled shorelines.

Initial hindcasting studies have also been carried out for the Gulf of Alaska portion of the spill and indicate that only about $10 \%$ of the oil traveled beyond the area around Gore Point; about $2 \%$ actually reached Shelikof Strait. These hindcast studies are continuing, and more detailed results will eventually be available for the entire spill area.

To summarize the floating oil distribution: heavy concentrations of floating oil were present in southwest Prince William Sound for about 2 weeks; reduced amounts (less by a factor of 10) were present for about 2 more weeks. After that time, many light sheens were reported, but the actual amounts of floating heavy oil were small. In the Gulf of Alaska during the first 2 weeks of April, scattered patches of heavy oil were present slightly offshore between Montague Island and the Chiswell Island group. Between the Chiswell and Barren islands, even more widely scattered patches and heavy shoreline effects were seen in the area on both sides of Gore Point. Beyond the Barren Islands, only widely scattered patches of mousse were observed around midApril. An exception was the strong convergence zone south of Cape Douglas and in the eastern end of Shelikof Strait, where bands of mousse coalesced. In these areas, shoreline effects were widely scattered and generally light.

\section{References}

Johnson, W. R., and T. C. Royer. 1986. A comparison of two current meters on a surface mooring. Deep Sea Res. 33:1127-1138.

Johnson, W. R., T. C. Royer, and J. L. Luick. 1988. On the seasonal variability of the Alaska coastal current. J. Geophys. Res. 93 (C10):12423-12437. 


\title{
Distribution and Relative Abundance of Sea Otters in South-central and Southwestern Alaska Before or at the Time of the T/V Exxon Valdez Oil Spill
}

by

\author{
A. R. DeGange, D. H. Monson, D. B. Irons, C. M. Robbins, and D. C. Douglas \\ U.S. Fish and Wildlife Service \\ 1011 E. Tudor Road \\ Anchorage, Alaska 99503
}

\begin{abstract}
Surveys of sea otters (Enhydra lutris) conducted before, immediately after, or at the time of the T/N Exxon Valdez oil spill were used to guide otter capture efforts and assess the immediate effects of the spill. Shoreline counts (by boat) of sea otters in Prince William Sound in 1984 suggested that a minimum of 4,500 sea otters inhabited nearshore waters of Prince William Sound. Areas of highest density within the western portion of Prince William Sound included the Bainbridge Island area, Montague Island, Green Island, and Port Wells. About 1,330 sea otters were counted from helicopters along the coast of the Kenai Peninsula. Highest densities of sea otters were found along the western end of the Kenai Peninsula. At Kodiak Island, about 3,500 sea otters were counted in coastal surveys from helicopters. Highest densities of sea otters were found in Perenosa Bay in northern Afognak Island, and in waters between Afognak, Kodiak, and Raspberry Islands. Along the Alaska Peninsula, about 6,500 sea otters were counted between Kamishak Bay and Unimak Pass. Areas of concentration included the Izembek Lagoon area, False Pass, the Pavlof Islands, Hallo Bay, and Kujulik Bay. Line transect surveys conducted offshore of the coastal strips indicate that at the time of the surveys relatively high densities of sea otters existed offshore at Kodiak Island and along the Alaska Peninsula, but not on the Kenai Peninsula.
\end{abstract}

At the time of the T/N Exxon Valdez oil spill, great concern existed for the safety and health of wildlife in the path of the spill. Sea otters (Enhydra lutris) were the source of much of this concern because they are one of the most susceptible marine mammals to contamination from oil (Costa and Kooyman 1982; Siniff et al. 1982; Geraci 1988; Ralls et al. 1988) and they were the most abundant marine mammal in the path of the oil.

The size and distribution of sea otter populations are dynamic, particularly in geographic areas that are in the process of recolonization (Garshelis and Garshelis 1984; Garshelis et al. 1986; Johnson 1987; Estes 1990). Unfortunately, recent data on the number of sea otters in some areas affected by the oil spill did not exist before the spill. Therefore, shortly after the grounding of the tanker, biologists from the U.S. Fish and Wild- life Service initiated aerial surveys of sea otters to identify concentrations of sea otters that might be at risk from the oil, and provide some direction to the oil spill response effort. We summarize data on the relative abundance and distribution of sea otters in the oil spill zone.

\section{Methods}

Sea otter surveys in Prince William Sound were conducted from June through August in 1984 and 1985. An 8-m open Boston Whaler was the primary survey vessel. The survey vessel was run parallel to the coast, about $100 \mathrm{~m}$ offshore. One observer counted all sea otters between the vessel and shore; another observer counted all sea otters outside the vessel, most of which were within 100 to 
$200 \mathrm{~m}$ from shore. Most surveys were done when wave height was $<0.3 \mathrm{~m}$. If large groups of sea otters were spotted in the distance, the survey boat stopped to make accurate counts before the sea otters dispersed at the vessel's approach. For additional details on methodologies for boat surveys in Prince William Sound see Irons et al. (1988).

Sea otter surveys outside Prince William Sound were conducted in early April through late May 1989 from a Bell 206 or Hughes 500 helicopter fitted with either pop-out floats or fixed floats (helicopters with pop-out floats were used preferentially because of unrestricted visibility). Both coastal and offshore line transect counts were conducted. Two observers flew during each survey. The surveys were flown in the direction that placed the forward observer on the coastal side of the helicopter. The helicopters flew parallel to the coastline about $200 \mathrm{~m}$ offshore, at a constant speed of 70 knots and an altitude of about $100 \mathrm{~m}$. The shoreside observer in the front seat was responsible for counting all sea otters between the helicopter and shore. The rear observer counted all sea otters beyond $200 \mathrm{~m}$ from shore. The pilot pointed out sea otters directly on the flight path that may have been missed by the observer in the rear seat. The helicopter deviated from the coast to survey offshore islands and rocks. Hover counts were conducted on every 20th observation to account for diving animals. During hover counts, the helicopter hovered or circled around the animal or group of animals to obtain the highest total count for that observation. The highest total count included the initial number of sea otters counted plus any additional animals observed while hovering. In some instances, hover counts were conducted at higher altitudes to avoid scaring sea otters. Large groups of sea otters $(>20)$ were circled to obtain the best possible count. Consequently, adjustments due to diving were not made for groups of more than 20 sea otters. Line transect surveys for sea otters were conducted offshore (outside of $400 \mathrm{~m}$ ) following the guidelines in Burnham et al. (1980). Data from the offshore line transect surveys are not summarized here.

The fact that sea otters dive and escape detection complicates the analysis of sea otter survey data. During boat surveys, the vessel speed was sufficiently slow that many diving seas otters were probably detected; nevertheless, some sea otters were undoubtedly missed. For the helicopter coastal counts, an average correction factor was used to adjust all groups of sea otters with less than 20 animals. Line transect data are not in- cluded; therefore, the numbers presented in this report are not population estimates.

For analysis, Prince William Sound was divided into 15 regions of unequal size (see Irons et al. 1988). To estimate sea otter density, the number of sea otters observed in each region was divided by the number of kilometers of shoreline surveyed. For areas outside Prince William Sound, the coastline was divided into segments based primarily on shoreline features such as points of land, bays, and lagoons. Wherever possible, the lengths of the segments were kept approximately equal. Densities of sea otters for areas outside Prince William Sound were calculated by dividing the total adjusted number of sea otters for each segment by the number of kilometers of shoreline in each segment. In this paper, high density refers to more than 2.5 sea otters per kilometer. Moderate densities are between 1.0 and 2.0 sea otters per kilometer.

\section{Results}

Within Prince William Sound in 1984-1985, sea otter densities varied from 0.2 to 2.7 sea otters per kilometer of shoreline. High densities of sea otters were found along the northwestern shore of Montague Island, at Green Island, in Port Wells, and in Orca Inlet (Fig. 1). Of those areas, only the Montague-Green Island area was affected by oil from the T/V Exxon Valdez. Areas with moderate densities of sea otters that were affected by oil included the Port Bainbridge and the Unakwik Inlet areas, although only a small portion of the latter area was affected. Irons et al. (1988) counted 4,509 sea otters from boats in Prince William Sound in 1984-1985. The number of sea otters counted in 1984-1985 in areas that were oilaffected in some way was 2,500 .

Survey techniques used by Irons et al. (1988) were not designed to sample offshore areas that might be occupied by sea otters. In one such area near Cordova, Monnett and Rotterman (1989) counted 3,500 sea otters from fixed-winged aircraft; many of these otters were associated with intertidal haul outs in Orca Inlet.

Densities of sea otters on the Kenai Peninsula, as determined from helicopter surveys at the time of impact of oil from the T/N Exxon Valdez oil spill in April 1989, ranged from 0.0 to 4.6 sea otters per kilometer. High densities were found on the west. ern end of the Kenai Peninsula near Seldovia and English Bay (Fig. 2). Those areas received little or no effect from the oil spill. Three areas of moderate 
Fig. 1. Densities of sea otters (number per kilometer of coastline) in Prince William Sound in 1984-1985.

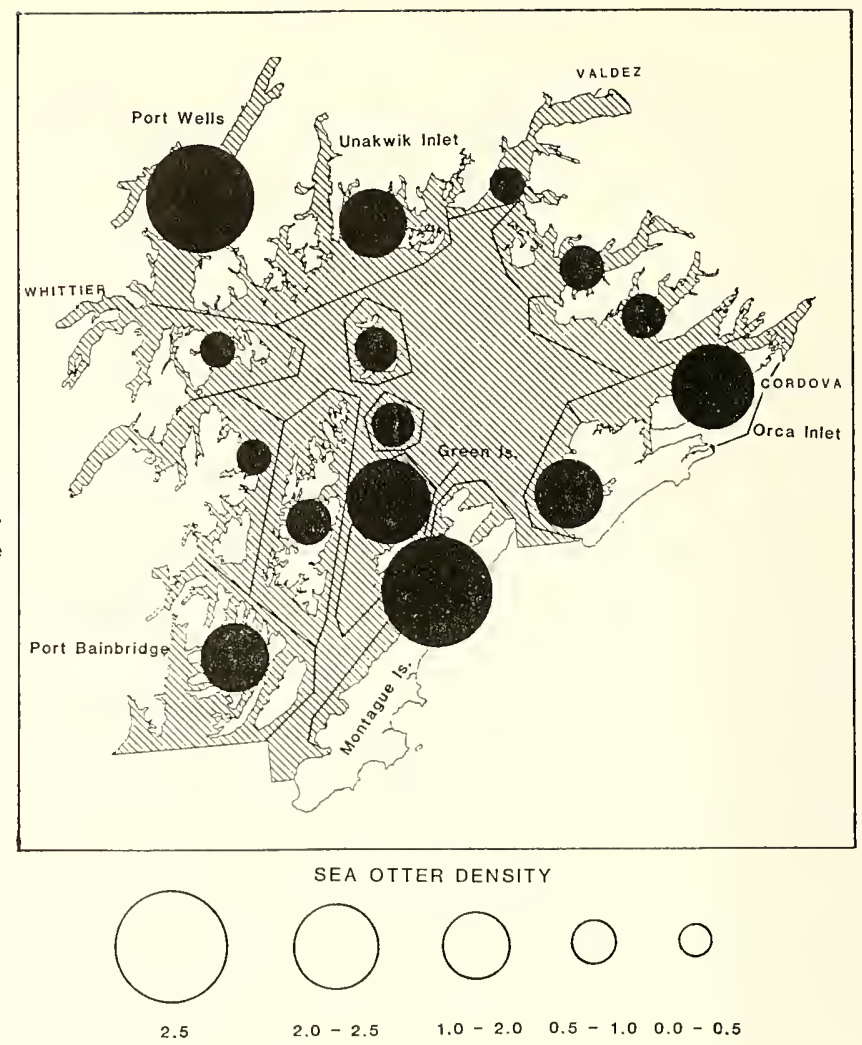

sea otter density were identified on the Kenai Peninsula: Whidbey Bay on the eastern end of the Kenai Peninsula, Chugach and Windy bays, and the greater Port Chatham area. While all three areas are considered within the oil spill zone, only the Chugach and Windy bays area was heavily affected by oil. Densities of sea otters for other areas on the Kenai Peninsula ranged from 0.0 to 0.78 sea otters per kilometer. About 1,330 sea otters were counted on the Kenai Peninsula during the spring survey, and all were potentially at risk from oil.

Densities of sea otters in the Kodiak Archipelago ranged from 0.0 to 4.4 sea otters per kilometer. Nine regions had high densities, including Perenosa Bay in Northern Afognak Island, and eight coastal segments in waters between Kodiak, Raspberry, and Afognak islands east to Spruce Island (Fig. 3). Moderate sea otter densities were found on the west side of Afognak Island, and in Seal Bay on northern Afognak, Kazakof Bay on southern
Afognak Island, Kizhuyak Bay on northern Kodiak Island, northern Chiniak Bay, and Spiridon Bay in western Kodiak Island. Regions that were hardest hit by oil included Shuyak Island, the western side of Afognak Island, Kupreanof Strait, and the bays on the northwestern part of Kodiak Island (Galt and Payton 1990). About 3,500 sea otters were counted in the Kodiak Archipelago during the spring 1989 survey; all were considered at risk.

On the Alaska Peninsula, high densities (within the range of those observed along the Kenai Peninsula and in the Kodiak Archipelago) were found at Hallo Bay south of Cape Douglas, near Kujulik Bay east of Chignik, north of the Shumagin Islands, in the Pavlof Islands, and in Bechevin Bay north of False Pass (Figs. 4 and 5). The highest densities of sea otters observed during the spring 1989 survey were found along the Alaska Peninsula. Densities were as high as 25.5 sea otters per kilometer. Densities of sea otters in excess of 14.0 per kilometer were found at False Pass, Amak 


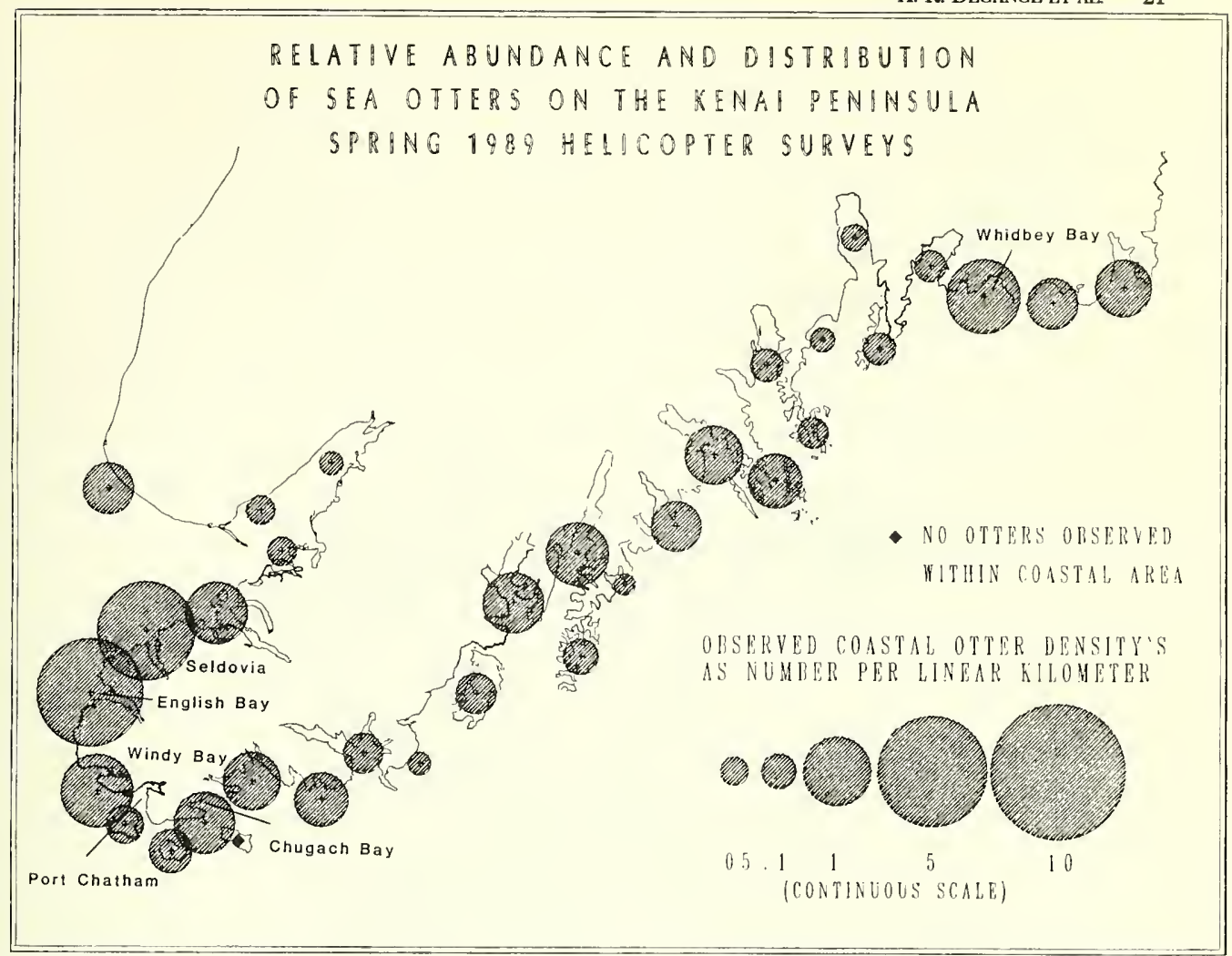

Fig. 2. Densities of sea otters (number per kilometer of coastline) along the Kenai Peninsula in April 1989.

Island, and near Izembek Lagoon (Fig. 5). Oil, in the form of a thick mousse, was found scattered along the coastline of the Alaska Peninsula south to the Chignik area (Galt and Payton 1990). Not one of the beaches southwest of Chignik was oiled. About 6,500 sea otters were counted during the spring 1989 survey along the Alaska Peninsula, including the southern half of Kamishak Bay, all of Unimak Island, and the north side of the Alaska Peninsula to Izembek Lagoon. Within the portion of the Alaska Peninsula that was affected by oil, about 2,500 sea otters were counted that were potentially at risk.

\section{Discussion}

The surveys conducted around the time of the T/V Exxon Valdez oil spill met the principal objective for which they were intended, that is, to iden- tify concentrations of sea otters to help guide the response effort. About 15,800 sea otters were counted in the survey area during boat and helicopter surveys. As stated earlier, the numbers presented here are not population estimates. They cannot be used as population estimates because it is likely that some sea otters were missed during the surveys and because offshore survey data are not included in the analysis. Strip sampling, which was used in this study, assumes that all animals in the search area were counted. This assumption is rarely fulfilled for most censuses of wildlife populations, particularly diving marine mammals. Although an attempt was made to limit surveys to the best conditions, factors such as weather, sea state, glare, observer capability, avoidance or repulsion of the survey animal, survey craft, and survey speed all resulted in missed animals. No analyses have been completed yet to correct the data for any of these factors. During helicopter surveys, observers 


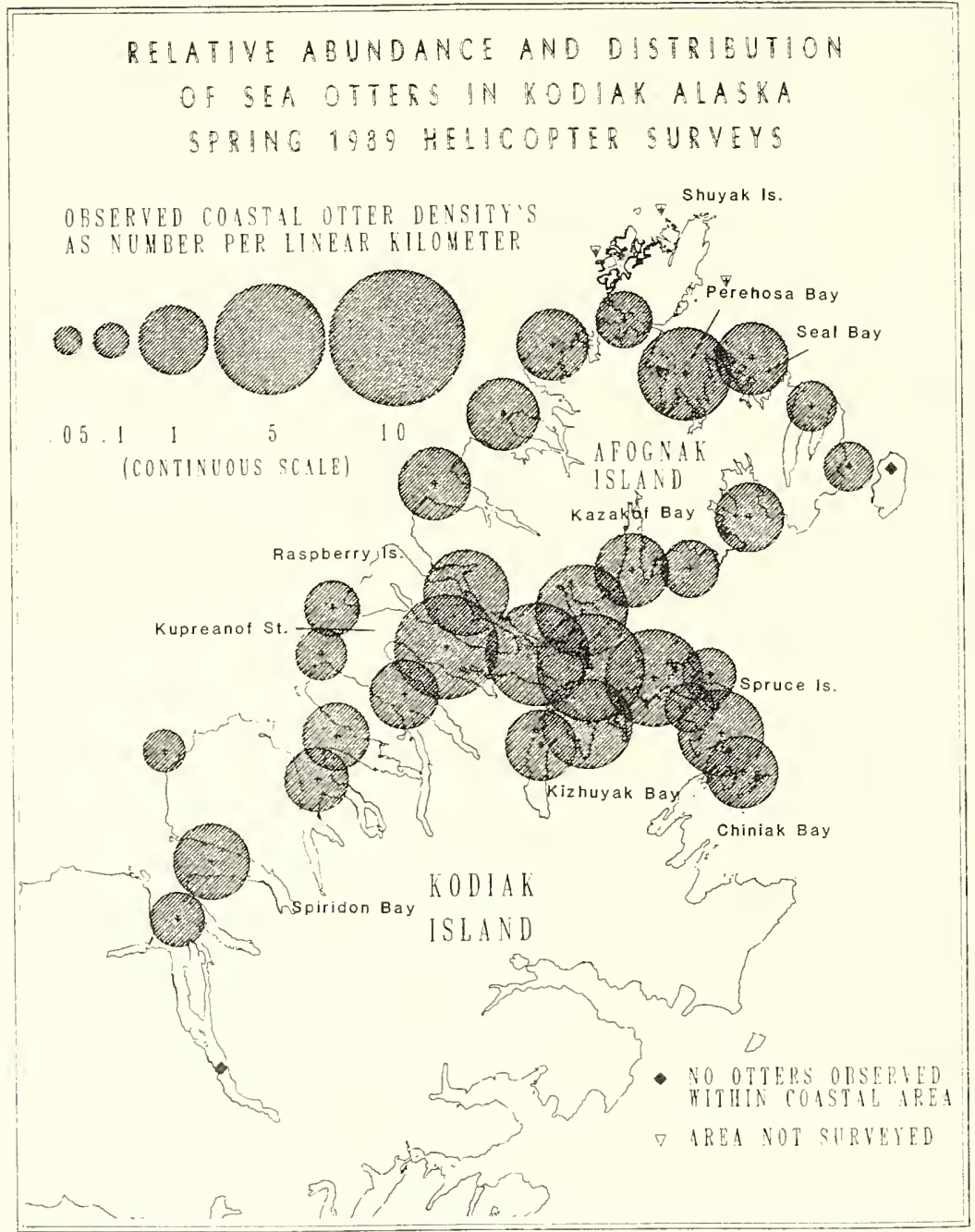

Fig. 3. Densities of sea otters (number per kilometer of coastline) in the northern Kodiak Archipelago in April 1989.

attempted to correct for animals that were diving by conducting periodic hover counts; however, single animals that were underwater were always missed. No attempt was made to correct the boat data for diving sea otters. Although some diving sea otters were missed during boat surveys, the prob- 


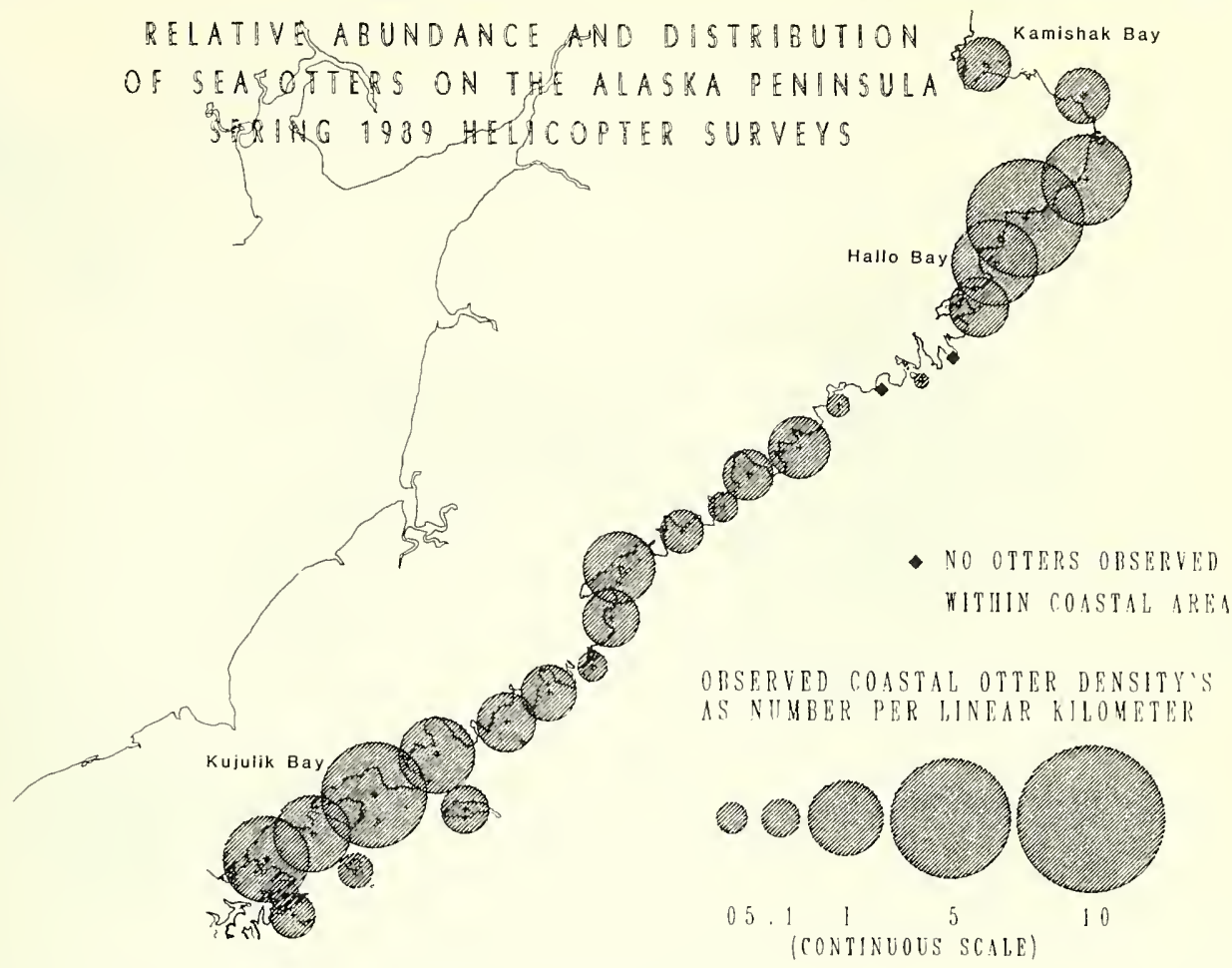

Fig. 4. Densities of sea otters (number per kilometer of coastline) along the Alaska Peninsula from Chignik to Kamishak Bay in spring 1989.

lem of missing diving sea otters was probably not as severe from boats as from helicopters because of the slower survey speeds of boats. Many sea otters inhabit some offshore ( $>400 \mathrm{~m}$ from shore) areas. This is particularly true of broad shallow areas such as the Sandman Reefs near the Shumagin Islands (an area that permits sea otters to feed far offshore) and areas like the Kodiak Archipelago, where large numbers of sea otters are frequently found resting over deep water several kilometers from shore (Drummer et al. 1990, DeGange and Monson, unpublished data). Because offshore areas that may contain even low densities of sea otters are extensive, surveys designed to sample only inshore waters may miss large numbers of sea otters.

Based on the timing of recovery of sea otter carcasses during the oil spill response and the number of carcasses recovered from major geo- graphic locations, it seems that the effects of the T/ Exxon Valdez oil spill on sea otters were most acute in Prince William Sound and along the Kenai Peninsula (DeGange and Lensink 1990). Several areas with moderate and high densities of sea otters were affected by the spill. At the time of the spill, these areas were occupied primarily by females, many of which were pregnant or lactating. The Green Island area of Prince William Sound was identified before the oil spill as an important region for pup rearing. Although some high-density habitat was affected by the spill, survey data indicate that the effects of the spill on sea otter populations could have been worse, particularly if the oil had gone to Orca Inlet near Cordova, or if high-density habitat at Kodiak Island and on the Alaska Peninsula had been more severely affected. Populations of sea otters at Kodiak Island and on the Alaska Peninsula were somewhat protected 


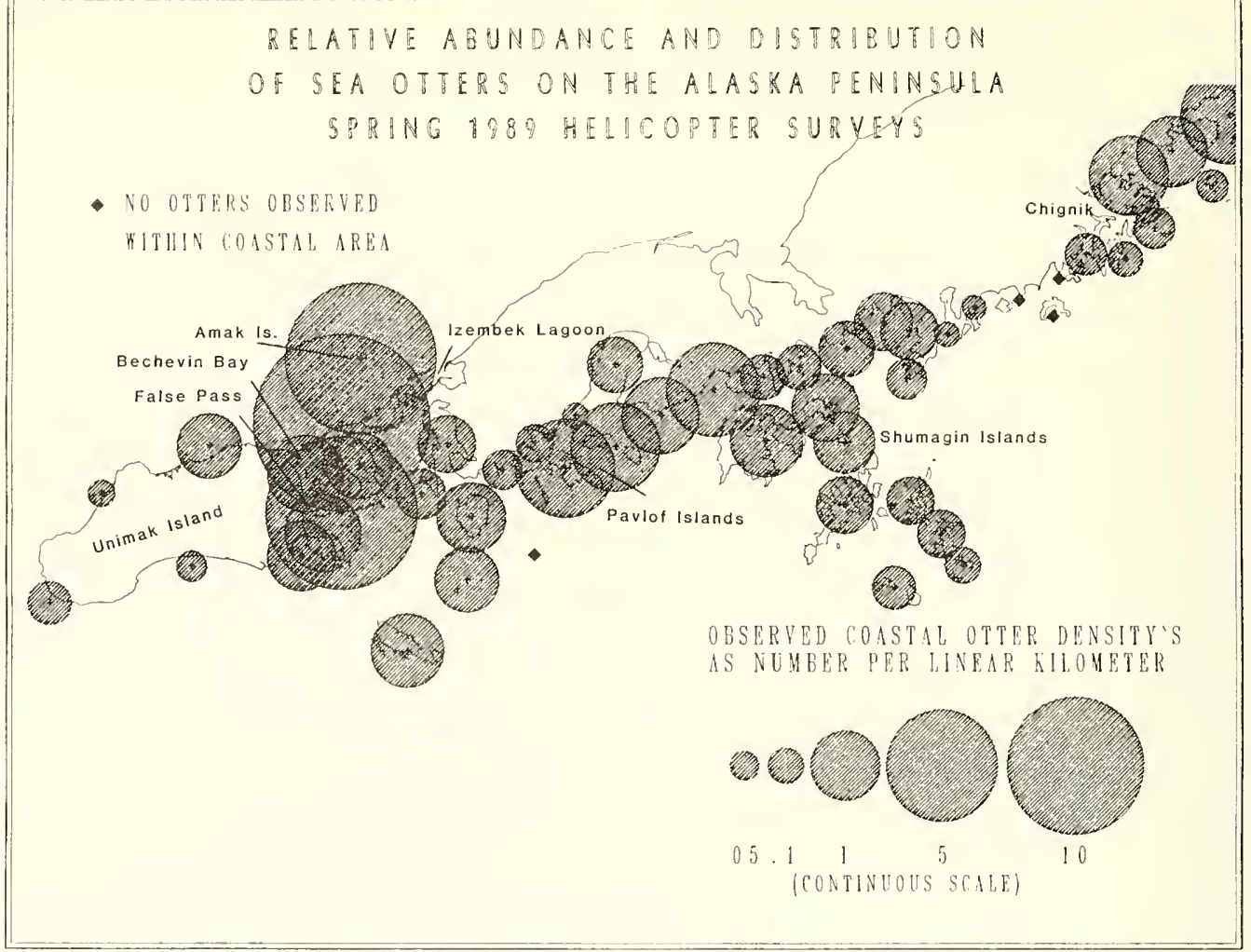

Fig. 5. Densities of sea otters (number per kilometer of coastline) along the Alaska Peninsula from Chignik to Unimak Pass in spring 1989.

from the oil spill by their distance from Bligh Reef (and hence the amount of time it took oil to travel there), and the weathered state of the oil (it seems that weathered oil did not affect sea otters as severely as freshly spilled crude oil; DeGange and Lensink 1990; Galt and Payton 1990).

The T/V Exxon Valdez oil spill demonstrated that our knowledge of the number of sea otters in various portions of south-central Alaska that potentially were at risk from oil was inadequate both from the perspective of guiding a response and for assessing damages. The most complete survey information available before the spill for Prince William Sound was 4 to 5 years old. Very little information was available for the Kenai Peninsula, the Kodiak Archipelago, and the Alaska Peninsula. Censusing sea otters is an inexact science. Therefore, as part of future oil spill contingency planning, we recommend that survey designs for sea otters, tailored for specific geographic areas, be in place. The T/N Exxon Valdez oil spill also made clear the need to frequently monitor populations of sea otters at greatest risk from oil. Surveys must be done with sufficient frequency and precision to statistically track changes in the distribution and abundance of sea otter populations. A survey of this kind should include the population of sea otters in Prince William Sound and anywhere else that oil-related development and transport occurs within their range.

\section{Acknowledgments}

L. F. Pank contributed ideas during all phases of project design, data collection, and analysis. S. Amstrup, V. Barnes, D. Dewhurst, C. Garner, G. Garner, S. Knick, D. Seagars, and J. Selinger assisted with the fieldwork. 


\section{References}

Burnham, K. P., D. R. Anderson, and J. F. Laake. 1980. Estimation of density from line transect sampling of biological populations. Wildl. Monogr. 72:1-202.

Costa, D. P., and G. L. Kooyman. 1982. Oxygen consumption, thermoregulation, and the effect of fur oiling and washing on the sea otter, Enhydra lutris. Can. J. Zool. 60:2761-2767.

DeGange, A. R., and C. J. Lensink. 1990. Distribution, age, and sex composition of sea otter carcasses recovered during the response to the T/N Exxon Valdez oil spill. Pages 124-129 in K. Bayha and J. Kormendy, tech. coords. Sea Otter Symposium: Proceedings of a symposium to evaluate the response effort on behalf of sea otters after the T/V Exxon Valdez oil spill into Prince William Sound, Anchorage, Alaska, 17-19 April 1990. U.S. Fish Wildl. Serv., Biol. Rep. 90(12).

Drummer, T., A. R. DeGange, L. McDonald, and L. F. Pank. 1990. A procedure to adjust for group size influence on line transect surveys. J. Wildl. Manage. 54:511-514.

Estes, J. A. 1990. Growth and equilibrium in sea otter populations. J. Anim. Ecol. 59.

Galt, J. A., and D. L. Payton. 1990. Movement of spilled oil from the T/V Exxon Valdez. Pages 4-17 in K. Bayha and J. Kormendy, tech. coords. Sea Otter Symposium: Proceedings of a symposium to evaluate the response effort on behalf of sea otters after the T/V Exxon Valdez oil spill into Prince William Sound, Anchorage, Alaska, 17-19 April 1990. U.S. Fish Wildl. Serv., Biol. Rep. 90(12).
Garshelis, D. L., and J. A. Garshelis. 1984. Movements and management of sea otters in Alaska. J. Wildl. Manage. 48:665-678.

Garshelis, D. L., J. A. Garshelis, and A. T. Kimker. 1986. Sea otter time budgets and prey relationships in Alaska. J. Wildl. Manage. 50:637-647.

Geraci, J. R. 1988. Physiologic and toxicologic effects on sea otters. Pages 217-224 in J. R. Geraci and D. J. St. Aubin, eds. Chapter 7, Synthesis of effects of oil on marine mammals. Outer Continental Shelf Study, Minerals Management Service 88-0049.

Irons, D. B., D. R. Nysewander, and J. L. Trapp. 1988. Prince William Sound sea otter distribution in relation to population growth and habitat type. U.S. Fish and Wildlife Service, Alaska investigations, Anchorage, Alaska. 31 pp. [unpublished report]

Johnson, A. M. 1987. Sea otters of Prince William Sound, Alaska. U.S. Fish and Wildlife Service, Alaska Fish and Wildlife Research Center, Anchorage, Alaska. $87 \mathrm{pp}$. [unpublished report]

Monnett, C., and L. M. Rotterman. 1989. Distribution and abundance of sea otters in southeastern Prince William Sound. Alaska Pacific University, Anchorage, Alaska. 30 pp. [unpublished report]

Ralls, K., and D. B. Siniff. 1988. Sea otters and oil: ecological perspectives. Pages 204-215 in J. R. Geraci and D. J. St. Aubin, eds. Chapter 6, Synthesis of effects of oil on marine mammals. Outer Continental Shelf Study, Minerals Management Service 88-0049.

Siniff, D. B., T. D. Williams, A. M. Johnson, and D. L. Garshelis. 1982. Experiments on the response of sea otters, Enhydra lutris, to oil. Biol. Conserv. 23:261-272. 


\title{
Role of the U.S. Fish and Wildlife Service in the Sea Otter Rescue
}

\author{
by \\ K. Bayha \\ U.S. Fish and Wildlife Service \\ 1011 E. Tudor Road \\ Anchorage, Alaska 99503
}

\begin{abstract}
The U.S. Fish and Wildlife Service is responsible for sea otter (Enhydra lutris) management and, as trustee agency for the T/V Exxon Valdez oil spill, was responsible for overseeing the sea otter rescue effort. The Service's goals for the effort were to provide assistance as requested to Exxon Company, U.S.A., and its contractors, ensure that those engaged in sea otter capture were covered by appropriate permits, monitor efforts of Exxon and its contractors to ensure they were commensurate with the threat to sea otter populations, and balance the public's demand for maximum effort to rescue sea otters with the ecological and practical realities. The decision to launch a rescue effort was not automatic. There were internal discussions where the pros and cons were expressed. It was recognized from the outset that from an ecological viewpoint the several hundred otters that might be salvaged would be insignificant. But because sea otters stimulate such strong emotional reactions in most people, public demand for animal rescue was high. Available data on the sea otters' ability to cope with oil contamination was scant. Therefore, it was decided to proceed and document the effort. This symposium and the proceedings represent the culmination of that decision.
\end{abstract}

One question asked of me during the spill response, by a citizen working at one of the sea otter (Enhydra lutris) centers, deserved a better answer than I gave at the time. She asked, "Why does the Fish and Wildlife Service get to make all the decisions concerning the fate of the rehabilitated sea otters?"

The Marine Mammal Protection Act gives the Service the responsibility for conservation of sea otters in Alaska. Implementing regulations of this act authorize the Service to designate persons to collect, clean, and rehabilitate sea otters for "...scientific research, public display, or enhancing the survival or recovery of a species or stock."

During the T/N Exxon Valdez oil spill, the U.S. Coast Guard provided the Federal on-scene coordinator, who was the ultimate Federal decision maker. In a non-Federal spill-such as the T/N Exxon Valdez incident-where the spiller accepts responsibility for the response, the Service's response role is to provide recommendations on ac- tions needed to protect fish and wildlife resources to the Regional Response Team and ultimately to the Federal on-scene coordinator, and to monitor the wildlife rescue and rehabilitation program conducted by the responsible party (Stieglitz 1990).

In support of the Alaska Regional Response Team (ARRT), the Service sent personnel to Valdez on 24 March to provide technical advice through the Department of the Interior's (DOI) on-scene representative. On $25 \mathrm{March}$, after consultation with the Service's on-scene representative, the DOI on-scene representative met with Exxon Company, U.S.A., staff and recommencied that Exxon obtain a sea otter expert to implement a rescue effort if needed.

R. Davis of Sea World Marine Research Institute (formerly Hubbs Marine Research Center) was identified in the ARRT Wildlife Protection Guidelines (developed in 1988 by a special interest group and interagency team) as an expert in cleaning, transporting, and rehabilitating sea otters (Alaska 
Regional Response Team 1988). Exxon, which had accepted responsibility for spill response activities, contracted with the institute (and later directly with Davis and T. M. Williams) for sea otter rescue and rehabilitation. Davis arrived in Valdez on 27 March.

Because of the emergency, Davis and his designees were given verbal authorization by the Service's on-scene spill coordinator. A letter of authorization was later issued by the Service permitting R. Davis and "...others with appropriate skill and training operating under your direct supervision..." to capture, transport, wash, treat, rehabilitate, and hold sea otters until they were ready for release (Stieglitz 1989). This permit also included performing necropsies on sea otters that died during rehabilitation. Davis launched the first capture boat on 29 March.

On 30 March, Davis requested Service assistance in capturing sea otters, a process that will be described further in papers that follow. The Service's goals in the overall sea otter response effort were to:

(1) help mobilize a capture effort as quickly as possible,

(2) monitor the overall capture effort and ensure that safe procedures were used,

(3) monitor the rehabilitation of sea otters,

(4) release rehabilitated sea otters to clean-water habitats,

(5) authorize the transfer to aquariums of any sea otters that were found to be unfit for release, thereby filling pending requests for sea otters for display and educational purposes, and

(6) learn as much as possible from this first major oil spill in sea otter habitat.

As the Federal agency charged with management of Alaskan sea otters, the Service was responsible for overseeing the rescue program and monitoring the performance of all personnel engaged in the rescue effort. Our monitoring was to ensure that the activities of Exxon's contractors were consistent with the Marine Mammal Protection Act, commensurate with the threat to the sea otter population, and at the same time responsive to public concern. This was not a simple task.

As indicated in the paper by DeGange et al. (1990), the portion of the Alaskan sea otter population in the path of the oil spill was but a small fraction of the statewide population. Overall, the Alaska sea otter population was large and healthy. We knew that from a biological perspective a rescue effort was not justified purely on the basis of pre- venting widespread population depletion or protecting the gene pool.

But sea otters evoke strong emotions among humans, possibly because many of their behaviors resemble ours. Indeed, Aleut legend holds that the sea otter is the brother of man. For much of the public, particularly those from California, where the sea otter is designated as "threatened" under the Endangered Species Act, the sea otter is symbolic of people's concern for the marine environment. Public demand for a rescue was intense from the very beginning and was sustained far longer than anticipated. To a large degree, I believe this demand was part of the atonement for the human insult to nature embodied in the oil spill. We simply felt we had to do all that could be done for the unfortunate animals affected by the spill.

How much of a rescue effort was enough became a matter of balancing biological constraints and issues as well as interpreting the public interest. As the oil spill moved out of Prince William Sound, threatening additional sea otter habitat, public concern did not wane. Rescue efforts were expanded to include the Kenai Peninsula and then the waters of the Kodiak Archipelago and Alaska Peninsula. Additionally, logistics became more difficult as distances from the location of oiled otters to Valdez increased and the Valdez Otter Rehabilitation Center became overcrowded. Thus, the Service took a strong position that a second rehabilitation center was needed in Seward.

Plans for releasing the first rehabilitated sea otters were complicated by fears that they may have contracted disease in captivity and that their release might constitute a threat to sea otters in the wild. Therefore, the Service directed that prerelease centers be built to house rehabilitated sea otters until it was determined that disease was not likely to be a problem, and it was safe to release them. Prerelease centers were established in Valdez and Little Jakolof Bay.

These aspects of the sea otter rescue effort will be explored in more depth in the papers that follow. Perhaps it is sufficient for me to say at this time that the Service took its responsibilities very seriously. If we seemed either too cautious or too aggressive, it should be remembered that we had the responsibility, but not unlimited authority. The Service needed to persuade those financially responsible and legally in charge of the oil spill response of the necessary steps. Writes W. O. Stieglitz (1990): "The relationship between the Service and Exxon was undoubtedly awkward, with roles and responsibilities often confused or 
controversial. To some extent, this is inevitable when a Federal agency oversees, without any tangible authority, the work of a private corporation...the Service should clarify in the National Contingency Plan the difference between trustees and spiller and the difference in response between federalized and non-federalized spills."

The Service also has a responsibility to ensure that we learn as much as possible from this precedent-setting experience. This symposium is one of the key steps in fulfilling that responsibility.

The Service's Alaska regional director has already committed to revising the Service's oil spill contingency plan. We anticipate that many recommendations that evolved from our experience in the sea otter response effort, and that are articulated in the proceedings of this symposium, will find a place in that revised plan.

\section{References}

Alaska Regional Response Team. 1988. Wildlife protection guidelines for Alaska. Tab D, Annex X. Pages A4-6 in Alaska region oil and hazardous substances pollution contingency plan. Anchorage, Alaska.

DeGange, A. R., and C. J. Lensink. 1990. Distribution, age, and sex composition of sea otter carcasses recovered during the response to the Exxon Valdez oil spill. Pages 124-129 in K. Bayha and J. Kormendy, tech. coords. Sea Otter Symposium: Proceedings of a symposium to evaluate the response effort on behalf of sea otters after the T/V Exxon Valdez oil spill into Prince William Sound, Anchorage, Alaska, 17-19 April 1990. U.S. Fish Wildl. Serv., Biol. Rep. 90(12).

Stieglitz, W. O. 1989. Letter to R. Davis, Hubbs Marine Research Institute. 4 May 1989. 2 pp.

Stieglitz, W. O. 1990. Memorandum from the Region 7 director to the director of the U.S. Fish and Wildlife Service. 7 February 1990. 11 pp. 


\title{
Alaska's Role in Mitigating the Effects of the T/N Exxon Valdez Oil Spill on Sea Otters
}

\author{
by \\ L. F. Lowry \\ Alaska Department of Fish and Game \\ 1300 College Road \\ Fairbanks, Alaska 99701
}

\begin{abstract}
Sea otters (Enhydra lutris), like other marine mammals but unlike other resident species of wildlife, are managed by Federal agencies, not by the State of Alaska. Much of the habitat essential to the sea otter population is State-owned tidal and submerged lands. It was this nearshore habitat in Prince William Sound and adjacent parts of the Gulf of Alaska that was most severely affected by the T/N Exxon Valdez oil spill. Three State resource agencies were involved in response to the spill-the Alaska Department of Environmental Conservation, Alaska Department of Natural Resources, and Alaska Department of Fish and Game (ADF\&G). The ADF\&G had a particular interest in sea otters because its charge is the conservation and management of fish and wildlife and their habitats. The Division of Habitat of the ADF\&G participated in the development of the Alaska Regional Response Team's Wildlife Protection Guidelines for Alaska, which were used in establishing the sea otter rescue program. The Division of Habitat evaluated the importance of habitats and effects of the spill on them, and made recommendations for mitigating measures and cleanup priorities and techniques. The ADF\&G Division of Wildlife Conservation conducted on-site evaluations of the distribution of oil and its effects on marine wildlife during the spill, and made recommendations for mitigation and cleanup. The staff of the ADF\&G were not directly involved in the sea otter capture and rehabilitation efforts, but were consulted regarding whether to implement the program and during the development of the sea otter release strategy. Particular concerns of the ADF\&G in regard to the release of rehabilitated sea otters were the need to ensure that released sea otters did not introduce disease into wild populations, the selection of appropriate areas for release, and the need to adequately monitor the fate of released animals.
\end{abstract}

In Alaska State government, three agencies share the responsibility for conservation and management of natural resources. The Alaska Department of Natural Resources is charged with management of land and waters owned by the State, and with the development and conservation of resources other than fish and wildlife. The Alaska Department of Environmental Conservation (ADEC) is charged with protection of air, land, and water quality, and prevention of environmental contamination. The Alaska Department of Fish and Game (ADF\&G) is charged with the mainte- 
nance, development, and enhancement of Alaska's fish and wildlife resources.

When Alaska became a State in 1959, the ADF\&G assumed management responsibility for all resident species of fish and wildlife, including sea otters (Enhydra lutris). The primary objectives of the ADF\&G's sea otter management program were to assist in the repopulation of vacant sea otter habitat, investigate basic sea otter biology and ecology, and determine the effects of harvesting on high-density sea otter colonies (Calkins and Schneider 1985). Much of this work was done in cooperation with personnel from the U.S. Fish and Wildlife Service (Kenyon 1969).

With passage of the Marine Mammal Protection Act in 1972, management authority for sea otters was transferred to the Service. However, because of the availability of experienced staff, and because the State was considering a request for return of marine mammal management, the ADF\&G continued a limited program of sea otter research. Those efforts provided some of the baseline data on sea otter distribution and abundance in areas that were later affected by the T/N Exxon Valdez oil spill (Pitcher 1975; Schneider 1976, 1979).

\section{Response to the T/N Exxon Valdez Oil Spill}

Sea otters spend much of their lives in the coastal zone, where they haul out in or near the intertidal zone and swim, feed, and socialize in nearshore waters. Much of the habitat essential to the sea otter population is State-owned tidal and submerged lands; this was the habitat most severely affected by the T/N Exxon Valdez oil spill. State agencies, therefore, had a major role in responding to the spill.

When the T/V Exxon Valdez ran aground in Prince William Sound, the ADEC became the lead State agency for responding to the oil spill. Because the ADEC was one of the few agencies that maintained staff and offices in Valdez, its role was especially essential in the hours and days immediately after the spill. Personnel from the ADEC were onboard the T/ Exxon Valdez within $3 \mathrm{~h}$ of the time it ran aground, and they attempted to ensure that Alyeska Pipeline Service Company and Exxon Company, U.S.A., carried out the oil spill contingency plan. The ADEC provided initial aircraft support for personnel from many different agencies; it also maintained a full-time public in- formation office whose staff provided current and accurate reports on the spill and its effects.

As soon as they were notified of the spill, the ADF\&G sent staff to Valdez. Personnel from the Division of Habitat provided information on the location of important habitats and wildlife concentrations to the Alaska Regional Response Team (RRT) and others. The Division of Habitat staff participated in relevant working groups and committees to try to mitigate the effects of the spill and cleanup on fish and wildlife and their habitats. At the time of the spill, the ADF\&G research vessel Montague was operating in Prince William Sound. Personnel from the ADF\&G Division of Habitat, Division of Wildlife Conservation, and Division of Commercial Fisheries boarded the Montague on 25 March 1989 and began tracking the movements of the oil and assessing its initial effects. The Montague, which was later replaced by the Resolution, provided essential logistics for the ADF\&G and Service researchers during the initial phase of the spill. The ADF\&G personnel continued to monitor, report on, and mitigate effects on wildlife throughout the spill and cleanup efforts.

\section{Involvement With the Sea Otter Rescue and Release}

On 24 March 1989, the ADF\&G representative of the Wildlife Protection Working Group of the Alaska RRT consulted with personnel from the Department of Interior (DOI) regarding measures necessary for wildlife protection. On 25 March, DOI's on-scene representative, with the concurrence of the $A D F \& G$, met with Exxon staff and recommended that Exxon hire a sea otter expert to come to Valdez and evaluate whether to initiate a rescue effort, and to implement the rescue program, if necessary. This recommendation led to the decision to initiate the sea otter rescue program.

The ADF\&G's Division of Wildlife Conservation is the State agency with responsibility for conservation and management of wildlife populations. Because sea otters are managed by the Service, Division of Wildlife Conservation staff did not work directly on the sea otter rescue and rehabilitation efforts. However, they regularly reported on the location of oil and oiled wildlife and assisted in the collection, transport, and processing of affected animals. For example, when staff aboard the Resolution sighted the first oil in Gibbon Anchorage on 30 March, they contacted Valdez to suggest that sea otter capture crews be sent to the area. Sea 
otter rescue efforts began in Gibbon Anchorage on 31 March.

The Service consulted with the ADF\&G during development of a strategy for the release of rehabilitated sea otters. The ADF\&G raised a concern regarding the possibility that released animals could transmit disease to wild sea otters or to other species. (Similar concerns were expressed in regard to the release of rehabilitated birds and seals.) Those concerns were based on well-documented experiences with disease transmission in terrestrial mammals (Choquette et al. 1961), and they were reinforced by a recent outbreak of distemper virus in European harbor seals, Phoca vitulina (Osterhaus et al. 1988). Although the risk of spreading disease was recognized as slight, experts agreed that it was not possible to certify that animals were free from disease before their release. Because large numbers of sea otters survived in the general region affected by the spill, and because the number of animals to be released was so small that it would probably not enhance population recovery, the State recommended that rehabilitated otters be kept permanently in captivity. If this most conservative approach could not be taken, the ADF\&G recommended that animals be carefully screened for disease before release. If rehabilitated sea otters were not going to be kept in captivity, the ADF\&G staff recommended that they be released in areas where local populations were below carrying capacity, and where they would not exacerbate existing conflicts with fisheries. Possible release areas identified were Washington and Oregon, which had previously received transplants of sea otters from. Alaska, and British Columbia, which had been developing plans for a sea otter transplant. Izembek Lagoon, Unimak Island, Unalaska Island, and the Yakutat area were identified as potential release locations in Alaska. Finally, the ADF\&G recognized that if rehabilitated sea otters were to be released, it was essential that they be monitored to determine their fate. In this regard, the State was fully supportive of Service plans to implant radio-tags or otherwise mark sea otters before their release.

\section{References}

Calkins, D. G., and K. B. Schneider. 1985. The sea otter (Enhydra lutris). Pages 37-45 in J. J. Burns, K. J. Frost, and L. F. Lowry, eds. Alaska Dep. Fish Game, Game Tech. Bull. 7.96 pp.

Choquette, L. P. E., J. F. Gallivan, J. L. Byrne, and J. Pilipavicius. 1961. Parasites and diseases of bison in Canada. Can. Vet. J. 2:168-174.

Kenyon, K. W. 1969. The sea otter in the eastern Pacific Ocean. U.S. Bur. Sport Fish. Wildl., N. Am. Fauna 68. 352 pp.

Osterhaus, A. D. M. E., J. Groen, P. De Vries, F. G. C. M. Uytdehaag, B. Klingeborn, and R. Zarnke. 1988. Canine distemper virus in seals. Nature 335:403-404.

Pitcher, K. W. 1975. Distribution and abundance of sea otters, Steller sea lions and harbor seals in Prince William Sound, Alaska. Appendix A in D. G. Calkins, K. W. Pitcher, and K. B. Schneider. Distribution and abundance of marine mammals in the Gulf of Alaska. Department of Fish and Game, Anchorage, Alaska. 56 pp.

Schneider, K. B. 1976. Assessment of the distribution and abundance of sea otters along the Kenai Peninsula, Kamishak Bay, and the Kodiak Archipelago. U.S. Dep. Commer., NOAA, OCSEAP Final Rep. 37(1986):527-626.

Schneider, K. B. 1979. Sea otter distribution and abundance, southern Kodiak Archipelago and the Semidi Islands. Department of Fish and Game, Anchorage, Alaska. 44 pp. 


\title{
Press Interest in Sea Otters Affected by the T/N Exxon Valdez Oil Spill: A Star is Born
}

by

\author{
B. T. Batten \\ U.S. Fish and Wildlife Service \\ 1011 E. Tudor Road \\ Anchorage, Alaska 99503
}

\begin{abstract}
For the Federal agency with responsibility for management and welfare of the sea otter (Enhydra lutris), as well as for scientists and volunteers devoted to studying and caring for it, the T/V Exxon Valdez oil spill transformed a biological species that was relatively unknown by the general public into a media icon. The anthropomorphic character of the sea otter helped it become a powerful symbol of the oil spill that was one of the world's top news stories of the year and one of the top environmental stories of the decade. The nature and extent of the press attention generated by the sea otters often led to strong public reactions to sea otter-related activities and decisions. Responding to and anticipating those reactions posed substantial challenges that affected the sea otter response effort in several ways. Scientists and managers who may be involved in future sea otter research and management activities should be prepared to recognize the sea otter's strong, new identity. That identity can be expected to generate a much higher level of public scrutiny of sea otter activities than in the prespill days, and future sea otter contingency planning should include adequate public information resources to respond to that scrutiny.
\end{abstract}

\section{The Sea Otter, the Oil Spill, and the Press: Background}

"... if one image stands out in the aftermath of America's worst oil spill, it is of these once-healthy animals rubbing their eyes and grooming their fur in a futile attempt to rid their coats of slimy crude oil." - Chicago Tribune, 9 April 1989. (Fig. 1)

Before 24 March 1989, the sea otter (Enhydra lutris), a marine mammal nearly extinct at the turn of the century, swam peacefully in the coastal waters of southern Alaska, enjoying little recognition from the general public. In the weeks and months after that date, when millions of gallons of oil spilled into Prince William Sound, this fuzzy, charismatic animal became the subject of an intense rescue, rehabilitation, and research effort, and in the process gained a new identity. Forged in the mind of the world's public by the ringing hammer of the mass media, this identity came to serve as a powerful symbol in many of the accounts and discussions of the world's most highly publicized environmental disaster. Furthermore, that identity became an unexpected and important player in sea otter-related decisions and activities.

I briefly examine the phenomenon behind the creation of this identity and how that identity played a role in decisions and activities after the oil spill. Several questions about sea otter-related efforts and public interest in them establish the framework for discussion. Those questions are What is the level of the interest in sea otters of the oil spill? How did the sea otter come to generate that level of interest? What were some of the effects of that interest? What are the future ramifications of that interest? 
wide. From the earliest accounts, sea otters were reported as being among the victims. Press inter-

\section{U.S. bureaucracy halts rescuers of sea otters}

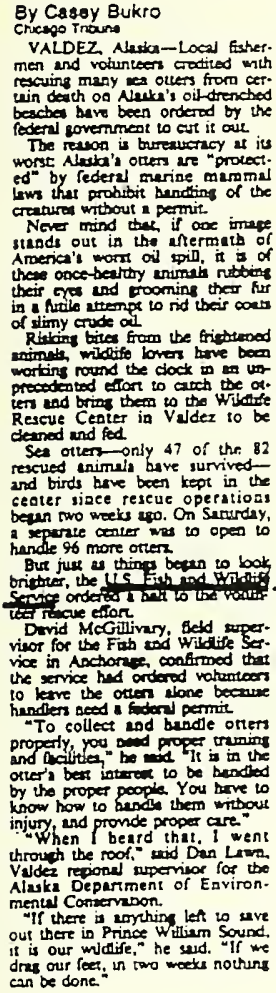

By Casey Bukro tiod wh ikn's ofl-drenched besches bave been ordered by the thal governmest to est it out The reston is bureweracy as its ") by federal marine mammal ins thes probibit bending of the creatures without a pertit. merien's worr oil will it is of

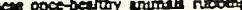
their and rooming thers he of limy crode of

Riting bite from the triftwoes (t) of en and bring theor to the Witetres ialez to be cleaned and fed

serued enimal a and birds have been koot in th ceter sizee fescue operations an two weeks apo. On serurday, Tepale conter west

But jus as thing beaten to bok

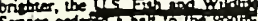
tet rivane efior

ary, field super.

per berane

-To collect ind bindle orters properly, you bad proper tramins

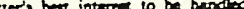
the proper peopla You heve to now how to atndis them withous fiury and pronde proper care"

When feard that, I went hrough the roof." and Dan Lewh. alder repionel apdervice for the mental Contervinon.

"If there is arythis left wo suve out there is Prince Whilim sound. cas be done.

Fig. 1. "U.S. bureaucracy halts rescuers of sea otters," Chicago Tribune, 9 April 1989.

\section{How Much Interest?}

Within hours after it occurred on 24 March 1989 , print and broadcast media carried accounts of the T/N Exxon Valdez oil spill in local (Alaska) media. When the size of the spill and the fact that it would take a heavy toll on wildlife and a pristine environment became apparent, the story quickly became national and international in scope, and by 25 March it was reported in media accounts world- est and consequently public interest expanded during the following weeks and months.

Because of the large number of players in the response scenario, press queries deluged virtually every agency and organization that might have some light to shed on developments. Though no account exists of the total number of press queries generated, the Anchorage press office of the U.S. Fish and Wildlife Service recorded more than 460 press queries that were related to the otters and the spill in the 6 months after the spill. Compared with a previous annual rate of about 140 queries on all topics per year, press interest in the spill and sea otters accounted for a $600 \%$ increase above the normal rate of interest in Service activities in Alaska. This total did not include the many queries received by the Service or Department of the Interior (DOI) employees on the scene in the four field stations of Valdez, Seward, Homer, and Kodiak or other offices in Anchorage.

As an indication of the international interest, the following countries were among those that sent queries:

- United States: All major national broadcast and print news organizations, scores of other newspapers, magazines, and broadcast outlets

- Great Britain: Reuters News Agency, London Times, British Broadcasting Corporation

- Canada: Numerous newspapers, radio stations, Canadian Broadcasting Corporation

- Australia: Australian Broadcasting Corporation

- Japan: Asahi Shimbun, Tokyo Broadcasting Station

- Soviet Union: Novosti Press Agency

- West Germany: Stern, Geo, Springer News Agency

At the end of 1989, an Associated Press poll of editors and news directors identified the oil spill as the third most important news story in the world for the year (Fig. 2). According to the poll, it was eclipsed only by the disintegration of commu. nism in Europe, and nearly tied with the crushing of China's Tiananmen Square prodemocracy movement. The spill was rated higher than the San Francisco earthquake, the war on drugs, Hurricane Hugo, and Zsa Zsa Gabor's traffic ticket. In their editions of 31 December 1989, both the Anchorage Times and the Anchorage Daily News 
2. NATONAORLD 1989 in review

Fig. 2. "Communist breakdown tops '89 stories," Anchorage Times, 31 December 1989.
Communist

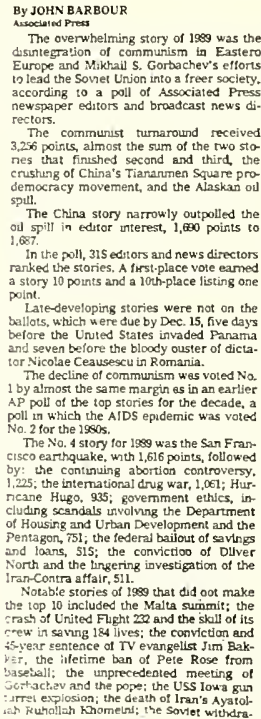

ung a voice in government, a more open guard In Poland, Solitaniy toon and began to build economic ties with the west to try ro pull the country poverty.

In the Soviet Uruon, Garbachev had 10 slow the rate of change while he struggled the economy with links 10 the pressed even there, etrunte nepublics relations also underwent once. Eas..h est even the mast resistant American doubters u onderng whatever had happened 10 "the evil empire.

2. Beijing was hostung the first ChireseSoviet summit in 30 years, but the historic in Tiananmen Square.

For seten weeks, the hundred-acre square had been occupled by thousands of de monstrators, demanding greater democracy and hit miluing the gavernment. For seven weeks, the goverm erance and restraint.

Then at 2 an sunday. June 4 birely two weeks after Gortachev left Beijing. a convoy of trucks accomps. ried by 10,000 foot soldiers of the Peopie's Liberation Army swept through the streets and openofire on the

By 5 a.tn., the square $*$ is charred hylks of vehicles and debris lett by the prolester Hundreds - perthaps thou sands - were dead

The United states con demsed mil China's milindawn on the promon demonstrators At year's end controversal
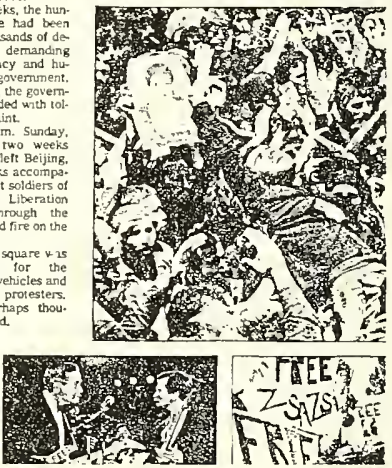
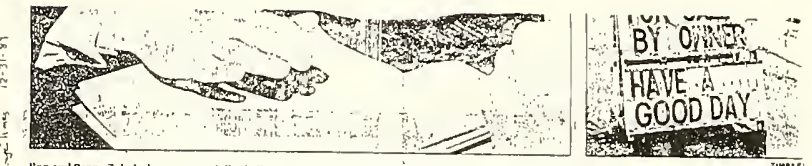

\&

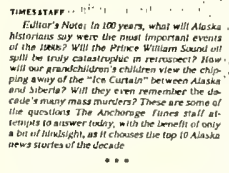

The spill

On Cooce Fritay in 2014 , news argentersions

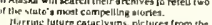

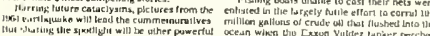

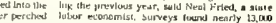
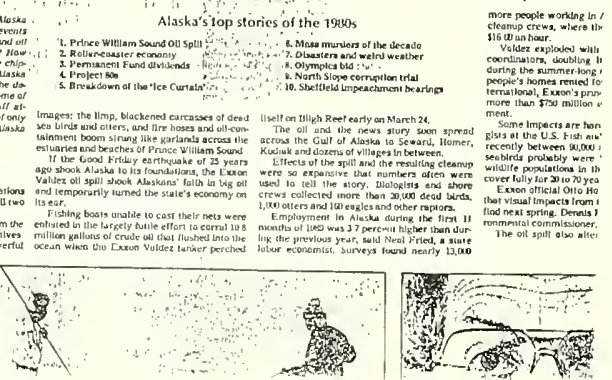

Fig. 3. "Times chooses oil spill... as decade's most important stories," Anchorage Times, 31 December 1989. 
rated the oil spill as the top Alaska story of the decade for the 1980's (Figs. 2 and 3).

\section{Why the Interest in Sea Otters?}

The T/V Exxon Valdez oil spill had several characteristics that gave it a high level of public interest, and therefore made it an irresistible story for the press. As an environmental disaster, it was preceded by a quarter of a century of gradually growing environmental awareness. It involved a highly visible corporate giant that controls more assets than most nations. And the oil, once it escaped the hold of the supertanker, continued to move into new areas during spring and summer, thereby ensuring a daily life of its own in press headlines. But most important, this story had what other disaster stories, including larger oil spills of the past, had lacked-the ultimate victim.

Although no people were physically harmed directly by the oil spill, the sea otters' injuries were extensive, dramatic, and visible to the general public through news photography. As a playful, photogenic, innocent bystander, the sea otter epitomized the role of victim. Though many more birds than otters were affected by the oil spill and generated enormous sympathy on their own, sea otters had never before been affected in previous spills, and generally upstaged the less anthropomorphic seabirds in media coverage. Small, furry, childlike, and vulnerable, sea otters became compelling victims with whom everyone could identify, and thereby made the perfect universal symbol for the injured party. Nearly a year after the spill, one national magazine summarized this sentiment when it referred to the Federal indictment for the oil spill as "the case of Otter et al. v. Exxon." (Fig. 4).

Capitalizing on the media appeal of the otters, press accounts often portrayed sea otters as pawns in successive conflicts that helped to keep the oil spill story in the headlines. Whether the adversaries in the conflicts portrayed were State or Federal agencies, members of the public, the Exxon Company, U.S.A., or anyone else, sea otters could be seen as victims at the center of controversy. These stories often elicited emotional responses from the general public, who in turn placed demands upon those actually conducting or responsible for the sea otter rescue activities. In several examples of this type of response, press accounts suggested the metaphor of otters as children in distress. The following examples from oil spill press coverage illustrate this phenomenon and the public's response:

Sea otter as vulnerable, innocent victim. The earliest accounts of the spill, especially network television news, focused heavily on the cute and frolicsome sea otters suddenly in distress, oiled, frightened, and dying, in a losing battle with the oil (Fig. 5). Hundreds of letters and phone calìs from the public, including members of Congress, deluged the Service and the DOI urging government officials to place all available resources toward sea otter rescue and rehabilitation efforts (Fig. 6).

Sea otter in custody battle. At the height of sea otter rescue activities, on-scene Service officials determined that many of the untrained volunteers

\section{After the Spill, Into the Dock}

Now Exxon itself faces federal criminal charges

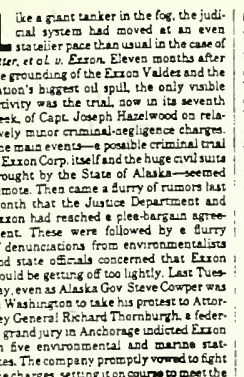

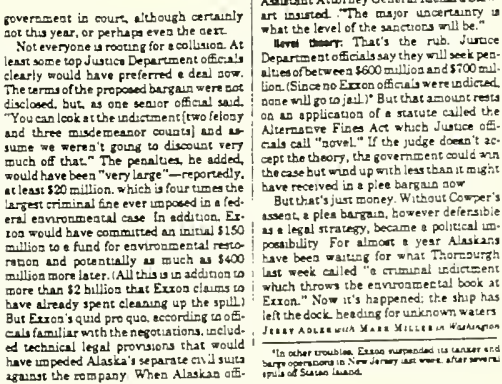
cole objected. Exron bacxed out of the des] The day aftet the indie:sent, unhappy Justice Deparment oficials wook the un. usual sep of brefing repore ens on the riss of tryag the case. Unfortunately for thet this carce out wunding as if the govers. rent thought it wight lose, as inpresion

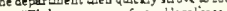

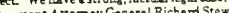

Fig. 4. "After the Spill, Into the Dock," Newsweek, 12 March 1990. 
Fig. 5. "Rescuing animals difficult," Anchorage Times, 2 April 1989.

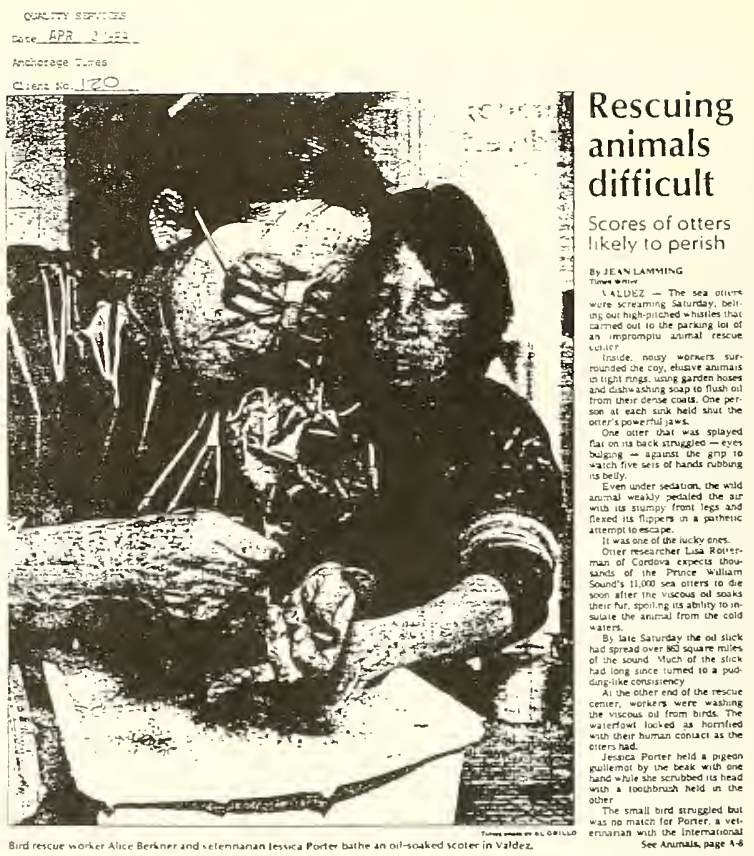

who were "rescuing" sea otters were doing more harm than good, and directed that only trained, designated individuals should continue the otter rescues, in accordance with existing rescue plans. One press account that circulated nationwide reflected heavily on the sentiments of volunteers who felt left out of the effort, and gave the impression that the rescue effort had been halted because of "bureaucracy at its worst," suggesting that the Service was merely trying to exert ownership over the sea otters by requiring that only permit holders could rescue the animals. No biologists or veterinarians were cited in the article as objecting to the decision, but by including objections of a bookstore owner and a State official-neither of whom had expertise in sea otter biology-the article gave the impression that the decision was not in the best interest of the otters (Fig. 1). The report triggered heavy protests from the public (Fig. 7), including members of Congress, who demanded that the decision be reversed and the rescues be continued (Fig. 8). The Secretary of the Interior personally signed letters to members of Congress and the editors of several major newspapers in the nation explaining the rationale behind the decision and pointing out that the rescues were continuing.

Sea otter care and welfare. Within 2 weeks of the spill, Service officials determined that the single sea otter rehabilitation center set up in Valdez would not be sufficient to accommodate sea otters still being rescued. At the Service's request, Exxon officials agreed to open a second center in Seward by 7 April, but the opening was delayed repeatedly. When calls and correspondence from Service officials were unsuccessful in getting the center opened, the Service released a statement to the press criticizing Exxon for "dragging its feet" and jeopardizing the welfare of the sea otters. After several news articles on the subject (Fig. 9) and the involvement of an international animal welfare organization, the center was opened and operating by early May.

Sea otter as abused dependent. To monitor their long-range fate, Service officials determined that some of the sea otters rescued and rehabilitated from the spill should be fitted with transmitters before their release. Sea otter center workers who disagreed with this decision made statements to 

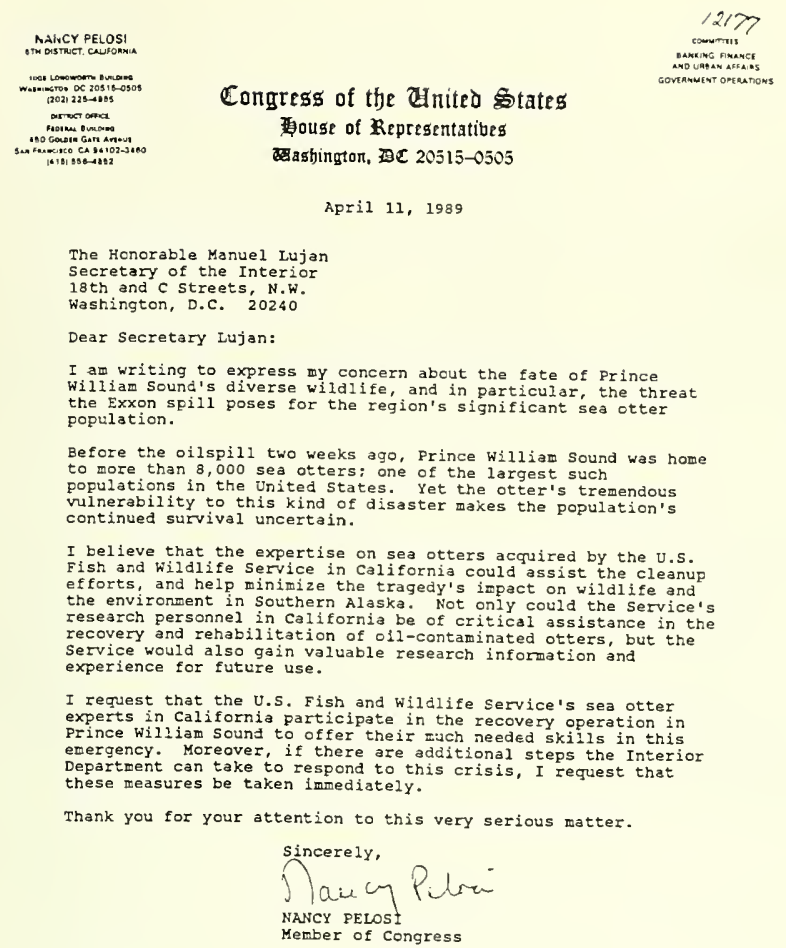

the press that this procedure was abusive to the sea otters because the transmitters had to be surgically implanted. In addition, they staged a confrontation with biologists in front of the press. Coverage of the event included videotape of the surgery and of a weeping worker cradling a dead otter. A report of the incident on a nationally televised "USA Today" program generated angry responses from some members of the public and was followed by a lawsuit filed by a Michigan-based group asking to halt the procedure (Fig. 10).

\section{The Effect of Public Interest}

In each of these four examples, as in others, the strength of the sea otter-as-symbol combined with sea otter-as-victim press accounts resulted in the involvement of an emotional public in virtually every aspect of sea otter activities. For specialists
Fig. 6. Letter from Congresswoman Nancy Pelosi to Secretary of the Interior Manuel Lujan, 11 April 1989. working with the sea otters, that public involvement translated into an enormous extra burden of not only having to make tough decisions or judgment calls in a crisis atmosphere, but also having to stop-often repeatedly-to explain or justify their decisions (K. Bayha and A.R. DeGange, U.S. Fish and Wildlife Service, Anchorage, Alaska, personal communication). Decisions affecting conduct of those activities could not be made strictly within the rational environment of a hermetically sealed science community, but rather in the shadow of a potentially hostile, emotionally charged public reaction to that decision.

One cost of this situation was the extra time required to complete or carry out some decisions. In the case of the volunteer sea otter rescuers early in spill activities, the Service decision was made in a relatively short time. Although the science community did not question the correctness of the decision, press accounts and public reaction, as noted, were 


\section{QUALTIYY SERVICES \\ Date APR 201989}

Anchorage Times

\section{Cient No. 120 Outraged by otter order \\ Dear Editor:}

I have just finished reading the article "Feds halt otter rescue" in The Anchorage Times April 10 and am appalled at the bureaucratic decision of the U.S. Fish \& Wildife Service to order volunteers to cease working to save the lives of sea otters coated by the oil spilled into Prince William Sound. The regulation prohibiting handling of protected species was designed to save the lives of otters, not to be used as a tool to condemn them to an agonizing death. One of the "reasons" used to justify the decision is the death of approximately 50 percent of the otters treated. That certainly is reverse thinking; 50 percent of the animals being treated are saved!

If the service is truly concerned about the lives of the sea otters and the continuation of the species, perhaps a more expedient solution could be found. The "experts" who are trained to "properly" handle otters should be on the scene. The spill happened nearly three weeks ago. Where have these experts been? Surely the phenomenon of oilcoated otters was not a completely surprising result of the spill. For what are they waiting?

Sheri Weinberger

Palmer

Fig. 7. "Outraged by otter order," Anchonage Times, 20 April 1989. strongly negative and required considerable resources in response to set the record straight. But this cost in resources needed to respond was only part of the price the Service paid under these circumstances. By having its decision challenged vociferously in the public forum of the media, the Service suffered an additional cost: the erosion of public confidence in the Service as an agency entrusted with making important natural resourcerelated decisions.

Subsequent decisions often took longer to finalize, due in part to the additional time required to reach out to members of the public or the press in an effort to preclude opposition resulting from similar misunderstandings. The sea otter release strategy, for example, which was essentially completed in a matter of weeks, took additional weeks to evolve because of concern about possible negative public reaction either to release locations or the possibility that released sea otters could transmit disease to wild sea otters. In response to these concerns, Service staff conducted extensive, timeconsuming communications with interested parties that were outside the organizational decisionmaking mechanism before finalizing the plan (K. Bayha, personal communication).

In addition to extra time needed to make decisions while taking into account the concerns of many interested parties, the high level of public interest required the Service to accommodate the press in some activities. For example, in the first release of a small number of otters, officials were swamped with requests from press representatives
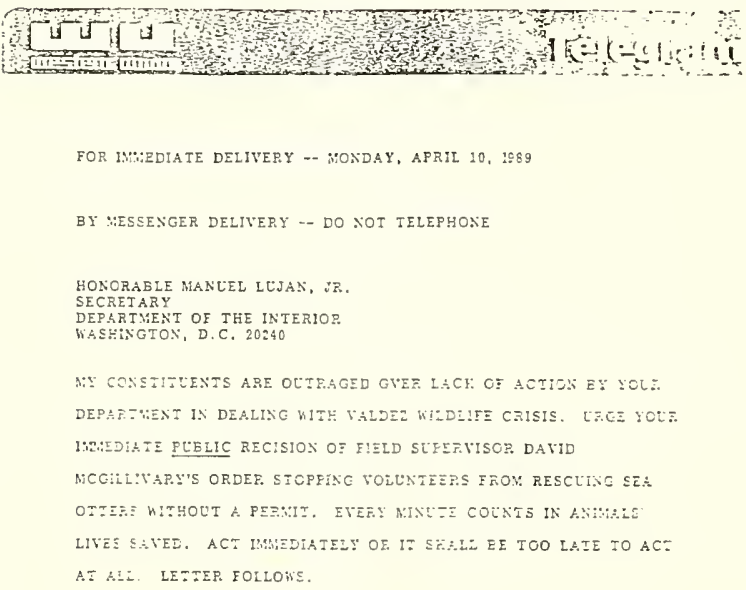

Fig. 8. Telegram from Congressman Frank Annunzio to Secretary of the Interior Manuel Lujan, 10 April 1989. 
QINATITY SERIIOS

DuLe APR 241989

Junesu Empire

\section{Feds, Exxon clash over need to open second otter rehab center}

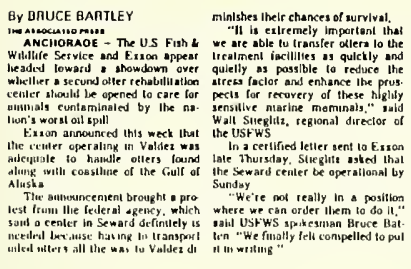

Ealten sald the agency astied on Apell 7 that a center capalite of han
dling 75 ollers be openol in Sew ard

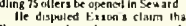

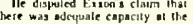
Valuez center. lie snid too 110 otters can be lnowied incre, and as of lalt this weck about so were being care Rager MtcManul. president of the Washinglun, i) C - based Cerler fur furnt mere than 100 oiled ollers this week of Core l'oint on the wule! edge of the peninsula And he sar
leclesal authorities liad likaind

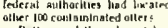
Rutlen sasd there hass I been
mim

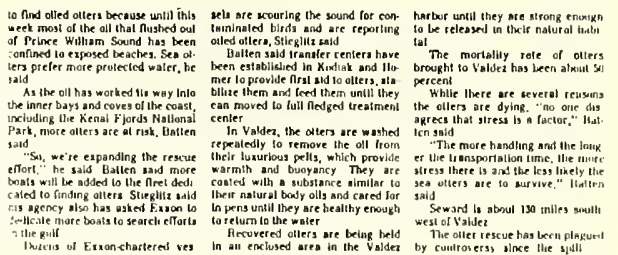

Fig. 9. "Feds, Exxon clash over need to open second otter rehab center," Juneau Empire, 24 April 1989.

eager to accompany and photograph the release. The release of those six otters had to be orchestrated to allow access by hordes of photographers and reporters, in a location selected to maximize photographic opportunities and access. Some scientists were concerned that the commotion of many extra people, boats, and helicopters could adversely affect the behavior of the stress-sensitive sea otters in their first days back in their natural environment (R. Gould, U.S. Fish and Wildlife Service, Anchorage, Alaska, personal communication).

Especially in an emergency situation such as an oil spill, with its implicit shortage of resources and overwhelming logistical and administrative demands, information and the time and means to distribute it becomes yet another valuable com- modity in short supply. The opportunities for failure are plentiful and enormous whether one is tending to the needs of sea otters or the needs of reporters - both of whom can require extreme care and demand lots of attention.

In retrospect, the high level of public interest in the events surrounding the distress of the sea otters was simply not anticipated. To respond to the extraordinary press interest, Service and other agency public affairs resources were diverted at the expense of existing public affairs programs both in Alaska and nationwide, and even those resources fell woefully short of meeting the demand for current information. Significant additional costs in time and stress were borne by the biologists, veterinarians, and other specialists
OUNITX SENIOES Dote NOV 141989

Nichor age Iimes

Groutp aims to stop research on otters

Lawsisit charges project's unnecessary By JACQUES PICARD

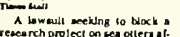
tecied by the Prince william. sound of spll was rued by a Michiganbised environume

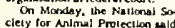
that it challenged the research project by the U.S. Fish and Whatile Service beccuse "the re sclentific purpose and is duplica.

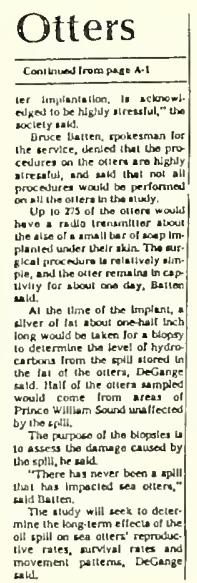

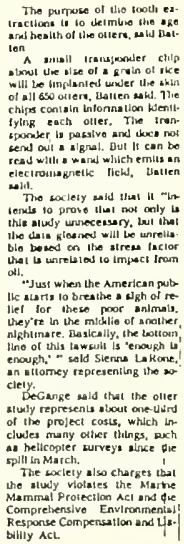

Fig. 10. "Group aims to stop research on otters," Anchorage Times, 14 November 1989. 
who were called upon to, in addition to their emergency duties, respond to press calls and conduct interviews and press tours. This extra responsibility lengthened the seemingly endless workdays for virtually all sea otter specialists involved in oil spill response activities, exacting a heavy toll on their time, energy, and morale. An early and substantial commitment of resources to provide the needed information through the press to the public could have increased the overall sea otter response efficiency immeasurably, leaving the sea otter specialists free to do their jobs.

\section{Future Ramifications of Interest in Sea Otters}

Though it may be considered a hindrance to sound scientific procedures, especially when expedience is important, the new public interest in sea otters cannot be denied. The expense of this expanded interest, whether it is calculated in lost time or information resources needed to respond, should be anticipated in the response plans to any future disaster affecting sea otters. It is the opinion of the author that the planning should provide for adequate public information resources at the earliest possible stage to help answer questions and anticipate potential problems born of public misperceptions. Of course, journalists usually prefer getting information directly from subjectmatter experts-biologists, veterinarians, decision makers-but trained information specialists available to work closely with sea otter specialists can provide valuable assistance in disseminating general information in response to frequently asked questions. In addition, such assistance may help achieve a proactive information dissemination program that can keep abreast of newsworthy developments through media releases and other information methodologies. A well-managed information program can effectively preempt many random, disruptive press queries that tend to detract from the other duties of sea otter specialists.

Given the sea otter's new identity, I believe that scientists involved in any high visibility sea otter activities should be prepared to accept that their subject is no longer an ordinary biological species, but a symbol, an icon-a media star. For better or for worse, the scientists working with sea otters must recognize that, in future disasters of this kind, the whole world will be watching not just the sea otters, but those who are studying and working with them. 


\title{
Capture Session
}

\author{
Chair: Carl Benz, U.S. Fish and Wildlife Service, Ventura, Calif. \\ Editors: Ed Klinkhart and Shana F. Loshbaugh.
}

\section{Overall Capture Strategy}

\author{
by \\ K. Bayha \\ U.S. Fish and Wildlife Service \\ 1011 East Tudor Road \\ Anchorage, Alaska 99503
}

and

K. Hill

P.O. Box 1290

Cordova, Alaska 99574

\begin{abstract}
The sea otter (Enhydra lutris) capture effort began in Prince William Sound on 30 March 1989 with two Exxon-chanered fishing vessels staffed with personnel experienced in capture and handling of sea otters (one of whom was a veterinarian) and intermittent access to an Exxon-chartered helicopter. The U.S. Fish and Wildlife Service responded to Sea World's request for assistance by fielding two more vessels on $1 \mathrm{April}$; those vessels were provided with sea otter biologists from California, a local veterinarian, and a second helicopter based out of Seward. This effort expanded as the oil left the sound, and it peaked with 14 capture crews and air support out of Valdez, Seward, Homer, and Kodiak. Initial instructions included a prioritized list of objectives, including preemptive capture of otters in imminent danger of being oiled. Preemptive capture was quickly abandoned because of the risk of chasing clean otters into oiled waters. The primary objective of capturing only oiled otters or stressed otters continued. Methods evolved from a simple dip-net operation to more difficult decisions involving lightly oiled otters and tangle nets. The decision about when to stop capture became a delicate balance involving public pressure to continue, documentation of no otters in stress, diminishing returns, Exxon Company, U.S.A.'s, pressure to reduce costs, and lack of a definitive test for detection of oil on otter pelage. As time wore on and our California sea otter biologists were in shorter supply, it became evident that a capture protocol and a training program for Alaska citizens were needed. An agreement was signed with Indigenous Conservators of the Environment, a newly established Alaska Native organization, to supply volunteers experienced with boats and nets while the Service arranged for on-the-job
\end{abstract}


training in capture and rehabilitation. Other problems encountered and solutions adopted are discussed.

On 25 March, P. Bergmann, the U.S. Department of Interior's member of the Regional Response Team, advised Exxon Company, U.S.A., that a sea otter (Enhydra lutris) rescue program was necessary. Once the decision to initiate a sea otter rescue was made things moved quickly. R. Davis of the Sea World Marine Research Institute was contracted to lead the rescue effort. $\mathrm{He}$ arrived in Valdez on 27 March 1989. He hired F. Weltz, skipper of the F/V Dancing Bear, to mun the first capture boat, which left port on 29 March. Coauthor $\mathrm{K}$. Hill, a veterinarian from Cordova who had substantial experience in sea otter capture, handling, and care, was hired as a second capturer. Hill in turn contracted the F/N Rhoda Mae, skippered by M. DeVille; they left Cordova on $30 \mathrm{March}$. Training for these crews consisted of hands-on instruction by Hill and Weltz, who had worked on previous sea otter research studies in Prince William Sound. C. J. Caissons of the Seattle Aquarium made a short trip on the Tres Suertes. Exxon made an HC 212 helicopter available to ferry otters from the boats to Cordova. After a few days on the Rhoda Mae, Hill rode the helicopter daily, providing direction to the capture crews and bringing otters to Valdez.

On 30 March, Davis requested that the U.S. Fish and Wildlife Service provide assistance with the capture effort. K. Bayha was assigned to direct the Service's effort. Bayha contracted for two fishing boats through the Cordova District Fishermen United union. The decision to use boat-based crews was sound because they provided mobility, avoided potential human-bear interaction problems associated with land-based field camps, and had navigational knowledge of the sound. By $2200 \mathrm{~h}$ on 1 April, the F/V Viking, under skipper S. Iversen, and the F/N Sea Raker, under skipper T. Jewell, left port with four crew members, four sea otter biologists recruited from California, and a veterinarian from Anchorage (Appendix A). Because the Service's Alaska-based sea otter biologists were already committed to other tasks and there were no capture protocols available, the Service's strategy was to bring in personnel who were experienced in capturing and handling sea otters.

To support the Service's capture teams, a Service-chartered helicopter (carrying a Service biologist as the otter handler) was based in Seward. This decision was made initially because we knew lodging and airport space at Valdez was limited, and we believed fuel support would be more certain in Seward. As the oil moved southwest this decision seemed even sounder.

Before the capture teams left Anchorage, Bayha provided them with written directions and objectives:

1. Locate and capture sea otters in jeopardy from oil slicks in Prince William Sound and move them out of harm's way or to Valdez for rehabilitation. In descending order of importance the capture team's priorities were:

a. Oiled sea otters,

b. Clean (unoiled) sea otters trapped by oil slicks and in imminent jeopardy, and

c. Dead sea otters (capture teams were to recover them).

2. Mark (tag) any released otters for subsequent identification and documentation of movements and survival.

3. Document rescue effort.

4. Conduct operations in a safe manner.

Preemptive capture (objective 1b) was canceled soon after the rescue effort began when it became evident that there were many stressed otters to occupy our energies, and that pursuit of healthy otters not yet in oiled waters could have caused them to swim into oiled waters. Only a few otters were preemptively caught and moved (Table).

Fixed-wing aircraft flights to spot otters were launched from Anchorage with Service biologists aboard to reconnoiter the spill area, locate concentrations of sea otters, and advise the capture crews. After seven such flights in the first 2 weeks, it was concluded that the otter transport helicopters and the capture boats were better able to develop their own search patterns, and the reconnaissance flights ended. In the initial days of the rescue, Hill had used information from aerial surveys by C. W. Monnett and L. M. Rotterman (Prince William Sound Science Center, Cordova, Alaska, personal communication), who had been studying sea otters in the area before the oil spill, to advise his capture crews.

Communication between boats and aircraft was a problem of considerable magnitude. The radio frequencies of the aircraft and the boats were not the same, so hand-held radios were used. The mountainous terrain around Valdez pre- 


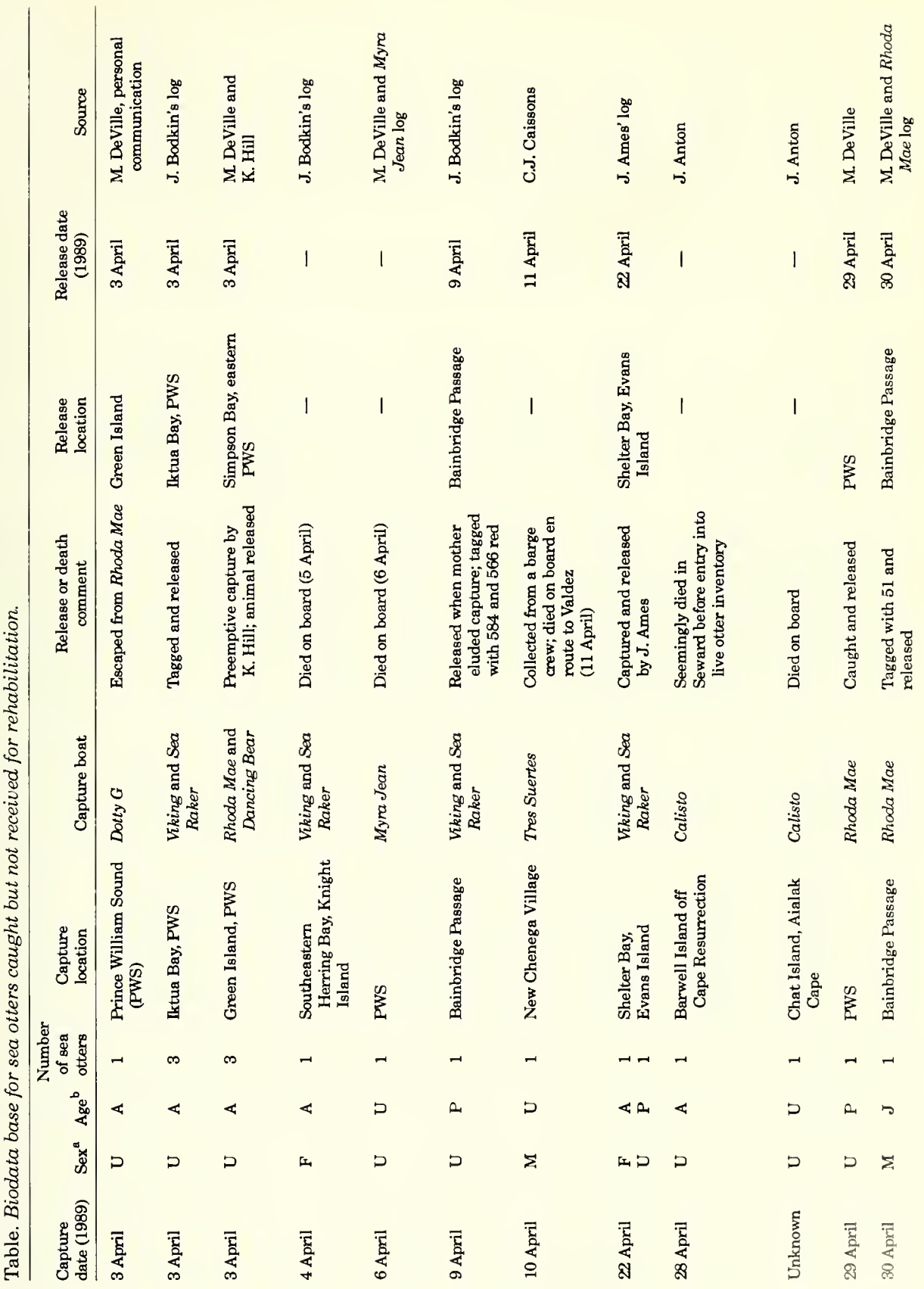




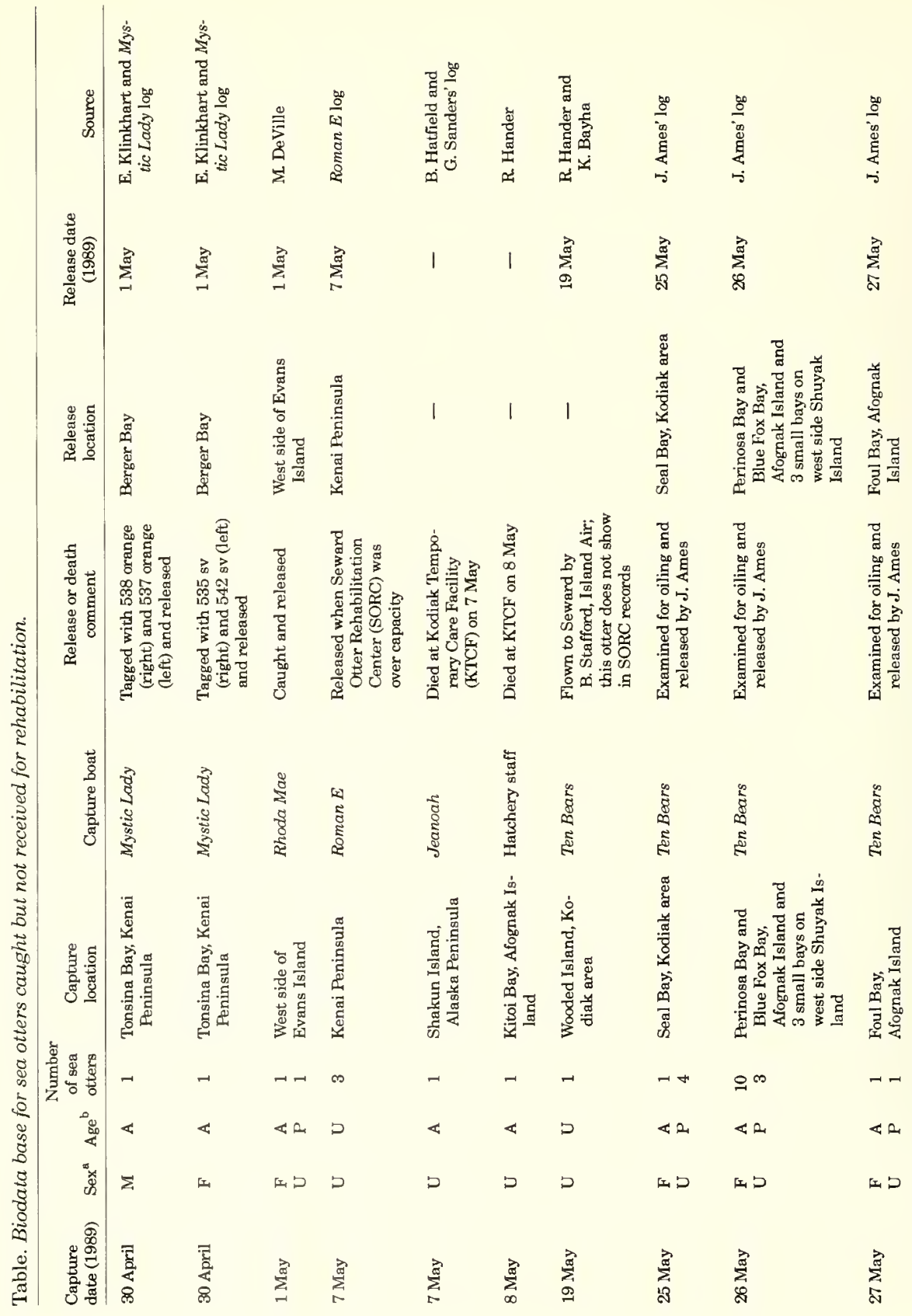




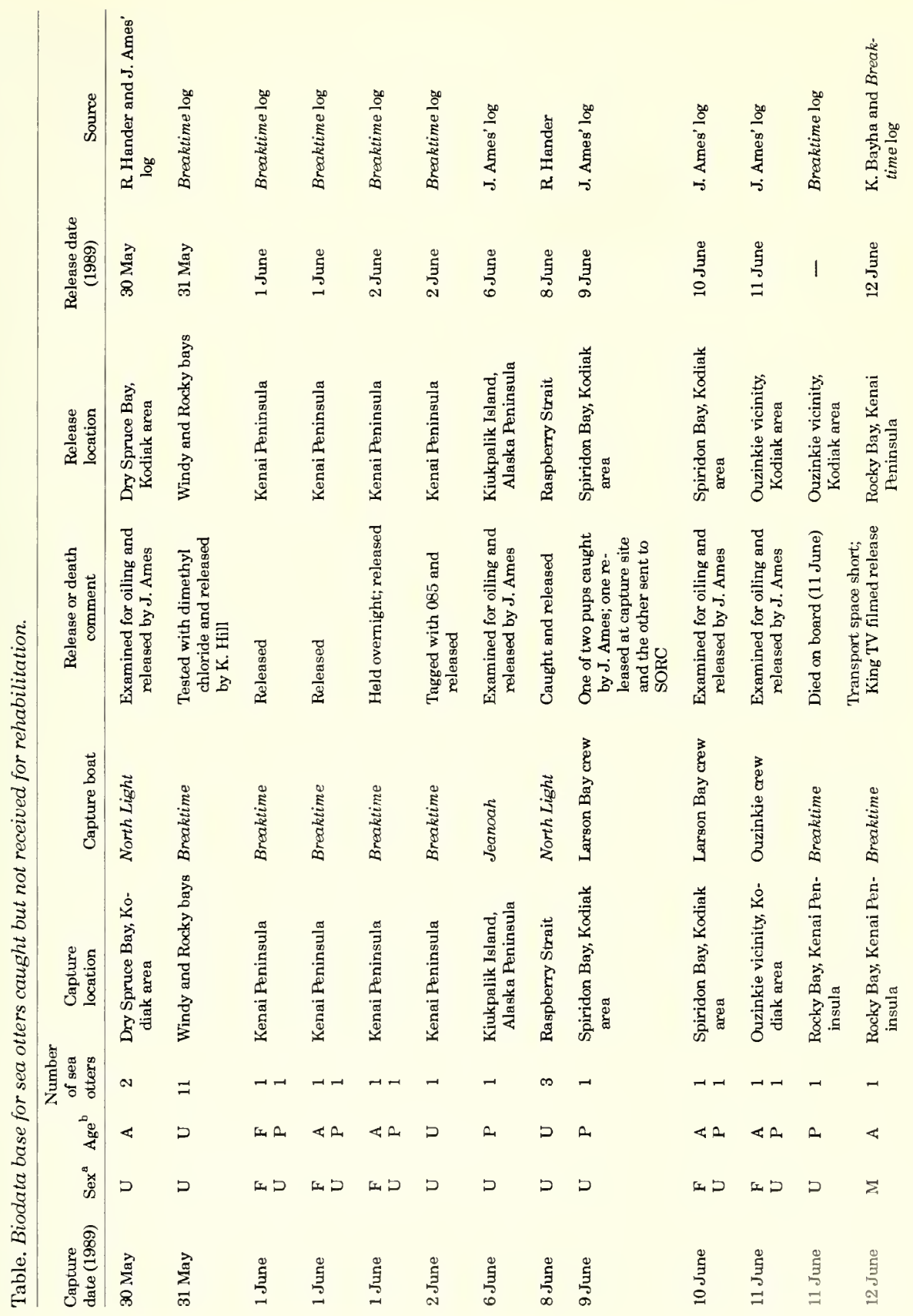




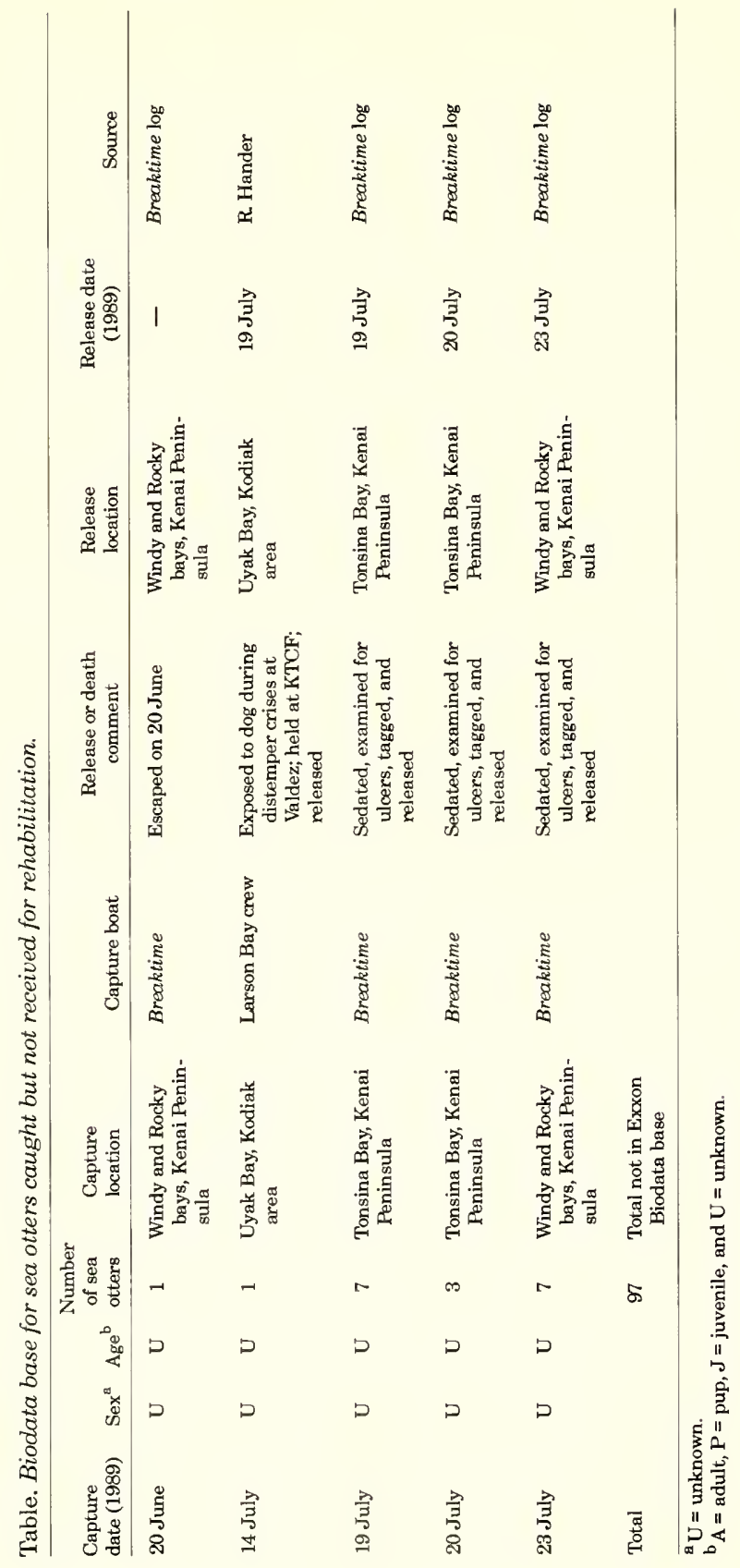


vented single side-band or other radio communication between the boats and the rehabilitation center. Dependable radio-telephone communication was not possible because of the heavy volume of radio traffic in Prince William Sound and the locations of the boats. When boats were near the shore, their crews usually could not contact the repeaters and had to leave their search patterns (for oiled otters) to find places where they could transmit their messages. By 5 April it was evident that we would have to rely on a combination of communication methods. Bayha and Hill began a pattern of daily telephone contact in which the latest events were reported, information deemed useful to boat crews was exchanged, and directions for the next day's search patterns were coordinated. Hill (aboard the 212 helicopter) and our otter handler (in the 208 helicopter) gave these directions to crews of the capture boats during rendezvous for picking up otters. When bad weather intervened, the helicopters would cover for each other. By 8 April it had become routine for one helicopter to attempt a morning flight to all four boats and the other to make an afternoon or evening flight. This helped to shorten the period otters had to be kept on the capture boats.

K. Weaverling, acting without Service authorization but at the direction of T. Monahan of Exxon, launched a 28-boat fleet from Cordova (dubbed the "mosquito fleet" by the press) to scour the sound in search of dead and live birds (T. Monahan, Exxon, Anchorage, Alaska, personal communication). Reports from a variety of sources soon reached the Service in Anchorage that crews of some, but not all (J. Bodkin, U.S. Fish and Wildlife Service, personal communication), of these "Exxon" boats were chasing otters to exhaustion, putting captured otters in holds without proper cages to keep them separated, and picking up unoiled pups left by their mothers while foraging or simply because they were easy to catch. At least one person was severely bitten while capturing a sea otter (R. Davis, University of California, San Diego, personal communication). On 6 April, the Service's regional director, under authority of the Marine Mammal Protection Act, issued a directive that only Service-approved capture boats were to continue sea otter capture. The director of the Valdez Otter Rehabilitation Center (VORC) had been issued a permit to take sea otters for rehabilitation. Our interpretation was that those capture crews launched by him and his designees were covered by that permit. While the media attention given to this halting of the mosquito fleet's capture activi- ties caused some public relations problems, it was necessary to avoid undesirable harassment of the otters and to protect enthusiastic but untrained persons from otter bites.

As the spill aged and moved out of the sound and the sea otter experts from California were needing to return home, we considered halting the rescue effort. Concern was growing, however, for the sea otters inhabiting waters off the Kenai Peninsula. Fixed-wing aircraft reconnaissance flights over the Kenai Fjords by National Park Service staff indicated that there were significant concentrations of marine birds and mammals, including sea otters, in the area. The Service launched a systematic helicopter census (DeGange 1990). As a result, more sea otter experts were requested from California (Appendix A). On 6 April, the Service made the decision to recommend building a second rehabilitation center in Seward. After weeks of negotiations, on 21 April Exxon committed to the Seward Otter Rehabilitation Center (SORC).

J. Styers, who was hired by Exxon to direct SORC, arranged for the first of five otter capture boats and crews hired through Exxon's oil field service contractor, VE Construction Company Inc., (VECO) to capture sea otters along the Kenai Peninsula (Appendix B). Two additional capture crews were launched from Homer to work the Cook Inlet side of the Kenai Peninsula to Gore Point (Appendixes A and B). An Exxon-chartered helicopter based out of Homer augmented otter transport capability on the Kenai Peninsula. By 17 April, the Service concluded that it needed to spread the available experts more thinly, and it reassigned some otter biologists to duty on these boats. By mid-April the Service began to reorganize its management effort to provide on-site coordinators in Seward, Homer, and Kodiak, as well as Valdez.

The rapid expansion of the number of personnel involved in the capture effort, and turnover among the Califormia sea otter biologists, dictated development of a training strategy. Service otter biologists G. VanBlaricom, assigned to assist with the establishment of SORC, and R. Jameson, then serving on the F/N Breaktime, were asked to develop a written capture protocol. K. Hill's 29 April draft sea otter handling protocol was integrated into the resultant product (Appendix C). The protocol was provided to all capture boats and served as the basis for a certification document (Appen$\operatorname{dix}$ D) that was completed for most of the personnel serving on the capture boats (see Appendix A).

About the time the California sea otter biologists were leaving (25 April), three Alaska Natives 
approached the Fish and Wildlife Service seeking a role in the sea otter rescue effort. They had established the Indigenous Conservators of the Environment (ICE) as a nonprofit, grassroots $\mathrm{Na}$ tive Alaskan environmental organization. On 29 April an agreement was signed in which the Service would provide travel and training for $\mathrm{Na}$ tive Alaskans selected by the ICE management staff for duty as volunteers on the capture boats and at SORC. The intent was to develop a trained group of Alaska Natives that could be mobilized as sea otter capture crews in future spills. A 1-day workshop taught by Service biologists C. Benz and M. Hogan on 18 May provided 14 ICE volunteers with a basic understanding of sea otter biology and capture techniques. Twelve ICE volunteers served on capture boats or at SORC.

As the oil moved into the Shelikof Strait between the Kodiak Archipelago and the Alaska Peninsula, J. Bellinger, Kodiak National Wildlife Refuge manager, mobilized his previously approved contingency plan. Two large vessels, chartered by VECO as bird and carcass retrieval boats, were staffed with Service otter biologists. In addition, Native Alaskan skiff crews were recruited at the villages of Larsen Bay and Ouzinkie (Appendixes A and B). Training for these people was provided by Service personnel.

Appendix E presents a summary of the sea otter capture effort by geographic zone. More details about capture methods and results are reported by Bodkin and Weltz (1990) and Hander (1990). These authors collectively tell the story of what happened in the three activity zones, each of which had distinctly different circumstances and problems requiring different solutions.

One problem common to all zones was deciding when to stop the capture effort. Because the Service had a pivotal role in these decisions, some insight into the strategy chosen is in order. In the sound, captures fell off markedly after the first 3 weeks (Bodkin and Weltz 1990). Halting the rescue effort in the sound was considered at that time, but as previously stated, concern about sea otters in the Kenai Fjords was increasing, so the emphasis was shifted there. We did, however, switch to a survey and monitoring mode in the sound about the time Service employees were pulled out to help the effort in the Kenai Fjords. It was felt that we needed to establish a record of searching for but not finding otters in distress before we could defensibly end capture operations. The Dancing Bear and Rhoda Mae continued operations for 5 weeks after the Viking and Sea Raker quit at the end of
April, to build this record and provide the capability to respond to reports of stressed otters. When these vessels ended their contracts about the end of May, capture responsibility in the sound was assigned to the directors of SORC and VORC.

Along the Kenai Peninsula the capture effort continued. The issue of slightly oiled versus non. oiled otters was in full swing. K. Hill had developed a test believed to be of value in detecting oil on otter fur. We decided to field test Hill's method in the search for criteria to use in the decision to stop the capture of otters. But this is another story to be told by Hill and Tuomi (1990).

We offer the following recommendations for con. sideration:

1. Before the next spill in sea otter habitat, the Service should develop a handbook containing criteria for deciding when to begin and end a sea otter rescue effort; protocols for capture, transport, and release back to the wild; chain. of-custody forms with instructions; and guidance concerning disposition of sea otters to aquariums.

2. The Service should train capture teams composed of local citizens in each of the coastal communities throughout the range of the sea otter, using volunteer fire departments as a model. The Service should develop and distribute a series of videotapes to instruct volunteers about sea otter life history and the proper techniques for capturing and handling sea otters.

3. The oil industry should establish caches of equipment in strategic coastal communities throughout the range of the sea otter. This equipment could be quickly deployed by trained capture teams in the event of a future spill.

\section{References}

Bodkin, J. L., and F. Weltz. 1990. Evaluation of sea otter capture after the T/N Exxon Valdez oil spill, Prince William Sound, Alaska. Pages 61-69 in K. Bayha and J. Kormendy, tech. coords. Sea Otter Symposium: Proceedings of a symposium to evaluate the response effort on behalf of sea otters after the T/ $\mathrm{V}$ Exxon Valdez oil spill into Prince William Sound, Anchorage, Alaska, 17-19 April 1990. U.S. Fish Wildl. Serv., Biol. Rep. 90(12).

Britton, R. L. 1990. Sea otter capture along the Kenai Peninsula, Alaska. Pages 70-77 in K. Bayha and J. Kormendy, tech. coords. Sea Otter Symposium: Proceedings of a symposium to evaluate the response effort on behalf of sea otters after the T/V Exxon Valdez oil spill into Prince William Sound, Anchor- 
age, Alaska, 17-19 April 1990. U.S. Fish Wildl. Serv., Biol. Rep. 90(12).

DeGange, A. R., D. H. Monson, D. B. Irons, C. M. Robbins, and D. C. Douglas. 1990. Distribution and relative abundance of sea otters in south-central and southwestern Alaska before or at the time of the T/N Exxon Valdez oil spill. Pages 18-25 in K. Bayha and J. Kormendy, tech. coords. Sea Otter Symposium: Proceedings of a symposium to evaluate the response effort on behalf of sea otters after the T/ $\mathrm{V}$ Exxon Valdez oil spill into Prince William Sound, Anchor* age, Alaska, 17-19 April 1990. U.S. Fish Wildl. Serv, Biol. Rep. 90(12).

Hander, R. 1990. Sea otter survey and capture effort, Kodiak Island Archipelago and Alaska Peninsula.
Pages 78-90 in K. Bayha and J. Kormendy, tech. coords. Sea Otter Symposium: Proceedings of a symposium to evaluate the response effort on behalf of sea otters after the T/N Exxon Valdez oil spill into Prince William Sound, Anchorage, Alaska, 17-19 April 1990. U.S. Fish Wildl. Serv., Biol. Rep. 90(12).

Hill, K., and P. A. Tuomi. 1990. Field test for detecting crude oil on the fur of sea otters. Pages 95-122 in K. Bayha and J. Kormendy, tech. coords. Sea Otter Symposium: Proceedings of a symposium to evaluate the response effort on behalf of sea otters after the T/N Exxon Valdez oil spill into Prince William Sound, Anchorage, Alaska, 17-19 April 1990. U.S. Fish Wildl. Serv., Biol. Rep. 90(12). 


\section{Key to Acronyms Used in Appendixes.}
ADF\&G - Alaska Department of Fish and Game
CDF\&G - California Department of Fish and Game
DEC - Department of Ecological Conservation
DVM - Doctor of Veterinary Medicine
FR - Fisheries Resources
FWS - U.S. Fish and Wildlife Service
ICE - Indigenous Conservators of the Environment
JPRF - Jakolof Pre-Release Facility
NERC - National Ecology Research Center
NWR - National Wildlife Refuge
PWS - Prince William Sound
R-1 - Region 1
R-8 - Region 8
RO - Regional Office
SORC - Seward Otter Rehabilitation Center
VORC - Valdez Otter Rehabilitation Center 


\section{Appendix A. Sea Otter Capture Personnel.}

\section{California-based Personnel in Order of Arrival}

J. Bodkin, FWS R-8, NERC-Santa Cruz (currently stationed in Anchorage, Alaska); otter capture on the Sea Raker

N. Siepel, FWS R-8, NERC-San Simeon; otter capture on the Sea Raker

J. Ames, volunteer-CDF\&G, Monterey; otter capture on the Viking; certifier

M. Kenner, volunteer-FWS R-8, NERC-Santa Cruz; otter capture on the Viking

R. Britton, FWS R-1, Ventura, otter capture on the Viking (replaced Kenner); later reassigned to Roman $E$; certifier of trainees

G. VanBlaricom, FWS R-8, NERC-Santa Cruz; rehabilitation facility; principal author of handling protocol; certifier of trainees; limited otter capture duty on the Breaktime

R. Jameson, FWS R-8, NERC-San Simeon; otter capture on the Viking (replaced Bodkin); helped draft otter handling protocol; certified captures on the Breaktime and Mystic Lady

B. Hatfield, FWS R-8, NERC-San Simeon; otter capture on the Sea Raker (replaced Siepel); reassigned to Jeanoah; trainee certifier in Uyak Bay

C. Benz, FWS R-1, Ventura; otter capture on the Viking (replaced Ames); reassigned to North Light; taught workshop for ICE volunteers

J. Estes, FWS R-8, NERC-Santa Cruz; otter capture on the Foxy Lady; certifier of trainees

G. Sanders, FWS R-1, Ventura; otter capture on the Jeanoah (replaced Hatfield)

\section{U.S. Fish and Wildlife Service Personnel from Alaska}

D. Dragoo, biotechnician, Alaska Maritime NWR; trainee on the Roman $E$

D. Kvasnikoff, biotechnician, Alaska Maritime NWR; otter capture on the North Light

D. Wiswar, Fairbanks FR; otter capture trainee in PWS (replaced Jameson)

D. Daum, Fairbanks FR; otter capture trainee in PWS (replaced Benz)

E. Sharpe, Anchorage RO; otter capture on the Roman E and Service representative at JPRF (replaced Britton); postrelease monitor on the Roman $E$

D. Monson, Anchorage, R-8; sea otter biologist; expert otter capture on the Ten Bears; radiotracking expertise

R. Hander, Kodiak NWR; otter capture on the Ten Bears

L. Dugan, Kodiak NWR; hand on the Ten Bears

R. Wilk, Kanuti NWR; otter transportation out of Seward

W. Stephensen, Marine Mammals Field Office; otter transportation out of Seward

D. Cramer, Anchorage FR; otter transportation out of Seward

M. Hogan, Marine Mammals Field Office; Service representative at JPRF (replaced Sharpe); release strategy

G. Sonnevil, Kenai FR; Service site coordinator at Valdez; supervised releases from Valdez

T. Early, Kanuti NWR; Service site coordinator at Seward; supervised releases from Seward

M. Hedrick, Kenai NWR; Service site coordinator at Homer; otter transportation out of Homer

A. Rappoport, Anchorage; acting Service site coordinator at Seward and Homer; coordinated releases from JPRF

K. Bayha, Anchorage; chief of sea otter rescue operations for the Service

\section{Contractor-employed Otter Capture Personnel}

F. Weltz, skipper and otter capture specialist on the Dancing Bear

M. Drawbridge, Sea World; otter capture on the Dancing Bear

C. Donohoe, Sea World; otter capture on the Dancing Bear 
J. Thomas, Dancing Bear

J. Harvey, Dancing Bear

R. Pirtel, Dancing Bear

K. Becker, Cordova; otter capture on the Dancing Bear

M. DeVille, skipper and otter capture specialist on the Rhoda Mae

K. Hill, otter capture instructor on the Rhoda Mae; transport out of Valdez

T. Andersen, otter capture on the Rhoda Mae

J. Patton, otter capture on the Rhoda Mae

R. Collins, otter capture specialist on the Rhoda Mae

S. Iversen, skipper on Viking

S. Kade, engineer on Viking

B. Kula, deckhand on Viking; acting skipper on Sea Raker

T. Jewell, skipper on Sea Raker

J. Jewell, engineer on Sea Raker

M. Lyda, deckhand on Sea Raker

J. Styers, Point Defiance Aquarium, Washington; SORC director; limited otter capture on Tres Suertes and Breaktime

C. J. Caissons, Seattle Aquarium, Washington; Tres Suertes, Breaktime

R. Smith, Point Defiance Aquarium, Washington; Tres Suertes

J. Hoak, Point Defiance Aquarium, Washington; Tres Suertes

J. Blake, skipper and otter capture on Breaktime

P. Wunnicke, trainee on Breaktime

J. Foster, animal capture specialist for aquariums; otter capture on Breaktime; designated team leader for FWS and certifier in latter days

B. Candopoulos, otter capture on Breaktime

S. Hill, cook and data recorder on Breaktime

J. Styers, assistant on Breaktime, Calisto

J. Rash, otter capture on Breaktime

C. McCormick, Anchorage veterinarian; otter capture on Breaktime

O. Ollestad, SORC dispatcher and otter capture on Breaktime

J. Reynolds, skipper and retired ADF\&G otter biologist on Mystic Lady

E. Klinkhart, retired ADF\&G otter biologist on Mystic Lady; postrelease monitor and Breaktime

L. Heckart, retired ADF\&G otter biologist on Mystic Lady; postrelease monitor and Breaktime

E. Haskins, skipper on Roman $E$

R. Haskins, deckhand on Roman $E$

K. Smith, Roman E

M. Bartholomew, skipper and otter capture on Foxy Lady

M. Kansteiner, otter capture on Foxy Lady and later on Roman E

K. Keisling, otter capture on Foxy Lady

A. Holnics, otter capture trainee on Foxy Lady

C. "Nina" Daley, skiff operator and otter capture on Foxy Lady

G. McIntire, skipper on North Light

G. Knight, crew member on North Light

R. Sheridan, VECO, Inc.; assistant on Ten Bears

G. Edwards, VECO, Inc.; assistant on Jeanoah

J. Anton, Calisto skipper; otter capture on Breaktime and Wayward

C. Rosencranz, Calisto alternate skipper

M. Graham, skipper of Wayward, crew partly certified

R. Fisher, Wayward

B. Vastbinder, Wayward

E. Knight, Wayward

S. Smith, Wayward

R. Davis, director of VORC; backup otter capture

T. M. Williams, assistant director of VORC; backup otter capture 


\section{Volunteers}

J. Thomas, volunteer veterinarian on Sea Raker

F. Bare, ICE management

J. Lanman, ICE management

T. Galaktionoff, ICE volunteer, management; otter capture trainee on Roman $E$

B. Morris, ICE volunteer; otter capture trainee on Roman E

C. Dolchok, ICE volunteer; otter capture on Roman $E$

R. Layland, ICE volunteer; otter capture on Roman E

J. Soper, ICE volunteer; otter capture trainee on North Light

J. Ivanoff, ICE volunteer; otter capture on North Light

A. Chudocken, ICE volunteer; otter capture trainee on Roman E

R. Trefon, ICE volunteer; otter capture on Roman E

R. Kakakuk, ICE volunteer; SORC

B. Reamey, ICE volunteer; SORC

L. Regan, ICE volunteer; SORC

A. Alford, Jr., ICE volunteer; SORC

F. Kakaruk, Jr., ICE volunteer; SORC

H. E. Hamilton, Jr., ICE volunteer; SORC

\section{Native Skiff Crews}

B. Oja, Larsen Bay, Alaska; otter capture

T. Alpiak, Larsen Bay, Alaska; otter capture

S. Davis, Larsen Bay, Alaska; otter capture

M. Carlson, Larsen Bay, Alaska; otter capture

R. Hochmuth, Larsen Bay, Alaska; otter capture

M. Naumoff, Larsen Bay, Alaska; otter capture

A. Squartsoff, Ouzinkie, Alaska; otter capture

J. Delgado, Ouzinkie, Alaska; otter capture

I. Squartsoff, Ouzinkie, Alaska; otter capture

A. Christofferson, Ouzinkie, Alaska; otter capture

K. Lariouoff, Ouzinkie, Alaska; otter capture

J. Squartsoff, Ouzinkie, Alaska; otter capture

L. Chichenoff, Ouzinkie, Alaska; otter capture; served on Ten Bears

D. Llanos, Ouzinkie, Alaska; otter capture; served on Ten Bears

\section{Minerals Management Service}

M. Baffrey, Anchorage, otter capture on Foxy Lady

N. Swanton, Anchorage, otter capture on Roman $E$

\section{Bureau of Reclamation}

C. Keller, Yakima, Washington, postrelease monitor off Kenai Peninsula 


\section{Appendix B. Recognized Sea Otter Capture Boats. ${ }^{\text {a }}$}

Capture boats

Prince William Sound

Dancing Bear-F. Weltz, skipper

Rhoda Mae-M. DeVille, skipper

S/S Viking-S. Iversen, skipper

Sea Raker-T. Jewell, skipper

Tres Suertes-C. J. Caissons, in charge

\section{Seward Zone}

Breaktime-J. Blake, skipper

Foxy Lady-M. Bartholomew, skipper

Calisto-J. Anton, skipper

Mystic Lady-J. Reynolds, skipper

Sea Ducer

Wayward-M. Graham, skipper

Homer Zone

Roman E-E. Haskins, skipper

North Light - G. McIntire, skipper

\section{Kodiak Zone}

Ten Bears-E. Stirrup, skipper

Jeanoah-J. Bongen, skipper

North Light-reassigned to Kodiak Zone

Wayward-reassigned to Kodiak Zone

Larsen Bay skiff crew

Ouzinkie skiff crew
Dates under contract
10 Apr-24 Jul

8 Aug-2 Sep

27 Apr-4 Aug

19 Apr-4 Aug

$21 \mathrm{Apr}-21$ May

$24 \mathrm{Apr}-24$ May

29 Apr--5 Jun

21 Apr-26 Jul

7 Aug-2 Sep

$30 \mathrm{Apr}-25 \mathrm{Jul}$

Total of 17 recognized capture crews, maximum of 14 in the ficld at one time.

17 Apr-4 Aug

30 Apr -4 Aug

5 May-25 Jul

13 May-26 May

10 Jun-4 Aug

12 Jun-4 Aug 


\section{Appendix C. Guidelines for Capturing and Handling Sea Otters.}

Capture of live sea otters should be attempted only by persons who have worked with people previously experienced in sea otter capture and handling. Trainees should have had hands-on experience with observation, capture, and handling of live sea otters in the field before they are certified as capture personnel. Sea otter capture typically is done with a large, salmon-type dip net, or with gill nets that have been modified for otter capture. Capture with gill nets is labor-intensive, and is relatively risky (both for the otters and the capture personnel) in rough seas or poor weather. Use of gill nets to capture sea otters should be done only in the presence of experienced personnel.

Selecting otters for capture:

1. Animals hauled out on rocks or beaches.

Hauling out is normal behavior for sea otters throughout Alaska. An otter resting on a rock or beach is not necessarily in distress. Otters with obviously matted fur or that show signs of lethargy or restricted mobility should be considered for capture.

\section{Animals in the water.}

Sea otters have many complicated behaviors associated with grooming, feeding, and mating. Common behaviors include rolling, somersaulting, repeated shallow diving, blowing of bubbles, and intensive rubbing and working of the fur with the mouth, forepaws, and hind flippers. These behaviors may be misinterpreted as indicators of stress by inexperienced observers. Healthy sea otter fur can be recognized by the characteristic "beading" or rapid "wicking away" of water when the animal is on the surface.

Sea otters in the water should be considered for capture if the fur retains a slick, wet appearance even after the animal has been on the surface for 10 seconds or more. Other signs of possible oiling include frequent head shaking (like a dog shakes its head after a swim), obvious shivering, tolerance of close approach by a boat, lethargy, or obvious emaciation. However, none of the above are certain indicators that the animal is in fact oiled. For example, occasional head shaking is common among healthy animals, and healthy young animals and adult males often will tolerate close approach by boat.

If a sea otter keeps its distance from an approaching boat and appears alert to the presence of the boat, it is probably in relatively good condition and should not be pursued.

Sea otter pups frequently are quite vocal, and their high-pitched calls are easily mistaken for signals of distress. A mother-pup pair should never be pursued simply because the pup is vocalizing frequently. Newborn pups may move relatively little, and may be mistakenly categorized as lethargic or dead by inexperienced observers. The fur of pups often is lighter in color than adult fur. Natural clean fur on pups may resemble the chocolate-brown color of weathered oil. In addition, it is common for mothers and pups to become temporarily separated while the mother dives for food. In such cases, the pup often vocalizes frequently. Thus, apparently abandoned pups should be watched from a distance for at least 15-20 min before any decision is made to attempt capture. Mother-pup pairs should be approached by boat with the intent to capture only if there is clear evidence of oiling or severe distress (such as shivering or obviously matted fur).

Handling sea otters after capture:

1. General precautions.

Sea otters are powerful, aggressive, dangerous animals when in captivity. Their strength, quickness, and determination should never be underestimated. Their jaws are particularly powerful, and are quite capable of crushing human hand and finger bones. Their forelimbs and forepaws are also surprisingly strong and dextrous, and can grasp and pull a human hand or arm with surprising strength and quickness. Although quite endearing in their natural habitat, sea otters must be regarded as dangerous in any sort of confining captive situation.

When handling a sea otter in any kind of net, restraining box, or sky kennel, the head of the animal should be watched constantly. It is 
essential to concentrate on movements of the otter's head when involved in any handling procedure that brings any part of the handler's body close to the otter.

A large salmon-type dip net should be available whenever handling captive sea otters. Dip nets allow relatively easy recapture should a captive otter escape confinement while on a boat deck or beach. If an escape occurs, it is important to remain calm, concentrate on the animal's movements, and have the dip net on hand. Should a captive otter escape onto a boat deck, it is not necessary to bail out. Captive otters usually are disoriented in such circumstances and can be readily recaptured with a dip net, as long as the response is not delayed. Handlers should be alert to the possibility of exceptions.

It is very dangerous for inexperienced persons to attempt to grasp a live sea otter directly with the hands. Sea otters have flexible bodies and very loose skin, and can easily turn toward and bite hands and arms, even if the grip seems quite sure.

A sea otter should never be grabbed by the nape of the neck or by the tail. Serious injury to the otter or the handler could result.

\section{Initial handling after capture.}

Sea otters that have been dip netted should be placed immediately into the capture box (see below). Otters captured in tangle nets should be placed in the capture box while still in the tangle net. Netting can be cut away from the rear end of the otter, allowing it to slide free into the box. A dip net and, if available, a bite bag (stuff bag or sleeping bag, filled tightly with foam rubber), should be on hand during the procedure.

If net bags are available, the capture box should be lined with an open net bag before putting the otter into the capture box. Once the otter enters the box, the net bag should be immediately pursed and the lid (if present) of the box closed. If net bags are not available, the otter should be placed directly into the capture box, and the lid immediately closed. A bite bag should be used to keep the otter in the box if there is no lid and no net bag.
Once the otter is secured in the capture box, it should be transported as soon as possible to the main boat for tagging and transfer to a sky kennel. If transport time exceeds half an hour and the otter is in a net bag, the otter should be removed and held over the side in the water for about $5 \mathrm{~min}$. This should be repeated at half-hour intervals if extended transport in the skiff is required.

\section{Tagging.}

Sea otters should receive a single flipper tag before transfer to the appropriate rehabilitation center. Position and color of tags will be determined by a U.S. Fish and Wildlife Service (Service) representative.

Tagging should be done while the otter is in the capture box, preferably while in a net bag. The otter should be restrained with a bite bag while the appropriate flipper is pulled up to a workable location on the edge of the capture box. The tagging hole can be cut with a narrow-bladed pocketknife, a single-hole paper punch, or a leather punch. The cutting implement should be as clean as possible (preferably swabbed with alcohol) before cutting the hole. If the flipper feels warm to the touch, ice should be applied before cutting in order to reduce bleeding. The tag should be inserted narrow end first, then pushed through so that the separated ends of the tag are at the trailing edge of the flipper. If possible, the separate ends of the tag should be secured with a small screw after tag insertion. A screw should be used only if the tag has a predrilled hole. It is crucial that the color, number, and position of the tag be recorded on the appropriate data sheet.

\section{Placing sea otters in sky kennels.}

If possible, sky kennels should have metal grates on the floor, such that there is space for urine and feces to collect without soiling the otter's fur. If grates are not available, place towels or rags in the kennel to absorb waste. Do not use oil-absorbent pads; they do not handle urine or feces well. Otters in kennels should not be doused with water, even if the fur is soiled with urine or feces. Oiled otters are likely to be hyperthermic, and dousing may only make matters worse. 
If the otter is in a net bag, it should be lowered into the kennel (held in vertical position, door end up) while still in the bag. The bag should be manipulated so that the bag opening is down, the purse line released, and the bag pulled upwards so that the otter falls free into the kennel.

If the capture box is equipped with a sliding door in one end, the sky kennel (with door open) should be placed against the sliding door. The sliding door can then be opened, allowing the otter to crawl into the kennel.

If the capture box does not have a sliding door, and the otter is not in the net bag, the otter should be returned to a dip net before transfer to a kennel. To transfer, tilt the kennel at about a $45^{\circ}$ angle, with the door open as far as possible. Hold the frame of the dip net flush against the door end of the kennel, such that the frame of the net is firmly against the lower edge of the door frame, and the door is entirely covered by the net. If there is a gap between the net frame and door frame, it is likely that the otter will slip through the gap and fall free. Once the net frame and kennel are in position, do the following in a continuous motion: Grab the bottom of the net well away from the otter's head and swing the otter upward above the kennel door, allowing the otter to fall through the door and into the kennel. Judicious use of a foot may be of help, especially if the otter gets hung up at the kennel door. If the otter doesn't drop into the kennel within a few seconds, lower it down and try again. Once the otter is in the kennel, pull the dip net away, close, and latch the kennel door. The procedure is best done with at least three people: one to hold the kennel, one to hold the net frame in position, and one to move the otter.

If desired, the kennel door can be removed before transfer. Door removal reduces the risk of entangling the dip net on the door catches. Remove the door by removing just enough kennel bolts to allow springing of the kennel frame. Make sure that the kennel is held in a vertical position (door opening up) once the otter is inside. The door should be replaced as soon as the otter is in the kennel. Watch fingers while replacing the door. A bite bag should be close at hand if door removal is done.

It is crucial that all capture records and related data forms be completed once the otter is secured in the sky kennel.

\section{Holding an otter in a sky kennel.}

The kennel should be held horizontally whenever possible. Accumulated water and urine can be drained by briefly standing the kennel on end, door down, to allow drainage.

Kennels should be placed under shelter to prevent wetting from rain or snow. However, it is crucial to maintain good ventilation. Kennels should be kept in a cool location and should not be covered with blankets or towels.

Sea otters must have access to drinking water. An otter that is panting and appears frantic to escape from a kennel likely is in dire need of water and requires an immediate response. They can handle either seawater or fresh water. The best way to deal with water needs is to provide clean chunks of ice or snow. Avoid placing so much snow or ice in the kennel that the otter is forced to lay on it. Accumulated ice water should be drained regularly as described above.

If the kennel is not equipped with a grate, towels or rags used to absorb waste should be changed frequently. To change towels, stand the kennel on end (door up), open the door, remove towels using a stick with a hook on the end, drop new towels in, close the door, and return the kennel to horizontal. Do not attempt to remove towels with hands. Have a dip net available whenever the kennel door is open.

\section{Transportation of otters in kennels.}

If transportation is by aircraft or boat, the kennel should be secured to the floor in horizontal position with cargo webbing or straps. Ventilation of the kennels must not be obstructed, and ice should be available onboard for the otter.

If it is absolutely necessary to transport kennels in tilted position, the door end should be tilted upward. The kennel should be 
returned to horizontal position as soon as possible after arrival.

If delays are encountered en route, the kennel must be placed in a cool, well-ventilated location that is sheltered from rain or snow.

7. Feeding of sea otters in kennels.

If transportation delays force extended (overnight) holding of a sea otter in a kennel, food should be offered at approximately 2-h intervals. Preferred foods are geoduck meat, fish fillets, or whole squid. Crab should be avoided because of excessive debris after feeding.

Food that has been thawed more than $24 \mathrm{~h}$ is not suitable for sea otters. All food should be refrigerated or stored on ice. Food need not be fully thawed before feeding to otters.

It is crucial to avoid overfeeding. Otters should be offered two or three pieces of food at each feeding. Captive otters are prone to gorging. Under the stressful circumstances of capture and holding, gorging can produce serious medical problems for otters. 


\section{Appendix D. Authorization for Capture of Sea Otters.}

This certifies that the person identified below is sanctioned by the U.S. Fish and Wildlife Service (Service) to capture sea otters in coastal Alaskan waters as part of the effort to rescue otters affected by the Exxon Valdez oil spill. The person authorized by this document has worked with a Service employee, named below, and has gained specific experience, in the field, in the following areas:

1. Observation of sea otter behavior, with emphasis on identification of behaviors which indicate that a sea otter has been oiled, is in distress, and is in need of rescue, treatment, and rehabilitation.

2. Use of gear appropriate for capture of wild sea otters, including dip nets and tangle nets.

3. Use of gear appropriate for restraining, holding, tagging, and transporting captive wild sea otters, including capture boxes, bite bags, net bags, dip nets, and sky kennels.

4. Techniques for care and husbandry of captive wild sea otters during holding and transportation, including feeding, watering, sanitation, and temperature regulation.

5. Completion of data forms associated with capture, holding, and transport of captive wild sea otters.

6. Necessary safety practices associated with the capture, holding, and transport of captive wild sea otters.

The person authorized by this document to capture sea otters recognizes that the capture, holding, and transport of sea otters is hazardous work, and that stringent adherence to appropriate safety precautions is essential in minimizing risks associated with this work.

Person authorized for sea otter capture:

Signature:

Name (print):

Date:

Authorizing Service person:

Signature:

Name (print):

Date: 


\section{Appendix E. Otter Captures by Boat Crews.}

Prince William Sound

Rhoda Mae

Dancing Bear

Viking and Sea Raker combined

Tres Suertes from barge

MV Growler, FWS LE

Resolution, ADF\&G staff

Cordova citizen (Orca Inlet)

DEC

Rogue volunteer in Valdez Harbor

Citizen float plane

"Mosquito Fleet"

Total captures

Born at VORC by mothers from PWS

VORC biographical data base

Kenai Peninsula Zone

Breaktime

Roman E

Foxy Lady

North Light

Mystic Lady

Breaktime, North Light, Mystic Lady

Breaktime, Roman E

Breaktime, Foxy Lady, Roman E

Breaktime, Foxy Lady

Foxy Lady, Roman $E$

Wayward

Sea Ducer, Shadow, Calisto

Boom tender and unknown

Mary $H$ and another bird boat

Jakolof rogues

Total captures

Born in captivity

SORC and Homer biographies

Kodiak Zone

Ten Bears

Jeanoah

Larsen Bay skiff crew

Ouzinkie skiff crew

North Light

Wayward

Sumner Strait crew via Ten Bears

Kitoi Bay Hatchery staff

Port Lyons citizen

Chignik citizen

Kodiak zone total captures

Total in Exxon biodata base less births

Total captures in the field
30

26

40

1

4

1

1

1

2

35

141

2

143

30

4

4

6

46

1

27

28

3

1

13

2

2

2

5

174

16

190

5

1

2

3

9

1

1

1

1

24

357

$-18$

339
6

1

6

1

1

1

14

1

3

158

37

3

1

68

7

4

6

48

1

27

28

3

1

13

2

2

5

42

3

219

1

1

26

20

3

4

2

5

32

3

59

88

9

436 


\title{
Evaluation of Sea Otter Capture After the T/V Exxon Valdez Oil Spill, Prince William Sound, Alaska
}

by

\author{
J. L. Bodkin \\ 1011 E. Tudor Road \\ Anchorage, Alaska 99503
}

and

F. Weltz

P.O. Box 982

Cordova, Alaska 99574

\begin{abstract}
After the T/N Exxon Valdez oil spill into Prince William Sound, the U.S. Fish and Wildlife Service and Exxon Company, U.S.A., began rescuing sea otters (Enhydra lutris). The primary objective of this operation was to capture live, oiled sea otters for cleaning and rehabilitation. Between 30 March and 29 May 1989, 139 live sea otters were captured in the sound and transported to rehabilitation centers in Valdez, Alaska. Within the first 15 days of capture operations, 122 (88\%) otters were captured. Most sea otters were captured near Knight, Green, and Evans islands in the western sound. The primary capture method consisted of dipnetting otters out of water and off beaches. While capture rates declined over time, survival of captured otters increased as the interval from spill date to capture date increased. The relative degree of oiling observed for each otter captured declined over time. Declining capture rates led to the use of tangle nets. The evidence suggests the greatest threat to sea otters in Prince William Sound occurred within the first 3 weeks after the spill. Thus, in the future, the authors believe rescue efforts should begin as soon as possible after an oil spill in sea otter habitat. Further, preemptive capture and relocation of sea otters in Prince William Sound may have increased the number of otters that could have survived this event.
\end{abstract}

Sea otters (Enhydra lutris) are considered particularly sensitive to oil contamination because for insulation they depend on the integrity of dense fur and a high metabolic rate, rather than subcutaneous fat (Kenyon 1969). Documented effects of oil contamination on sea otters include elevated metabolic rates and activity (Costa and Kooyman 1982; Siniff et al. 1982). Siniff et al. (1982) also demonstrated that sea otters have at least some ability to detect oil on the water and may avoid it to some degree, although once completely oiled, otters die within $24 \mathrm{~h}$ unless the pelage is cleaned.

On 24 March 1989 the T/N Exxon Valdez ran aground on Bligh Reef, Prince William Sound (PWS), Alaska. The subsequent release of nearly 11 million gallons of crude oil posed a serious 
threat to sea otters in the sound. In response to this threat the U.S. Fish and Wildlife Service and Exxon Company, U.S.A., initiated a sea otter rescue operation. We describe and review the sea otter capture aspect of this rescue operation.

Because no rescue plan existed for such a catastrophe, a list of personnel and equipment to be used in such an event was not available, and a week passed before the first capture vessels were deployed on 30 March. Consequently, rescue efforts were never at the leading edge of the oil, and operations had to be concentrated in areas where oil had been present for several days. The authors believe this delay kept us from observing the response of sea otters to initial oil exposure, and from developing rescue procedures that may have been more effective in mitigating the risk to otters.

The initial objectives of this operation, in descending order of priority, were to capture live, oiled sea otters for cleaning and rehabilitation, capture nonoiled otters that were at risk of oiling (for relocation), collect dead otters and other wildlife for mortality assessment, and document the rescue effort and the distribution, abundance, adult-topup ratios, and behavior of sea otters. Additional aspects of the capture operation included collecting live, oiled birds and arranging for their transport to Valdez, Alaska, and documenting the effects of the spill on other flora and fauna in PWS.

\section{Capture Areas and Methods}

Prince William Sound has numerous large and small islands, bays, inlets, and passages (Fig. 1). A series of large outer islands effectively protects PWS from oceanic swells; this allowed small skiffs to work near the shore making the capture of animals hauled out on beaches practical. The complex geography of PWS, and prevailing weather

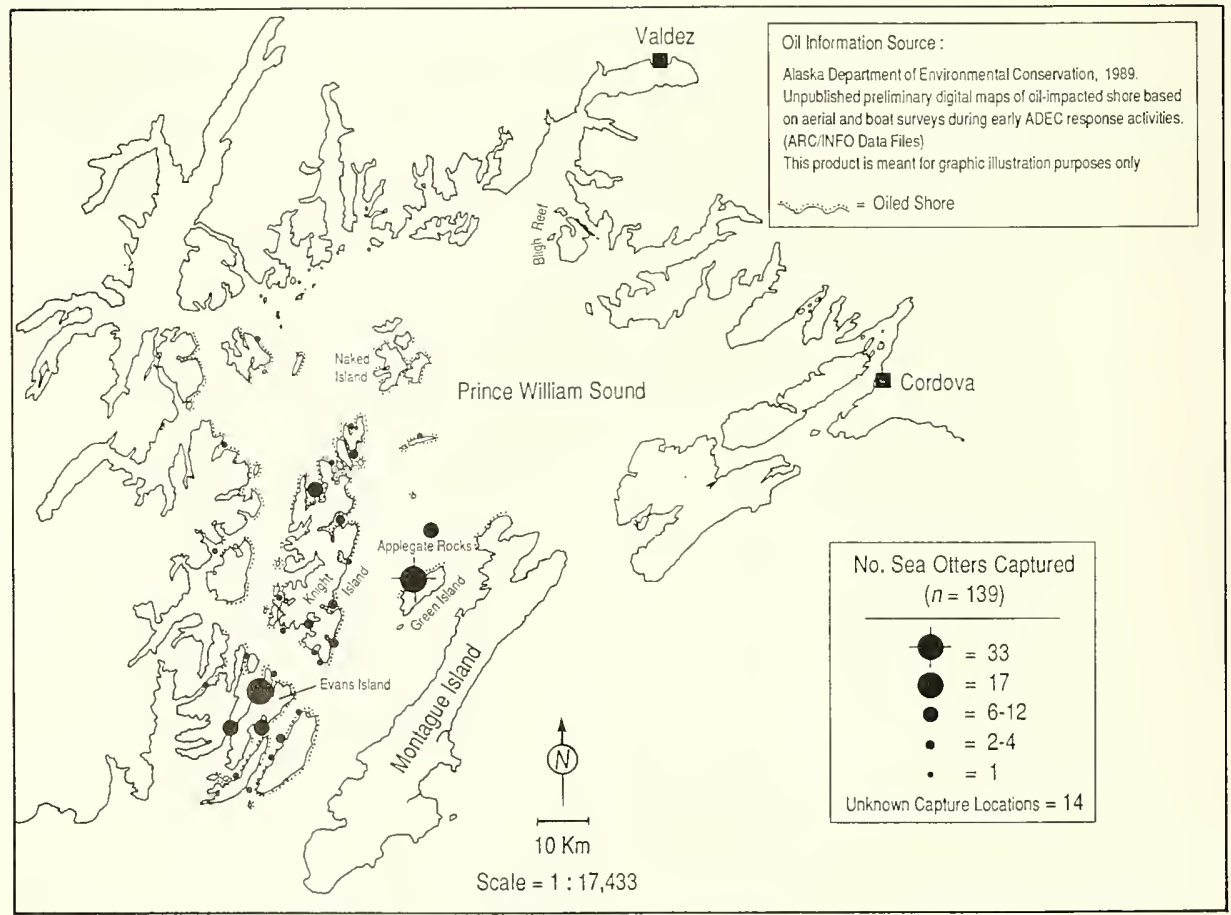

Fig. 1. Numbers and distribution of sea otters captured for rehabılıtation in Prince William Sound, Alaska, 1989. 
and sea conditions after the spill, seemed to greatly affect the distribution and abundance of oil, often on a small spatial scale. Consequently, there was considerable variation in the timing and extent of exposure of otters to oil.

Four large charter vessels provided a mobile base for our capture operations. Capture crews (two or three persons) operated from small skiffs (3-5 m) powered by outboard motors (15-25 hp). Helicopters based in Seward and Valdez brought supplies to vessels and transported otters to the Valdez Otter Rehabilitation Center (VORC). Capture crews were supported by information received from persons flying fixed-wing aircraft. Communications were through VHF marine band radio with Valdez, Seward, and Anchorage. Crews captured sea otters, held them aboard "mother" vessels and arranged for helicopter transport to VORC.

Sea otter capture operations in PWS began on 30 March 1989. During the first few weeks of capture operations the vessel Dancing Bear worked around Green Island and the east side of Knight Island, and the Rhoda Mae worked around Applegate Rocks, and Green, Latouche, and Chenega islands. At the same time the Sea Raker and the Viking worked near Evans Island and the north and west sides of Knight Island (Fig. 1). Capture operations were effectively over by 1 May 1990 .

Otter groups were usually located by observers aboard the mother vessels, often from the crow's nest of the vessel's mast. The distribution and abundance of sea otters and oil were recorded on 1:80,000-scale navigation charts. Observations included the number of sea otters present and their locations, the quantity or evidence of oil in the environment, and the behavior of the otters. Oil on individual animals was not usually visible from this perspective; however, oil was occasionally so pervasive as to preclude an animal from avoiding it.

After locating otter concentrations, capture crews departed the mother vessel and began searching for otters from their skiffs, usually along the shoreline. Sea otters were either in the water or hauled out on beaches, intertidal rocks, or ice floes. The initial primary capture method was dipnetting with large salmon landing nets, some of which had 2-m-long wooden handles. Otters were approached with one person operating the skiff from the stern and another poised on the bow prepared to dip the animal out of the water. Most otters approached for dipnetting avoided capture. Those that were dipnetted out of the water were usually caught within the first few moments of the chase. Occasionally, it was possible to follow an animal swimming underwater, either visually or by watching a bubble trail rising from the otter's pelage. Animals were occasionally chased for extended periods (>20 $\mathrm{min}$ ); however, we know of no instance in which a clean otter was chased into oiled water in the capture process.

For a hauled-out animal, the vessel approach was made to cut off the animal's escape to the water, while the net handler left the skiff and pursued the animal onshore.

Before and during capture, crew members evaluated the general condition of the otter; this evaluation included behavior, observable oil, and an assessment of the animal's vigor.

Once an animal was captured, a crew member immediately placed it in a plywood box lined with a large-mesh (10-cm) bag to which a purse line was attached, or in a kennel of a size suitable for a large dog (see Appendix for materials and equipment list). Once an otter was restrained, often with the aid of a stuff sack filled with soft foam, we made a more detailed physical examination of the animal. We recorded relative age (pup, juvenile, or adult), sex, and degree of oiling (heavy, moderate, light, or not apparent). Most otters that appeared free from oil and that had been captured in an area without floating oil were released back into the wild. Each animal retained was weighed and (usually) tagged on a hind flipper with a numbered, color-coded, plastic sheep ear tag (Temple Tag Co.). The animal was then placed in an individual animal kennel. Other data collected included date, time, location, capture method, tag information, and disposition of the animal. Data were recorded on formatted data sheets printed on waterproof plastic paper. Two identical data sheets were produced; one copy was affixed to the kennel in which the otter was transported to Valdez; the other was retained by the capture crew. Equipment shortages occasionally caused deviation from these procedures.

Captured animals were then taken to the mother vessel to await transport to VORC. Animals held aboard the mother vessel more than a few hours were offered food, and kennels were rinsed with seawater. The behavior of each animal while in the kennel was observed and recorded, as was the type and quantity of food offered. On 7 April, the Sea Raker and Viking crews ceased rinsing oil out of kennels and began lining each kennel with sorbent pads in an effort to absorb oil from the pelage. Soiled pads were replaced with clean ones as needed.

On 7 April, the crew of the Sea Raker, anticipating further decline in capture rates, began using 
tangle nets in Iktua Bay, near Evans Island. More than 50 otters had been seen in this large bay during initial surveys. While Iktua Bay appeared relatively free of oil, portions of Prince of Wales Passage, at the mouth of the bay, had extensive oil deposits on the shoreline. Several otters had been dipnetted in this bay; all of these had some degree of oiling.

Tangle nets float from a corkline along the surface, have no lead line, and are sewn from a light multifilament twine into a $23-\mathrm{cm}$ mesh that hangs down in the water about $5 \mathrm{~m}$; they are about $91 \mathrm{~m}$ long. Nets were set in protected waters of 10-25 m depth and anchored at both ends with slack anchor line to allow for tidal changes. Animals usually swam into these nets during the night and became entangled. Nets were checked at dawn and several other times each day. Nets were pulled out of the water before inclement weather.

\section{Results}

Initial aerial reconnaissance and information from vessels in PWS indicated that oil was traveling in a west-southwest direction. The heaviest oiling occurred around Naked, Knight, Green, and Evans islands, the passages through southwest PWS, and out into the Gulf of Alaska. Observations of oiled sea otters generally coincided with the distribution of oil. The distribution of sea otters in the spill area was clumped.

Between 30 March and 29 April, 138 live sea otters were captured in southwestern PWS and transported to VORC, and one unoiled but sick otter was captured on 29 May (Fig. 1). In addition, crews handled 23 other otters. We captured and released at least 14 sea otters (9 adults and 5 pups) back into PWS (Bayha and Hill 1990) because we could not detect oil on their pelage, and they were captured in areas relatively free of floating oil. Additionally, one pup's mother could not be caught, so the pup was released. Another otter escaped, and three otters died while being held for transport aboard vessels (Bayha and Hill 1990). Two otters were captured away from the spill, and two were born at VORC (Williams et al. 1990).

Daily capture rates ranged from 9.0 otters per vessel per day on 1 April to zero on several days (Fig. 2). Several factors affected the rate at which otters were captured. For example, a decline over time in the capture rate of live, oiled otters occurred because of mortality and the prior removal of live, oiled otters. Also, the increasing ability of remaining otters to avoid capture, and inclement weather on 10 and 11 April, also reduced our capture rates. In addition, on 6 April, all vessels received instructions to halt capture efforts because there was a lack of space at VORC. These instructions were rescinded the next day. On or about 5 April, persons under contract to Exxon began capturing sea otters, some of which were transferred to one of the four designated capture vessels for transportation to Valdez. On 7 April, the Service requested these persons cease capturing sea otters. The capture by unauthorized vessels may have inflated the catch per unit effort values for those days, but this inflation should be offset

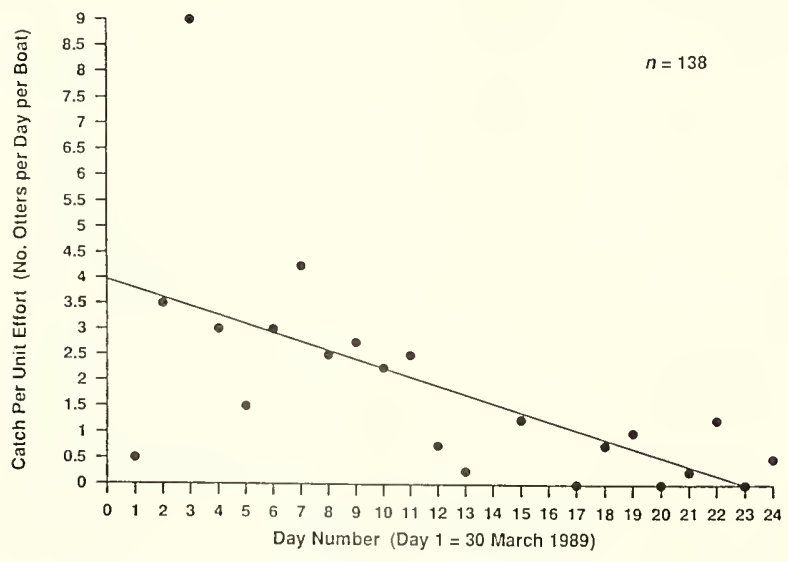

Fig. 2. Sea otter capture rates over time, Prince William Sound, Alaska, 1989. 
by the reduced capture effort caused by lack of space for otters at VORC.

Seven otters were sent to VORC because we could not positively detect oil on their pelage in the field. At VORC, four of the seven were found to be oiled, illustrating the difficulty in determining light oiling in the field and the need for an accurate procedure to do so. Also, capture personnel need criteria for deciding if an otter should be released into the wild or removed from it.

We captured 139 live sea otters and transported them to VORC; dipnetting accounted for the capture method of 127 (91\%) otters and tangle nets for $12(9 \%)$. Personnel from VORC examined 122 otters for the presence of oil. They considered 5 of the 122 (4\%) clean, and $117(96 \%)$ oiled.

For part of the otter rescue period, crews used both dip nets and tangle nets to capture otters. Forty-four of 48 animals (92\%) captured by dip nets, after the initiation of the use of tangle nets, were considered oiled (determined by VORC staff). Ten of 11 otters captured in tangle nets used during the same period were considered oiled (91\%). Although the sample of tangle-net captured animals was small, the capture ratio of oiled to nonoiled otters was similar between capture methods during the time when both methods were used. This comparison suggests that tangle nets, when placed near oiled otters, may not be only capturing oiled otters.

Survival of sea otters increased as the time between the spill date and the capture date increased (Fig 3). This correlates with a decline in the degree of oiling observed on otters over time (Fig. 4). Survival during the first week of capture operations was low, and the degree of oiling observed in otters during this period was high. As the degree of oiling declined and the number of heavily oiled otters declined, otter survival increased. Several factors may account for these patterns, including mortality that had already occurred (271 carcasses had been processed by 15 April), the removal of heavily oiled otters by capture crews, and a decrease in the quantity and toxicity of (weathering) oil. Also, improved cleaning and rehabilitation methods at VORC may have contributed to increased otter survival.

No sea otters were captured in PWS after 29 May. Between 30 April and 1 June 1989 the sea otter capture operation continued; however, only stressed animals were targeted. Capture crews felt continued capture efforts were unwarranted and counterproductive. The retrieval rate of carcasses had diminished, and survival of animals in the wild seemed to be increasing. Repetitive counts in the affected area indicated that sea otter abundance seemed to stabilize during May. Between 1 June and 23 July, when the last vessel was recalled, activities were limited to monitoring otter abundance and distribution. Those otters remaining in the wild appeared healthy, had only a small chance of exposure to oil, and their numbers seemed stabilized.

\section{Discussion}

As a result of the complex geography of PWS and the distribution of the sea otters, many otters
Fig. 3. Sea otter survival over time, Prince William Sound, Alaska, 1989.

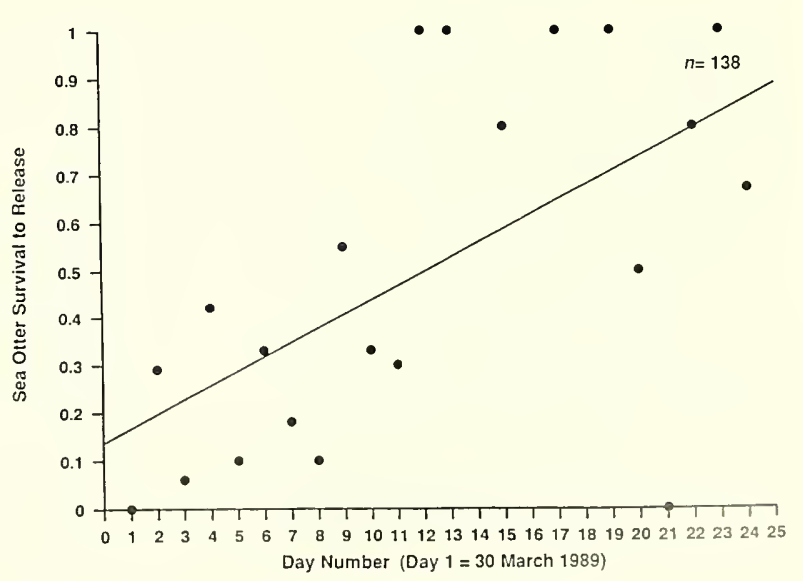




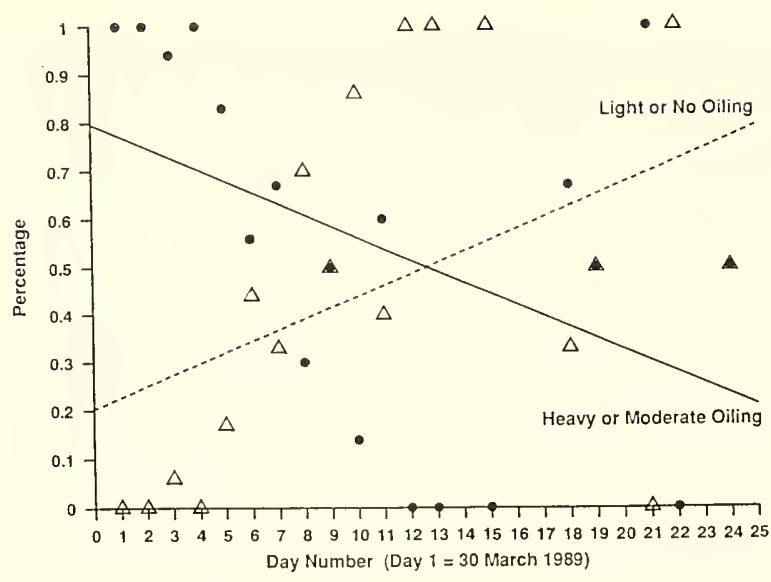

Fig. 4. Relative oiling (heavy or moderate versus light or none) of sea otters in Prince William Sound, Alaska, 1989.

may have inadvertently avoided contamination because of their precise location as oil moved through western PWS. About $10 \%$ of the sea otters we captured in western PWS were oil-free. We do not know if this resulted from active or passive avoidance. However, several observations of otter distribution within the oil spill track suggested that sea otters may have actively avoided oil after initial exposure. Few otters were seen resting in oiled water; resting animals usually selected clean water. On only two occasions did we observe otters hauled out on heavily oiled beaches, and these animals were severely oiled.

Published accounts of movements and home ranges of sea otters (Kenyon 1969; Ribic 1982; Garshelis and Garshelis 1984) suggest that largescale movements of otters into or out of western PWS during April 1990 were unlikely. Animals living along shorelines in the line of oil movement were most vulnerable and probably suffered the greatest losses (e.g., Applegate Rocks, Herring Bay [Knight Island], and Green Island).

Although we were rarely able to observe oil on an otter before capture, behavioral clues often indicated the presence of oil on a sea otter observed from a distance. In such instances, we frequently saw exaggerated grooming, particularly of the head, and extended, vigorous shaking of the head and upper body. Several animals were so preoccupied with grooming they were unaware of the approaching capture vessel until they were in the dip net. We occasionally observed lethargy and emaciation, usually in heavily oiled otters.
Hauled-out animals were easier to evaluate for presence and extent of oiling. A clumped pelage with visible spikes, emaciation, and lack of alertness often indicated an oiled otter. And, although sea otters regularly haul out to rest, they usually do so in groups. A single hauled-out otter could indicate stress or illness. A trail of oil from the water to a resting animal indicated that that animal was oil-contaminated. Oiled otters seemed to select clean beaches when they were available, as few otters were observed hauled out on oiled beaches.

We were asked if sea otters could inadvertently be chased from clean waters into oily waters as a result of capture efforts. Based on our sea otter capture experiences in California and Alaska, we believe there is little likelihood of inadvertently ehasing a clean otter into oiled waters during the capture process. While chasing an otter for dipnetting, there is usually little linear distance traveled by the otter. And, because oil is usually visible, capture can be terminated if forced oiling becomes a possibility. However, the possibility of inadvertently harassing otters, clean or oiled, into contact with oil is a risk that all persons working in the spill track should realize. Unnecessary human contact with otters should be avoided. The responsibility of deciding which otters were most suitable for capture and rehabilitation appropriately rested with capture crews in the field.

The issue of preemptive capture of otters was frequently raised. The discussion focused on the relative merit of removing an otter from the risk of oiling, compared with the risk of translocation- 
induced stress and mortality, given an unknown probability of otter oiling. In western PWS, the probability of oiling may have approached $90 \%$ for otters residing along shorelines exposed to the spill track, based on an unbiased sample of 36 ( 3 clean and 33 oiled) otters captured by the Sea Raker and Viking. Although capture efforts were concentrated in areas of heavy oiling, total effort was widely distributed (Fig. 1). Heaviest otter oiling and the greatest number of otter deaths occurred during the first 2-3 weeks after the spill. Survival was extremely low for those animals oiled right after the spill. Capture rates were somewhat slowed by the limited holding capacity of the cleaning center. An otter relocation effort before the arrival of oil would have reduced the strain on the rehabilitation center during the start-up phase. Had a large effort been mounted to capture sea otters along the shores of western PWS before the arrival of oil there, the number of animals that survived this event may have been significantly higher. Such a relocation effort would have required the rapid deployment of a large capture force using all available capture methods (tangle nets, dip nets, and underwater capture), and an accurate prediction of the tracks of the spilled oil. Because the threat to sea otters declined rapidly over time, the authors believe relocation to eastern PWS may have been adequate to protect many otters from oiling. However, some mortality could be expected with the preemptive capture and translocation of otters. On the basis of experiences with translocation in California, we believe that $10 \%$ mortality could be expected from such an operation. We also suggest that mortality may have been much higher had the oil remained in PWS longer.

\section{Conclusions}

Most sea otters did not seem to have the ability to avoid oil from a spill of this magnitude in their environment. The initial effects of Exxon Valdez oil in western PWS included severe oiling of many sea otters living near exposed shores within the oil track. Most of the heavily oiled otters were captured during the first 10 days of the rescue operation. Mortality among this first group was high. Capture rates declined after about 10 days of capture effort. Those otters that avoided heavy oiling or became oiled after about 7 April had a higher rate of survival. The degree of oiling of sea otters declined over time. These conclusions are based on the authors' direct observations and information in the biodata base (Williams et al. 1990).

The delayed response to the PWS oil spill meant capture efforts were focused on otters that were already oiled. Had our rescue efforts begun sooner, capture crews may have been better able to reduce the time between otter oiling and cleaning, and could have captured otters for relocation before oiling. An earlier response to this crisis would also have allowed a research program to be set up that could have adciressed questions about how sea otters respond to oil in their environment and the fate of sea otters left in a contaminated environment.

The authors make the following recommendations for future sea otter rescue efforts:

1. Begin response efforts immediately. The response time between the grounding of the tanker and the deployment of the first capture vessel was 7 days. For each day this response time could be reduced, the effectiveness of rescuing sea otters would be increased.

2. Heavy initial oiling and mortality suggest that preemptive capture may be warranted in front of the leading edge of an oil spill, particularly along a less complex coast. Effective preemptive capture would require accurate assessment of oil movements and otter distribution and abundance. Preemptive capture would not require a cleaning center, but a field holding pen may be necessary.

3. The decline in sea otter mortality and degree of oiling observed over time suggests that rehabilitation efforts may be ineffective in reducing losses at the population level after the first 4-6 weeks of oil exposure. The duration of a rescue effort may depend on the persistence of oil in the environment.

4. Capture vessels and equipment, including skiffs, outboards, nets, and tackle (Appendix) need to be cataloged and available on short notice. Much of the equipment we received was adequate; however, some was not (e.g., shaft lengths of outboards and inadequate cargo space in Bell Jet Ranger 206 helicopter).

5. Communications between vessels, rehabilitation centers, and Anchorage were inadequate. If another such spill were to occur in Alaska, we suggest tapping into available commercial vessel communications networks (single-side band radio), which provided a consistent communications link with the city of Cordova. Improved communications would facilitate helicopter 
transport of injured animals, thereby increasing their chances of recovery. Holding time aboard vessels should be minimized.

6. A list of experienced and trained persons should be maintained and kept current.

7. Standard data-collection and recording methods must be developed and used.

8. Many questions could have been addressed during this rescue operation with a minimum of effort and coordination. For example, what is the response of otters to oil? What is the fate of oiled otters left in the wild? What is the fate of unoiled otters remaining in this contaminated environment? The Service's decision not to initiate research designed to address such questions has left large gaps in our understanding of the effects of such events. The answers to these questions would help future rescue efforts. We suggest that radiotelemetry and radio-tagging be used to address such questions in future oil spills. We should design studies in anticipation of future events.

9. Alternatives to sea otter rescue operations should be considered. It is likely that PWS rescue efforts did little to alter the effect of the spill on the PWS sea otter population. In the future, an initial response should consider at what level we should focus our efforts-individual otter or population?

\section{Acknowledgments}

We thank J. Ames, K. Bayha, R. Britton, R. Davis, A. Franzmann, T. Gornall, K. Hill, T. Jennings, M. Kenner, E. Klinkhart, S. Loshbaugh,
N. Siepel, J. Thomas, Jon Thomas, and J. Warburton for their contributions to this project.

\section{References}

Bayha, K., and K. Hill. 1990. Overall capture strategy. Pages 41-60 in K. Bayha and J. Kormendy, tech. coords. Sea Otter Symposium: Proceedings of a symposium to evaluate the response effort on behalf of sea otters after the T/V Exxon Valdez oil spill into Prince William Sound, Anchorage, Alaska, 17-19 April 1990. U.S. Fish Wildl. Serv., Biol. Rep. 90(12).

Costa, D. P., and G. L. Kooyman. 1982. Oxygen consumption, thermoregulation, and the effect of fur oiling and washing on the sea otter, Enhydra lutris. Can. J. Zool. 60: 2761-2767.

Garshelis, D. L., and J. A. Garshelis. 1984. Movements and management of sea otters in Alaska. J. Wildl. Manage. 48:665-678.

Kenyon, K. W. 1969. The sea otter in the eastern Pacific Ocean. U.S. Fish WildI. Serv., N. Am. Fauna 68. $352 \mathrm{pp}$.

Ribic. C. A. 1982. Autumn movement and home range of sea otters in California. J. Wildl. Manage. 46:795-801.

Siniff, D. B., T. D. Williams, A. M. Johnson, and D. L. Garshelis. 1982. Experiments on the response of sea otters, Enhydra lutris, to oil contamination. Biol. Conserv. 23:261-272.

Williams, T. M., J. McBain, R. Wilson, and R. Davis. 1990. Clinical evaluation and cleaning of sea otter affected by the T/V Exxon Valdez oil spill. Pages 236-257 in K. Bayha and J. Kormendy, tech. coords. Sea Otter Symposium: Proceedings of a symposium to evaluate the response effort on behalf of sea otters after the T/V Exxon Valdez oil spill into Prince William Sound, Anchorage, Alaska, 17-19 April 1990. U.S. Fish Wildl. Serv., Biol Rep. 90(12). 


\section{Appendix. Equipment and Supplies for Sea Otter Rescue.}

- Support vessels (large enough to carry 5-m skiff and accommodate three people) with appropriate communication and safety equipment

- Capture skiffs, 4-6 m, rigid hull or inflatable (center console preferred), with safety equipment, spare parts, and toolbox

- Outboard motors, 15-70 hp, spare props, fuel lines, and tanks

- Large salmon landing nets with 2-m wooden handles, three per vessel

- Hand-held VHF radios

- High-quality, weatherproof binoculars

- Holding boxes, $19-\mathrm{mm}$ plywood, $1 \mathrm{~m}$ long $\times 0.65 \mathrm{~m}$ wide $\times 0.65 \mathrm{~m}$ high

- Net bags, with purse line, to line holding box

- Stuff sacks filled with soft foam

- Large (dog size) air transport animal kennels (model 300P and 400P, Doskocil Manufacturing)

- 50-kg scale

- Suitable animal tags (Temple, Roto)

- Survival suits, personal flotation devices, and rain gear for capture crew

- Tangle nets, three per crew, $91 \mathrm{~m}$ long, 23-cm stretch mesh, multifilament line, no lead line, with corkline, ground tackle, and large floats

- Standardized capture data forms on waterproof paper

- Weatherproof notebooks, pencils, and pens

- One-gallon Ziploc bags

- Sorbent pads, paper towels, and cloth towels

- Field identification guides to birds and mammals

- Large, heavy-duty garbage bags

- Waterproof toolboxes for gear

- Photographic equipment

- Appropriate navigational charts

- Gloves: heavy (welder's) and surgical

- Cable ties

- Duct tape

- Museum tags

- Appropriate frozen otter food

- Leather punch: single or farmer's ear punch

- Blunt scissors and pocketknife 


\title{
Sea Otter Capture Along the Kenai Peninsula
}

\author{
by
}

\author{
R. L. Britton and C. T. Benz \\ U.S. Fish and Wildlife Service \\ 2140 Eastman Avenue \\ Suite 100 \\ Ventura, California 93003
}

and

J. J. Foster

2033 South 304 th

Federal Way, Washington 98003

\begin{abstract}
The major emphasis of the sea otter (Enhydra lutris) rescue efforts along the Kenai Peninsula was from Nuka Bay to Port Chatham. Professional and volunteer personnel worked on contract fishing vessels conducting surveys and capturing sea otters using dipnetting and tanglenetting methods. Training of both professional and volunteer replacement personnel was conducted on the job. Dipnetting techniques were abandoned after a few weeks because of the evasive vigor of the otters, and tangle nets became the primary capture method. From the field perspective, provisions for capture vessels, including capture supplies and equipment repairs, were provided haphazardly without an apparent schedule by a "chain of command," which made the acquisition process difficult. On several occasions this compromised the safety of the inflatable capture boats. Capture efforts were also affected by field management decisions being delivered from the cleaning and rehabilitation facilities without adequate field input to determine the level of capture effort possible. Inadequate radio communications between the field and the base, erroneous reports and updates on oil spill location, absence of adequate sea otter capture criteria, and long periods of unpredictably bad weather resulted in the capture of fewer sea otters than was possible when they could have benefited the most.
\end{abstract}

The Kenai Peninsula from Resurrection Bay west to Kachemak Bay extends into the Gulf of Alaska in a series of rocky exposed headlands, small fjords, and embayments with small, protected sand beaches. The open coast of the peninsula is sculpted by winds, high tides, strong currents, and storms, which make access to the fjords and headlands difficult at best, and sometimes impossible. The biological communities include offshore kelp beds, abundant rocky intertidal fauna, and less abundant sand beach zones. These communities and the shallow to moderate nearshore coastal depths along the Kenai Peninsula made this excellent sea otter (Enhydra lutris) habitat before the T/N Exxon Valdez oil spill.

From 15 April until 28 July 1989, sea otters were captured off the Kenai Peninsula (Fig. 1) in an effort to rescue them from the crude oil making its way out of Prince William Sound. Storms and currents in late March pushed oil out of the sound and into the Gulf of Alaska. It was hoped that the same storms would continue to push the oil offshore, where it would eventually be broken up and weathered. The storms abated and the oil was 


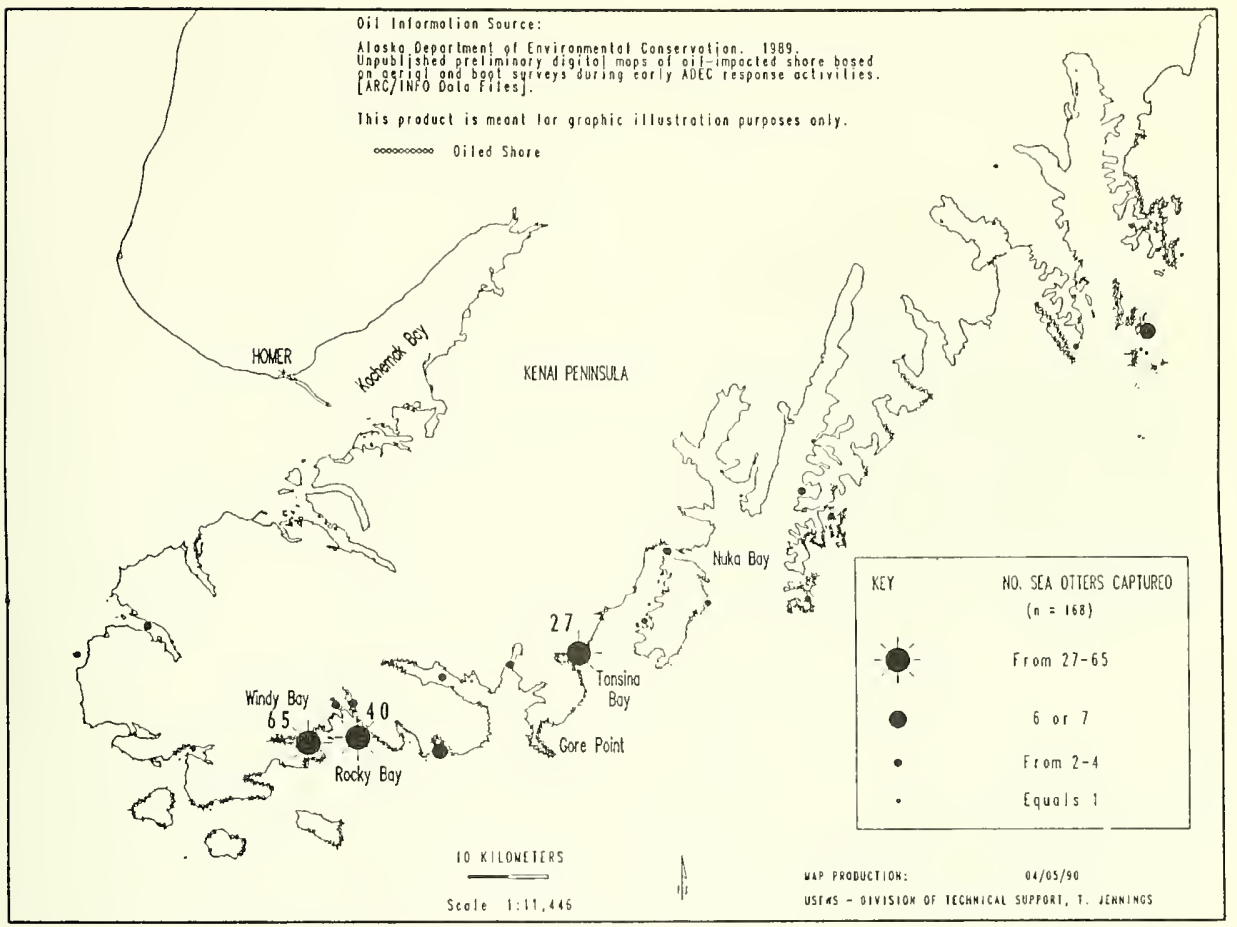

Fig. 1. Number and distribution of sea otters (Enhydra lutris) captured for rehabilitation near the Kenai Peninsula, Alaska, 1989.

driven toward Kodiak by 8 April (Townsend and Heneman 1989). With rumors of oil reaching the Chiswell Islands on 11 April, and reports of the leading edge of the oil off Gore Point on 12 April (Townsend and Heneman 1989), U.S. Fish and Wildlife Service personnel began surveys to determine effects related to known populations of sea otters and seabirds. From Resurrection Bay to Kachemak Bay, oiled sea otters were captured with dip nets and tangle nets until it was not possible to determine by visual or tactile inspection whether they were oiled. The main concern for terminating the capture operation was whether more damage than good was being done by capturing animals that were unoiled and not likely to be injured by the level of oiling occurring within the region in question. These concerns resulted in a number of oiled and unoiled animals being released. Other concerns for otter health and safety as well as several tangle net escapees accounted for a number of animals that are not included in the Exxon biodata base (Bayha and Hill 1990). In addition to concerns over the sea otters, there were logistical problems that occur during any spill. These problems involved aquatic and aerial support of capture teams, and lessons to be learned for training and use of personnel.

\section{Surveys}

On 12 April 1989, Service personnel from the Alaska Maritime National Wildlife Refuge flew over the Kenai Peninsula counting marine mammals and observing seabirds from Point Naskowhak to Nuka Island. They confirmed oil as mousse on the east side of Gore Point, saw light sheen in Port Dick, and observed oiled birds on east Chugach Island. They counted 465 sea otters, 245 sea lions, and 7 harbor seals without reference 
capturing, there were 11 days of stormy weather, or $31 \%$ of the time that the vessel could not operate.

The animals that were oiled early could often be captured while resting or sleeping, while grooming vigorously, and while hauled out on beaches or rocks for illness, hypothermia, or rest. As the oil dispersed and weathered, chronic oiling produced sea otters that were not always obviously impaired. They could effectively evade capture by dip net, making them difficult as well as time-consuming to capture. In California, dipnetting is generally considered effective only on the young, inexperienced sea otters. Older animals are more difficult to dipnet and must be chased with boats for long periods. This method added additional stress and was not clearly more advantageous than leaving them in the wild to survive or until they became sicker and easier to capture. When we used a dip net we agreed not to pursue an animal for more than three to five capture attempts, so as not to tire and stress the animal needlessly.

Tangle nets were used a great deal more on the Kenai Peninsula than in Prince William Sound. They had been used successfully in Prince William Sound to capture animals, but the animals were often so oiled that dipnetting was the most effective technique (Bodkin and Weltz 1990). On the Kenai Peninsula, the tangle nets were placed in areas of known oiling and known otter concentrations and proved to be effective. The most commonly used tangle nets were modified floating gill nets that were anchored at the up-current end and placed in an area of observed otter movement. We kept 2 - $h$ watches and assessed tides and weather daily to determine the best locations for the nets. Because many of the nets were new, they had bright white floats that were highly visible, making capture extremely difficult during the day. The best results were achieved by working the nets throughout the night. An excellent variation of this technique was used by the crew of the Mystic Lady; they employed a skiff capable of deploying the corkless net off a hydraulic spool that could be set and retrieved in a few minutes. The crew would select a small island or surge rock, throw the anchor onto the rocks, back off while deploying the net, and leave a small float on the outer end. Then the animals were slowly herded toward the net. The sea otters tended to move around the rocks and often tangled themselves in the net, which had a low visibility foam core floating line (Fig. 2).

Generally, the sea otters were thoroughly wrapped in the tangle nets and had to be quickly cut from the nets. Efficient and speedy handling of

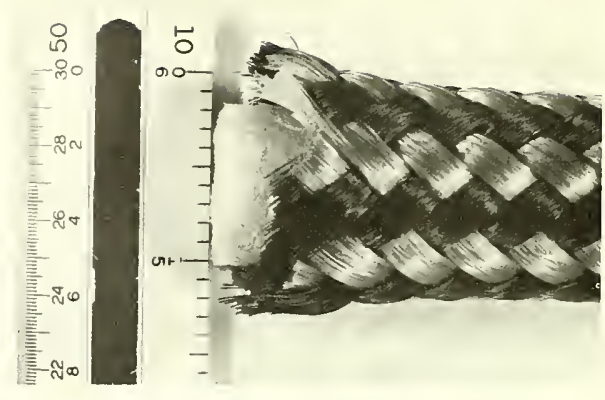

Fig. 2. Photograph of the foam core line.

young sea otters was particularly important, as they would occasionally spin violently in the net, along their sagittal axis, when being hauled aboard, and within a few seconds they could restrict their own breathing in an apparent effort to twist free of the net. Once cut from the net, they were placed in restraint boxes and returned to the larger vessel for transfer to a kennel and processing.

The nets became very ragged, and net repairs were necessary. Several Alaska Native volunteers had extensive experience with net repair techniques and took the responsibility of constantly patching holes and replacing small sections of the main nets with pieces from nets too ragged to use. Because nets were difficult to obtain, these volunteers were responsible for keeping the capture on the Kenai Peninsula at peak efficiency.

Recognizing oiled sea otters was relatively easy in the beginning, but became more difficult toward May. Abnormal behavior of the otters exposed to chronic or low levels of oil became more and more subtle. Alaska sea otter behavioral data are not abundant (Kenyon 1969, 1982; Estes 1980; Rotterman and Simon-Jackson 1988), and skilled observers are required for proper interpretation, particularly with the additional unknowns of the effects of light-to-moderate oil contamination. These effects occurred through direct oiling of the pelage, 
ingestion during grooming, or ingestion of contaminated prey species (VanBlaricom 1990).

The tangle net captures were complicated further in mid- to late May by the onset of increased pupping. There is the potential for abandonment of a pup by its mother if the mother can free itself from the net first. The pup might be swept away by tides and currents should the mother be entangled alone. The pup could drown if it is entangled next to any adult sea otter trying to escape the net. The pup could be killed by an adult male sea otter if entangled too closely together. Extreme precautions were taken during this time to avoid disturbing unoiled mother and pup pairs.

During this period of increased pupping there also appeared to be immigration into the Windy Bay, Rocky Bay, and Bootlegger Bay region (Table 1). Observers conducting surveys on 29 April counted 87 sea otter adults and 7 sea otter pups in this region. On 24 May, the observers counted 85 adults and 24 pups. Within that period nearly 60 sea otters had been removed from the area during capture operations, and most of the captured animals had been females.

When the capture teams were operating at peak efficiency, they were able to capture more animals than could be rehabilitated in the space provided. By the time the SORC was fully operational there had been 58 Kenai animals captured (K. Bayha, personal communication). Some had been sent to Valdez for washing, and some had been washed in Seward under the best conditions available.

\section{Releases}

On many occasions otters were released (Bayha and Hill 1990) because the rehabilitation facilities had reached their capacity, sick animals were captured late in the day after the final helicopter flight, or bad weather resulted in the possible long-term holding of otters. It did not matter whether the animal was sick or not during long periods of holding. The problems of keeping pelage clean, adequate thermoregulation, and feeding were too complex when dealing with otters in an unknown state of oiling, and these factors were much more predictable than the stress factors involved. The first releases were a male and a female captured by the Mystic Lady at Tonsina Bay on April 30. The two animals did not fit in the helicopter that was transporting three other captured animals. The two otters were held overnight and released on 1 May. The male, flipper-tagged with orange tags, was resighted in Tonsina Bay on 9 July, having returned to an oiled site from the release location in Berger Bay on Nuka Island (about $15 \mathrm{~km}$ ). Subsequent releases by Breaktime, Roman E, and Mystic Lady involved 39 additional animals. Most animals were released from the nets on the same day as capture, but four were released after being held overnight. Six otters escaped from the net or the animal carriers. Five animals escaped from nets, usually because of inadequate tangling (not included in Table 2 of Bayha and Hill 1990), and one tagged animal was placed in too small a cage and flexed the door open before loading onto a helicopter. This animal was seen on one occasion in Rocky Bay a week after the escape. Two groups of animals were released that were involved in investigations. On 31 May, 11 sea otters were released in Windy Bay-Rocky Bay after it was determined they were unoiled, on the basis of a proposed dichloromethane hair test. During 19-23 July, 17 animals were released, that had been captured for veterinarians to search for oral ulcers in the wild population. A single otter was released at a capture site in Rocky Bay while King TV crews were filming operations. This large male otter was released because transport space on the helicopter to Seward was limited.

Capture operations on the Kenai Peninsula ended with the capture of a female sea otter pup off the Pye Islands on 28 July. One hundred seventy-five sea otters were captured and sent to shore, 13 otters were released, 1 otter escaped, and 28 otters were released after hair tests and ulcer inspections, for a total of 219 otters captured off the Kenai Peninsula. Sixteen sea otter pups from the Kenai were born alive in captivity, and a number of pups were stillborn.

Of the 176 sea otter adults of known sex, 74\% were females and $26 \%$ were males (Table 2); of the 20 sea otter pups of known sex, $70 \%$ were females and $30 \%$ were males; of the total of 245 sea otters, $89 \%$ were adults and $11 \%$ were pups. Observations of pups captured in the wild, with and without their mothers, and of pups born in captivity showed that 21 pups survived and 17 pups died (Table 3), for a $55 \%$ survival rate.

\section{Logistics}

The tangled logistics of the Kenai Peninsula operation may be better understood by considering the agencies and groups involved. There were Exxon personnel, Exxon Manley on Perl Island, 
Table 2. Sea otters (Enhydra lutris) from the Kenai Peninsula.

\begin{tabular}{|c|c|c|c|c|c|c|c|}
\hline \multirow[b]{2}{*}{ Sea otters } & \multicolumn{3}{|c|}{ Adults } & \multicolumn{3}{|c|}{ Pups } & \multirow[b]{2}{*}{ Total } \\
\hline & Female & Male & Unknown & Female & Male & Unknown & \\
\hline Captured in the field & 120 & 42 & & 7 & 1 & & 170 \\
\hline Released or escaped in the field & 4 & 2 & 38 & & & 4 & 48 \\
\hline Pups born in captivity & & & & 7 & 5 & 11 & 23 \\
\hline Pups stillborn & & & & & & 4 & 4 \\
\hline Total & 124 & 44 & 38 & 14 & 6 & 19 & 245 \\
\hline
\end{tabular}

individual contractors, helicopter services, fixedwing services, SORC, U.S. Fish and Wildlife Service (USFWS)-Anchorage, USFWS-field, USFWS-Homer, USFWS-Seward, VORC, VECO-Homer, VECO-Seward, and volunteers. Even if someone had surfaced as a coordinator, it would have been difficult to coordinate such an array of organizations into a cohesive, working unit. The four most important areas of logistical concern were aquatic support for supplying vessels and personnel, aerial support for transport of animals and personnel, communications coordination, and volunteer coordination.

Support of the vessels by the Exxon/VECO system was irregular. Early in the capture operation, food, fuel, and water were generally inadequate because of weather and random scheduling. As the fleet grew, there were enough large resupply vessels and enough good weather to allow adequate provisioning. Supplies for the capture and transport process were never adequate. Supplies ordered often never arrived, were untimely, or were not the ordered item. There was an ill-defined Exxon-VECO-USFWS chain of command that never seemed to function cohesively for the field operations. Part of the problem was the intense demand and competition for the requested items. This system compromised the safety of more than one capture team working in open water.
Aerial support was scheduled by USFWSHomer, USFWS-Seward, USFWS-Anchorage, VECO-Homer, and VECO_Seward. When aircraft arrived in the field they were used to transport otters and personnel to the centers in Valdez, Seward, and Homer (Cramer 1990). Helicopters and amphibious aircraft presented their own kinds of problems. They were absolutely necessary for getting animals off the Kenai Peninsula in a timely manner. They were scheduled for two daily flights, late morning and late evening, but they were often delayed, sometimes because of weather, and occasionally because of the distance between capture sites, the capacity of the helicopter, or mechanical problems. Designated landing sites and points of rendezvous were selected by pilots and reused as weather and vessel proximity allowed. These flights also relayed messages from the field, and orders from employers and facilities, and they became the primary method of communicating.

Field communications were difficult from the Kenai Peninsula to either Homer or Seward. The terrain and distances involved incapacitated normal marine operator traffic. A common communication method was to send out information through the Exxon-Manley relay on Perl Island, but it was often overloaded with traffic. Sending a message that had to be relayed was not reliable unless it was designated as an emergency mes-

Table 3. Sea otter pups (Enhydra lutris) from the Kenai Peninsula.

\begin{tabular}{|c|c|c|c|c|c|c|}
\hline \multirow[b]{2}{*}{ Sea otters } & \multicolumn{3}{|c|}{ Survived } & \multicolumn{2}{|c|}{ Died } & \multirow[b]{2}{*}{ Total } \\
\hline & Released & Aquarium & $\begin{array}{c}\text { Unknown } \\
\text { Disposition }\end{array}$ & $\begin{array}{c}\text { Died/ } \\
\text { Euthanasia }\end{array}$ & Stillborn & \\
\hline Pups captured with mothers & 7 & 4 & & & & 11 \\
\hline Pups captured without mothers & & 2 & & 2 & & 4 \\
\hline Pups born in captivity & 4 & 2 & 2 & 11 & 4 & 23 \\
\hline Total & 11 & 8 & 2 & 13 & 4 & 38 \\
\hline
\end{tabular}


sage. Receiving messages proved to be just as difficult. We did not receive accurate oil location data, and we did not receive veterinarian information on the otters' health and degree of oiling. Most communications traffic arrived by helicopter message, and there were many people sending out recommendations, guidance, and policy; it was often impossible to tell which was priority or authorized.

\section{Personnel}

Participants in the Kenai Peninsula capture operations were from several organizations and a variety of backgrounds. The Service provided 15 people from Alaska and California to work on capture boats. The VE Construction Company provided at least 36 people, including the boat contractors and their crews. These two groups had the personnel with the most sea otter handling experience available. The Indigenous Conservators of the Environment provided eight volunteers, and Minerals Management Service assisted by providing two capture personnel. Many of these 61 people were involved in the training process. Training consisted of the transfer of survey, capture, and handling techniques from an experienced person to a new or inexperienced person. Training was simple and effective, and the personnel fell naturally into some or all of the categories of the capturing and handling processes. Dipnetting was the most difficult technique to teach unless the person already had skills in handling of small boats or netting of large, active animals. The capture method most easily learned was the tangle net technique.

Personnel were responsible for keeping logs and records of events and animals captured. These records were as varied as the keeper's background. The field record keeping and tagging of the animals were done when forms and tags were available. Field capture forms were from Prince William Sound, VORC, SORC, USFWS-California, and private vessels' logs. Most had the spaces for the necessary data used in identifying animals' capture locations, capture dates, and capture teams. Tagging was conducted by personnel who had tagging experience. Tags were generally from Service sources. There was no color or numbering strategy, but on the Kenai Peninsula it was agreed to try to tag the $4 / 5$ (outermost) location and left flipper for females, right flipper for males. Leather punches, paper punches, and pocketknives were used to cut holes for the flipper tags. Pocketknives were discouraged because of potential damage to the flipper.

Personnel problems encountered did not generally affect the capture efforts, but screening of participants should include elimination of persons who are afraid of the water, are prone to seasickness, have never been in small boats, have never handled outboard engines, or are unfamiliar with the handling of wild animals. Several people arrived who were not useful because they were too uncomfortable in a field situation.

People generally worked well together and were productive during the aggravation of bad weather, unexplained delays, inadequate or absent equipment, stress of isolation, and the vagaries of individual personalities. It was the human factor that kept the capture operation as effective as it was in spite of the limitations.

\section{Summary}

The Kenai Peninsula operation's sporadic capture-hold strategy rendered capture data inadequate for assessing trends in the capture of oiled animals. Raw data suggest, however, that of the females captured with pups and of the pregnant females giving birth to pups in captivity, there appeared to be a higher survival of pups born in the wild than of pups born in captivity.

Logistically, communications are extremely crucial to the field and rehabilitation center operations. We believe that the following recommendations should be considered in preparing for a future response effort. In conjunction with communications, a single field operations coordinator should be designated. Finally, if the decision to capture sea otters is made, it will be necessary to mobilize the capture operation quickly. The rehabilitation centers should be capable of expanding to meet the needs of all the animals arriving. This expansion must initially be rapid, then taper off until the decision is made to stop capturing.

\section{References}

Estes, J. A. 1980. Enhydra lutris. Mamm. Spec. 133. 8 pp. Kenyon, K. W. 1969. The sea otter in the eastern Pacific Ocean. N. Am. Fauna 68. 352 pp.

Kenyon, K. W. 1982. Sea otter (Enhydra lutris). Pages 704-710 in J. A. Chapman and G. A. Feldhamer, eds. Wild mammals of North America: biology, man- 
agement, economics. Johns Hopkins University Press, Baltimore, Md.

Rotterman, L. M. and T. Simon-Jackson. 1988. Sea otter, Enhydra lutris. Pages 237-275 in J. W. Lentfer, ed. Selected marine mammals of Alaska: species accounts with research and management recommendations. Marine Mammal Commission, Washington, D.C.

Townsend, R., and B. Heneman. 1989. The T/N Exxon Valdez oil spill: a management analysis. Center for Marine Conservation, Washington, D.C. 239 pp.

Bayha, K., and K. Hill. 1990. Overall capture strategy. Pages 41-60 in K. Bayha and J. Kormendy, tech. coords. Sea Otter Symposium: Proceedings of a symposium to evaluate the response effort on behalf of sea otters after the T/N Exxon Valdez oil spill into Prince William Sound, Anchorage, Alaska, 17-19 April 1990. U.S. Fish Wildl. Serv., Biol. Rep. 90(12).

Bodkin, J. L., and F. Weltz. 1990. Evaluation of sea otter rehabilitation after the T/N Exxon Valdez oil spill, Prince William Sound, Alaska. Pages 61-69 in K. Bayha and J. Kormendy, tech. coords. Sea Otter
Symposium: Proceedings of a symposium to evaluate the response effort on behalf of sea otters after the T/ Exxon Valdez oil spill into Prince William Sound, Anchorage, Alaska, 17-19 April 1990. U.S. Fish Wildl. Serv., Biol. Rep. 90(12).

Cramer, D. W. 1990. Transportation of sea otters to rehabilitation centers. Pages 91-94 in K. Bayha and J. Kormendy, tech. coords. Sea Otter Symposium: Proceedings of a symposium to evaluate the response effort on behalf of sea otters after the T/N Exxon Valdez oil spill into Prince William Sound, Anchorage, Alaska, 17-19 April 1990. U.S. Fish Wildl. Serv., Biol. Rep. 90(12).

VanBlaricom, G. R. 1990. Capture of lightly oiled sea otters for rehabilitation: a review of decisions and issues. Pages 130-136 in K. Bayha and J. Kormendy, tech. coords. Sea Otter Symposium: Proceedings of a symposium to evaluate the response effort on behalf of sea otters after the T/N Exxon Valdez oil spill into Prince William Sound, Anchorage, Alaska, 17-19 April 1990. U.S. Fish Wildl. Serv., Biol. Rep. 90(12). 


\title{
Sea Otter Survey and Capture Effort, Kodiak Island Archipelago and Alaska Peninsula
}

by

\author{
R. F. Hander \\ U.S. Fish and Wildlife Service \\ Kodiak National Wildlife Refuge \\ 1390 Buskin River Road \\ Kodiak, Alaska 99615
}

\begin{abstract}
From 17 April through 4 August 1989, U.S. Fish and Wildlife Service personnel conducted a post-oil spill impact survey and capture operation for sea otters (Enhydra lutris) in the coastal waters of the Kodiak Island Archipelago and Alaska Peninsula. Service objectives were to find and capture distressed sea otters, collect data on relative abundance and distribution of otters, and collect dead otters. Eighteen trained otter-handling personnel worked out of four chartered vessels. In addition, village skiff crews in Ouzinkie and Larsen Bay on Kodiak Island were involved in the survey and capture effort. Systematic coastline surveys were conducted along the Alaska Peninsula from Cape Douglas to Puale Bay, around Afognak and Shuyak islands, and along the west side of Kodiak Island. Field observations from boat and village skiff crews were reported to staff at the Kodiak National Wildlife Refuge. The primary capture method was dipnetting from inflatable and hard-bottom skiffs. We captured 28 otters, of which 22 were transferred to the Kodiak Temporary Care Facility and then to the Seward Otter Rehabilitation Center. In addition, we recovered 196 dead otters. Sea otters observed in or near areas of oil seemed to take no action to avoid oil. During the initially critical 3-4 weeks of the capture effort, inadequate capture and handling materials, training, otter food provisions, and poor radio communications were problems. Feedback information from otter rehabilitation centers for possible immediate and future capture efforts were lacking. I give recommendations for beginning a well-organized contingency plan to expedite the initial effort when the need is most critical-in an oil spill.
\end{abstract}

The Kodiak Island Archipelago and Alaska Peninsula support significant concentrations of sea otters (Enhydra lutris; Simon-Jackson 1985).

On 24 March 1989, the T/N Exxon Valdez ran aground in Prince William Sound, Alaska, spilling an estimated 11 million gallons of crude oil. By 9 April 1989, the oil had spread to the Kodiak Island Archipelago, and shortly after to the Alaska Peninsula, and had affected coastal shoreline areas.

From 17 April through 4 August 1989, rescue personnel conducted a post-oil spill impact survey and tried to capture sea otters in the coastal waters of the Kodiak Island Archipelago and Alaska Peninsula (Fig. 1). Our objectives were to find and capture distressed or obviously oiled sea otters, collect data on relative otter abundance and distribution, and collect dead otters. The survey included the Kodiak Island Archipelago from Spruce Cape westward to Uyak Bay, and all of Afognak and Shuyak islands (Figs, 2, 3, 4). Cape Douglas south to Puale Bay on the Alaska Peninsula (Fig. 5) was also surveyed.

\section{Capture Support}

The U.S. Fish and Wildlife Service, Exxon Company, U.S.A. (Exxon), and VE Construction Company (VECO) provided capture materials, in- 
cluding chartered vessels, food provisions, skiffs, outboard motors, protective clothing, dip nets, tangle nets, hand-held radios, sea otter capture forms, and binoculars. Vessels and villages involved, the time each served, and the areas each covered are listed in Table 1.

Exxon and VECO provided chartered fixed-wing aircraft and helicopters to transport otters from the field to the Kodiak Temporary Care Facility (KTCF), the Seward Otter Rehabilitation Center (SORC), or the Valdez Otter Rehabilitation Center (VORC).

KTCF was financially supported by Exxon and operated by volunteer and veterinarian V. Vanek, who had received intense clinical otter treatment training at VORC and SORC. Space for this facility was donated inside work area of the National Marine Fisheries Service (NMFS) offices at Gibson Cove, Kodiak. The Kodiak center was opened on 18 May. There were four $1.2-\times 1.2-\mathrm{m}$ and two 2.4- $\times 1.2-\mathrm{m}$ holding pens in the NMFS work area. Pens were constructed of Chemgrate floors, seinenet siding, and wood with plywood angled from the pen floor to a gutter drain for convenient washing with water hoses. An ice maker, freezer space for food and blocked ice, and other essential materials were also donated by NMFS. KTCF was also equipped with an otter-handling box and a locked cabinet for storage of treatment materials. Captured otters received immediate medical attention and were stabilized by Vanek. Many volunteers provided around-the-clock monitoring until arrangements were made to have the otter transferred to SORC or VORC (V. Vanek, personal communication 1989).

J. Ames, a marine biologist with the California Department of Fish and Game (detailed as a tem. porary wildlife biologist for the Service), trained wildlife crews in otter behavior, capture and handling techniques, and data form completion for live and dead animals. From 24 May through 12 June, Ames instructed crew members who were to be in direct contact with otters. During training, otters were captured in the Kodiak and Alaska Peninsula areas to demonstrate capture and handling skills as well as collect data from hands-on examinations

Table 1. Vessels, villages, and related personnel that participated in the survey and capture effort, 1989.

\begin{tabular}{|c|c|c|c|}
\hline Boat or village name & Area covered & Period & Trained personnel and affiliation \\
\hline M/N Ten Bears & $\begin{array}{l}\text { Kodiak Island } \\
\text { Afognak Bay } \\
\text { Shuyak Island }\end{array}$ & 17 April-4 August & $\begin{array}{l}\text { D. Monson } \\
\text { D. Llanos } \\
\text { L. Chichenoff } \\
\text { R. Hander }\end{array}$ \\
\hline F/N Jeanoah & $\begin{array}{l}\text { Kodiak Island, } \\
\text { Alaska Peninsula }\end{array}$ & 30 April-4 August & $\begin{array}{l}\text { B. Hatfield } \\
\text { G. Sanders }\end{array}$ \\
\hline F/N North Light & $\begin{array}{l}\text { Kodiak Island } \\
\text { Afognak }\end{array}$ & 5 May-25 July & $\begin{array}{l}\text { D. Kvasnikoff } \\
\text { J. Ivanoff }\end{array}$ \\
\hline F/N Wayward & $\begin{array}{l}\text { Kodiak Island, } \\
\text { Alaska Peninsula }\end{array}$ & 13 May-26 May & J. Ivanoff ${ }^{\mathrm{c}}$ \\
\hline Larsen Bay & $\begin{array}{l}\text { Uyak Bay } \\
\text { Spiridon Bay } \\
\text { Zachar Bay }\end{array}$ & 10 June-4 August & $\begin{array}{l}\text { M. Carlson } \\
\text { B. Aga } \\
\text { R. Hochmuth }\end{array}$ \\
\hline Ouzinkie & $\begin{array}{l}\text { Spruce Island } \\
\text { Afognak Bay } \\
\text { Kazakof Bay } \\
\text { Whale Island }\end{array}$ & 12 June-4 August & $\begin{array}{l}\text { T. Helms } \\
\text { J. Squartsoff } \\
\text { I. Squartsoff } \\
\text { A. Squartsoff } \\
\text { K. Larionoff } \\
\text { A. Christofferson } \\
\text { J. Delgado }\end{array}$ \\
\hline
\end{tabular}

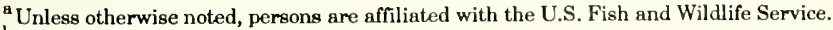

${ }^{\mathrm{b}}$ VECO-VE Construction Company.

${ }^{\mathrm{c}}$ ICE-Indigenous Conservators of the Environment.
} 
Fig. 1. Kodiak Island Archipelago and Alaska Peninsula.

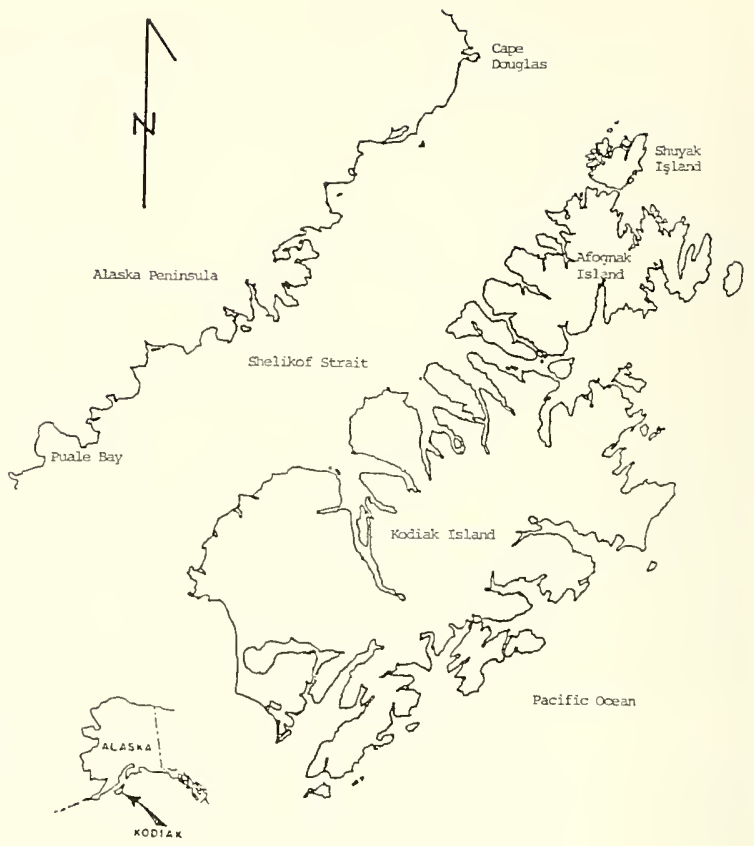

for oil. Thirty-five examinations of captured otters produced no instances of oiled sea otter fur.

\section{Capture Method}

The primary capture method was dipnetting from skiffs. Large salmon dip nets with deep netting and 1.8-2.4- $\mathrm{m}$ handles were used to retrieve otters from the water and off rocks. Otters that displayed normal behavior, as described in Bayha and Hill (1990), or that were exceedingly difficult to catch were presumed to be in an unstressful situation and were left alone. Otters could only be pursued with dip nets in reasonably calm water because of the inability to follow their bubble trails in marginal water conditions.

Captured otters were immediately transferred to net bags and grate-floored kennels and taken to the vessel or nearest village. Once at the vessel, the animal was weighed while still in the net bag, flipper-tagged, and externally examined for oil. Its general condition was recorded on a sea otter record form (Appendix). Captured otters were placed in the water for about 5 min to prevent overheating, then placed in clean kennels, given crushed or chunked ice to eat, and moved to the coolest area possible. Captured mothers and pups were separated after processing and placed in kennels with the doors facing each other. If the animal was held on a vessel or at a village for an extended period, it was fed according to capture and handling guidelines (Bayha and Hill 1990). The Kodiak National Wildlife Refuge (KNWR) was notified, and it arranged fixed-wing aircraft, helicopter, or boat transport to Kodiak. There, the animal would be met by authorized personnel and taken to the Kodiak Temporary Care Facility. Village wildlife personnel took the same steps as vessels. Personnel in processing captured otters-after capture, the animal was taken to the village, and the Kodiak refuge staff was notified to arrange transport to KTCF.

Tangle nets were used for capture only by the capture crews on the fishing vessels Jeanoah and North Light. These nets were used minimally because of the seeming lack of oiled and distressed otters in the area of Kodiak Island and Alaska 


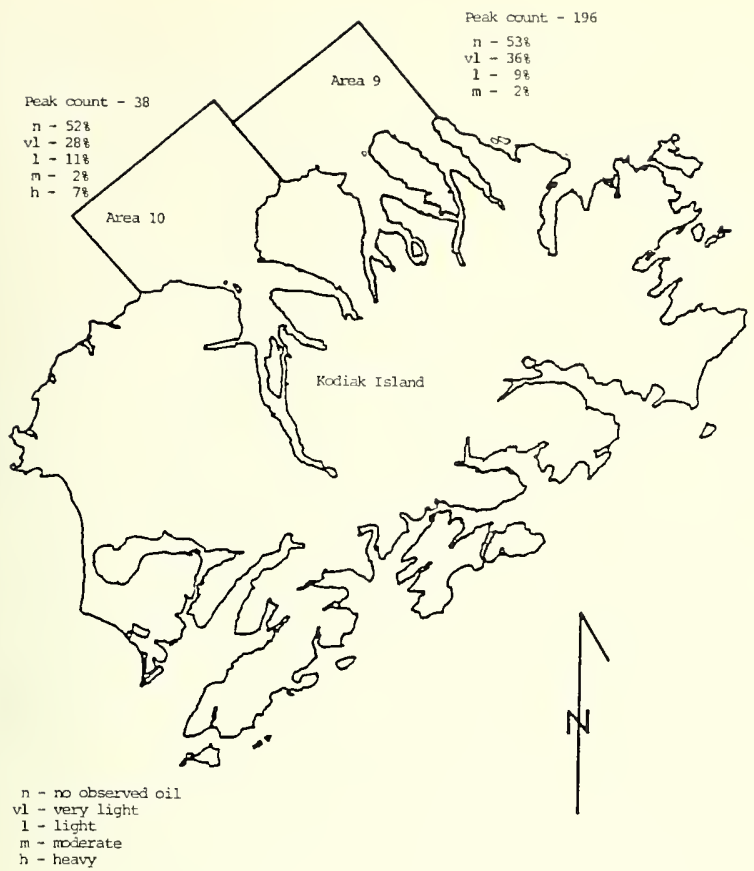

Fig. 2. Peak sea otter (Enhydra lutris) counts and percentage of oil-affected coastline by area, Kodiak Island, 1989.
Peninsula. It was feared that the indiscriminate nature of this capture method (i.e., these nets caught both oiled and unoiled otters) could cause undue stress to single adults and possibly separate mothers from pups. Tangle nets may be more appropriate in an area where there are numerous obviously oiled otters.

Dead otters were collected by otter capture boats and skiff crews as well as wildlife collection boats and oil cleanup crews. Relatively fresh carcasses were iced down or kept as cold as possible without complete freezing and were sent to SORC for necropsy.

\section{Survey Methods}

The Ten Bears was the lead boat dedicated to sea otter capture on the Kodiak Archipelago. The Ten Bears crew conducted repeated systematic coastline skiff surveys on the west side of Kodiak Island and around Afognak and Shuyak islands (Figs. 2, 3, 4). An offshore distance of $150 \mathrm{~m}$ was maintained during the surveys to allow a maxi- mum calculated width coverage of $300 \mathrm{~m}$ of observable area perpendicular to the shoreline. Most outlying islands and rocks were also surveyed. Locations and numbers of otters in a particular area at a given time were recorded on waterproof maps, with adult and pup numbers recorded separately.

The Jeanoah conducted coastline skiff surveys on the Alaska Peninsula from Cape Douglas to Puale Bay, including most outlying islands and reefs (Fig. 5). The Jeanoah was also used as a collection vessel for dead wildlife. This was not compatible with the sea otter survey efforts because of the difference in time it takes each assignment to be accomplished. The dual purpose mission resulted in a loss of flexibility that was essential to respond to reports of distressed animals, survey at a rate that would cover reasonable amounts of area, and obtain quality observation time.

The Kupreanof and Raspberry straits area was covered by the North Light to supplement the Ten Bears' effort (Fig. 3). The F/N Wayward was re- 
Fig. 3. Peak sea otter (Enhydra lutris) counts and percentage of oil-affected coastline by area, Afognak Island, 1989.

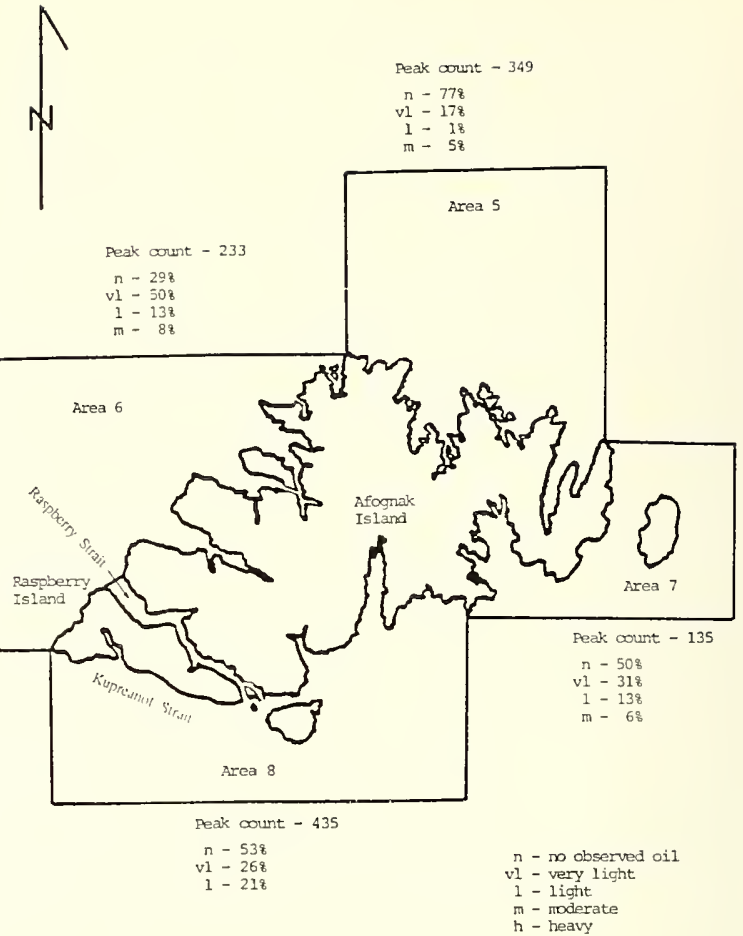

quested to assist the Jeanoah on the Alaska Peninsula (Fig. 5). The KNWR had little contact with the Wayward during its stay in the Kodiak and Alaska Peninsula area. There are no records of observations or survey information from the North Light or the Wayward. Numerous attempts to contact persons that were on these vessels were made; however, these participants were unresponsive to all information requests.

The Ouzinkie wildlife skiff crew searched areas around Spruce Island, Afognak Bay, Kazakof Bay, and East Whale Island. Larsen Bay wildlife crews searched Spiridon, Zachar, Uyak, and Larsen bays.

All operations were dictated by weather conditions, which hampered operators' ability to consistently survey areas during specific periods.

\section{Capture Results}

Twenty-eight otters were received at KTCF, of which 22 were transferred to SORC (Table 2). Of the 28 captured otters, 19 were captured by dipnetting and 9 were captured in tangle nets. Of the 28 , there were 19 adult females, 1 adult male, 2 female pups, and 6 male pups (Table 2). Six adult females, 2 female pups, and 1 male pup died or were euthanized while at KTCF or SORC. The majority (64\%) were captured in May (Fig. 6).

Crews logged available location information about 196 dead otters (Table 3 , Fig. 7); the animals were then placed in locked freezer vans in the fenced confines of the Kodiak National Guard Armory. Of the 196, only 176 are currently accounted for; the other fresh carcasses were sent directly to necropsy facilities. Of the 176 known otter carcasses, 129 were adults and 47 were pups. Of these, 15 adults and 12 pups were retrieved from the Alaska Peninsula, and 114 adults and 35 pups were retrieved from the Kodiak Archipelago. Forty-seven percent of the dead otters were retrieved during May and June. Although these data are incomplete, we estimate that about $40 \%$ of the otters were recovered around the Kodiak Island area (Table 3, Fig. 7). 
Table 2. Live sea otters captured on the Kodiak Island Archipelago and Alaska Peninsula, 1989.

\begin{tabular}{|c|c|c|c|c|c|c|}
\hline Capture date & Location & Sex & $\begin{array}{c}\text { Weight } \\
\text { in } \mathbf{k g}\end{array}$ & $\mathrm{Age}^{\mathrm{a}}$ & $\begin{array}{c}\text { ID } \\
\text { number }\end{array}$ & $\begin{array}{c}\text { Tag } \\
\text { number }\end{array}$ \\
\hline 1 May & Alaska Peninsula & $\mathbf{F}$ & $\mathrm{ND}^{\mathrm{b}}$ & A & sw008 & ND \\
\hline 7 May & Alaska Peninsula & F & ND & A & ND & ND \\
\hline 8 May & Afognak Island & F & ND & A & ND & $\mathrm{ND}$ \\
\hline 17 May & Kodiak lsland & F & ND & A & ND & $\mathrm{ND}$ \\
\hline 19 May & Kodiak Island & $\mathrm{F}$ & 20 & A & sw90 & $121 \mathrm{YL}$ \\
\hline 21 May & Kodiak Island & $\mathrm{F}$ & 11 & A & SW110 & BO36RD, 523YL \\
\hline 23 May & Kodiak Island & $\mathrm{F}$ & 15 & A & SW113 & 147YL \\
\hline 23 May & Kodiak Island & $\mathrm{F}$ & 24 & A & SW112 & $148 \mathrm{YL}$ \\
\hline 24 May & Kodiak Island & $\mathrm{F}$ & 17 & A & SW114 & BO112RD \\
\hline 25 May & Kodiak Island & $\mathrm{F}$ & 23 & A & SW115 & $149 \mathrm{YL}$ \\
\hline 25 May & Kodiak Island & $\mathrm{F}$ & 28 & A & SW116 & $150 \mathrm{YL}$ \\
\hline 25 May & Kodiak Island & $\mathrm{F}$ & 28 & A & SW 119 & $\mathrm{ND}$ \\
\hline 25 May & Kodiak Island & $\mathrm{F}$ & 14 & A & SW120 & $\mathrm{ND}$ \\
\hline 25 May & Kodiak Island & $\mathrm{F}$ & 26 & A & SW121 & $153 \mathrm{YL}$ \\
\hline 25 May & Kodiak Island & $\mathrm{F}$ & 21 & A & SW123 & $154 \mathrm{YL}$ \\
\hline 25 May & Kodiak Island & M & 39 & A & SW122 & BO12RD \\
\hline 25 May & Afognak Island & $\mathrm{F}$ & 25 & A & SW117 & 0040R \\
\hline 25 May & Afognak Island & M & 5 & $\mathrm{P}$ & SW118 & $\mathrm{ND}$ \\
\hline 6 June & Kodiak Island & $\mathrm{F}$ & 1 & $\mathrm{P}$ & SW131 & ND \\
\hline 12 June & Afognak Island & $\mathrm{F}$ & $22^{\mathrm{c}}$ & A & SW137 & $003,094 \mathrm{GY}$ \\
\hline 12 June & Afognak Island & M & $5^{c}$ & $\mathrm{P}$ & SW138 & ND \\
\hline 18 June & Kodiak Island & $\mathrm{F}$ & 29 & A & SW149 & $194 \mathrm{YL}$ \\
\hline 13 July & Kodiak Island & $\mathrm{F}$ & 17 & A & $\mathrm{NA}^{\mathrm{d}}$ & $\mathrm{ND}$ \\
\hline 23 July & Kodiak Island & M & 5 & $P$ & SW173 & $\mathrm{ND}$ \\
\hline 23 July & Alaska Peninsula & M & 6 & $\mathrm{~S}$ & SW172 & ND \\
\hline 26 July & Kodiak Island & M & 11 & $\mathrm{~S}$ & SW174 & ND \\
\hline 30 July & Kodiak Island & M & 3 & $\mathrm{P}$ & SW176 & $\mathrm{ND}$ \\
\hline 20 August & Kodiak Island & $\mathrm{F}$ & 2 & $\mathrm{P}$ & SW177 & ND \\
\hline
\end{tabular}

${ }^{\mathrm{a}} \mathrm{A}=$ adult; $>12 \mathrm{~kg} ; \mathrm{S}=$ sub-adult, $6-11 \mathrm{~kg}$; and $\mathrm{P}=$ pup, $<5 \mathrm{~kg}$.

${ }^{\mathrm{b}} \mathrm{ND}=$ no data.

${ }^{c}$ Capture weight. All others are admisaion weights at the Seward Otter Rehabilitation Center.

dOtter was released near original capture aite (see text).

Table 3. Dead otters retrieved from the Kodiak zone, 1989.

\begin{tabular}{|c|c|c|c|c|c|c|c|c|}
\hline \multirow{2}{*}{$\begin{array}{l}\text { Area } \\
\text { retrieved }\end{array}$} & \multicolumn{7}{|c|}{ Month retrieved } & \multirow[b]{2}{*}{ Total } \\
\hline & April & May & June & July & August & September & No date & \\
\hline Alaska Peninsula & 0 & 16 & 4 & 3 & 1 & 3 & 1 & 28 \\
\hline Afognak Island & 1 & 7 & 7 & 9 & 2 & 2 & 0 & 28 \\
\hline Shuyak Island & 0 & 5 & 3 & 1 & 7 & 2 & 0 & 18 \\
\hline Kodiak Island & 0 & 5 & 21 & 6 & 11 & 6 & 2 & 51 \\
\hline No data & 0 & 8 & 6 & 13 & 16 & 8 & 0 & 51 \\
\hline Total & 1 & 41 & 41 & 32 & 37 & 21 & 3 & 176 \\
\hline
\end{tabular}


Fig. 4. Peak sea otter (Enhydra lutris) counts and percentage of oil-affected coastline by area, Shuyak Island, 1989.

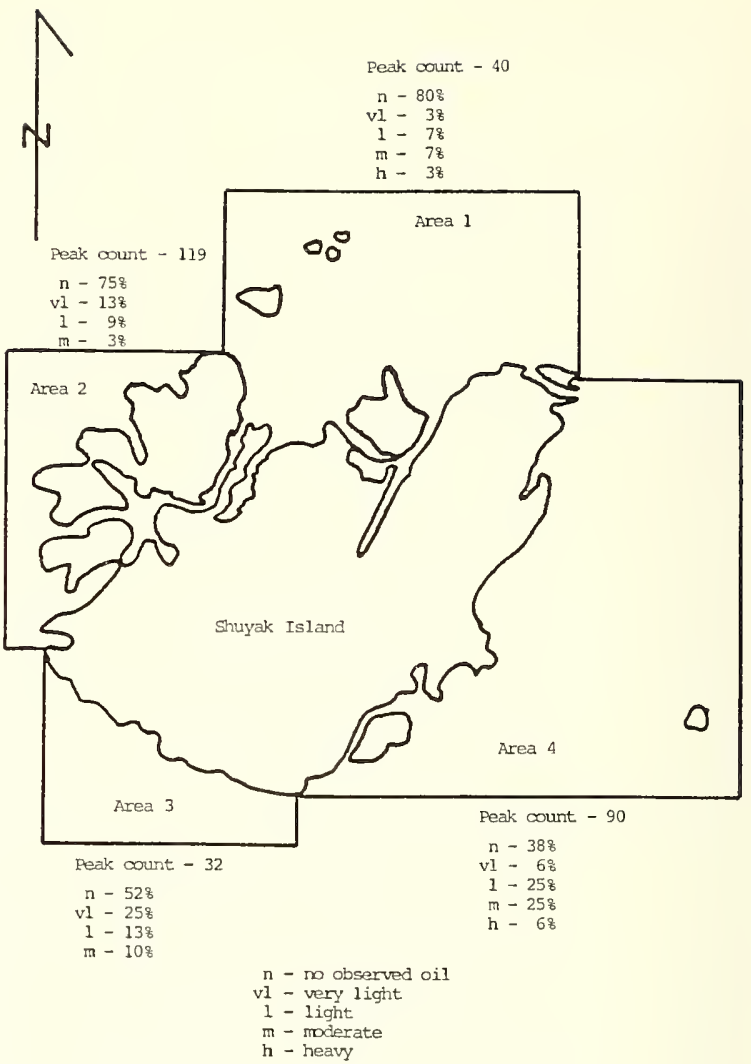

\section{Survey Results}

As oil moved out of Prince William Sound it was broken up by wave action and other natural weathering, resulting in sporadic patches of constantly moving oil. Oil effects began at the north end of the Kodiak Island Archipelago on about 9 April, and by 20 April oil was documented on the Alaska Peninsula. Oil eventually affected about $3,057 \mathrm{~km}$ of shoreline in the Kodiak zone (J. Bellinger, U.S. Fish and Wildlife Service, personal communication). Large areas of sheen, and sheen interspersed with mousse patties, were present on the east and west sides of the Kodiak Archipelago and along the Alaska Peninsula. The heaviest oil effects occurred in the North Shuyak Island (3\% of area), East Shuyak Island (6\%), West Kodiak Island (7\%), and
Alaska Peninsula (4\%) areas (Table 4; Community Development Department 1989).

Otters observed in or near these affected areas took no clear evasive action to avoid the oil. These observations were made by the skiff crew of the Ten Bears in Uyak and Uganik bays on Kodiak; Afognak Strait, Izhut Bay, Kupreanof Strait, Seal Bay, and Perenosa Bay on Afognak Island; and Andreon Bay, Big Bay, and Shuyak Strait on Shuyak Island. Weather permitting, we tried to give extra observation time to these animals. Otters seemed to behave normally while swimming in oiled areas. Tolerance of otters to approach by capture crews varied from 10 to $200 \mathrm{~m}$, depending on weather, visibility, and whether the animal was hauled out. Young otters and mothers with pups were more tolerant to approach by capture crews than were older, single otters. Many hauled-out 


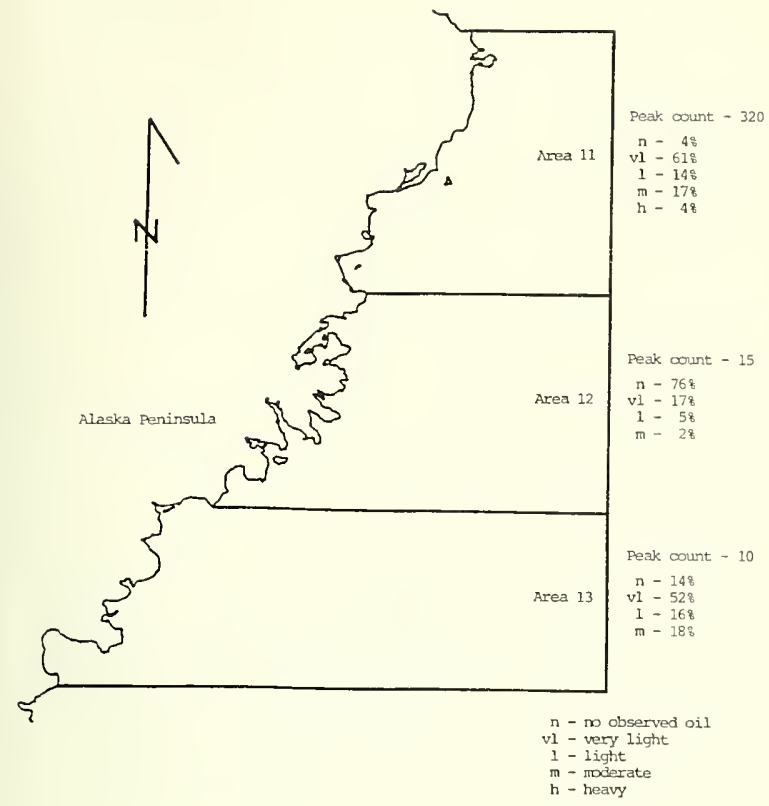

Fig. 5. Peak sea otter (Enhydra lutris) counts and percentage of oil-affected coastline by area, Alaska Peninsula, 1989.

otters were observed on the Kodiak Island Archipelago and Alaska Peninsula throughout the entire capture effort. Most hauled-out otters were on isolated rocks and small islands.
The Service team recorded and mapped 161 different surveys of otters resulting in a combined peak count of 2,012 sea otters observed (Table 5) on the Kodiak Archipelago and Alaska Peninsula.

Fig. 6. Sea otters (Enhydra lutris) captured from the Kodiak zone (percent of total capture), 1989.

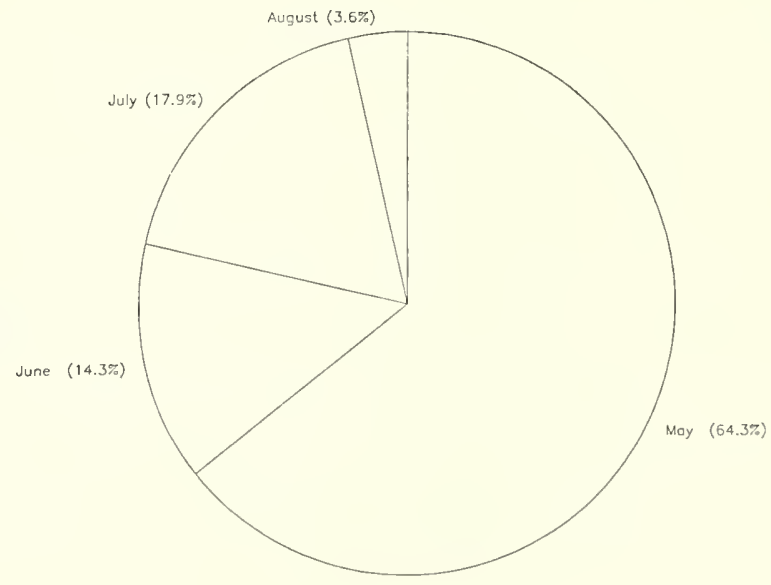


Fig. 7. Dead sea otters (Enhydra lutris) retrieved from the Kodiak zone, 1989.

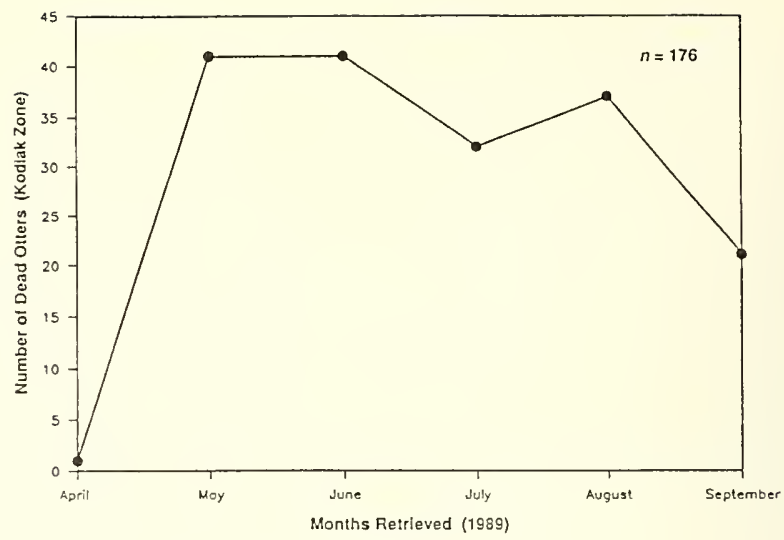

Peak counts from the four major areas indicated that Afognak Island had $76 \%$ more otters than Shuyak Island, $80 \%$ more than Kodiak Island, and $70 \%$ more than the Alaska Peninsula (Figs. 2, 3, 4,5 ). Percentages of the area counts that were pups ranged from 15 to $24 \%$ for Shuyak Island, 12 to $30 \%$ for Afognak Island, and 20 to $24 \%$ for Kodiak Island. This type of data was lacking for the Alaska Peninsula (Table 5).
- Thirty-nine percent of all peak counts were made from 18 April to 15 May (Table 5). Areas with large concentrations of otters were West Shuyak (Fig. 4, Area 2), Blue Fox Bay and Foul Bay (Fig. 3, Area 6), Perenosa Bay and Seal Bay (Fig. 3, Area 5), Izhut Bay (Fig. 3, Area 7), and Kupreanof Strait, Raspberry Strait, and Marmot Bay (Fig. 3, Area 8). Uganik Bay had the greatest concentrations in West Kodiak (Fig. 2, Area 9),

Table 4. Percentages of oil-affected coastline by area for Kodiak Archipelago and Alaska Peninsula sea otter survey areas, $1989 .^{a}$

\begin{tabular}{lcccccc}
\hline $\begin{array}{l}\text { Area } \\
\text { number }\end{array}$ & $\begin{array}{c}\text { Area } \\
\text { surveyed }\end{array}$ & None(\%) & $\begin{array}{c}\text { Very } \\
\text { light (\%) }\end{array}$ & Light (\%) & Moderate (\%) & Heavy (\%) \\
\hline$(1)$ & North Shuyak & 80 & 3 & 7 & 7 & 3 \\
$(2)$ & West Shuyak & 75 & 13 & 9 & 3 & 0 \\
$(3)$ & South Shuyak & 52 & 25 & 13 & 10 & 0 \\
$(4)$ & East Shuyak & 38 & 6 & 25 & 25 & 6 \\
$(5)$ & North Afognak & 77 & 17 & 1 & 5 & 0 \\
$(6)$ & West Afognak & 29 & 50 & 13 & 8 & 0 \\
$(7)$ & East Afognak & 50 & 31 & 13 & 6 & 0 \\
$(8)$ & South Afognak & 53 & 26 & 21 & 0 & 0 \\
$(9)$ & West Kodiak & 53 & 36 & 9 & 2 & 7 \\
$(10)$ & West Kodiak & 52 & 28 & 11 & 2 & 4 \\
$(11)$ & Alaska Peninsula & 4 & 61 & 14 & 17 & 0 \\
$(12)$ & Alaska Peninsula & 76 & 17 & 5 & 18 & 0 \\
$(13)$ & Alaska Peninsula & 14 & 52 & 16 & & \\
\hline
\end{tabular}

a Classification adapted from Kodiak Island region oil assessment map (Community Development Department 1989). None $=$ no observed oil; very light oil $=<1 \%$ shoreline surface oiled, or $<1$ m-wide band; light oil $=1 ; 10 \%$ shoreline surface oiled, or $1-3$ $\mathrm{m}$-wide band; moderate oil $=11-50 \%$ shoreline surface oiled, or $3-6 \mathrm{~m}$-wide band; and heavy oil $=>50 \%$ shoreline 8 surface oiled, or $>6 \mathrm{~m}$-wide band.

${ }^{b}$ See Figs. 1-5 for exact geographic area. 
Table 5. Kodiak Island and Alaska Peninsula sea otter survey results conducted by the Ten Bears and Jeanoah, 1989.

\begin{tabular}{|c|c|c|c|c|c|}
\hline \multirow[b]{2}{*}{$\begin{array}{l}\text { Area } \\
\text { number }\end{array}$} & \multirow[b]{2}{*}{$\begin{array}{c}\text { Area } \\
\text { surveyed }\end{array}$} & \multirow[b]{2}{*}{$\begin{array}{c}\text { Total } \\
\text { surveys }\end{array}$} & \multicolumn{3}{|c|}{ Peak count } \\
\hline & & & Number & $\begin{array}{l}\text { Percent } \\
\text { pups }\end{array}$ & Period $^{b}$ \\
\hline (1) & North Shuyak & 7 & 40 & 15 & IV \\
\hline (2) & West Shuyak & 21 & 119 & 24 & II \\
\hline (3) & South Shuyak & 8 & 32 & 16 & 1 \\
\hline (4) & East Shuyak & 13 & 90 & 20 & IV \\
\hline (5) & North Afognak & 33 & 349 & 30 & II \\
\hline (6) & West Afognak & 21 & 233 & 23 & III \\
\hline (7) & South Afognak & 22 & 435 & 12 & III \\
\hline (8) & East Afognak & 9 & 135 & 15 & III \\
\hline (9) & West Kodiak & 11 & 196 & 20 & I \\
\hline (10) & West Kodiak & 3 & 38 & 24 & I \\
\hline (11) & Alaska Peninsula & 11 & 320 & $\mathrm{ND}^{\mathrm{c}}$ & I \\
\hline (12) & Alaska Peninsula & 1 & 15 & $\mathrm{ND}^{\mathrm{c}}$ & 1 \\
\hline (13) & Alaska Peninsula & 1 & 10 & 10 & II \\
\hline
\end{tabular}

see Figs. 1-5 for exact geographic area.

${ }_{\text {period-I }}=18$ April-15 May; II = 16 May-12 June; III = 13 June-10 July; and IV = 11 July-4 August.

$\mathrm{c} \mathrm{ND}=$ no data.

and Shaw Island and the Shakun Islets had the greatest concentrations on the Alaska Peninsula (Fig. 5, Area 11). The effectiveness of this survey type is variable, and results should be interpreted with caution based on completeness of coverage and survey conditions.

\section{Discussion}

The capture effort in the Kodiak Island and Alaska Peninsula dealt with sporadic and dispersed oil, which required judging at a distance whether an animal had been oiled. In most instances, otters that were captured had no obvious external oiling but showed symptoms that led to capture. After 12 June, some otters were singled out for capture because of natural infirmities. This date was about 4 weeks after most of the oil had evaporated, dispersed, washed up on shorelines or out to sea, collected sediment and sank, or had been cleaned up (Piatt et al. 1989). Consequently, these animals added to the already crowded conditions at rehabilitation centers.

One adult animal was captured about $2.4 \mathrm{~km}$ off Seven-Mile Beach near Larsen Bay on the west side of Kodiak Island. The animal was transported from the skiff to the helicopter in back of a pickup truck along with two dogs. The otter was reported to have had its nose out of the water about $5.1 \mathrm{~cm}$, and it appeared to be shaking and very tired before capture. Most of the domestic dogs in Larsen Bay are not annually vaccinated for any of the common canine diseases. While the otter was in transport in the kennel, the dogs were on the kennel and barking at the otter. Vanek was not aware of any disease outbreaks at that time, and she presumed the probability of exposure of the otter to canine disease was low. On initial examination by Vanek, the otter did not appear oiled, its fur was in good condition, and there were no clear signs of hypothermia. At first the animal would tire quickly when feeding and then stop eating, but its feces remained normal throughout its 7 . day stay at Kodiak. The otter regained its strength, and the decision was made to release it near the original capture site. The otter was released at Harvester Island on 19 July.

One adult female otter was captured and transported to Kodiak from the Shakun Islets. The emaciated otter with matted fur was found hauled out on a rock; she exhibited some head shaking, and was lethargic when approached and dipnetted. She died that same evening. 
A female with a pup in Foul Bay, Afognak Island, was captured because of her abnormal behavior. Upon initial examination the female otter was somewhat lethargic, emaciated, and apparently partially paralyzed in both hind legs. Her pup initially appeared healthy. Another otter captured near Port Lions was acting abnormally and was captured. It had bilateral cataracts and partial paralysis in its hind legs. Both of these adult otters were captured because of naturally occurring problems that caused abnormal behavior.

The capture efforts of the initial 3-4 weeks in the Kodiak Island and Alaska Peninsula were slowed by the inability to immediately dispatch vessels and capture crews with proper capture and handling equipment, the lack of safety equipment, and inadequate capture and handling training for crews in those areas where there could be stressed animals. Radio communications with the coordination center at KNWR were often weak and at times nonexistent, slowing response time for logistical support and affecting the ability to pass on timely information. These problems were eventually corrected, and operations became more efficient.

Feedback from otter rehabilitation centers regarding the condition of captured otters was inadequate. Field assessment criteria developed from experiences of rehabilitation centers and capture teams would improve capture decisions made by field personnel. The diverse behavior among sea otters makes assessment difficult, especially during an operation involving the observation of many animals that are assumed to be oiled. No results were received of necropsies performed on animals retrieved from the Kodiak Archipelago and Alaska Peninsula areas.

\section{Conclusions and Recommendations}

Although the survey and capture effort was initially confusing, organization between agencies fell in place, and operations proceeded with few problems. The overall effects of oil on sea otters in the Kodiak Archipelago and Alaska Peninsula areas were minimal in relation to events that occurred in Prince William Sound. I recommend that a well-organized contingency plan be put in place to expedite the initial response by respective agencies. Agencies that may become involved in an oil spill or other environmental emergency should consider the recommendations listed below:
1. Keep updated survey information on seasonally indexed concentrations of sea otter populations to know where to deploy initial rescue efforts.

2. Keep an inventory of capture equipment (e.g., vessels, skiffs, dip and tangle nets, kennels) at the spiller's expense. This equipment should be readily available on short notice and solely dedicated to sea otter capture.

3. Keep a current list of experienced Service-approved personnel to place on each vessel to direct trained personnel and field operations, and to report directly to Service project leaders.

4. Conduct standardized skiff surveys during the capture effort to document and support other indexed survey data if the particular situation allows.

5. Dedicate a specific radio frequency to sending and receiving information to Service headquarters, thus minimizing competition with crowded frequencies, or outfit chartered vessels with the Service frequency.

6. Keep a list of trained veterinarians or biologists that could be called to manage a temporary care facility such as KTCF. These persons should be compensated for their services by the company or companies responsible for the spill.

7. Require rehabilitation facilities to provide feedback to project leaders on the status of captured otters to help field personnel assess symptoms in the field and to make more accurate capture decisions.

8. Report necropsy results to project leaders to help them evaluate when capture efforts should be stopped.

9. Mark and document otters properly before they leave the capture vessels or villages to avoid confusion at rehabilitation centers.

10. Avoid the use of entanglement nets where there is not an obvious problem of numerous distressed otters.

11. Begin a training course for otter-handling procedures. In the event of future emergencies, an inventory should be kept of persons who have completed the course.

\section{Acknowledgments}

I thank S. Christian for manuscript typing and K. Bayha, J. Bellinger, D. Caulkins, T. Chatto, B. Hatfield, E. Klinkhart, J. Kormendy, S. Losh- 
baugh, G. Sanders, V. Vanek, and D. Zwiefelhofer for support, guidance, and helpful reviews of the manuscript.

\section{References}

Bayha, K., and K. Hill. 1990. Overall capture strategy. Pages $41-60$ in K. Bayha and J. Kormendy, tech. coords. Sea Otter Symposium: Proceedings of a symposium to evaluate the response effort on behalf of sea otters after the T/N Exxon Valdez oil spill into Prince William Sound, Anchorage, Alaska, 17-19 April 1990. U.S. Fish Wildl. Serv., Biol. Rep. 90(12).
Community Development Department. 1989. Kodiak Island Borough, Kodiak Island region oil assessment coverage map.

Piatt, J. F., C. J. Lensink, W. Butler, and M. Kenziorek. 1989. Marine birds killed in the T/V Exxon Valdez oil spill: an interim report. Alaska Fish and Wildlife Service, Anchorage, Alaska. 36 pp. [unpublished re. port]

Simon-Jackson, T., M. Vivion, and D. Zwiefelhofer. 1985. Sea otter survey, Kodiak Archipelago, Alaska. Marine Mammal Project, wildlife assistance. Report to Kodiak National Wildlife Refuge. 11 pp. [unpublished report] 


\section{Appendix. Sea Otter Record.}

Date Collected:

Tag number: Record number:

Right Foot: Tag position Color

Left Foot: Tag position Color

Area Collected:

Collected By:

Method of Capture:

Time Captured: Time Transported:

Condition: (Good, Fair, Poor)

Amount of Oil:

Location of Oil:

Sex:

Weight (otter + trap): Trap Only: Otter wt:

Anesthetic used? Type: Dose:

Disposition (Final): Expired ( ) Released ( ) Euthanized ( )

Date out: Release Site:

Remarks: 


\title{
Transportation of Sea Otters to Rehabilitation Centers
}

\author{
by
}

\author{
D. W. Cramer \\ U.S. Fish and Wildlife Service \\ Alaska Fish and Wildlife Research Center \\ 1011 E. Tudor Road \\ Anchorage, Alaska 99503
}

\begin{abstract}
The rescue effort of sea otters (Enhydra lutris) oiled during the T/N Exxon Valdez oil spill required transportation of captured otters from remote locations to rehabilitation centers. Avoiding additional stress to the otters was a primary concern. The centers received 344 live otters, and 300 otters were transferred between centers. Logistics, weather, terrain, and communications all combined to present many problems. Methods and procedures had to be devised and modified to fit varying situations. Bell 206 and Bell 212 helicopters provided most of the transportation because they were already on lease and available. Airplanes and boats were also used to transport otters. More than 96 fiberglass airline flight kennels served as cages. Radio communication between capture boats, transportation vehicles, and rehabilitation centers was the biggest problem encountered in the transportation of sea otters.
\end{abstract}

I describe methods and problems in transporting sea otters (Enhydra lutris) from oil-affected areas to rehabilitation centers. The recommendations I present may be useful if another oil spill in similar habitat requires a rescue operation of sea otters.

The T/N Exxon Valdez oil spill on 24 March 1989 affected a large area of remote Alaskan coastal wilderness and its associated wildlife. Floating oil, spread by wind and tides, moved out of Prince William Sound to the southwest. There it entered most of the bays along the Kenai Peninsula between Seward and Homer. The oil continued across Cook Inlet into the Shelikof Strait, affecting both Kodiak Island and sections of the Alaskan Peninsula. In total, more than $1,600 \mathrm{~km}$ of coastline and otter habitat were oiled.

The objective of the transportation phase of the sea otter rescue effort was to move oiled otters, already under stress, from remote capture locations to the rehabilitation centers with the least possible delay or additional stress to the animals. The rescue effort to save oiled otters was distinctive both in the large number of otters handled (Table) and the difficult logistics in transportation to rehabilitation centers. An otter rescue effort of this magni- tude had never been attempted in previous oil spills; therefore, methods and procedures had to be devised and modified to fit varying situations. With no previous guidelines to follow, the operation depended on trying different procedures because situations changed as the oil spread.

\section{Logistics}

Many factors complicated the capture and transportation of otters. These factors included distance of travel, remoteness of capture sites, limitations in communication, unpredictable weather, and rugged terrain.

The Valdez Otter Rehabilitation Center (VORC) was the original rehabilitation center. As the oil spread to the south and west of Prince William Sound, however, it became necessary to establish a second treatment center at Seward (the Seward Otter Rehabilitation Center [SORC]), with holding facilities at Homer and Kodiak. Seward was chosen as the base for rescue operations because of its central location on the Kenai Peninsula-by air, Valdez and Homer are each about $161 \mathrm{~km}$ from Seward. Of the 344 otters delivered 
Table. Number of sea otters (Enhydra lutris) transported between 30 March and 30 September 1989 during the T/VExxon Valdez oil spill.

\begin{tabular}{|c|c|c|c|c|c|}
\hline Otters & $\begin{array}{c}\text { Valdez } \\
\text { Otter } \\
\text { Rehabilitation } \\
\text { Center }\end{array}$ & $\begin{array}{c}\text { Seward } \\
\text { Otter } \\
\text { Rehabilitation } \\
\text { Center } \\
\end{array}$ & $\begin{array}{c}\text { Homer } \\
\text { Temporary } \\
\text { Care } \\
\text { Facility } \\
\end{array}$ & $\begin{array}{c}\text { Kodiak } \\
\text { Temporary } \\
\text { Care } \\
\text { Facility } \\
\end{array}$ & Total \\
\hline Received live from field & 141 & 157 & 18 & 28 & 344 \\
\hline Died during transport & 0 & 0 & 1 & 0 & 1 \\
\hline Died in field, received at morgue & 490 & 88 & 100 & 198 & 876 \\
\hline Transferred in from other centers & 33 & 26 & 99 & 0 & 158 \\
\hline Transferred out from center ${ }^{\mathrm{a}}$ & 95 & 150 & 122 & 23 & 390 \\
\hline Rogue otters, to release sites & 1 & 0 & 5 & 0 & 6 \\
\hline
\end{tabular}

${ }^{a}$ Included otters transferred to other centers, released to the wild, and sent to aquariums.

to shore alive, 157 were taken to SORC, 141 to VORC, 18 to the Homer Temporary Care Facility, and 28 to the Kodiak Temporary Care Facility (Table). Some of the otters from Homer (14) and Kodiak (24) were later transferred to SORC (31) or VORC (7) for treatment. Ninety-nine otters from SORC were moved to the Jakolof Pre-Release Facility and were later released at various sites near Homer.

The shoreline of the oil-affected area is broken into many sheltered fjords, lagoons, and bays separated by high mountains and glaciers. This geography made direct communication between the capture boats and the rehabilitation centers impossible because radio transmissions require line-ofsight targets for operation in the absence of a repeater. Often a capture boat had to relay information to Seward through radio operators aboard other vessels. Telephone communications with the boats through a marine operator worked at times. However, with the large number of boats working on all phases of the cleanup, it often took many hours to get an open line. If a boat was working in a sheltered bay, communication with the rehabilitation centers by any means was impossible. Messages were also relayed to capture boats by aircraft pilots flying over areas occupied by capture boats. Additional trips to the capture areas were often necessary to check for animals needing to be brought in to one of the centers, and to drop off or pick up personnel, equipment, and supplies.

The weather patterns of this area are erratic, often changing several times during any day. Along with wind and rain, fog from the glaciers would shut down rescue efforts and delay or cancel flights. When the fog was localized around glacier areas, flights were sometimes rerouted around them, which added to the transportation time.

\section{Transportation}

Three types of transportation-helicopters, airplanes, and boats - were used to bring otters from the field to the rehabilitation centers. The helicopters served many other functions during the oil spill cleanup. However, picking up otters and conducting related support work received top priority for helicopter use. Because the helicopters were already available to pick up otters, there was limited need for additional aircraft.

A Bell 206 helicopter on lease to the U.S. Fish and Wildlife Service was stationed in Seward. Additional support came from a Service-chartered Bell 206 in Homer and a third in Kodiak. A Bell 212 helicopter also was leased by Exxon Company, USA. These four helicopters were the primary vehicles for transporting otters.

The Bell 206 can carry three medium or two large kennels. At $161 \mathrm{~km} / \mathrm{h}$ it has a cruising time of $3 \mathrm{~h}$, using 25-27 gallons of fuel per hour. The landing area for this kind of helicopter must be at least $10 \mathrm{~m}$ in diameter because this is the length of the main rotor blade. The cost to lease the 206 was $\$ 700$ a day availability charge, plus $\$ 490$ for each flight hour.

The Bell 212 (civilian model of a military Hughes UH1H or "Huey") can carry 6 to 12 cages, depending on the size of kennels used. At $161 \mathrm{~km} / \mathrm{h}$ its cruising range is $2.5 \mathrm{~h}$, using $100-120$ gallons of fuel an hour. The landing area required is $15 \mathrm{~m}$ in diameter. The cost of a 212 was $\$ 1,000$ a day availability charge, plus $\$ 1,400$ for each flight hour. 


\section{Discussion}

Each helicopter model had its advantages and disadvantages. The Bell 212 has a larger capacity and can transport more animals each trip. This was especially useful when transferring otters between centers. Most of the trips from the field, however, were with no more than three otters, so the Bell 206 was sufficient most of the time. Engine noise level was higher inside the Bell 212, and this may have increased stress on the otters.

Flights were kept below $305 \mathrm{~m}$ when feasible because the otters seemed calmer at lower altitudes. This was possible on flights over water; however, when weather caused rerouting over land, higher altitudes for short periods were necessary to clear the mountains. On these flights the otters were noisier and more active.

The broken coastline of the area from Prince William Sound to the Alaska Peninsula has many mountains rising straight up from the sea. This limited helicopter landing areas and sometimes required finding a pickup point away from the capture sites. The smaller landing area required by the 206 allowed more possible pickup points at the capture areas.

Both helicopter types were also useful in logistical support for the capture operations. In conjunction with picking up animals, personnel were ferried to and from capture sites. Material and equipment resupply was important to keep the rescue and rehabilitation operation functioning as efficiently as possible.

Fixed-wing aircraft, both float and wheeled planes, were useful in some situations. When the weather allowed, float planes were able to land in sheltered bays and pick up otters near the capture boats. Otters captured at Kodiak were transferred to SORC in wheeled planes that were able to land at Seward Airport, or by commercial flights through Anchorage. Fixed-wing aircraft could have been used more in the transfer work. This would have freed the helicopters to shuttle between the capture sites and local airports, where the animals could then be flown to a rehabilitation center.

Boats were used to transport most dead otters; however, some dead otters were brought in by the helicopters in conjunction with the pickup of live otters. Usually only when the capture area was close to a rehabilitation center were boats used to transport otters to the centers. Otherwise, boats traveled the longer distances too slowly, and the extra travel time added to the stress of the animals. One otter was transported by boat from the
Chiswell Islands to SORC, a 4-h trip. This animal became extremely agitated and chewed a hole through the kennel. When it finally arrived at the Seward Center this otter was suffering from hyperthermia and dehydration.

Communications between the capture boats and the rehabilitation centers were crucial but needed improvement. Better relay facilities would reduce uncertainties at both ends. Captures were often delayed because capture personnel did not know if a flight was coming or if it had been grounded because of weather or some other factor. If otters were captured and no flight came, the animals would spend unnecessary time in cages on the boats, increasing their stress.

Standard fiberglass dog transport kennels were used because they were readily obtainable in different sizes. However, it was difficult to get enough kennels of the right size to each capture site. Custom-built cages, designed to fully use the cargo space in the helicopters, would have increased the number of animals able to be transported on each trip. Floorboard slats should be used in all cages to keep the otter out of water and other wastes that accumulate on the cage floor.

\section{Recommendations}

\section{Communications}

Communications between the capture boats and the rehabilitation centers presented a major problem. Good communications are vital to a successful rescue operation. When direct contact by the ship radios is hampered because of terrain, an adequate number of relay stations are necessary to cover all areas where capture operations are taking place. Telephone communication through marine operators and U.S. Coast Guard stations could be improved by assigning reserved times for use by rescue personnel. During this spill the increased number of boats present caused an overload in the system, and delays constantly occurred.

When direct contact by any method is impossible, a message relay system using aircraft pilots needs to be developed. The large number of aircraft and boats used during oil spill cleanup make it likely that some aircraft will be near capture boats at least daily. Pilots in the Exxon Valdez spill were always cooperative and delivered or picked up messages as needed. 


\section{Transportation}

Helicopters were available and provided most of the transportation. They are very effective at landing in areas with rugged terrain and small beaches. Float planes can be used if the weather permits; kennels can be easily transferred into them, they hold six or more kennels, and they are less expensive to operate than helicopters. However, rough seas and small bays often prevented float planes from landing at capture areas. Boats are practical only when the capture area is close to the rehabilitation center. If the distance to travel takes more than $1 \mathrm{~h}$, undue stress is placed on the otter.

\section{Stress}

Care must be taken to handle the otters without allowing unnecessary additional stress. The animals are already agitated after capture and confinement on the boat. The kennel should be the proper size for the otter, with floorboard slats or screening to keep the otter separated from urine, feces, and other substances that collect on the kennel floor. Chunks of ice placed in each kennel serve as a pacifier and source of water. Noise must be kept to a minimum around otters in kennels. High altitude also seemed to increase stress, so all flights should be as low as safely possible. 


\title{
Field Test for Detecting Crude Oil on the Fur of Sea Otters
}

\author{
by \\ K. Hill \\ Prince William Sound Science Center \\ P.O. Box 705 \\ Cordova, Alaska 99574 \\ and \\ P. A. Tuomi \\ College Village Animal Clinic \\ 2036 E. Northern Lights Boulevard \\ Anchorage, Alaska 99508
}

\begin{abstract}
The need to have a field test that could determine whether a sea otter's (Enhydra lutris) fur had been oiled became evident after the T/V Exxon Valdez oil spill in March 1989. We describe and trace the evolution of such a field test conducted at the Seward Otter Rehabilitation Center. Whether the need for such a test still exists (given another oil spill in sea otter habitat) is discussed. We discuss possible scenarios for determining disposition of sea otters oiled to varying degrees.
\end{abstract}

After the T/N Exxon Valdez grounding, sea otters (Enhydra lutris) were affected by spilled crude oil. The effects of oil on these animals were obvious at first, but as time went on, the effects became variable or not readily detectable in the field.

It became clear that a field test was needed to detect whether otters had been affected by oil. Lacking laboratories on the capture vessels, it was necessary to devise a simple method to detect crude oil contamination on otter fur; the method could not require laboratory equipment that might be too sensitive to the motion of the small capture boats. The primary purpose of such a test was to determine whether an otter had such a significant amount of oil on its pelage that it would need washing.

\section{History}

Two distinct philosophies existed regarding the role of the sea otter rescue effort. Early proposals to remove healthy otters from possible future oiling in the path of the oil spill (preemptive capture) were rejected by the U.S. Fish and Wildlife Service for various reasons. Instead, it was determined that otters that had been contaminated with oil were to be washed and supported until they could safely be returned to the wild (Bayha 1990).

When the F/N Rhoda Mae and the F/ Dancing Bear first arrived at Applegate Rocks and Green Island to capture sea otters on 29 March 1989, it was obvious that animals were oiled. There were large accumulations of crude oil in the water and 
on the beaches. Otters were swimming in oil at sea, and they were wallowing and walking in it on shore. Swimming otters exhibited unusual behavior, such as raising half out of the water and shaking, in what appeared to be an attempt to remove the oil from their fur. Dead animals were already on the shore. The first otters encountered on Applegate Rocks and Green Island had crude oil dripping off their bodies and were so lethargic that they were easy to capture.

Within a week or two, however, capture crews found that the animals were able to elude capture, and it was difficult to see oil on their pelage. When otters are wet with seawater, they appear dark brown to black, and it is difficult to distinguish small amounts of crude oil on such a background. Tests were devised by the capture crews to determine if animals were oiled. One method was to place an oil-absorbent cloth in the cage with the otter. If black appeared on the cloth, the animal was probably oiled. This test was inadequate when animals were lightly oiled because small amounts of oil could not be seen on these cloths or on the white walls of an animal's cage.

Thus, within 2 weeks of the grounding of the Exxon Valdez, crews aboard the capture vessels could not differentiate between animals that were lightly oiled or unoiled. Crews began to question whether it was in the best interest of the otters to pick them up to wash them. Capturing sea otters and submitting them to the rehabilitation procedure posed considerable risk to the animals. This risk had to be weighed against the possible benefits of washing to remove small amounts of crude oil and holding otters in an oil-free, but stressful, environment.

Questions arose about when capture should be stopped and about related issues including:

(1) Were animals coming in contact with oil but as the oil weathered was less oil actually absorbed into the fur?

(2) Could a sea otter survive in the wild with some oil contamination of the fur still present?

(3) Could a sea otter groom some quantity of oil out of its fur without becoming ill from oil ingestion?

(4) How much internal oil toxicity occurred when little external contamination could be detected?

These questions were hotly debated, and a consensus still has not been reached.

Some previous studies have been undertaken to determine whether sea otters can survive in the wild with some amount of oiling. Costa and Kooy- man (1980) speculated that the sensitivity to crude oil contamination would increase with decreasing air and water temperatures and when stormy weather conditions prevail. They pointed out that those same conditions are those in which oil spills are most likely to occur, and they suggested that decreased prey availability would further reduce the chance of recovery of these animals during such unfavorable conditions.

Siniff et al. (1982) oiled four sea otters with $25 \mathrm{~mL}$ of Prudhoe Bay crude oil and followed them for short periods in the wild. They found that while the four otters had increased their activity, probably because of grooming, all four apparently survived the oiling. Only a small portion of the pelage of these 4 animals was oiled, however, and food was abundant in the study area.

Williams et al. (1988) found that crude oil that had weathered for 5 days did not penetrate as well into the fur because it was more viscous than fresh crude oil. Therefore, the thermal conductivity of the fur was not reduced as much in pelts contaminated with the weathered crude oil as it was in pelts contaminated with fresh crude oil. The implication is that as crude oil weathers, sea otter fur is not as likely to absorb it, and therefore, the fur would retain more of its insulating capacity.

C. Monnett (Prince William Sound Science Center, Cordova, Alaska, personal communication) has observed at least 10 otters implanted with radio transmitters frequenting the chronically oil-contaminated small boat harbor in Cordova; none showed ill effects. Some of these animals were observed swimming in oily sheens and were known to have survived for 12 to 24 months after oil exposure.

Anecdotal evidence also exists of specific sea otters (named by local townspeople in the Valdez and Whittier harbors) that have survived years of low-level chronic contamination by hydrocarbons.

These observations suggest that sea otters can survive some hydrocarbon contamination, but how much may depend on many factors, including the specific chemical composition of the oil, prey availability, how much of the coat is oiled at the same time, and weather conditions.

To clarify the effects of low-level oiling, a method was needed to measure light oil contamination of the fur and to distinguish light contamination from unoiled fur. A field test that was usable aboard the capture vessels was important in order to standardize individual observations and to allow the crews to identify otters that were not oiled. This would mean that these animals 
would not be needlessly subjected to the stressful rehabilitation process.

In late April, a suitable solvent for a field test was chosen after consultation with J. Payne, a research chemist at Science Applications, Inc. (La Jolla, California). He suggested using dichloromethane (methylene chloride, or DCM) because it is nonflammable, capable of separating oil from protein (in this instance, otter hair and fecal contaminants), and is a very good solvent for crude oil, even in the presence of small amounts of water. Experiments were undertaken to determine whether DCM would permit the identification and quantification of crude oil contamination of sea otter fur.

\section{Methods for the Field Test of Dichloromethane}

To quantify the amount of oil present on an otter, a known volume of its fur was mixed with DCM, and the color of the resulting supernatant was compared with a set of standards (prepared from the fur of dead sea otters) that had subjective interpretations of light, medium, heavy, and no crude oil contamination.

Sea otter fur is very lightweight per volume. Weighing fur samples would have required special scales, which were not suitable for use on the small capture vessels. This problem was resolved by sampling the reasonably constant volume obtained by tamping the fur samples into the first $1.9 \mathrm{~cm}$ of a $3-\mathrm{mL}$ tapered centrifuge tube. Two milliliters of DCM were then added to the tube, and the mixture was shaken for $2 \mathrm{~min}$ to produce a supernatant that varied in color from dark brown to clear, depending on the degree of crude oil contamination of the fur.

To verify the efficacy of the field test, a spectrophotometer was used to determine the relative optical density of experimental supernatants and to watch for the peaks typical of crude oil. Absorbance patterns (Fig. 1) were demonstrated for dilutions of Prudhoe Bay crude oil, with absorbance peaks typically noted in the 230 to $260 \mathrm{~nm}$ range, using ultraviolet light (Fry 1989).

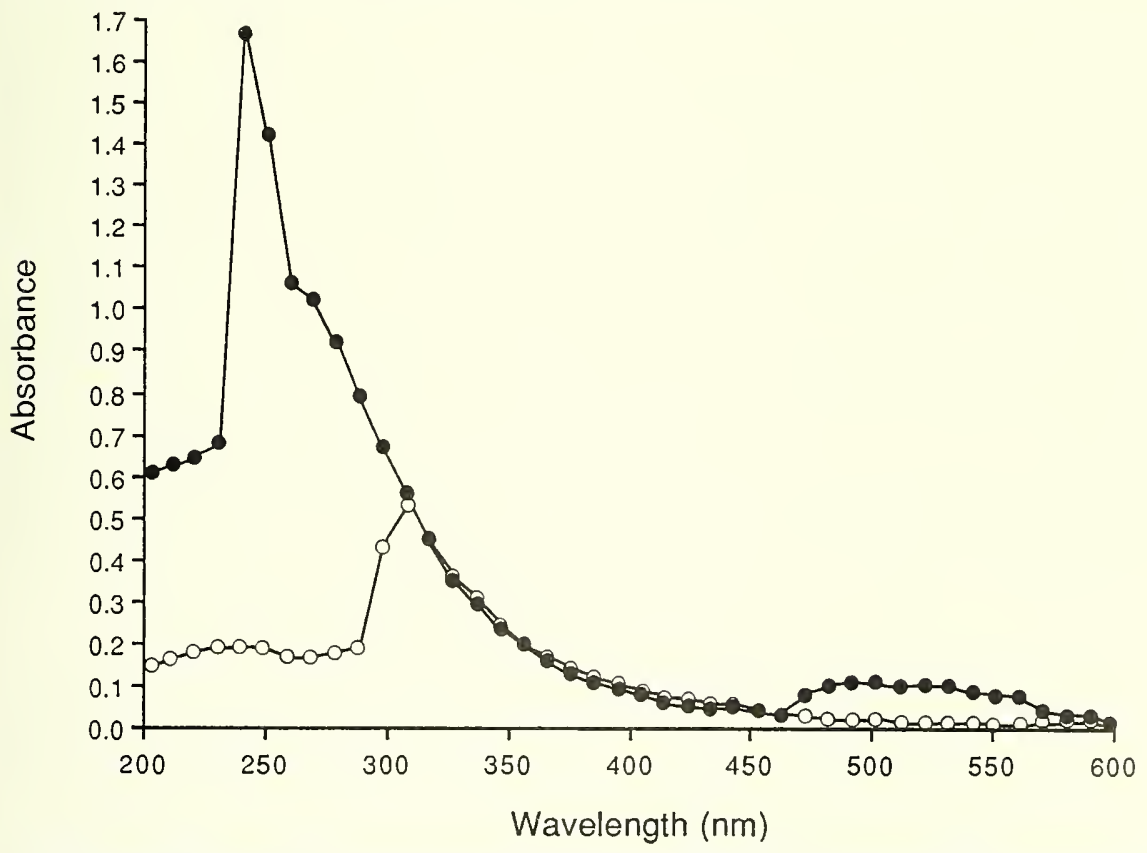

Fig. 1. Spectral absorbance of weathered Prudhoe Bay crude oil dissolved in dichloromethane using ultraviolet and tungsten light. $\bullet=$ hydrogen lamp, $0=$ tungsten lamp. 


\section{History of the Seward Otter Rehabilitation Center Study}

Before applying the DCM test in the field, we had to decide if animals could be left in the wild in a contaminated environment. Sea otters that were unoiled initially could eventually come in contact with crude oil, either externally, internally, or both. No agreement could be reached on how to handle otters that tested negative by the DCM test. Some people thought that clean, vigorous animals that were in proximity with oil could eventually become oiled and therefore should be caught and sent through the rehabilitation process. Others thought that lightly oiled otters could be left in the environment because they would probably survive and thrive despite light oiling. Further work was needed to determine whether lightly oiled otters could survive in the wild.

The best course would have been to compare a group of animals in an oiled environment with one in a nearby clean area. Because of time constraints in a crisis situation, we decided to use the more controlled environment of the Seward Otter Rehabilitation Center (SORC). A study was designed to determine if the recovery period would be prolonged if lightly oiled otters were not washed, as compared with similar otters that were washed. We hoped that the results might shed some light on whether lightly oiled otters could survive in the wild.

A study plan was written and submitted to the Service with the following objectives:

(1) correlate the visual field dichloromethane (FDCM) test with spectrophotometric measurements of the same sample;

(2) compare coat condition, evaluated over a minimum of 14 days, in washed and unwashed otters; and

(3) determine whether the FDCM test is sufficient to determine (in the field) whether otters need to be washed.

The study plan was approved by the Service, and the study began on 17 June 1989.

\section{Study Methods}

Sixteen sea otters were captured from the oilaffected Windy and Rocky bays off the southern Kenai Peninsula between 17-23 June. These otters were sent to SORC, where they were randomly divided into two groups of eight. One group was washed with diluted Dawn dishwashing detergent according to the standard SORC protocol, while animals in the second group were not washed. All otters were sedated and weighed within $24 \mathrm{~h}$ of admission, and blood and fur samples were obtained. Standard admissions medications were administered (Wilson et al. 1990), and sedation was reversed immediately after treatment or washing. All otters were placed in saltwater pools as soon as possible after this initial handling, and no other medical treatments were administered until the end of the study period. Each ar:imal was to be observed for 14 days after admission to the center. Progress through the center was graded on several criteria designed to measure the animal's time of recovery to a releasable condition. A subjective grading system was used to measure coat condition while animals recovered (Rash et al. 1990). Grooming behavior, food intake, and daily time budgets were recorded for each otter by regular SORC observers. On the 14 th day after initial handling, each otter was again sedated, blood and fur samples taken, and weight recorded. Complete blood counts and blood chemistry analyses were obtained from the initial samples and from the samples on the 14th day, and a portion of each blood sample was archived for future hydrocarbon assay. During this study period, any animals captured that had heavy or medium oil contamination were to be excluded from the study and washed as usual.

The fur samples were taken from three areas on each of the 16 animals at admission and at the end of the study. Additional samples were obtained immediately after final rinsing of the eight washed otters. The three areas were selected because they were the areas more likely to be oiled in the wild. One site was the dorsum of the neck, which is at the waterline when an otter is swimming in its usual belly-up position. Another site was over the bony protuberance of the right stifle, which could be oiled when an animal hauls out or is swimming in water. The third site was the middle of the abdomen, which can become oiled when an otter hauls out.

The fur samples were wrapped in aluminum foil and kept frozen $\left(-1^{\circ} \mathrm{C}\right)$ until the end of the study. Each sample was then thawed at room temperature, and the standard volume of fur was packed into the first $1.9 \mathrm{~cm}$ of a 3-mL glass centrifuge tube and mixed with $2.0 \mathrm{~mL}$ DCM by stirring with a glass rod. A panel of three independent observers evaluated the color of the supernatant by comparing it with the FDCM standards. The supernatant 
was then collected into a $2.5-\mathrm{mL}$ glass syringe with a 20-gauge stainless steel spinal needle attached to a 25-mm disposable micropore filter (pore diameter $0.2 \mu$ ). The volume of the sample was noted, and the filtered supernatant was dispensed into a separate $5-\mathrm{mL}$ glass test tube. An equal volume of DCM was added to the sample, and the test tube was plugged. with a cork and shaken to mix the contents. A 2.0-mL aliquot of the diluted sample was placed in a quartz cuvette, and ultraviolet absorbance was measured with a Hitachi DB 100, dual beam, UV/VIS Spectrophotometer (University of Alaska Marine Laboratory, Seward, Alaska). Readings were made from 190 to $500 \mathrm{~nm}$ at $10-\mathrm{nm}$ increments.

Baseline ultraviolet absorbance readings were made using hair samples from a sea otter from Point Defiance Zoo (Fig. 2), and from varying dilutions of DCM extracts of Prudhoe Bay crude oil (Fig. 3 ), weathered Prudhoe Bay crude oil (mousse) from one of the capture sites (Fig. 4), pool water (Fig. 5), and incoming seawater (Fig. 6).

\section{Results}

Prudhoe Bay crude oil was detected by the FDCM and by the spectrophotometric test in only one of the fur samples. The neck sample taken at admission from otter SW150 was positive for light oiling by the FDCM test; this sample produced a relative absorbance peak of 75 at $240 \mathrm{~nm}$ by spectrophotometric measurement (Fig. 7). None of the remaining samples showed any color on the FDCM test, and there were no peaks typical of Prudhoe Bay crude oil on the absorbance graphs of the supernatants produced from these samples (Appendix). There was positive correlation between the visual field test and the spectrophotometer, but the lack of more than one positive sample made this correlation meaningless.

Spectrophotometric absorbance on the neck sample from SW150 was 15 times the absorbance for the fur from the stifle and abdomen of this animal at admission. Samples of the fur taken from the same three sites after SW150 was washed and at the end of the study all show

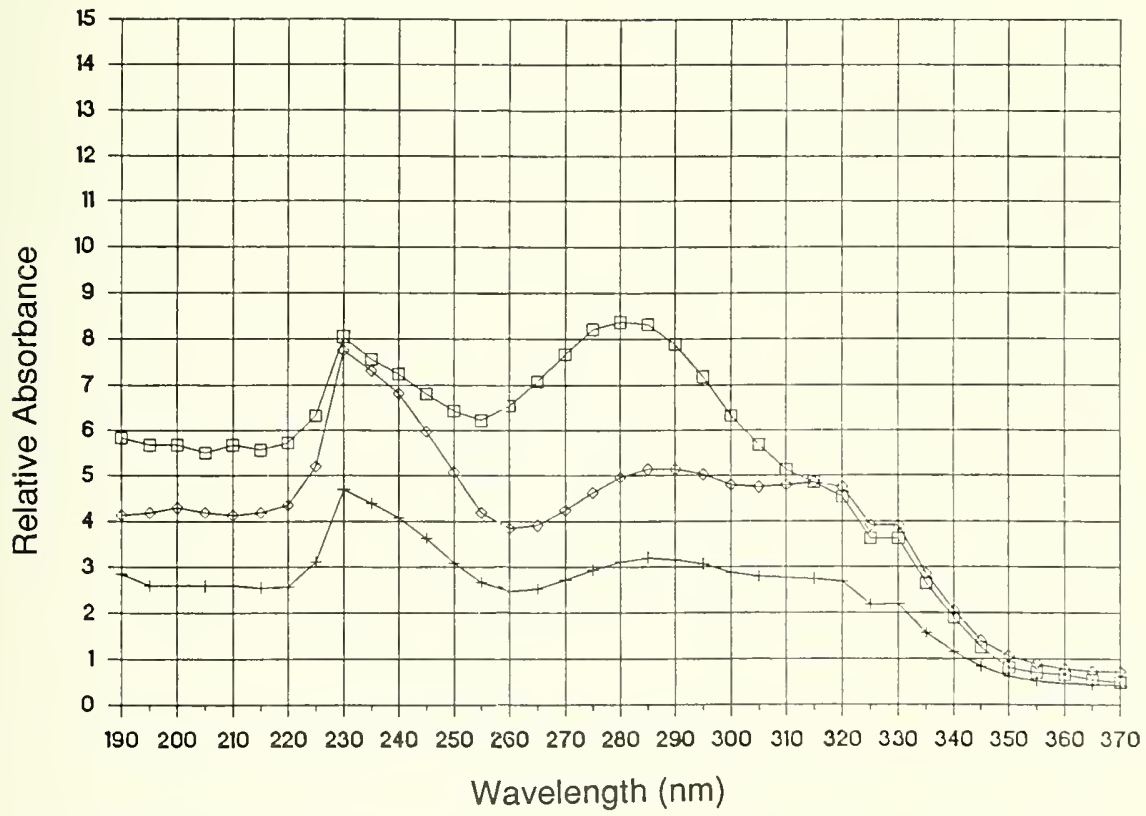

Fig. 2. Relative absorbance of dichloromethane extract from fur sample from a Point Defiance Zoo sea otter (Enhydra lutris). $\mathrm{Q}=$ neck, $+=$ belly, $\diamond=$ femur. 


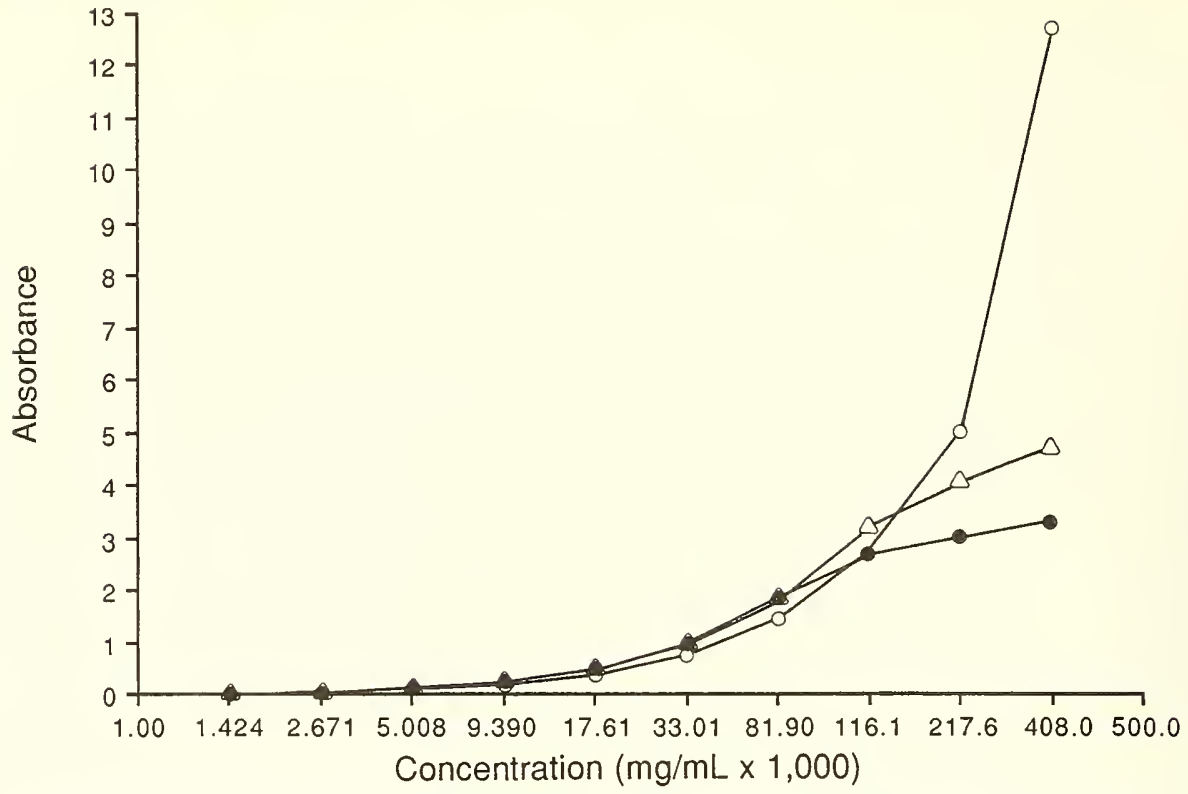

Fig. 3. Relative absorbance of varying dilutions of dichloromethane extract of Prudhoe Bay crude oil. $\bullet=230 \mathrm{~nm}$, $\Delta=235 \mathrm{~nm}, 0=240 \mathrm{~nm}$.

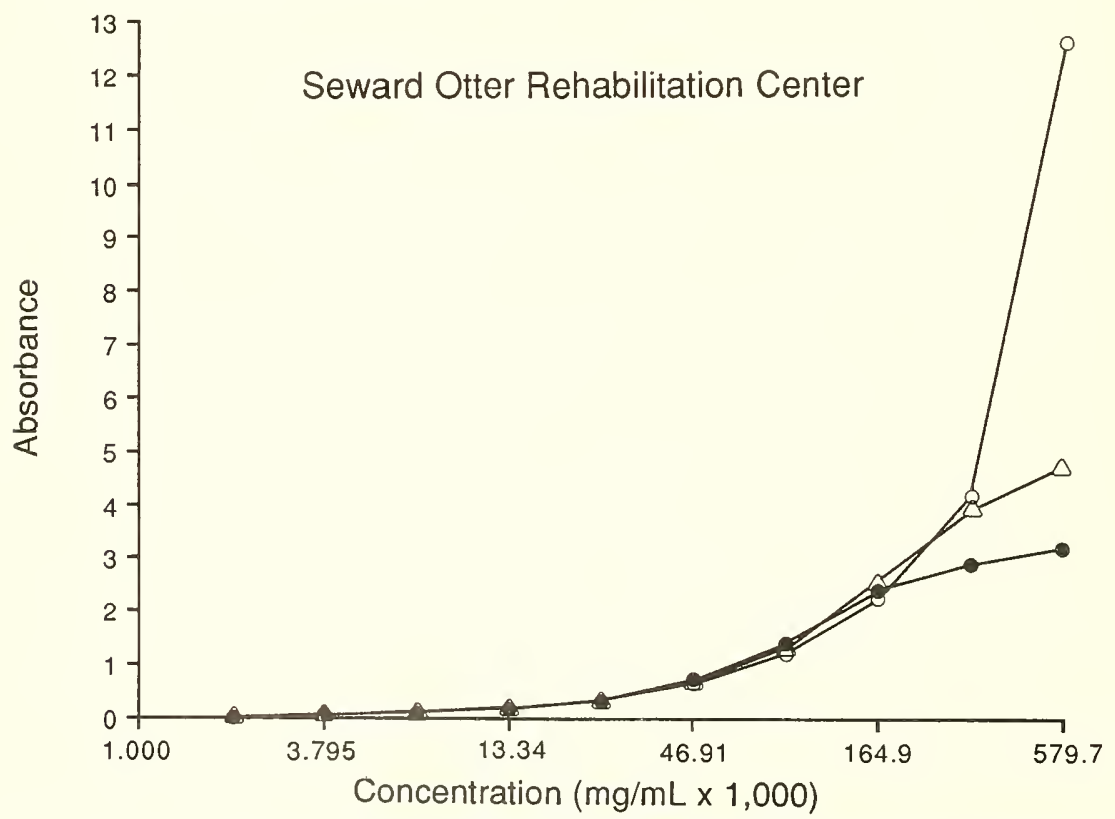

Fig. 4. Relative absorbance of varying dilutions of dichloromethane extract of weathered Prudhoe Bay crude oil. - $=230 \mathrm{~nm}, \Delta=235 \mathrm{~nm}, 0=240 \mathrm{~nm}$. 


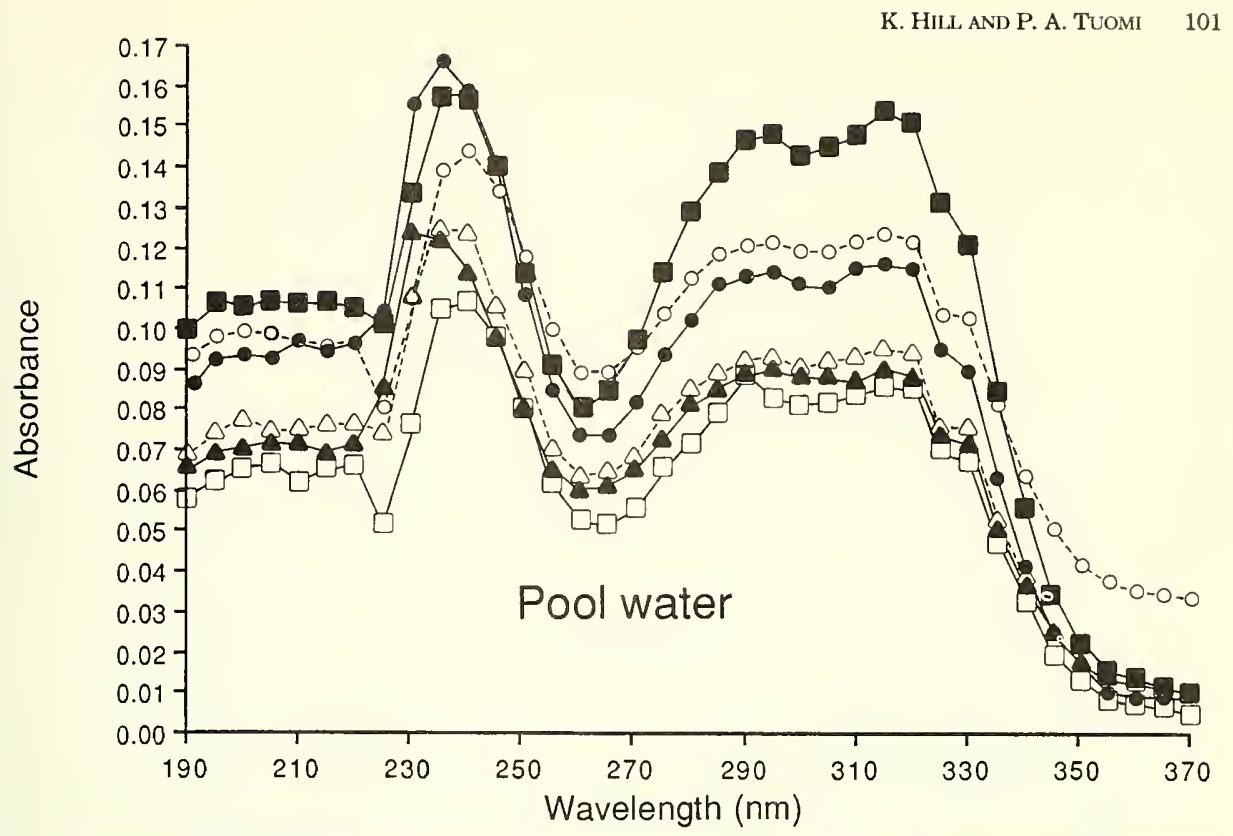

Fig. 5. Relative absorbance of dichloromethane extract from seawater from sea otter (Enhydra lutris) pools at the Seward Otter Rehabilitation Center. $\mathrm{P}=$ pool.

$\boldsymbol{\Delta}=\mathrm{P} 1,--=\mathrm{P} 2,-\Delta-=\mathrm{P} 3,-=\mathrm{P} 4,-\mathrm{O}^{-}=\mathrm{P} 5,-\mathrm{O}^{--}=\mathrm{P} 6$.

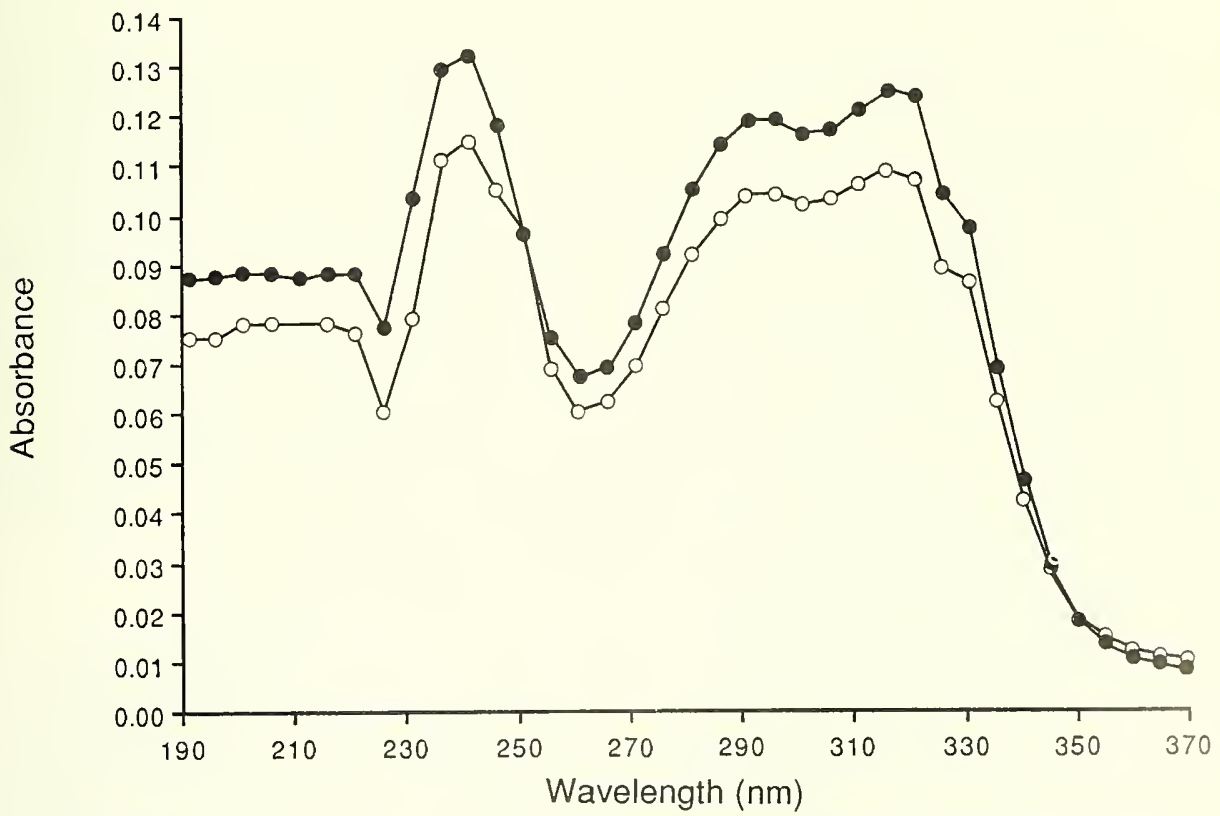

Fig. 6. Relative abscibance of dichloromethane extract from incoming seawater at the Seward Otter Rehabilitation Center. $\bullet=$ incoming salt water, $0=$ reverse osmosis water. 
Otter SW-150 (washed)

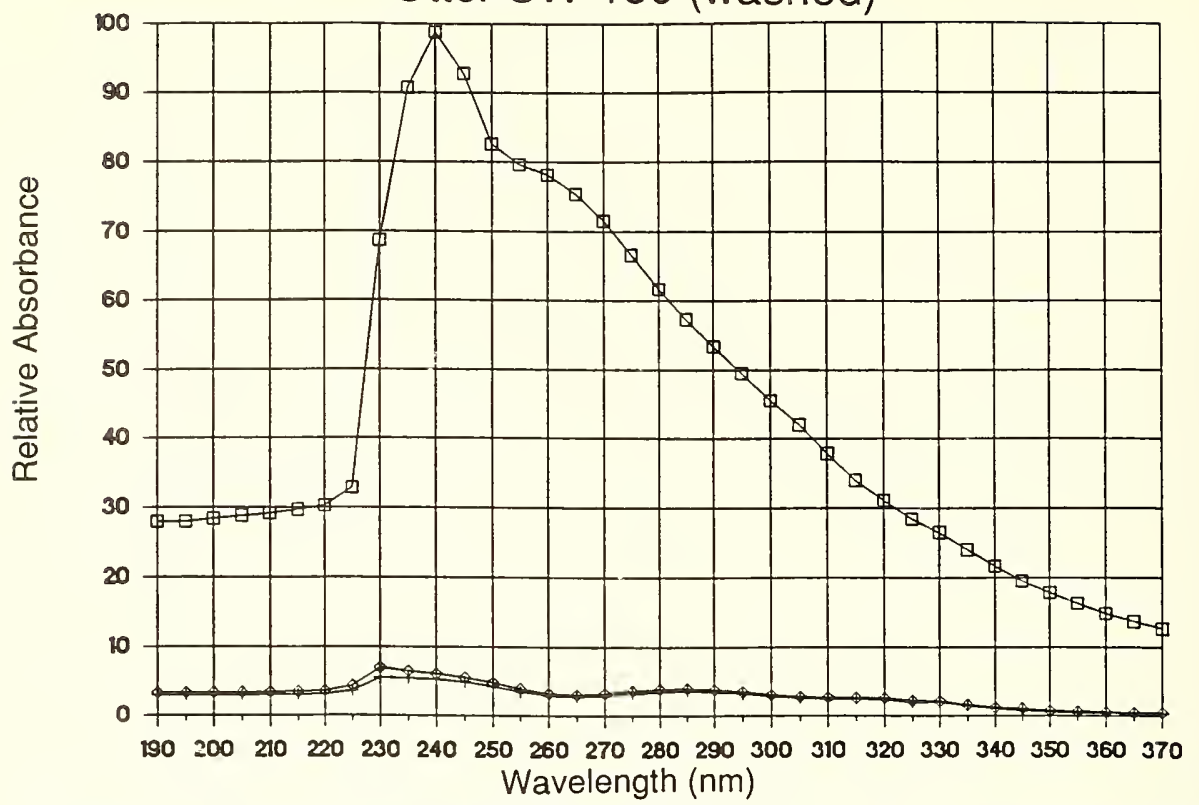

Fig. 7. Relative absorbance of dichloromethane extract of sea otter (Enhydra lutris) fur samples taken from otter SW150 at admission to the Seward Otter Rehabilitation Center. $\square=$ neck, $+=$ belly, $0=$ femur.

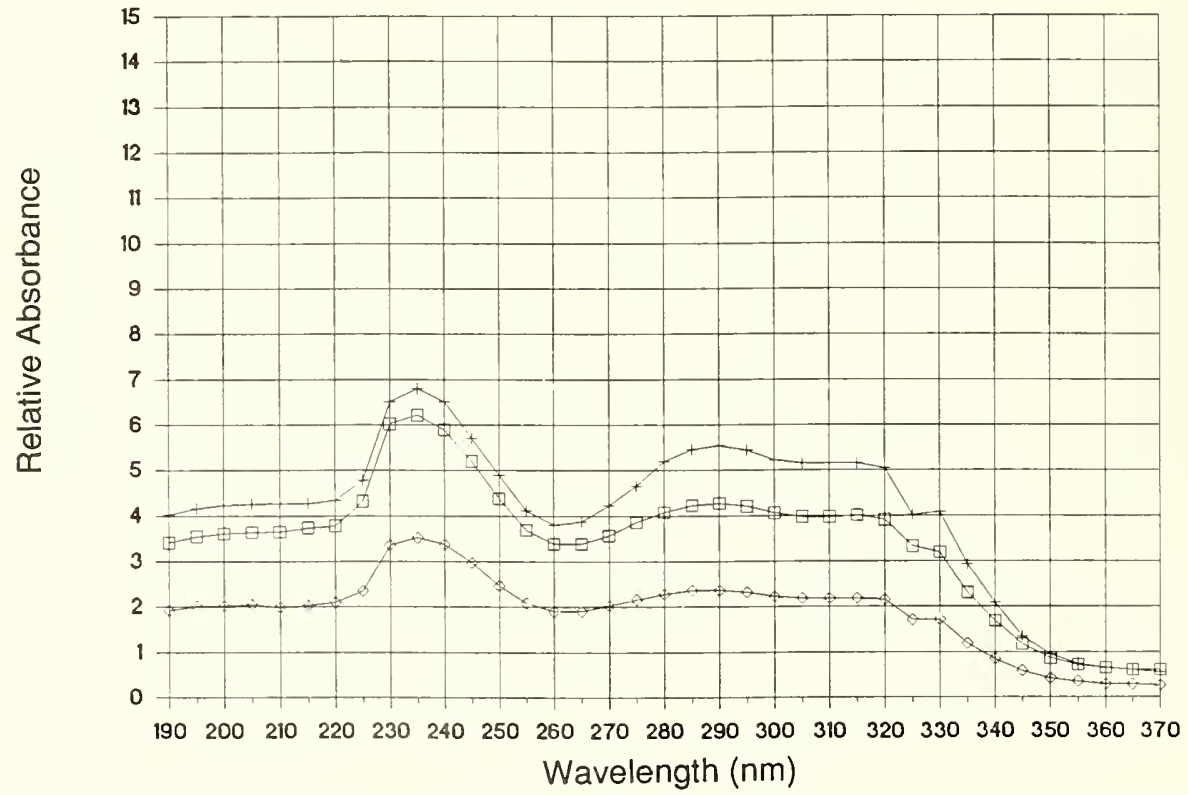

Fig. 8. Relative absorbance of dichloromethane extracts of sea otter (Enhydra lutris) fur samples from otter SW150 immediately after washing. $\square=$ neck, $+=$ belly, $\diamond=$ femur. 


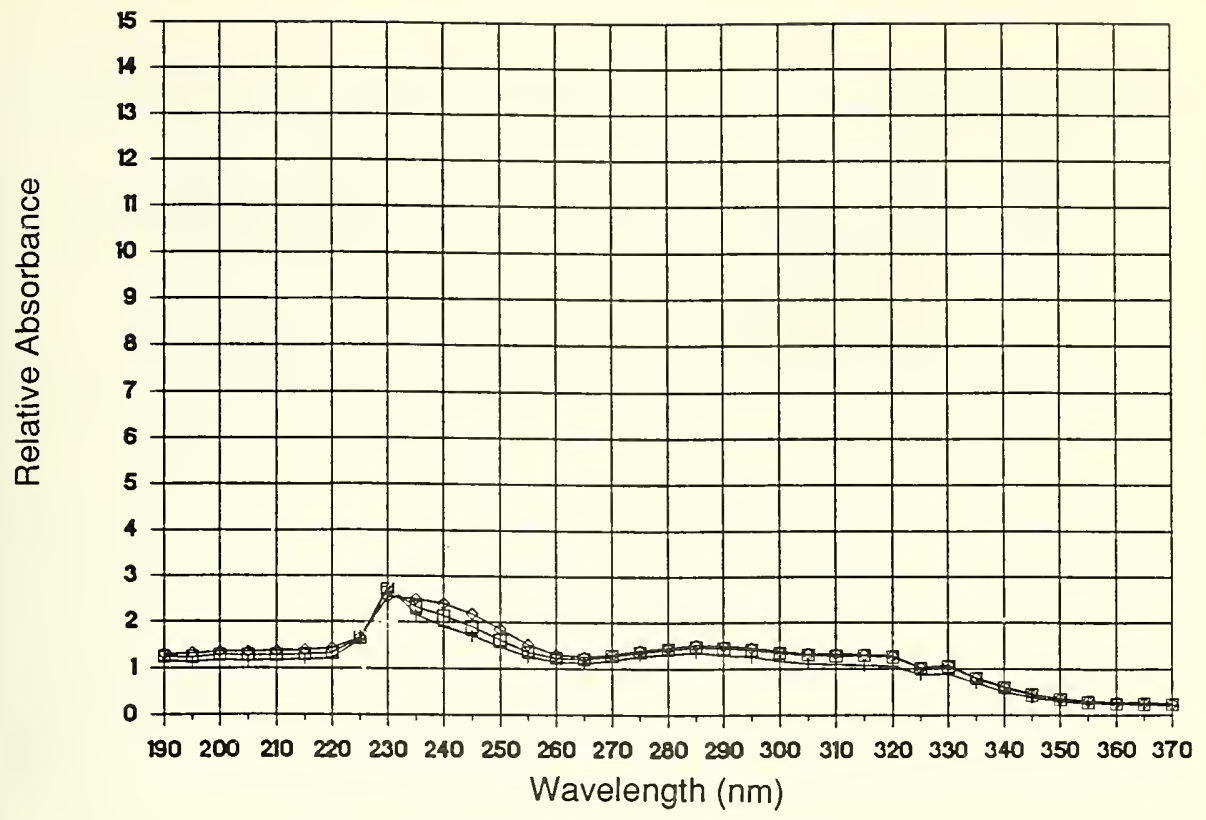

Fig. 9. Relative absorbance of dichloromethane extracts of sea otter (Enhydra lutris) fur samples taken from otter SW150 at 14 days after washing.

similar absorbance curves typical of those seen in all of the other otters in the study, indicating that Prudhoe Bay crude oil was apparently removed during the washing process (Figs. 8 and 9).

Comparison of subjective scores of coat condition for the washed and unwashed groups indicated that on some days the washed otters had a better average score than the unwashed otters, and on other days the reverse was true. Behavior patterns, weights, and food intake were also equally variable in both groups (Tables 1 and 2). There was no consistent trend that would suggest that washed otters did better than unwashed animals (or vice versa) at any stage during the study (Fig. 10).

\section{Discussion}

Because only one otter was found to be contaminated by crude oil, it is not possible to say whether the FDCM test was sufficient to determine if otters need to be washed.

Some of the problems with the experimental design of this study were as follows:
1. Because the 16 animals were divided into two groups, each group contained only 8 animals. This number was too small to detect significant differences in outcome between washed and unwashed otters.

2. Other uncontrolled variables in the experimental group that could skew the results included: a. Variation in the degree of oiling and the area of the fur oiled among the lightly oiled otters. Recovery progress could be variable because of the amount or location of the oil, rather than whether individuals were washed or not.

b. Some otters could have been stressed or have had internal toxicity, which would affect their recovery rate.

c. Doubt whether the identity of those animals that were washed versus unwashed could be kept secret in the environment of SORC. If the blind nature of the study were compromised, some animals might have been treated differently.

d. Sex and age variables that could play a role in recovery times. For example, three pregnant otters were included in the unwashed 
Table 1. Status of unwashed study sea otters (Enhydra lutris) on day 14.

\begin{tabular}{|c|c|c|c|}
\hline $\begin{array}{l}\text { Otter } \\
\text { no. }\end{array}$ & $\begin{array}{l}\text { Coat/ } \\
\text { groom } \\
\text { condition }\end{array}$ & $\begin{array}{l}\text { Weight } \\
+/- \\
\text { (pounds) }^{b}\end{array}$ & Significant lab values (days $1-14$ ) and special notes ${ }^{c}$ \\
\hline SW142 & $2+/ 3$ & $-12^{\mathrm{e}}$ & $\begin{array}{l}\text { PCV 49-48, PT 196-88, LDH 424-261, CPK 524-80. Pupped day } 6 \text {, kept } \\
\text { pup. Mod. crust at base of coat all over. Fecal positive for parasite ova }\end{array}$ \\
\hline SW 143 & $2 / 3$ & $-11^{\mathrm{e}}$ & $\begin{array}{l}\text { PCV 48-47, PT 190-117, LDH 542-353, CPK 634-221, } \\
\text { WBC 10,700-9,300, Seg 92-83. Pupped day 7, pup taken day } 15 \text {. } \\
\text { Light crust on the back of neck. Fecal positive for parasite ova }\end{array}$ \\
\hline SW145 & $2 / 3$ & -1 & $\begin{array}{l}\text { PCV } 44-40 \text {, PT } 217-251 \text {, WBC } 11,900-6,800 \text {, Seg } 88-72 \text {. Red skin, esp. } \\
\text { ventral. Thin coat, light crust. Fecal positive for parasite ova }\end{array}$ \\
\hline SW151 & $2 / 3$ & -9 & $\begin{array}{l}\text { PCV 53-29, PT 258-179, WBC } 10,000-5,700 \text {, Seg } 90-80 \text {. Crust not } \\
\text { checked. Fecal positive for parasite ova }\end{array}$ \\
\hline SW153 & $3 / 3$ & +6 & $\begin{array}{l}\text { PCV } 50-49 \text {, PT } 236-107, \mathrm{LDH} 427-161, \mathrm{CPK} 1133-55 \text {. Moved to pond day } \\
\text { 6. No crust in coat }\end{array}$ \\
\hline SW154 & $3 / 3$ & +3 & $\begin{array}{l}\text { PCV } 44-49 \text {, PT } 289-98 . \text { Moved to pond day } 6 \text {. Fecal positive for parasite } \\
\text { ova }\end{array}$ \\
\hline SW156 & $1 / 3$ & -9 & $\begin{array}{l}\text { PCV 50-43, PT } 1130-158 \text {, OT } 2485-221, \text { LDH } 574-296 \text {, CPK } 485-147 \text {, } \\
\text { WBC } 8,000-9,600 \text {, Seg } 84-90 \text {. Very light crust all over. Good appetite. } \\
\text { Fecal positive for parasite ova }\end{array}$ \\
\hline SW159 $9^{d}$ & $2 / 3$ & $-13^{\mathrm{e}}$ & $\begin{array}{l}\text { PCV 49-37, PT 292-122, LDH 359-383, CPK 520-218, } \\
\text { WBC 12,100-16,700, Seg 86-97. Stillborn pup (dystocia) day } 3 \text {, } \\
\text { mult. blood draws on days 2-5, antibiotics given days 5-12. } \\
\text { Mod. light crust, esp.head and shoulders-biopsied }\end{array}$ \\
\hline \multicolumn{4}{|c|}{ Coat and groom grades: 1 = poor, $2=$ improv } \\
\hline
\end{tabular}

group; these otters delivered pups (two live and one stillborn) during the study period.

3. The study goals were too ambitious. We had too many hypotheses and too few animals in each group to adequately test those hypotheses.

The study failed to attain its objectives. Comparing the accuracy of the FDCM test with the spectrophotometric measurements was inconclusive because only one otter had a single oiled site, and all other comparisons were of negative samples.

Comparison of washed and unwashed otters did not demonstrate any significant differences between the two groups. Fifteen out of 16 otters had no demonstrable oiling of the coat in the first place. Interestingly, the two otters (SW144 and SW150) that had the highest readings at entry by the spectrophotometer had higher coat condition scores (meaning better coats) at entry than any of the other otters that had no detectable oil. This would lead one to question whether the scoring system for coat condition can be used as an indication of light oiling.

Our third objective, to determine whether the FDCM test was sufficient to decide whether animals could be left in the wild, was too ambitious for the scope of the study. This would be a difficult objective for any study, but the fact that only one oiled animal was included made it impossible to evalulate the test.

\section{Conclusions}

A field test to quantify the degree of oiling on the fur of oil-contaminated sea otters, and other tests, are needed to

(1) determine when to stop otter capture, because capture and holding have their own set of risks 
Table 2. Status of washed study sea otters (Enhydra lutris) on day 14.

\begin{tabular}{|c|c|c|c|}
\hline $\begin{array}{l}\text { Otter } \\
\text { no. }\end{array}$ & $\begin{array}{c}\text { Coat/ } \\
\text { groom } \\
\text { condition }^{\mathbf{a}}\end{array}$ & $\begin{array}{l}\text { Weight } \\
+/- \\
\text { (pounds) }^{b}\end{array}$ & Significant lab values (days 1-14) and special notes ${ }^{\mathrm{c}}$ \\
\hline 141 & $2 / 3$ & +1 & $\begin{array}{l}\text { PCV 52-48, PT 155-151, LDH 393-246, CPK 356-109. Focal dry scab } \\
\text { (shoulder). Fecal positive for parasite ova }\end{array}$ \\
\hline 144 & $2+/ 3$ & -6 & $\begin{array}{l}\text { PCV 52-40, PT 144-168, WBC } 8,700-13,400, \text { Seg } 83-78 \text {. Moved to pond } \\
\text { day } 8 \text {. Small amt. dark crust. Red skin at hocks }\end{array}$ \\
\hline 146 & $3 / 3$ & -1 & $\begin{array}{l}\text { PCV 53-48, PT } 265-123 \text {, LDH } 541-175 \text {, CPK } 399-87 \text {. Moved to pond day } \\
\text { 10. Pale crust on top of head and stifle }\end{array}$ \\
\hline 150 & $1+/ 3$ & +3 & $\begin{array}{l}\text { PCV 43-35, PT 178-309, OT 289-421. Poor appetite. Continued poor condi- } \\
\text { tion through day } 28 \text {. Crust not checked. Fecal negative for parasite ova }\end{array}$ \\
\hline 152 & $2+/ 3$ & -8 & $\begin{array}{l}\text { PCV 48-43, PT } 287-182 \text {, LDH } 487-349 \text {, CPK } 166-343 \text {. Moved to pond day } \\
\text { 14. Crust not checked. Fecal positive for parasite ova, passed tapeworm }\end{array}$ \\
\hline 155 & $2+/ 3$ & -1 & $\begin{array}{l}\text { PCV } 51-47 \text {, PT } 181-97 \text {, WBC } 9,600-7,000 \text {, Seg } 83-73 \text {. Moved to pond day } \\
\text { 9. Mod. dark crust over whole body }\end{array}$ \\
\hline 157 & $3 / 3$ & +3 & PCV 51-50, PT 146-111. Moved to pond day 6. Crust not checked \\
\hline 158 & $1 / 3$ & -1 & $\begin{array}{l}\text { PCV } 49-42 \text {, PT } 336-126 \text {, OT } 615-215 \text {, LDH } 544-306 \text {, CPK } 1487-76 \text {, WBC } \\
9,000-12,000 \text {, Seg } 85-87 \text {. Poor appetite days } 11-14 \text {, coat deteriorated. } \\
\text { Light crust all over, biopsy of head and shoulder. Fecal positive for para- } \\
\text { site ova }\end{array}$ \\
\hline
\end{tabular}

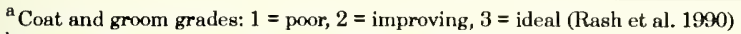

${ }^{b}$ Weight $=$ weight gain or loss during 14 days of study.

${ }^{\mathrm{c}} \mathrm{PVC}=$ packed cell volume, $\mathrm{PT}=$ serum glutamic pyruvic transaminase, $\mathrm{LDH}=$ lactic dehydrogenase, $\mathrm{CPK}=\mathrm{creatinine}$ phosphokinase, $\mathrm{WBC}=$ white blood cells, $\mathrm{Seg}=$ segmented white blood cells, and OT = glutamic oxaloacetic transaminase.

for the animals in terms of stress, social disruption, and sometimes death;

(2) diagnose variously affected animals that may need different treatment protocols based on their external oiling or internal toxicity;

(3) determine the cause of death for animals found dead in their own habitat after an oil spill; and

(4) identify the source of contamination. The spectrophotometer, for example, could show peaks specific for bunker oil or diesel fuel.

Further work should be done on the FDCM and other tests by using fur samples from dead otters collected after contamination with Prudhoe Bay crude oil to identify the best field test for use in future oil spills. Additionally, field blood tests would be valuable to detect if an animal has been affected by crude oil toxicity. The blood tests should evaluate the health of an animal even if it had not been externally oiled; this would help determine whether an otter needed to be washed, supported with veterinary care, or both.

\section{Recommendations}

We should anticipate the studies that will need to be done during a crisis situation such as the Exxon Valdez oil spill, and we should have study plans in place that can be instituted with preapproved permits on short notice in the event of a similar disaster.

Additional studies need to be completed as soon as possible to determine to what extent animals can survive in the wild with small amounts of crude oil contamination. This information could be used during subsequent spills so that animals not requiring rescue and rehabilitation can be identified.

\section{Acknowledgments}

We thank P. Chen and D. Mays for their assistance in performing the laboratory procedures. We also thank the staffs of the Seward Otter Rehabil- 


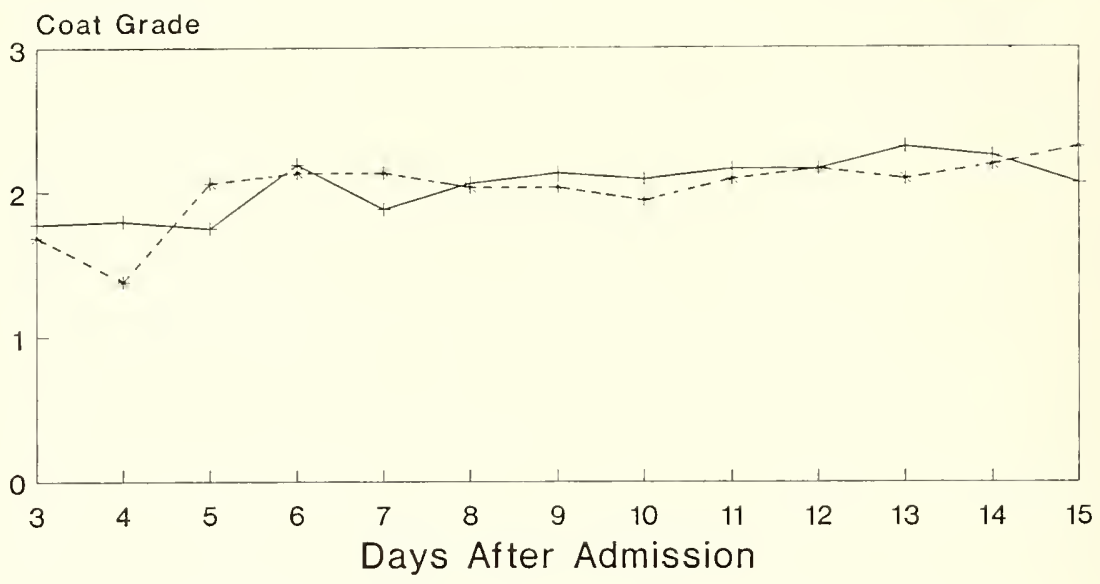

\section{--8 UNWASHED OTTERS +8 WASHED OTTERS}

NOTE: Max. Achievable Coat Grade is 3.0

Fig. 10. Comparison of daily average coat grades for washed and unwashed sea otters (Enhydra lutris). Maximum achievable coat grade is 3 .

itation Center and the University of Alaska Marine Laboratory, Seward, for the use of their facilities and for their cooperation and time in supporting this study.

\section{References}

Bayha, K. 1990. U.S. Fish and Wildlife Service's role in the sea otter rescue. Pages 26-28 in K. Bayha and J. Kormendy, tech. coords. Sea Otter Symposium: Proceedings of a symposium to evaluate the response effort on behalf of sea otters after the T/N Exxon Valdez oil spill into Prince William Sound, Anchorage, Alaska, 17-19 April 1990. U.S. Fish Wildl. Serv., Biol. Rep. 90(12).

Costa, D. P., and G. L. Kooyman. 1980. Effects of oil contamination in the sea otter, Enhydra lutris. Final Report, Research Unit 7, Outer Continental Shelf Environmental Assessment Program, U.S. Natl. Oceanic Atmos. Adm. 03-7-022-35130. 18 pp.

Fry, D. M. 1989. Evaluation of field tests for detection of oil in sea otter fur and in feces of birds and sea otters.
University of California, Davis. 11 pp. [Unpublished manuscript]

Rash, J. A., C. R. McCormick, R. Alexander, S. J. Nichol, and D. C. Perrollaz. 1990. Coat gradation and conditioning of sea otters at the Seward Otter Rehabilitation Center. Pages 258-273 in K. Bayha and J. Kormendy, tech. coords. Sea Otter Symposium: Proceedings of a symposium to evaluate the response effort on behalf of sea otters after the T/V Exxon Valdez oil spill into Prince William Sound, Anchorage, Alaska, 17-19 April 1990. U.S. Fish Wildl. Serv., Biol. Rep. 90(12).

Siniff, D. B., T. D. Williams, A. M. Johnson, and D. L. Garshelis. 1982. Experiments on the response of sea otters, Enhydra lutris, to oil contamination. Biol. Conserv. 23:261-272.

Williams, T. M., R. A. Kastelein, R. W. Davis, and J. A. Thomas. 1988. The effects of oil contamination and cleaning on sea otters, Enhydra lutris. I. Thermoregulatory implications based on pelt studies. Can. J. Zool. 66:2776-2781.

Wilson, R., C. R. McCormick, T. D. Williams, and P. A. Tuomi. 1990. Clinical treatment and rehabilitation of sea otters. Pages 326-337 in K. Bayha and. J. Kor- 
mendy, tech. coords. Sea Otter Symposium: Proceedings of a symposium to evaluate the response effort on behalf of sea otters after the T/V Exxon Valdez oil spill into Prince William Sound, Anchorage, Alaska, 17-19 April 1990. U.S. Fish Wildl. Serv., Biol. Rep. 90(12). 


\section{Appendix. Relative Absorbance of Dichloromethane Extracts of Sea Otter Fur Samples from all Study Otters at Admission and Day 14 (ES = end of study).}
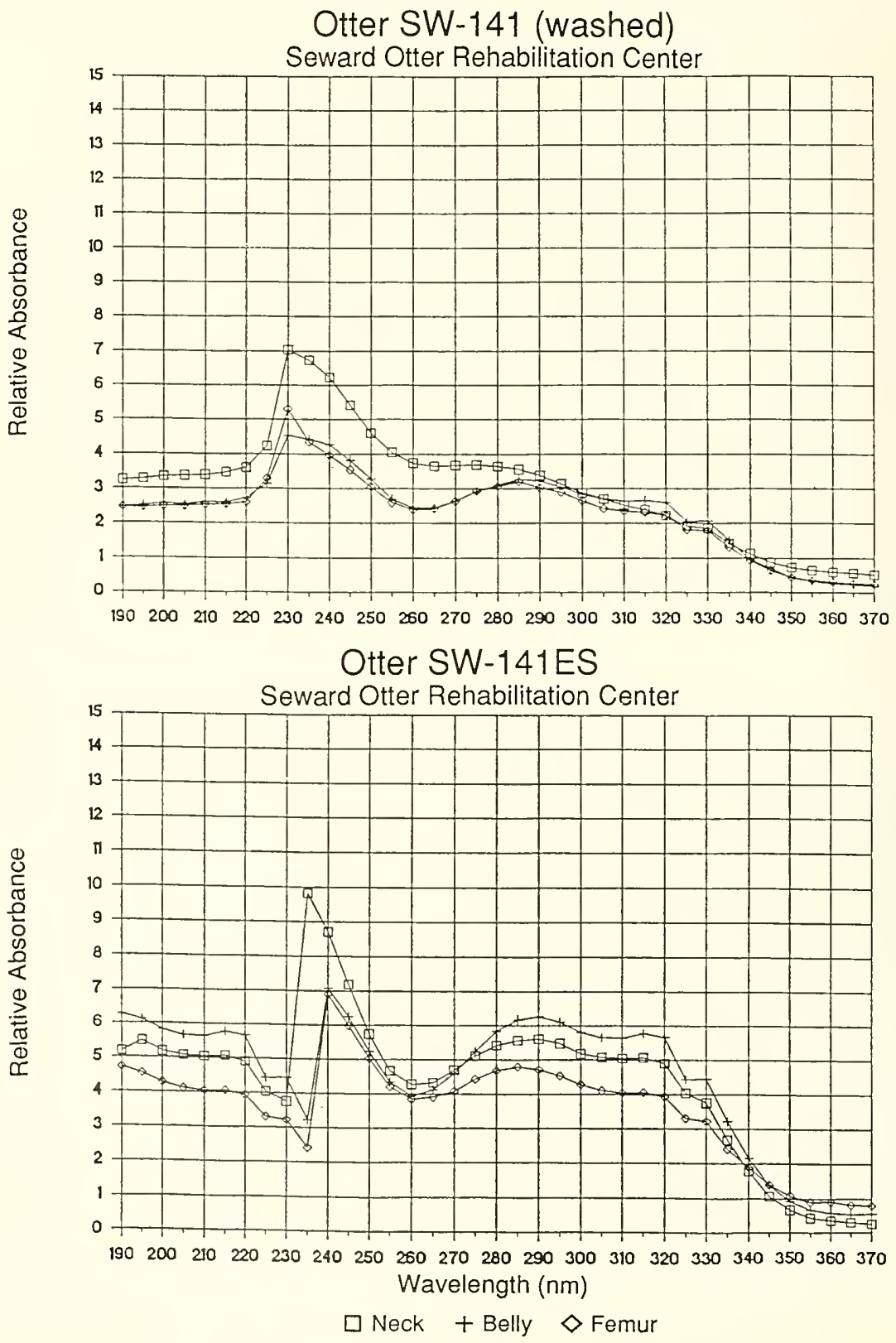
Otter SW-142 (not washed)

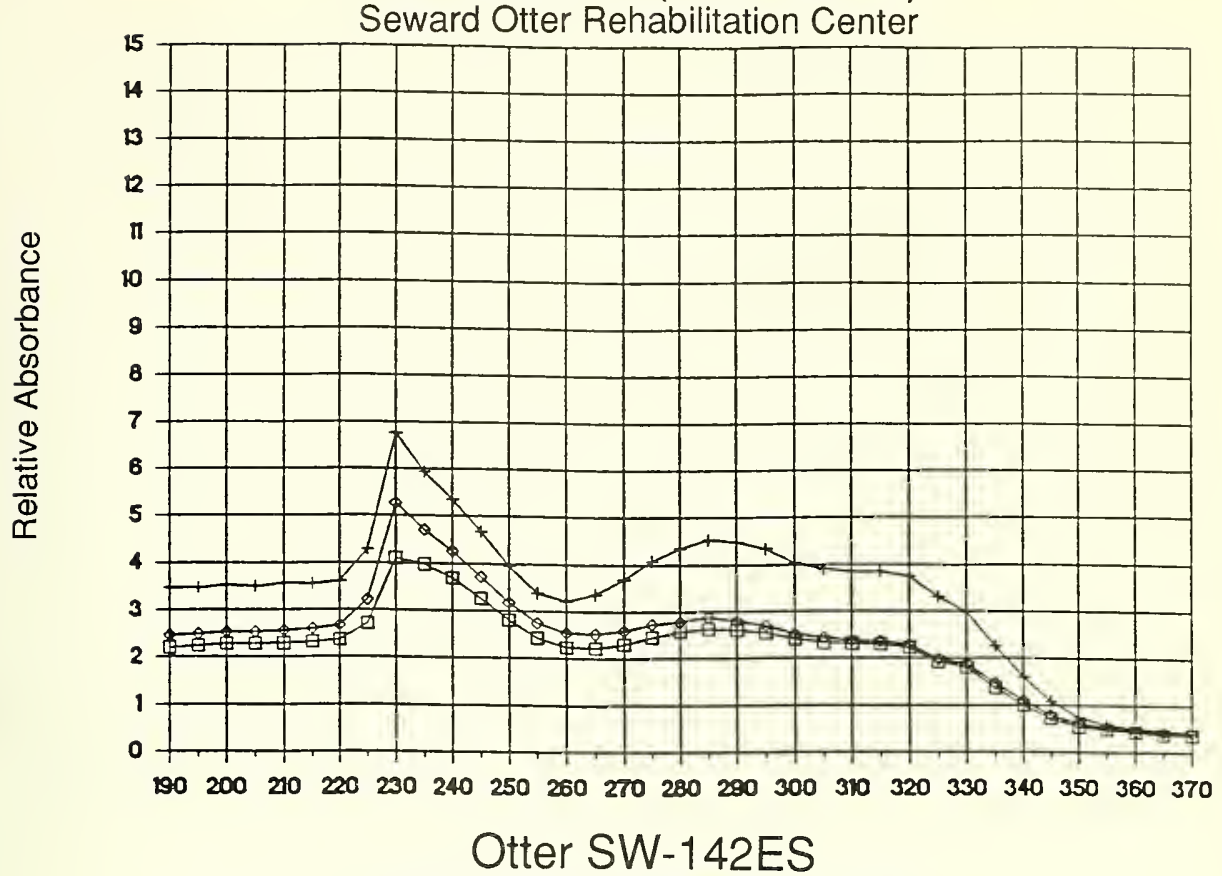

Seward Otter Rehabilitation Center

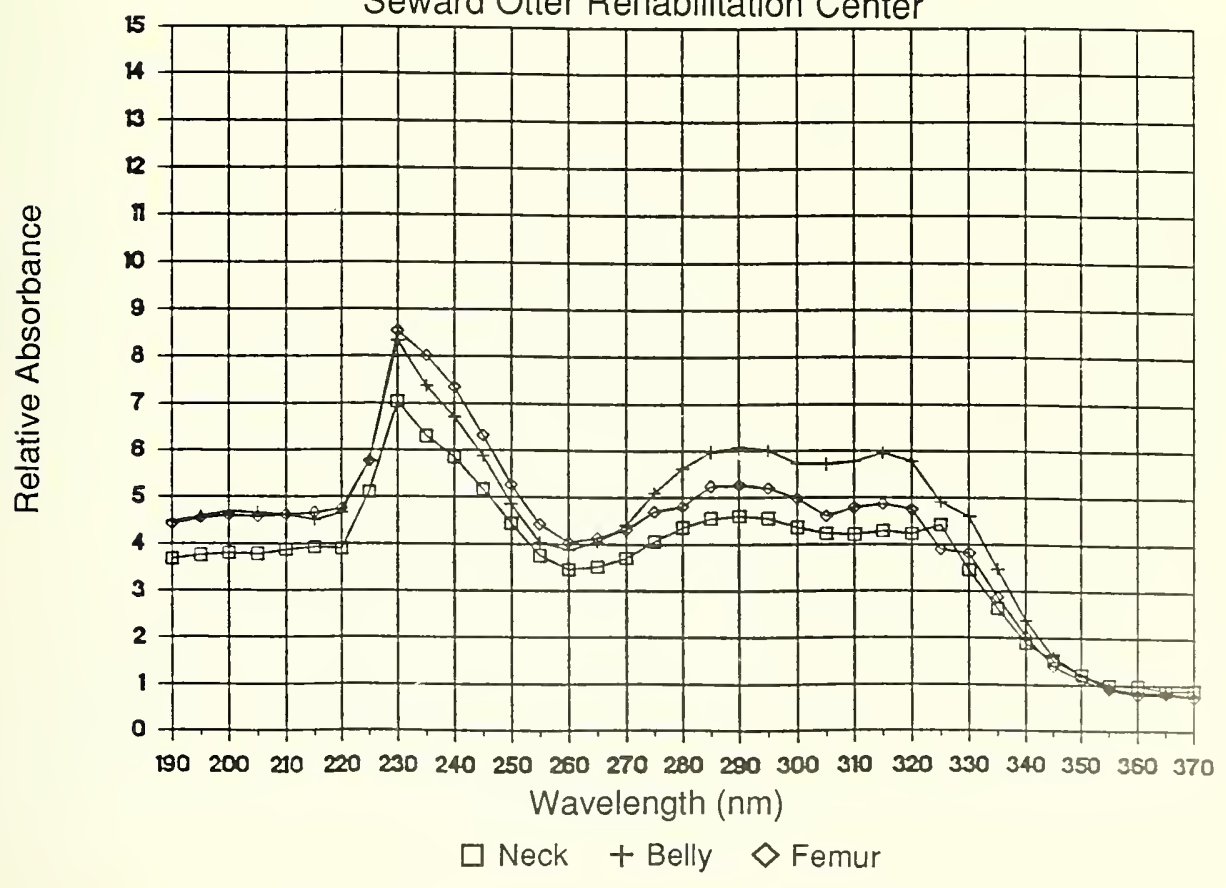




\section{Otter SW-143 (not washed)}

Seward Otter Rehabilitation Center

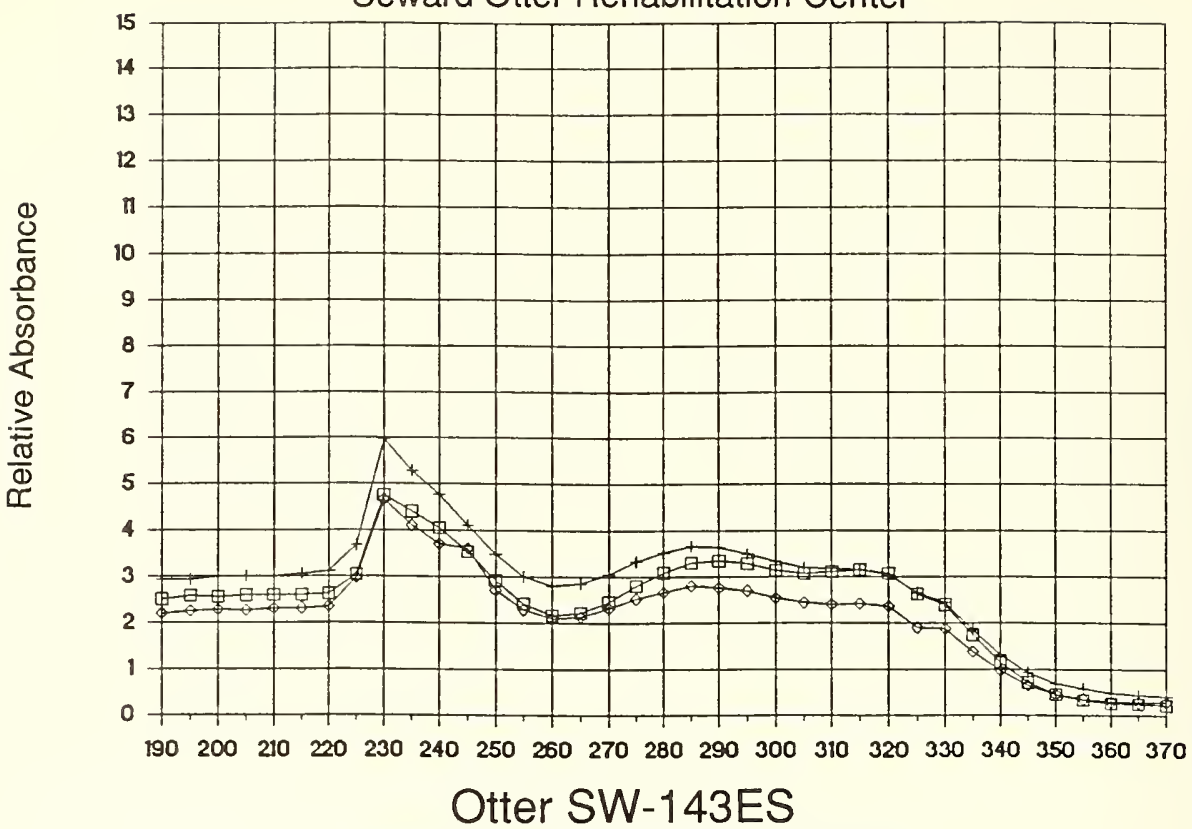

Seward Otter Rehabilitation Center

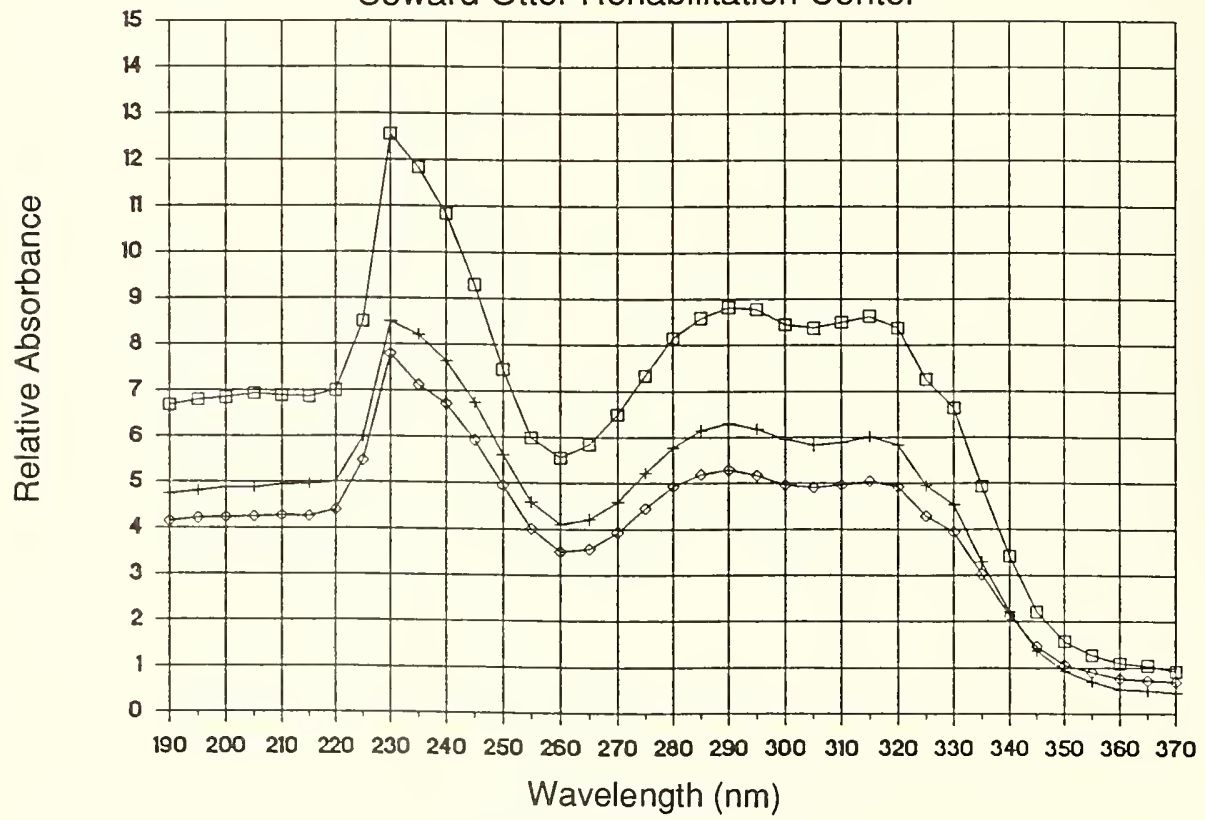




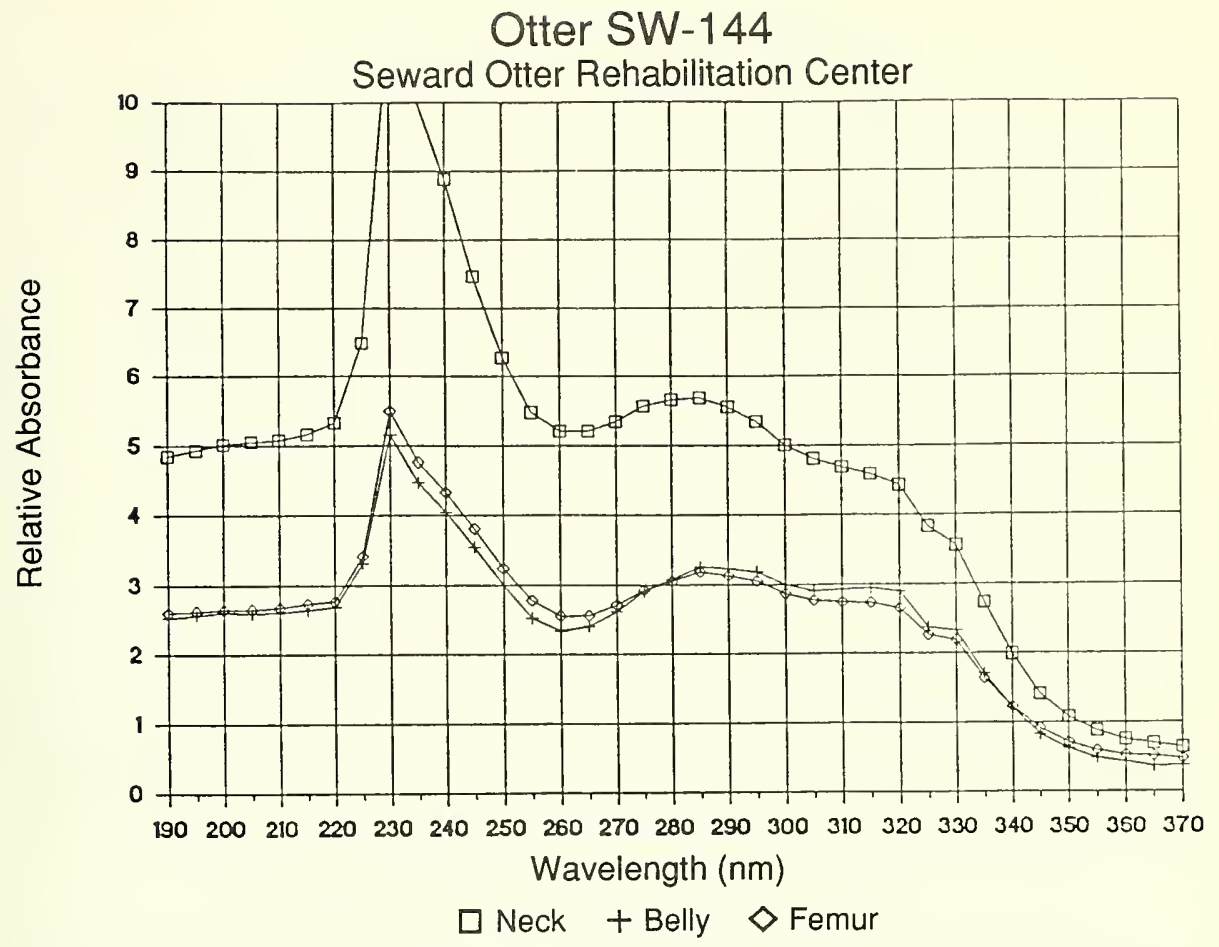




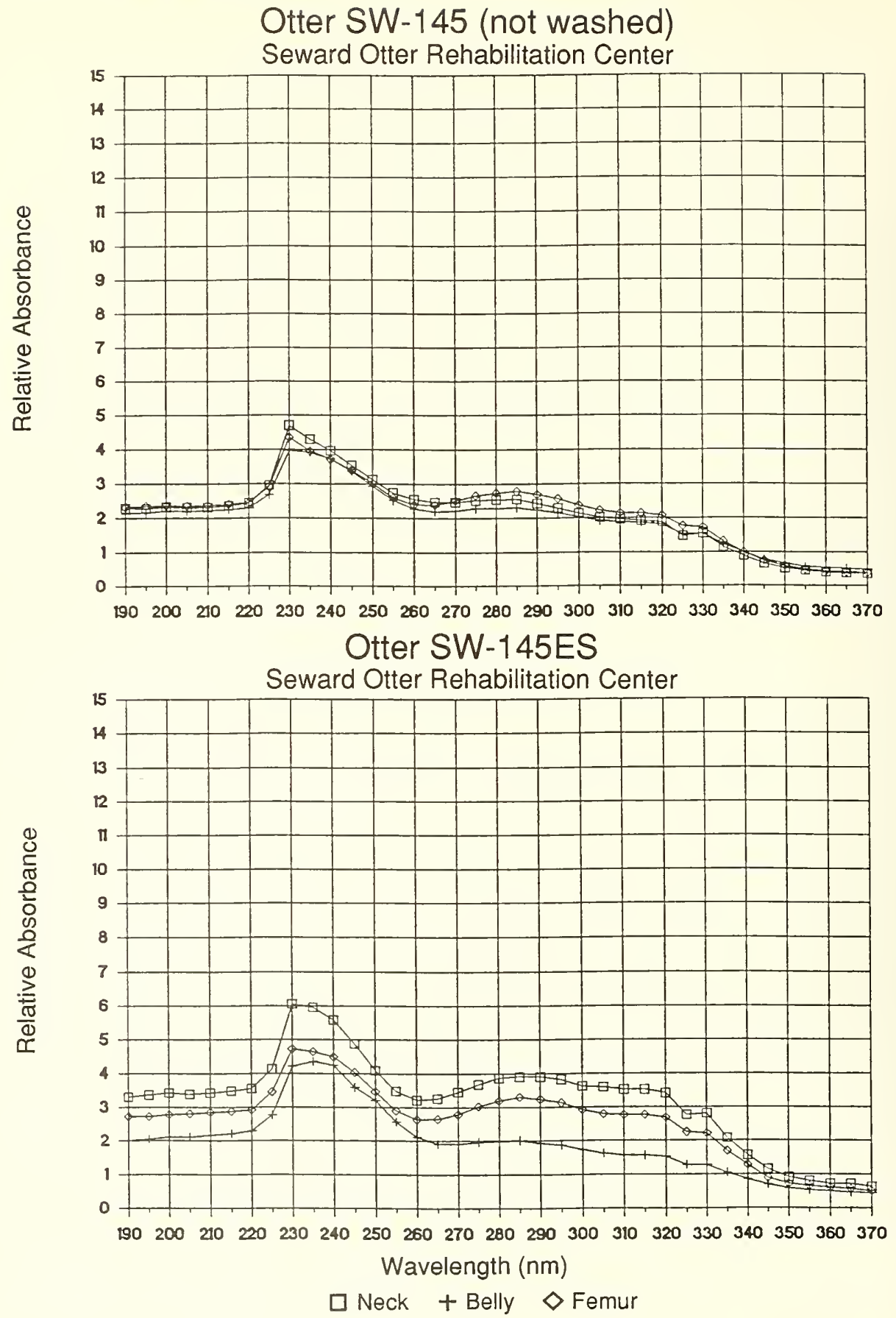




\section{Otter SW-146 (washed)}

Seward Otter Rehabilitation Center

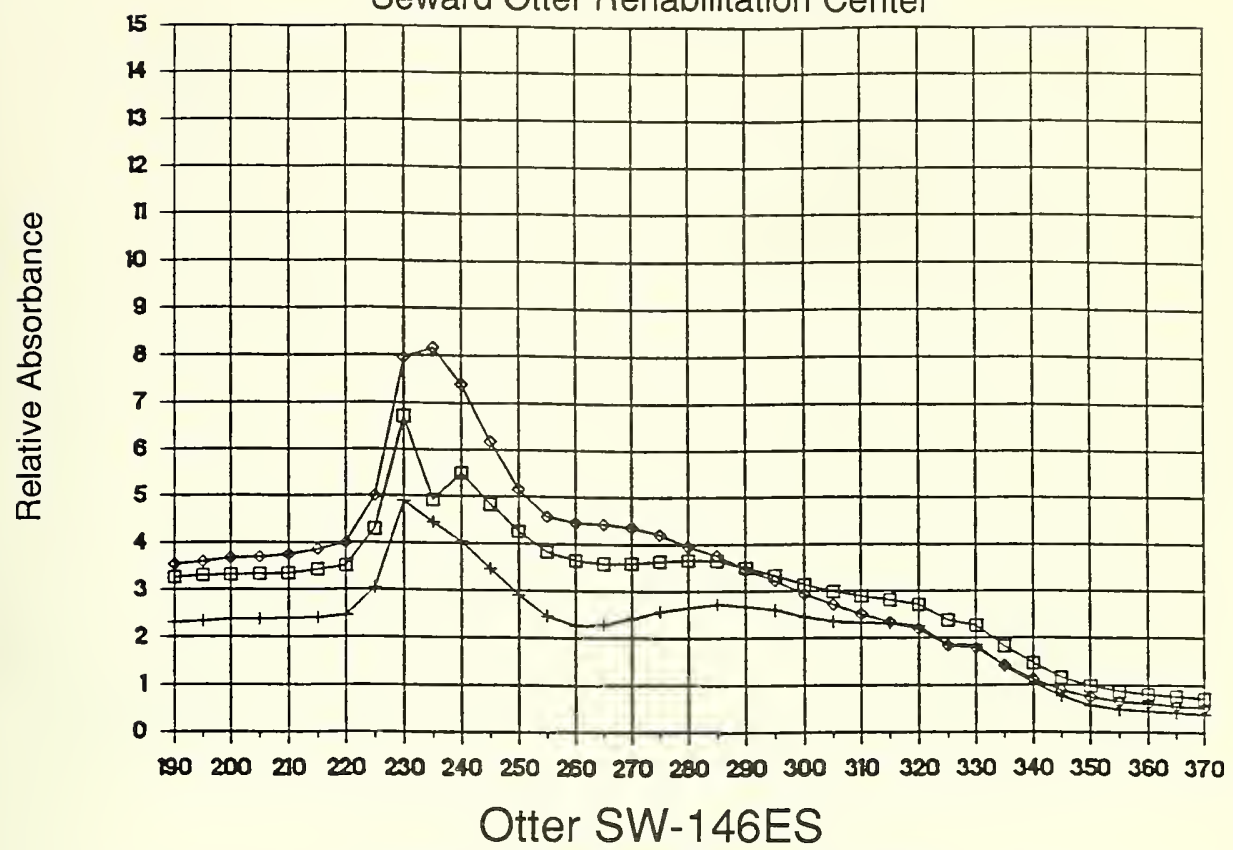

Seward Otter Rehabilitation Center

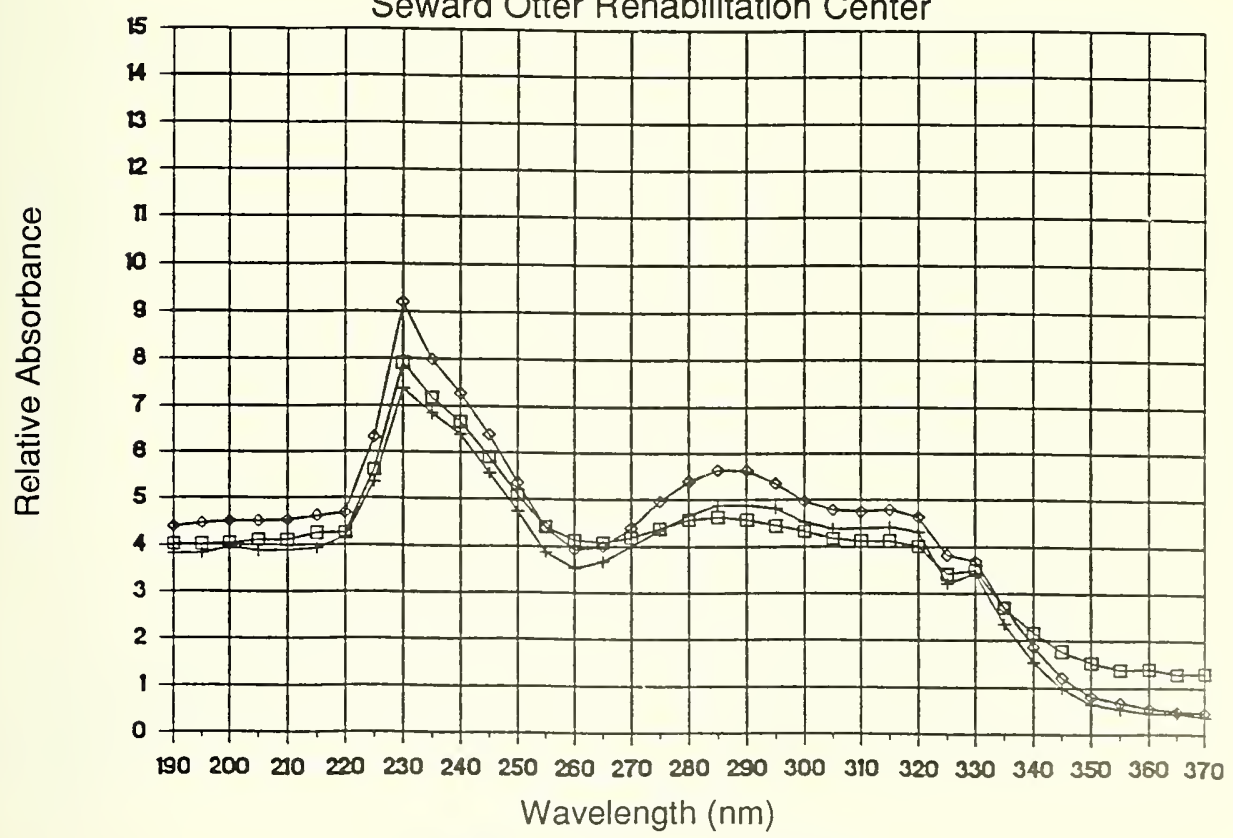



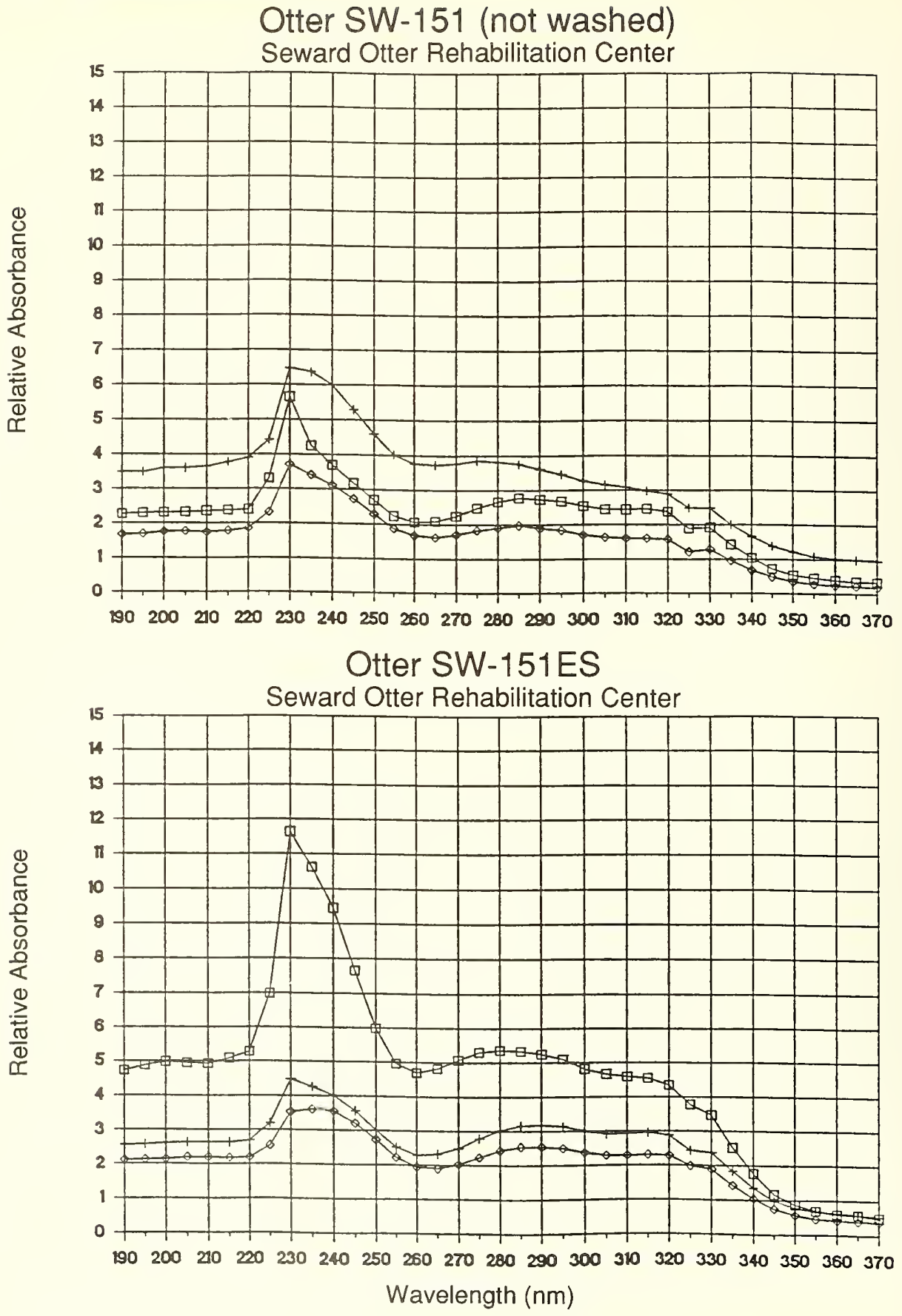
Otter SW-152 (washed) Seward Otter Rehabilitation Center

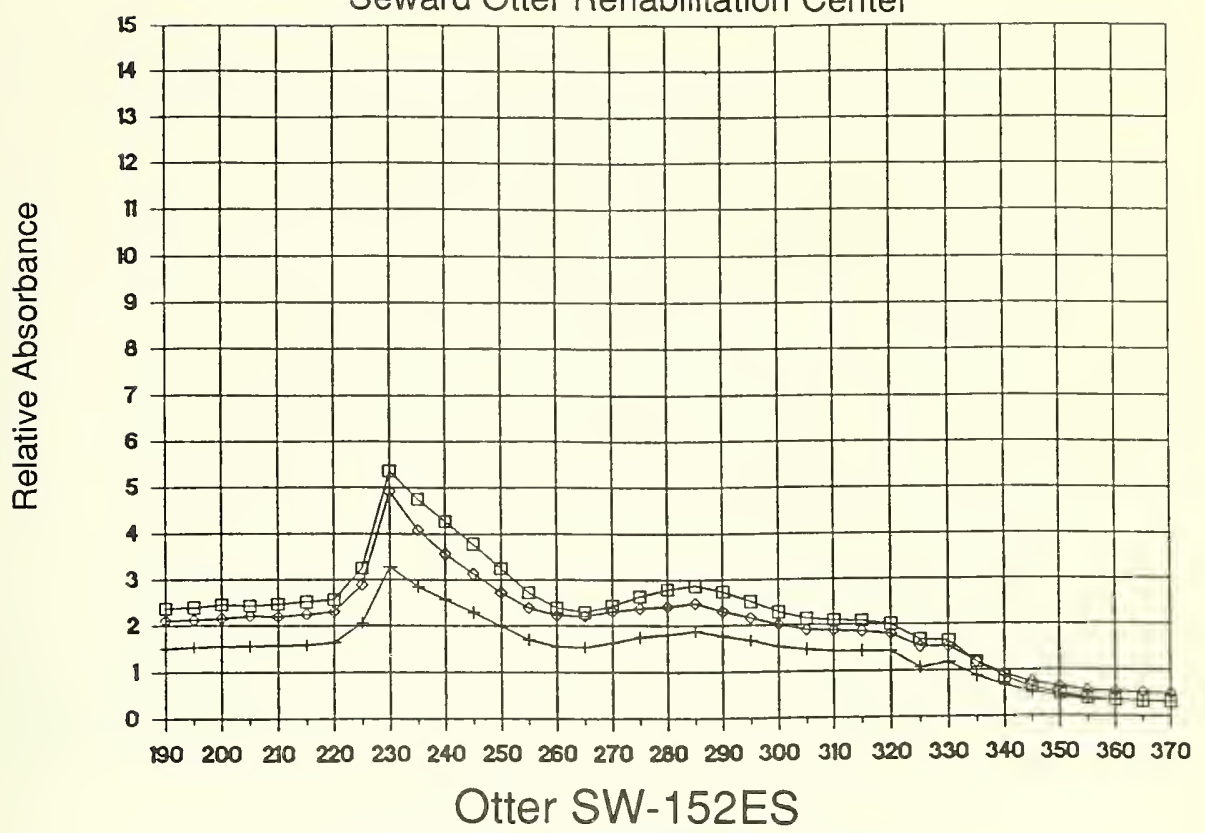
Seward Otter Rehabilitation Center

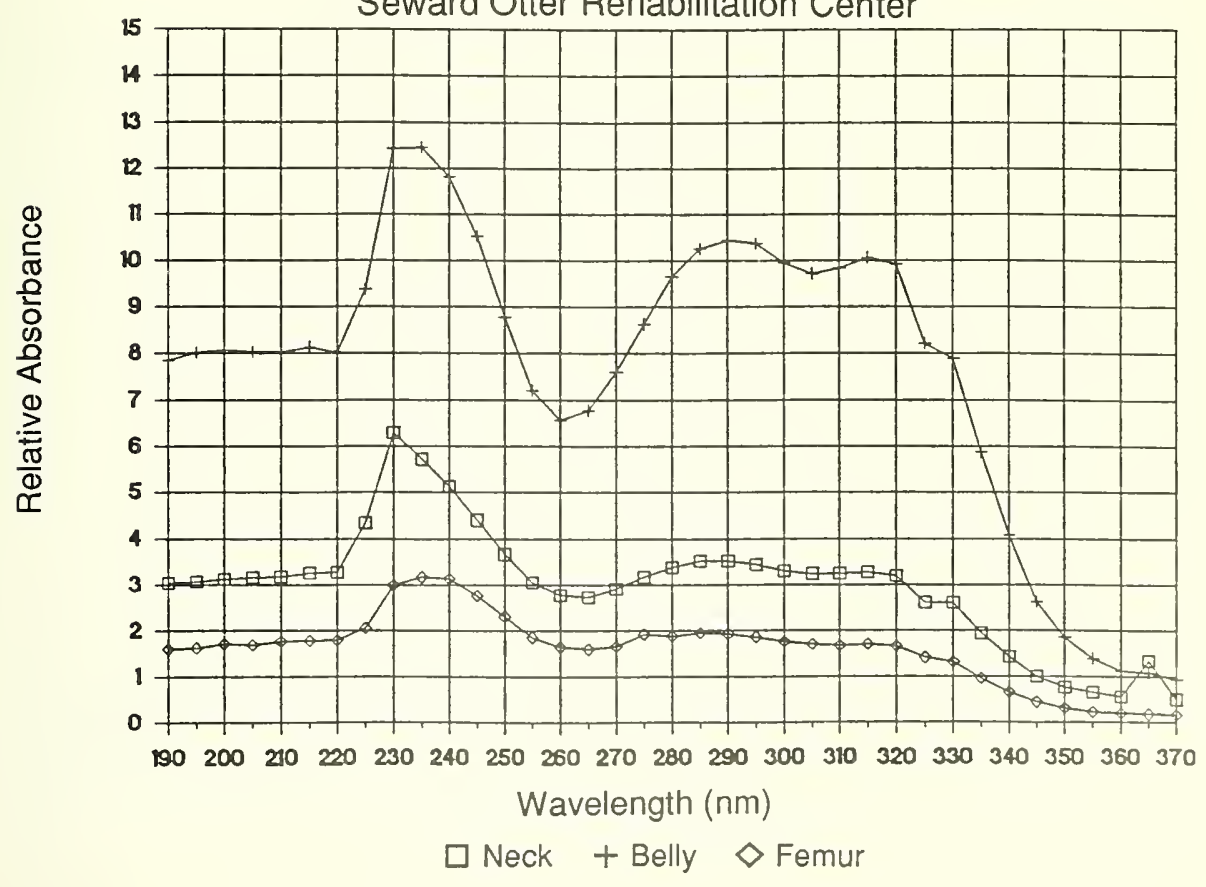


Otter SW-153 (not washed) Seward Otter Rehabilitation Center

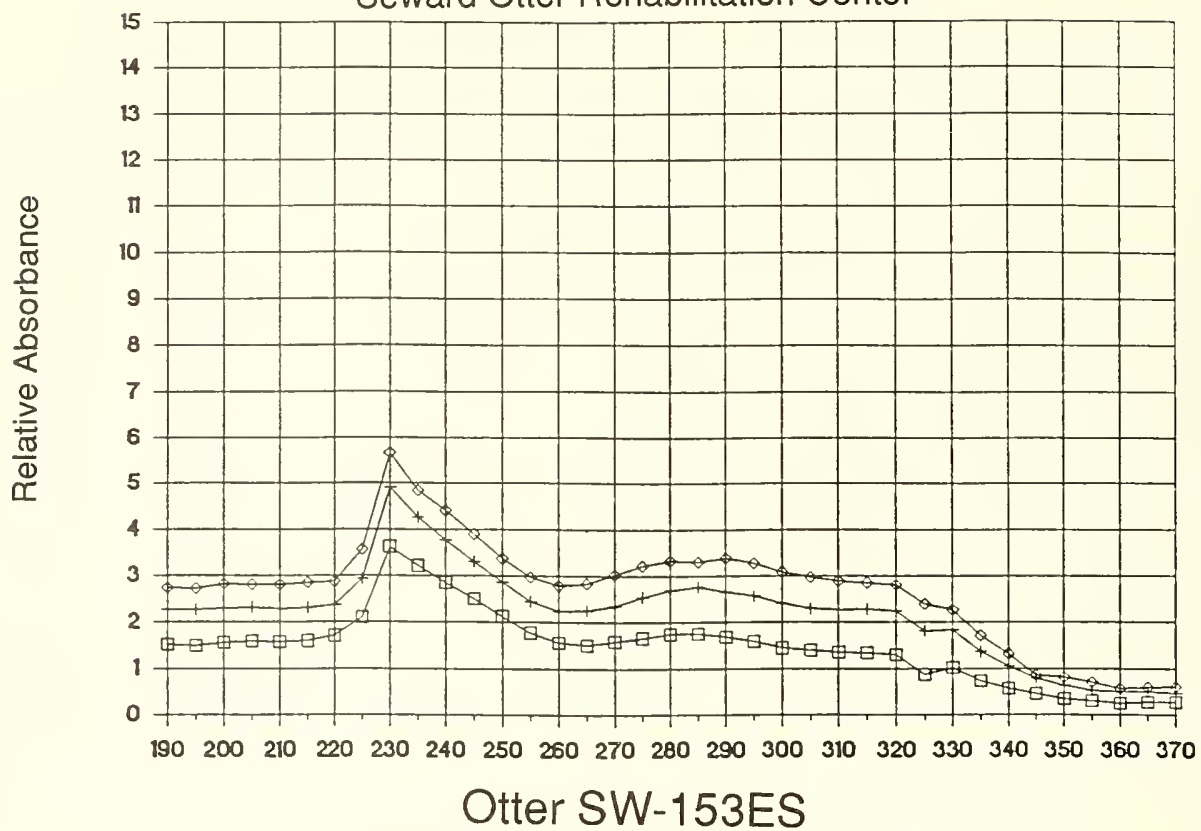

Seward Otter Rehabilitation Center

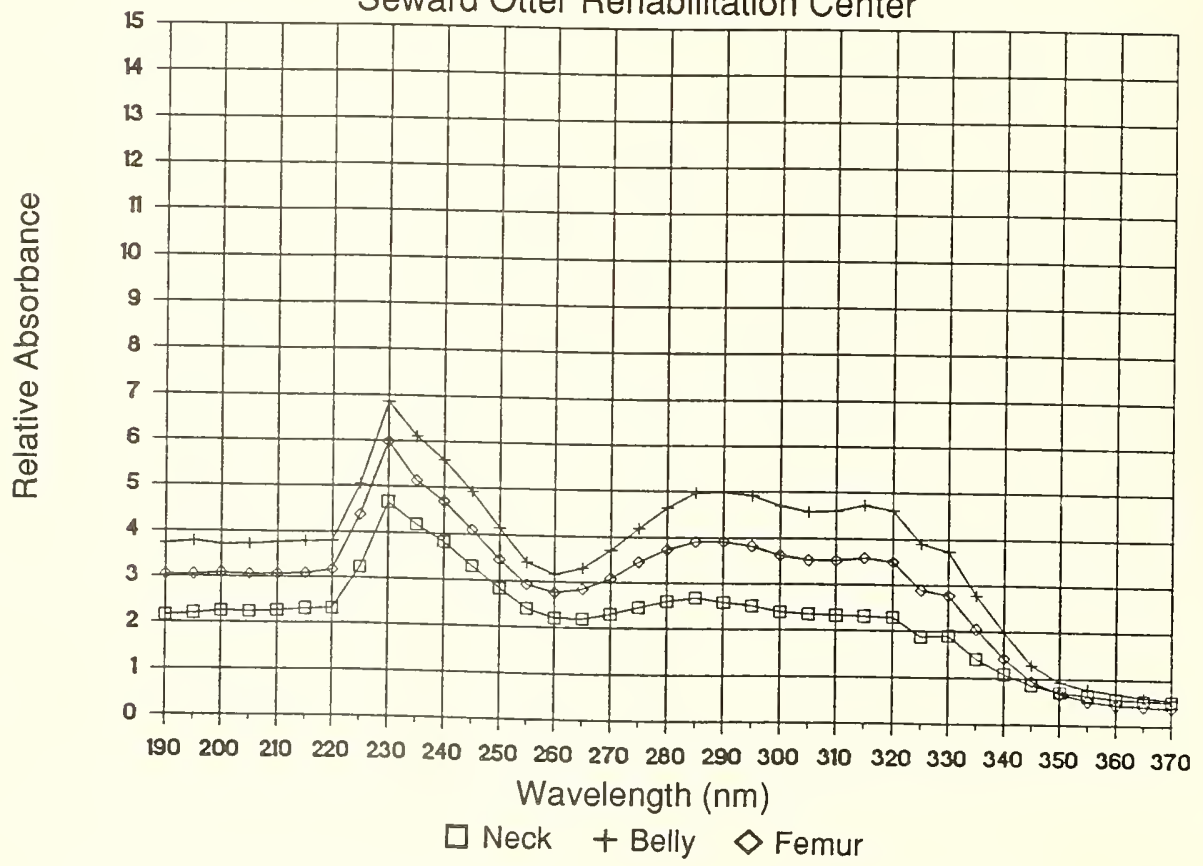


Otter SW-154 (not washed)

Seward Otter Rehabilitation Center
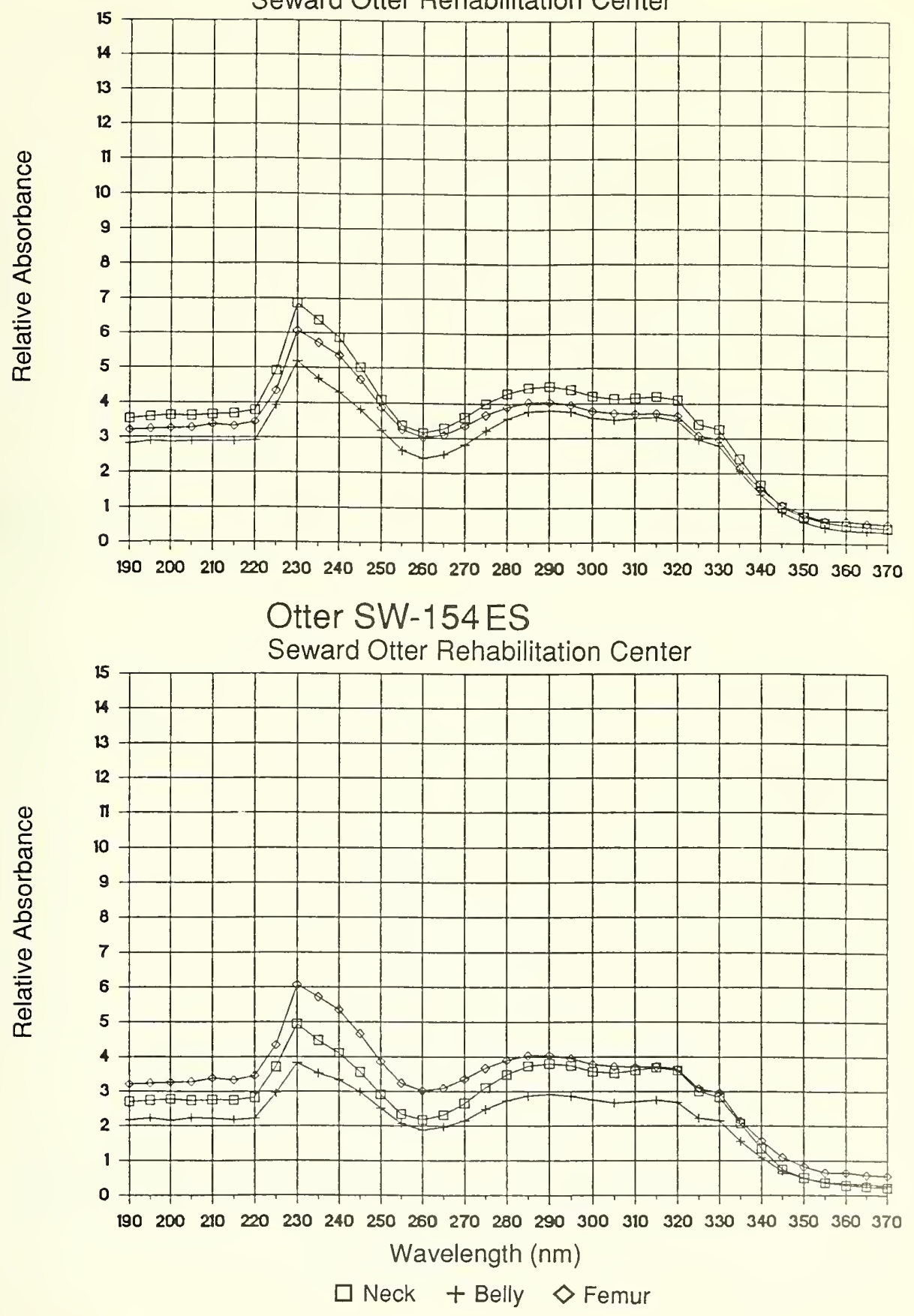
Otter SW-155 (washed) Seward Otter Rehabilitation Center

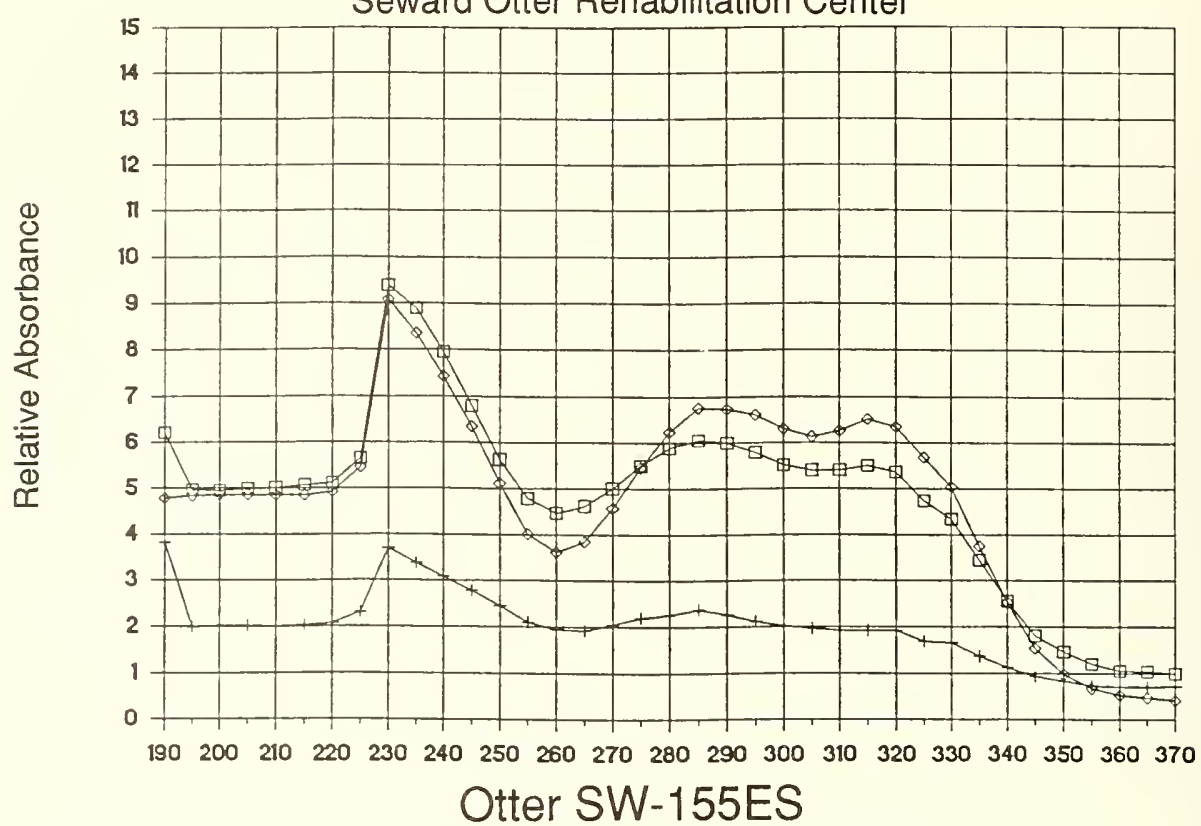
Seward Otter Rehabilitation Center

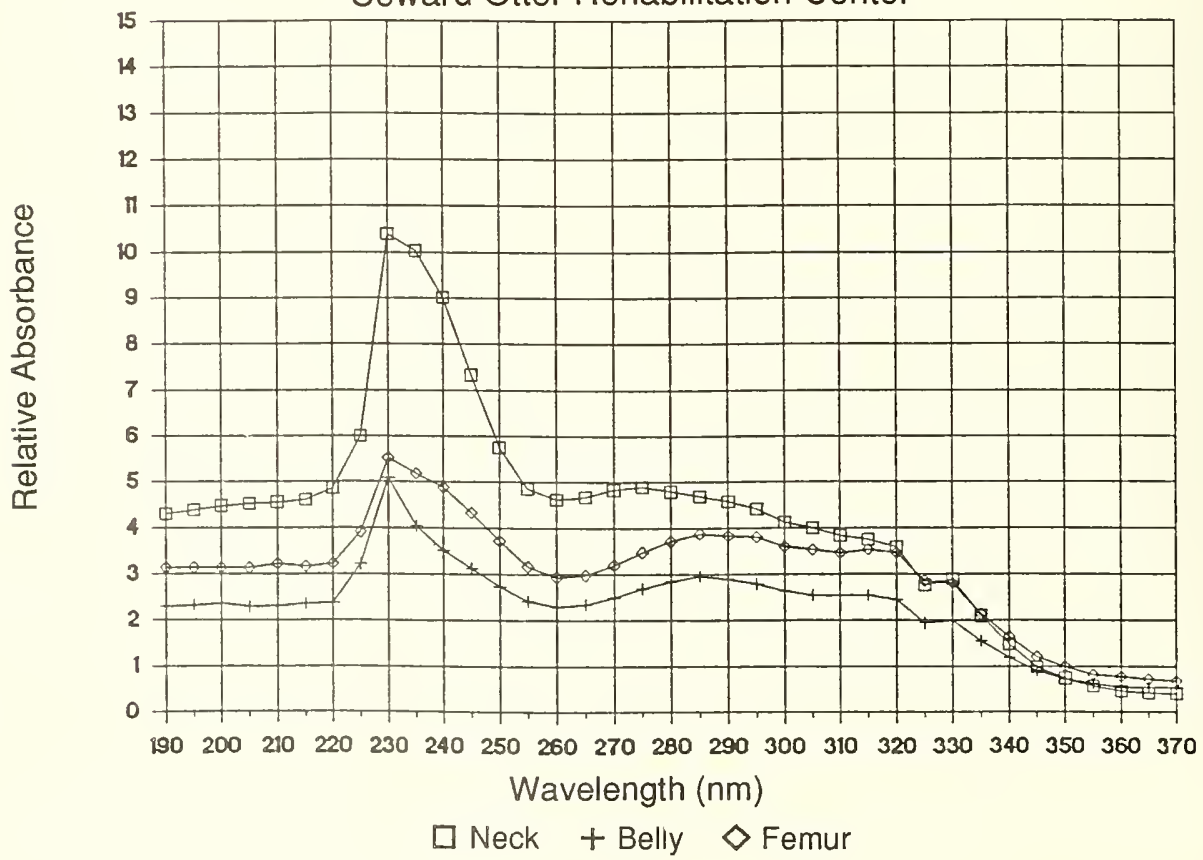


Otter SW-156 (not washed) Seward Otter Rehabilitation Center

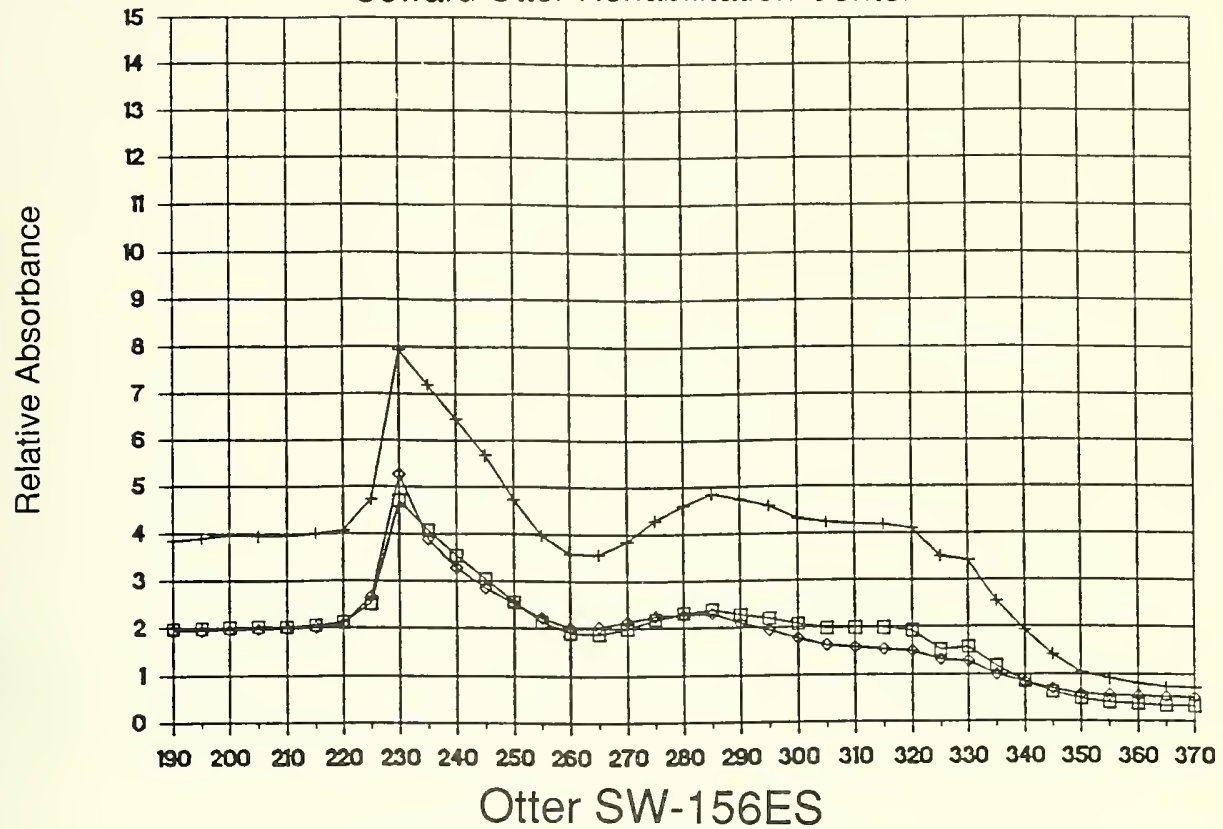

Seward Otter Rehabilitation Center

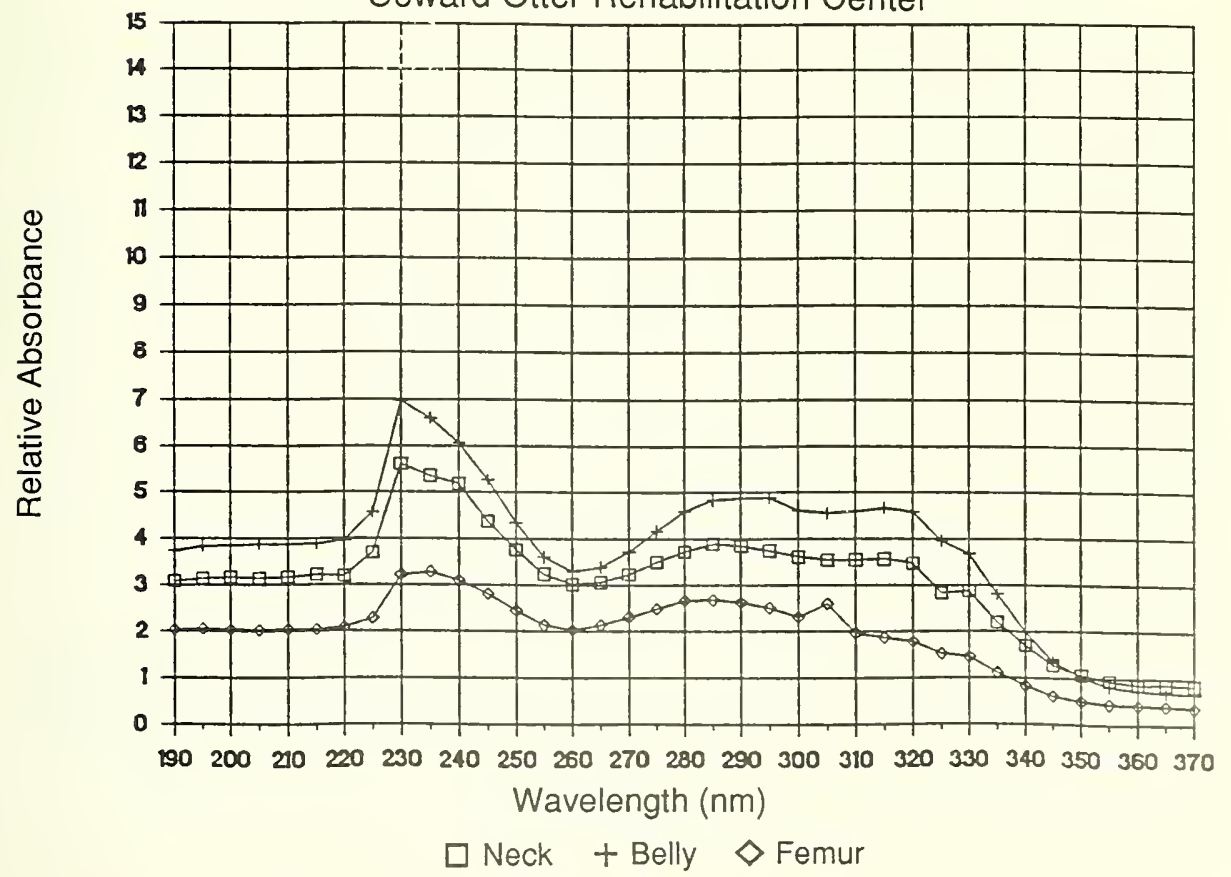


Otter SW-157 (washed) Seward Otter Rehabilitation Center

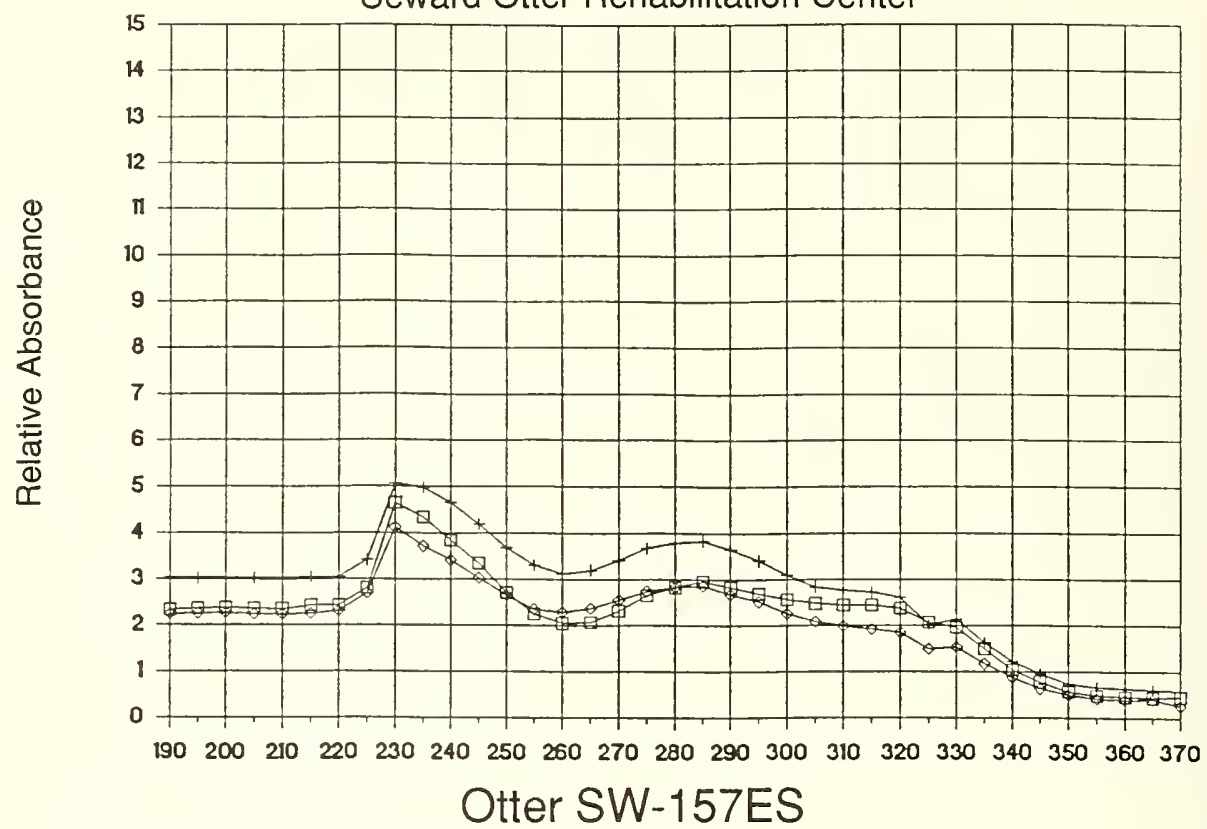

Seward Otter Rehabilitation Center

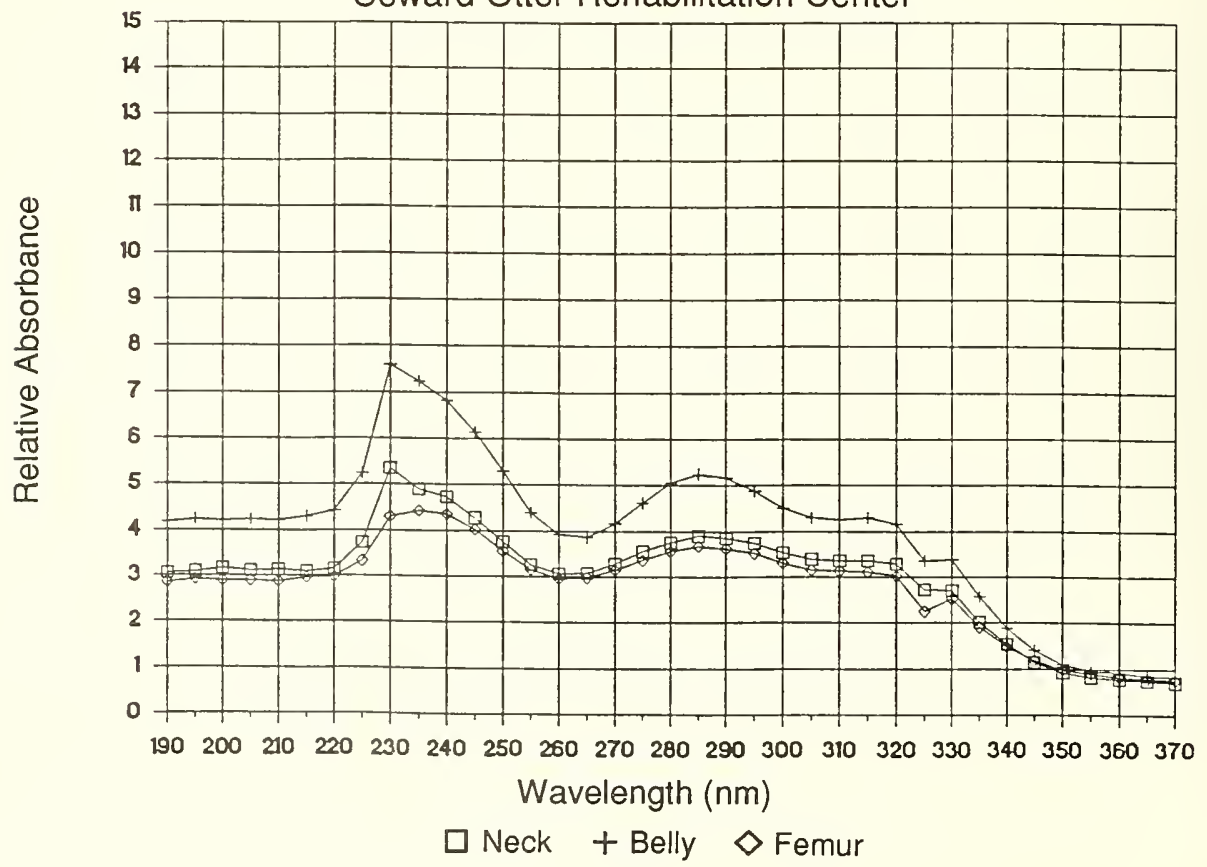




\section{Otter SW-158 (washed)}

Seward Otter Rehabilitation Center

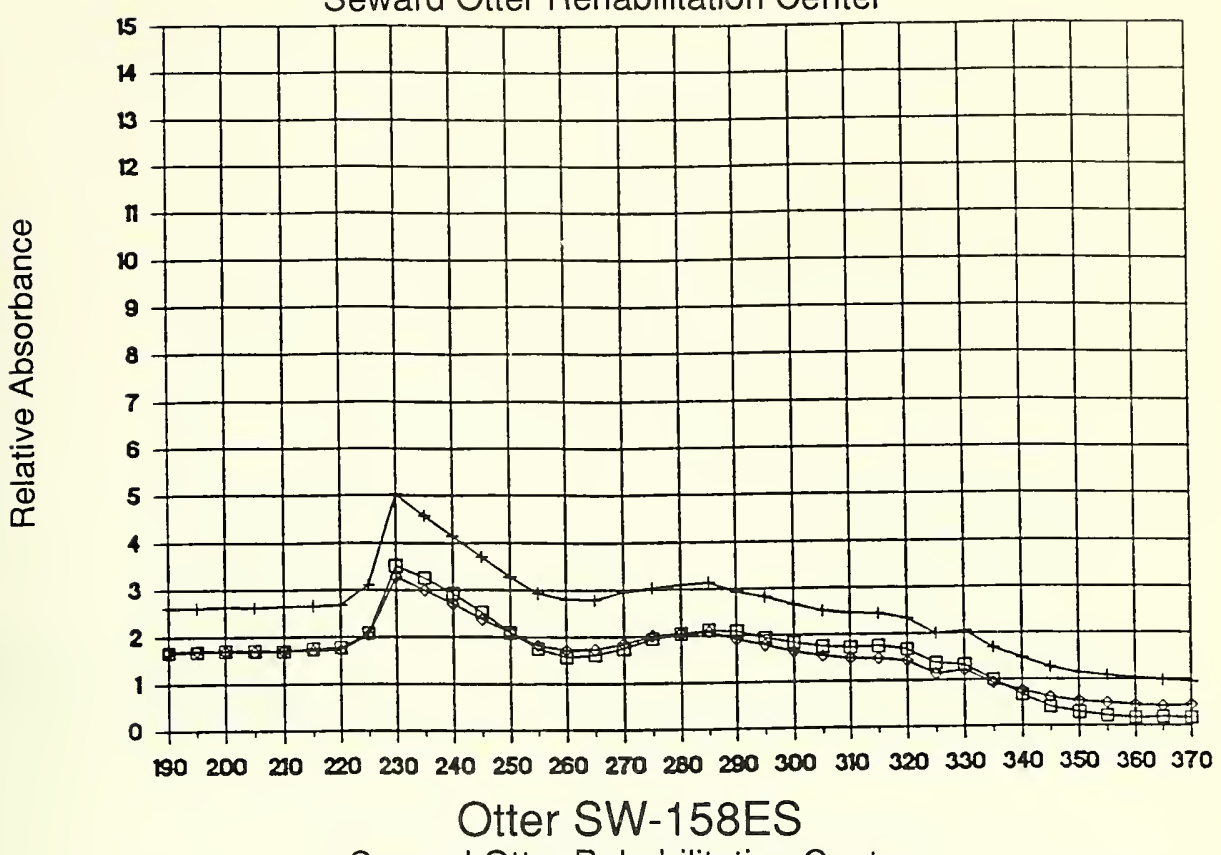

Seward Otter Rehabilitation Center

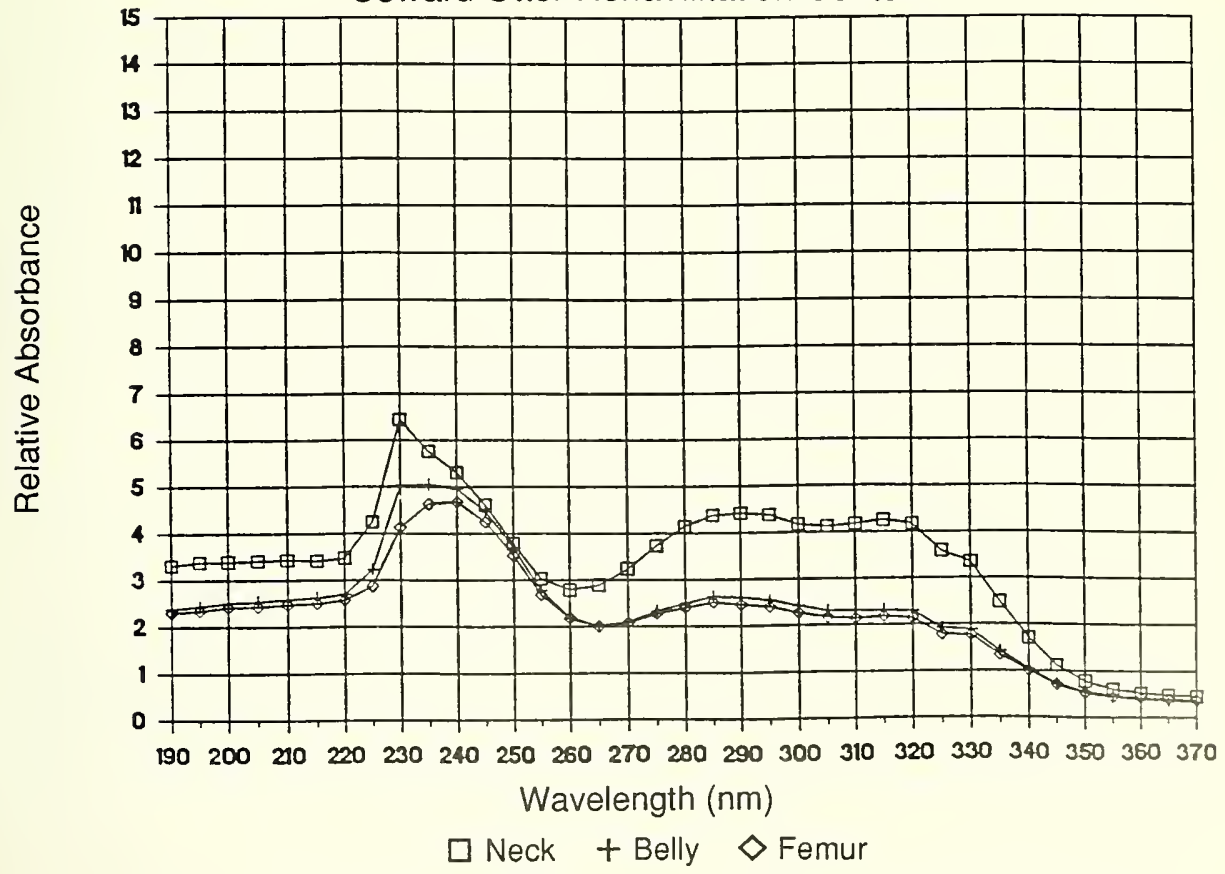




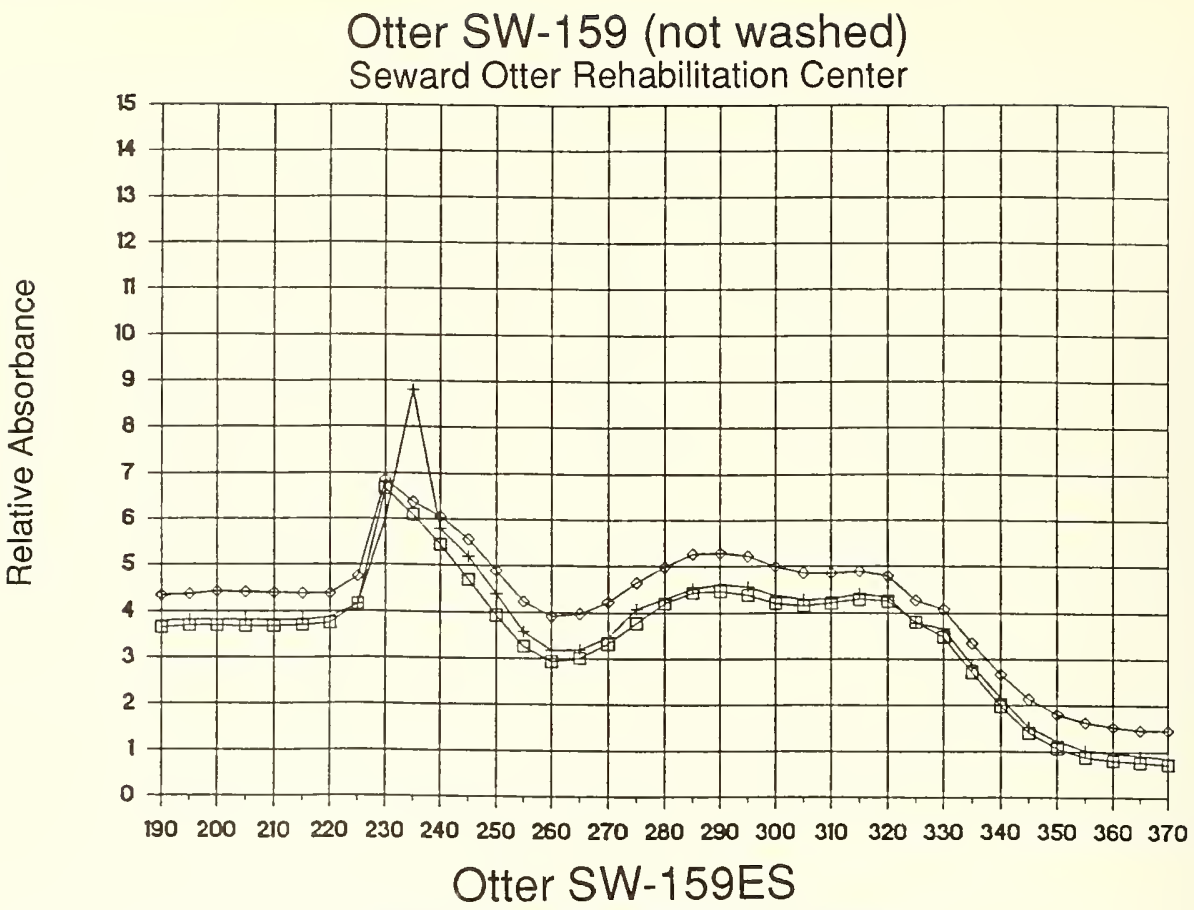
Seward Otter Rehabilitation Center

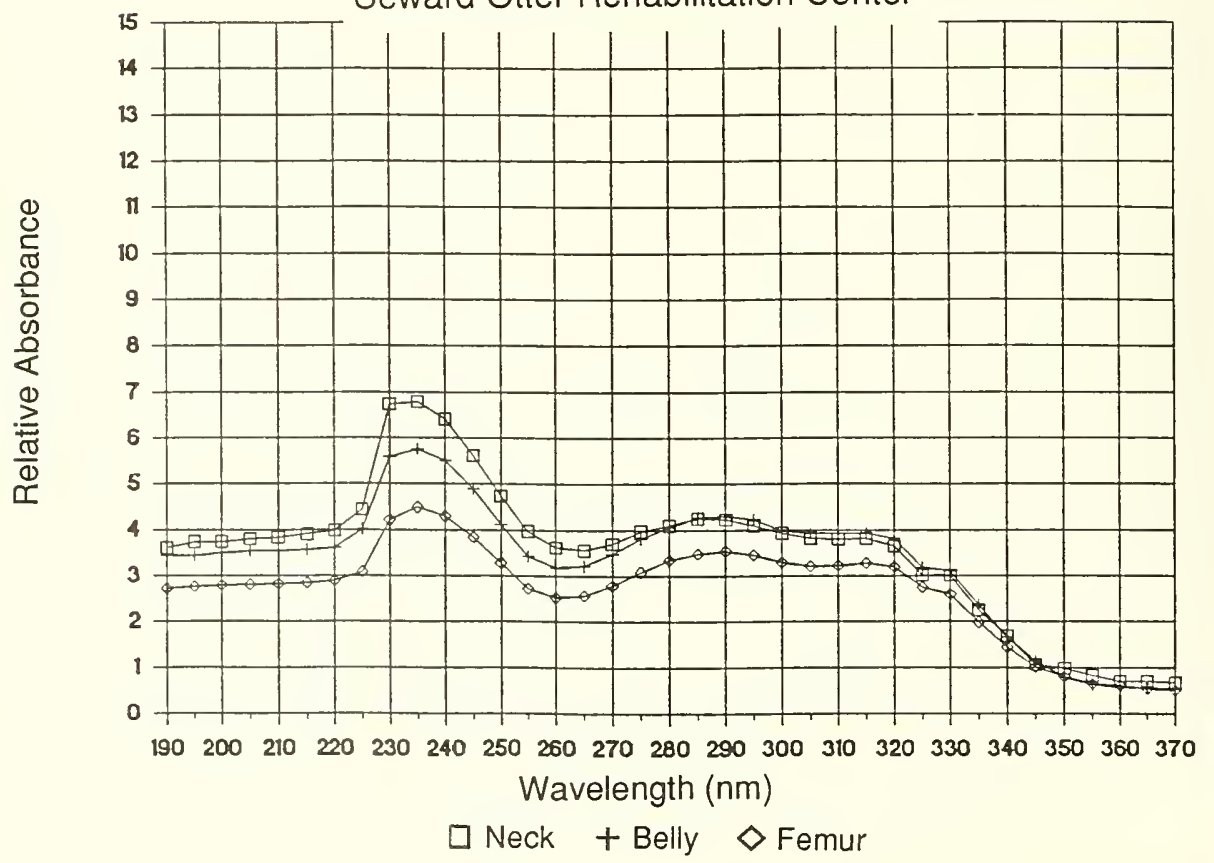




\title{
Analysis of Sea Otter Fur for Crude Oil Contamination
}

\author{
by
}

\author{
D. C. Perrollaz and J. A. Rash \\ Marine Animal Resource Center \\ 220134 th West \\ Seattle, Washington 98199
}

\begin{abstract}
After the release of oil into the surrounding ecosystem, a major effort was launched to capture the contaminated sea otter (Enhydra lutris) population of Prince William Sound. Techniques were then sought as a method for oil detection in sea otter fur. Thin layer chromatography (TLC) is a relatively simple and inexpensive analytical technique that is useful in the laboratory and in the field. The greatest asset of TLC in the field is its accuracy and quick turnaround time. With control animals as a comparison, differences were determined between squalene (natural polar oils) and the less polar Prudhoe Bay crude petroleum products. Crude oil exhibits very characteristic bands and can be easily standardized to determine oil concentrations in an otter's coat. TLC can be used to determine the more toxic biodegradation products that can affect the sea otter coat from contamination of Prudhoe Bay crude oil.
\end{abstract}

[Editors' note: This paper was presented at the symposium but the authors did not provide a manuscript for publication in these proceedings. The technique described was not used in the T/V Exxon Valdez oil spill response.] 


\title{
Distribution, Age, and Sex Composition of Sea Otter Carcasses Recovered During the Response to the T/V Exxon Valdez Oil Spill
}

\author{
by \\ A. R. DeGange \\ U.S. Fish and Wildlife Service \\ 1011 E. Tudor Road \\ Anchorage, Alaska 99503 \\ and \\ C. J. Lensink \\ National Wildlife Refuge Association \\ 13641 Jarvi Drive \\ Anchorage, Alaska 99515
}

\begin{abstract}
Nearly 900 sea otter (Enhydra lutris) carcasses were recovered in or adjacent to coastal areas affected by the T/ Exxon Valdez oil spill. The time of carcass recovery and the condition of carcasses indicate that most oil spill-induced mortality occurred early in the response period. In fact, by 19 May about $70 \%$ of the carcasses had been found. The majority of the carcasses (56\%) were from Prince William Sound, suggesting that mortality was more acute there than in other geographic areas. Examination of the recovered carcasses indicated that more adult female sea otters were killed by the oil in Prince William Sound and along the Kenai Peninsula than other sex and age cohorts, reflecting greater abundance of adult females in those regions. Many of the adult females in those areas were pregnant or lactating. Pups made up a higher proportion of the carcasses collected in the western portion of the spill zone, reflecting the advanced pupping chronology at the time the search effort reached the Alaska Peninsula and the Kodiak Archipelago.
\end{abstract}

Sea otters (Enhydra lutris) are considered one of the most highly sensitive of marine mammals to oil pollution (Kenyon 1969; Kooyman et al. 1977; Costa and Kooyman 1982; VanBlaricom and Jameson 1982; Hansen 1985; Davis et al. 1986; Geraci 1988; Ralls and Siniff 1988). When oiled, the insulative quality of the pelage of sea otters is lost (Kooymen et al. 1977), resulting in hypothermia and eventually death (Costa and Kooyman 1982; Siniff et al. 1982). Toxic effects of exposure to crude oil through inhalation of vapors or ingestion are also likely, although they were undocumented for sea otters before the T/V Exxon Valdez oil spill (Geraci 1988). Oil spilled from the T/N Exxon Valdez traveled more than $700 \mathrm{~km}$ from its point of origin and affected hundreds of kilometers of coastal sea otter habitat (Galt and Payton 1990). The sea otter population at risk from the oil residing in coastal areas affected by the spill exceeded 15,800 animals (DeGange et al. 1990). We provide 
a preliminary analysis of the sea otter carcasses that were found in or adjacent to the oil spill zone during the response to the oil spill, which occurred in spring, summer, and early fall 1989.

\section{Methods}

Collection of sea otter carcasses in Prince William Sound began within a few days of the oil spill. As oil exited Prince William Sound and spread westward along the Kenai Peninsula, Kodiak Archipelago, and Alaska Peninsula, collection efforts were initiated in those areas as well. Carcasses were collected by a variety of private persons and persons from State and Federal agencies and private industry. At the peak of the collection effort, more than 100 vessels contracted by Exxon Company, U.S.A., were engaged in capture or collection of marine birds and mammals. Facilities to store dead animals recovered in the oil spill zone were established at Valdez, Seward, Homer, and Kodiak. Sea otter carcasses were usually transported by boat or aircraft to the collection facilities within a few days of recovery.

Collection facilities were staffed with biologists from the U.S. Fish and Wildlife Service and the U.S. Minerals Management Service. Turnover of staff at the facilities undoubtedly compromised the data set to some degree, especially at Seward and Kodiak, and to a lesser extent at Valdez later in the response period. Most of the carcasses were examined for date of recovery, location of recovery, degree of decomposition, degree of oiling, sex, and reproductive status (pregnant or lactating). Age of each carcass was qualitatively assessed by a combination of physical characteristics. Each carcass was measured for length and weight. A premolar was taken from most carcasses for precise aging (Schneider 1973; Garshelis 1984). Fetuses were removed from pregnant females and frozen. Female reproductive tracts were removed and preserved in $10 \%$ buffered formalin. Because dates on which the animals were found were rarely the time of death, each carcass was examined to determine if death occurred before or after the spill. At least for Prince William Sound, the degree to which skin and skeletal remains were dried or bleached and the extent to which carcasses had decomposed provided a means for crudely estimating time of death. However, with increasing time after the spill, time of death became increasingly difficult to estimate, especially for those carcasses that had been scavenged. Unless there was evidence to the contrary, all intact carcasses were considered to be from animals that died after the spill. Because the acute period of sea otter mortality in Prince William Sound seemed to be short and the collection effort intense, the bias in estimates of time of death are relatively small for the sound, but the bias may be large for carcasses from the Kodiak Archipelago and the Alaska Peninsula.

\section{Results}

Few or no sea otters died in Prince William Sound while the oil stayed near the spill site at Bligh Reef or spread offshore. However, on 27 March, strong northeasterly winds pushed the oil into important sea otter habitat in the central and western portions of the sound. The first otter carcass was brought to Valdez on 30 March, 6 days after the spill. Otter carcasses continued to be recovered in the spill zone until the oil spill response was halted on 15 September.

Most of the spill-induced mortality of sea otters occurred early in the spill period (Fig. 1). By 21 April, 44\% (382) of the sea otter carcasses had been found. By 20 May, more than $70 \%$ of the carcasses were recovered. Based on conservative adjustments of the amount of time carcasses remained "at large" after death, an even higher percentage of sea otters had died by 20 May. Mortality of sea otters was clearly most acute in Prince William Sound, where about $56 \%$ of the carcasses were recovered (Fig. 2). Nearly all of the carcasses in Prince William Sound that were recovered during the response were found within 7 weeks after the spill. Most of those were found within the first 4 weeks after the spill. Similar proportions of sea otters were found along the Kenai Peninsula (21.6\%) and in the Kodiak Archipelago (18.0\%; Fig. 2). Only $4.6 \%$ of the carcasses were found on the Alaska Peninsula. Some of the most badly decomposed carcasses found on the Kenai Peninsula may have originated in Prince William Sound, while some of those found on Kodiak Island may have died on the Kenai Peninsula or in the Barren Islands. The geographic pattern of recovery of sea otter carcasses (Fig. 2) is in strong contrast to the pattern of recovery of bird carcasses, where most of the mortality and recovery occurred outside of Prince William Sound (Piatt et al. 1990).

Sex was recorded for most of the carcasses. Contrasting patterns in the proportions of males and females were evident among areas. At both Kodiak Island and on the Alaska Peninsula, males and females were about equally represented in the 


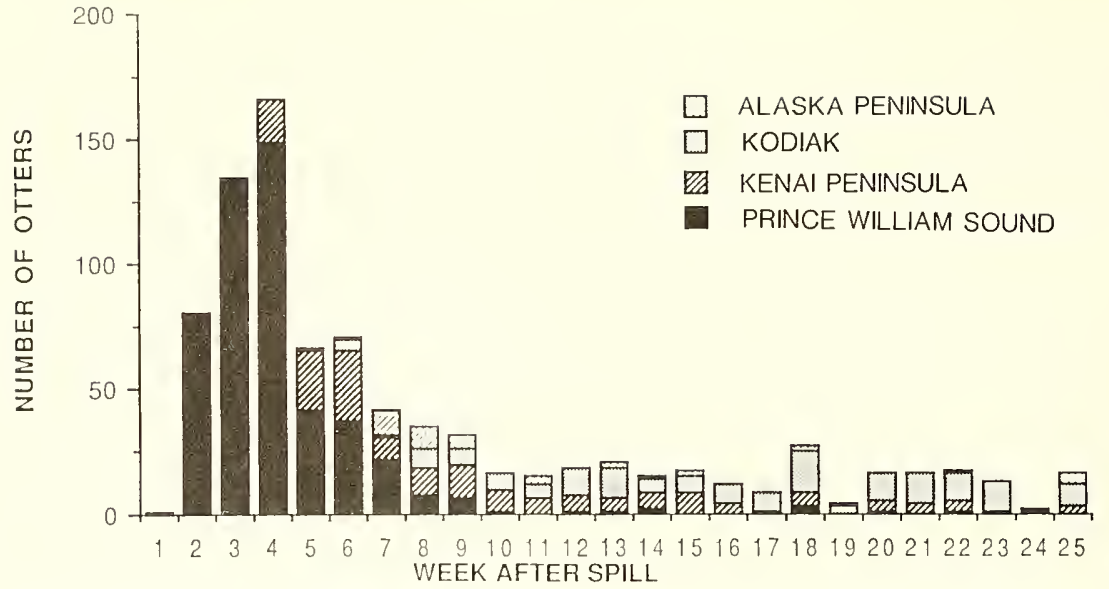

Fig. 1. Number of dead sea otters (Enhydra lutris) collected by weekly period after the oil spill.

sample (Fig. 3). The proportion of males and females in the samples from the Kenai Peninsula and Prince William Sound was skewed toward females (Fig. 3). In fact, more than $60 \%$ of the sea otters identified by sex from both areas were females. Analysis of the age composition of the carcasses will be completed after analysis of the premolars removed for sectioning is finished. It seems that age composition varied by geographic area. In both Prince William Sound and on the Kenai Peninsula, adults made up a large proportion of the carcasses. Pups were the dominant age class col- lected at Kodiak and on the Alaska Peninsula. Sex composition also seemed to vary by age. In Prince William Sound and on the Kenai Peninsula, females predominated in the sample of large otters that presumably were adults.

The T/V Exxon Valdez oil spill occurred at a time when many adult females were pupping or were in the latter stages of pregnancy. Many of the carcasses of adult female sea otters from Prince William Sound and the Kenai Peninsula that were examined for reproductive status were from animals that were pregnant or lactating.
SEA OTTEAS FOUND DEAD

$(N=878)$

Fig. 2. Proportion of dead sea otters (Enhydra lutris) found during the spill response by geographic area.

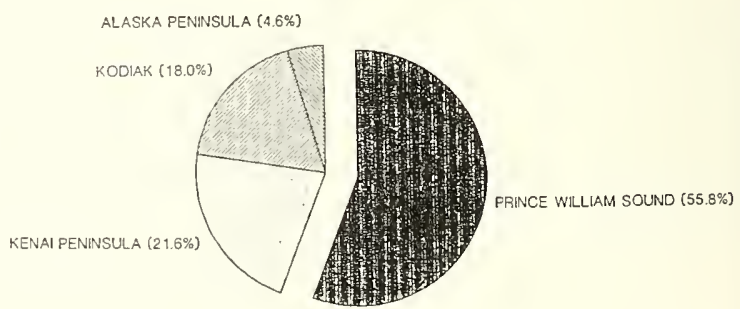




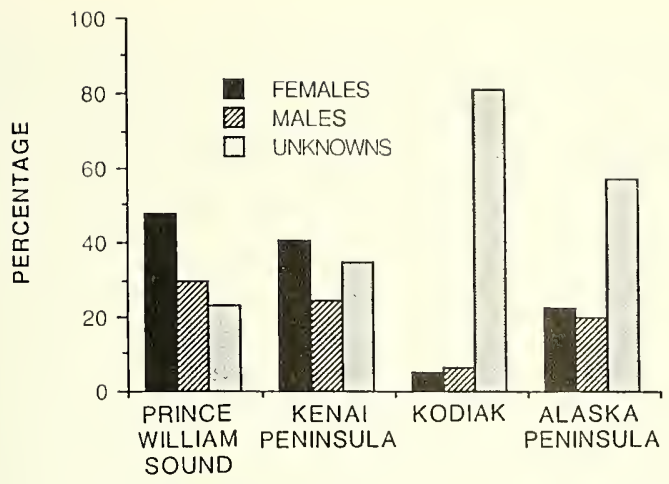

Fig. 3. Sex of sea otters (Enhydra lutris) found dead during the oil spill response by geographic area.

\section{Discussion}

Two problems confound our ability to estimate the number of sea otters that died as a result of the T/N Exxon Valdez oil spill: incomplete information on the proportion of carcasses that represent spillrelated mortalities and lack of data on the recovery rates of carcasses. We have assumed that the presence of oil on carcasses is indicative of oil-induced mortality; however, for some otters that died from other causes and later drifted into patches of oil or onto oiled beaches, this assumption is false. For example, many oiled pup carcasses found on the Alaska Peninsula could have been from pups that died from natural causes, and later the carcasses became oiled. As previously mentioned, only 379 carcasses were scored for degree of oiling. Oiling data suggest that a high proportion of animals in the sound were oiled, but outside the sound the proportion of oiled carcasses dropped sharply. More than likely, a large proportion of carcasses in the sound were spill-related deaths, but the proportion of spill-related deaths decreased as the oil spread westward. Data on recovery rates of carcasses are unavailable; however, we can state with certainty that the carcass count, together with the sea otters that died in the otter treatment centers, is an underestimate of the total spill-related mortality.

Data on the timing of recovery of carcasses and the location of recovery suggest that mortality of sea otters was most severe in Prince William Sound. This pattern relates to the extent that sea otter habitat in western Prince William Sound was covered with oil, and the changing characteristics of oil over time (Craddock 1977; Malins 1977). Because of the broad coverage of oil in western Prince William Sound, and the rapidity with which it spread, many sea otters were unable to avoid the oil, even if they tried (Siniff et al. 1982). This is especially true of sea otters in offshore habitats lacking oil-free refugia, such as near Smith and Seal islands, and Applegate Rocks north of Green Island. As oil was carried outside the sound, much of the toxic volatile fractions had evaporated (Galt and Payton 1990), and the oil and seawater formed an emulsion (mousse) that occurred in patches that may have been easier for the otters to avoid. All available data from the carcass collections, capture effort, and condition of live sea otters as they were admitted to the otter treatment centers suggest that fewer sea otters were killed or injured outside of Prince William Sound than inside, and that overall mortality probably decreased with the westward spread of the oil.

What we knew about the age and sex composition of sea otters in Prince William Sound and along the Kenai Peninsula before the oil spill correlated with what we observed after the oil spill. With the exception of pups on the Alaska Peninsula, it seems that sea otters of various sex and age classes were killed in relative proportion to their abundance in each geographic area.

Sea otters were nearly extirpated from their range in Alaska as a result of uncontrolled hunting before 1911, when they received Federal protection (Kenyon 1969; Rotterman and Simon-Jackson 1988). Existing sea otter populations grew out of small remnant populations that persisted in isolated areas (Kenyon 1969). The populations of sea otters that now occupy Prince William Sound and the Kenai Peninsula presumably had as their origin a small remnant population that existed in the southwest corner of Prince William Sound (Lensink 1962; Kenyon 1969).

The pattern of reoccupation of vacant habitat by sea otters in Prince William Sound has been described by numerous authors (Lensink 1962; Pitcher 1975; Garshelis et al. 1984; Garshelis et al. 
1986; Johnson 1987; Irons et al. 1988). Typically, male sea otters are the first to invade vacant habitat that may be rich in food resources. At least in some habitats, densities of sea otters are highest during the period of occupation by males (Johnson 1987). As food resources diminish through exploitation by sea otters, the male groups move on to new habitat and the vacated areas are backfilled by breeding females, immature sea otters, and breeding males. The breeding males may move seasonally to male areas on the front of the expanding population (Garshelis et al. 1984). Densities of sea otters and biomass of their prey tend to be lower in female areas than when the same areas are occupied by males. Extensive surveys of the entire sound in 1984-1985 failed to find any distinct male areas (Irons et al. 1988) although portions of Nelson Bay, Orca Inlet, and Hawkins Cutoff are still predominantly male (Monnett and Rotterman 1989). Large segments of the male population, therefore, were safe from the spilled oil.

The portions of Prince William Sound and the Kenai Peninsula that were affected by oil spilled from the T/N Exxon Valdez have been occupied by sea otters for many years (Lensink 1962; Pitcher 1975; Schneider 1976; Johnson 1987; Irons et al. 1988). Based on the length of time of occupation, we would predict that females would numerically dominate males in those long-occupied areas. Indeed, the proportion of females in samples of sea otters captured at Green Island in the southwestern part of Prince William Sound during the 1970's and early 1980's ranged from 62-87\% (Schneider 1978; Garshel is et al. 1984; Johnson 1987). The sex ratios of sea otter carcasses recovered in Prince William Sound and on the Kenai Peninsula are consistent with the notion that females predominated in those populations.

Not only were many female sea otters killed as a result of the oil spill, but also the spill occurred at a time of intense reproductive activity (Garshelis and Garshelis 1984). Although pups may be present in the population throughout the year (Kenyon 1969; Johnson 1987), a peak in pupping occurs in spring through early summer in Prince William Sound (Johnson 1987; Monnett 1988). The oil spill occurred at a time when many adult females were pupping or near term in their pregnancies. As described above, many of the female carcasses recovered from the Kenai Peninsula and Prince William Sound were from animals that were pregnant or lactating. In addition, portions of western Prince William Sound, particularly the shallow waters near Green Island, are recognized as important pup-rearing habitat (C. W. Monnett, Prince William Sound Science Center, Cordova, Alaska, personal communication). Therefore, not only were many sea otters killed in those areas, but also the most important reproductive component of the population was removed.

The implications for the recovery of the sea otter population residing within the oil spill zone in Prince William Sound and the Kenai Peninsula to prespill levels are uncertain. We cannot predict the extent that repopulation will be limited to growth of the surviving population or result from immigration of sea otters from adjacent oil-free habitats. The long-term effects of the oil spill, resulting from acute or chronic exposure of sea otters to hydrocarbons and other toxic compounds, may affect repopulation through reduced survival, birth rates, or recruitment, thus delaying the recovery of the population. These long-term effects of the spill are under investigation.

\section{Acknowledgments}

We thank all of those persons who assisted with the often unpleasant and depressing job of examining dead sea otters at the collection centers in Homer, Kodiak, Seward, and Valdez. B. Ballachey assisted with data analysis.

\section{References}

Costa, D. P., and G. L. Kooyman. 1982. Oxygen consumption, thermoregulation, and the effect of fur oiling and washing on the sea otter, Enhydra lutris. Can. J. Zool. 60: 2761-2767.

Craddock, D. R. 1977. Acute toxic effects of petroleum on arctic and subarctic marine organisms. Pages 1-93 in D. C. Malins, ed. Effects of petroleum on arctic and subarctic marine environments and organisms. Vol. II. Biological effects. Academic Press, New York. 9.

Davis, R. W., T. M. Williams, R. Kastelein, J. A. Thomas, L. H. Cornell, T. D. Williams, and E. R. Yohe. 1986. Sea otter oil spill mitigation study. Outer Continental Shelf Study, Minerals Management Service 86-0009. $219 \mathrm{pp}$.

DeGange, A. R., D. H. Monson, D. B. Irons, C. M. Robbins, and D. C. Douglas. 1990. Distribution and relative abundance of sea otters in south-central and southwestern Alaska before or at the time of the T/ Exxon Valdez oil spill. Pages 18-25 in K. Bayha and J. Kormendy, tech. coords. Sea Otter Symposium: Proceedings of a symposium to evaluate the response effort on behalf of sea otters after the T/V Exxon Valdez oil spill into Prince William Sound, Anchor- 
age, Alaska, 17-19 April 1990. U.S. Fish Wildl. Serv., Biol. Rep. 90(12).

Galt, J. A., and D. L. Payton, 1990. Movement of spilled oil from the T/V Exxon Valdez. Pages 4-17 in K. Bayha and J. Kormendy, tech. coords. Sea Otter Symposium: Proceedings of a symposium to evaluate the response effort on behalf of sea otters after the T/N Exxon Valdez oil spill into Prince William Sound, Anchorage, Alaska, 17-19 April 1990. U.S. Fish Wildl. Serv., Biol. Rep. 90(12).

Garshelis, D. L. 1984. Age estimation of living sea otters. J. Wildl. Manage. 48:456-463.

Garshelis, D. L., and J. A. Garshelis. 1984. Movements and management of sea otters in Alaska. J. Wildl. Manage. 48:665-678.

Garshelis, D. L., J. A. Garshelis, and A. T. Kimker. 1986. Sea otter time budgets and prey relationships in Alaska. J. Wildl. Manage. 50:637-647.

Garshelis, D. L., A. M. Johnson, and J. A. Garshelis. 1984. Social organization of sea otters in Prince William Sound, Alaska. Can. J. Zool. 62:2648-2658.

Geraci, J. R. 1988. Physiologic and toxicologic effects on sea otters. Pages 217-224 in J. R. Geraci and D. J. St. Aubin, eds. Synthesis of effects of oil on marine mammals. Chapter 7. Outer Continental Shelf Study, Minerals Management Service 88-0049.

Hansen, D. J. 1985. The potential effects of oil spills and other chemical pollutants on marine mammals occurring in Alaskan waters. Outer Continental Shelf Report, Minerals Management Service 85-0031. 2 pp.

Irons, D. B., D. R. Nysewander, and J. L. Trapp. 1988. Prince William Sound sea otter distribution in relation to population growth and habitat type. U.S. Fish and Wildlife Service, Alaska Investigations, Anchorage. 31 pp. [unpublished report]

Johnson, A. M. 1987. Sea otters of Prince William Sound, Alaska. U.S. Fish and Wildlife Service, Alaska Fish and Wildlife Research Center, Anchorage. 87 pp.

Kenyon, K. W. 1969. The sea otter in the eastern Pacific Ocean. U.S. Fish Wildl. Serv., N. Am. Fauna 68. $352 \mathrm{pp}$.

Kooyman, G. L., R. W. Davis, and M. A. Castellini. 1977. Thermal conductance of immersed pinniped and sea otter pelts before and after oiling with Prudhoe Bay crude. Pages 151-157 in D. A. Wolfe, ed. Fate and effects of petroleum hydrocarbons in marine ecosystems and organisms. Proceedings of a symposium, 10-12 November 1976, Seattle, Washington. Pergamon Press, New York.

Lensink, C. J. 1962. The history and status of sea otters in Alaska. Ph.D. thesis. Purdue University, Lafayette, Ind. $188 \mathrm{pp}$.
Malins, D. C., editor. 1977. Effects of petroleum on Arctic and subarctic marine environments and organisms. Vol. I. Nature and fate of petroleums. Academic Press, New York. 321 pp.

Monnett, C. W. 1988. Patterns of movement, postnatal development and mortality of sea otters in Alaska. $\mathrm{Ph} . \mathrm{D}$. dissertation, University of Minnesota, Minneapolis. 134 pp.

Monnett, C. W., and L. M. Rotterman. 1989. Distribution and abundance of sea otters in southwestern Prince William Sound. U.S. Fish and Wildlife Service, Anchorage, Alaska. 20 pp. [unpublished report]

Piatt, J. F., C. J. Lensink, W. Butler, M. Kendziorek, and D. R. Nysewander. 1990. Immediate impact of the Exxon Valdez oil spill on marine birds. Auk 107:387-397.

Pitcher, K. W. 1975. Distribution and abundance of sea otters, Steller sea lions, and harbor seals in Prince William Sound, Alaska. Alaska Department of Fish and Game, Anchorage. 76 pp. [unpublished report]

Ralls, K., and D. B. Siniff. 1988. Sea otters and oil: ecological perspectives. Pages 204-215 in J. R. Geraci and D. J. St. Aubin, eds. Synthesis of effects of oil on marine mammals. Chapter 6. Outer Continental Shelf Study, Minerals Management Service 88.0049.

Rotterman, L. M., and T. Simon-Jackson. 1988. Sea otter, Enhydra lutris. Pages 237-271 in J. W. Lentfer, ed. Selected marine mammals of Alaska: species accounts with research and management recommendations. Marine Mammal Commission, Washington, D.C.

Schneider, K. B. 1973. Age determination of sea otter. Alaska Department of Fish and Game. Final report, Federal Aid in Wildlife Restoration Project W-17-4 to W-17-8. 23 pp.

Schneider, K. B. 1976. Assessment of the distribution and abundance of sea otters along the Kenai Peninsula, Kamishak Bay, and the Kodiak Archipelago. Final report. Outer Continental Shelf Environmental Study Program. Nat. Oceanic Atmos. Adm. Res. Unit 240. $72 \mathrm{pp}$.

Schneider, K. B. 1978. Sex and age segregation of sea otters. Alaska Department of Fish and Game. Final report, Federal Aid in Wildlife Restoration Project W-17-4 to W-17-8. 45 pp.

Siniff, D. B., T. D. Williams, A. M. Johnson, and D. L. Garshelis. 1982. Experiments on the response of sea otters, Enhydra lutris, to oil contamination. Biol. Conserv. 23:261-272.

VanBlaricom, G. R., and R. J. Jameson. 1982. Lumber spill in central California waters: implications for oil spills and sea otters. Science 215:1503-1505. 


\title{
Capture of Lightly Oiled Sea Otters for Rehabilitation: A Review of Decisions and Issues
}

by

\author{
G. R. VanBlaricom \\ U.S. Fish and Wildlife Service \\ 272 Applied Sciences Building \\ University of California \\ Santa Cruz, California 95064
}

\begin{abstract}
Oil spilled from the T/V Exxon Valdez spread along the coast of the Kenai Peninsula during April and May 1989. Sea otter (Enhydra lutris) capture teams concentrated their efforts in Tonsina Bay, Rocky Bay, and Windy Bay because of high densities of sea otters and heavy oil accumulation in these areas. Many of the sea otters encountered by capture teams were lightly oiled, relatively active, and difficult to capture with dip nets. As a consequence, tangle nets were used to capture lightly oiled animals. Use of tangle nets resulted in capture of some unoiled animals and may have forced some previously unoiled animals into contact with floating oil. The effect of light oiling on sea otters is an important, contentious issue. One view is that lightly oiled otters should not have been captured. This view is based on the premise that risks to sea otters associated with light oiling are less than risks associated with capture, transport, treatment, and holding. The alternative view is that the decision to capture lightly oiled animals was correct, and that risks associated with capture and rehabilitation are less than risks of reduced survival and various sublethal consequences of light oiling. No existing data are sufficient to understand the effects of light oiling on sea otters. In the absence of such data, I argue that the decision to capture lightly oiled sea otters was proper, conservative, humane, and of value with regard to management of future oil spills; and that there is a compelling need for definitive research on the effects of light oiling on sea otters to improve management of future rehabilitation programs after oil spills.
\end{abstract}

Oil spilled from the T/V Exxon Valdez was first seen outside of Prince William Sound (PWS) on 30 March 1989. By mid-April, spilled oil was present along the southern coast of the Kenai Peninsula (KP) from PWS to Chugach Island (Skinner and Reilly 1989; Galt and Payton 1990). Many coves, bays, fjords, and passages with openings to the east, southeast, or south received heavy oil contamination because of frequent easterly or southeasterly winds and the consequent downwind movement of floating oil (Galt and Payton 1990).

Efforts to capture oiled sea otters (Enhydra lutris) off $\mathrm{KP}$ began on 15 April 1989 near the Chiswell Islands. Subsequent efforts focused primarily at three sites farther to the west (Tonsina, Rocky, and Windy bays) because of heavy oil inun- dation (Galt and Payton 1990), large numbers of sea otters, and the proximity of safe anchorages for capture vessels.

Initially, otters were captured with dip nets along KP. Sea otters still in the water were pursued from small skiffs. Sea otters hauled out on beaches or rocks were pursued on foot (Britton et al. 1990). Many oiled sea otters had been captured with dip nets in PWS (Bodkin and Weltz 1990). However, dip nets were relatively ineffective along KP. In contrast to the situation in PWS, most sea otters encountered along $\mathrm{KP}$ seemed to be contaminated with less oil and were more elusive (Britton et al. 1990). In addition, most sea otter habitat along KP had greater wave action 
and more extensive surface kelp canopies than in PWS, making dipnetting more difficult along KP.

As a result of the heavy oiling of some locations along KP and frequent reports from fishing crews and bird rescue staff of sea otters in oil, the U.S. Fish and Wildlife Service determined that efforts to capture oiled otters along KP should be expanded, despite the seemingly greater vigor of oiled otters off KP compared with oiled otters in PWS. Thus, capture teams began using modified entangling gill nets, hereinafter termed "tangle nets" (gill nets in which the negatively buoyant lead line is replaced with unweighted line that is slightly negatively buoyant when wet). Deployment of tangle nets markedly increased the rate of capture of sea otters in heavily oiled areas along KP (Davis and Styers 1990; Williams et al. 1990). Once tangle nets had been distributed to all capture teams working along $\mathrm{KP}$, the limiting factor in the sea otter rescue effort shifted from capture rate to rate of processing and rehabilitation of sea otters at the otter rehabilitation centers in Valdez and Seward. Tangle nets also were used in PWS, but only on a limited scale (Bodkin and Weltz 1990).

The decisions to expand capture efforts off KP and to use tangle nets as the primary technique have been questioned and criticized (e.g., Townsend and Heneman 1989; Ames 1990). Criticisms are based on two primary points. First, sea otters are known to be susceptible to a stereotyped stress syndrome when in captivity (Williams and VanBlaricom 1989). On occasion the syndrome is fatal, even when conditions of handling and veterinary care are good. Second, most sea otters captured off KP were judged to be lightly oiled on arrival at otter rehabilitation centers in Valdez and Seward. Some of the otters from KP seemingly were entirely free of contaminating crude oil (Williams et al. 1990). There is some evidence (Siniff et al. 1982; Ames 1990) suggesting that lightly oiled otters are capable of surviving without treatment. Thus, the capture effort off KP was viewed by the critics as unacceptably nonselective, bringing into captivity animals that needed no treatment for oil contamination, and further subjecting the animals to the life-threatening stresses of captivity. The critics argue that the capture effort off $\mathrm{KP}$ was more lengthy, spatially far-flung, and costly than was necessary for a prudent response to the oil spill. Implicit in the criticisms is the notion that spilled oil along KP was sufficiently fragmented and weathered that the large-scale rescue effort for sea otters was not justified.
I explore the following question: Would lightly oiled sea otters captured along KP have fared better had they not been captured, or were risks of stress in captivity balanced by the benefits of treatment and rehabilitation? I review available information on captivity stress and the effects of light oiling on sea otters, discuss problems in accurately assessing the degree of oiling of sea otters, offer a commentary on the proper course of action for lightly oiled sea otters, and conclude with an appeal for new research on the consequences of different levels of oil contamination for sea otters.

\section{Effects of Captivity on the Health of Sea Otters}

Early studies of captive sea otters indicated susceptibility to stress as a consequence of capture, handling, transport, and long-term holding (Kenyon 1969). Recent studies associated with the sea otter translocation project in California provide the most complete quantitative record of patterns of stress in captive animals that were healthy at the time of capture (VanBlaricom 1989; Williams and VanBlaricom 1989; Rathbun et al. 1990). In the translocation project (in progress at this writing), about one in three otters brought in to captivity shows at least one behavior seemingly related to stress. Most otters recover and return to seemingly normal behavior within $48 \mathrm{~h}$, but about 1 in 20 otters brought into captivity dies of captive stress syndrome.

Sea otters subject to captive stress syndrome typically display behavioral symptoms of stress only when left undisturbed in a holding pool. If such animals are subsequently pursued, netted, handled, or otherwise disturbed, behavioral indications of stress are immediately superseded by normal evasive behavior. Once captured, even sea otters with well-developed symptoms of stress are able to struggle vigorously and resist handling, showing strength and determination comparable to otters with no symptoms of stress. Thus, it is difficult to recognize symptoms of stress in a sea otter reacting to overt human disturbance, except for those few animals for which the stress syndrome is in an advanced stage and the individuals are near death. Although not conclusive, these observations suggest the possibility that animals able to evade capture efforts in the field off KP were not necessarily healthy, and may have been in need of treatment for effects of oil. 
The rates of stress manifestation and mortality noted above apply to sea otters handled under well-controlled, relatively favorable conditions. Sea otters captured in areas affected by the T/N Exxon Valdez oil spill generally experienced far less favorable circumstances. Principal problems included remote location, rough terrain, inclement weather and rough seas, ineffective radio communication, and inadequate treatment, rehabilitation equipment, and facilities (Cramer 1990). After capture, oiled sea otters often experienced transport delays, inadequate supplies of food and water, inadequate control of environment (temperature, noise, and disturbance) during transport, soiling of fur by urine or feces, and delays in veterinary attention. Although definitive data are lacking, it is likely that rates of occurrence of captive stress syndrome were higher for sea otters rescued after the oil spill than for sea otters involved in the California translocation project. However, a substantial proportion of the otters captured off KP after the oil spill obviously survived capture, transport, treatment, and rehabilitation, seemingly without suffering permanent impairment as a consequence of captive stress. For sea otters captured along $\mathrm{KP}$, the survival rate during treatment and rehabilitation was more than $80 \%$ (Cramer 1990). Even if mortality during captivity was entirely due to stress and was entirely independent of oiling, the survival rate was relatively good in view of the logistical difficulties mentioned above.

\section{Potential Health and Fate of Oiled Sea Otters Left Without Treatment and Rehabilitation}

To date, acute mortality of sea otters resulting from spilled oil has been a primary focus of interest. There has been little discussion and no quan. titative assessment (at this writing) of potential chronic effects of oiling on sea otters. Indeed, it has been suggested (Ames 1990) that short-term survival of sea otters in contaminated habitat is sufficient evidence of long-term health and survival.

Oil spilled from the T/N Exxon Valdez spread widely and capriciously, contaminating many areas along $\mathrm{KP}$ where sea otters are relatively abundant, and contaminating large areas of the shallow-water habitat in which sea otters forage for benthic invertebrates. For example, there were persistent accumulations of floating oil in surface kelp canopies in the Chiswell Islands, Rocky Bay, and Windy Bay in April and May 1989 (VanBlaricom, unpublished observations from helicopters). Kelp canopies are often used by sea otters for resting and, less frequently, feeding, and for delineation of territories by adult male otters during breeding season (Jameson 1989).

The persistence of spilled oil poses the risk of contamination of sea otters by several different paths. Otters subject to light or moderate amounts of oil contamination may have survived the acute, short-term effects of oiling, but could have ingested sufficient amounts of spilled oil while grooming to produce chronic effects known to occur in vertebrates subject to oil contamination. Such effects may include liver necrosis, reproductive impairment, and carcinogenesis (National Research Council 1985). Otters using surface kelp canopies as centers of activity may have experienced repeated light oiling resulting in chronic sublethal pathologies such as those listed above. Otters feeding in contaminated benthic habitats may have experienced repeated light oiling because of persistent spilled oil in the habitat (for example, adhering to shells of prey), or may have ingested oil by consuming contaminated prey. Benthic invertebrates may sequester and concentrate spilled petroleum hydrocarbons in fatty tissues (National Research Council 1985). Consumption of such organisms may provide a pathway for internal contamination of sea otters.

To my knowledge, data are insufficient to evaluate the occurrence or importance in sea otters of any of the potential pathways of sublethal or chronic contamination summarized above. However, variations on each of the listed pathways have been documented as sources of difficulty for other vertebrates in studies of previous oil spills (National Research Council 1985). Bodkin and Weltz (1990) examined data on otters captured by tangle nets in heavily oiled parts of PWS. When set overnight, use of tangle nets approaches random capture of sea otters more closely than other available capture techniques. About $90 \%$ of otters so captured were found to be oiled. Given the concentrated oiling of those portions of KP where capture efforts were most intensive, it is likely that comparably high rates of oiling occurred among resident sea otters. Thus, it is probable that most otters in heavily oiled sites of KP were, at the very least, exposed to risks of sublethal or chronic health problems caused by spilled oil.

It has been suggested that evidence is sufficient to argue that sea otters may be capable of surviving low levels of oil contamination for extended 
periods without suffering impaired health or shortened life (Ames 1990). The cited evidence is of two types. The first is a published study (Siniff et al. 1982) in which four sea otters were experimentally contaminated with small amounts of oil and released in PWS. Three of the four otters were followed for about 3 weeks and were known to be alive at the termination of fieldwork. Contact with the fourth otter was lost 4 days after release. Because the fates of the otters were not determined, there are three possible outcomes: the otters could have died as a result of the acute effects of oiling; the otters could have recovered completely and lived normal lives; or the otters could have suffered chronic or sublethal effects of oiling. There is no basis for elimination of any of these possible outcomes, given the available data. On the basis of their data, Siniff et al. (1982) proposed that lightly oiled sea otters should not be captured and treated during an oil spill. They conceded, however, that the data were not conclusive. Thus, their study does not provide unequivocal evidence that sea otters can survive light oiling without ill effects.

The second line of evidence involves unpublished anecdotal observations of individual sea otters in California, apparently living for extended periods in harbors where oil sheens are common. Such observations provide no information on possible sublethal effects of chronic light oiling, nor is there any quantitative basis for comparing the level of chronic oiling in harbors with the level of oiling experienced by sea otters after the T/N Exxon Valdez disaster. Given the reported heavy oiling of primary capture areas along $\mathrm{KP}$ (Galt and Payton 1990), the most likely scenario is that degree of oiling along KP after the oil spill greatly exceeded degrees of oiling experienced by sea otters living in harbors along the California coast. Without quantitative documentation, anecdotal observations are far from adequate to support the position that sea otters generally can survive light oiling without harm.

\section{On Assessing the Level of Contamination of Sea Otters by Oil}

Much of the discussion of effects of light oiling on sea otters presumes that the level of oil contamination was accurately assessed during capture and treatment of sea otters. In fact, level of oil contamination of sea otters generally was assessed visually and arbitrarily, without reference to any independent assay of concentration of spilled oil in the pelage. Such assessments had several pitfalls. Different observers often held very different assessments of the degree of oiling of captive sea otters. For example, on 15 April 1989, I captured the first two oiled sea otters taken outside of PWS, with the assistance of B. Candopoulos and J. Blake of the F/V Breaktime. Both otters were captured after we determined their behavior to be abnormal in a manner consistent with likely effects of oiling. After capturing the animals, I very nearly released both because I was not convinced that any oil was present on either animal. I chose to transfer the otters to the rehabilitation centers only because of the observed behavioral anomalies and the knowledge that heavy oil contamination had occurred in the capture area. I was later informed by staff at the Valdez Otter Rehabilitation Center that substantial oil was found on both otters during the washing procedure. A second pitfall results from the grooming behavior of otters (T. D. Williams, Monterey Bay Aquarium, Monterey, California, personal communication). Sea otters that became oiled but subsequently moved into clear water could groom the pelage until oiling was no longer apparent, ingesting substantial quantities of oil in the process. Such animals might be in poor condition as a direct consequence of oiling, but seem unoiled based on visual inspection of the pelages. Oiled female otters were observed to groom their oiled pups until the pelage of the pups appeared clean. The females seemingly ingested oil in the process of cleaning the pups.

New information, based on chromatographic assay of samples of pelage of "lightly oiled" otters captured in the aftermath of the oil spill, suggests substantial variability in crude oil contamination levels (D. C. Perrollaz and J. Rash, Marine Animal Resource Center, Seattle, Washington, unpublished report). Although preliminary, the new data indicate that visual estimates of degree of oiling may be unreliable for sea otters other than those with obvious heavy oiling. In some instances, relatively high concentrations of crude oil were found in the pelage of otters that did not appear to be heavily oiled. For example, the highest crude oil concentration found in samples analyzed to date came from a sea otter categorized as lightly oiled. 


\section{On Choosing the Conservative Course When the Data are Not Definitive}

The T/N Exxon Valdez disaster was a precipitous, chaotic event that required many decisions without the benefit of supporting data. The problem of lightly oiled sea otters was an outstanding example. Was it proper to capture and treat lightly oiled otters, or should the otters have been left to recover on their own? As indicated above, a definitive answer was not availabile at the time, and remains unavailable at this writing. Given the uncertainty, available data on risks of capture-related harassment and captivity stress were weighed against available data on the risks of long-term pathologies relating to spilled oil and the ambiguities of arbitrary visual assessment of health and degree of oiling in the field. The U.S. Fish and Wildlife Service concluded that risks associated with use of tangle nets and capture and handling of lightly oiled sea otters seemed to be less than risks associated with leaving sea otters on their own in an obviously contaminated habitat. Ames (1990) to the contrary notwithstanding, I submit that this conclusion was proper. Given published evidence regarding sublethal or chronic effects of oil, the likely possibility of widespread contact with oil by sea otters, the difficulty of determining the condition or degree of oiling of sea otters in the field, and the relatively high survival rate of captured sea otters in spite of operational difficulties in all phases of captivity, I concur that the properly conservative course was to capture, treat, and rehabilitate as many sea otters as possible in areas known to be heavily contaminated with spilled oil. Because the deployment of tangle nets was the only effective means available of increasing the capture rate, use of tangle nets was consistent with the conservative approach.

\section{Research Benefits and Needs}

The risks of research on vulnerable wildlife often are more than balanced by results, sometimes including unexpected new insights that contribute to the resolution of significant management and theoretical problems (Ralls and Brownell 1989). The extension of capture activity to KP was a significantly positive development for the management of future oil spills. The eventual examination of data from lightly oiled sea otters taken off KP will contribute to an understanding of the limits of the T/V Exxon Valdez disaster. Had capture efforts been limited to animals with obvious, acute difficulties, the establishment of policies for rescue operations in future oil spills would be difficult, if not impossible. Because lightly oiled sea otters were included in the rescue effort, data will be available on a substantially larger portion of the spectrum of pathologies (or lack thereof) suffered by oiled animals. Although such an approach ran the risk of subjecting otherwise healthy animals to captivity stress, it ultimately contributed to a process that should provide ben. efits to sea otters and sea otter populations throughout the range of the species in the North Pacific Ocean, over many future generations of sea otters and people.

I reiterate my view that the selection of the conservative approach was difficult, lacking the support of conclusive data. When available data are less than definitive, one must rely on the judgment of experienced individuals for decisions. Complex, insidious, rare events such as major oil spills may, however, confound the experience and expertise of even the most astute and objective observers. When such problems are recognized, the only reasonable solution is to pursue the contentious questions with the appropriately designed research.

It is the opinion of the author that it is crucial that knowledge of the effects of seemingly light oiling on sea otters be expanded. If one is to minimize the effects of a large oil spill, one would like to know the threshhold of oil contamination below which a sea otter is better off left alone, and above which the sea otter should be captured and treated. Several steps would be helpful in addressing this question. The data gathered during the $\mathrm{T} / \mathrm{V}$ Exxon Valdez disaster must be integrated, assimilated, and, most important, disseminated. Two important categories of follow-up work must be maintained: studies of survival and behavior of sea otters treated for oil effects, then returned to natural habitat (Monnett et al. 1990); and longterm studies of survival and health of sea otters treated for the effects of oil, then held in captivity for follow-up evaluation (Gruber and Hogan 1990). There is a need for development of a reliable, easily administered, quantitative field test to determine the degree of oil contamination of sea otters at the time of capture, building on the work of Hill and Tuomi (1990) and Perrollaz and Rash (unpublished report). Finally, there is a need for design and pursuit of additional studies investi- 
gating long-term and acute consequences of various degrees of oiling for sea otters, focusing on specific questions left unresolved by data from the T/N Exxon Valdez experience.

\section{Acknowledgments}

I thank R. L. Britton, J. A. Estes, R. J. Jameson, E. G. Klinkhart, S. F. Loshbaugh, and O. J. Ollestad for constructively critical comments on an earlier version of this paper.

\section{References}

Ames, J. 1990. Impetus for capturing, cleaning, and rehabilitating oiled or potentially oiled sea otters after the T/V Exxon Valdez oil spill. Pages 137-141 in K. Bayha and J. Kormendy, tech. coords. Sea Otter Symposium: Proceedings of a symposium to evaluate the response effort on behalf of sea otters after the T/N Exxon Valdez oil spill into Prince William Sound, Anchorage, Alaska, 17-19 April 1990. U.S. Fish Wildl. Serv., Biol. Rep. 90(12).

Bodkin, J. L., and F. Weltz. 1990. Evaluation of sea otter capture after the T/V Exxon Valdez oil spill, Prince William Sound, Alaska. Pages 61-69 in K. Bayha and J. Kormendy, tech. coords. Sea Otter Symposium: Proceedings of a symposium to evaluate the response effort on behalf of sea otters after the T/N Exxon Valdez oil spill into Prince William Sound, Anchorage, Alaska, 17-19 April 1990. U.S. Fish Wildl. Serv., Biol Rep. 90(12).

Britton, R. L., C. T. Benz, and J. Foster. 1990. Sea otter capture along the Kenai Peninsula. Pages 70-77 in K. Bayha and J. Kormendy, tech. coords. Sea Otter Symposium: Proceedings of a symposium to evaluate the response effort on behalf of sea otters after the T/N Exxon Valdez oil spill into Prince William Sound, Anchorage, Alaska, 17-19 April 1990. U.S. Fish Wildl. Serv., Biol. Rep. 90(12).

Cramer, D.W. 1990. Transportation of sea otters to rehabilitation centers. Pages 91-94 in K. Bayha and J. Kormendy, tech. coords. Sea Otter Symposium: Proceedings of a symposium to evaluate the response effort on behalf of sea otters after the T/V Exxon Valdez oil spill into Prince William Sound, Anchorage, Alaska, 17-19 April 1990. U.S. Fish Wildl. Serv., Biol. Rep. 90(12).

Davis, R. W., and J. Styers. 1990. History of the sea otter rehabilitation centers. Pages 142-157 in K. Bayha and J. Kormendy, tech. coords. Sea Otter Symposium: Proceedings of a symposium to evaluate the response effort on behalf of sea otters after the T/ E Exxon Valdez oil spill into Prince William Sound, Anchorage, Alaska, 17-19 April 1990. U.S. Fish Wildl. Serv., Biol. Rep. 90(12).
Galt, J. A., and D. L. Payton. 1990. Movement of oil spilled from the T/V Exxon Valdez. Pages 4-17 in K. Bayha and J. Kormendy, tech. coords. Sea Otter Symposium: Proceedings of a symposium to evaluate the response effort on behalf of sea otters after the T/V Exxon Valdez oil spill into Prince William Sound, Anchorage, Alaska, 17-19 April 1990. U.S. Fish Wildl. Serv., Biol. Rep. 90(12).

Gruber, J., and M. E. Hogan. 1990. Transfer and placement of nonreleasable sea otters in aquariums outside Alaska. Pages 428-431 in K. Bayha and J. Kormendy, tech. coords. Sea Otter Symposium: Proceedings of a symposium to evaluate the response effort on behalf of sea otters after the T/ Exxon Valdez oil spill into Prince William Sound, Anchorage, Alaska, 17-19 April 1990. U.S. Fish Wildl. Serv., Biol. Rep. 90(12).

Hill K., and P. A. Tuomi. 1990. Field test for detaching crude oil on the fur of sea otters. Pages 95-122 in K. Bayha and J. Kormendy, tech. coords. Proceedings of a symposium to evaluate the response effort on behalf of sea otters after the T/N Exxon Valdez Oil Spill into Prince William Sound, Anchorage, Alaska, 17-19 April 1990. U.S. Fish Wildl. Serv., Biol. Rep. 90(12).

Jameson, R. J. 1989. Movements, home range, and territories of male sea otters off central California. Mar. Mammal Sci. 5:159-172.

Kenyon, K. W. 1969. The sea otter in the eastern Pacific Ocean. U.S. Fish Wildl. Serv., N. Am. Fauna 68. $352 \mathrm{pp}$.

Monnett, C. W., L. M. Rotterman, C. Stack, and D. Monson. 1990. Postrelease monitoring of radio-instrumented sea otters in Prince William Sound. Pages $400-420$ in K. Bayha and J. Kormendy, tech. coords. Sea Otter Symposium: Proceedings of a symposium to evaluate the response effort on behalf of sea otters after the T/V Exxon Valdez oil spill into Prince William Sound, Anchorage, Alaska, 17-19 April 1990. U.S. Fish Wildl. Serv., Biol. Rep. 90(12).

National Research Council. 1985. Oil in the sea. Inputs, fates, and effects. National Academy Press, Washing. ton, D.C. 601 pp.

Ralls, K., and R. L. Brownell, Jr. 1989. Protected species research permits and the value of basic research. BioScience 39:394-396.

Rathbun, G. B., R. J. Jameson, G. R. VanBlaricom, and R. L. Brownell, Jr. 1990. Reintroduction of sea otters to San Nicolas Island, California: preliminary results for the first year. Natural History of Orange County. In press.

Siniff, D. B., T. D. Williams, A. M. Johnson, and D. L. Garshelis. 1982. Experiments on the response of sea otters, Enhydra lutris, to oil contamination. Biol. Conserv. 23:261-272.

Skinner, S. K., and W. K. Reilly. 1989. The Exxon Valdez oil spill. A report to the President of the United 
States. Cutter Information Corporation, Arlington, Mass. 72 pp.

Townsend, R., and B. Heneman. 1989. The Exxon Valdez oil spill: a management analysis. Center for Marine Conservation, Washington, D.C. 239 pp.

VanBlaricom, G. R. 1989. Patterns of captive stress during translocation of sea otters. Presentation to the Committee of Scientific Advisors, Marine Mammal Commission, Monterey, Calif. [unpublished report]

Williams, T. D., and G. R. VanBlaricom. 1989. Rates of capture myopathy in translocated sea otters, with implications for management of sea otter rescue fol- lowing oil spills. Presentation to the eighth biennial conference on the biology of marine mammals, Pacific Grove, Calif. [unpublished report]

Williams, T. M., J. McBain, R. K. Wilson, and R. W. Davis. 1990. Clinical evaluation and cleaning of sea otters affected by the T/N Exxon Valdez oil spill. Pages 236-257 in K. Bayha and J. Kormendy, tech. coords. Sea Otter Symposium: Proceedings of a symposium to evaluate the response effort on behalf of sea otters after the T/N Exxon Valdez oil spill into Prince William Sound, Anchorage, Alaska, 17-19 April 1990. U.S. Fish Wildl. Serv., Biol. Rep. 90(12). 


\title{
Impetus for Capturing, Cleaning, and Rehabilitating Oiled or Potentially Oiled Sea Otters After the T/N Exxon Valdez Spill
}

\author{
by
}

\author{
J. Ames \\ California Department of Fish and Game \\ 2201 Garden Road \\ Monterey, California 93940
}

\begin{abstract}
The T/ Exxon Valdez grounding was the first major oil spill that affected large numbers of sea otters (Enhydra lutris). The spill response was, therefore, original and predictably quite confused, particularly at first. New information and situations led to new methodologies from day to day. For a variety of reasons, many sea otters were captured, held, transported, and cleaned when they might have been better off left alone. Earlier research had suggested that lightly (but observably) oiled sea otters could survive on their own. This information was unknown to or forgotten by some decision makers, or preempted for unknown reasons. I believe that sea otter captures continued for 2 to 3 months beyond when they were useful. It is likely that some otters died and that several mother-pup bonds were broken (thereby creating several dependent orphans) only because the animals were "rescued." Possible reasons for extended captures were poor communication at all levels, but particularly between capture boats and cleaning centers; some capture crews having little background with sea otters; no wildlife agency being in charge"; favorable press reports about the rescue effort; and high wages paid by the Exxon Company.
\end{abstract}

\section{Background}

My background with sea otters (Enhydra lutris) dates from 1972 to the present as a marine biologist working on the California Department of Fish and Game's sea otter project. I have developed expertise in sea otter capture and handling, acquired limited knowledge of husbandry, and participated in many behavioral studies and censuses. Through the years, I have worked with a variety of sea otter researchers and am well acquainted with sea otter literature. I have attended numerous sea otter-oil spill contingency planning meetings in California.

While performing behavioral and census observations over the years, I have occasionally observed sea otters in or near petroleum sheens around Morro Bay, Monterey, and Moss Landing (California) harbors. Several identifiable sea otters lived for as long as several years in these environments, from which I concluded that sea otters could withstand low levels of petroleum contamination even over long periods.

Previous research (Costa and Kooyman 1981, 1982; Siniff et al. 1982; Davis et al. 1986) implied that, in at least some instances, low levels of oiling could be handled by otters on their own. In one experiment, two otters were captured, oiled, and released and then followed in the wild (Costa and Kooyman 1981). Even from a distance these animals could be visually identified as oiled (D.P. Costa, Long's Marine Lab, University of California, Santa Cruz, personal communication). One was 
followed for 20 days and one for 43 days, and neither appeared to be in distress.

With this background and these biases, I arrived in Alaska on 31 March 1989 to help with the sea otter rescue effort that followed the T/N Exxon Valdez oil spill.

\section{Introduction}

Sea otters, more than other marine mammals, rely on their fur to maintain body temperature because they do not have a thick layer of fat or blubber. Matting or clumping of the fur due to oiling results in less trapped air and, therefore, increased body heat loss. If the heat outflow is great, then the otter may become hypothermic and die. It seemed prudent then to capture oiled sea otters, clean them, and allow their fur's water repellency to restore itself. This process was known from previous studies to take I-2 weeks in captivity (Costa and Kooyman 198I; Davis et al. 1986). Unfortunately, capturing wild sea otters and holding them in captivity is stressful. Even with good facilities there is about $5 \%$ mortality in unoiled otters (Williams and VanBlaricom 1989).

After the spill by the T/V Exxon Valdez, decisions had to be made about which sea otters to capture and how long after the spill to continue the capture effort. Having no one clearly in charge hampered these decisions. These decisions were further complicated because, early on, badly oiled otters exhibited pathological lesions resulting from ingestion or inhalation of petroleum products, in addition to capture and hypothermia stress lesions and symptoms. These ingestion and inhalation problems had not been reported in any previous oil-related sea otter experiments, and it was not known what level of exposure might have led to these lesions. In spite of the many uncertainties, however, it is my view that sea otter captures continued far beyond the time when they were of benefit to the otters.

\section{Assignments and Activities}

Upon my arrival in Alaska I was assigned aboard the F/V Viking, one of two U.S. Fish and Wildlife Service-chartered capture vessels (F/N Viking and F/N Sea Raker). By 2 April 1989 (day 9 of the spill), I was on board and on Prince William Sound. We found oil coverage of the shoreline and water surface ranging from extremely heavy to almost undetectable. During 2-7 April 1989 (spill days 9-14), with four skiffs working, we were able to catch 20 otters (one to six per day) with dip nets. About three-fourths of the otters were obviously oiled, which means that oil could be felt and clumped fur seen with the animal in hand. Occasionally, clumped fur was observable at a distance. A few otters were released immediately when no obvious oil was found on them, before a firm policy was established on the Sea Raker and Viking. The policy, derived from prevailing opinion, was to send all animals caught to cleaning centers because inhalation of fumes may have caused damage even if no significant amount of oil had been contacted directly; contaminated food may have been ingested (later analyses indicated that lethal ingestion or inhalation problems were obvious only during the first 2-3 weeks of the spill; T. M. Williams, International Wildlife Research, Inc., La Jolla, California, personal communication); and spilled oil was so prevalent that even if otters had avoided it thus far, they were likely to contact it eventually (preemptive captures). During this initial period (days 9-14) we recovered about two dead, oiled sea otters per day.

During spill days 15-20 (8-13 April 1989), we captured 16 otters, an average of almost three per day. Many of these were captured in tangle nets, as we were having increasingly poor success with dip nets. A few of the early captured animals (dip net only) were not obviously oiled, which means that oil was not visible or palpable on a restrained animal. A larger percentage of the animals captured in tangle nets than in dip nets were not obviously oiled, although cleaning center personnel later determined many of these to be lightly oiled. The decision to use tangle nets was certainly not unanimous. One advantage of using tangle nets was that more animals could be cap. tured. Some participants thought that preemptive captures were in order (and no one was certain they were not). A second advantage was that many of the capture crew believed that the people with the expertise to tell us whether an animal actually needed capturing were at the cleaning centers (e.g., physiologists, veterinarians, veterinary pathologists, and chemists).

Disadvantages of using tangle nets were that they are indiscriminate (i.e., obviously oiled as well as not obviously oiled otters were caught); oil might contaminate the tangle nets and thereby make the nets a detriment to otters; and some of us weren't eager to capture animals that we 
weren't sure needed help (i.e., we weren't sure preemptive captures were a good idea).

During this period, we chased with dip nets almost every otter we saw, and most could not be caught. A few otters that we chased and could not catch were obviously oiled (as judged by their clumped fur or the nearly continual head-shaking behavior). Despite being obviously oiled, these animals were healthy enough to avoid capture for periods as long as an hour (we gave up, not the otters). Very few of the oiled otters we caught were easily captured. Even otters hauled out on beaches were hard to capture unless we could get to them before they got to the water.

Captured otters that could not be transported quickly often degenerated into obvious poor health, particularly those that were obviously oiled. Several animals kept overnight on board the Viking and Sea Raker fared poorly. As a result, our crews eventually decided not to capture animals, and even to release any animals captured, if they were not likely to be transported the same day.

During this period (days 15-20), we picked up an average of just less than one dead, oiled otter per day.

On days 21-24 (14-17 April 1989), fewer and fewer animals could be captured by dip net. More important, only a single dead otter was picked up, and no obviously oiled, live otters were observed. Through the entire period, in all but the worst oiled areas, many live (and apparently healthy) otters were observed. By this time, I was of the opinion that capturing was no longer indicated and suggested that a monitoring mode was in order. On 17 April 1989 I returned to California.

I returned to Alaska about 5 weeks later. On this trip I first spent 3 weeks (24 May-13 June 1989 - days 59-80 of the spill) in the northern and western Kodiak Island Archipelago and the Katmai National Park of the Alaska Peninsula aboard several mother vessels and capture skiffs. During this period I saw about 2,600 individual sea otters (not a complete count but counts of disjunct areas), all of which were apparently healthy. Certainly none of them was obviously oiled. Part of my assignment during this period was to train wildlife crews to capture and handle sea otters safely. As a result, we captured 35 otters. I did not see, feel, or smell oil on any of these animals. An additional 18 otters were observed 10-50 feet away, with and without binoculars, for 10 to $30 \mathrm{~min}$. I saw no clumped fur or other indication of oiling or ill health. A single dead otter, a newborn pup, was picked up during this period, and no obvious oil was noted on it.

I then spent about 2 weeks (14 June-30 June 1989 days 81-97 of the spill) in Seward at the otter cleaning and rehabilitation facility. I spent 1 day observing capture operations on the Kenai Peninsula, and I visited the Jakolof Pre-Release Facility briefly.

\section{Discussion}

I believe that when we sent to cleaning centers otters on which no oil could be found after touching, smelling, and looking, we should have received instructions not to continue capturing further animals that were not obviously oiled-this did not happen. Apparently, this was because of the low survival rate of the obviously oiled otters at the cleaning center. Perhaps the poor survival rate could have been improved by substantially shortening the time in transport cages (by an order of magnitude or so, i.e., $2.4 \mathrm{~h}$ rather than $24 \mathrm{~h}$ ), although the more heavily oiled otters may have died anyway. The lightly oiled and unoiled otters, on the other hand, were surviving quite well, and may have survived as well if left alone in the wild, as suggested by previous research. The higher survival rate at the Seward Otter Rehabilitation Center as opposed to the Valdez Otter Rehabilitation Center might have been strictly a function of the lower percentage of obviously oiled otters that were sent to Seward.

It is likely that some, and perhaps many, sea otters died only because they were captured. Similarly, captivity permanently interrupted several mother-pup bonds, thereby creating several orphans that were then dependent on humans. Many of these pregnant females and mother-pup pairs were not obviously oiled.

Although the idea for preemptive captures may have had some merit early in the spill response, it should have been discontinued after the first few weeks, when the number of fresh, dead oiled otters being found declined to low levels. Sea otter captures for rehabilitation continued for 2-3 months, however; in my view, they were largely unnecessary and probably detrimental. A monitoring and studying mode was all that was warranted. A tagging study would have been useful at this time (as it would have throughout the spill response) to help resolve the capture versus not-capture controversy. 


\section{Conclusions and Recommendations}

I know of no person who intentionally carried on activities for personal benefit at the expense of sea otters. Certainly most, if not all, were doing what they thought best for the otters. I simply disagree with the decision to continue sea otter captures beyond the first few weeks of the spill. It is entirely possible that the overall effect of rescuing sea otters was a negative one, and future research should be directed at clarifying this point.

Perhaps the worst problems rescue people faced were those related to poor communications. Alaskan atmosphere and geography apparently are such that communication is often difficult and sometimes impossible. This often led to lengthy waits in transport kennels for otters. The health of otters in general, and obviously oiled otters in particular, worsened in transport kennels. Greatly improving communications may not be possible; how. ever, research on improved field handling, first aid, field stress reduction, and the feasibility of field cleaning of obviously oiled otters would be worthwhile.

Capture crews with little sea otter background should not be asked to provide much of the information on whether captures need to continue.

I agree with those who believe that having a wildlife agency in charge of a spill response is a good idea.

Unless used in an active manner where specific animals can be targeted, the use of tangle nets should probably be avoided. However, if preemptive captures are intended, tangle nets are probably the best option.

The otter rescue effort was tremendously expensive. Even though sea otter experts did not see the rescue effort as vital to the survival of the otter population as a whole, individual otters were suffering and dying. Exxon had created the problem, and Exxon should pay for the rescue and rehabilitation, no matter what the cost. This reasoning was accepted until gas prices went up $\$ 0.25$ per gallon and it became common knowledge that the entire cleanup might be tax-deductible (i.e., we were all paying). A periodic cost-benefit analysis by wildlife agencies might be helpful.

The otter rescue effort seemed to be well received by the public. Amid a tremendous amount of criticism on many other fronts, it might have been a bright spot and, therefore, one in which to keep putting effort. A periodic review of the forces driving an operation would be a good idea.

Exxon was paying high wages. Many people working in the rescue effort were probably making far more than they would have at their regular jobs. (There were many volunteers too.) The process of deciding on the continuation of rescue efforts should avoid placing people in an obvious conflictof-interest situation.

Finally, I must place my criticisms in perspective: Exxon's lack of preparedness for this spill and virtual deceit about the state of that preparedness eclipsed in importance any possible poor decisions or mismanagement by anyone else. Had the containment and cleanup personnel, machinery, and materials been in place and operational as they were supposed to be, the disastrous spread of oil might have been avoided.

\section{Acknowledgments}

I thank the following people who hold similar views to mine, who provided data or ideas that were useful, or who supported airing a view that was not being widely aired: R. Davis, A. DeGange, J. Estes, R. Hardy, B. Hatfield, K. Hill, R. Jameson, M. Kenner, E. Klinkhart, D. Kvasnikoff, C. Lensink, C. Monnett, L. Rotterman, N. Siepel, D. Siniff, T. Thomas, F. Weltz, and T. Williams.

\section{References}

Costa, D. P, and G. L. Kooyman. 1981. Effects of oil contamination in the sea otter, Enhydra lutris. Pages 65-107 in Environmental assessment of the Alaskan continental shelf. Final reports of principal investigators. Vol. 10. Biological studies.

Costa, D. P., and G. L. Kooyman. 1982. Oxygen consumption, thermoregulation, and the effect of fur oiling and washing on the sea otter, Enhydra lutris. Can. J. Zool. 60:2761-2767.

Davis, R. W., J. A. Thomas, T. M. Williams, R. A. Kastelein, L. H. Cornell, B. E. Joseph, T. D. Williams, R. A. Pastorak, and E. R. Yohe. 1986. Sea otter oil spill mitigation study. Pacific OCS region, Minerals Management Service, Department of the Interior (contract 14-12-0001-30157). 220 pp.

Siniff, D. B., T. D. Williams, A. M. Johnson, and D. L. Garshelis. 1982. Experiments on the response of sea otters, Enhydra lutris, to oil contamination. Biol. Conserv. 23:261-272.

Williams, T. D., and G. R. VanBlaricom. 1989. Rates of capture myopathy in translocated sea otters, with implications for management of sea otter rescue following oil spills. Page 72 in paper presented at 
the eighth biennial conference on the biology of marine mammals, Pacific Grove, California, 7-11 December 1989. (Abstract). 


\title{
Rehabilitation Session A: Facilities and Records
}

\author{
Chair: Robert Hardy, California Department of Fish and Game, Morro \\ Bay, California. \\ Editors: Glenn R. VanBlaricom and Randall W. Davis.
}

\section{History of the Sea Otter Rehabilitation Centers}

\author{
by
}

\author{
R. W. Davis \\ International Wildlife Research \\ Texas A\&M University \\ Department of Marine Biology \\ P.O. Box 1675 \\ Galveston, Texas 77553
}

and

J. Styers

Wildlife Rapid Response Team, Inc.

5601 N. 37th Street

Tacoma, Washington 98407

\begin{abstract}
The first sea otter (Enhydra lutris) rehabilitation center opened at the Prince William Sound Community College in Valdez on 27 March 1989. Oiled otters began arriving on $30 \mathrm{March}$, averaging 10 per day until 9 April, after which the new arrivals averaged only 1-2 per day. To accommodate the many animals, the center was moved into the gymnasium of a former elementary school on 2 April. As otters were rehabilitated, they were placed in floating pens in the small boat harbor. When vessels required the harbor space, the otters were moved to salmon raceways or a large, floating salmon pen at the Solomon Gulch Hatchery near Valdez. By 1 April, the southern edge of the oil spill had reached the coast of the Kenai Peninsula. A second rehabilitation center to clean and care for oiled otters opened in Seward on 8 May and was fully operational. By 25 May, a prerelease center designed to hold rehabilitated otters from Seward opened in Little Jakolof Cove near Homer on May 17. On 15 May, the first seven rehabilitated sea otters were released in Simpson Bay, Prince William Sound. The release plan for the remaining otters was completed in early July. Rehabilitated otters were released in eastern Prince William Sound and along the Kenai Peninsula during July
\end{abstract}


and August; 45 of the otters released in Prince William Sound had radio transmitters implanted in their abdomens. Of the 357 otters treated at the three rehabilitation centers, 197 were released, 132 died, and 28 of the 37 otters placed in seaquariums survived. All three centers were closed by 13 September 1989 .

When the T/N Exxon Valdez ran aground on 24 March 1989, P. Gates (U.S. Department of the Interior's regional environmental officer for Alaska, and Regional Response Team representative) was notified of the oil spill by the U.S. Coast Guard. According to an established procedure, Gates then notified E. Robinson-Wilson, the U.S. Fish and Wildlife Service's response management coordinator. P. Bergmann (regional environmental assistant for the U.S. Department of the Interior) and E. Robinson-Wilson traveled to Valdez on 24 March at Gate's request (P. Gates, U.S. Department of Interior, Anchorage, Alaska, personal communication). At the recommendation of P. Bergmann, W. Stillings (Exxon Company, U.S.A.) asked R. Davis (Sea World Research Institute) to organize and direct a sea otter (Enhydra lutris) rehabilitation program. Davis had been identified in the Alaska Regional Response Team's Wildlife Frotection Guidelines as having expertise in cleaning and rehabilitating oiled sea otters. He and colleagues T. M. Williams, J. Thomas, and R. Kastelein had developed techniques to clean and rehabilitate oiled sea otters during a study for the Minerals Management Service in 1984 (Davis et al. 1986).

\section{Sea Otter Rehabilitation Centers and Prerelease Facilities}

\section{Valdez Otter Rehabilitation Center}

On 27 March, Davis arrived in Valdez and began designing a sea otter cleaning and rehabilitation center at the Copper Basin Hall in the Prince William Sound Community College (see Appendix A for a chronology of events at the otter centers). That same day, a severe storm spread the oil slick in a southwesterly direction toward Smith Island, Green Island, and Knight Island, areas known to be used by sea otters (Fig. 1). On 28 March, T. M. Williams (Sea World Research Institute) and veterinarian J. McBain arrived in Valdez and began organizing a washing room and veterinary clinic. Marine mammal specialists throughout North America were contacted by telephone and asked to assist in the rescue effort. At the same time, volun- teers were recruited to help with construction of the rehabilitation center. The staff eventually grew to more than 150 specialists and volunteers.

The Valdez Otter Rehabilitation Center (VORC) received its first oiled sea otter (from Smith Island) on 30 March. Two days later, 18 otters arrived, the maximum number received in a single day. Oiled sea otters continued to arrive at an average of 10 per day until 9 April, after which an average of only 1 or 2 otters arrived each day until 6 May. With indoor space for fewer than 20 animals, the number of otters arriving at the rehabilitation center rapidly exceeded the capacity of VORC. By 5 April, VORC had received 73 otters, of which 40 were still alive (Fig. 2). Many of the otters that died showed toxic reactions to the oil. To relieve the overcrowded conditions and to help treat the most serious cases of oil exposure, six otters (one of which died in transit) were sent to Sea World San Diego (2 April), six to the Point Defiance Aquarium in Tacoma, Washington (12 April), and six to the Vancouver Aquarium (17 April). At the same time, we began designing a larger rehabilitation center.

The gymnasium at the Growden-Harrison Complex (part of the Prince William Sound Community College) was chosen as the site for the new sea otter rehabilitation center on 2 April. Construction contractors (VECO, Inc.) worked nonstop to complete the critical care facility in 4 days. However, we continued to clean oiled otters at the Copper Basin Hall until the new cleaning facility was completed in late April. We also established a pathology laboratory in a small salmon cannery (the Salmon Exchange) in Valdez to perform necropsies on otters that died in the center.

On 13 April, we began placing rehabilitated otters in floating pens at the Valdez boat harbor. Of the 122 otters that had been treated, 51 were still alive. On 22 April, the rehabilitated sea otters were transferred to a salmon hatchery (the Solomon Gulch Hatchery), which was across the bay from Valdez. This move was necessary because the three slips we were using for the holding pens were needed for fishing boats. At the Solomon Gulch Hatchery, the otters were held in two salmon raceways for the first month. Beginning on 22 May, 65 otters were transferred from the raceways to the hatchery's large, floating salmon pen ("the octagon") $300 \mathrm{~m}$ offshore. This floating pen was large 


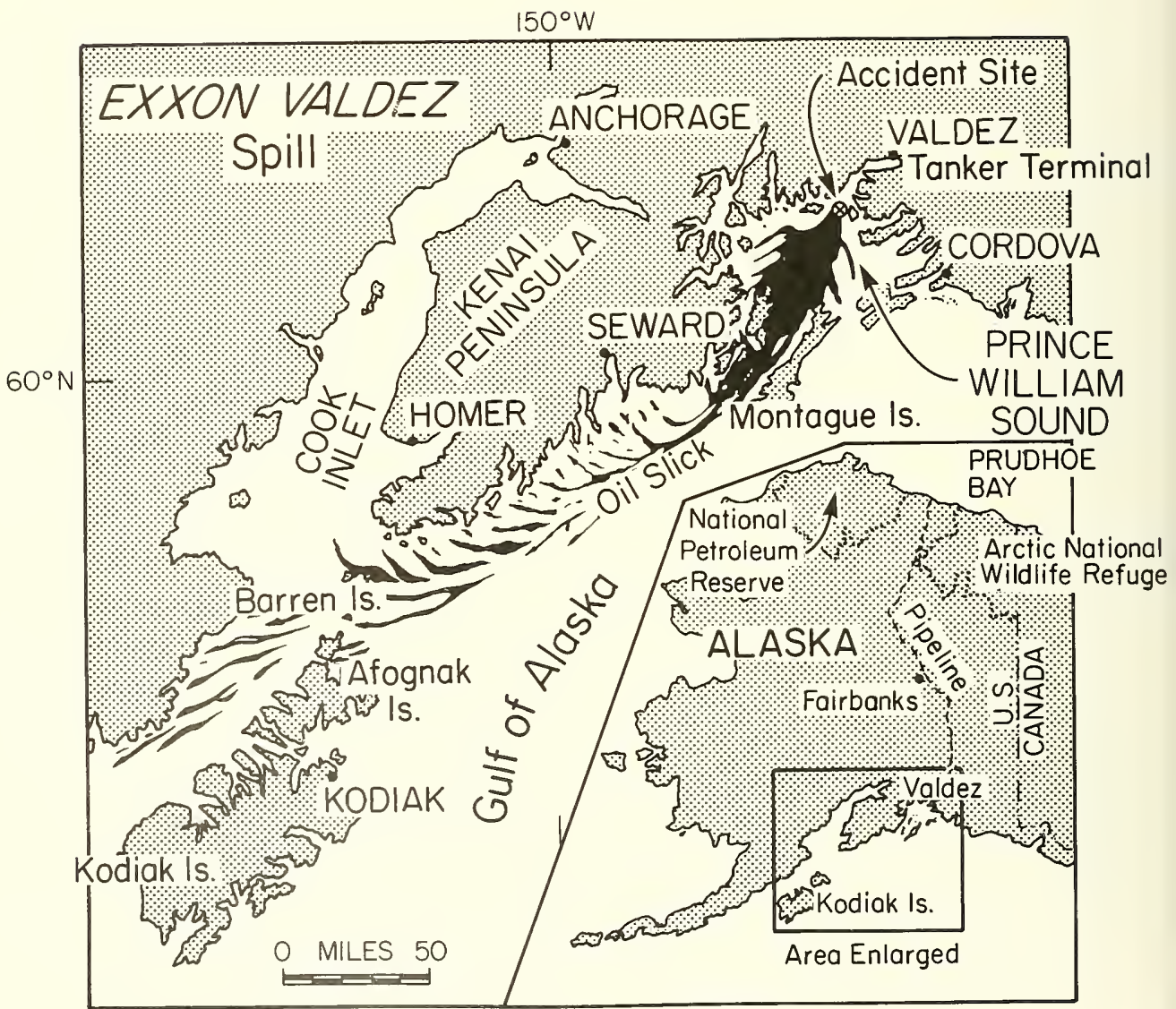

Fig. 1. Geographical area affected by the oil spill. 
Fig. 2. Comparison of the number of live sea otters (Enhydra lutris) in the rehabilitation centers.

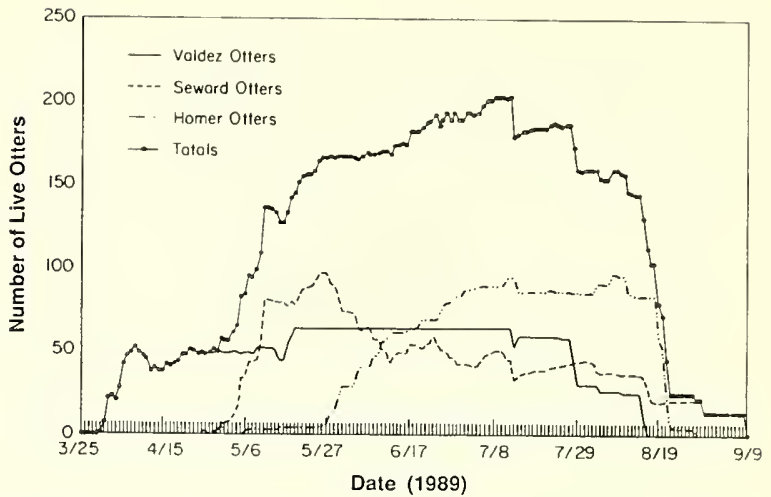

enough to accommodate 180 otters and was available through the summer. The rehabilitated otters remained in the octagon until they were released.

With most of the rehabilitated otters in floating pens awaiting release, we no longer needed the otter pens at the Growden-Harrison Complex. On 1 June, we consolidated our operations and moved the rehabilitation center adjacent to the pathology laboratory at the salmon cannery. The new center site, which included the Salmon Exchange building and three trailers from the Growden-Harrison Complex, was used for administration, otter food preparation, veterinary care, and pathology.

The facilities at the Salmon Exchange were closed on 18 August after all otters were released. Overall, VORC received 156 otters from the wild, of which 63 survived, 85 died in the center, and 8 died after being transferred to seaquariums. The maximum number of otters at VORC at one time was 64 (Fig. 2).

Beginning in early June, sea otter biographical information, medical records, necropsy results, and feeding records were entered into a computerized data base at the Prince William Sound Community College. The computer group was moved to Exxon offices at the Royal Center in Valdez on 29 August. When Exxon summer operations in Prince William Sound finished on 15 September, the sea otter files and computer data base were moved to Exxon offices in Anchorage for storage and completion of the remaining work.

Seward Otter Rehabilitation Center, the Jakolof Pre-Release Facility, and the Homer Temporary Care Facility

By 1 April, the southern edge of the oil spill had moved out of Prince William Sound and along the coast of the Kenai Peninsula. As a result, the Ser- vice asked Exxon to build a second rehabilitation center in Seward. On 7 April, at the recommendation of VORC's director, the Exxon environmental program manager selected J. Styers to direct the new rehabilitation center. Styers immediately began to organize a staff, select a site, and design the new center. However, difficulties in securing a lease agreement and uncertainty over the need for a second rehabilitation center delayed construction until 21 April. Consequently, the first five oiled sea otters captured along the Kenai Peninsula between 15-18 April were sent to VORC (Williams et al. 1990).

Seventeen oiled sea otters were captured from 1 May to 4 May and temporarily held in cages at the Seward Bird Rehabilitation Center until the otter center was opened on 8 May. Two additional weeks were required to complete construction of the pools and the floating pens in a seawater pond. From 5 May to 21 May, 91 otters were sent to the Seward Otter Rehabilitation Center (SORC), and 7 pups were born. Until SORC reached its full capacity (about 80 otters) in late May, some otters continued to be held in cages at the Seward Bird Rehabilitation Center. To relieve the overcrowded conditions, 21 otters were transferred to VORC from 17 May to 20 May, and the temporary holding facility at the bird center was closed. Otters continued to arrive at SORC at an average rate of one per day until $31 \mathrm{July.}$

In early May, the Service recommended that Exxon build a prerelease center at Little Jakolof Cove to hold rehabilitated otters from SORC. The first otters were transferred from Seward to the Jakolof Pre-Release Facility (JPRF) on 28 May; 99 otters were eventually transferred to this center from 28 May to 7 August. Overall, SORC received 187 otters, of which 151 survived and 36 died; 21 of 
the 151 otters completed their rehabilitation at the Valdez Center. A maximum of 97 otters were held at the Seward Center at one time (Fig. 2). The Seward Center was closed on 12 September after the rehabilitated otters were released, transferred to JPRF, or sent to the Point Defiance Aquarium.

A temporary care facility for sea otters was started in Homer as a private effort by local resident N. Hillstrand. Hillstrand had worked as a volunteer at VORC, then returned on 9 April to organize a holding center at the Homer Junior High School; this center could hold about 10 otters. Initially, otters that arrived in Homer from the Kenai Peninsula were stabilized before being flown to the rehabilitation centers in Valdez or Seward. The first oiled sea otter arrived at the Homer facility on 25 April. At the same time, Hillstrand began preparations for the Jakolof Pre-Release Facility at Little Jakolof Cove and the Kasitsna Bay Research Center, which were along the southern shore of Kachemak Bay (across from Homer).

On 10 May, the Kenai Peninsula Borough began supporting the prerelease center with oil spill cleanup funds that had been donated by Exxon. The primary purpose of this facility was to hold rehabilitated otters from SORC until the Service completed a release plan for the Kenai Peninsula. On 15 May, the first six floating pens were placed in Little Jakolof Cove. At the same time, Exxon accepted direct financial responsibility for the project. The temporary holding facility at the Homer Junior High School was closed on 23 May, and its three adult otters and one captive-born pup were transferred to JPRF. The first rehabilitated otters from Seward began arriving at JPRF on 28 May. Of the 125 otters held at this center, 99 came from the Seward Center, and 14 came directly from the wild or were born to otters already in captivity. The maximum number of otters held at one time was 94 (Fig. 2). This facility was closed on 6 September after the rehabilitated otters were released.

\section{Kodiak}

In addition to Homer, a temporary care center was built at the National Marine Fisheries Service law enforcement center in Kodiak in late April. Otters from the Kodiak Archipelago and Alaska Peninsula were held for 1-2 days at this center until they were flown to the Seward Center. J. Bellinger of the Service directed the operation, and V. Vanek, a local veterinarian, provided medical care.

\section{Sea Otter Release}

As the Federal trustee for sea otters (Marine Mammal Protection Act of 1972), the Service was responsible for the disposition of rehabilitated otters. Because we were using temporary holding centers that were not designed for wildlife rehabilitation, holding large numbers of sea otters was logistically difficult and posed health problems. As a result, the senior staff at the rehabilitation centers requested that otters be released as soon as possible.

On 15 May, the first six rehabilitated sea otters from VORC, and a territorial male that entered the holding pen, were released by the Service in Simpson Bay, Prince William Sound (Table). Biologists from the Service attached small radio transmitters to the hind flippers of these otters so that they could be tracked for several weeks. Information on their movements was used in preparing the release strategy for the remaining otters.

After prolonged deliberation and consultation with experts on sea otter management and biology, the release strategy for the remaining otters was completed in early July. In general, it called for otters captured in Prince William Sound to be released in the eastern (unoiled) part of the sound, and otters captured along the Kenai Peninsula and around Kodiak Island to be released in unoiled areas of the Kenai Peninsula. The release strategy contained additional Service stipulations that as many as 60 otters would have radio transmitters implanted in their abdomens and be released in Prince William Sound so that they could be tracked for 2-3 years. A prerelease blood sample was to be taken from each otter as part of a final health assessment.

Surgical implantation of radio transmitters in sea otters at VORC was scheduled to begin on 13 July. In the early morning, before the Service surgical team arrived, unknown persons cut the nets in the floating pens at the octagon facility at the Solomon Gulch Hatchery. Thirteen of the 65 otters escaped, but five of these were recaptured. The persons responsible, and their reasons for releasing the otters, were never determined, but opposition to the planned surgeries was known to exist among some of VORC's staff. Despite this incident, 23 otters at the Valdez Center had transmitters implanted from 13 July to 17 July. Thirteen female otters (nine with transmitters) were released on 27 July in Sheep Bay, and 15 male otters (12 with transmitters) were released on 28 July in Nelson Bay; both bays are 
Table. Disposition of sea otters from the rehabilitation centers at Valdez and Seward and the prerelease facility at Little Jakolof Cove.

\begin{tabular}{|c|c|c|c|}
\hline Date (1989) & $\begin{array}{c}\text { Number } \\
\text { of } \\
\text { otters }\end{array}$ & Location of release & Center $^{\mathrm{A}}$ \\
\hline 2 April & 1 & Sea World ${ }^{b}$ & VORC \\
\hline 12 April & 4 & Point Defiance Aquarium ${ }^{c}$ & VORC \\
\hline 13 April & 2 & Monterey Bay Aquarium & VORC \\
\hline 17 April & 4 & Vancouver Aquarium ${ }^{\mathrm{d}}$ & VORC \\
\hline 24 April & 1 & Valdez Bay & VORC \\
\hline 15 May & 7 & Simpson Bay & VORC \\
\hline 19 May & 1 & Valdez Bay & VORC \\
\hline 12 June & 1 & Kachemak Bay & HTCF \\
\hline 17 June & 2 & Little Jakolof & HTCF \\
\hline 13 July & 8 & Valdez Bay ${ }^{e}$ & VORC \\
\hline 14 July & 4 & Little Jakolof & HTCF \\
\hline 15 July & 4 & Little Jakolof & HTCF \\
\hline 27 July & 13 & Sheep Bay & VORC \\
\hline 28 July & 1 & Herring Island, Kachemak Bay & HTCF \\
\hline 28 July & 15 & North Fork, Nelson Bay & VORC \\
\hline 4 August & 4 & Sea World & VORC \\
\hline 5 August & 1 & Little Jakolof & HTCF \\
\hline 11 August & 10 & Little Jakolof & HTCF \\
\hline 13 August & 2 & Little Jakolof & HTCF \\
\hline 15 August & 6 & Nelson Bay & VORC \\
\hline 15 August & 8 & Sheep Bay & VORC \\
\hline 16 August & 3 & Nelson Bay & VORC \\
\hline 16 August & 8 & Sheep Bay & VORC \\
\hline 16 August & 7 & Sheep Bay & SORC \\
\hline 17 August & 7 & Taylor Bay & SORC \\
\hline 17 August & 1 & Picnic Harbor & SORC \\
\hline 19 August & 7 & North Arm of Nuka Bay & HTCF \\
\hline 19 August & 16 & James Lagoon, McCarty Fjord & HTCF \\
\hline 20 August & 8 & James Lagoon, McCarty Fjord & HTCF \\
\hline 21 August & 25 & Harris Bay & HTCF \\
\hline 21 August & 2 & Herring Island, Kachemak Bay & HTCF \\
\hline 22 August & 18 & South Shore, Sheep Bay & HTCF \\
\hline 22 August & 3 & Nelson Bay & HTCF \\
\hline 22 August & 4 & Harris Bay & SORC \\
\hline 30 August & 4 & Little Jakolof & HTCF \\
\hline 11 September & 13 & Point Defiance Aquarium & SORC \\
\hline Total & 225 & & \\
\hline $\begin{array}{l}{ }^{\mathrm{a}} \text { VORC }=\text { Valdez Ott } \\
\text { Facility. } \\
{ }^{\mathrm{b}} \text { Does not include } 4 \\
{ }^{\mathrm{c}} \text { Does not include } 2 \\
{ }^{\mathrm{d}} \text { Does not include } 2 \\
{ }^{\mathrm{e}} \text { One otter escaped }\end{array}$ & $\begin{array}{l}\text { litation Cen } \\
\text { t died in caI } \\
\text { t died in caI } \\
\text { t died in caI }\end{array}$ & Seward Otter Rehabilitation Center, a & omer Temp \\
\hline
\end{tabular}


in eastern Prince William Sound. On 15-16 August, the remaining 24 otters were released in Nelson Bay and Sheep Bay; 22 of these received only flipper tags, and 2 (a male and female) had abdominal radio transmitters.

Four rehabilitated otters at VORC had chronic health problems, including partial paralysis, blindness, liver damage, and poor coat condition. Because their survival in the wild was judged to be unlikely by the veterinary staff, these otters were sent to Sea World San Diego on 4 August.

At SORC, abdominal radio transmitters were surgically implanted in 10 otters from 15 July to 4 August; 7 of these animals were released on 16 August in Nelson Bay in Prince William Sound, and 3 were transferred to JPRF. Otters without radio transmitters were released in Taylor Bay (7), Picnic Harbor (1), and Harris Bay (4) from 17 August to 22 August. On 11 September, 13 orphaned sea otter pups, which were too young to be released (less than 6 months), were transferred to the Point Defiance Aquarium.

At the Homer Temporary Care Facility, the Service gave permission to release one otter on 12 June and two pregnant otters on 17 June in Kachemak Bay. Similar releases were made on 14 and 15 July (four females with pups), 28 July, and 5 August (one otter each day), 11 August (three females with pups and four females without pups), and 13 August (two otters). On 11 August, abdominal radio transmitters were surgically implanted in 12 otters; these 12 along with 3 otters that had received radio transmitters in SORC and 5 other otters without radio transmitters, were released in Sheep Bay and Nelson Bay in eastern Prince William Sound on 22 August. From 19 August to 21 August, 56 otters without radio transmitters were released along the southern coast of the Kenai Peninsula in Nuka Bay, James Lagoon, and Harris Bay. Of the remaining otters,
Fig. 3. Comparison of staff levels at the rehabilitation centers.

Fig. 4. Ratio of personnel to sea otters (Enhydra lutris) for the total program (i.e., all rehabilitation and prerelease centers).
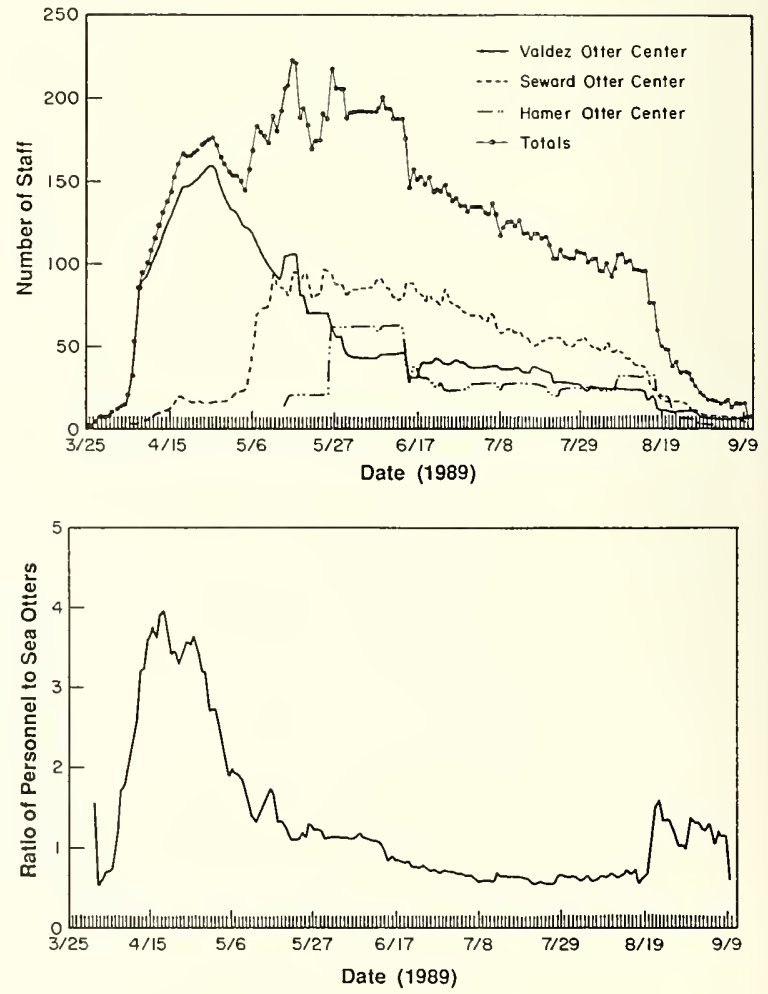
two were released in Kachemak Bay (21 August) and four in Little Jakolof Cove (30 August).

\section{Personnel and Cost Analysis}

\section{Staffing Requirements}

The Valdez Otter Rehabilitation Center had 159 paid staff and did not use volunteers after early April (Fig. 3). The Seward Center had 36 paid staff and 63 volunteers. The Jakolof Pre-Release Facility had 35 paid staff and 28 volunteers for a maximum of 63 . When all major centers are considered together, the ratio of personnel to otters reached a peak of 1:3.9 in April (the period of heaviest oiling and the most severe toxic reactions) and showed a steady decline to about 1:0.5 through July and early August (the period when most of the otters were rehabilitated and awaiting release; see Fig. 4). In September, the ratio increased as the last otters were released and the activities of the remaining staff were directed toward preparation of a computerized data base and data analysis.

\section{Cost Analysis}

From 24 March to 15 September 1989, Exxon spent about $\$ 18,300,000$ to support the sea otter rescue program (Fig. 5; see Appendix $\mathrm{C}$ for a cost itemization). This amount was divided into the following categories:

\section{Category}

1. Salaries for staff

Amount Percentage

2. Construction of rehabilitation centers

$\$ 5,900,000 \quad 32$

3. Boat and aircraft charters

$4,200,000 \quad 23$

$3,200,000 \quad 18$

$3,300,000 \quad 18$

4. Supplies and operations

5. Sea otter food 950,000

5

6. Aquariums and miscellaneous costs

Total

$\frac{750,000}{\$ 18,300,000} \frac{4}{100}$

\section{Conclusions and Recommendations}

Exxon's sea otter rescue program rehabilitated 225 otters at an estimated cost of $\$ 18,300,000$ ( $\$ 81,300$ per otter). Historically, this ranks as the most expensive program to rehabilitate oiled wildlife ever sponsored by a private company or government agency. However, with advance preparation, more cost-effective rehabilitation programs are possible.

A rehabilitation center must include a well-organized administration, veterinary staff, and husbandry staff. Volunteers can be used successfully in rehabilitation programs as long as they are well organized and trained.

Because the immediate release of rehabilitated sea otters may not be possible, oil spill contingency plans should include prerelease centers designed to hold otters for up to 6 months.

For a rapid and effective response, rehabilitation centers and a trained staff need to be established as part of an oil spill contingency plan for sea otters and other marine mammals.

\section{References}

Davis, R. W., T. M. Williams, J. A. Thomas, and R. A. Kastelein. 1986. Sea otter oil spill mitigation study. Minerals Management Service Rep. 86-0009. $219 \mathrm{pp}$.

Williams, T. M., J. McBain, R. Wilson, and R. Davis. 1990. Clinical evaluation and cleaning of sea otters affected by the T/V Exxon Valdez oil spill. Pages 236-257 in K. Bayha and J. Kormendy, tech. coords. Sea Otter Symposium: Proceedings of a symposium to evaluate the response effort on behalf of sea otters after the T/V Exxon Valdez oil spill into Prince William Sound, Anchorage, Alaska, 17-19 April 1990. U.S. Fish Wildl. Serv., Biol. Rep. 90(12).

Fig. 5. Cost analysis for the sea otter rescue program. 


\section{Appendix A. Chronology of Events for the Sea Otter Rehabilitation Centers.}

Valdez

24 March

27 March

$30 \mathrm{March}$

2 April

2 April

6 April

12 April

13 April

17 April

22 April

15 May

22 May

1 June

13 July

13,14 , and 17 July

27 July

28 July

4 August

15 August

16 August

18 August

29 August

\section{T/N Exxon Valdez runs aground on Bligh Reef}

First rehabilitation center (Valdez Otter Rehabilitation Center, or VORC) opens in the Copper Basin Hall at the Prince William Sound Community College

The first oiled sea otter arrives at VORC

Begin construction of the new VORC in the gymnasium at the Growden-Harrison Complex (formerly an elementary school and now part of the Prince William Sound Community College)

Send six otters to Sea World San Diego; one dies in Anchorage and four eventually die in San Diego

VORC moves out of the Copper Basin Hall and into the Growden-Harrison Complex

Send six otters to Point Defiance Aquarium; two ultimately die and one is transferred to Sea World

The first rehabilitated sea otters are placed into floating pens in the small boat harbor in Valdez

Send six otters to Vancouver Aquarium, British Columbia

Transfer rehabilitated otters from floating pens in the small boat harbor to the Solomon Gulch Hatchery

Service releases six rehabilitated sea otters with flipper radio-tags in Simpson Bay, Prince William Sound

Otters being held at the Solomon Gulch Hatchery are transferred to a large, floating salmon pen ("the octagon") in Port Valdez Bay

Move VORC out of the Growden-Harrison Complex and into the Salmon Exchange

Unknown persons cut the nets at the octagon holding pens; 13 rehabilitated otters escape; 5 are recaptured

Abdominal radio transmitters are implanted in 23 otters at the octagon holding pens

Release 13 rehabilitated male otters (12 with abdominal radio-implants) in Nelson Bay, Prince William Sound

Release 15 rehabilitated female otters ( 9 with abdominal radio-implants) in Sheep Bay, Prince William Sound

Four sea otters with chronic health problems are sent to Sea World San Diego

Release six otters in Nelson Bay and eight otters in Sheep Bay, Prince William Sound

Release 11 otters in Nelson Bay, Prince William Sound

Rehabilitation center at Salmon Exchange and octagon closes; demobilization completed on 25 August

Transfer work on the computerized data base from the community college to Exxon's offices in the Royal Center in Valdez 
15 September

Transfer work on the computerized data base from Valdez to Exxon offices in Anchorage

\section{Seward}

1 April

7 April

21 April

2 May

5 May

8 May

17-20 May

28 May

15 and 27 July

16 August

17 August

22 August

11 September

12 September
Oil spill threatens Kenai Peninsula. Service asks Exxon to open a sea otter rehabilitation center in Seward (Seward Otter Rehabilitation Center, or SORC)

J. Styers is selected to be the director of the rehabilitation center in Seward; site selection and facility design begin

Groundbreaking and construction begin on new center

First otter from Kodiak arrives

First oiled sea otter from the Kenai Peninsula is cleaned. Cleaned otters are temporarily held at the Seward Bird Rehabilitation Center

Basic facilities for treating oiled sea otters are usable

Twenty-one otters transferred to VORC to relieve crowding at SORC

First rehabilitated sea otters are transferred to the Jakolof Pre-Release Facility (JPRF)

Abdominal radio transmitters implanted in 10 otters

Seven otters with radio-implants are released in Sheep Bay, Prince William Sound

Seven sea otters are released in Taylor Bay, and one is released in Picnic Harbor, Kenai Peninsula

Four otters are released in Harris Bay, Kenai Peninsula

Thirteen sea otter pups are transferred to the Point Defiance Aquarium

SORC closes and is winterized for possible use in 1990

Homer Temporary Care Facility established at the Homer Junior High School

First oiled otter arrives from Tonsina Bay and is cleaned at the temporary care center

10 May

15 May

23 May

28 May

17 June

14 July

11 August

13 August

19-21 August
Kenai Peninsula Borough begins providing funds for construction of Jakolof Pre-Release Facility, or JPRF

Exxon assumes financial responsibility for JPRF

Homer Temporary Care Facility at the Homer Junior High School is closed; four remaining otters are transferred to JPRF

First transfer of otters from SORC to JPRF

Release two pregnant otters in Little Jakolof Cove

Release four females with their pups (eight total) in Little Jakolof Cove

Abdominal radio transmitters implanted in 12 otters. Ten otters without transmitters released in Little Jakolof Cove

Two late-term pregnant otters released in Little Jakolof Cove

Otters without radio transmitters released in Nuka Bay (7), James Lagoon (24), and Harris Bay (25), and two rogues at Herring Islands in Kachemak Bay along the Kenai Peninsula 
22 August

Twelve otters with abdominal radio transmitters and nine otters without transmitters are released in Sheep Bay and Nelson Bay in Prince William Sound

30 August Last four otters released. Demobilize center 


\section{Appendix B. Key Personnel and Staff Directories for the Rehabilitation Centers.}

\section{Key Personnel}

1. Exxon environmental program manager:

M. Maki

2. Exxon coordinators for birds and sea otters:

T. Monahon

R. Ortega

3. Senior staff:

R. Davis, senior director, Sea Otter Rehabilitation Program

T. M. Williams, director, Valdez Otter Rehabilitation Center

J. Styers, director, Seward Otter Rehabilitation Center

T. McCloskey, operations manager, Seward Otter Rehabilitation Center

N. Hillstrand, director, Homer Pre-Release Facility

4. Veterinarians:
J. Balke
C. McCormick
R. Basaraba
S. Rap
C. Bittner
D. Sawyer
J. Blake
P. Schroeder
D. Brigmon
H. Spalding
R. Broshes
J. Tuomi
T. Gornall
P. Tuomi
G. Grady
N. Utkov
J. Groff
V. Vanek
K. Harris
S. Wagner
C. Harvey-Clark
T. D. Williams
K. Hill
R. Wilson
M. Isenhart
T. M. Work
M. Jones
G. Wrightson

J. McBain

5. Veterinary technicians:

P. Chen

L. Kari
A. Christiansen
J. Cunard
D. DeVaul
C. Evans
A. Green
L. Hamblen

L. Kelly

D. Mays

B. Miller

J. Rash

T. Thomas

C. Westra

6. Toxicologist:

R. V. Chalam 


\section{Staff directories}

Valdez Otter Rehabilitation Center

Adams, S.

Adamthwaite, $\mathrm{M}$.

Adkins, B.

Armitstead, C.

Aytch, W.

Baird, L.

Balke, J.

Ballesterov, S.

Basaraba, R.

Basham, M.

Bates, M.

Bell, R. J.

Bennett, R.

Berrey, D.

Bittner, C.

Bizzanelli, R.

Blake, J.

Braumberger, D.

Bressler, M.

Bridgman, R.

Brooks, K.

Brown, N.

Burke, G.

Burr, $\mathrm{H}$.

Butler, J.

Carr, M.

Casson, C.

Castleman, M.

Chalam, R. V.

Chapman, B.

Chen, $\mathrm{P}$.

Christiansen, A.

Clark, M.

Clarke, J.

Coiley, P.

Corey, C.

Coulter, W.

Cripe, J.

Crisp, K.

Cross, J.

Cunard, J.

Curtis, S.

Darbonne, $\mathrm{O}$.

Datta, J.

Davis, G.

Davis, $R$.

Davis, S.

Day, J.

DeVaul, D.

Donofrio, G.
Doss, D.

Dudley, M.

Ennen, L. A.

Ernst, R.

Elperszce, F.

Evans, C.

Ezell, B.

Ezell, S.

Facer, R.

Ferrante, $P$.

Finstad, G.

Fitz-Gibbons, J.

Fleagle, T.

Francis, P.

Fritze, M.

Fry, M.

Gallagher,

Mary Garrett

Godomski, Jim

Goodman, Richard

Gornall III, Tag

Graham, L.

Green, A.

Green, J.

Groff, J.

Groundwater, P.

Grunditz, R.

Guenther, R.

Gunion, D.

Haebler, M.

Hale, A.

Hamblen, L.

Hans, D.

Hardy, B.

Harlan, R.

Heathman, Don

Hendricks, J.

Hill, K.

Holbrook, R.

Holliker, A.

Hoppmann, M.

Houck, J.

Howe, $\mathrm{T}$.

Huber, R.

Hubinsky, C.

Hudson, B.

Hudson, C.

Humphrey-Dahl,V.

Hunter, L.

Hymer, J.
Isenhart, $\mathrm{M}$.

Jenkins, R.

Jenkins, T.

Jenks, B.

Jennings, $P$.

Jones, M.

Kari, L.

Kelly, L.

Kelsey, T.

Kincaid, S.

King, C.

King, R.

Klein, J.

Kleinhans, L.

Knight, R.

Knuepfer, G.

Kresh, D.

Kurtz, J.

Landry, D.

Lapella, E.

Lillie, J.

Lillie, $\mathrm{P}$.

Lorenzo, D.

Loshbaugh, S.

Maillard, H.

Maki, M.

Maleski, E.

Marksberry, J.

Marquardt, $\mathrm{K}$.

Masson, M.

Matters, $M$.

Maurer, M.

Maynes, L.

Merry, D.

Michaelson, N.

Micic, V.

Millard, G.

Miller, K.

Minish, $\mathrm{K}$.

Mitsui, B.

Morrison, J.

Mosenthin, E.

Mucler, M.

Mulcahy, M.

Murphy, D.

Murphy, L.

Murphy, T.

McBain, J.

McBain, L.

McCarthy, K. 
McCormick, C.

McCollum, C.

McDonough, D.

McGuire, S.

McHole, D.

McKim, T.

McNally, D.

McPhersen, R.

Neece, M.

Nelson, J.

Nielsen, B.

Nielsen, R.

Norton, L.

Osburn, J.

Paul, D.

Peers, R.

Peterson, B.

Peterson, E.

Pettit, M.

Pierce, L.

Pike, G.

Pittman, L.

Pittman, M.

Poland, D.

Porritt, D.

Privett, B.

Quintero, B.

Rapp, S.

Rash, J.

Rice, B.

Rich, K.

Richards, J.

Rideout, B.

Roletto, J.

Romey, T.

Rooth, S.

Rudd, L.

Rynshoven, P.
Salcedo, J.

Samms, A.

Sassic, P.

Sawyer, D.

Scanlon, K.

Schaedler, C.

Schlichting, $P$.

Schroeder, P.

Sclenk, B.

Shaw, D.

Sheldon, D.

Small, K.

Smith, D.

Smith, L.

Smith, R.

Snodgrass, J.

Stack, C.

Stern, S.

Stevens, C.

Stevens, S.

Stewart, J.

Stolpe, S.

Stough, R.

Stoughton, L.

Suchin, K.

Suits, J.

Swanson, B.

Swanson, K.

Sweitzer, A.

Tabler, $\mathrm{H}$.

Taylor, D.

Thomas, M.

Thomas, T.

Tomlinson, J.

Tomlinson, P.

Tomlinson, $\mathrm{T}$.

Tonsha, M.

Toor, A.
Tormquist, C.

Truit, B.

Tundidor, J.

Tuomi, J.

Tuomi, $\mathrm{P}$.

Utkov, $\mathrm{N}$.

Vans, F.

Vanlandingham, C.

Vasey, $\mathrm{K}$.

Vicary, C.

Violett, B.

Walter, L.

Watkins, D.

Watson, R.

Watts, J.

Weiss, F.

Welch, C.

Westra, C.

Westy Wheatley, E.

Whitehead, T.

Wicken, M.

Wigdahl, D.

Wiles, J.

Wilkinson, B.

Williams, B.

Williams, G.

Williams, $\mathbf{M}$.

Williams, T. D.

Williams, 'T. M.

Wilson, J.

Wilson, $\mathrm{R}$.

Winkley, B.

Wood, B.

Woodbery, B.

Wrightson, G.

Wunnicke, $\mathrm{P}$.

Ydon, R.

Yonikos, $\mathrm{P}$.

\section{Seward Otter Rehabilitation Center}

Anton, J.

Anton, N.

Brigmon, D.

Cassen, C. J.

Chen, P.

Christiansen, A.

Coiley, P.

Colgan, G.

Della Rocca, M.

Dumas, C.

Ferrante, P.

Fisher, R.

Foster, J.
Geis, E.

Gornall III, T.

Hackett, S.

Hancock, R.

Harvey-Clark, C.

Henderson, $\mathrm{R}$.

Holonko, T.

Kahlstrom, A.

Kelly, L.

Kerns, P.

Kunnuk, I.

Kurihara, J.

Loquvam, J.
Mackie, P.

Marquardt, K.

Mays, D.

McCloskey, T.

McCormick, C.

McKay, S.

Michaelson, N.

Miller, B.

Nadeau, J.

Neece, M.

O’Malley, T.

Ollestad, O.

Olsen, M. 


\begin{tabular}{|c|c|c|}
\hline $\begin{array}{l}\text { Ord, R. } \\
\text { Otten, J. } \\
\text { Peers, R. } \\
\text { Prochazka, J. } \\
\text { Rainville, S. } \\
\text { Rash, J. } \\
\text { Roletto, J. } \\
\text { Romey, T. } \\
\text { Rose, S. } \\
\text { Schmidt, K. } \\
\text { Spalding, H. }\end{array}$ & $\begin{array}{l}\text { Stough, R. } \\
\text { Styers, A. } \\
\text { Styers, J. } \\
\text { Styers, J. } \\
\text { Suellentrop, L. } \\
\text { Swarthout, D. } \\
\text { Thomas, T. } \\
\text { Thomas, T. } \\
\text { Tuomi, P. } \\
\text { Utkov, J. N. } \\
\text { Valet, S. }\end{array}$ & $\begin{array}{l}\text { VanBlaricom, G. } \\
\text { Vasey, K. } \\
\text { Vastbinder, W. } \\
\text { Vicary, C. } \\
\text { Wiles, J. } \\
\text { Williams, T. D. } \\
\text { Wilson, F. } \\
\text { Work, T. } \\
\text { Wunnicke, P. }\end{array}$ \\
\hline \multicolumn{3}{|c|}{ Homer Temporary Care Facility and Little Jakolof Cove Pre-release Facility } \\
\hline $\begin{array}{l}\text { Ackert, D. } \\
\text { Almond, D. } \\
\text { Balke, J. } \\
\text { Baugher, T. } \\
\text { Brown, N. } \\
\text { Christiansen, A. } \\
\text { Curtis, S. } \\
\text { Dequattro, S. } \\
\text { Dunn, P. } \\
\text { Falardeau, S. } \\
\text { Fletcher, B. } \\
\text { Galvan, J. } \\
\text { Grady, G. } \\
\text { Hafemeister, L. } \\
\text { Hart, M. }\end{array}$ & $\begin{array}{l}\text { Heneghan, J. } \\
\text { Heneghan, T. } \\
\text { Hill, K. } \\
\text { Hillstrand, N. } \\
\text { Ireland, C. } \\
\text { Jenkins, H. } \\
\text { Kaun, B. } \\
\text { King, T. } \\
\text { Knodel-Fidler, K. } \\
\text { Loshbaugh, S. } \\
\text { Mario, J. } \\
\text { Marquardt, K. } \\
\text { Mead, T. } \\
\text { McCue, R. } \\
\text { McDonald, J. }\end{array}$ & $\begin{array}{l}\text { Million, M. } \\
\text { Rapp, S. } \\
\text { Rhyneer, B. } \\
\text { Robertson, M. } \\
\text { Schulz, S. } \\
\text { Simonis, L. } \\
\text { Stark, R. } \\
\text { Thomas, S. } \\
\text { Tillet, C. } \\
\text { Tingook, T. } \\
\text { Tolle, J. } \\
\text { Tuomi, P. } \\
\text { Williams, T. D. } \\
\text { Wunnicke, P. }\end{array}$ \\
\hline
\end{tabular}




\section{Appendix C. Cost Analysis and Itemization.}

From 24 March to 15 September 1989, Exxon spent about $\$ 18,300,000$ ( $\$ 81,300$ per otter) to support the sea otter rescue program. This amount was divided into the following categories:

Category

1. Salaries for staff

2. Construction of rehabilitation centers

3. Boat and aircraft charters

4. Supplies and operations

5. Sea otter food

6. Aquariums and miscellaneous costs

Total
Amount

$$
\$ 5,900,000
$$$$
4,200,000
$$$$
3,200,000
$$$$
3,300,000
$$$$
950,000
$$$$
750,000
$$

$\$ 18,300,000$
Percentage

32

23

18

18

5

4

100

Cost itemization:

1. Salaries included the staff at the three otter centers as well as contract personnel (VE Construction Company, Inc.) on the capture boats.

2. Construction costs included materials and contract labor costs to build the rehabilitation centers at Valdez and Seward, the prerelease facility centers at Valdez and Seward, the prerelease facility at Jakolof Cove, and temporary care facilities at Homer and Kodiak Island.

3. Boat and aircraft expenses included 13 capture boats, a dedicated Bell 212 helicopter, and other aircraft for transporting sea otters.

4. Supplies and operations included costs for food, lodging, and transportation for the staff as well as various supplies, equipment, and lease expenses.

5. Sea otter food included a variety of frozen and fresh seafood.

6. Aquarium expenses included payments to Sea World, Monterey Bay Aquarium, Point Defiance Aquarium, and Vancouver Aquarium, all of which received otters. 


\title{
Valdez Otter Rehabilitation Center
}

by

\author{
R. W. Davis \\ International Wildlife Research \\ Texas A\&M University \\ Department of Marine Biology \\ P.O. Box 1675 \\ Galveston, Texas 77553
}

and

\section{T. M. Williams}

Naval Oceans Systems Center

P.O. Box 997

Kailua, Hawaii 96734

\begin{abstract}
The Valdez Otter Rehabilitation Center was first opened in the Copper Basin Hall at the Prince William Sound Community College on 27 March 1989. About $280 \mathrm{~m}^{2}$ were available for cleaning and holding sea otters (Enhydra lutris). This area was used until 6 April. The new rehabilitation center, built at the Growden-Harrison Complex (a former elementary school), provided $576 \mathrm{~m}^{2}$ each of indoor and outdoor space. Fifty-six holding pens were built in the gymnasium for the critical care facility. Three trailers next to the gymnasium provided space for administration, a veterinary clinic, a clinical laboratory, otter washing, animal food preparation, staff lounge, and a staff office. The yard was used for outdoor pens and a reservoir. Pens with pools were plumbed for seawater from two plastic reservoirs $(3,785 \mathrm{~L}$ each) filled by a tanker truck. Rehabilitated otters were held in floating pens in the Valdez. Harbor, or raceways and pens at the Solomon Gulch Hatchery. The large, octagonal salmon pen in Port Valdez Bay was well suited for long-term holding because it enabled rehabilitated otters to regain muscle condition by swimming and diving. In addition to the otter center, there was a facility adjacent to the Copper Basin Hall for rehabilitating oiled harbor seal pups. The pens were similar to those used for sea otters. Paid staff reached a maximum of 159 in late April; volunteers were not used after early April. The number of personnel per otter peaked at 3.5 in April (the period of heaviest oiling and the most severe toxic reactions) and declined steadily to about 0.6 through July and early August (when most of the otters were rehabilitated and awaiting release).
\end{abstract}

The first sea otter rehabilitation center in Valdez, Alaska was in the Copper Basin Hall at the Prince William Sound Community College. About $280 \mathrm{~m}^{2}$ were available for cleaning and holding sea otters; this space was divided into six rooms with connecting hallways and two lavatories. Several closets and one small room were used to store supplies. We shared two rooms with workers from the International Bird Rescue Research Center. One of the rooms served as a communications center, and the other room was used as a staff dining area. 
Three cleaning stations (Fig. 1) were installed in one room that had a kitchenette; this room also served as a small veterinary clinic. Each cleaning station consisted of a wooden stand and a 189-L barrel that was cut lengthwise to form a basin; wire screen $(2.54 \times 2.54 \mathrm{~cm})$ was placed across the basin to support the otter while it was washed. The building's normal hot water supply was insufficient for cleaning three sea otters simultaneously, so an additional boiler ws installed in a shed adjacent to the building. Eight holding pens were made from plastic cargo totes $(0.9 \times 0.9 \times 0.6 \mathrm{~m})$ that could be filled with fresh water from a garden hose; although seawater would have been preferable, it was not available at the Copper Basin Hall. A small wooden bench $(0.3 \times 0.9 \mathrm{~m})$ in each tote provided a haul-out area for otters. Wastewater from the cleaning stations and totes drained through polyvinyl chloride (PVC) pipes into a lavatory sewage line.

Food for the otters, including clams, fish fillets, and crabs, was purchased from a wholesale seafood supplier (SeaHawk Sea Foods) in Valdez and stored in two chest freezers $\left(1.4 \mathrm{~m}^{3}\right.$ each). After thawing the food in a sink, it was placed in plastic buckets with ice and distributed to husbandry personnel; each otter was then fed by hand.

A separate room was used as a nursery for orphaned pups from the wild and pups that were

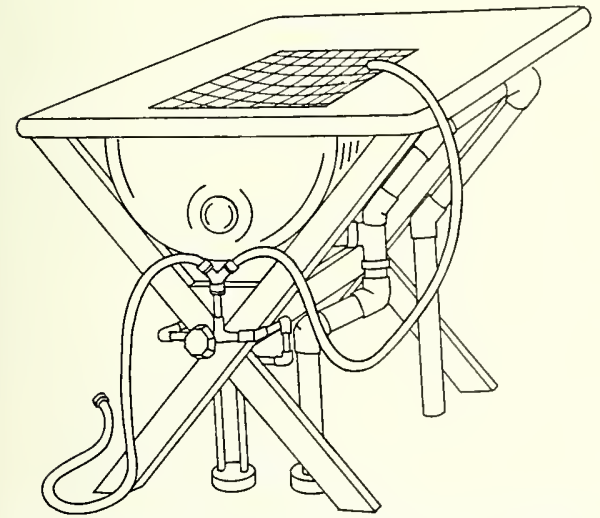

Fig. 1. Table used to clean oiled sea otters (Enhydra lutris). The sedated otter was placed on the plastic screen during washing. Each table was plumbed with hot and cold fresh water; water temperature was controlled with a mixing valve. The water fell into a plastic basin and drained into the sewer. born in captivity but whose mothers were unable to care for them. The pups rested on a water bed and were hand fed a formula developed at the Monterey Bay Aquarium.

To perform postmortem examinations on sea otters that died in the center, we rented a small salmon cannery (The Salmon Exchange) that was near the Valdez boat harbor. The $139 \mathrm{~m}^{2}$ building was divided into a salmon processing area, retail sales area, office, store room, walk-in freezer, and lavatory. The salmon processing area, which had several large, stainless steel tables and sinks, was converted into a necropsy and pathology laboratory. Tissue samples for toxicology were stored in the freezer at $-10^{\circ} \mathrm{C}$.

The new Valdez Otter Rehabilitation Center at the Growden-Harrison Complex opened on 6 April. It provided $576 \mathrm{~m}^{2}$ of indoor space for a critical care facility and an equivalent amount of outdoor space for pens and pools. Fifty-six holding pens were built in the gymnasium as part of the critical care facility; each pen could hold two otters. Three trailers $(3.05 \times 15.25 \mathrm{~m})$, which were placed next to the gymnasium, provided space for administration $\left(37 \mathrm{~m}^{2}\right)$, a veterinary clinic $\left(23 \mathrm{~m}^{2}\right)$, a clinical laboratory $\left(9.3 \mathrm{~m}^{2}\right)$, sea otter washing facilities $\left(23 \mathrm{~m}^{2}\right)$ staff dining area $\left(23 \mathrm{~m}^{2}\right)$, sea otter food preparation $\left(14 \mathrm{~m}^{2}\right)$, and a staff office $\left(9.3 \mathrm{~m}^{2}\right)$.

Three cleaning stations and a veterinary clinic were built in the sea otter washing trailer. The clinic was used as an examination room and to store drugs and medical supplies. An adjacent trailer housed the administrative offices and staff for the rehabilitation center, including secretarial staff, the personnel office, communications (telephones and FM base station), central files, and photocopying. A clinical laboratory for sea otter blood analysis was also in this trailer.

The third trailer was used for sea otter food preparation, a staff lounge, and a veterinary office. Frozen seafood was thawed under cold water in eight sinks and sorted on a large $(0.6 \times 3.1 \mathrm{~m})$ stainless steel counter. One-pound food portions were placed in plastic bags and stored on ice until delivered to the husbandry staff. The staff lounge was used primarily for meals, which were catered three times a day. This eating area was separated from the animal pens to ensure good hygiene. Fifteen portable toilets and three outdoor sinks were provided for the staff. A portable hot water system provided 60 gallons of water a minute for the washing area and critical care unit. 
The holding pens in the gymnasium were built in modules consisting of four plastic cargo totes that were separated with plywood partitions. A sliding door at the front of each tote could be removed to provide access to the otters (Fig. 2). Each tote $(0.9 \times 0.9 \times 0.6 \mathrm{~m})$ had a floor drain $5.1 \mathrm{~cm}$ in diameter and a side-mounted overflow drain positioned $20.3 \mathrm{~cm}$ above the bottom of the tote; drains could be opened or closed independently. Each pair of pens shared a hot and cold freshwater supply that was regulated with a shower valve. A wire mesh rack in each tote prevented the otter from lying in dirty water and debris. When the otters had regained their ability to thermoregulate in water, the wire racks were removed and the totes were filled with fresh water to a depth of $20.3 \mathrm{~cm}$ (the height of the overflow drain). A small wooden bench $(0.3 \times 0.9 \mathrm{~m})$ mounted along one side of the tote provided haulout space for the otter when the tote was filled with water.

Although these totes could be used as either dry pens or small pools, they had several problems. First, the plywood partitions did not allow adequate ventilation. This caused volatile ammonia from the urine to accumulate in the humid, stagnant air at the bottom of the tote. Second, the floor drain was too small (it should have been $10-15 \mathrm{~cm}$ in diameter) and often became clogged with food, which further contributed to the accumulation of ammonia. The humid air prevented the otter's newly cleaned fur, which had not yet regained its water-repellent quality, from staying dry. This problem was partly remedied by increasing venti- lation with fans. Third, the shallow water depth of the pens prevented the otters from rolling and tumbling while grooming. As a result, the otters tended to groom the upper half of their bodies but neglected the lower half. Because normal grooming is essential for the full restoration of an otter's fur, this problem slowed the rebabilitation process. Fourth, the confined space within the totes and the opaque wooden walls (as opposed to netting) may also have altered normal grooming behavior and slowed an otter's recovery. Most otters became more alert and groomed more regularly after they were placed in outdoor pens with net walls. However, in early April the outdoor air temperature regularly fell below freezing; therefore, many of the otters with serious health problems were kept indoors until they could thermoregulate in the cold air.

The yard northeast of the gymnasium was used for the holding pens and seawater reservoirs (Fig. 3). Two types of wooden pens were built; dry pens (Fig. 4) and pens with a plastic tote swimming pool (Figs. 5, 6, 7). Each of the 42 dry pens could hold one otter. However, because these pens did not allow the otters to groom in water, they were seldom used after an adequate number of pens with pools were built. Fourteen of the pens with pools could hold 1 or 2 otters (Figs. 5 and 6), and four could hold three or four otters (Fig. 7). Pools were plumbed for seawater from two plastic reservoirs $(3,785 \mathrm{~L}$ each) that were filled twice daily by a tanker truck. Overflow from the pools entered the sewage line. Animal waste from the
Fig. 2. Holding pens for the critical care facility. The pens were constructed from plastic totes and plywood.

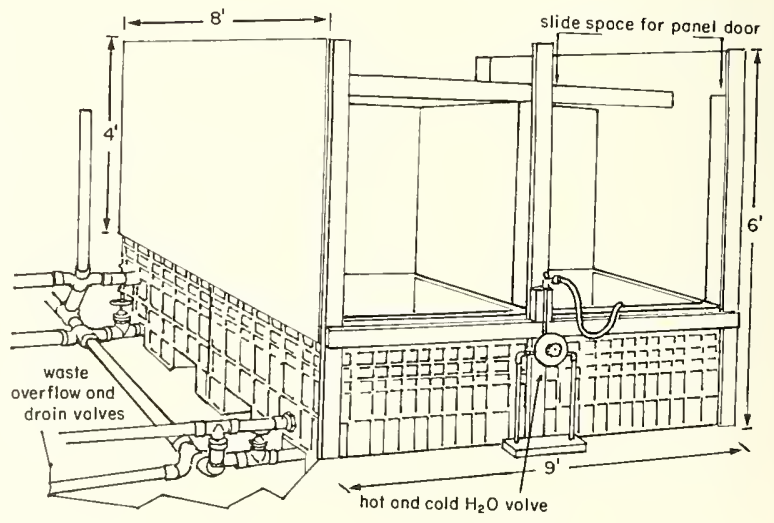




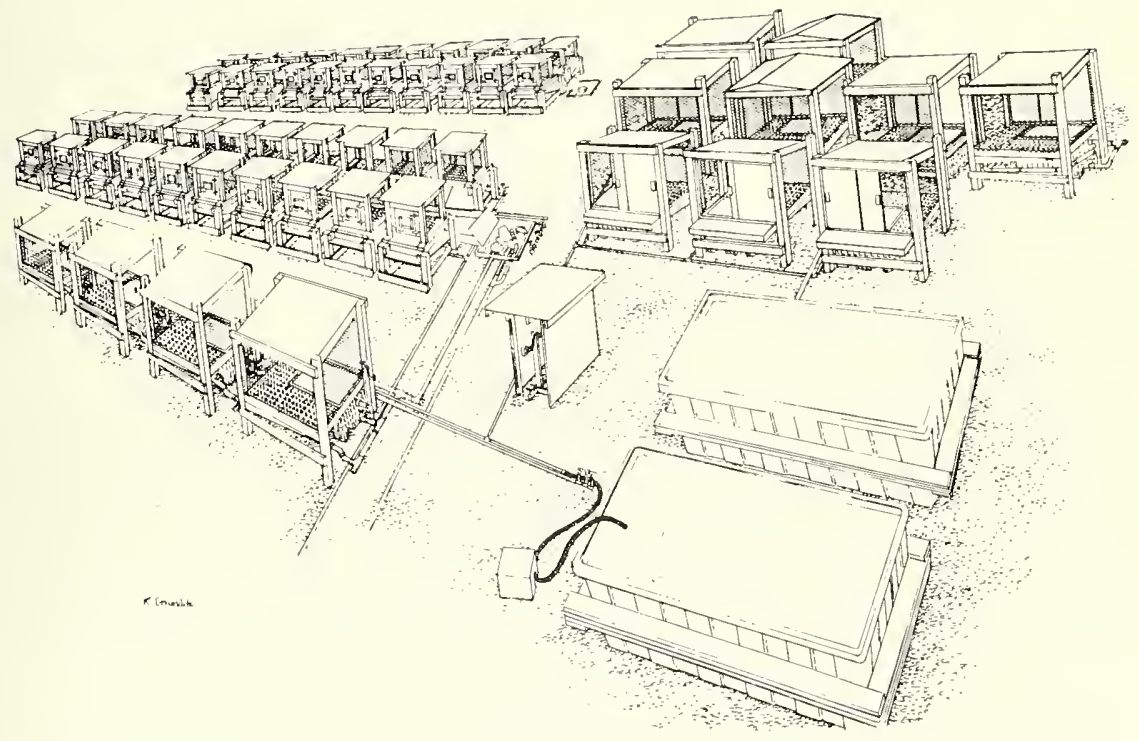

Fig. 3. Outdoor sea otter (Enhydra lutris) pens at the Valdez Otter Rehabilitation Center. Forty of the pens were dry, and 13 had plastic totes. Seawater, which was stored in two fiberglass reservoirs, was pumped into the pen pools. Wastewater was pumped into a sewage line.

dry pens was washed along a raceway and into a sump that was connected to a sewage line.

After the otters had recovered from the acute effects of oiling and had regained the water repellent-quality of their fur, they were transferred to floating pens in the small boat harbor (Fig. 8). The pens $(6.1 \times 6.1 \times 1.5 \mathrm{~m})$ were constructed from PVC pipe $5.08 \mathrm{~cm}$ in diameter and herring net. An area $(0.9 \times 3.1 \mathrm{~m})$ on the dock adjacent to each pen was enclosed with plywood to provide haul-out space; a small ramp led from the water onto the dock. An infrared heat lamp was mounted at one end of the haul-out space so that otters could warm themselves. This design was suitable for holding otters several months. However, the otters were constantly exposed to noise and visual disturbance from harbor activities, and water quality was poor because of fuel contamination.

When the slips we were using in the harbor were needed for fishing boats, we moved the otters to two salmon raceways at the Solomon Gulch Hatchery. The seawater raceways were about 
Wooden Outdoor Pen

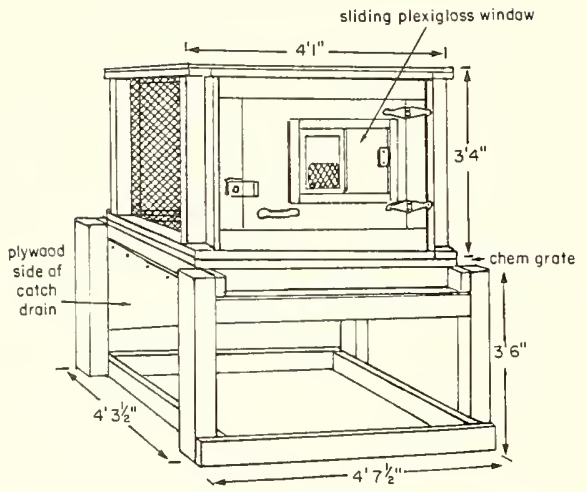

Fig. 4. Wooden sea otter (Enhydra lutris) pen. The floor was made of plastic grate, and the walls were made of plywood and herring net. A catch basin beneath the cage drained into a central raceway. These pens were replaced with pens that had pools.

$3.1 \mathrm{~m}$ wide, $18.3 \mathrm{~m}$ long, and $1.5 \mathrm{~m}$ ( 5 feet) deep. Each one was partitioned with movable net barriers into separate pens. A floating plywood platform was placed in each section so that the otters could haul out. A small wooden hut next to each raceway provided shelter for the husbandry personnel.
In June, the sea otters were moved from the salmon raceways to an offshore salmon pen that provided more space for swimming and diving (Fig. 9). This large, floating pen, about $61 \mathrm{~m}$ in diameter, was octagonal in shape and consisted of eight pie-shaped sections. Each netted section was $4.6 \mathrm{~m}$ deep and could hold $20-30$ otters. Haulout platforms were placed in each section. A small house in the center of the structure provided shelter for the staff. Two skiffs were used to transport personnel and supplies from the shore to the floating pen.

In addition to the otter rehabilitation center, a facility adjacent to the Copper Basin Hall was completed in June for holding rehabilitated harbor seal pups (Phoca vitulina; Fig. 10). Pens with pools were salvaged from the otter center. One of the seawater reservoirs was converted into a large pool, where the seal pups were allowed to swim twice daily.

\section{Personnel}

\section{Staffing Requirements}

Of the three otter rehabilitation centers, Valdez had the highest number of paid staff and did not use volunteers after early April. The number of staff reached a maximum of 159 in late April, when the rehabilitation center at the GrowdenHarrison Complex was fully operational, and we still had many otters that required intensive care
Fig. 5. Front view of a wooden pen with a tote pool; this size pen could hold one or two sea otters (Enhydra lutris). The floor was made of plastic grate and the walls were made of plywood and herring net.

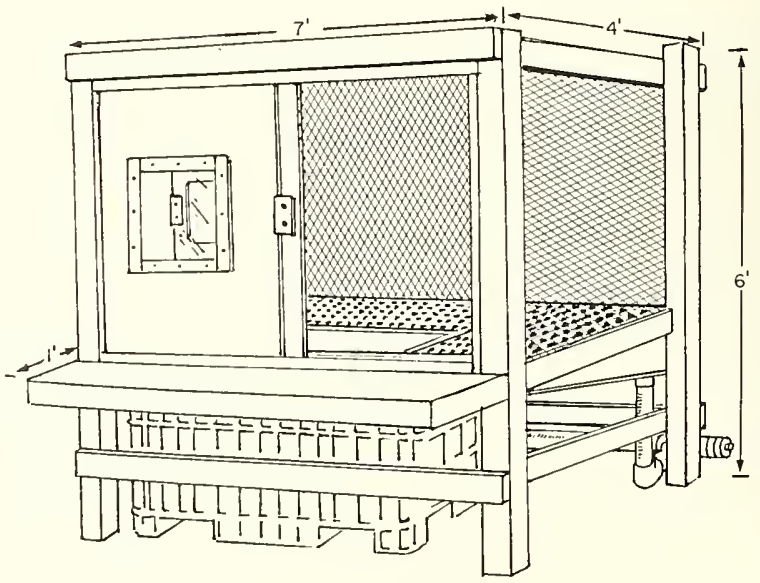




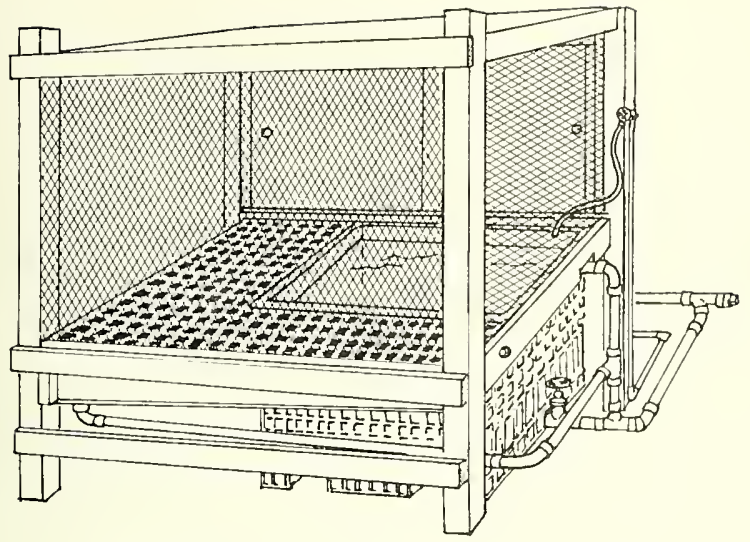

Fig. 6. Rear view of a wooden pen with a tote pool (same as Fig. 5). The pool was plumbed with seawater and had a floor drain and a skimmer drain.

Fig. 7. Rear view of a wooden pen with a tote pool that was designed for three or four sea otters (Enhydra lutris). The basic design and materials are similar to the pens shown in Figs. 5 and 6.
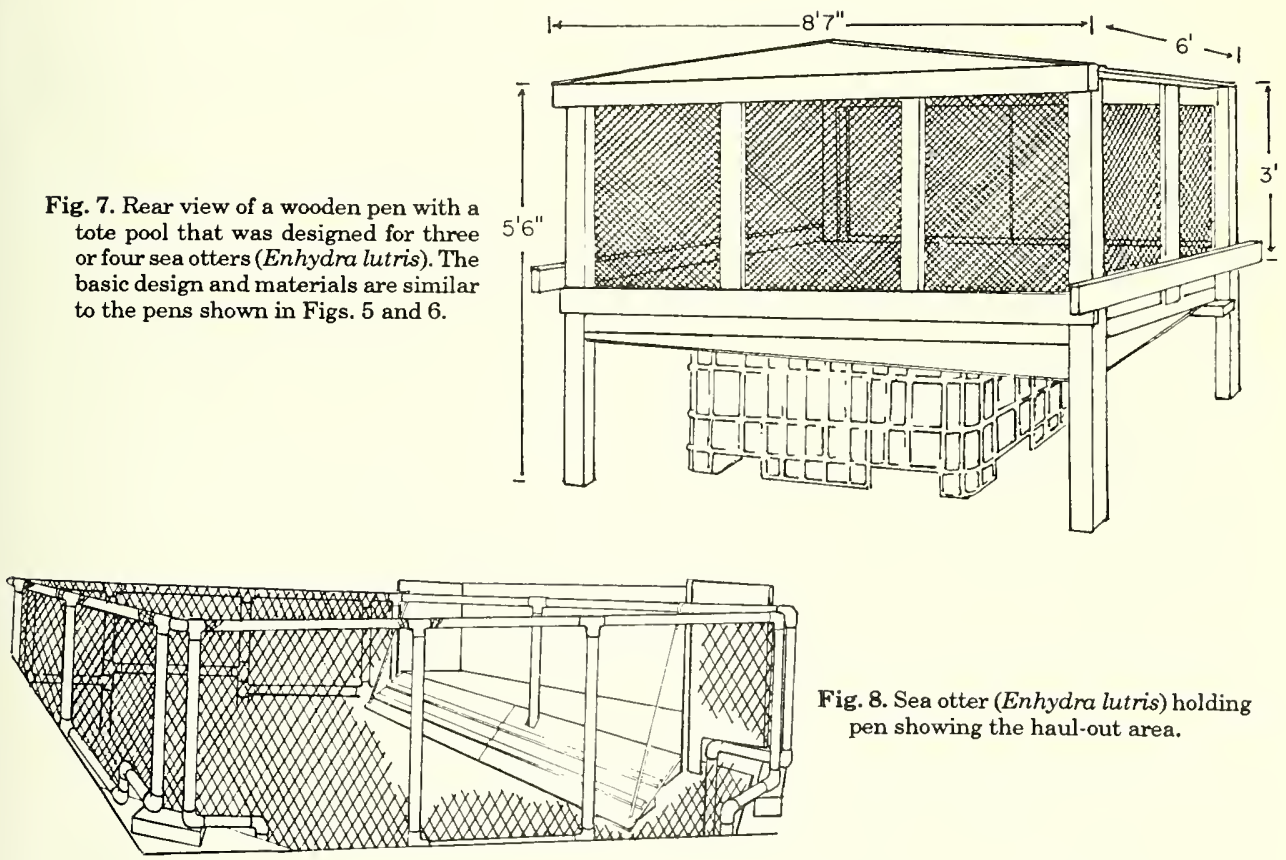

Fig. 8. Sea otter (Enhydra lutris) holding pen showing the haul-out area.

(Fig. 11). At this same time, the number of personnel per otter reached a maximum of 3.5 (Fig. 11). As the health of the animals improved, they were placed in seawater pens, and the number of staff that was needed to feed and care for the animals declined. As a result, the number of personnel per otter steadily declined in May and remained con. stant at about 0.6 from June to July. In August, the ratio increased as the rehabilitated otters were released, and the activities of the remaining 
Fig. 9. The floating, octagonal salmon pen used to hold sea otters (Enhydra lutris). Each netted section was $4.6 \mathrm{~m}$ (15 feet) deep and could hold 20-30 otters. Haul-out platforms were placed in each section. Some sections also contained smaller, secondary pens. The small hut was used by the otter handlers.

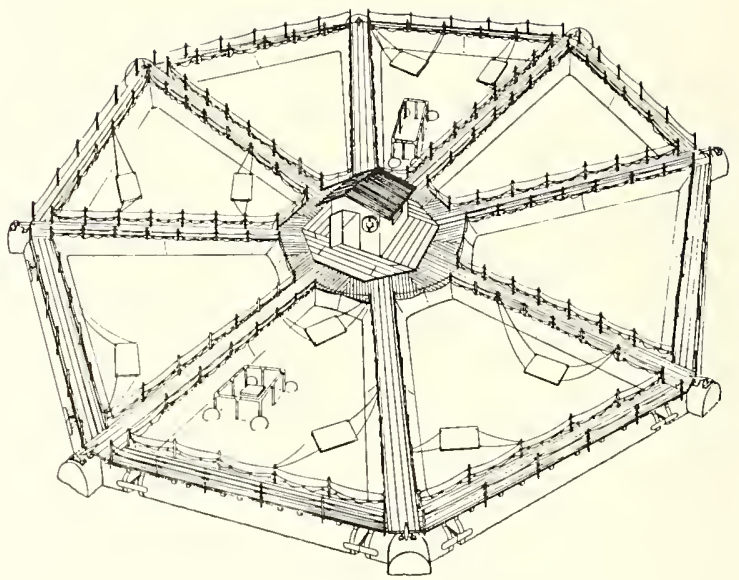

staff were directed toward data base preparation and analysis.

\section{Staff Organization}

The following organizational outline has been idealized to illustrate necessary personnel at the Valdez Otter Rehabilitation Center. For the most part, these staff positions existed in practice, although some employees assumed multiple responsibilities. As staff members rotated through the center, different employees held some of the following positions:

\section{Critical Functions}
A. Director
B. Operations supervisor

1. Husbandry shift coordinators (two shifts)

a. Animal monitors, handlers, and cage cleaners

b. Nursery staff

c. Sea otter cleaning crews

2. Animal food coordinator

a. Kitchen staff

3. Veterinary coordinator

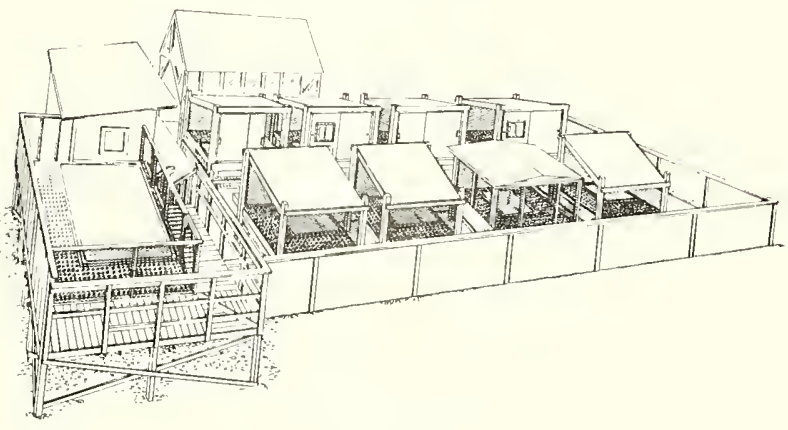

Fig. 10. Holding center in Valdez for harbor seal pups. Each pen had a tote pool that was plumbed with seawater. Seals were exercised in the larger seawater pool twice daily. 

a. Clinical veterinarians
b. Veterinary pathologists
c. Veterinary technicians
d. Toxicologist

C. Logistics supervisor

1. Secretarial staff

2. Housing and meals coordinator

3. Supplies and equipment procurer

4. Facilities maintenance

5. Security

6. Transportation coordinator

a. Aircraft and ship transportation

b. Ground transportation

7. Communications coordinator

D. Personnel supervisor

1. Accounting and payroll

2. Training

E. Documentation supervisor

1. Archives

2. Computer data entry

F. Public relations coordinator

2. Responsibilities of the director and staff supervisors

A. Director

1. Supervised and directed response operations associated with the cleaning and rehabilitation of oiled sea otters. The U.S. Fish and Wildlife Service supervised capture operations

2. Ensured that Exxon environmental program manager and program coordinators were kept fully informed on all issues relating to the capture, rehabilitation, and release of sea otters

3. Maintained contact with designated representatives of the Service, members of the Regional Response Team, and others directly involved with the capture, cleaning, and rehabilitation of oiled sea otters

4. Obtained Service authorization to capture and rehabilitate oiled sea otters

5. Designated and met regularly with supervisors; established priorities to ensure efficient and effective operations

6. Met with press relations coordinator to organize press briefings and respond to press inquires

7. Approved all requests for personnel, equipment, supplies, and construction

8. Approved the discharge of personnel

B. Operations supervisor
1. Coordinated the cleaning, husbandry, food preparation, and veterinary care of sea otters in the center

2. Worked with the logistics supervisor to identify and maintain required equipment and supplies

3. Worked with the personnel supervisor to recommend hiring or discharge of personnel for sea otter cleaning, husbandry, food preparation, and veterinary care

4. Ensured that all husbandry staff were properly trained and clothed to meet health and safety standards

5. Established safety protocols to protect animal monitors and handlers from injury

6. Supervised the cleaning and care of oiled otters

7. Worked with the documentation supervisor to ensure that proper records were maintained and that each otter was identified with a flipper tag

8. Worked with the logistics supervisor to arrange for the purchase and delivery of seafood for the otters

9. Instituted quality-control procedures for the preparation and distribution of otter food to the husbandry staff

10. Coordinated with the veterinary staff to ensure proper care and treatment for otters in the center. Ensured that all otters that died in the center were necropsied, and that tissue samples were taken for toxicological and histopathological analysis

C. Logistics supervisor

1. Worked with the operations supervisor to determine the equipment and supply needs for personnel and the center

2. Established a communications network between capture boats, aircraft, ground transportation, and the center

3. Chartered capture boats

4. Coordinated the transportation of otters from capture boats to the center and from the center to long-term holding facilities or for release into the wild

5. Coordinated the transportation of personnel and supplies to and from capture boats and rehabilitation centers

6. Arranged housing and meals for staff

7. Established security procedures for personnel entering the Valdez Center. En- 
sured that no domestic animals entered the Valdez Center

8. Supervised secretarial staff

D. Personnel supervisor

1. Worked with the operations supervisor and logistics supervisor to establish staffing needs. Actively recruited paid and volunteer staff

2. Worked with logistics supervisor to ensure that personnel were properly housed and fed

3. Ensured that personnel received proper training in their particular jobs

4. Maintained personnel records and administered payroll

E. Documentation supervisor

1. Established protocols and forms for the documentation of sea otters during capture, cleaning, rehabilitation, and release

2. Worked with the operations supervisor to ensure that each otter was identified with a flipper tag and that animal handlers were properly trained to keep husbandry records

3. Worked with the veterinary coordinator to ensure that all medical and necropsy data were properly recorded and filed

4. Maintained records and supervised the distribution of copies to responsible government agencies

5. Coordinated the formation of a computer data base for all records

F. Public relations coordinator

1. Worked with the director and Exxon media relations officer to coordinate press briefings and media interviews

\section{Recommendations}

To be effective, a rehabilitation center must include a well-organized staff for administration, veterinary care, and husbandry. Volunteers can be successfully used in rehabilitation programs if they are well organized and trained.

In addition to cleaning oiled sea otters, the rehabilitation centers must provide for the special husbandry requirements of ill and pregnant animals. Of critical importance are appropriately
STAFF LEVELS VS. OTTERS RECEIVED

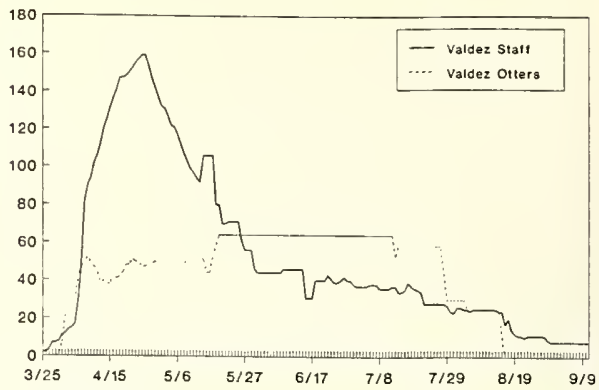

RATIO OF PERSONNEL TO OTTERS

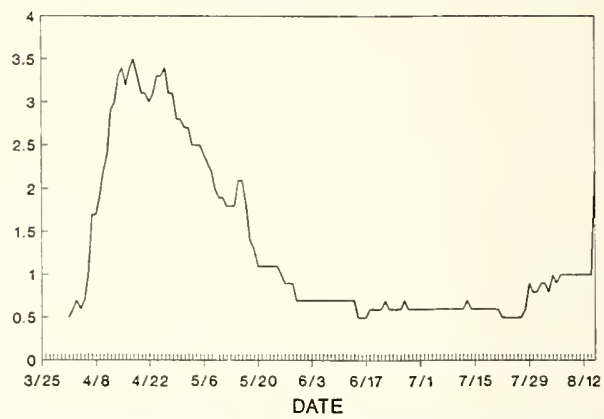

Fig. 11. The total number of staff, sea otters (Enhydra lutris), and the ratio of staff to otters at the Valdez Otter Rehabilitation Center.

designed pens and pools with an adequate supply of seawater.

After washing, otters should be moved from critical care areas to outdoor pens as soon as they can thermoregulate at ambient air temperatures. Rehabilitated otters should be placed in floating seawater pens as soon as they have regained the water-repellent quality of their fur and recovered from the toxic effects of the oil. Because the immediate release of rehabilitated sea otters may not be possible, a prerelease area (e.g., the octagonal floating pen) should be available that provides space for the otters to socialize and exercise.

For a rapid and effective response in oil spills and other such events, rehabilitation centers and a trained staff need to be established as part of an oil spill contingency plan for sea otters and other marine mammals. 


\title{
Seward Otter Rehabilitation Center
}

\author{
by
}

\author{
J. Styers and T. McCloskey \\ Wildlife Rapid Response Team \\ 9301 164th Avenue, K.P.S. \\ Longbranch, Washington 98351
}

\begin{abstract}
The need to open another otter rehabilitation center became clear in the first days of April. The oil began to move toward the Kenai Peninsula, Kodiak Island, and the Alaska Peninsula. This large area was home to thousands of sea otters (Enhydra lutris) and presented an insurmountable logistical and communications problem to otter rescue efforts that at the time were centered in Valdez, Alaska. To address this situation, Exxon Company, U.S.A. and the U.S. Fish and Wildlife Service decided to open a second otter rehabilitation center in Seward, Alaska. Several communities bid for this center, but Seward was picked as the most logical, based on several factors (i.e., housing, location, accessibility, and driving distance to Anchorage). We describe the overall approach of the Seward Otter Rehabilitation Center and how the center was organized, designed, and constructed. The T/N Exxon Valdez oil spill was the first spill to affect such a large number of sea otters. As a result, those responding to the incident had to start from scratch in their efforts to organize and carry out response operations. At the Seward Center, we benefited by the lessons learned at the Valdez Otter Rehabilitation Center, and we hope that any future response effort directed at sea otters will benefit from our operation in Seward.
\end{abstract}

On 7 April 1990, the senior author was hired by Exxon Company, U.S.A. to direct the Seward Otter Rehabilitation Center (SORC). He flew to Seward on 9 April and began the search for a location, office, staff, and city support. By 10 April, he had found a site and office space, contacted J. Stewart of Norcon Construction to begin planning, met with Mayor H. Geisler, and hired his first staff members. T. McCloskey was hired as operations manager, T. Gornall and T. Williams as assistant directors, and R. Stough as administrative coordinator. These people had all proven themselves at the Valdez Otter Rehabilitation Center (VORC); later they became an integral part of SORC.

\section{Management}

The first task we undertook on arriving in Seward was to establish an organization. Our goal was to form a highly structured, tightly knit, function- oriented organization. Because we were working with paid staff, volunteers, city officials, government agencies, Exxon, and the other otter rehabilitation centers, we knew we had to be well organized and efficient. There had to be a clearly defined organizational structure that could be understood by everyone. One person had to be in charge, with a group of supervisors that would support this organizational concept. The person in charge of operations would be responsible for the day-today operations of the center, while the director would handle the political and overall management of the center - one person could not handle both these functions.

In establishing the rest of the organization, we identified the following major functions that would be carried out at the center: administration, capture, cleaning, rehabilitation, food preparation, nursery and veterinary services, and volunteer activities. For each function, we established the position of coordinator and asked the coordinators to identify additional staff needs within their areas 
of responsibility. For the most part, we gave the coordinators absolute authority to organize and direct the resources of their areas. At the same time, we made it clear to all the coordinators that they were equal in terms of authority. The operations manager became involved in the decisionmaking process only when a problem emerged that was not being addressed or could not be resolved in a timely fashion. This happened infrequently.

Superimposed on the director's and coordinators' abilities to determine staff needs was Exxon's decision to establish a cap on the total number of paid employees at SORC. When we arrived in Seward, we indicated that we believed SORC could be run effectively and efficiently with 30 to 50 paid staff. The maximum number of staff approved by Exxon was 36 . This cap created difficulties for our husbandry staff, which at one point was caring for 92 animals. Even in the later stages of the rescue effort we were in charge of many animals, including orphaned pups, that needed critical care. Because of the limitation on paid staff, we were required to rely on many volunteers to carry out the necessary dayto-day operations.

\section{Volunteers}

From the beginning, it was clear that we would have to rely on volunteers to help operate the center. Within one week, J. Prochazka from the California Marine Mammal Center developed a volunteer orientation program. Before opening the center, we presented this program to nearly 200 people in Seward and Anchorage. T. Thomas was then appointed volunteer coordinator and managed the volunteer program until the center closed. Managing a volunteer organization is not an easy task; Thomas had a full-time job with hundreds of daily problems. We learned that if volunteers are going to be used, a trained and professional volunteer coordinator must be in charge, with a direct line to the operations manager and director. For the most part, our volunteers worked out extremely well, and we could not have run SORC without them.

\section{The Seward Center}

Our goal in planning SORC was to create a permanent, transportable facility that could be "stored" and used during a future contaminant incident in Alaska. For this reason, the structural components of the center were placed inside ten 2.4- $\times$ 15.2-m ATCO trailers. The outside components (e.g., totes, pools, walkways, roofs, plumbing, and tanks) were designed so that they could be disassembled and stacked or stored either inside or outside the trailers.

\section{Design}

On our first day in Seward, we developed a preliminary site plan for a 14-trailer center on land owned by and immediately adjacent to the University of Alaska Marine Science Center. The overall concept of the facility was to create a flow-through treatment process. This plan (conceived by T. Gornall and SORC management staff) called for a step-by-step rehabilitation approach under which cleaned and thoroughly dried animals would be reintroduced to salt water as quickly as possible and moved, over 10 to 20 days, to progressively larger tanks as their coat condition, behavior, and overall health returned to normal.

With a basic center design in hand, we began a four-part planning process. First, we assembled a start-up staff, and the operations manager orchestrated meetings to discuss the overall center layout and the design of each trailer. Each meeting had a stated objective and lasted until the objective was achieved. The goal of each meeting was to reach decisions in a collaborative fashion and move on to the next issue. As originally conceived, the first stage of rehabilitation would have occurred inside six unheated trailers. However, Gornall believed that rehabilitating otters at VORC were faring far better outside. Thus, in the final design, we substituted outside totes and pools for four of the trailers.

Second, we hired a local engineer to survey the property and design the water supply, wastewater handling, and electrical supply systems. We were extremely fortunate to find this engineer who not only possessed the desired skills, but also had the patience and perseverance to rapidly prepare alternative systems as the planning process evolved. In addition, Williams effectively handled many of our negotiations with State and local regulatory agencies, and was present during the construction phase to advise the construction crew on systems design questions.

Third, we established a positive and direct working relation with J. Steward of Norcon, who managed the construction operation. We realized that we would need Steward's expertise and that of the building trades to refine and improve our 
center design. From the beginning, we involved Steward and M. Wilson (also of Norcon) in our meetings. Indeed, Steward, Wilson, and members of their construction crew brought many ideas to the table, which greatly improved on those ideas generated by Williams and our staff.

Fourth, we focused on integrating Exxon into our deliberations. On the second day in Seward we presented Exxon with a preliminary site plan. On the third day we met with R. Ortega (of Exxon) to review our plans. In the weeks that followed we kept Exxon staff advised of our progress and invited Exxon personnel to attend our planning meetings. Exxon's day-to-day involvement in our activities was greatly enhanced with the arrival of $R$. Laws, who took an active interest in our efforts. He and R. Spilman were our visible link to Exxon.

\section{Construction}

Because of Exxon's inability to secure a lease for our original site, and because of protracted lease negotiations with the city of Seward on the eventual facility site, we began work on the trailers while they were in storage at the Norcon warehouse in Seward. When the lease was signed, site clearance work began immediately, and the first seven trailers arrived on-site the next day. To coordinate the construction effort, operations manager McCloskey worked with J. Steward to develop a detailed construction schedule. In addition, the operations manager held a daily construction meeting at $0700 \mathrm{~h}$ with Exxon and Norcon staffs to discuss progress, the day's activities, problems, and what was needed to complete construction operations as quickly as possible. Our goal was to complete the center before animals arrived. Unfortunately, this goal could not be realized because many animals began to arrive in Seward as soon as construction began. These animals could not be shipped to VORC because of a quarantine on that center during this time. Also, Exxon was operating under a directive from the U.S. Fish and Wildlife Service to open SORC in a time that was established without regard to the status of construction operations or the effect of construction activities on the animals.

At the end of each morning meeting, the operations manager prepared a memo detailing the decisions of the meeting and gave the memo to Exxon to ensure that Exxon was aware of and authorized ail construction activities. Exxon's representative checked and signed the memo and forwarded it to Norcon for implementation, at which time Norcon would order materials. This process worked fairly well, but it did lengthen the construction period because the construction crew had to wait on materials that would take anywhere from 1 day to 1 week to arrive from Anchorage or the lower 48 States.

\section{Staffing}

Our philosophy on hiring staff was simple. Hire the best, treat them well, and let them do their jobs. Both the director and operations manager owned their own businesses. This proved to be a great asset in the management of this center. The director, with more than 20 years of marine mammal expertise, was able to understand the concerns of the veterinary and husbandry personnel.

Any problems that occurred were generally handled within the chain of command. Because the staff had a posted organizational chart, there was never a doubt about whom to go to with problems. The director only became involved in problems when they could not be worked out within the chain of command.

Staff meetings, where information was given to the entire staff, were held twice a week. Volunteers were not included in these meetings. It was extremely important to keep staff informed of all events going on throughout the center. With so many people working closely together, rumors could destroy the entire working environment. Letting staff know what was going on and explaining the decisions that were made kept morale and working conditions at their best.

Working with local officials proved invaluable. On 9 April, upon arriving in Seward, the senior author made the acquaintance of Mayor Geisler and soon had secured his support and friendship. Later this proved helpful in procuring a city lease and all the permits required to open the center. Geisler later gave the center a city proclamation of a job well done.

All staff were hired by Exxon and were therefore Exxon employees, which caused some friction. Management often felt caught in the middle between what was best for the animals, cost-effectiveness, government agencies, the media, staff, and volunteer opinions. Also, Exxon accountants from Houston, Dallas, and Los Angeles were put in charge of running a cost-effective center. However, their lack of experience with sea otters and husbandry procedures made this a difficult and 
challenging situation. Much of our time was spent justifying expenditures, staffing, food, housing, materials, and animal health care needs. It would be helpful in the future if oil industries would have someone on their staffs that understood animal health care.

\section{The Center}

Initial capture operations along the Kenai Peninsula were conducted by G. VanBlaricom, a U.S. Fish and Wildlife Service representative assigned to assist in establishing SORC. VanBlaricom later provided technical assistance to the capture teams operating out of Seward; this assistance included drafting a capture protocol. At its height, our capture operations had seven boats operating in the Gulf of Alaska (from Prince William Sound to Gore Point), Cook Inlet (Gore Point to Kachemak Bay), and Shelikof Strait. Weather permitting, these boats patrolled the coastline looking for heavily oiled areas where sea otters were observed swimming in oil. Most of the animals treated at SORC came from the heavily oiled areas of Windy-Rocky Bay, Tonsina Bay, and Nuka Island. When heavily oiled areas were found, modified gill nets (tangle nets) were deployed to capture animals moving to, from, or through oiled areas. The tangle net technique was used for personnel safety reasons and because it was the least stressful capture method for the animals. VanBlaricom trained O. Ollestad to take over communication with capture teams. She established a good working relationship with pilots, the Service, boat skippers, and Exxon.

\section{The Closing of the Seward Center}

Throughout the summer, we were besieged with rumors of how long we would be in operation. As July approached it became clear that SORC would be operating until at least the end of August. As more animals were sent to the Homer Temporary Care Facility, Exxon began pressuring us to reduce staff, beginning in mid-August. By 1 September, our staff of 36 paid employees and more than 600 volunteers had dwindled to 7 paid employees and 2 volunteers. This was taken very hard by some and welcomed by others. Many of these people had worked 7 days a week, $12 \mathrm{~h}$ (minimum) a day, since 27 March-a long time, to say the least. We had experienced burn-out, physical and mental fatigue, joy, and disappointment. However, we still had 13 pups that were being transferred to the Point Defiance Aquarium in Tacoma, Washington. Several staff members accompanied these pups to the aquarium and continued working there for several more months. The center closed on $11 \mathrm{Sep}$ tember 1989, with the departure of the pups to Washington.

\section{Point Defiance Aquarium, Washington}

All the pups arrived in Tacoma in good condition. Some took a little longer than others to get their coats back in shape, but within a week all were doing well. The senior author had left for Tacoma on 1 September to get the aquarium ready. T. Otten, the director of Point Defiance Aquarium, had assigned a small section of land behind the polar bear exhibit for our use. Point Defiance Aquarium had taken several oiled adult otters earlier that summer and had two large dry pens that we could use. T. Gornall donated a large fiberglass tank, and we ordered two other 4.0- $\times 1.2-\mathrm{m}$ deep fiberglass tanks. These were the same as we used in SORC; however, we designed the overflow and inlet pipes slightly different to enhance the water quality and accessibility. We also painted the inside of the tanks a light blue for better visibility. For haul-out areas we used existing plastic tables from the Point Defiance Aquarium cafe. These worked out well, as we could move them to any position in the tank.

As of this writing, four pups have been moved to the John G. Shedd Aquarium in Chicago, three have gone to Sea World San Diego, and three others left for Japan in early March. One of these pups died in early March of unknown causes. Unfortunately, our three youngest animals died. Tests showed they were chronically ill and probably lived as long as they did only because of the intensive care they received, both at SORC and at the Point Defiance Aquarium.

\section{Acknowledgments}

All the staff and volunteers at SORC should be commended for their hard work, long hours, and dedication. It is not feasible to thank them all in this paper. You know who you are and so do we! We thank the Tacoma staff for its support and continued effort. T. Gornall deserves an extra special 
thanks for his persistence; R. Stough and K. Vasey for staying to the very end; the entire nursery staff, who had the hardest job of all; J. Otten, who headed our husbandry unit and gave her all to this project; and Exxon, for allowing us to lead this fine group in an important and successful project. 


\title{
Homer Temporary Care Facility and Jakolof Pre-Release Facility
}

by

\author{
L. Redman \\ P.O. Box 2731 \\ Homer, Alaska 99603
}

\begin{abstract}
The sea otter (Enhydra lutris) temporary care center in Homer, Alaska, was opened at the Homer Junior High School pool building on 8 April 1989. The first otter arrived on 25 April. About $92.0 \mathrm{~m}^{2}$ of indoor space and $557.4 \mathrm{~m}^{2}$ of outdoor space were available for otter care and pen building. This building was used to care for otters until 20 May, when a new prerelease facility began operation in a small lagoon with a narrow entrance in the back of Little Jakolof Bay on the south coast of Kachemak Bay. This prerelease center used twenty $4.3-\times 8.5-\mathrm{m}$ and six $4.3-\times 4.3-\mathrm{m}$ floating pens with a $3.7-\mathrm{m}$ depth of underwater space surrounded by seine netting. The floating pens bordered a long, solid floating dock. Two of the 2.4- $\times$ 7.6-m dock sections were used for holding and weighing otter food, and one of the sections was used for the husbandry building. This building held a VHF solar-powered radio, supplies, current records, and information. An A-frame cabin was used for preparing meals for the crew and for VHF communication, and provided a laundry, shower, and limited housing. Two other houses were available for sleeping, along with 75.7 ha for tent sites. A helicopter pad was about $305 \mathrm{~m}$ from the A-frame building. The food preparation area and office were at Kasitsna Bay, 15 to 20 min away by boat. At the height of operation the paid staff numbered 35 . The most otters in captivity at one time was 96 . At this time the otter-to-personnel ratio was approximately 1:0.3. Each husbandry person was responsible for 6 to 20 otters, depending on otter health. Live shellfish were purchased locally to feed the sea otters. Recycling of some supplies was practiced to minimize pollution and costs. The Jakolof Pre-Release Facility also practiced "soft" transfers and releases. With a small crew, otters were successfully maintained in a natural, quiet setting for as long as 3 months.
\end{abstract}

\section{History of Facilities}

\section{Homer Temporary Care Facility}

The Homer Temporary Care Facility (HTCF) was originally called the Homer Otter Center and was initiated 8 April 1989 at the unused pool building of Homer Junior High School, with the goal of receiving, washing, and rehabilitating oiled sea otters (Enhydra lutris) in a low-impact setting.

By the time the first influx of otters arrived (25 April-7 May), 20 portable cages, 16 pen stands, 48 fox cages, 3 washing stations with plumbing approved by the Alaska Department of Environmental Conservation, 2 freezers full of donated and purchased frozen seafood, and a fish- cutting table were ready for use on-site. Tote pens were under construction.

Eighteen otters were brought through the Homer Facility directly from capture sites on the outer coast of the Kenai Peninsula. By 1 May, the first 6 of these 18 sea otters had been directed by the U.S. Fish and Wildlife to the Valdez Otter Rehabilitation Center (VORC) and 7 to the Seward Otter Rehabilitation Center (SORC). One died on arrival at HTCF because of hyperthermia, and one died in transit to VORC, apparently because of stress. The last three lightly oiled otters received at HTCF (two were pregnant females) were left untreated and held at HTCF. In the meantime, preparations were being made in the Homer area for a new facility that could receive and temporarily hold 
treated otters. This facility became known as the Jakolof Pre-Release Facility (JPRF). The last three otters were eventually transported with a 5-day-old pup (born at HTCF) to the JPRF on 20 May.

Most of the otters that came directly to HTCF were found within $48 \mathrm{~km}$ of Homer and were kept as long as 4 days before being transported to VORC or SORC, where they would be washed, rehabilitated, treated, and monitored for medical complications due to oiling.

\section{Jakolof Pre-Release Facility}

The Jakolof Pre-Release Facility was originally called the Kachemak Otter Center. The remote site, in Little Jakolof Bay on the south coast of Kachemak Bay across from Homer, included 75.7 ha of leased land bordering a sheltered lagoon, with a helicopter pad $305 \mathrm{~m}$ from an A-frame building. The A-frame was used for meal preparation and VHF communication, and provided a laundry, shower, and limited housing. Besides the A-frame, many tent site locations were available for sleeping on the property, along with two houses on nearby property.

Of the 121 otters held at JPRF, only 2 died on-site. The peaceful, quiet, seminatural setting of JPRF probably contributed to the low mortality. There were four live births of healthy pups, and three of these pups were eventually released with their mothers. Although one pup died, the pups that arrived from the SORC and the pups born at JPRF generally fared well.

The maximum number of otters harbored in captivity at the lagoon at the same time was 96 . At this time there were two wild male otters, "rogues," in the lagoon. A large percentage of the otters boarded at JPRF were originally lightly oiled and had been treated and held at the SORC. The otters at JPRF were generally healthy and required less attention than otters at the Valdez and Seward centers.

The otters were held in groups of as many as eight animals per pen. Four to five otters was the average number per pen. Bonded pairs were kept together.

\section{Philosophy}

Both the HTCF and the JPRF attempted to meet the needs of the sea otters as closely as possible. The primary goal was to respect rather than dominate the animals by furnishing their natural needs. The JPRF attempted to approximate their natural habitat by feeding live shellfish and working around the animals in a peaceful, gentle way.

It was hypothesized that limited human interaction before sea otters reentered the wild would help reduce domestication. Physical otter manipulation other than that necessary to ensure health and release was discouraged. Any marking or study procedures, it was believed, should have been conducted earlier at other rehabilitation facilities.

The JPRF followed a policy encouraging a minimum of human effect on the natural environment. The reduction of disposable waste products, use of biodegradable cleansers, and active recycling helped reduce freight and preserve the natural environment. Although pursuing an environmentally sensitive policy was a goal, it was difficult to achieve in an emergency mobilization mode. Advance planning and serious efforts are necessary to more fully achieve this goal.

\section{Pens}

At HTCF the portable cages (Fig. 1) worked well for transferring and temporarily holding otters, but not for holding for a long time. Tote pens were the smallest enclosures acceptable for holding apparently healthy otters for several weeks. Tote pens (Fig. 2) included a small saltwater pool and a deck. Seawater was supplied from a donated water truck that was refilled daily.

The JPRF used twenty $4.3-\times 8.5-\mathrm{m}$ and six 4.3- $\times 4.3-\mathrm{m}$ floating pens with a $3.7 \cdot \mathrm{m}$ depth of underwater space surrounded by seine netting (Fig. 3). These floating pens stabilized and were ready to receive otters when the dock arrived, and the pens were attached along it. The pens bordered the dock and had haul-out areas on the far ends, which allowed the otters to rest away from people. Because otters often tried unsuccessfully to crack shellfish on wooden edges of the haul-out areas, it is recommended that metal rims be installed or large rocks anchored onto the decks for shell cracking.

The dock was $45.7 \mathrm{~m}$ from land and was anchored to the bottom of the lagoon and to the shore to provide stability in the strong tidal currents in the lagoon. The husbandry building was at one end of the dock (Fig. 4) and held a VHF solar-powered radio, limited veterinary supplies, rubber and welding gloves, reference information, and current records. An observation tower was at the other end of the dock from the husbandry building. Additional dock sections next to the husbandry building 
Fig. 1. Portable cages.
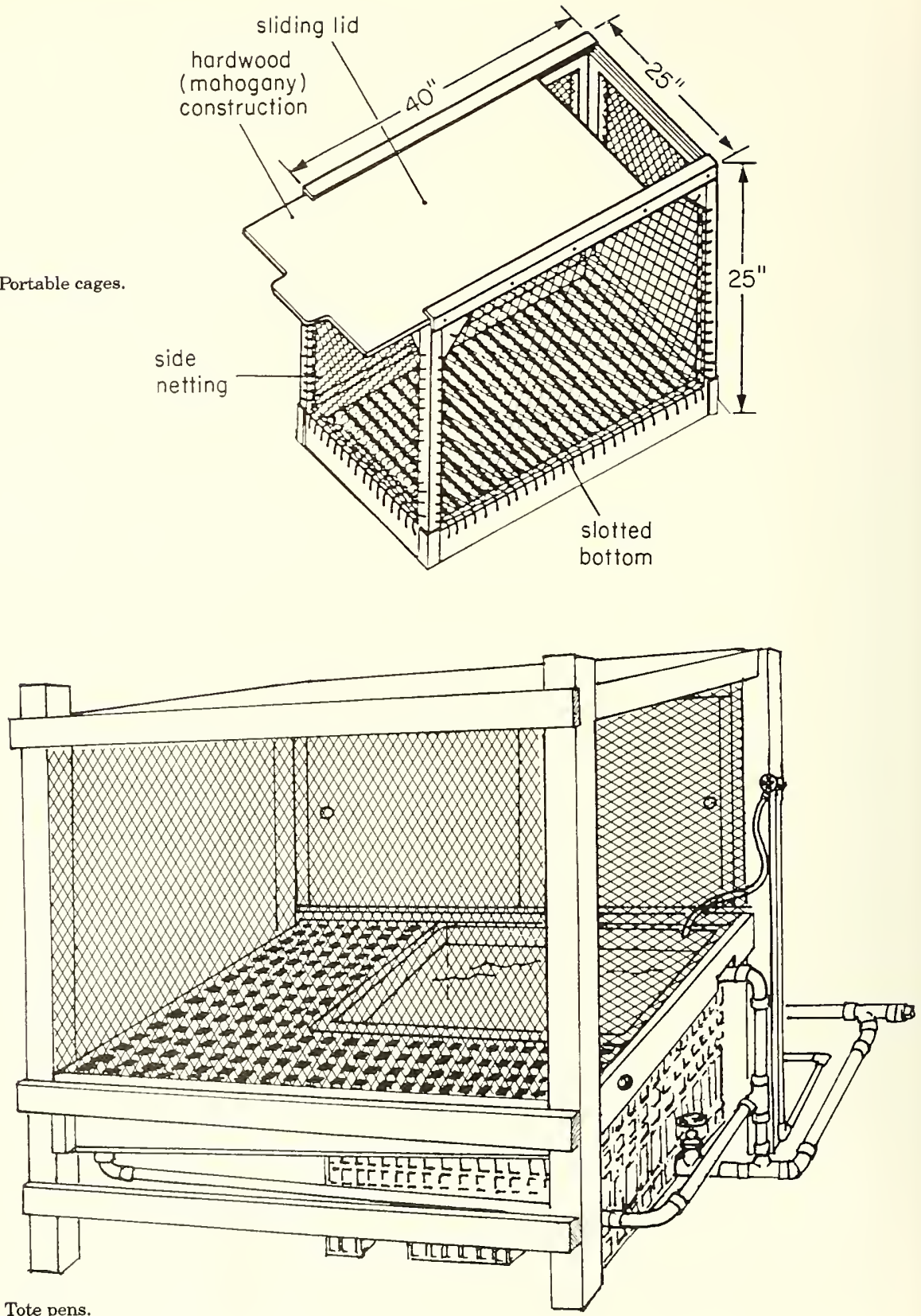

Fig. 2. Tote pens. 


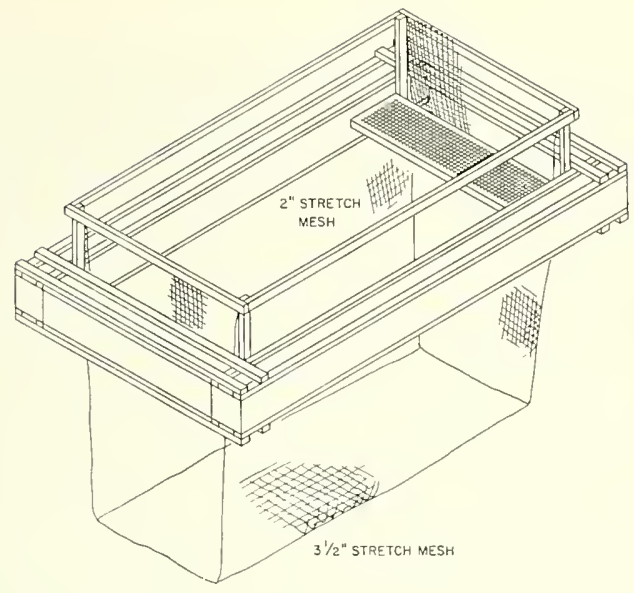

Fig. 3. Floating pens.

were used for holding and weighing otter food. An outhouse was on land, proximal to the floats.

\section{Otter Care and Reducing Stress}

\section{Pen Cleaning}

The cleaning of pens was perhaps the most disturbing and stressful process for the otters of all the otter care activities at HTCF and JPRF. The most successful method for cleaning shells from floating pens at JPRF required a crew of three people. One person stood with a long-poled skimming net on one of the long pen sides; the others stood opposite holding pull-ropes attached to the skim net. The net-pullers put the seafood dregs into garbage bags, which were emptied into Kachemak Bay. These heavy-duty garbage bags were rinsed in the sea and reused for pen cleaning.

A slot or purse seine net opening could help in the future to reduce pen cleaning stress at a prerelease facility. A diver could open the slot to allow easy exit of hundreds of pounds of shells that might accumulate every few days. If the slot was near the dock, support people could more easily receive bags of shells from a diver.

A major problem was cleaning the mats of microscopic algal "scum" off the $5.7-\mathrm{cm}$-mesh seine netting. The scum accumulated rapidly and stuck persistently. The resulting diminished water exchange led to elevated fecal coliform bacteria counts in the pens, though coliform counts stayed within acceptable limits.

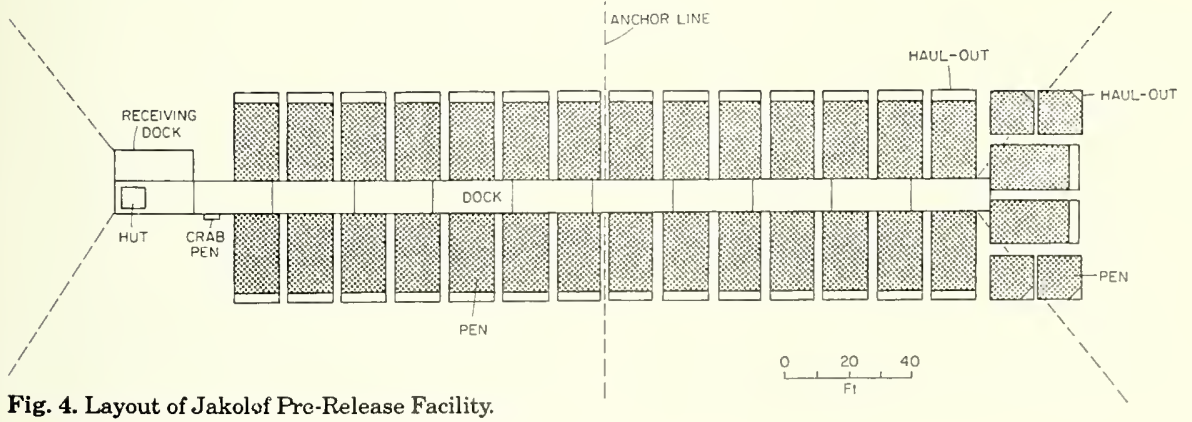


Biodegradable soaps were used to help prevent further contamination of the water, and Betadine and Nolvasan antiseptics were disposed of away from the area.

The larger $8.9-\mathrm{cm}$-mesh netting on a few of the last pens built worked better because the algae could not grow dense enough to obstruct water flow. An initial concern was that the otters would reach through the $8.9-\mathrm{cm}$ netting and get their limbs caught; however, this was never observed.

\section{Quiet Atmosphere}

Great care was taken to keep all construction and human noise to a minimum around the otters. Pens were constructed away from the animals, and when repairs were necessary a battery-operated screw gun was used rather than a hammer. Boat traffic was kept to a minimum, and motors were run at low throttle in the lagoon. Staff approached the pens by rowboat, kayak, or canoe.

The otters were monitored during feeding, which was four times a day. Otters with questionable health were monitored more frequently as needed; otherwise otters were left quietly alone and monitored from an elevated position at the end of the floats. At night, after the last feeding, the floats were silent, and the otters slept peacefully unless harassed by a wild otter.

Certain otters were very skittish around people and would dive underwater if approached from even 15 to $30 \mathrm{~m}$ away. Female otters with pups, and other otters sensitive to disturbance, fared best when placed as far from the husbandry building as possible.

When moving pens was necessary, rather than transfer otters from pen to pen, entire pens were moved slowly by hand to a different location.

\section{Wild Otter Containment}

Wild male sea otters, or rogues, often entered the lagoon because it was difficult to successfully seal off its entrance. (A net with a lead line was strung across the lagoon entrance but did not prevent rogues from invading the site.) The rogues attacked the captive males and mated with the captive females through the netting. To maintain order and peace, the rogues were captured and held. When translocating these otters was tried, they swam right back.

In the future, finding a method for successfully preventing healthy wild otters from entering a rehabilitation or prerelease facility is highly recom. mended. Construction of a fence around the perimeter of the pens, or a small lagoon such as the one at the JPRF, along with a sturdy underwater fence extending above the water at the entrance, may exclude rogue otters from a prerelease facility.

\section{Identification}

Otter flipper tags were difficult to read because flippers constantly moved in the water. One could stand next to an otter for 5 to 10 min using binoculars and still be unable to read a tag because it was either upside down or moving. Such close observation was disturbing to the otters. In the future, if tags must be used, the use of color stripes on tags for identification is recommended. Tag numbers should be legible when an otter is on its back with flippers facing upward (Loshbaugh 1990).

Husbandry personnel should monitor the same pens over time to notice relative changes in otter behavior. When monitoring the same pens, observers had no problem recognizing individual otters on the basis of size, shape, and color unless more than three otters were in a pen. One way to avoid the need for tags for prerelease observations is to house fewer otters per pen and monitor the animals with more personnel.

\section{Soft Transfer, Release, and Capture}

Soft transfer, soft release, or soft capture mean using approaches that reduce stress to sea otters caused by human manipulation. Otters were moved several times at the HTCF by opening the pen door flush with the smaller cages and luring the otters into them with food and curiosity rather than transferring them by dip net. Otters were allowed to take their time until they quietly moved on their own. At JPRF a folding passageway was used successfully to allow otters to move themselves from one pen to the next. Soft transfer is a recommended procedure to reduce sea otter stress in captivity.

Soft releases occurred in the lagoon, primarily for mothers with pups, and for the weak otters that were freed last. The net was unhooked from the nails on one side of the pen to afford otters a quiet, unobstructed exit. A door was also left open.

One soft capture of a rogue otter occurred when half of a floating pen net was dropped into the water. The net, which was attached to ropes, was raised when the rogue surfaced inside. (It seemed to enter the pen more because of curiosity than the lure of food). 


\section{Captive Stress Behavior}

A problem developed in healthy otters staying in the floating pens for more than 2 months (and many otters were kept in the pens as long as 3 months). This confinement was stressful to the otters and resulted in nervous boredom shown by such activities as porpoising and continuous lap swimming, pounding and playing with empty feeding buckets, gnawing on the wooden pen frames, and bellowing by males separated from females (Michaelson 1990). Therefore, otters should be moved into larger spaces or released into their natural habitat after 2 months in floating pens.

\section{Release Preparations}

To avoid overheating, large blocks of ice were placed in the otter transport kennels during helicopter release flights. It was best to transport sea otters on cool, cloudy days to reduce the risk of hyperthermia.

\section{Food}

In the first 6 days at the HTCF, otters were fed prepared food (i.e., frozen, filleted seafood from processors). After 1 May they also received live, intact shellfish collected in Kachemak Bay.

At JPRF a mixture of fresh and prepared food was used. The percentage of fresh seafood was continually increased to as much as $90 \%$ near release time. Fresh food, complete with bones and shells, was preferred by otters at both facilities. Mussels composed about 70 to $90 \%$ of the fresh food diet.

Once at the JPRF, the otters received 25 to $40 \%$ of their body weight daily, in four separate feedings. Fresh food offered included mussels, crab, sea urchins, butter clams, and cockles. Prepared food offered included cod, scallops, clams (mostly geoduck, Panope generosa), and squid. Observations of uneaten seafood remaining in the pens and feeding buckets revealed that crab was the favored live food and geoduck was the most popular frozen seafood. Fresh bull kelp was frequently placed in pens. The otters ate the kelp, used it in apparent play behavior, and for anchoring while resting.

Two and one-half gallon buckets with $2.5-\mathrm{cm}$ holes in the sides and bottom were lowered into pens for feeding the otters to minimize recognition of humans as a source of food. Food was tossed directly to animals with special needs, however, such as some mothers with pups, subdominant males, and animals with poor appetites.

As the amount of fresh food (versus frozen seafood) was increased, floats were constructed that could hold as much as $817.2 \mathrm{~kg}$ of shellfish daily. Shellfish hung from the float edges into the water in plastic mesh bags. A garden wagon with two bicycle tires was used on the dock to carry food to pens.

The food preparation area was in a nearby bay (15-20 min by boat from the pens). The food preparation personnel had access by road from there to a cannery where ice and frozen food were stored.

The preparation area included a small building with hot and cold running water and a large wooden deck edged with plastic totes for thawing seafood. One tote next to the off-loading ramp was kept full of ice, which was transferred to a plastic garbage container on the deck for packing coolers.

Food preparation personnel estimated amounts of food needed for 24 -h increments. At the height of the operation, this translated to nearly $908 \mathrm{~kg}$ of frozen seafood in addition to the $817.2 \mathrm{~kg}$ of live shellfish given daily.

\section{Personnel}

\section{Staffing Requirements}

Because of financial limitations, the HTCF relied heavily on volunteer labor. Most HTCF volunteers later were hired as full-time staff at JPRF. Compared with the Seward and Valdez Otter Rehabilitation Centers, JPRF had the fewest paid staff and did not use volunteers. The number of staff at JPRF reached a maximum of 35 by the end of July, when the facility had 96 captive otters and two rogues. Because there were no otters needing intensive care and most otters seemed healthy, the ratio of overall personnel to otters at this stage of maximum efficiency reached 0.3:1.

\section{Job Categories and Functions}

Principal job categories were director, on-site coordinator, personnel coordinator, office staff, camp operators, food preparers, husbandry staff, and veterinarians (Appendix).

The director communicated with key officials in nonprofit organizations, other otter centers, the Exxon Corporation, the U.S. Fish and Wildlife Service, and other government agencies to acquire funds and support for the otter facilities. 
The on-site coordinator was a local boat operator familiar with use of radios, boats, tides, and the area's regional resources. She worked with the director to coordinate water traffic and also coordinated and helped with receiving supplies, transporting personnel, maintaining booms to prevent oil from entering the site, keeping unauthorized personnel away from pens, and showing authorized personnel the facility.

A personnel coordinator arranged rotating work schedules for the staff, aided communication, resolved conflicts, organized meetings and social functions, and helped release the pressure that built among personnel living and working in a bush camp.

Two office workers (one part-time) filed and duplicated otter records, maintained medical notes, and calculated otter feeding amounts. An office coordinator was essential for handling payroll, transmitting work-orders, relaying communication, helping coordinate transport of personnel, helping support operations, and providing information to the public.

Camp operations included two boat operators (including the on-site coordinator) and one crew member providing transportation for otter food, people, and supplies. Two to four carpenters worked on pen construction and camp maintenance. Operations staff included a full-time cook and an assistant. The cooking staff greatly improved overall staff morale. A "rover" was available to help where needed in camp operations and food preparation.

Two people were required to handle the otter food responsibilities-a food coordinator and a preparation (prep) person. The food coordinator estimated and ordered otter food, estimated and picked up daily amounts of frozen food from the cannery freezer, and actively helped with food preparations. The prep person thawed food in the totes, packed them in coolers with crushed ice, labeled the coolers, and carried them to a boat for pickup at the appropriate tidal time. Prep personnel receiver empty coolers, which they washed and disinfected along with the totes and food prep area. They disposed of cardboard seafood boxes by burning them on the beach.

Live shellfish deliveries came at sporadic times, depending on the tides. The person receiving "live" food was on call $24 \mathrm{~h}$ per day. After weighing shellfish and writing a fish ticket receipt for Exxon, this person hung bags around the float in the water and, at appropriate times, towed the float into the lagoon.
The husbandry coordinator was in charge of overseeing pen cleaning and maintenance, training staff, overseeing basic record keeping, listening to suggestions from caretakers, overseeing rogue containment, making otter transfers, and deciding how to group otters.

Husbandry personnel were trained by on-thejob experience and by working with more experienced people. All husbandry personnel, including the husbandry coordinator, received 6 to 20 otters to feed and monitor, depending on the health of their otters. They generally monitored the same pens, which enabled them to become familiar with individual otters, thus detecting any unusual behaviors. They kept daily records of otter behavior and highlighted any abnormal activity.

The duties of each caretaker included feeding the appropriate amount and type of food, monitoring assigned otters, keeping accurate food and observation records, cleaning dock and floats, cleaning nets, and working peaceably with other caretakers.

A veterinarian was available on site $24 \mathrm{~h}$ per day.

\section{Personnel Management}

The process of decision making was cooperative, with maximum input solicited from all staff. Effective, constructive communication and cooperation allowed rapid assimilation of new ideas and were essential to the successful operation of the facilities at Homer and Little Jakolof Cove.

Human interaction in a field camp situation is never completely without conflict, and mandatory time-off as well as frequent meetings and social gatherings are essential to group communication, unity, and sanity (Styers and McCloskey 1990).

The following schedules are recommended:

1. For the first 7 weeks, each individual should work $12 \mathrm{~h}$ per day for 10 days, with 4 days off away from the site (an average of $60 \mathrm{~h}$ per week); after that, reduce staff time to $8 \mathrm{~h}$ per day for 10 days on site with 4 days away (an average of $40 \mathrm{~h}$ per week).

2. Daily meetings during regular day-shift hours should be held proximal to otters, with all available husbandry personnel except one on the floats, and at least one representative from camp operations, office workers, record keepers, food preparers, and management present. 


\section{Conclusions}

1. To minimize stress for sea otters, a rehabilitation or prerelease facility must be centered around the needs of its patients:

a. It must be in a natural, quiet, protected environment.

b. Once sea otters reach a prerelease site, otter handling should be minimized or discontinued.

c. Human refuse must not compromise the natural habitat for sea otters and other members of the biological community.

d. Metal rims or large rocks should be anchored to the haul-out platforms in the pens to aid in shell cracking.

e. Cleaning floating pens may be improved by using a diver to empty shells through an underwater slot in the bottom of each net.

f. Use of mesh netting $8.9 \mathrm{~cm}$ or larger in floating pens should reduce accumulation of microscopic algal scum, thus aiding water exchange and reducing fecal coliform bacteria buildup.

g. Human activity must be conducted in a quiet, calm, unobtrusive way. Construction should take place far away from the animals, and pen repairs should create minimum disturbance.

h. Otters sensitive to disturbance should be located away from the area of maximum human activity on floats (i.e., husbandry building).

i. Wild otters should be prevented from contacting captive otters; one way might be to develop underwater fencing to protect pens.

j. It is possible to identify otters without the use of flipper tags at a prerelease facility; if tags are used, they should be color-coded and easy to read while in motion.

k. Soft transfers, releases, and captures were used successfully and are recommended pro. cedures for otter maneuvering.

1. Apparently healthy sea otters should not be confined in $4.3-\times 8.5 \cdot \mathrm{m}$ pens longer than
2 months or they may exhibit elevated captive stress behaviors.

m. Otters should be transported with ice blocks on calm, cool days.

n. Abundant, live, fresh shellfish and bull kelp should be offered to sea otters. Food should be offered by bucket rather than by hand.

o. Husbandry personnel should monitor the same otters over time to aid early detection of abnormal behaviors.

2. Frequent meetings with maximum input solicited from all staff members are recommended to allow rapid assimilation of new ideas.

3. Reasonable working hours with mandatory time away from location are policies that may help prevent "burn-out."

4. Personnel adept at boating skills and familiar with local resources are essential to the success of a facility.

\section{References}

Loshbaugh, S. F. 1990. Record keeping for an otter rehabilitation center. Pages 182-223 in K. Bayha and J. Kormendy, tech. coords. Sea Otter Symposium: Proceedings of a symposium to evaluate the response effort on behalf of sea otters after the T/N Exxon Valdez oil spill into Prince William Sound, Anchorage, Alaska, 17-19 April 1990. U.S. Fish Wildl. Serv., Biol. Rep. 90(12).

Michaelson, N. E. 1990. Behavioral observations of rehabilitating sea otters in prerelease holding pens. Pages 313-320 in K. Bayha and J. Kormendy, tech. coords. Sea Otter Symposium: Proceedings of a symposium to evaluate the response effort on behalf of sea otters after the T/V Exxon Valdez oil spill into Prince William Sound, Anchorage, Alaska, 17-19 April 1990. U.S. Fish Wildl. Serv., Biol. Rep. 90(12).

Styers, J., and T. McCloskey. 1990. Seward otter rehabilitation center. Pages 167-171 in K. Bayha and J. Kormendy, tech. coords. Sea Otter Symposium: Proceedings of a symposium to evaluate the response effort on behalf of sea otters after the T/N Exxon Valdez oil spill into Prince William Sound, Anchorage, Alaska, 17-19 April 1990. U.S. Fish Wildl. Serv., Biol. Rep. 90(12). 


\section{Appendix. Personnel at the Jakolof Pre-Release Facility.}

Director

Personnel coordinator

Office coordinator

Office staff

On-site coordinator

Operations staff

Skiff operator

Skiff crew

Carpenters

Cooks

Records coordinator

On-site records coordinator

Husbandry coordinator

Husbandry staff

Part-time staff

Veterinarians (main)

(visiting)

Otter food coordinator

Live-food receiver
Nancy Hillstrand

Linda Redman

Tia Heneghan

Jeanette Galvan

Marsha Million

Ron Tingook

Rory Stark

Barrett Fletcher

Jack McDonald

Mike Robertson

Steve Shultz

Liz Simonis (main cook)

Susan DeQuattro

Sherry Falardeau

Barb Kaun

Shana Loshbaugh

Amy Christiansen

Kurt Marquardt

Dave Almond

Tina Baugher

Nancy Brown

Steve Curtis

Leslie Hafemeister

Colette Ireland

Tricia King

Kaleen Knodel-Fidler

John Mario

Rob McCue

Tim Mead

Linda Redman

Barb Rhyneer

Sandra Thomas

Carol Tillet

Jeanne Tolle

Denise Ackert

Polly Dunn

Rick Harness

Kathy Hill

Halle Jenkins

Glenn Grady

Neal Utkov

Jenny Balke

Chris Harvey-Clark

Scott Rapp

Pam Tuomi

Paul Wunnicke

Jim Heneghan 
Food preparation staff

U.S. Fish and Wildlife Service On-site representative

Part-time representatives
Steve Curtis

Tricia King

Barb Rhyneer

Ron Britton

Mimi Hogan

Elizabeth Sharpe 


\title{
Record Keeping for an Otter Rehabilitation Center
}

\author{
by \\ S. F. Loshbaugh \\ 64770 Pitzman Avenue \\ Homer, Alaska 99603
}

\begin{abstract}
Record keeping was not a priority during planning and emergency phases of the sea otter (Enhydra lutris) rescue and rehabilitation. Once initiated, records provided summaries for administrators, aid for clinicians, feedback for staff, and information for the press and oversight agencies. Since the release of the otters, the records remain useful for assessing reponse effectiveness, planning for future disasters, providing data for researchers, recording history, and documenting for litigation. At otter rehabilitation centers, the types of records fell roughly into the following categories: otter demographics, clinical, husbandry-behavioral, and pathological. To set up effective record keeping in the future, the administration must set priorities for which data to collect. Standard office supplies and equipment, including a large-capacity photocopier and secure file cabinets, meet supply needs. Records personnel need aptitude for detail, skills in office procedures, basic understanding of life sciences or medicine, continuity, and authority to do their jobs. The human element is crucial for successful records. Cooperation from all supervisors and adequate briefing of staff are required. Set aside an undisturbed location for records, find and keep competent personnel, and establish a data manager to oversee records and computerization. Animal identification was a major problem at animal rehabilitation centers. Use legible tags and consistent tagging procedures, provide binoculars for observations of groups, describe all animals in detail when admitted, establish a consistent numbering scheme and use it for all animals, label dead otters clearly, and use implanted transponder chips as a backup for tracing animals. Have master forms ready beforehand, use white paper and black (waterproof) pens on forms, double-check animal numbers against other identification frequently, and use computers to maximize effectiveness. The data set is variable in quality but valuable. Protocols explain some methods but are often lacking or undated. Different measuring devices, calculation methods, or circumstances compromised accuracy. Organization of the data set remains incomplete and should be addressed to maximize the learning value of the sea otter rescue project.
\end{abstract}


Record keeping was the ugly duckling of the sea otter (Enhydra lutris) rescue and rehabilitation project. To the best of my knowledge, record keeping was not considered in the prespill contingency plans nor in the original staffing of any of the three otter rehabilitation centers. It is natural that documentation was not a priority in the chaos of the initial emergency response. By the end of the first week in Valdez, however, record-keeping procedures were initiated. Subsequently, record keeping became a significant part of the project, and we regretted information lost from the critical first days of the sea otter rescue.

I describe the records collected at the otter rehabilitation centers and their uses for those not familiar with them, and recommend ways to collect data so that future animal rescue and rehabilitation projects can document efforts from the beginning and avoid delays that we experienced. I discuss only animal records, not personnel or expenditure accounting.

\section{Uses of the Records}

The records were used for several purposes while the otter rehabilitation centers were operating. Uses differed among centers, and often staff did not exploit records fully, so the following list represents an idealized situation:

Summaries for administration. Daily statistics at the Valdez Otter Rehabilitation Center (VORC) could be relayed to agencies, the science meetings, or the press. At the Seward Otter Rehabilitation Center (SORC) a daily computer summary of animal conditions kept administrators abreast of animal care issues.

Aid for clinicians. Veterinarians referred to an otter's husbandry records, treatment schedules, and progress notes while making clinical judg. ments. These records included previous treatments and notes from other veterinarians.

Feedback for staff. Husbandry charts and veterinary notes contained information for husbandry workers about how each animal had fared during earlier shifts. For example, workers could learn whether an otter was not eating because it was anorectic or because it had just eaten a big meal and was sated; they could be aware if an otter tended to become hypothermic after getting wet; and they could be wary if an otter had special problems.

Information for the press and oversight agencies. Otter counts were reported daily to the U.S. Fish and Wildlife Service and made available to the press if requested. Sometimes records personnel answered inquiries about particular animals, such as where a pup had been captured or why an animal was considered unreleasable. Records also provided information to the Service for choosing implant candidates and for matching otters with release sites.

Since the otter centers closed, the records have continued to provide information. They will probably be used for years for some of the following purposes:

Help assess response effectiveness and plan for future disasters. The records should be consulted in the development of future contingency plans. They can provide mortality comparisons of otters from different stages of the spill and various clinical and husbandry regimes.

Provide data for researchers. Eyewitness information in the rehabilitation center records may contradict previously published scientific literature and needs to be investigated by sea otter experts. Clinical, pathological, and husbandry data came from a larger sample size than was previously available to researchers.

Historical record. The T/N Exxon Valdez oil spill cleanup was a major event in environmental history. Our actions will be scrutinized by future stewards of the wilderness.

Documentation for litigation. Attorneys for both the Exxon Company, U.S.A., and the Service have expressed interest in these records.

\section{Types of Records}

Animal records at the three otter rehabilitation centers came from capture boats, veterinarians, veterinary technicians, husbandry staff, food preparation supervisors (whose figures overlap with accounting), and from the records coordinators themselves. The types of data can be roughly grouped into the categories of sea otter demographics, clinical notes, husbandry and behavioral notes, and pathological data. Sometimes one form contained several types of data or summarized information from various areas.

Demographic information was first collected in the field on the capture boats. When capture crews were trained and field protocols determined, capture forms were provided to the crews (Figs. 1 and 2). The crews were supposed to record geographic and individual otter information. Once received at an otter center, each animal was 
Fig. 1. Sea Otter Capture Record (B)-a sample capture record from an unidentified capture boat on 15 April 1989. This form was from the otter translocation projects in California and was not modified for the oil spill project.
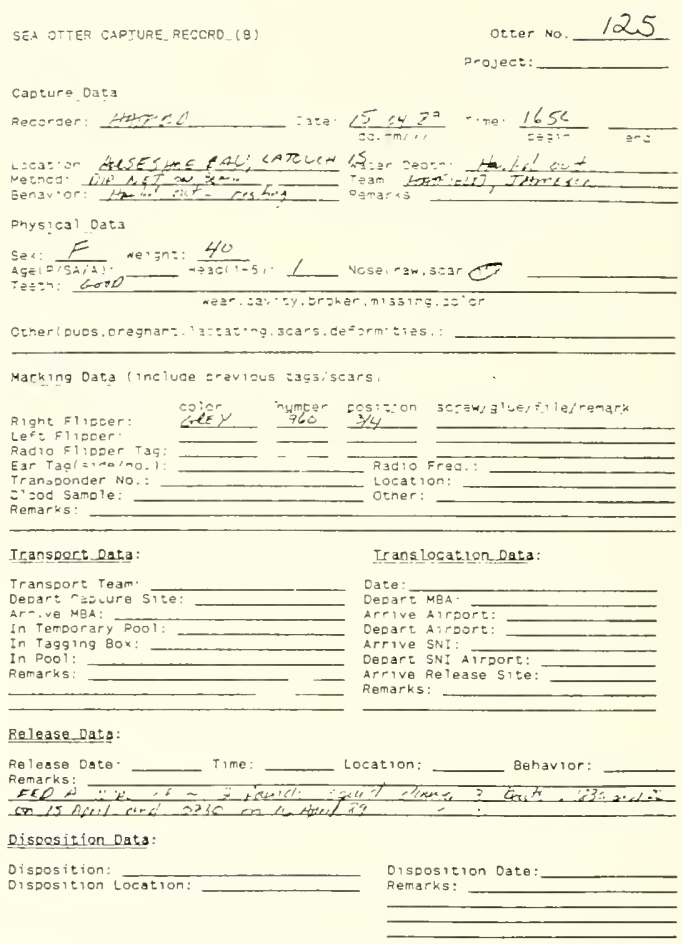

logged in and assigned an identification number so that it could be traced through all subsequent records (Fig. 3). A daily census of otters was kept at each center (Fig. 4). Release forms recapitulated the identification and geographic information when otters were returned to the wild (Fig. 5). Demographic data recorded on these forms included counts of sea otters, sex ratios, animal weights, estimates of age, pregnancy and pupping counts, and locations of origins and dispositions of treated otters.

Clinical information was generally written by veterinarians and veterinary technicians, beginning as soon as the sea otter was admitted to a center. They recorded initial condition and treatments on the admission records (Fig. 6). At SORC a separate anesthesia record was developed (Fig. 7). Surgeries (Fig. 8) and prerelease examinations (Fig. 9) had their own forms. Veterinarians had treatment schedules (Figs. 10 and 11) and their own notes, which they transferred onto the husbandry forms at VORC (Fig. 12). Veterinari- ans wrote their notes in red ink to make them conspicuous, but this distinction does not show on photocopies.

Clinical data logged in these records included anesthesia dosages, other treatments, surgical procedures, vital signs (temperature and respiration), and symptoms observed by husbandry personnel (e.g., shivering, panting, abnormal eliminations, bleeding, lesions, excessive vocalizations, anorexia, lethargy, impaired mobility, swelling, and corneal opacity). Admission and husbandry records also noted the times of blood and other culture sampling.

Laboratory results were also recorded, some of which were generated in-house and some from outside laboratories; most of these dealt with blood (Figs. 13 and 14). Standard blood test protocols called for hematology, blood chemistry, and toxicological analysis. Miscellaneous reports included bacterial cultures (Fig. 15), urinalyses, serology, coagulation assays, hydrocarbon panels, and radiology reports. 


\section{$5 \omega-81$}

SES OTTEF. ChF UURE RECOPS

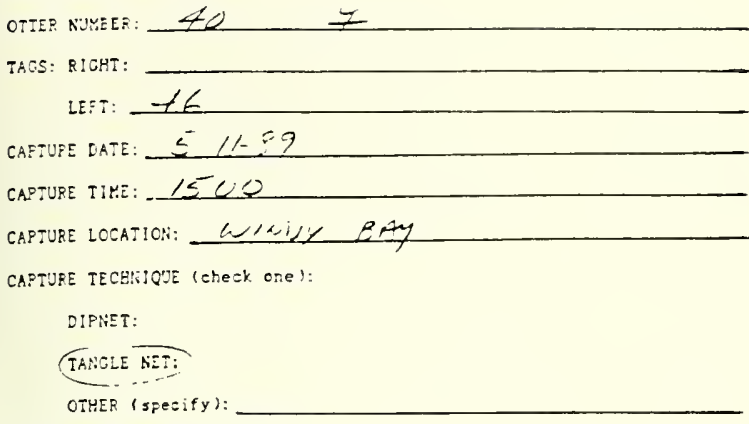

IF D:PNET (check one):

OTTER HaULED OUT WHEN CAPTLRED:

OTIER IN WHTEK WEE: CAPTUKED (record esturesed water depth):

IF TANCLE NET: Extigated water depth:

CONDITION OF OTTER AT TIUE OF CAFTURE (eheck ODE):

ALERT:

LETHARGIC:

COMATOSE:

SUBJECTIVE ESTIUATE OF DEGREE OF OILING aT TIME OF CAPTURE (check one):

BEAVY:

EODERATE:

LICHT:

NONE:

CAPTURE PERSOH:LL E. A'CNANANT

VESSEL: MYSTR LUY

RECORDER:

In addition, the veterinary technicians kept daily summaries (progress notes) of each otter's condition (Figs. 16, 17, 18, and 19); they were handwritten at VORC and the Jakolof Pre-Release Facility (JPRF) and computerized at SORC. These summaries provided overviews of each otter's progress and the treatments used, which were useful for animals in critical care but unwieldy for large numbers of healthy animals.

Husbandry forms made up the bulk of all records collected; hundreds were generated daily at the height of the project. Husbandry personnel each monitored from 1 to 30 animals, noting behavior and health. During the intensive care phase, they recorded the animals' activities at recommended intervals, plus feedings, eliminations
Fig. 2. Sea Otter Capture Record-a sample record from the F/N Mystic Lady on 11 May 1989. (This form was developed in Seward by G. VanBlaricom, U.S. Fish and Wildlife Service, Santa Cruz, California). (including the presence of oil in stools), housing changes, or other notable events (Figs. 20 and 21).

As time passed and the otters required less individualized care, feeding information was recorded separately so it could be better quantified (Figs. 22 and 23). The types and amounts of food were recorded; food was weighed to estimate caloric consumption and the percentage of body weight eaten. This procedure resulted in a measurement of appetite, to correlate with other indicators of animal health.

A few distinct records evaluated progress of the pelage during rehabilitation (Fig. 24). Grooming received particular attention while each otter was restoring its fur to normal. Frequency and type of grooming were noted, and a system was developed 
Fig. 3. Record Log of Sea Otters Received Live-a sample admission log from Homer, used at the Homer Temporary Care Facility and the Jakolof Pre-Release Facility. There were analogous logs at the Valdez and Seward Otter Rehabilitation centers.

ACHEMAK EAV OTTEP CENTEP 1080

PECCRD LOG - SEA OTTERS RECEIVED LIVE

\begin{tabular}{|c|c|c|c|c|c|c|}
\hline otter * & $-127^{\circ}$ color & dote in & location collected & $\begin{array}{l}\text { tranferred } \\
\text { from }\end{array}$ & final disposition & date out \\
\hline $\mathrm{H}-1$ & notag & $4-25$ & TonsIna BAY & & $\begin{array}{l}\text { DiEO in transit } \\
\text { to yalolez }\end{array}$ & 4.27 \\
\hline $\begin{array}{l}H-2 \\
P U P\end{array}$ & no tag & 4.26 & PORT GRAHAM & & $\begin{array}{l}\text { SALDEZ } \\
\text { SENT TO VALDEZ }\end{array}$ & 4.27 \\
\hline $\mathrm{H}-3$ & 582 brown & $4 \cdot 28$ & TONSINA BAY & & $\begin{array}{l}\text { YALDEZ }=\mid \overline{51} \\
\text { SENT TO VALDEZ }\end{array}$ & 4.29 \\
\hline $\mathrm{H}-4$ & 583 brown & $4-28$ & TONSINA BAY & & $\begin{array}{l}\because A L O E 2=153 \\
\text { SENT TO VALDEZ. }\end{array}$ & 4.29 \\
\hline $\mathrm{H}-5$ & $587 \mathrm{red}$ & $4-29$ & BERGER BAY & & $\begin{array}{l}\text { VALDEZ }=152 \\
\text { SENT TO VALDEZ }\end{array}$ & 4.29 \\
\hline $\mathrm{H}-\overline{5}$ & 585 oronge & $4-29$ & TONSINA BAY & & SEWARD - I & $5-1$ \\
\hline $\mathrm{H}-7$ & 586 arange & 4.29 & TONSINA BAY & & $\begin{array}{l}\text { SEWARD } \\
\text { SENT TO SEW }\end{array}$ & $5-1$ \\
\hline $\mathrm{H}-\mathrm{B}$ & 589 crange & 4.29 & Tonsina BAY & & $\begin{array}{l}\text { SEWARD } \\
\text { SENT TO SEWARD }\end{array}$ & $5-1$ \\
\hline$H-9$ & 5 orange & $4-30$ & TONSINA BAY & & SENTT TO SEWARD & $5-1$ \\
\hline $\mathrm{H}-10$ & 5 orame & $4-30$ & TONSINA BAY & & SENT TO SEWARD & $5-1$ \\
\hline $\mathrm{H}-11$ & 5 orange: & $4-30$ & TONSINA BAY & & $\begin{array}{l}\text { SEWARD } \\
\text { SENT TO SEWARD }\end{array}$ & $5-1$ \\
\hline $\mathrm{H}-12$ & motika & $4-30$ & $\begin{array}{l}\text { WEST ARM, } \\
\text { PORT DICK }\end{array}$ & & DIED & 4.30 \\
\hline $\mathrm{H}-13$ & PUP & $4-30$ & $\begin{array}{l}\text { WEIT ARM, } \\
\text { PORT DRCK. }\end{array}$ & & $\begin{array}{l}\text { SKWARD } 4 \\
\text { SENT TO SEWARD }\end{array}$ & $5-1$ \\
\hline $\mathrm{H}-14$ & 570 red & $5-6$ & WINDY BAY & & $\begin{array}{l}\text { JAMES LAGOON } \\
\text { MCCARTY FIORD }\end{array}$ & $8-19$ \\
\hline $\mathrm{H}-15$ & 516 yellow & $5-6$ & PICNIC HARBOR & & SEWARD $S W-45$ & $5-7$ \\
\hline $\mathrm{H}-16$ & 522 & $5-7$ & ROCKY BAY & & RELEASEDE JAKOLOF & $7-14$ \\
\hline $\mathrm{H}-17$ & 521 green & $5-7$ & RockY BAY? & & NUKA BAY & $8-19$ \\
\hline $\mathrm{H}-18$ & notag & $5-26$ & LITTLE JAKOLOF & & LITTLE JAKOLOF & $8-30$ \\
\hline $\begin{array}{l}\mathrm{H}-19 \\
\text { Pue }\end{array}$ & notag & $5-15$ & $\begin{array}{l}\text { BORN AT HOMER } \\
\text { TO } \mathrm{H}-14\end{array}$ & & DIED AT JAKOLOF & $5-25$ \\
\hline 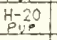 & no tag & $5-25$ & $\begin{array}{l}\text { BURN AT JAKOLOF } \\
\text { TO H-16 }\end{array}$ & & RELEASED@ JAKOLOF & $7-14$ \\
\hline $\mathrm{H}-2 \mathrm{2}$ & no tag & $6-9$ & LITTLE JAXOLOF & & $\begin{array}{l}\text { RELEASED @ } \\
\text { ITTLE JAKOLOF }\end{array}$ & $6-12$ \\
\hline $\mathrm{H}-22$ & no tas & $7-4$ & LITTLE JAKOLOF & & $\begin{array}{l}\text { RELEASED } \\
\text { HCRRINGIS. }\end{array}$ & $7-28$ \\
\hline $\begin{array}{l}\mathrm{H}-23 \\
\text { Pup }\end{array}$ & no tag & $7-5$ & $\begin{array}{l}\text { BORN AT SAROLOF } \\
\text { To SW-29 }\end{array}$ & & $\begin{array}{l}\text { RELEASEOE } \\
\text { LITLE JAKOLOF }\end{array}$ & $8-11$ \\
\hline H-24 & notag & $7 \cdot 12$ & $\begin{array}{l}\text { DORN AT JAROLOF } \\
\text { TO SW-18 }\end{array}$ & & $\begin{array}{l}\text { RELEASLDE } \\
\text { LITTLE JAKOLOF }\end{array}$ & $8-11$ \\
\hline $\mathrm{H}-25$ & notag & $7-22$ & LITTLE JAKOLOF & & $\begin{array}{l}\text { RELEASED } \\
\text { HERRING IS. }\end{array}$ & $8-21$ \\
\hline $\mathrm{H}-2 \mathrm{~S}$ & no taq & $7-29$ & LITTLE JA KOLOF & & $\begin{array}{l}\text { RELEASED } \\
\text { HERRING IS. }\end{array}$ & $8-21$ \\
\hline $\mathrm{H}-27$ & & & & & & \\
\hline$H-2 B$ & & & & & & \\
\hline
\end{tabular}

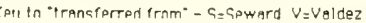

at SORC for rating pelage condition (Rash et al. 1990).

Later, husbandry records became simpler and briefer as animals became healthy and staffing was reduced. When groups of sea otters were housed in floating pens it was impossible to obtain the detailed observations that had been possible during earlier intensive care phases (Figs. 25, 26, and 27).

The husbandry records contain a wealth of behavioral data, often in anecdotal form. We observed grooming and feeding behaviors (Michaelson 1990), plus manipulations of inanimate objects for feeding tools or play. Interactions between otters were recorded, including bonding (recurring amiable physical contact between two or more otters over time, sometimes including vocal distress if separated), mother otters adopting unrelated orphan pups, breeding, and pupping. Detailed reports were made of pups being born and of their development at various ages. Some of the most interesting notes describe repeated instances of altruistic behavior.

Pathological data make up the last category of records. The only pathology forms in the otter files at present are necropsies (Fig. 28). These contain preliminary information on mortality statistics, gross pathological damage, sea otter anatomy, fetal development, animal weights, and condition of the pelage. It would have been helpful to planners and clinicians if pathological data had been readily available during the course of the otter rehabilitation.

\section{Priorities}

To set up effective record keeping in a future animal rescue, the administration should first consider which data are most important to collect, 
SEA OTTERS

* daily and cumulative totals *

DAILY TOTAL

\begin{tabular}{|c|c|c|c|c|c|c|c|}
\hline DATE- & $14 / 7 / 59$ & $4 / 8$ & $4 / 9$ & $4 / 10$ & $4 / 11$ & $4 / 12$ & $4 / 13$ \\
\hline \multirow{2}{*}{$\begin{array}{l}\text { RECEIVED LIVE } \\
\text { RECEIVED DEAD }\end{array}$} & 12 & 9 & 10 & 3 & 1 & O & 5 \\
\hline & & & & & & & \\
\hline $\begin{array}{l}\text { RECETVED DEAD } \\
\text { DIED AT CENTER }\end{array}$ & 7 & 2 & 6 & 5 & 3 & 0 & 1 \\
\hline \multirow{2}{*}{$\begin{array}{l}\text { LIVE AT CENTER } \\
\text { EUTHANIZED }\end{array}$} & 48 & 52 & 53 & 51 & 49 & 42 & 44 \\
\hline & 2 & 3 & 3 & 0 & 0 & 1 & 0 \\
\hline \multirow{4}{*}{$\begin{array}{l}\text { EUTHANIZED } \\
\text { NO. WASHED } \\
\text { MO. RELEASED } \\
\text { RELEASE SITES: }\end{array}$} & 8 & 8 & 7 & 3 & 1 & 0 & 2 \\
\hline & 0 & 0 & 0 & 0 & 0 & 6 & 2 \\
\hline & \multicolumn{7}{|c|}{$4 / 12 / 866$ to POINT DEFIANCE } \\
\hline & \multicolumn{7}{|c|}{$4 / 13 / 862$ pUPS to MONTEREY } \\
\hline
\end{tabular}

CUMulative total

\begin{tabular}{|c|c|c|c|c|c|c|c|}
\hline DATE - & $4 / 7 / 89$ & $4 / 8$ & $4 / 9$ & $4 / 10$ & $4 / 11$ & $4 / 12$ & $4 / 13$ \\
\hline \multirow{2}{*}{$\begin{array}{l}\text { RECEIVED LIVE } \\
\text { RECEIVED DEAD }\end{array}$} & 94 & 103 & $1 / 3$ & 116 & 117 & $1 / 7$ & 122 \\
\hline & & & & & & & \\
\hline DIED AT CENTER & 38 & 40 & 46 & 51 & 54 & 54 & 55 \\
\hline \multirow{2}{*}{$\begin{array}{l}\text { LIVE AT CENTER } \\
\text { EUTHANIZED }\end{array}$} & 46 & 50 & 53 & 51 & 49 & 42 & 44 \\
\hline & $z$ & 5 & 8 & 8 & 8 & 9 & 9 \\
\hline \multirow{3}{*}{$\begin{array}{l}\text { No. WASHED } \\
\text { No. RELEASED } \\
\text { RELEASED }\end{array}$} & 88 & 96 & 103 & 106 & 107 & 107 & 109 \\
\hline & 6 & 6 & 6 & 6 & 6 & 12 & 14 \\
\hline & & & & & & & \\
\hline \multicolumn{8}{|l|}{ RELEASE SITES } \\
\hline
\end{tabular}

Fig. 4. Daily and Cumulative Totals of Sea Otters-a sample census record from the Valdez Otter Rehabilitation Center, 7 April through 13 April 1989. There were analogous census records at the Seward Otter Rehabilitation Center and the Homer Temporary Care Facility. including information required by regulating agencies, funding sources, in-house staff, the scientific community, the public, and legal counsel. Data goals must also realistically accommodate the resources available, including staff size, expertise, and equipment. We must acknowledge the possible inaccuracies written down by untrained or unscrupulous staffers. Veterinarians or people trained in animal behavior might be better observers. Finally, administrators should consider potential future uses of the records, beyond the project at hand, and decide priorities accordingly.

\section{Supply and Personnel Needs}

If a rescue and rehabilitation effort for sea otters or other large animals is attempted again, the initial record needs could be modest and need not interfere with an effective response. Paper, a pencil or pen, and a watch are all that are required to jot brief notes about what is done.

As the response becomes organized, specific items should be ordered to meet record-keeping needs for a major project (Table 1). The only large items required are a photocopier and a locking file cabinet. These should be part of any modern office or administrative center and may be acquired beforehand. However, this equipment must be dedicated to records personnel. During the 1989 program, workers monopolized several large-capacity photocopiers and filled six four-drawer filing cabinets. Minor items such as labels, rulers, and bankers' boxes may be useful. We recommend that a computer or typewriter be available for generating forms. Computerization should be used from the beginning to store, handle, and display data from records (Swarthout 1990).

Records personnel need work space where papers can be sorted or stored before filing without 
Fig. 5. Sea Otter Release Form-a sample release record from the Jakolof Pre-Release Facility, 21 August 1989.

KACHEMAK BAY OTTER CENT . JAKOLOF BAY PRE-RELEASE FACILITY

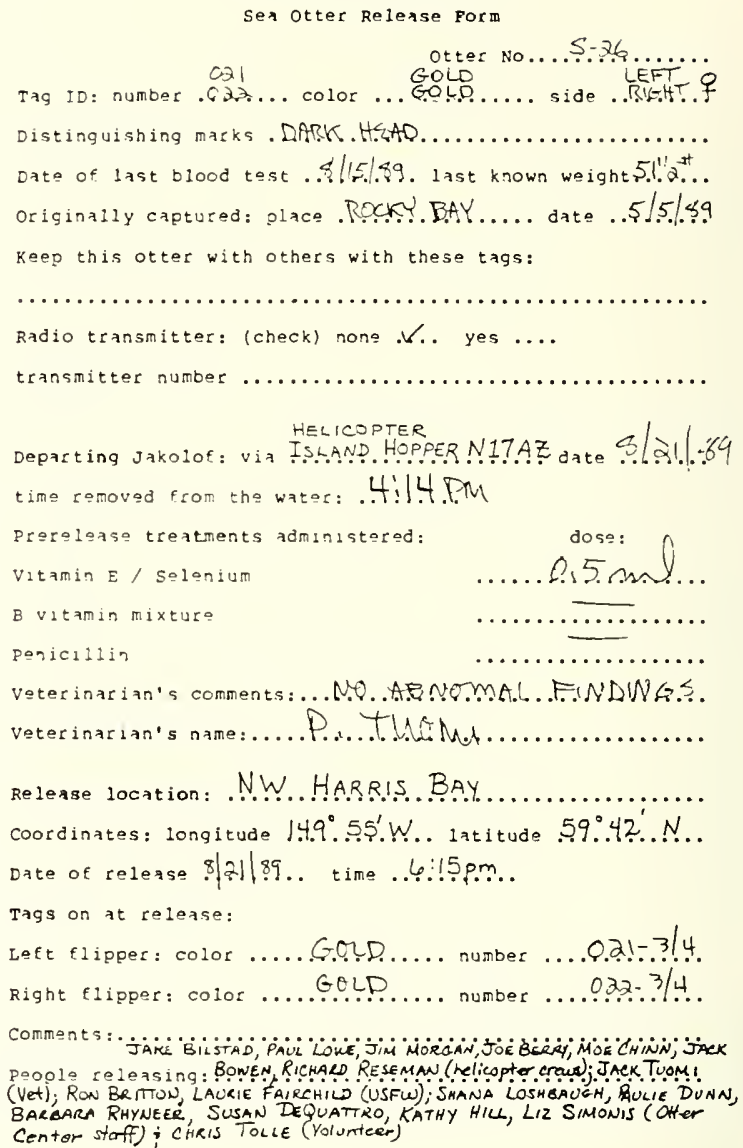

Sen otter Relense form

Table 1. Equipment to order for record keeping.

Animal tags (legible, numbered identification tags)

Livestock ear punch

Disinfectant (for the ear punch)

Wall clock

Wall calendar

Photocopier (high capacity for large projects)

Locked file cabinet (several for large project)

White copier paper (letter size)

Photocopier supplies (toner, ink, etc.)

Third-cut manila file folders (letter size)

Clipboards (letter size)

Waterproof black pens being disturbed by unauthorized personnel. A drop box or basket should be installed where staff can conveniently leave papers for the records department.

Personnel selected to work in records must have a commitment to the quality of the data and should have a broad viewpoint of the project. In a small project, records can be handled by the support office staff or by veterinary technicians. In a large project it may be more feasible to have a separate department handle records. In either situation, the records personnel must work in tight coordination with the computer personnel. 


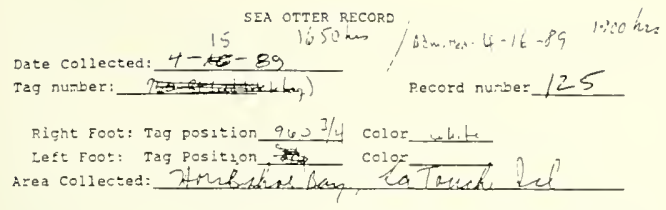

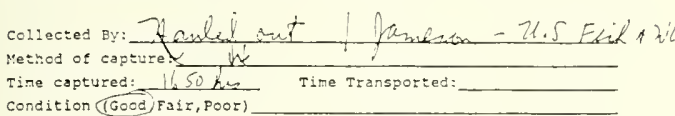

Condition (Good) Fair, Poor) _.

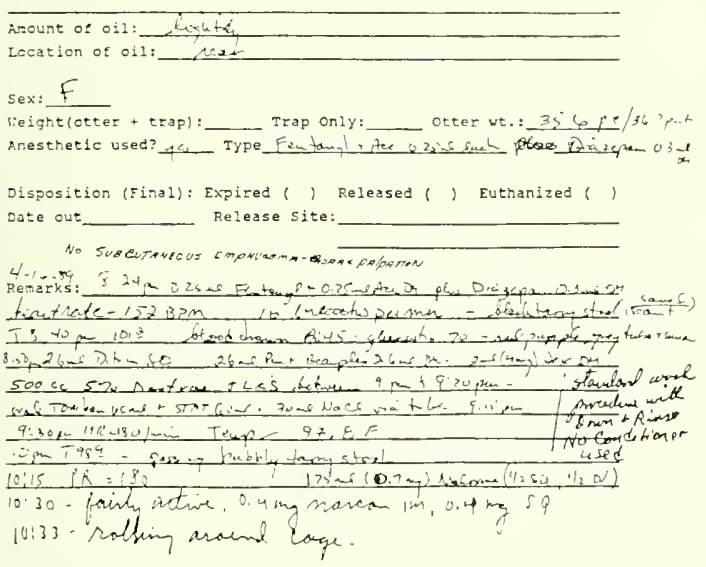

Fig. 6. Sea Otter Record-a sample admission record from the Valdez Otter Rehabilitation Center, 16 April 1989. This form was also used on a few cap. ture boats in the early weeks of the program. Note that early forms lacked the names of the facilities.
Indeed, the records and the computerized data base are closely related, and one supervisor should oversee both.

Record keepers must be detail-oriented and have aptitude in filing systems, data handling, and biology. Table 2 shows some background experience and work histories that may indicate skills needed for records personnel.

Once personnel are selected to keep records, they should not be changed unless absolutely necessary. Use staff rather than temporary employees or volunteers. Continuity in records is particularly important to avoid loss or distortion of data.

The rehabilitation center administration must give the records personnel adequate authority, tell them what data are sought and why, and give them power to request data from professionals and various departments. Otherwise, people may keep papers for their own use and neglect to forward information to the central records.
Table 2. Backgrounds for records personnel.

Scientific data handling

Veterinary records

Medical records

Ward clerk work

File clerk work

Accounting or bookkeeping

Editing

Veterinary technician work

Medical transcribing

Medical studies

Veterinary studies

Nursing studies

College zoology studies

Computer data entry

Computer data base analysis

Pharmacy work

Library work

Emergency medical services 
Fig. 7. Anesthesia Record-a sample anesthesia report used during washing at the Seward Otter Rehabilitation Center, 14 May 1989. Note that the center name and the prefix "SW" on the animal number are missing.

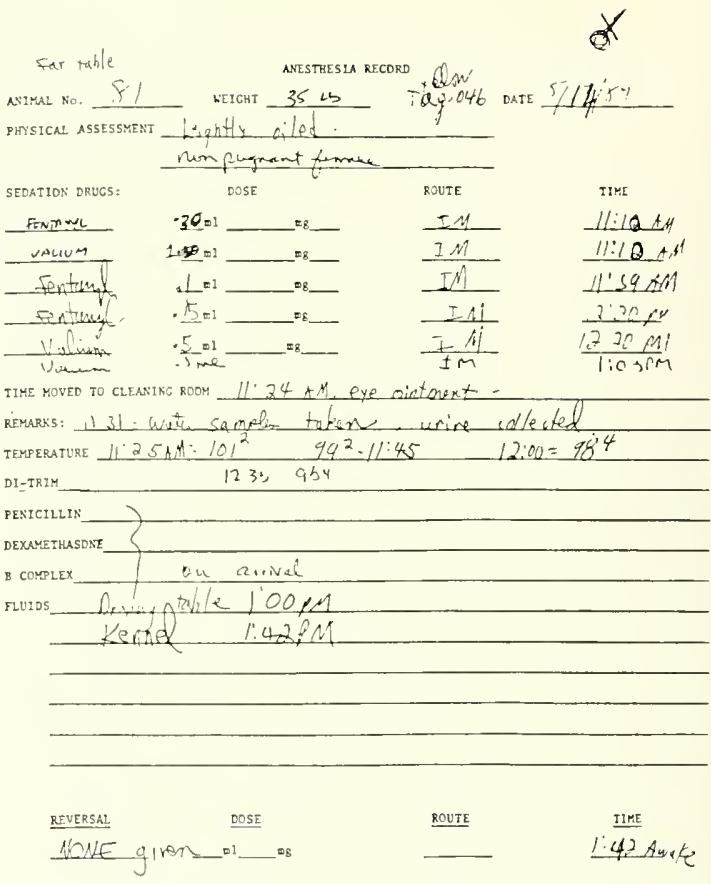

\section{Discussion and Recommendations}

\section{Personnel Issues}

Proper staffing and a smooth linkage with the overall otter rescue program are crucial to maintaining records. As I have stressed, our greatest problem was lack of continuity. Records and data management did not receive high enough priority in early staffing plans, so we had to borrow staff from the office, veterinary technicians, or husbandry. Data managers need control over their staffs, including the authority to make decisions about layoffs.

We also need consistent methods and measurements documented in written, dated protocols and carried out under reliable supervision. This was difficult in a project where everyone was learning as they went. For example, differentials on blood work were performed in-house by several technicians with inconsistent results and no notations on methods used or accuracy.
Cooperation from supervisors in all departments is essential. A vital function of supervisors, often overlooked during the 1989 project, was briefing staffers on how to complete records correctly. Records personnel could not individually explain forms to all staffers. Explaining the "why" and "how" of the forms dramatically improved record keeping. Supervisors who communicated well with records people tended to produce clear records that reliably reached the files; those who were less effective communicators produced confusing records or duplicated effort. Cooperative supervisors helped develop good forms, ensured that forms were filled out properly in their departments, suggested additional data to record, and sometimes lent personnel to help with filing or to answer questions.

To ensure better records management in future projects, I recommend (a) setting aside a distinct place for records at the beginning, where they can be safely stored without unauthorized access and without needing to be moved until the project is completed; (b) finding competent records personnel and maintaining them throughout the project 


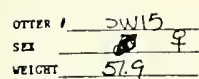

vetcat

sod condition Coot

ANESTHETIC

\begin{tabular}{|c|c|c|c|c|}
\hline TIME & $0: 46$ & $10: 48$ & $10: 48$ & \\
\hline pRoG & catrum & $a_{3} \operatorname{sen} 4$ & valixna & \\
\hline ADHIN,ROUTE & ln & $\ln$ & 11 & \\
\hline DOSAGE & 3 3nc & $\begin{array}{l}3 \\
12 \mathrm{~m}\end{array}$ & $\begin{array}{c}.5 \\
2.5 \mathrm{~m} \gamma\end{array}$ & \\
\hline
\end{tabular}

Tioe to surgical plase of anestbesia: 10.02

The eurgery begar: $\quad$ D.OS

Time aurgery completed

\section{2}

CIMICAL OBSERATIONS:

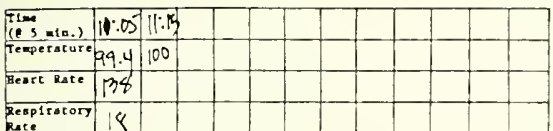

Rate

PROALES:

\begin{tabular}{|l|l|l|l|l|}
\hline Sim & & & \\
\hline Selzures & & & & \\
\hline Octher & & & & \\
\hline
\end{tabular}

ANESTHETIC REVERSAL: RURCAN

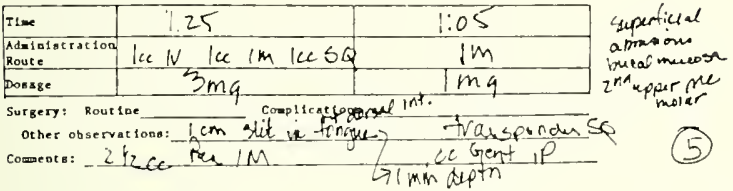

Fig. 8. Sea Otter Anesthesia for Im. plants-a sample surgery report from the Seward Otter Rehabilitation Cen. ter, 17 July 1989 . Note that the form lacks places for the center name and date.
Fig. 9. Prerelease Examination and Blood Testing Results-a sample of examination results from the Jakolof Pre-Release Facility, 31 July 1989. This report was generated on a com. puter.
JAKOLOF BAY PRE-RELEASE FACILITY

Pre-rolease examination and blood testing results

pact two: individual rosults

$5 W-18$

Dato: $7-3:-89$

Tag: 525 Gray, right fllooer

Sex: $\mathrm{mal}$ e

Welght: old 84 lbs, new 98 lbs

Sedation: $2.5 \mathrm{mg}$ Fontanyl IM

2. 5 mg Valium IM

1.0 mig Fontanyl IM

roversal $2.5 \mathrm{mg}$ Narcan IM

Exam :

Oral exam revealed good teeth but some signs of wear. No oral nor genital lesions notad. Foet good. No wounds, no abrormalities observed.

Length: 59 inches

Temper aturo: 103

Blood rosults: pending

Examined by Glen Grady, DVM and Nail Utkov, DVM 


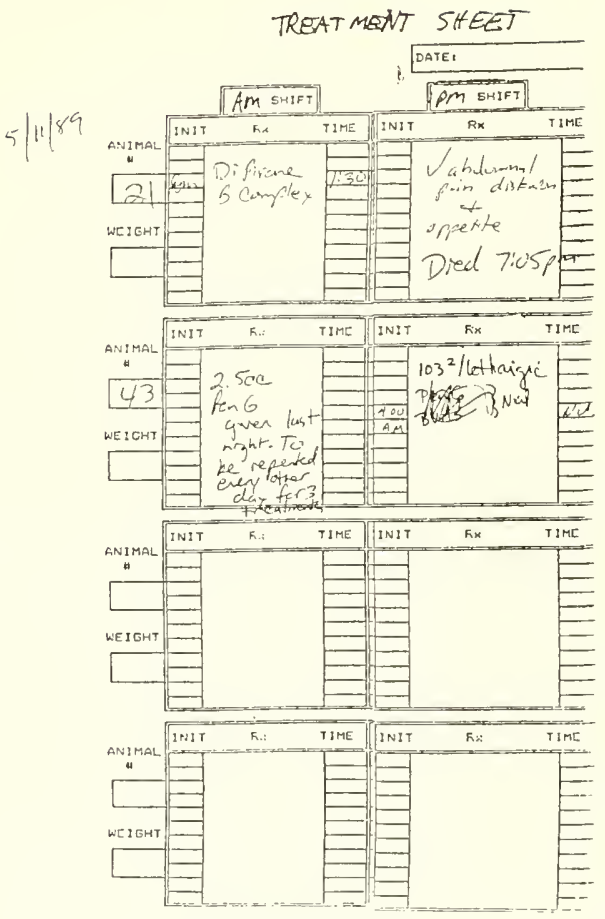

Fig. 10. Treatment Sheet-a sample of the treatment notes made by veterinarians at the Seward Otter Rehabilitation Center, 11 May 1989. This information was transferred to each animal's individual husbandry records.

for continuity; and (c) having a single data manager who is included in staff meetings.

\section{Animal Identification}

We customarily used flipper tags to mark each otter. Animals that were not tagged were easy to confuse. Tagging them on capture boats ensured that we could correlate their origins with later data. When this was not done, we sometimes lost the information because capture records were misplaced between the boats and the otter centers. Early on, so many animals died that the morgue was swamped with untagged otters. No system was in place to identify them for pathology, so the links between capture, clinical, and necropsy data were broken. Sometimes the Service did not have tags available for days at a time. Even when tags were used, they had drawbacks. For a long time there was no proper punch for attaching them; the proper tool to use is a livestock punch. The tags used were actually ear tags for sheep. Light-colored tags such as red, yellow, white, silver, light blue, or lime green were more visible than dark or brownish ones. Unanticipated problems included color-blind observers who could not distinguish red from orange or brown tags, and some tags that were numbered only on one side, generally-in accordance with "Murphy's law" - the side not visible when the otter was floating at rest. Some otters repeatedly chewed their tags off. In addition, flipper tags were too small to be easily identified at a distance. As a result, we realized that flipper tags were less than ideal.

Another method of identification was physical description. This was helpful but never adequate alone because sea otters, especially juveniles and young females, appear similar. Nonetheless, it was valuable to have an animal's weight, sex, and distinguishing marks, such as lighter fur or nose scars. This information helped identify animals when they lost their tags or when numbers were miscopied.

Every animal admitted to the otter centers received an identification number, which was distinct from its flipper tag number. These numbers were assigned sequentially as each animal arrived. After SORC opened, a prefix of "V," "SW," or " $\mathrm{H}$ " was added to differentiate animals admitted at VORC, SORC, or the Homer Temporary Care Facility (HTCF). Unfortunately, several inconsistencies confused these numbers. Originally no one knew the HTCF would be authorized as a longterm otter center, so all " $\mathrm{H}$ " sea otters transferred to VORC and SORC from the HTCF during April and May were reassigned " $\mathrm{V}$ " or "SW" numbers. By the time the JPRF was approved, the Kachemak Bay staff had numbered to "H-14," and they continued from there. Therefore, the total of all "V," "SW", and " $\mathrm{H}$ " numbers exceeds the actual number of otters in the project.

When all the otters at the centers were captured from oiled areas the numbering was fairly consistent. Troubles arose when otters came in from other sources-pups born at otter centers and territorial male otters, referred to as "rogues," who insisted on attacking project otters in floating pens. No one wanted these animals counted as part of the oil spill casualties, but once they were captive and receiving care, their origins were often forgotten. At VORC, we decided to keep the se- 


$$
\begin{aligned}
& \text { Xet / Ang I \& E? }
\end{aligned}
$$

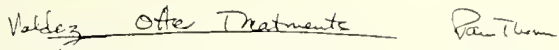

$$
\begin{aligned}
& 7 / 21 \text { cleak Pens. "srik qivis" }
\end{aligned}
$$

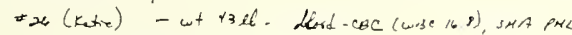

$$
\begin{aligned}
& P E \rightarrow N A t=\text { mangetive. }
\end{aligned}
$$

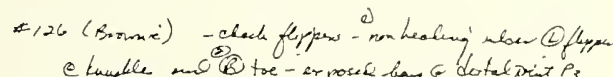

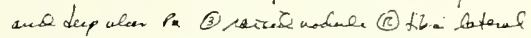

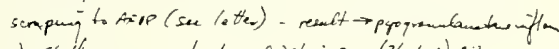

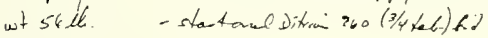

$$
\begin{aligned}
& \text { Head-cac-war, STA }
\end{aligned}
$$

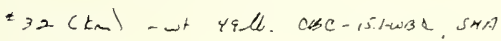

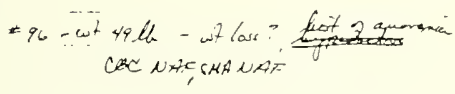

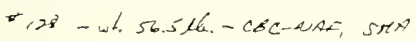

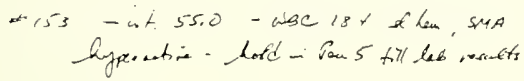

Fig. 11. Treatment Sheet-a sample of treatment notes made by a veterinarian (P. A. Tuomi) at the Valdez Otter Rehabilitation Center, 21 July 1989. This information was transferred to each animal's individual husbandry records. quential numbering, but to classify such otters with a letter code, " $\mathrm{P}$ " for "pup" or " $\mathrm{V}$ " for "volunteer," after the regular otter number. At SORC, personnel decided not to count a pup born in captivity unless it lived for more than 1 day. They assigned each surviving pup the same number as its mother, with a "P" after it. This was also done with the last pup born at VORC. This system caused problems because SORC has records or necropsies on some pups with no numbers, and because records of pups and their mothers got confused if staffers neglected to write down the " $\mathrm{P}$ " on each sheet. It also makes it unclear how many pups were born or died at SORC.

A further problem with identification numbers arose in pathology. In the early days of the project pathologists received many unidentified dead otters, so they set up their own numbering system. They kept their system of "path numbers" throughout the project, and it is not always clear which path numbers correlate with which otter numbers.

For better animal identification in future projects I recommend (a) finding better flipper tags- more difficult for otters to remove and more legible; (b) providing binoculars to observers when animals are penned in groups or in any large enclosure; (c) describing all animals in detail on capture and admission documents; (d) establishing a consistent numbering and identification system for all centers in advance and not changing it in midproject; (e) using sequential numbers for animal identification and designating an "otter category" for each animal to accommodate differences such as unoiled otters, pups born alive, stillbirths, and rogue otters (it would be less confusing to have one numbering system with an additional column for "category" than it would be to have a separate numbering system for each type of animal); (f) finding a way to label dead otters so that pathologists can correlate their results with clinical histories-perhaps just tying a tag with the identification number around a leg; and $(\mathrm{g})$ inserting transponder chips in each otter at the time of capture to allow precise identification, dead or alive, any time thereafter, as a backup to other methods of tracing animals. 
Fig. 12. Otter Husbandry-a husbandry record from the Valdez Otter Rehabilitation Center, 27 April 1989. Note the separate blocks for identification and feeding information, and that the column headings are generally ignored.

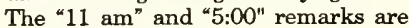
veterinarians' notes, in red ink on the original records.

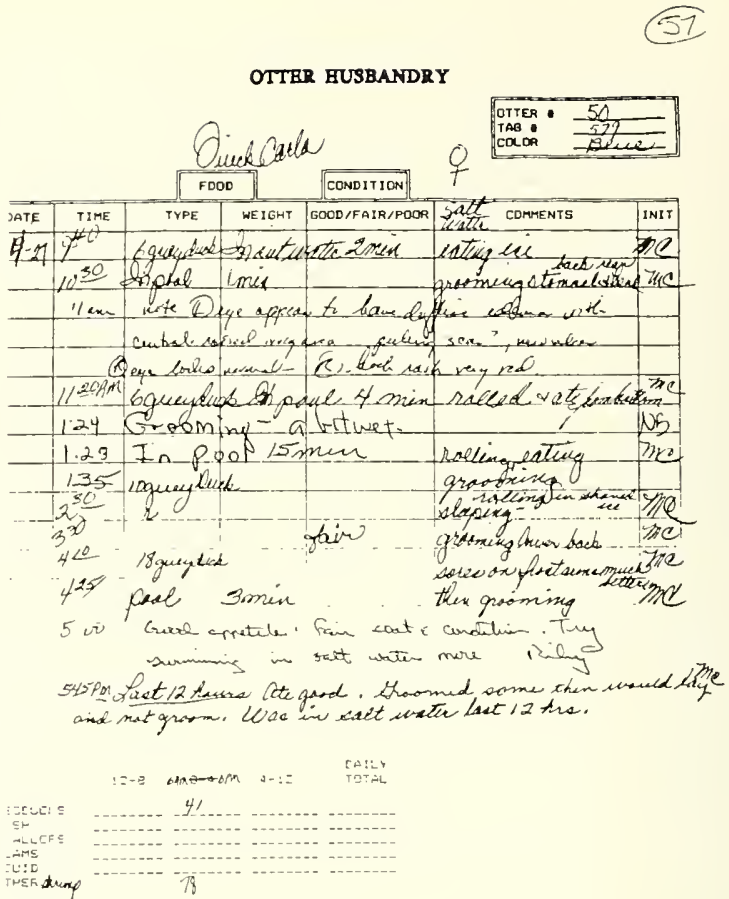

\section{Paperwork}

Forms presented challenges because we had to invent most of them on-site. No one had the time or inclination to fill out lengthy forms. Our task was to maximize the data and minimize the paperwork. Simplicity and completeness were essential. A check mark under a heading worked better than a lengthy explanation of something normal, yet staffers needed room to elaborate on unusual observations. Each form had to be clearly identified as to date, otter center, which animal it pertained to, and who had written the notes. If we did not do this, papers became worthless if separated from their files. Ambiguities had to be avoided. For example, forms at VORC asked ior the otter's "tag \#" and then "color." Of course this meant "tag color" but several people filled out "brown" for "color" (since otters are brown) before we clarified the form. We had many problems with records that did not reproduce on photocopiers. In hindsight, the forms must be easy to computerize: their meanings must be consistent and quantifiable wherever possible.
Paperwork proliferated as various departments and records personnel developed many forms. By trial and error we ran through many good and bad forms, often perfecting one just as changing circumstances made it obsolete. Sometimes we discontinued forms because no one filled them out correctly (Fig. 25). Other forms omitted crucial identification on the header (Fig. 8). Forms had to be filled out with dark ink on white paper and had to have margins to prevent illegible or chopped-off photocopies. Good forms were legible, clear, and informative (Figs. 5, 7, and 22). Some forms were tailored for specific situations or specific personnel (Fig. 29). Ultimately, forms were only as accurate as the effort of the people filling them out.

For paperwork in future otter centers I recommend (a) having master forms (Appendix) be part of contingency planning to avoid losing data early in an emergency animal rescue; (b) providing staffers with black, waterproof pens (erasable, if possible); (c) instructing staffers to frequently double-check identification on otter records against the animals' actual tags and descriptions; and (d) using computers wherever possible to avoid redundancies. 

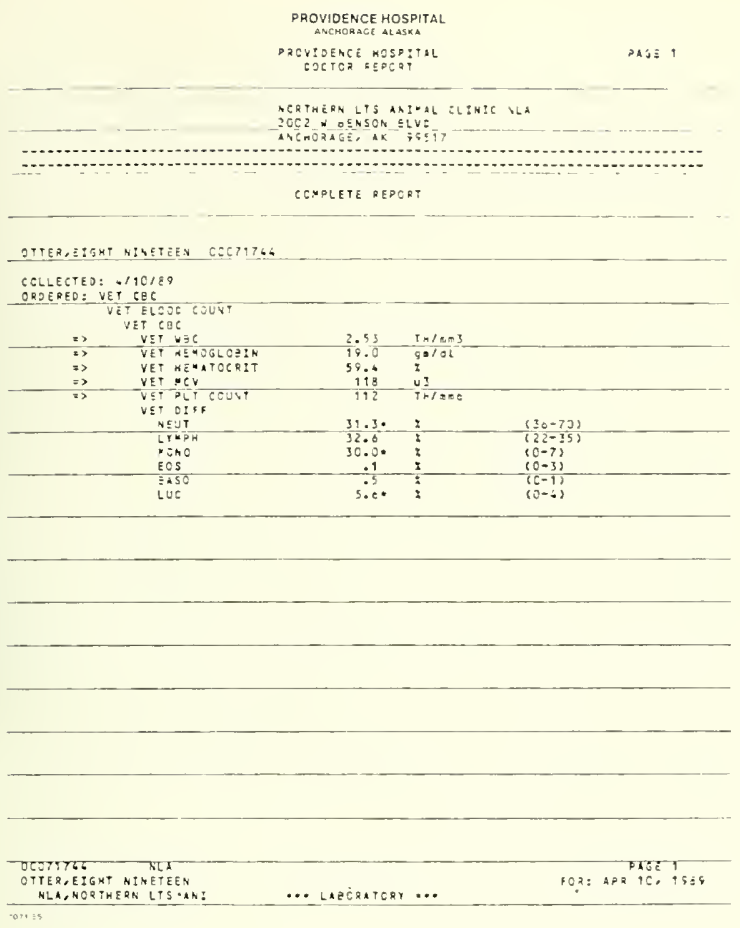

Fig. 13. Providence Hospital Doctor Report-a sample of a lab report (veteri. nary complete blood count) made at Providence Hospital, Anchorage, 10 April 1989. Note that it is identified with a tag number, not with the otter identification number.

\section{Quality of Data}

The quality of the information in the otter records was variable; we may never be able to evaluate the accuracy of the data collected. The oil spill was not a controlled experiment and, therefore, most data are not reproducible. Nonetheless, information in the files is valuable. We have a limited time to improve the quality by "cleaning it up" and answering questions while events are still fresh in the minds of participants.

The methods used to derive particular information were often not documented. Written protocols from various departments describe clinical and husbandry procedures; some papers list criteria for data and guidelines for observers writing husbandry notes (Michaelson 1990). Often these are lacking, however, or do not specify when they were implemented. One problem was the variety of measuring devices and methods used without notation. For example, otters were weighed alert and wiggling, or sedated and inert; on a digital scale or on a hanging fish scale; wet or dry. No one knows the error range of the body weights listed in the records. Food consumption listed in records was derived by several methods. For example, on the progress notes from JPRF (Fig. 19), one person calculated total food per otter per day as a fixed percentage of the animal's body weight, such as $20 \%$, regardless of what the pen actually received. Another person figured the total weight actually fed to the entire pen and divided that by the total number of otters present. Neither was accurate; we finally abandoned the measure altogether.

To evaluate these data we must be realistic. The staff was untrained, and circumstances changed constantly. Many of these data cannot be scientifically quantified or tested. Those of us charged with collecting and organizing records had to adjust to changing conditions. Changes in the animals' health necessitated changes in data collection. For example, by the time we learned what to record for critical care, the otters were healthier and were moved into large groups where such data were neither necessary nor accessible. Often, especially at SORC and JPRF and after the 


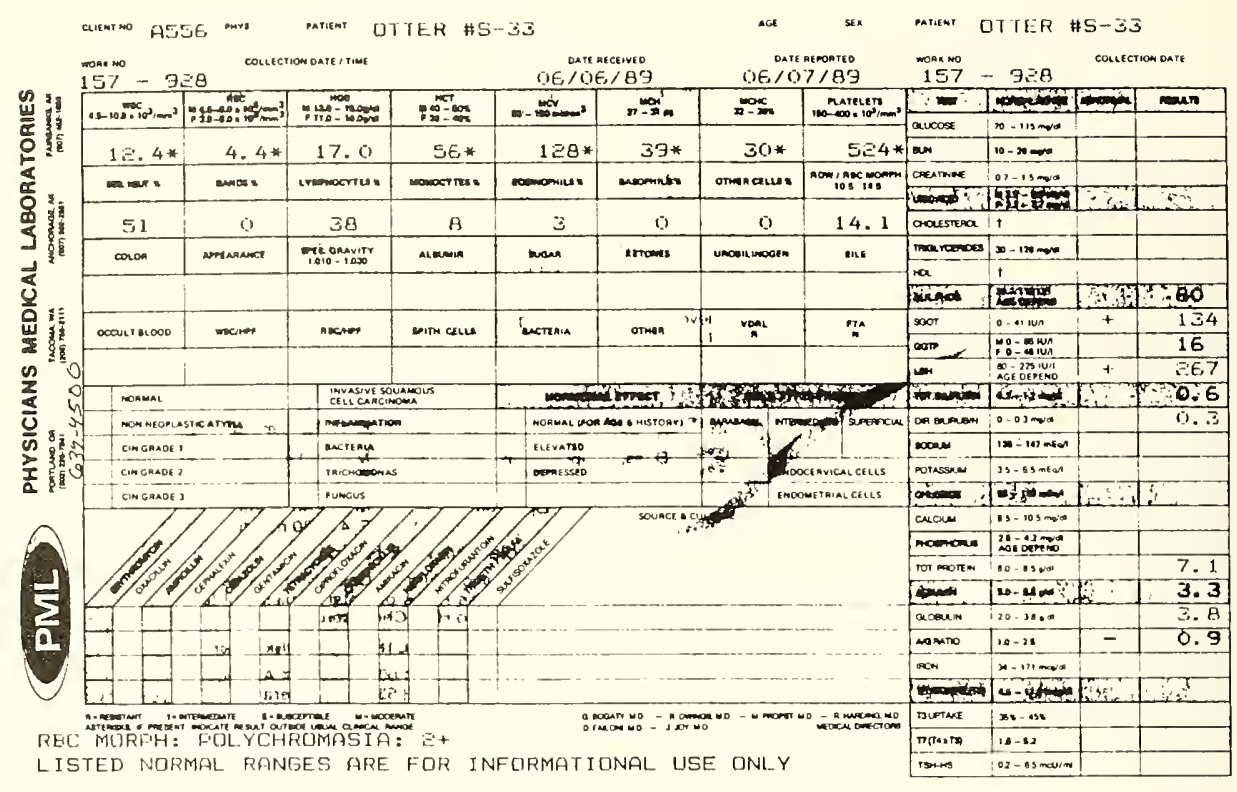

2227941

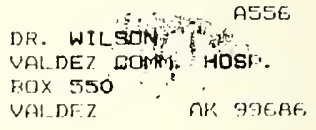

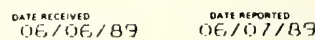

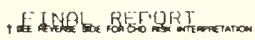

Fig. 14. Test Results, Physicians Medical Laboratories-a sample of blood test results from Physicians Medical Laboratories, 7 June 1989. Most laboratory results filed at the otter centers are on these forms.

centers closed, the records department was too understaffed to effectively clean up the files. We worked under these constraints with mixed results. At VORC we had support from the administration and key people in other departments, who helped us compile enough records to begin a data base. The SORC had few people for record keeping but excellent computer capability from the beginning, so they entered a lot of information directly into the computer, bypassing the need for some of the forms used at VORC. At the octagon prerelease holding area at VORC and at JPRF we adjusted to the large pen housing by switching to pen charts with modest expectations for obtaining specific data.

\section{Conclusion}

Master forms for use in the event of another sea otter rescue are provided (Appendix). Let us hope they will never be needed. I hope that the data set we already have will prove useful to sea otter biologists and others. Do not be daunted by its size and disarray; it contains precious things. I also hope that in the future more attention and staffing will be allocated to record keeping. Even now, a year after we began at Valdez, the records have not been proofread, and there is no key to their use. Let us not waste this opportunity to learn as much as possible from our mistakes, lest we make them again. 


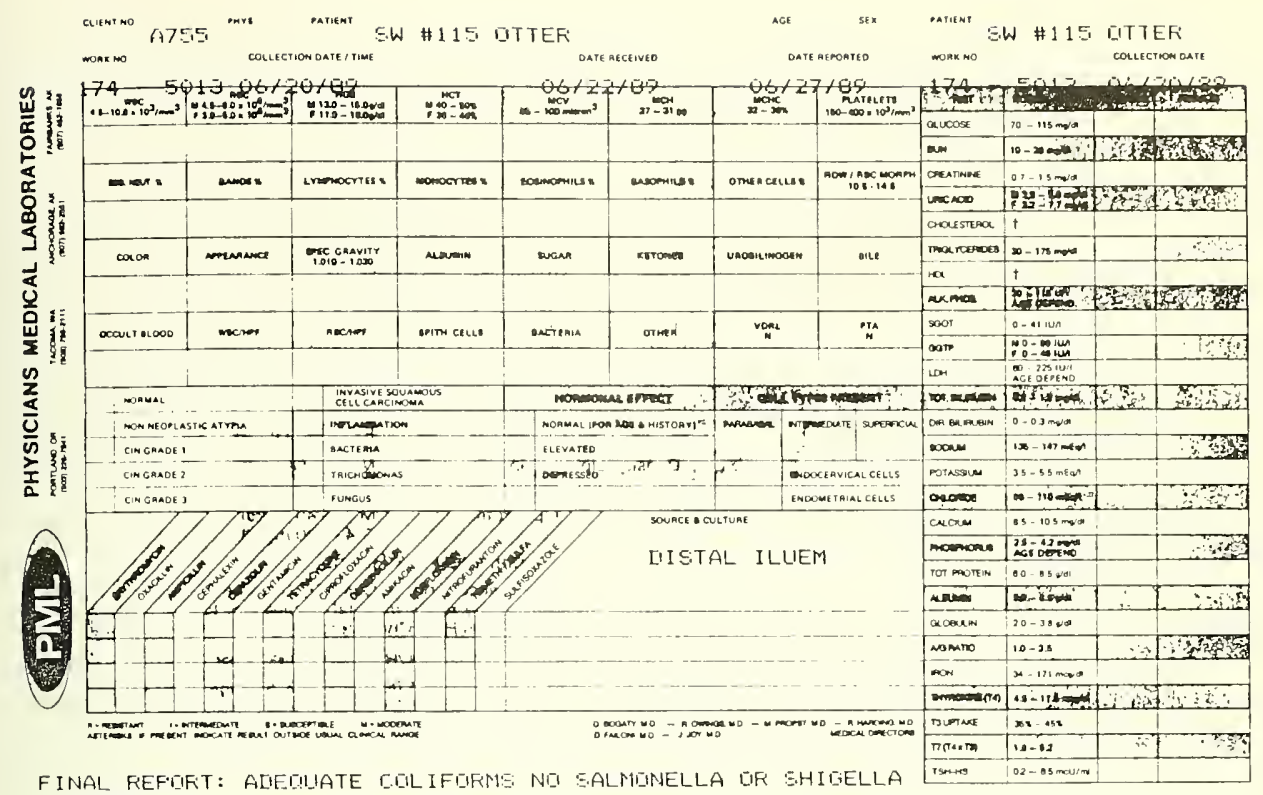

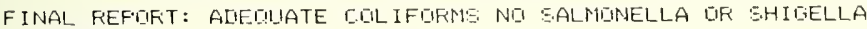
RECRIVEFIE[I.

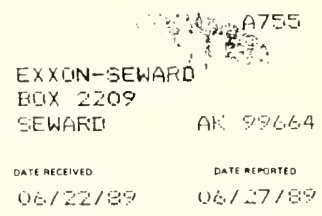

Fig. 15. Test Results, Physicians Medical Laboratories-a sample of bacterial culture results from Physicians Medical Laboratories, 27 June 1989.

\section{Acknowledgments}

I thank R. Davis, R. Hardy, and D. Swarthout for their help in preparing and reviewing this paper.

\section{References}

Michaelson, N. E. 1990. Behavioral observations of rehabilitating sea otters in prerelease holding pens. Pages $313-320$ in K. Bayha and J. Kormendy, tech. coords. Sea Otter Symposium: Proceedings of a symposium to evaluate the response effort on behalf of sea otters after the T/V Exxon Valdez oil spill into Prince William Sound, Anchorage, Alaska, 17-19 April 1990. U.S. Fish Wildl. Serv., Biol. Rep. 90(12).
Rash, J. A., C. R. McCormick, R. Alexander, S. J. Nichol, and D. C. Perrollaz. 1990. Coat gradation and conditioning of sea otters at the Seward Otter Rehabilitation Center. Pages 258-273 in K. Bayha and J. Kormendy, tech. coords. Sea Otter Symposium: Proceedings of a symposium to evaluate the response effort on behalf of sea otters after the T/V Exxon Valdez oil spill into Prince William Sound, Anchorage, Alaska, 17-19 April 1990. U.S. Fish Wildl. Serv., Biol. Rep. 90(12).

Swarthout, D. J. 1990. Animal rehabilitation center data base. Pages 224-235 in K. Bayha and J. Kormendy, tech. coords. Sea Otter Symposium: Proceedings of a symposium to evaluate the response effort on behalf of sea otters after the T/N Exxon Valdez oil spill into Prince William Sound, Anchorage, Alaska, 17-19 April 1990. U.S. Fish Wildl. Serv., Biol. Rep. 90(12). 
Fig. 16. Progress Notes-a sample of the first summary progress notes made by veterinary technicians at the Valdez Otter Rehabilitation Center. The form is from a hospital for humans, and notes cover 16 April through 27 April 1989.

$$
\text { Teg } \# \text { ax? }
$$

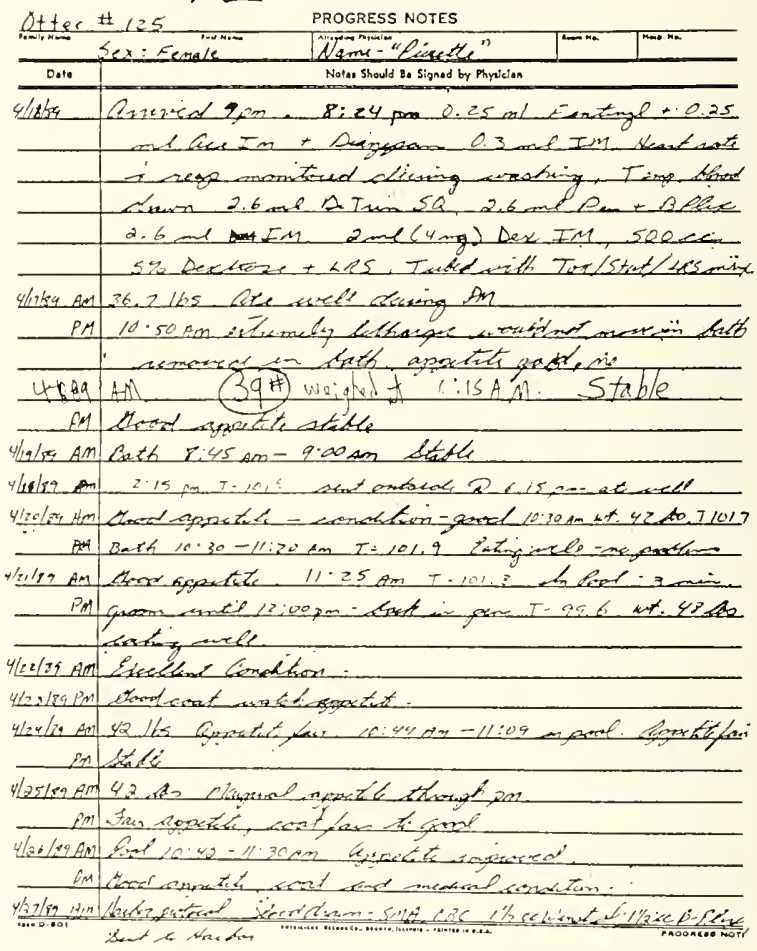




\begin{tabular}{|c|c|c|c|c|c|c|c|}
\hline \multicolumn{2}{|c|}{ rate of arrival 5-5 97} & \multicolumn{3}{|c|}{ PROGRESS NOTES } & \multicolumn{3}{|c|}{ OTTER $18-$ TAG 525} \\
\hline$\frac{\text { Date/shift }}{\text { Weather }}$ & $\mathrm{P}, \mathrm{Appetice}$ & Stool & $\underset{\text { amount Suthere }}{\text { Crooming }}$ & $\frac{\text { Coat }}{\text { Lof }}$ cond. & Swimm $1 n g$ & General behav. & $\frac{\text { Comments }}{\text { We } 1 \text { I Tht }}$ \\
\hline $5-11$ & $10^{1} 2 m$ & & & & & & \\
\hline $5-12$ & 16.16 & & & & & & \\
\hline $\begin{array}{l}5-13 \\
\text { Am- Man } \\
0 . m \sin \end{array}$ & eatim wall & & groms chat & & $\begin{array}{l}\text { buffle rals } \\
\text { + groons }\end{array}$ & & $\begin{array}{l}\text { chews on caqe } \bar{M} \\
\text { stressed in }\end{array}$ \\
\hline $\begin{array}{l}5 / 14 / 89 \\
\text { nam } / \text { colo }\end{array}$ & 12.25 & & face & & $\begin{array}{l}\text { Swimming } \\
\text { - Play lacy }\end{array}$ & & \\
\hline $\begin{array}{r}5.158^{9} \\
\quad+8 \\
\end{array}$ & 9.0 & & $\begin{array}{l}\text { groogns in } \\
\text { pool }\end{array}$ & & $\begin{array}{l}\text { rolliagt- } \\
\text { grooming }\end{array}$ & & Tried to escape \\
\hline $\begin{array}{l}5-16 \\
50 n+4\end{array}$ & 9.4 & & $\begin{array}{l}\text { grooming } \\
\text { vigor. }\end{array}$ & +7 & $\begin{array}{l}\text { resting on } \\
\text { back? } \\
\text { nates }\end{array}$ & rolling & haye pos \\
\hline $5-17$ & $\begin{array}{l}\text { No fool } \\
\text { repont } \\
\text { but common } \\
\text { buy ut nell }\end{array}$ & & head, & & $\begin{array}{l}\text { rifted } t \\
\text { swain dot }\end{array}$ & $\begin{array}{l}\text { raftingin uebr } \\
\text { playing. grooming }\end{array}$ & $\begin{array}{l}\text { Apted by worte } \\
\text { futring in Lg pool. }\end{array}$ \\
\hline $5-18$ & 18.5 & & $\begin{array}{l}\text { grooming al } \\
\text { orer. }\end{array}$ & & $\begin{array}{l}\text { Floding } \\
\text { rolling }\end{array}$ & Swem mos & ofdu \\
\hline $\begin{array}{l}5.1^{a} \\
\text { blawistue }\end{array}$ & $19.75^{ \pm}$ & & oul & & $\begin{array}{l}\text { in wata } \\
\text { rolkay }\end{array}$ & $\begin{array}{l}\text { alot of tume } \\
B A R\end{array}$ & \\
\hline
\end{tabular}

Fig. 17. Progress Notes-a sample of the progress notes (11 May through 19 May 1989) made by veterinary technicians at the Seward Otter Rehabilitation Center before the notes were computerized. 


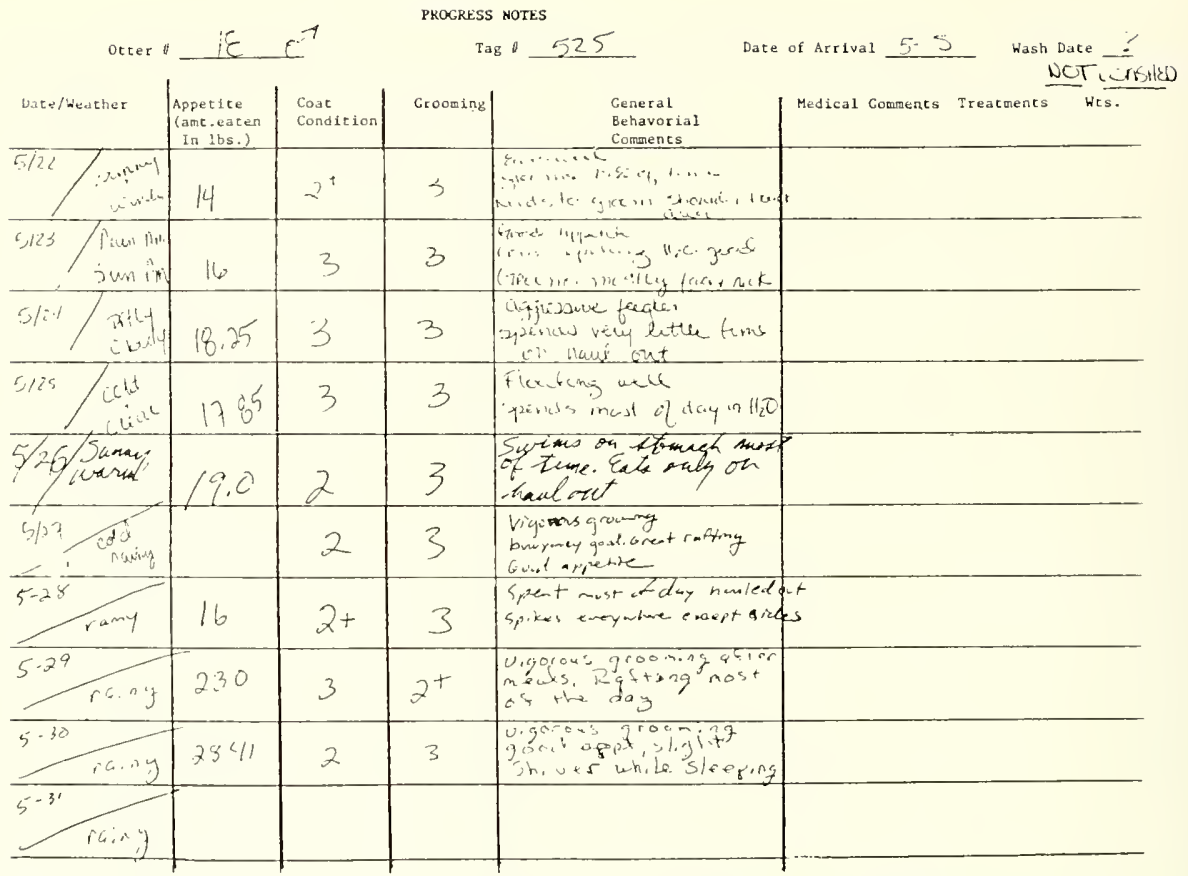

Fig. 18. Progress Notes-a sample of the progress notes (22 May through 31 May 1989) made by veterinary technicians at the Seward Otter Rehabilitation Center before they were computerized. Note the evaluations of pelage. 
LITTLE JAKOLOF FRE-FIDEASE PROCRESS MOTES

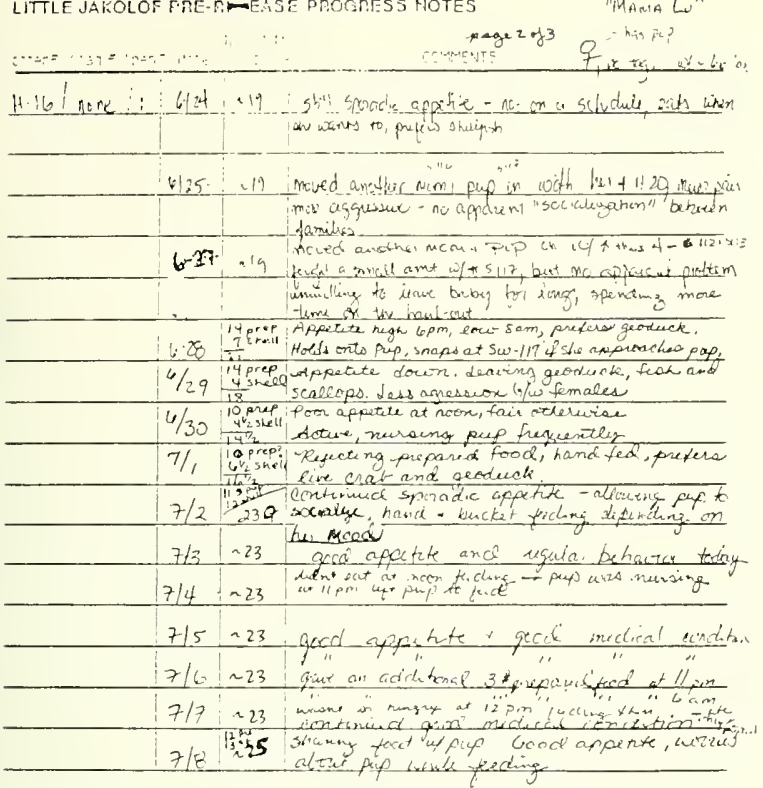

Fig. 19. Progress Notes-a sample of the progress notes (24 June through 8 July 1989) made by records personnel and veterinary technicians at the Jakolof Pre-Release Facility. Note that the figures for food consumption were calculated two different ways.

Key for Progress Notes

food consumed = pens total rood divided by = of otters in pen

(any otter ofl dlet will be listed in comments)

comments = stable unless otherwise noted

any signiricant indings IIsted here

(1.e. oirths, orop in appetlte, wounds, etc.)

OTTER HUSBANDRY

\begin{tabular}{|c|c|c|c|c|c|c|}
\hline \multirow{3}{*}{ Date } & & OTt & \multirow[b]{2}{*}{$36.710^{\prime} \mathrm{s}$} & & $\operatorname{Tag} \# 960+$ & \multirow[b]{2}{*}{ Ini } \\
\hline & Time & Food & & status & Coments & \\
\hline & & Type & Weinit & $\begin{array}{l}\text { Eooftrain } \\
\text { Good }\end{array}$ & & $-1,2$ \\
\hline $4 / 17 / 84$ & $5.45 \mathrm{om}$ & & & & sleeping & $n$ \\
\hline & 60,000 & BloLk-IeC & & & Eating & \\
\hline & 60.15 & & & & Resting & \\
\hline $4 / 17$ & 625 & Shixnye & 3 & & aptopenobees & \\
\hline & 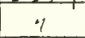 & & & & $\rightarrow$ rsine & \\
\hline $4 / 17$ & 645 & $\begin{array}{l}\text { Sheomes } \\
\text { Shedench }\end{array}$ & 8 & & ive ohearm & \\
\hline & 200 & & & & Les cluversit & \\
\hline & 110 & & & & sees & \\
\hline $4 / 17$ & $800 p$ & $\begin{array}{l}\text { Elwhing } \\
\text { Skituat }\end{array}$ & 20 & lumes & CHew -ment bem & \\
\hline & $8 / 5$ & & & & & \\
\hline & $945 \mathrm{~m}$ & stabec & & & 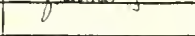 & 35 \\
\hline & $9: 00 \mathrm{on}$ & & & & Stepins & $\ln$ \\
\hline & Ais $1 \times$ & & & & sleepins & IPf \\
\hline & $930 \mathrm{mon}$ & & & & Gooman/Resting & \\
\hline & $9: 45$ & & & & 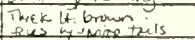 & $\mathrm{rm}$ \\
\hline & $10: 05 \mathrm{vm}$ & & & & Sleeping & \\
\hline & 1025 & seselop & 2 & & Shaver ${ }_{5}$ & \\
\hline & 1040 & & & & Slexpuize & 616 \\
\hline & LOK5' & xor $2 \cdots$ in & 44 & & olumbers & $4+2$ \\
\hline & 1255 & , & . 4 & & - Postinm & $x \sqrt{x}$ \\
\hline
\end{tabular}

Fig. 20. Otter Husbandry-a sample husbandry record from the Valdez Otter Rehabilitation Center, 17 April 1989. 
Fig. 21. Observation Chart-a sample husbandry record from the Seward Otter Rehabilitation Center, 1 June 1989.

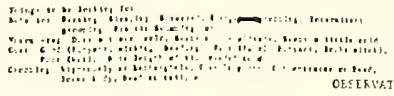

OESE KVHTIO: CHART

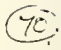

s.J

$0: \operatorname{IrR}: 20$

ThG 525

(9) $0^{7}$

\begin{tabular}{|c|c|c|c|c|c|}
\hline DAIE? & OESERTITIOY & 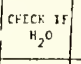 & $\begin{array}{l}\text { CHECK } 1 \text { F } \\
\text { HAUL OUT }\end{array}$ & BERAVIOR/OBSERVATJOK & $\begin{array}{l}\text { PURATION or } \\
\text { EERALIOR }\end{array}$ \\
\hline 6.1189 & $=30 x$ & & $\checkmark$ & 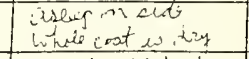 & \\
\hline \multirow[t]{12}{*}{$6.1-89$} & 0630 & & $v$ & grauming hind $q>$ & \\
\hline & 0635 & 5 & & $\begin{array}{l}\text { (While cages were } \\
\text { being dienned) }\end{array}$ & \\
\hline & 0660 & & 5 & $\begin{array}{l}\text { growming bellywlforet } \\
\text { paus }\end{array}$ & $10 \mathrm{~min}$ \\
\hline & 070 & & $r$ & $\begin{array}{l}\text { graoming bare bneak, } \\
\text { hind g's } \\
\text { feeding on haul ost }\end{array}$ & \\
\hline & $\begin{array}{l}0125 \\
0750\end{array}$ & & $\checkmark$ & $\begin{array}{l}\text { grooming chest } \\
\text { resting }\end{array}$ & \\
\hline & $\begin{array}{l}0820 \\
0900\end{array}$ & 2 & $\sqrt{2}$ & $\begin{array}{l}\text { sleeping } \\
\text { dorein + grtout }\end{array}$ & $\begin{array}{l}\text { somint } \\
\text { 2min }\end{array}$ \\
\hline & $\begin{array}{l}0902 \\
0940\end{array}$ & & $\checkmark$ & $\begin{array}{l}\text { rubbing chost } \\
\text { grooming hind g's, neck - }\end{array}$ & \\
\hline & $\begin{array}{r}1025 \\
1030 \\
\end{array}$ & $\checkmark$ & $\checkmark$ & $\begin{array}{l}\text { using face thands } \\
\text { resting - still } \\
\text { fast proviberb + augoning }\end{array}$ & 10 meñ \\
\hline & & & & 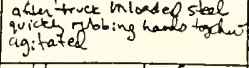 & \\
\hline & 1040 & & $\sqrt{v}$ & $\begin{array}{l}\text { rubbing nect w/ res flipper } \\
\text { grooming tind } a^{\prime} \text { s }\end{array}$ & \\
\hline & $\begin{array}{l}11: 00 \\
11: 30 \\
11,10\end{array}$ & & $\int_{v}^{v}$ & $\begin{array}{l}\text { Sleeping on back } \\
\text { Geding } \\
\text { arosming face }\end{array}$ & \\
\hline & 1150 & & IV & reoting on back & \\
\hline
\end{tabular}




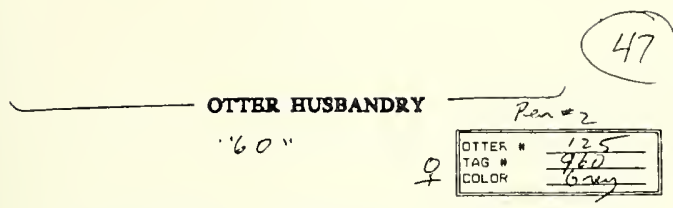

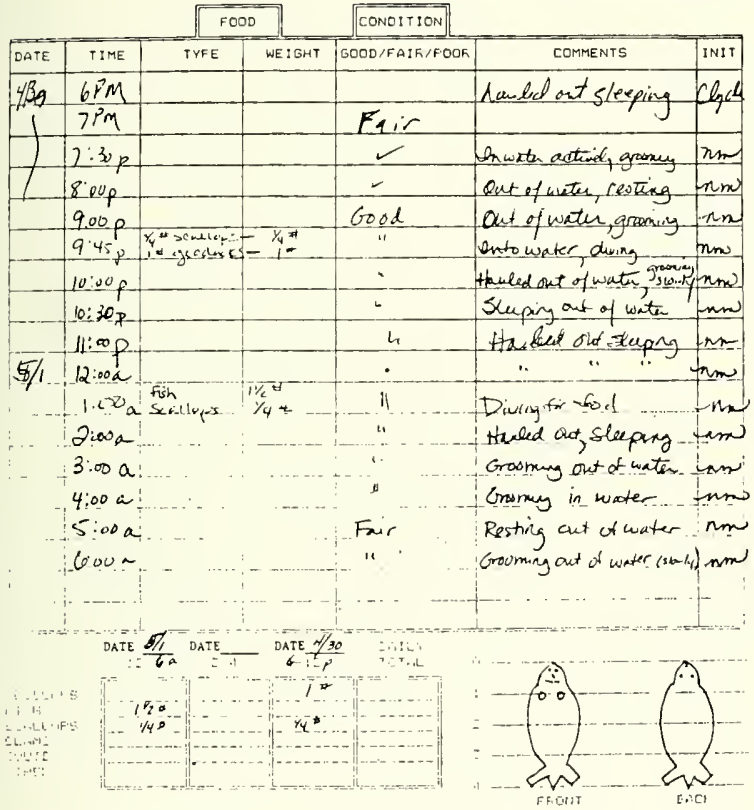

Fig. 22. Otter Husbandry-a sample husbandry record from the Valdez Otter Rehabilitation Center, 30 April and 1 May 1989. Note the separate blocks for identification, food intake, and the diagram for evaluating pelage. 
Fig. 23. Otter Diet Chart-a sample feeding record from the Seward Otter Rehabilitation Center, 12 June 1989. Note the separate block for recording eliminations. 
"zent"

FOR CONDITIOR OTTER $\frac{125}{\text { They }}$ TATE $=4 / 28$ TIRE

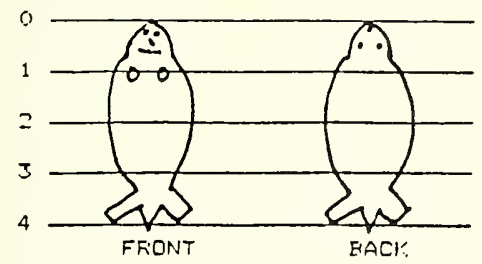
P.X.

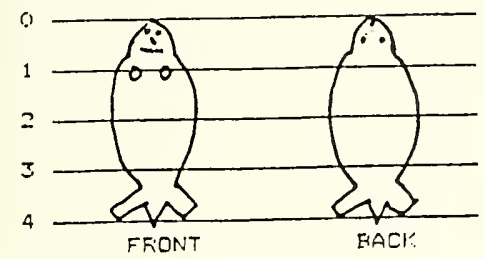

PLEASE COLOR IN AREA THAT APPEARS BLACK AND SLICK WHILE THE ANIMAL IS SWIMMING.

PLEASE FILL IN ONCE IN THE A.M. HOURS AND ONCE IN THE P.M. HOURS.
Fig. 24. Fur Condition-a sample pelage evaluation form from the Valdez Otter Rehabilitation Center, 28 April 1989. Few of these forms exist, and this one is not completed. 
Fig. 25. Otter Pen Observation Chart-a sample husbandry record from the Jakolof Pre-Release Facility, 22 June 1989. Note that the observer only completed the feeding information. This form covers an entire pen (in this example, seven otters) for one 12-h shift.

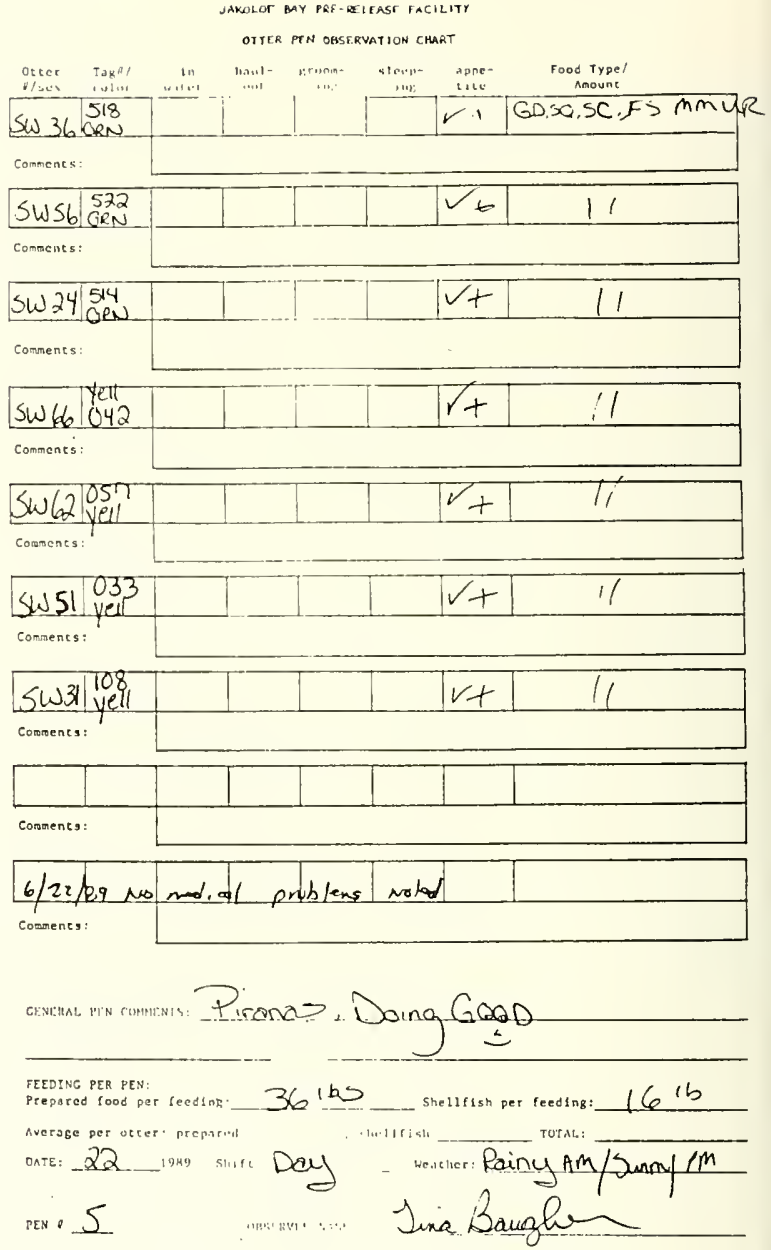




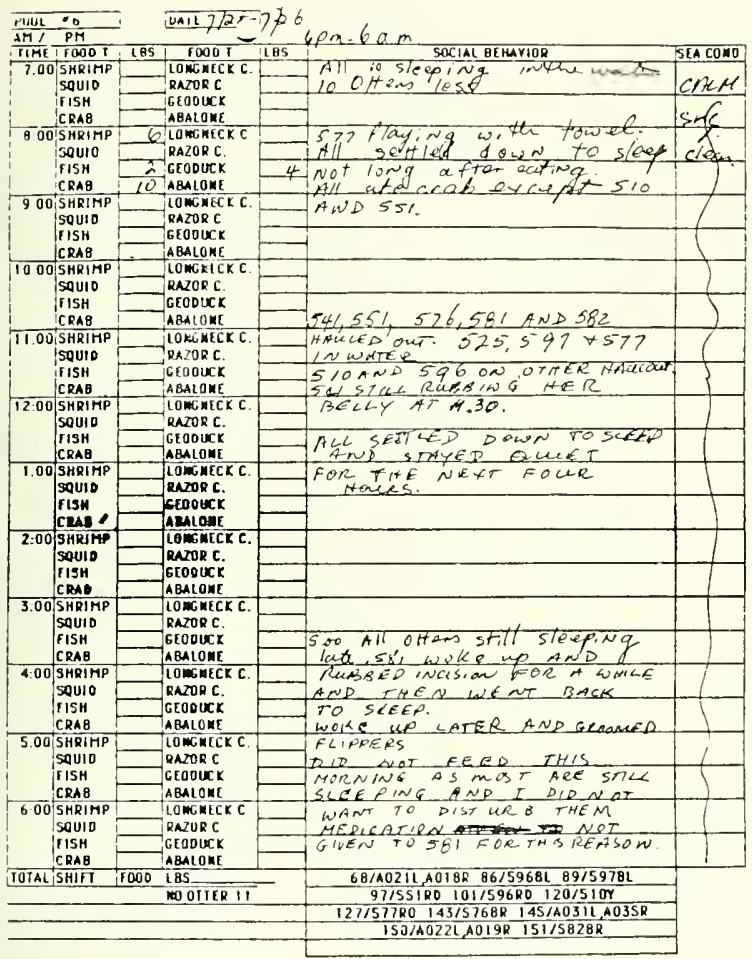

Fig. 26. Otter Pen Observation Chart-a sample husbandry record from the octagon at the Valdez Otter Rehabilitation Center, 25 and 26 July 1989 (night shift). This form covers an entire pen (in this example, 11 otters) for one 12-h shift. 
Fig. 27. Husbandry Observationsa sample husbandry record from the Jakol of Pre-Release Facility, 21 through 29 July 1989. It was designed for one animal but was sometimes used for additional space to record observations of an entire pen (in this example, seven otters).

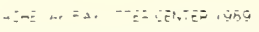

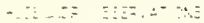

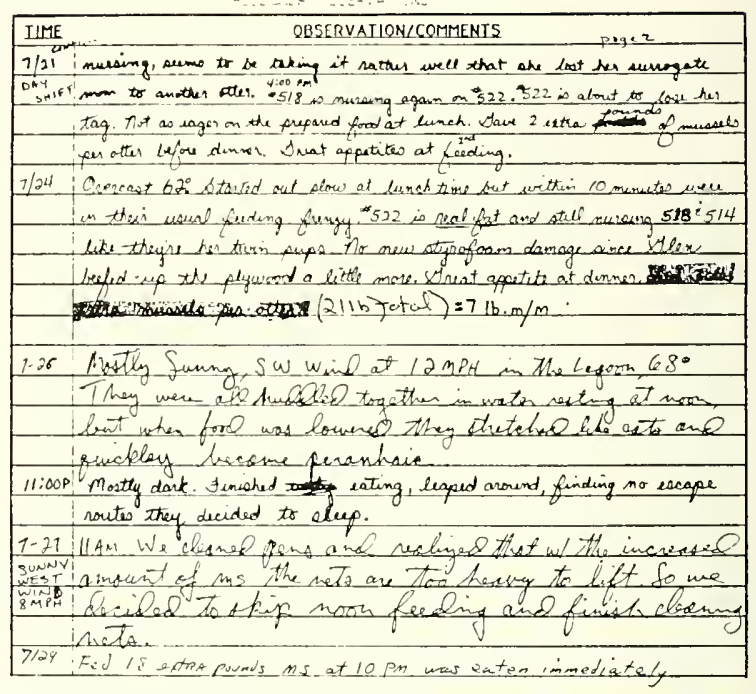

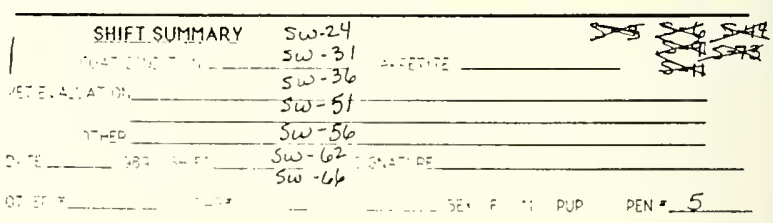


$\operatorname{mH}_{\text {GROSO NEROPSY REPORT }}$

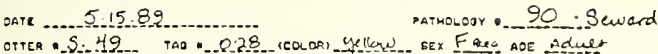

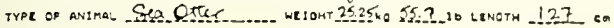

DATE/TIME or DTATK 320 : 51489

CLINICAL ABSTRACT,

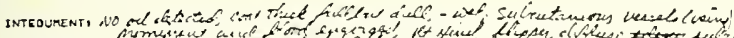

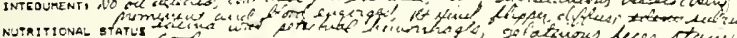

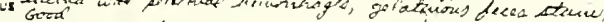

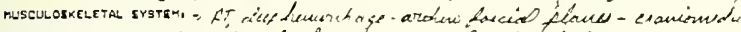

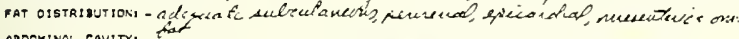

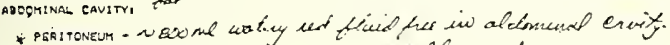

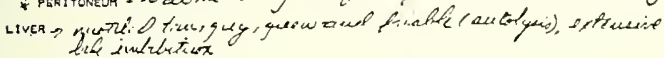

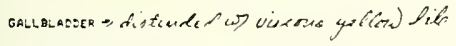

otsestive SYSTEM,

esophasus neרerad

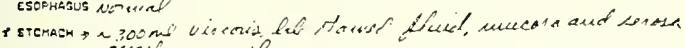
giondy urikde

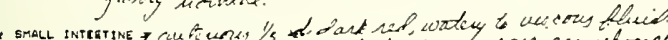

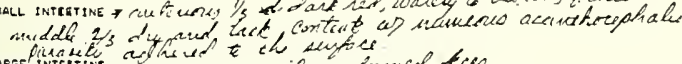

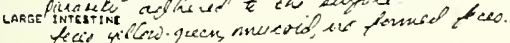

$$
\text { feis gict }
$$

PANCECasi atrusel

ENOROCAINES

TAYOAD arzunal.

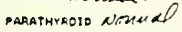

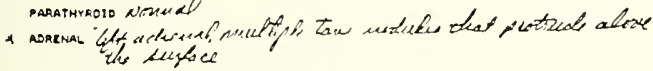

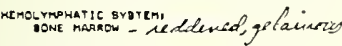

$$
\text { the seysec }
$$

LrMPH Nopes $\rightarrow$ wesual

throuse $1 / A$

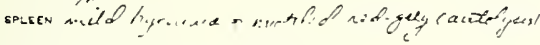

CARDBOVASEULAR EYSTEMt

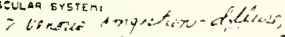

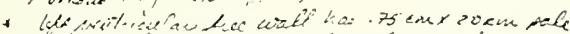

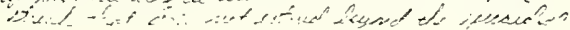

Fig. 28. Gross Necropsy Report-a sample pathology report from the Valdez Otter Rehabilitation Center pathology laboratory (although referring to a Seward Otter Rehabilitation Center animal), 15 May 1989. Note the pathology number, which differs from the otter center identification number. 
Fig. 29. Behavior/Observation-a sample of a form used at the Seward Otter Rehabilitation Center on a study of grooming and time budgets, 17 July 1989 . A small number of animals were observed closely with notations at 15 -min intervals.

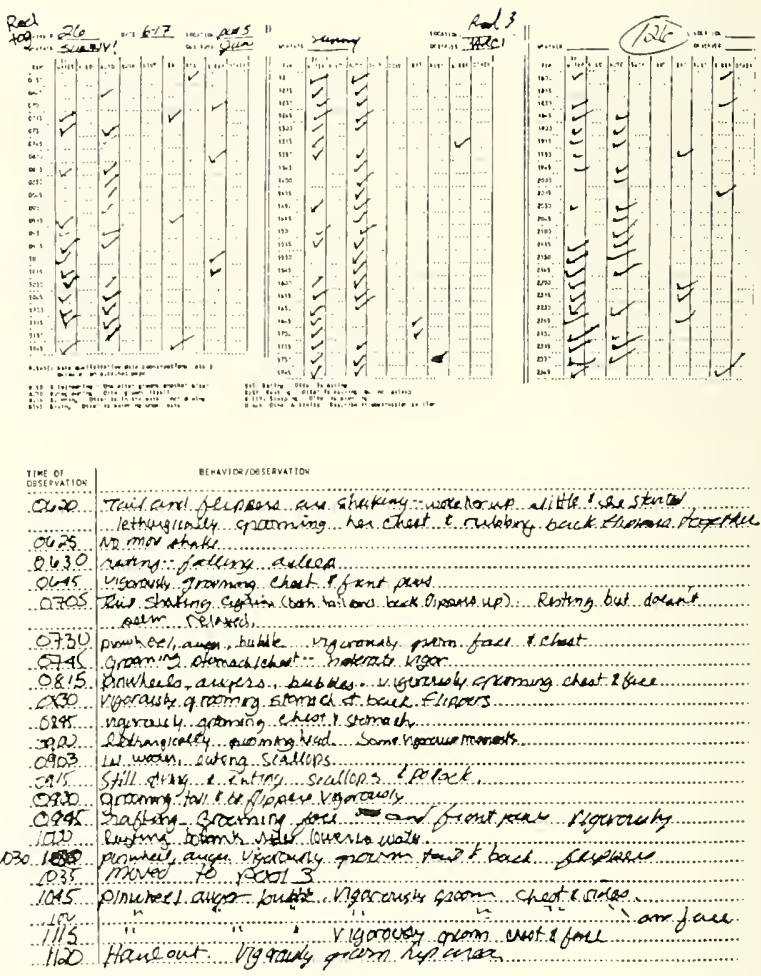




\title{
Appendix. Master Forms for a Sea Otter Rescue Project.
}

\author{
PROJECT NAME \\ YEAR \\ OTTER CENTER NAME \\ Sea Otter Capture Form \\ Otter number \\ (to be assigned later)
}

Capture boat:

Capture supervisor:

Capture:

Date:

Capture time: am $\mathrm{pm}$

Location:

Coordinates:

$\mathrm{N}$; W

otter captured: in water, hauled out, other

Method: dipnet, tangle net, other

Notes on capture:

Otter description:

Sex: male female unknown

Approx. age: pup juv adult aged

Weight:

weighed estinated

Distinguishing marks:

Tag: number

color

location

On the boat the otter did the following (Circle all that apply)

sleep groom vomit pass oil

eat shiver bleed pass blood

drink pant wheeze seizure

Disposition:

Date removed from capture boat:

Turned over to:

Condition: dead comatose lethargic calm active 


\section{PROJECT NAIIE \\ YEAR \\ OTTER CENTER NAME}

Sea otter Admission Form

Adrit date:

Time of delivery:

Delivered to center by:

Capture location: otter identification \#

am pri

\section{Description}

Sex: M F Pregnant Sex not determined

Approx age: Pup Juvenile Adult Aged

Weight: Gross __ Tare ___ Net

Type of scale

oil: none very light light medium heavy very heavy hair test results

Condition: comatose bleeding seizuring emphysema normal (may circle more than one) other

Washing

not washed incoriplete wash complete wash

Time begun: __am $\mathrm{pm}$ ended: _a am $\mathrm{pm}$

Tine

Temperature

Respirations

Notes:

Vet in charge: 


\section{PROJECT NAME \\ YLAR \\ OTTER CENTER NAME \\ Sea Otter Sedation \& Treatments Record}

Date:

Otter \#

Tag

Reason for sedation: admission washing physical exam surgery: type other

Anesthesia:

Type

Dose

Time

Route

Reversal

sedation level: none light moderate heavy variable

Treatments:

Antibiotics: type

dose

$\begin{array}{lll} & \text { type } & \text { dose } \\ \text { Steroids: } & \text { type } & \text { dose } \\ \text { vitamins: } & \text { type dose } & \text { dose } \\ \text { type } & \text { dose }\end{array}$

sub-Q fluids:

STAT:

activated charcoal:

other:

Samples taken:

Glucostix

Blood sample: none SMAC CBC toxicology other

other samples: none urine lesion culture tissue biopsy

Notes:

After reversal, animal recovered at (time) and was returned to (place).

Veterinarian's signature 


PROJECT NAME
YEAR
OTTER CENTER NAME

Daily and Cumulative Census

Date:
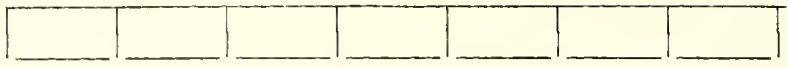

DAILY TOTALS

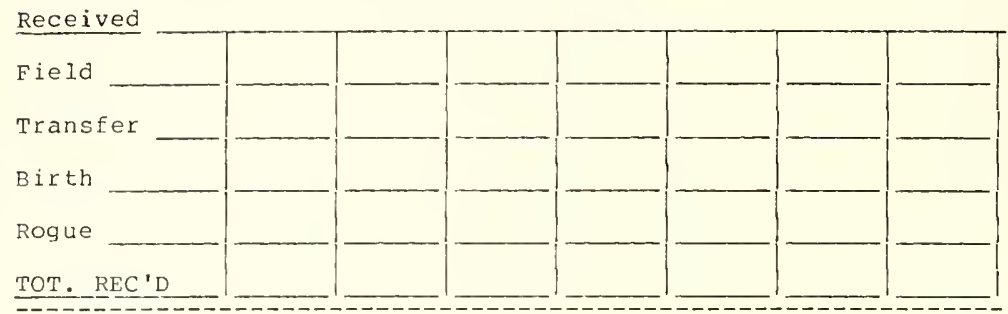

Departed

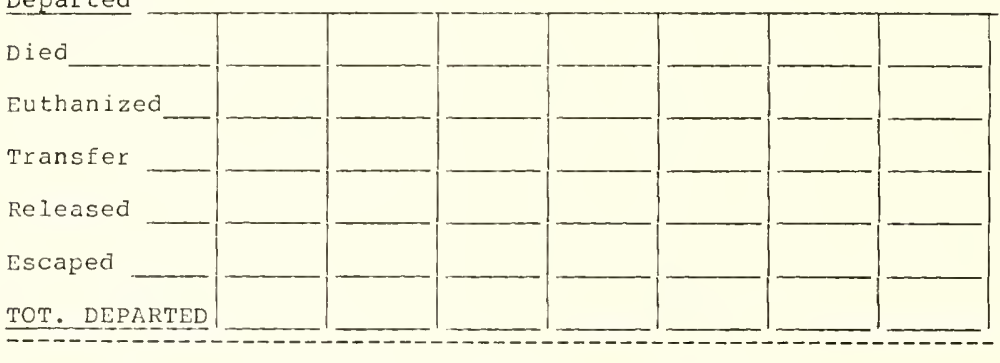

LIVF, AT CENTER

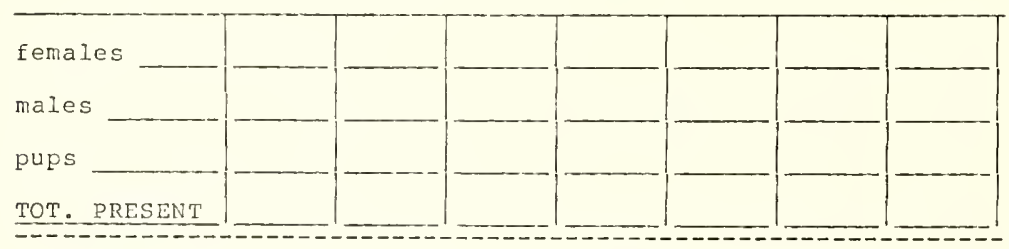

CUnULATIVE TOTALS

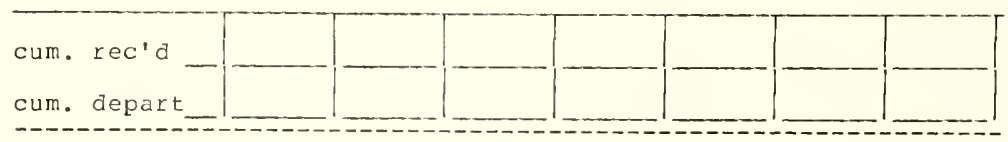


PROJECT NAME

YEAR

OTTER CENTER NAME

\section{Sea Otter Record Log -- Admissions}

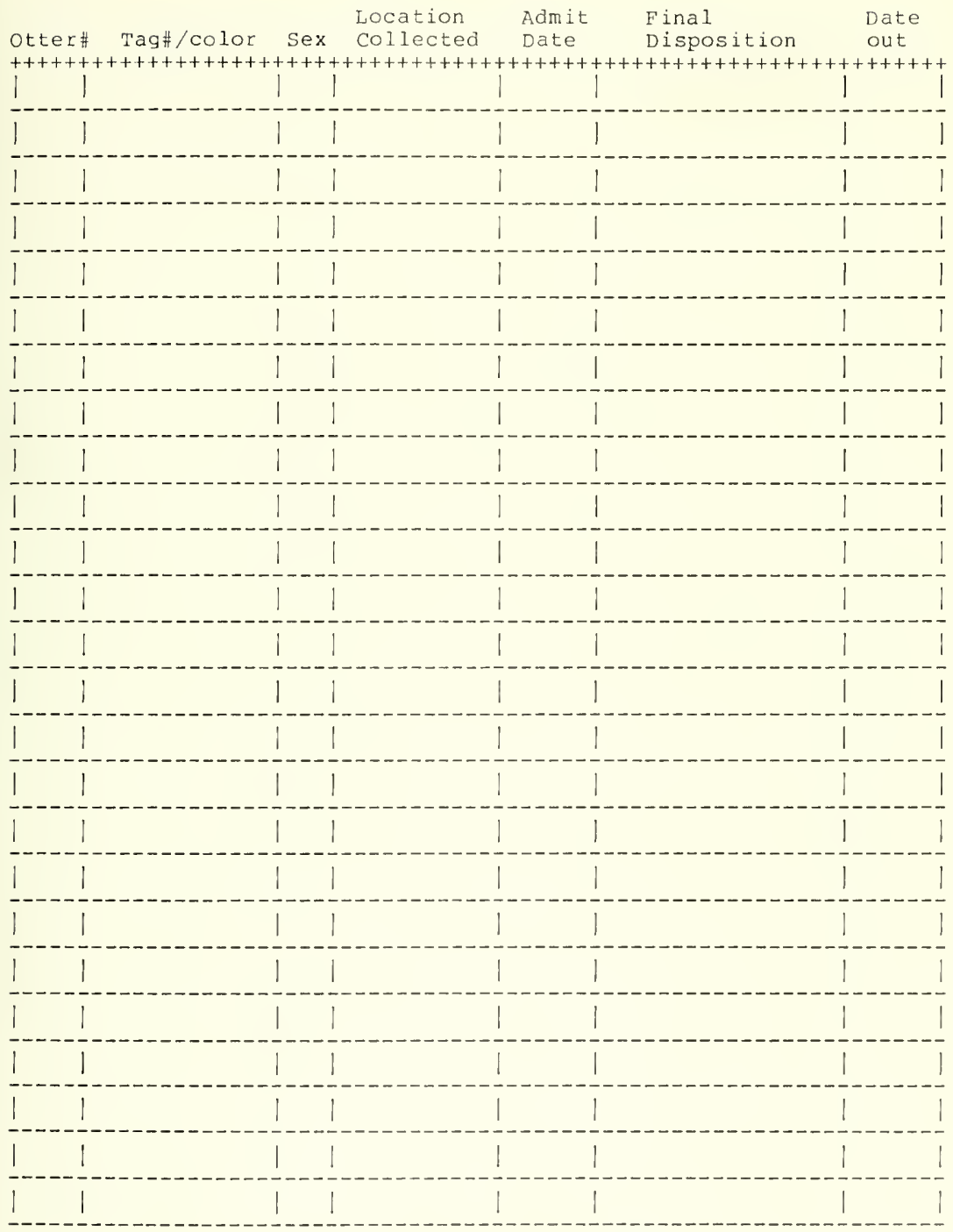


PROJECT NAME

YEAR

OTTER CENTER NAME

\section{Sea Otter Record Log -- Transfers}

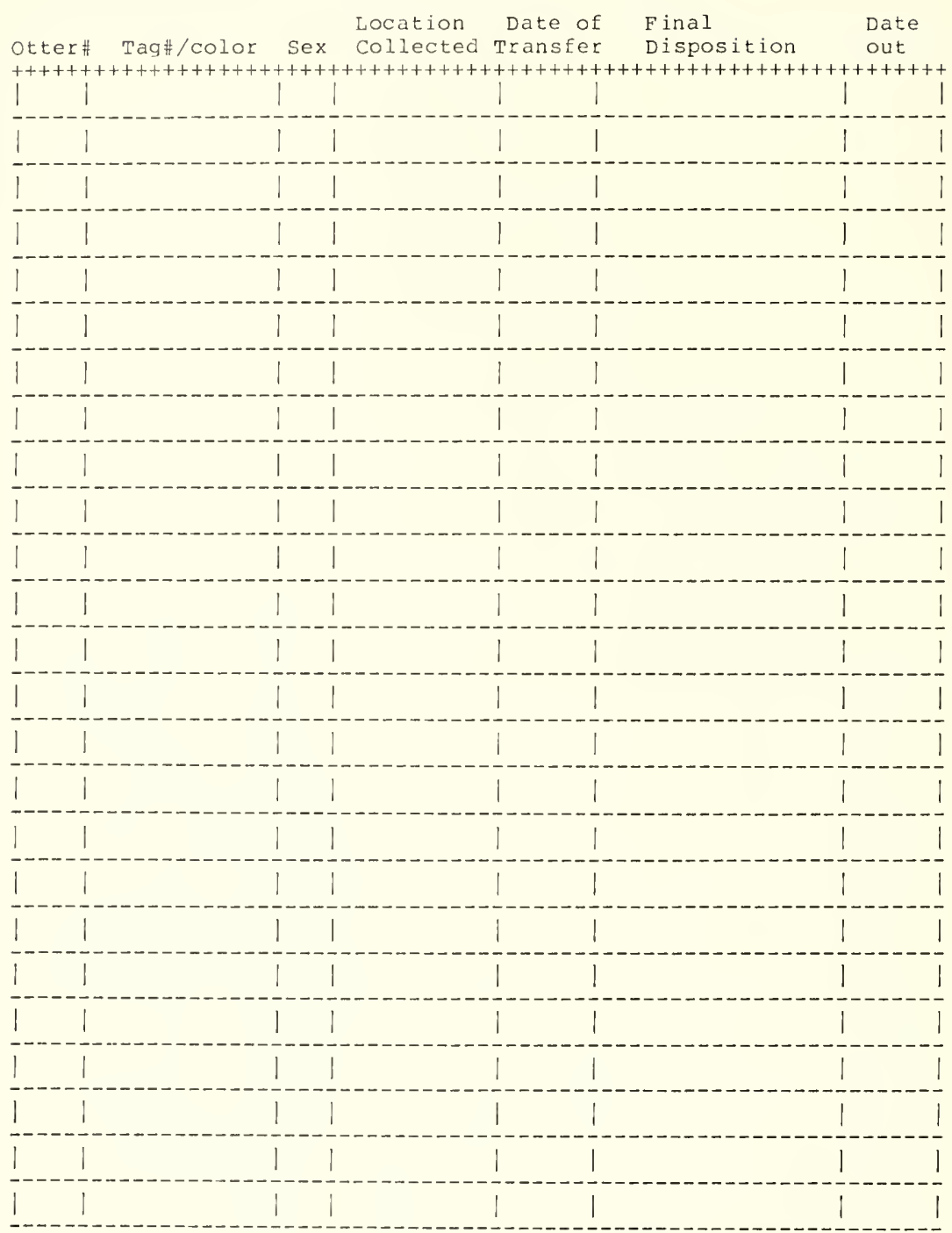




\section{PROJECT NAME \\ YEAR \\ OTTER CEIJTER NAME}

\section{Sea Otter Intensive Care Husbandry}

Date:

Shift: otter number

Tag \#

Location:

Observations:

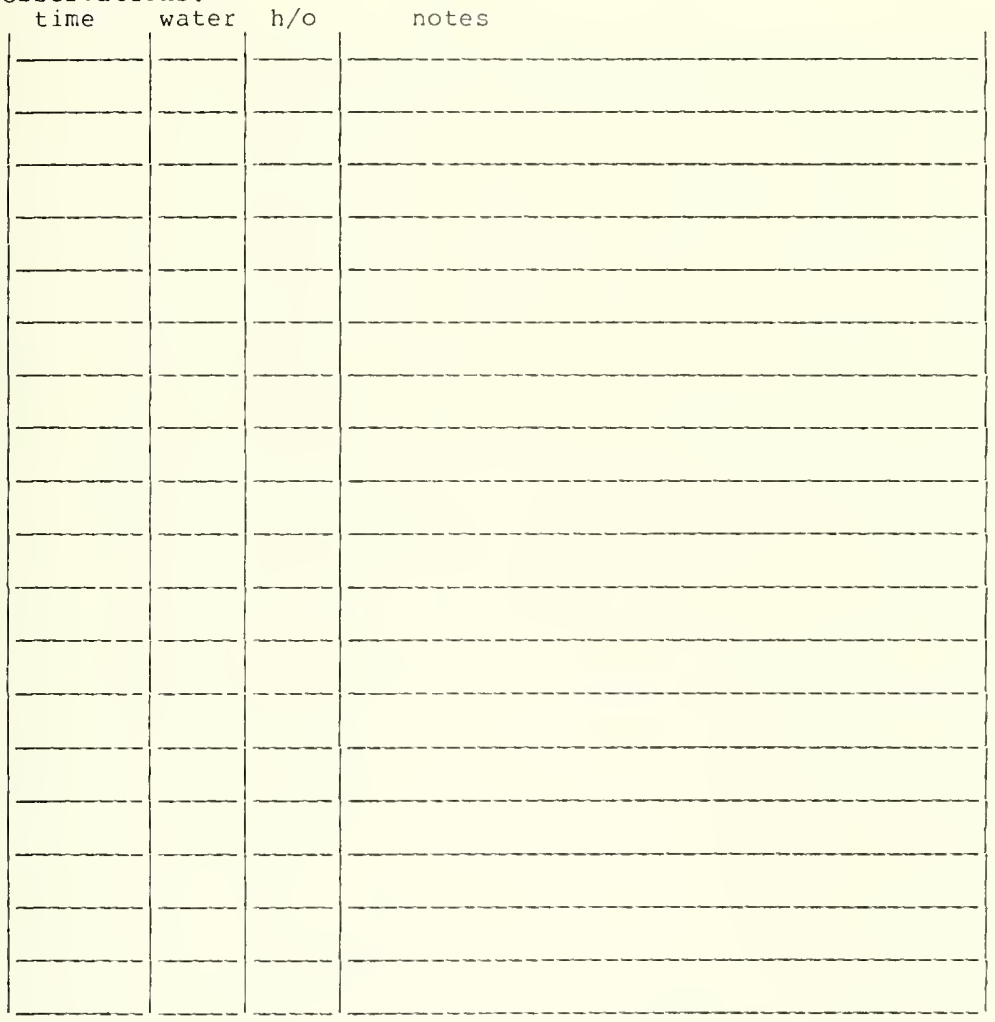

Rate coat condition:

grooming :

Notes for next shift:

observer's signature: 


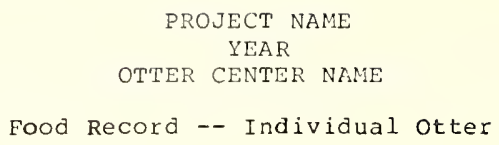

Date:

Shift:
Otter number:

Taq \#
Tag color

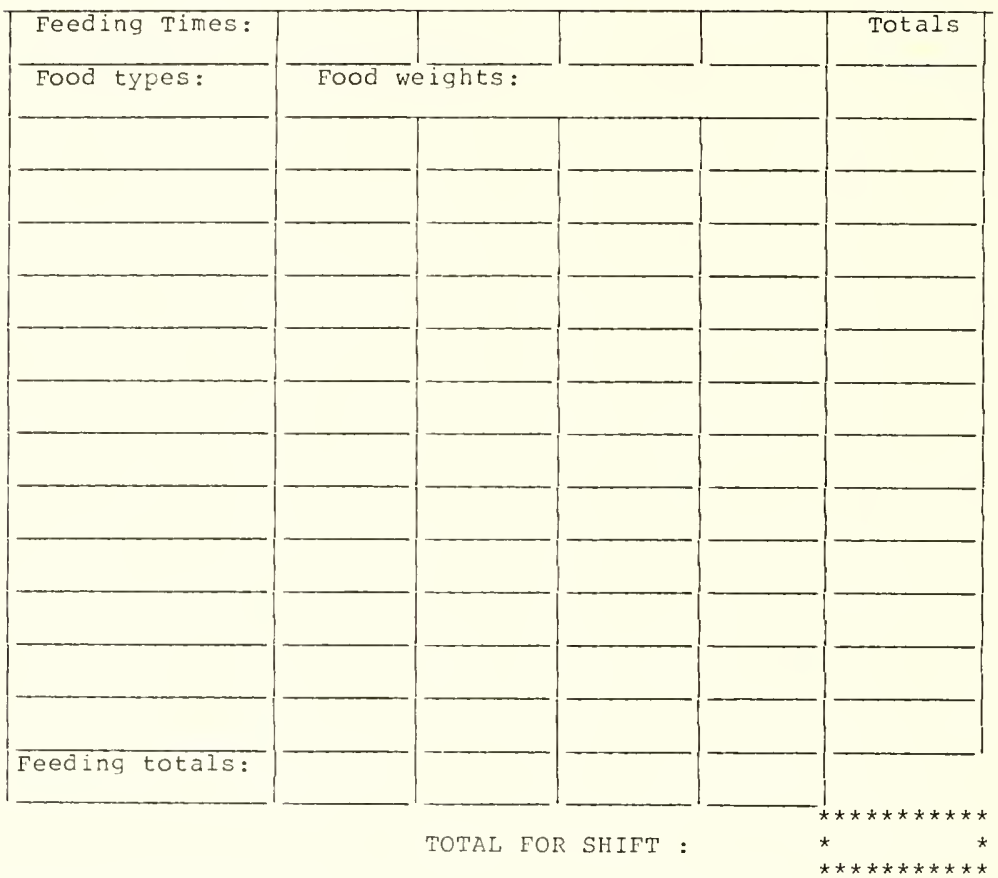

Foods refused:

Foods preferred:

Appetite (circle one): none poor fair good excellent Signature of observer: 


\section{PROJECT NAME \\ YEAK \\ OTTER CENTER NAME \\ Sea Otter Pup Care}

Date:

otter number:

Shift:

Name:

Weight :

and Length:

as of this shift

Method of feeding: intubation syringe self combination

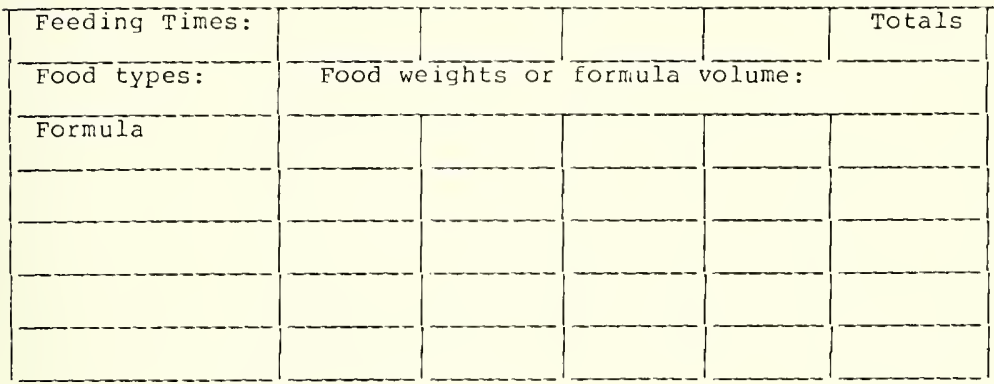

Total eaten this shift:

Eliminations:

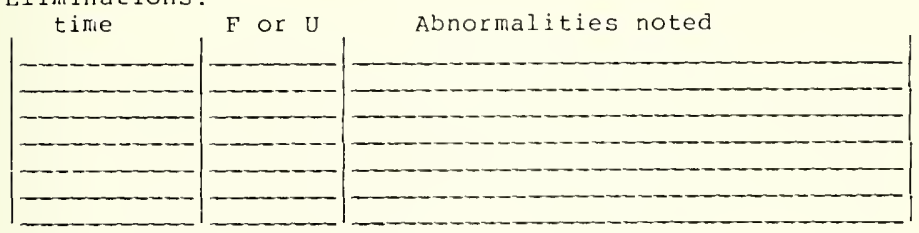

Behavioral notes:

Medical notes:

Nursery observer's signature:

veterinarian's signature: 


\section{PROJECT NAME \\ YEAR \\ OTTER CENTER NAME \\ Sea otter Pen chart}

Date:

Pen \#

otters in pen:

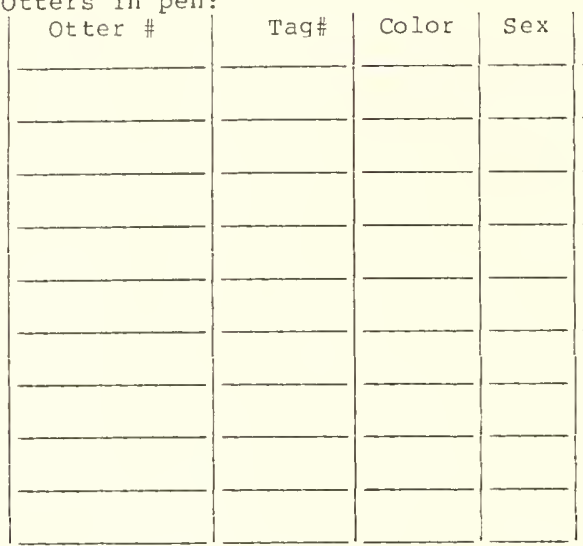

otters removed from pen:

otters added to pen:
Shift:

Location:

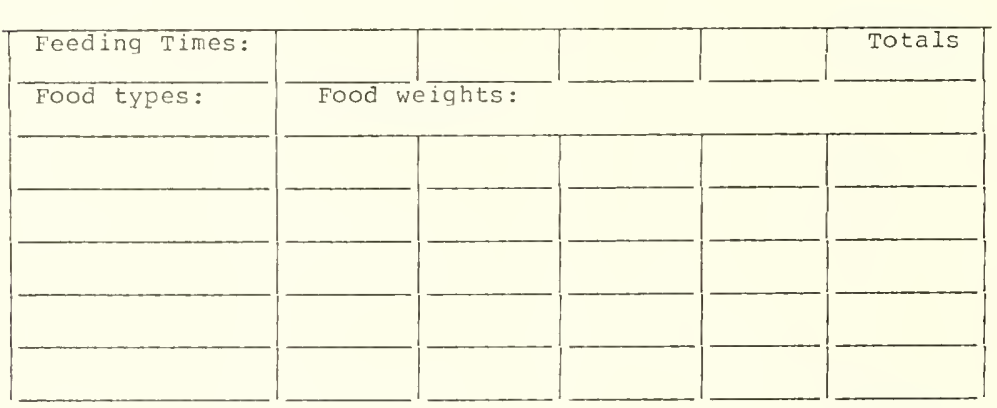

Total Eood weight for pen for shift: Notes:

Signature of monitor: Why? 


\section{PROJECT NAME \\ YEAR \\ OTTER CENTER NAME}

Sea Otter Individual Observations/Treatments

Otter \#

sex

Concerns:

Medical Notes / Behavioral Observations

weight
Tag color

Category

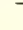


PROJECT INAME

YEAR

OTTER CENTER NAME

Sea Otter Physical Exam

Date:
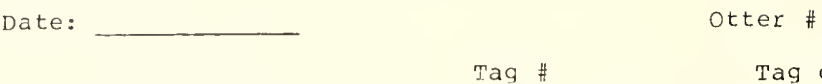

Tag color

Sex

Age

weight

Category

Concerns:

Condition: comatose

bleeding seizuring

emphysema

normial

Examination:

Overall condition:

Pelage:

Dentition:

Oral lesions:

Eyes:

other notes on head:

Forelimbs and paws:

Abdomen:

Hindlimbs and flippers:

Genitalia:

Wounds or incisions:

Length:

Notes:

Please see sea otter sedation \& Treatments Record for other notes.

Veterinarian's signature: 


\section{PROJECT NAME \\ YEAR \\ OTTER CENTER NAME}

Sea Otter Release Form

Otter No

Tag ID: number color side

Distinguishing marks

Date of last blood test last known weight originally captured: place date

Keep this otter with others with these tags:

Radio transmitter: (check) none __ yes

transmitter number

Departing center: via date

time removed from the water:

Prerelease treatments administered:

dose:

Vitamin E / Selenium

B vitamin mixture

Penicillin

Veterinarian's comments:

Veterinarian's name:

Release location:

Coordinates: longitude latitude

Date of release time

Tags on at release:

Left flipper: color number Right flipper: color number Comments : Release supervised by: 


\title{
Animal Rehabilitation Center Data Base
}

\author{
by
}

D. J. Swarthout

Online Services of Homer

P.O. Box 671

Homer, Alaska 99603

\begin{abstract}
A data base was designed and created to record the demographical, behavioral, nutritional, medical, and laboratory test data for injured sea otters (Enhydra lutris) cared for at the Seward Otter Rehabilitation Center after the T/N Exxon Valdez oil spill. While recording this data for future research and potential litigation is important in its own right, compiling all important data in a well-designed data base makes it readily available for custom report generation during the crisis. Such reports proved valuable for keeping the medical and husbandry staff informed about the animals' condition on a day-to-day basis. Several reports developed during the existence of the otter rehabilitation center are discussed, some problems are described, and several recommendations are made concerning computer operations for future animal rescue efforts.
\end{abstract}

The following is a brief description of the data base developed at the Seward Otter Rehabilitation Center (SORC) in summer 1989. The data base contains an enormous amount of data concerning the many sea otters (Enhydra lutris) that were cared for at SORC after the T/V Exxon Valdez oil spill: biographical data for almost 200 animals; nutrition data, broken down to the calorie level, for almost 4,000 otter-feeding days; behavioral assessments for about 4,000 observation days; more than 300 laboratory blood analysis results; and about 3,000 medical treatments.

\section{Background}

It may have been somewhat accidental that SORC produced a data base. I was hired to provide inventory control services to the project and I arrived on 1 May 1989 with computer, printer, and software to begin my job. After handing out a lot of wall clocks and rain suits over the first few weeks while developing a workable computerized inventory control system, I realized that what I was developing was really unnecessary for the job at hand. That job could be done by merely touring the stockrooms periodically with a paper and pencil and jotting down items to reorder. That's when I began to turn my attention to the problem of recording in some way the vast amounts of data being generated by the care-giving staff.

One day I watched a veterinary technician assemble progress reports for six animals destined for the Jakolof Pre-Release Facility (JPRF). These reports contained summaries of each animal's observed behavior, medical treatments, and feeding preferences for the preceding several days. The information was gleaned from several files kept in different areas of the facility: medical data from the veterinary clinic, behavior and biographical data from folders in the staff offices, and nutrition data from the food-preparation trailer. Once the information was in hand, it was copied and then cut and pasted together to make the complete reports. As the reports were being finished, someone decided that a different group of otters would be moved. This made it necessary to repeat the whole tedious process again. At this point I realized that a much better method-an automatic method--was essen- 
tial. I decided to turn my full attention to gathering data, with the automatic generation of a Progress Summary report to replace the hand assembled ones as my first goal. The report I developed is presented here.

\section{Major Components of the Data Base}

\section{Database Management System}

The database management system (DBMS) used at SORC was MicroRim's R:Base. R:Base is a state-of-the-art relational DBMS for IBM-compatible personal computers. Other database programs with equivalent power exist, such as DBase, Paradox, and others, but R:Base was used because I had several years experience with it, had a copy of it with me when I arrived, and could therefore get online promptly with the necessary reporting services.

No attempt has been made to include coverage of the DBase data bases developed at the Valdez Otter Rehabilitation Center (VORC). The two DBMS packages, R:Base and DBase, although different operationally, have the ability to import and export data in a variety of file transfer formats. This makes integration of the two data sets fairly straightforward, though time consuming, when considering the large amount of data involved.

\section{Tables}

A short description of the major tables contained in the SORC data base follows. There are several other tables in the data base, but they serve subsidiary purposes and do not store any important otter data.

Data were entered into these tables by using specially designed screen forms. Rules can be associated with the data entry forms to reduce errors. For example, a rule associated with the OtterBio table (described below) prevents entry of a new animal record unless the supplied otter number is unique; in other words, it must not already be in the table. Similar rules require that certain fields be filled in before accepting the entry. The otter number is one of those entries, as is the admission date (column AdmitDat).

\section{Biographical Data}

Table OtterBio (Fig. 1) contains individual sea otter biographical data. The otter number (Otter\#),

\begin{tabular}{|c|c|c|c|c|}
\hline$\#$ & Name & Type & Length $^{a}$ & Data Description \\
\hline 1 & Otter\# & TEXT & 6 & Unique for each otter \\
\hline 2 & Tag\# & TEXT & 6 & Tag \# of first tag \\
\hline 3 & Sex & TEXT & 1 & \\
\hline 4 & AdmitDat & DATE & & Admission date \\
\hline 5 & Weight & REAL & & \\
\hline 6 & CapLoc & TEXT & 40 & Capture location \\
\hline 7 & Comment & NOTE & & \\
\hline 8 & Oiled & TEXT & 1 & Light? Heavy? \\
\hline 9 & Status & TEXT & 1 & Alive? In Valdez? \\
\hline 10 & WashDat & DATE & & Date animal washed \\
\hline 11 & Pregnant & TEXT & 1 & [Y/N] \\
\hline 12 & DispDat & DATE & & Date died, shipped, etc. \\
\hline 13 & tagcolor & TEXT & 3 & Color of first tag \\
\hline 14 & length & REAL & & Length of animal \\
\hline 15 & BirthDat & DATE & & If animal born here \\
\hline 16 & Tag\#2 & TEXT & 6 & Tag \# of second tag \\
\hline 17 & Tag\#2Col & TEXT & 3 & Color of second tag \\
\hline
\end{tabular}

Number of characters

Fig. 1. Column definitions for Table OtterBio.

the principal key to all other tables in the data base, is a unique six-character code assigned at the time of admission. This table contains individual sea otter biographical data records. It was meant to store nonvariable information about an animal. When an animal was first received, entries were made in this table and all columns for which data were available were filled in.

Other tables in the data base were designed to store variable data (i.e., data that changes over a period). For example, the Weight column in this table was only filled in if we had an animal weight at the time of admission. Later, when an animal was weighed, an entry was made in table Weights, which was created expressly for the purpose of recording the ongoing and changing weight values.

OtterBio is the table upon which all other tables depend. The six-character otter number is the field that is used to connect or relate all the tables in the data base to one another. Data, with the single exception of the otter number itself, need never be redundant in this relational data base. To retrieve information concerning a particular animal from any of the other tables, all that is needed is the otter number. For example, an animal's sex is recorded only once, in column "Sex" in the OtterBio table. Whenever knowledge of an animal's sex was needed for a report, one needed only to specify it in terms of the OtterBio table entry. 
OtterBio was not meant to be regularly updated unless an animal was euthanized, released, moved to a prerelease site, or died. At such time, the one-character "Status" column and disposition date (DispDat) were changed to reflect the animal's final disposition.

\section{Behavioral Data}

Table Behavior (Fig. 2) contains daily observational data, coat and grooming evaluations, and current cage locations. The data contained in this simple table are much more readily accessible than those from the corresponding file of raw observational notes.

The coat (pelage) and grooming are evaluated on a scale of 1 to 3 to describe an animal's grooming performance and coat condition.

The behavioral comment field is a synopsis of reports from husbandry staff, who wrote hourly comments about each animal. The husbandry staff's decision to summarize these observations into one line considerably reduced the bulk of the observational data. The comment appears on both the daily Progress Summary and the daily Behavior Summary as an indicator of an animal's general condition.

Column Star in the Behavior table was used to indicate that an animal warranted special observation. The person making the behavioral evaluations placed an asterisk (") in this field to alert the rest of the husbandry staff to be especially watchful of this animal. Moreover, any animal thus marked automatically had a Progress Summary report generated for it on the day it was starred.

Feeding Data

Table Meals (Fig. 3) contains the daily total weights of all food items eaten for each otter. The table has several computed columns (columns

\begin{tabular}{lllll} 
\# & Name & \multicolumn{2}{l}{ Type Length $^{\mathrm{a}}$} & Data description \\
\hline 1 & Otter\# & TEXT & 6 & \\
2 & Coat & TEXT & 2 & Coat condition \\
3 & Groom & TEXT & 2 & Grooming behavior \\
4 & BComment NOTE & & Behavioral comment \\
5 & ObsDat & DATE & & Observation date \\
6 & Weather & NOTE & & Weather (in a word) \\
7 & Star & TEXT & 1 & Watch this animal! \\
8 & Tote\# & TEXT & 3 & Cage/pool number
\end{tabular}

${ }^{\mathrm{a}}$ Number of characters

Fig. 2. Column definitions for Table Behavior.

\begin{tabular}{|c|c|c|c|c|}
\hline$\#$ & Name & Type L & Length $^{a}$ & $\begin{array}{l}\text { (Expressions) for } \\
\text { computed columns or } \\
\text { \{Data Description\} }\end{array}$ \\
\hline 1 & Otter\# & TEXT & 6 & \\
\hline 2 & FeedDat & DATE & & \\
\hline 3 & Geo & REAL & & \{Geoduck, a large clam\} \\
\hline 4 & Scallop & REAL & & \\
\hline 5 & Cod & REAL & & \\
\hline 6 & Mussel & REAL & & $\{40 \%$ meat by weight $\}$ \\
\hline 7 & Pollack & REAL & & \\
\hline 8 & Shrimp & REAL & & \{Shelled tails only\} \\
\hline 9 & WShrimp & REAL & & $\begin{array}{l}\text { \{Whole shrimp, } 50 \% \\
\text { meat }\}\end{array}$ \\
\hline 10 & Squid & REAL & & \\
\hline 11 & Clam & REAL & & $\begin{array}{l}\text { \{Butter clam, } 34 \% \\
\text { meat\} }\end{array}$ \\
\hline 12 & ClamMeat & REAL & & \{Clam meat, no shells\} \\
\hline 13 & Crab & REAL & & $\{$ Green crab, $50 \%$ shell $\}$ \\
\hline 14 & RzClam & REAL & & $\{$ Razor clam, $40 \%$ meat $\}$ \\
\hline 15 & Formula & REAL & & $\begin{array}{l}\text { \{pups: enter mL. } \\
\text { eaten\} }\end{array}$ \\
\hline 16 & TotalWt & REAL & & $\begin{array}{l}\text { 'geo'+'scallop'+'cod' } \\
\text { +'mussel'•.40 } \\
\text { +'pollack'+'shrimp' } \\
\text { +'wshrimp'*.50 } \\
\text { +'squid'+'clam'*.34 } \\
\text { +'clammeat'+'crab'*.50 } \\
\text { +'rzclam'*.40+ } \\
\text { ('Formula'*.926)/453.6 }\end{array}$ \\
\hline 17 & Gcal & REAL & & $(' G e o '-382)$ \\
\hline 18 & ScalCal & REAL & & ('scallop' $78 * 4.54)$ \\
\hline 19 & CodCal & REAL & & $(\operatorname{cod} * 4.54 * 74)$ \\
\hline 20 & MussCal & REAL & & ('mussel'*77*4.54*.40) \\
\hline 21 & PollCal & REAL & & ('pollack'*4.54•91) \\
\hline 22 & ShrmpCal & REAL & & $($ 'shrimp'*4.5*4*90) \\
\hline 23 . & WSrmpCal & REAL & & ('shrimp'*4.54*90*.50) \\
\hline 24 & SquidCal & REAL & & ('squid'*4.54*84) \\
\hline 25 & ClamCal & REAL & & 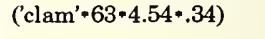 \\
\hline 26 & CMeatCal & REAL & & ('clammeat'*4.54*63) \\
\hline 27 & CrabCal & REAL & & $\left(\mathrm{crab}^{\prime} * 81 * 4.54 * .50\right)$ \\
\hline 28 & $\mathrm{RzClmCal}$ & REAL & & $\left(\mathrm{RzClam}^{\prime} \cdot 63 \cdot 4.54 \cdot .40\right)$ \\
\hline 29 & FormuCal & REAL & & ('Formula'*1.61) \\
\hline 30 & TotalCal & REAL & & $\begin{array}{l}\text { ('gcal't'scalcal'+'codcal' } \\
\text { +'musscal' +'pollcal' } \\
\text { +'shrmpcal' } \\
\text { +'wsrmpcal' 'squidcal' } \\
\text { +'clamcal' +'cmeatcal' } \\
\text { +'crabcal' +'rzclmcal' } \\
\text { +'FormuCal') }\end{array}$ \\
\hline
\end{tabular}

$\overline{{ }^{\mathrm{a}} \text { Number }}$ of characters

Fig. 3. Column definitions for Table Meals. 
whose contents are computed from values in other columns), including one for total weight (in pounds) eaten and one that computes the caloric value of each meal based on its constituent weights. The value of TotalWt (total weight of food eaten) is used in the Progress Summary and the Behavior Summary.

\section{Medical Treatments}

Table Treatmts (Fig. 4) describes the medical treatments received by each animal. It is used not only as an archive for information but also as part of the daily Progress Summary report.

There is a point concerning column Treatmt that bears on the design of this table and others. Column Treatmt is a text column with room for 40 characters. Data are entered about the drug or vitamin being administered, the method of application, and the strength of the dose. Subsequent searches for a particular treatment then require a text search based on earlier information about the drug, for example, how the name is spelled.

The other way to handle this kind of information is to assign a one-character field for each drug. A $Y$ or $N$ is entered depending on whether or not that particular drug was administered. Searches for a particular drug are made easier with this method because the search criterion is simple; a $Y$ in a column named Narcan means the drug was administered, an $N$ or a null (an unfilled field) means it was not. The problem with this method is that every time a different drug is added, a new column must be added to the table. If a data entry form or report is generated, then it must be changed to reflect the addition of the new column. Such changes are time consuming and may produce errors.

Because R:Base has powerful built-in string searching functions (that is, scanning a column in a table for certain sequences of numbers or alphabetic characters), the method described above need not be used. One can run searches for certain

\begin{tabular}{lllll} 
\# & Name & Type & Length $^{\text {a }}$ & Data description \\
\hline 1 & Otter\# & TEXT & 6 & \\
2 & TmtDat & DATE & & Treatment Date \\
3 & Treatmt & TEXT & 40 & Desc. of treatment \\
4 & Duration & TEXT & 15 & Duration of treatment \\
5 & MComment NOTE & & Vet's comment
\end{tabular}

${ }^{\mathrm{a}}$ Number of characters

Fig. 4. Column definitions for Table Treatmts. drugs by using just a portion of the drug name, or even search the Comment column for occurrences of words with special significance and, through output redirection to the system printer, generate short, ad hoc reports based on the results of those searches.

\section{Blood Parameters}

Table Blood (Fig. 5) is for blood test results. Many of the column names are acronyms and are meaningful only if one has a background in blood chemistry or medical laboratory work. The columns in this table were selected to facilitate loading data from the DBase data bases in Valdez, as well as from the Reflex (tm) data base maintained by T. D. Williams (Monterey Bay Aquarium, Monterey, California).

\section{Body Weight}

Table Weights (Fig. 6) contains animal weights and weighing dates. The data in this table are useful for tracking an animal's weight during its stay at the center. Declining weight may indicate a health problem, whereas weight gain, especially for pups, is a good sign. An animal's most recent weight and weighing appear in this table and in the Frogress Summary report.

\section{Reports}

The reporting function is one of the most important to consider when designing a data base. Some of the reports designed for SORC proved more useful than others. The reports in the following tables (Figs. 7, 8, 9, 10, and 11) are presented in approximate order of popularity and usefulness.

\section{Progress Summary}

The Progress Summary report (Fig. 7) assembles 4 days of data for a given animal from five different tables: OtterBio, Meals, Behavior, Weights, and Treatmts.

Although this is the first report shown, the flow of data was as follows. Typically, the medical treatments and food weight data for the previous $24 \mathrm{~h}$ were entered during the night shift. In the morning the husbandry supervisor would condense the behavioral observations and determine a coat and grooming evaluation for the previous $24 \mathrm{~h}$. The data were entered into the "Behavior" table. If an animal warranted special attention as judged by the observational data, it was starred to initiate a Progress Summary report. 


\begin{tabular}{|c|c|c|c|c|c|c|c|c|}
\hline$\#$ & Name & Type I & Length $^{a}$ & Data description & \# & Name & Type Length ${ }^{a}$ & Data description \\
\hline 1 & Otter\# & TEXT & 6 & & 29 & Choles & REAL & Cholesterol (\%) \\
\hline 2 & TmtDat & DATE & & Date blood drawn & 30 & Trigl & REAL & Triglycerides (\%) \\
\hline 3 & TmtTime & TIME & & Time blood drawn & 31 & AlkPhos & REAL & Alkaline \\
\hline 4 & AnalDat & DATE & & Date blood analyzed & & & & Phosphatase (\%) \\
\hline 5 & AnalTime & TIME & & Time blood analyzed & 32 & SGOT & REAL & $\begin{array}{l}\text { Aspartate amino- } \\
\text { transferase }\end{array}$ \\
\hline 6 & Lab & TEXT & 8 & Name of laboratory & 32 & SGPT & REAL & Alanine amino- \\
\hline 7 & WBC & REAL & & White Blood Cell count & 30 & SUFI & KLFW & transferase \\
\hline 8 & $\mathrm{RBC}$ & REAL & & Red Blood Cell count & 34 & GGTP & REAL & GammaGlutamyl- \\
\hline 9 & HGB & REAL & & Hemoglobin (conc.) & & & & Transpeptidase \\
\hline 10 & HCT & REAL & & Hematocrit & 35 & $\mathrm{LDH}$ & REAL & Lactate \\
\hline 11 & $\mathrm{MCV}$ & REAL & & Mean Corpuscular & & & & DeHydrogenase \\
\hline & & & & & 36 & TotBili & REAL & Total Bilirubin (conc.) \\
\hline 12 & $\mathrm{MCH}$ & REAL & & Mean Corpuscular & 37 & DirBili & REAL & Direct Bilirubin (conc) \\
\hline & & & & Hemoglobin & 38 & $\mathrm{Na}$ & REAL & Sodium (conc.) \\
\hline 13 & $\mathrm{MCHC}$ & REAL & & MCH Concentration & 39 & $\mathrm{~K}$ & REAL & Potassium (conc.) \\
\hline 14 & Plates & TEXT & 3 & Platelets & 40 & $\mathrm{Cl}$ & REAL & Chloride (conc.) \\
\hline 15 & Seg & REAL & & Segments (\%) & 41 & $\mathrm{Ca}$ & REAL & Calcium (conc.) \\
\hline 16 & Bands & REAL & & Bands (\%) & 42 & $\mathrm{P}$ & REAL & Phosphorus (conc.) \\
\hline 17 & Lymph & REAL & & Lymphocytes (\%) & 43 & $\mathrm{Fe}$ & REAL & Iron (conc.) \\
\hline 18 & Mono & REAL & & Monocytes (\%) & 44 & Albumin & REAL & Albumin (conc.) \\
\hline 19 & Eos & REAL & & Eosinophylles (\%) & 45 & Globulin & REAL & Globulin (conc.) \\
\hline 20 & Baso & REAL & & Basophylles (\%) & 46 & $\mathrm{~A} / \mathrm{G}$ & REAL & Albumin:globulin ratio \\
\hline 21 & Other & REAL & & Other than above (\%) & 47 & BUN & REAL & Blood Urea Nitrogen \\
\hline 22 & Hemolyzd & TEXT & 1 & Blood hemolyzed? [Y/N] & 48 & Bun/Cre & REAL & BUN/Creat ratio \\
\hline 23 & Note1 & NOTE & & Hematology comment & 49 & NRBC & REAL & Nucleated RB cells \\
\hline 24 & Glucose & REAL & & Glucose (conc.) & 50 & Retic & REAL & Reticulates (\%) \\
\hline 25 & BuffCoat & REAL & & Buffy coat (\%) & 51 & Cortisol & REAL & Cortisol (conc.) \\
\hline 26 & TotProt & REAL & & Total Protein (\%) & 52 & $\mathrm{CO} 2$ & REAL & Carbon dioxide (conc.) \\
\hline 27 & Creat & REAL & & Creatinine (\%) & 53 & CPK & REAL & Creatine-Phosphokinas \\
\hline 28 & UricA & REAL & & Uric Acid (\%) & 54 & Note2 & NOTE & Overall Comment \\
\hline
\end{tabular}

${ }^{\mathrm{a}}$ Number of characters

Fig. 5. Column definitions for Table Blood.

After the behavior data were entered, the Progress Summary reports for the starred animals were automatically generated and copies distributed to all husbandry and medical personnel. Of

\begin{tabular}{lllll}
$\#$ & Name & \multicolumn{2}{c}{ Type Length $^{\text {a }}$} & Data description \\
\hline 1 & Otter\# & TEXT & 6 & \\
2 & TmtDat & DATE & & Date of weighing \\
3 & Weight & REAL & Weight, in pounds \\
\multicolumn{2}{l}{ a Number of characters } & &
\end{tabular}

Fig. 6. Column definitions for Table Weights. course, a report could be generated for any animal at any time.

\section{Behavior Summary}

The Behavior Summary report (Fig. 8) was distributed daily to all husbandry staff. It summarizes the behavior for all animals at the center. Additional information includes weight of food eaten (from column TotalWt in table Meals), the animal's present cage or pool location, and its coat and grooming evaluations. It is during the entry of data for this report that an animal might get starred for special observation by the husbandry supervisor. 


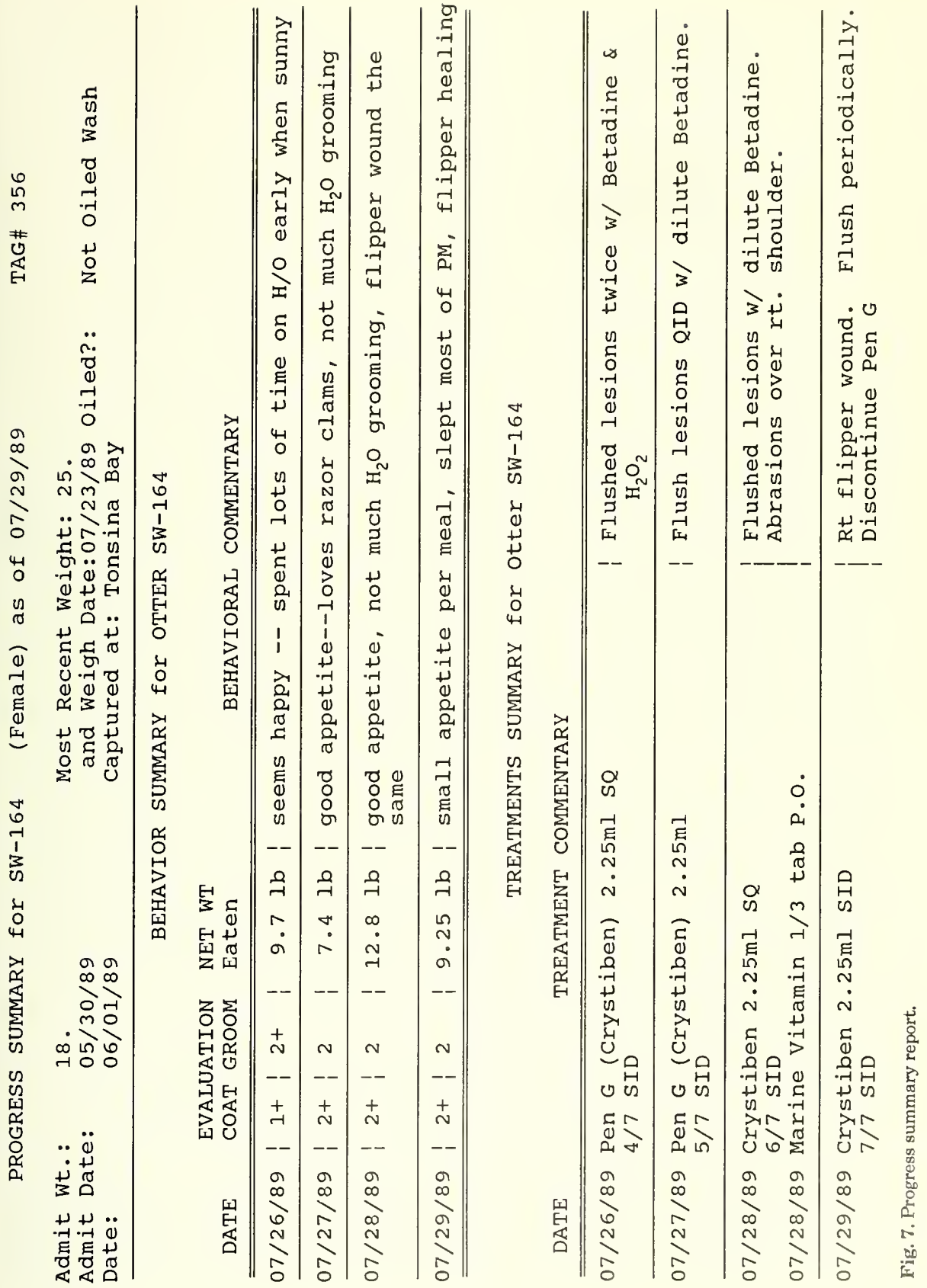




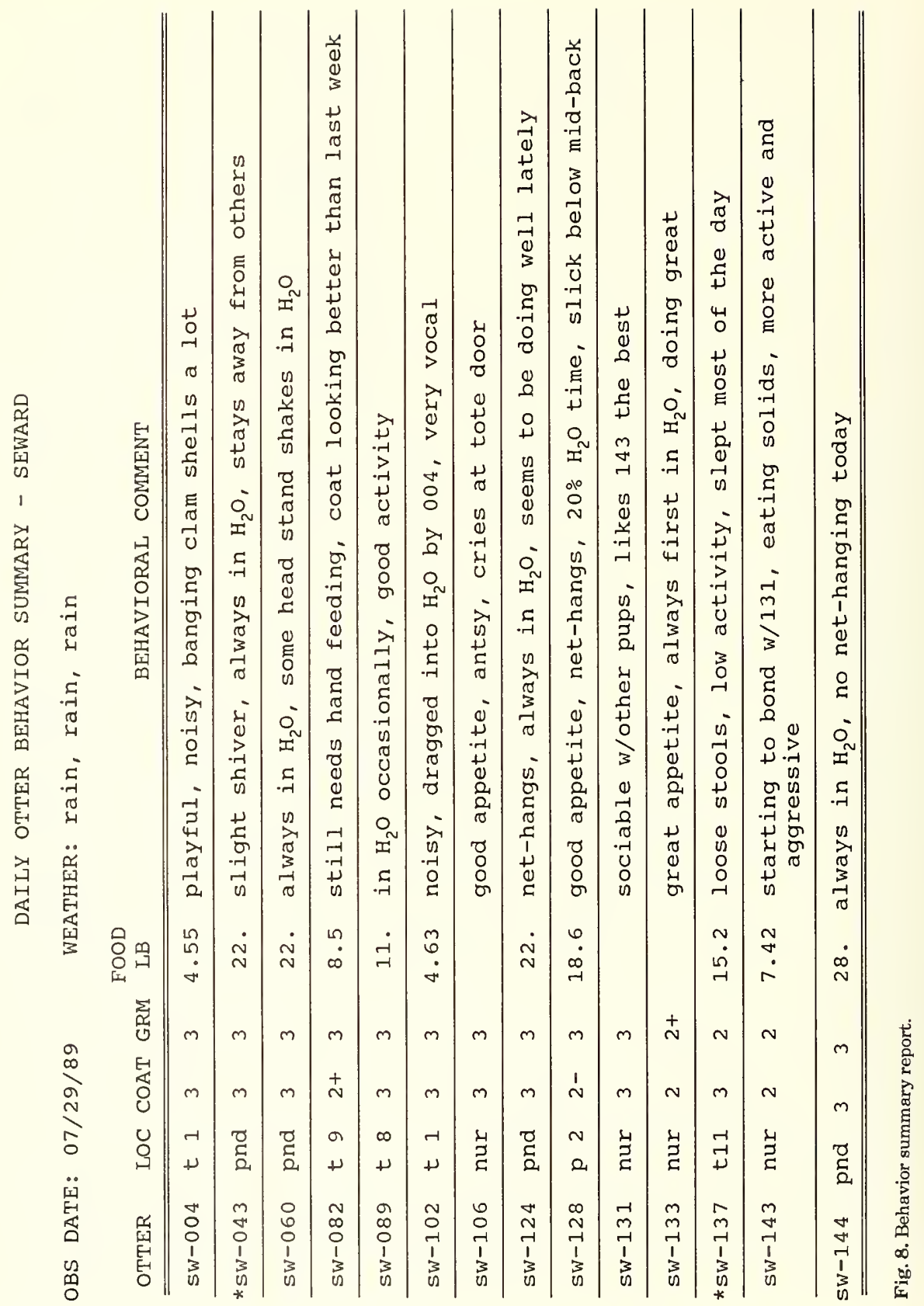


$\stackrel{\infty}{\sigma} 0$

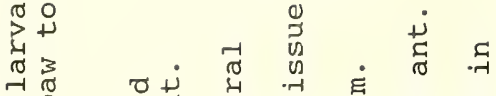

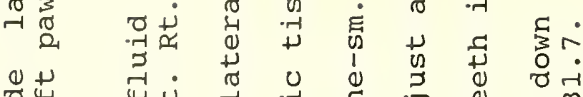

ठㅂ

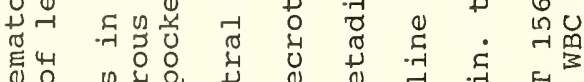

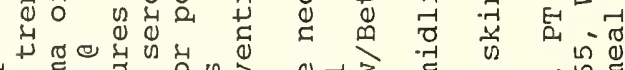

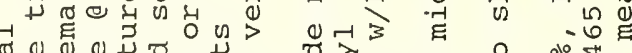

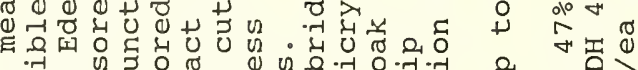

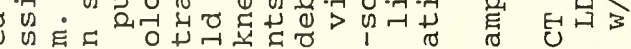

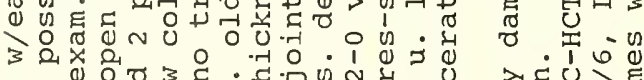
U 1 出

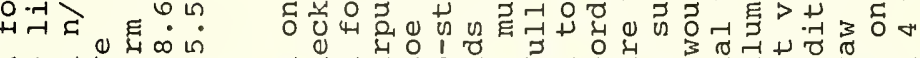

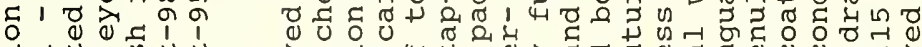
-

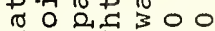
$>$ 出

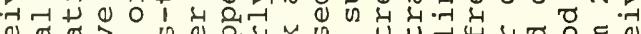
б

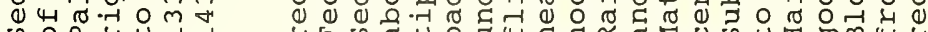
以 0 म中 म

$\sum_{H} \quad \sum_{H} \quad \sum_{H}$

की $\sum_{H}$ के के $\sum_{H}$

\&

再

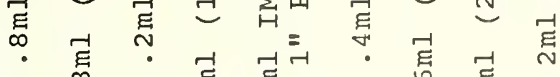

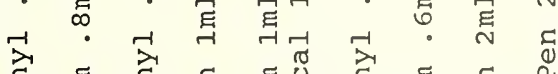

窟

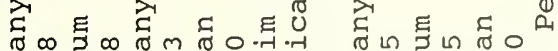

H

ב...

E $\because \cdots$.

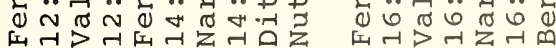

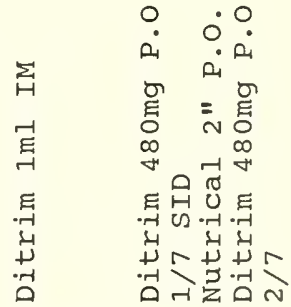

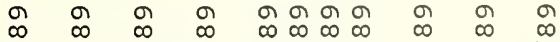




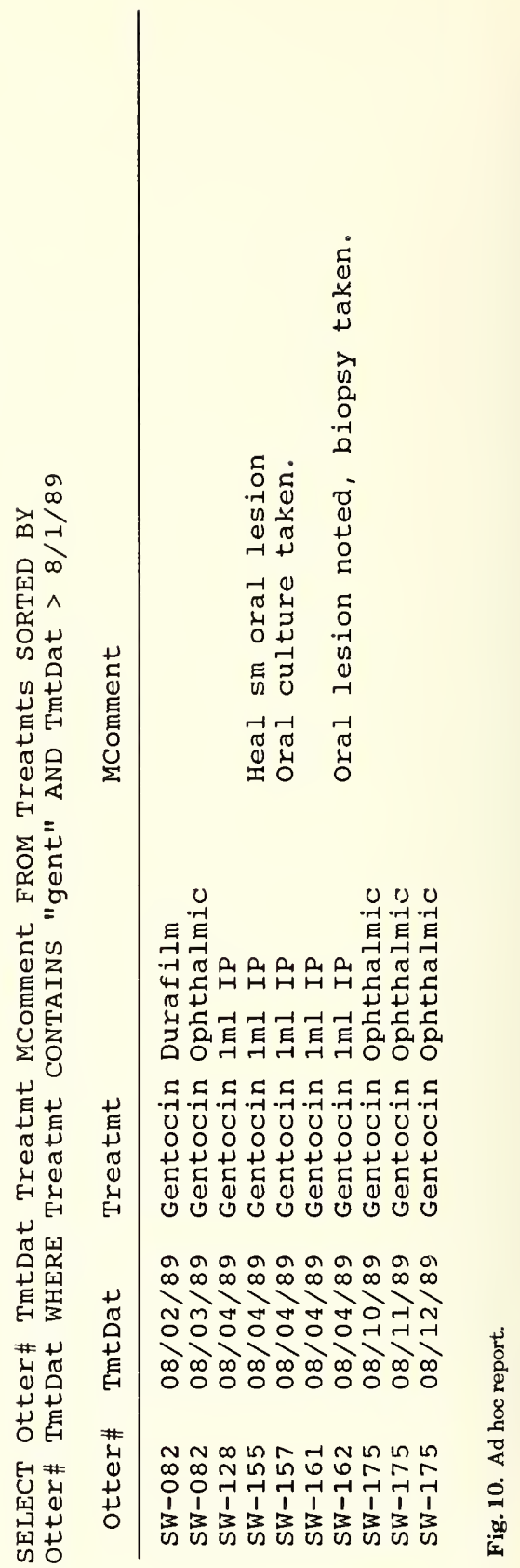




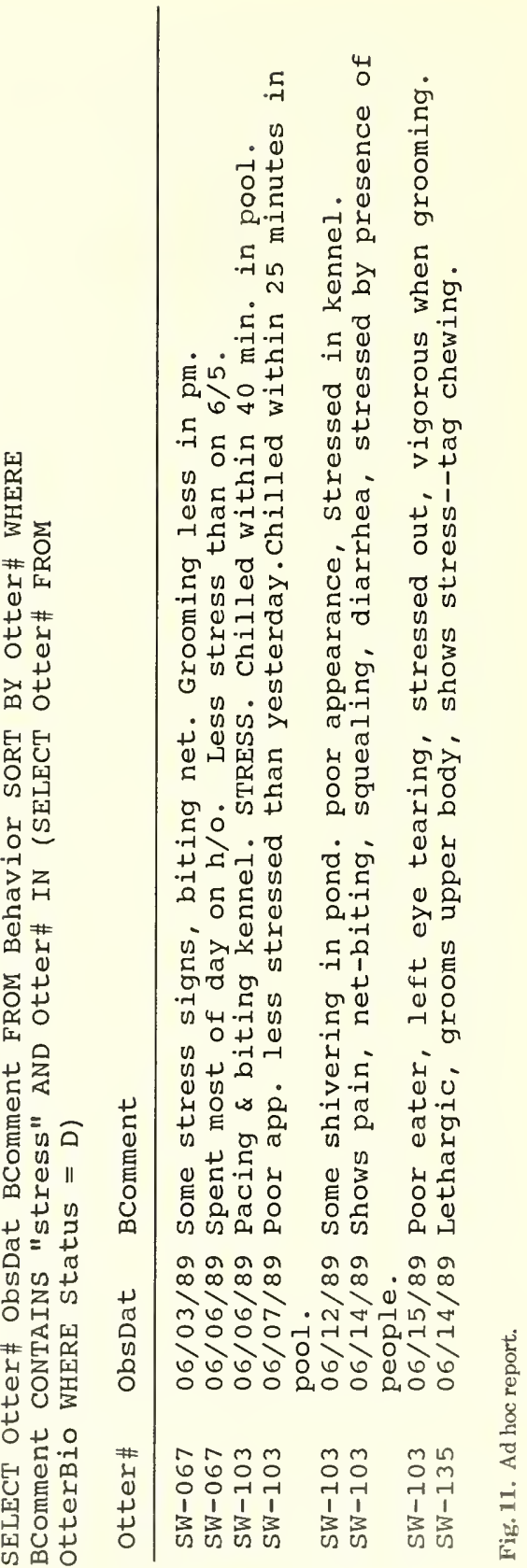




\section{Treatment Summary}

Figure 9 shows a shortened example of a Treatment Summary report. Sometimes, when an animal had serious health problems, this report would contain many pages. The report lists the contents of table Treatmts for a given animal, sorted by treatment date.

\section{Examples of Ad Hoc Reports}

Fully formatted reports are not the only way to obtain information from a data base. Most database software has some means to select only a subset of the total number of records in a data base to be displayed. Figure 10 shows a sample of the output from an ad hoc report generated when a veterinarian asked whether any animals had received ophthalmic medicine (Gentocin) since the first of August. The R:Base command that generated the report is given at the top of the figure.

Figure 11 is an example of a more complicated query, to see whether observed stress is related to an animal's survival rate. We searched the entire Behavior table looking for occurrences of the word stress in column BComment. For the purposes of this query, we wished the search to include only animals who had died. As before, the RBase command used to perform the query is shown at the top of Figure 11.

In other words, SELECT rows from table Behavior that have the word "stress" anywhere in the behavior comment (displaying only the Otter\# Observation-Date and Behavior-Comment and sorting by Otter\#). In addition, the second SELECT statement limits the search only to animals whose Status field in table OtterBio contains a $D$ to indicate they have died.

Note that we can find the text string "stress" even when it is part of another word. I ran an identical search for animals that had been sent to the JPRF and found that the word stress had, at one time or another, appeared in their observational commentary as well.

\section{Summary and Recommendations}

When SORC was opened in early May 1989, there were a few portable computers with plans only to use them for basic word processing of protocols, memos, and forms. Future animal rescue programs should give computer operations a high priority. There is no better way to preserve the data collected for future use while at the same time making it available to rescue workers who need to be kept informed of the status of the animals in their care.

One of the most important recommendations I could make is that there be an overall computer manager responsible for standardizing all aspects of data gathering and storage. The database design, data collection, and data entry for this project were made during the day-to-day rescue activities, with little time for intraproject communication. It is amazing that so much of the data were saved given the stressful circumstances under which they were compiled. Although it is impossible to predict the computer requirements of the next major animal rescue effort, the following paragraphs summarize how the four computers at the Seward Center were used.

\section{Computer Hardware}

By the project's end, we had in service two AT-class Hewlett-Packard computers and a LaserJet printer, which were lent to us by the HewlettPackard Company for the duration of the project; one AT-class Compaq Portable with dot matrix printer, which was supplied by the Exxon Company; and a personal XT-class IBM-compatible and dot matrix printer. It would be prudent to have at least one computer reserved strictly for database operations; another for the creation of data forms, spreadsheet applications, and protocol preparation; and another for word processing. Each computer should have its own printer.

To complete work in a reasonable amount of time, AT-class computers are highly desirable. In addition to having hard disks, at least one of the units should be equipped with 5.25 -inch and 3.5-inch floppy disk drives. Both drives should be capable of reading and writing in standard and high-density formats. Thus, the minimum configuration for a rehabilitation center is two computers for animal-related tasks, with another avail. able for word processing. The data manager can then be developing new reports, designing database additions, and ensuring data integrity while other people are doing the time-consuming job of collecting and entering raw data and generating routine reports.

\section{Computer Software}

The sea otter data base was not the only computer-related task at the center. We did the weekly 
payroll accounting and daily otter counts using a spreadsheet program. Good backup software is essential. The database files were fairly large, about 2.5 megabytes, and couldn't be simply copied to floppy diskettes as insurance against data loss. We used a program called CoreFast (Core International, Boca Raton, Florida), which compresses the database files while it rapidly transfers them from the hard disk to floppy disks. Several of these programs are available (e.g., PC-Backup, FastBack) at reasonable prices. Having this type of software reduces the risk of data loss.

Minimum software requirements for an animal rescue project are some kind of popular DBMS software, Lotus 1-2-3 (or compatible) spreadsheet software, WordPerfect or Microsoft WORD for word processing, and suitable backup programs or file compression utilities.

\section{Problems and Possible Solutions}

A big limitation on a project of this size was the lack of networking hardware and software. A network allows two or more people at different work stations to access the same data base simultaneously. Thus, with a network in place, the data manager could be developing the data base or its reporting capability, while someone else was entering new data from a different terminal. We developed work-arounds involving the use of mul- tiple copies of the database files to allow two people to work on the same data base simultaneously, but we occasionally lost data.

Another problem was that it was virtually impossible to track an animal after it was transferred to another center. For example, when animals at SORC were shipped to the JPRF, there was no mechanism in place to provide updated information to the originating center.

We also had problems with animal identification numbers. Each center used similar, but not identical, naming conventions. In several instances, animals were known by completely different identification numbers in other facilities. Moreover, if an animal died and was subsequently necropsied, the pathology number assigned by the investigating team had, in many cases, no relation to the identification number used by the centers. Perhaps these problems had little effect on our ability to provide care for the otters, but they made it difficult to provide accurate and complete case histories now that the project is over.

The motivation for creating the data base and associated reports was to provide up-to-date medical and husbandry information to animal caregivers. Other reasons for keeping good records in electronic form include permanent documentation, litigation, research, contingency planning, and education. 


\section{Rehabilitation Session B: Husbandry}

Chair: Robert Hardy, California Department of Fish and Game, Mora Bay, California.

Editors: Glenn R. VanBlaricom and Randall W. Davis.

Clinical Evaluation and Cleaning of Sea Otters Affected by the T/N Exxon Valdez Oil Spill

T. M. Williams

International Wildlife Research

La Jolla, California 92038

J. McBain

3658 Ingraham Street

San Diego, California 92109

R. K. Wilson

Arctic Animal Hospital

Anchorage, Alaska 9950

and

R. W. Davis

International Wildlife Research

Texas A\&M University

Department of Marine Biology

P.O. Box 1675

Galveston, Texas 77553 


\begin{abstract}
After the T/N Exxon Valdez oil spill, medical condition and degree of oiling were evaluated in 339 sea otters (Enhydra lutris) on arrival at rehabilitation centers. Criteria used to determine condition included behavior, respiratory rate, body temperature, and appetite. We assessed exposure to petroleum hydrocarbons by determining the percentage coverage and penetration of oil on an otter's pelage, and by measuring total petroleum hydrocarbon concentration in blood samples. Both medical condition and degree of oiling were dependent on when otters encountered the spill. Heavily oiled animals arriving within 14 days of the spill showed the greatest number of critical disorders. At the Valdez Otter Rehabilitation Center, about $50 \%$ of the otters were heavily or moderately oiled. Hypothermia, hypoglycemia, and emphysema were diagnosed in many of these animals. In comparison, 2 heavily oiled and 20 moderately oiled sea otters were treated at the Seward Otter Rehabilitation Center; the remainder were lightly oiled or unoiled. Fewer than $2 \%$ of these otters displayed symptoms of hypothermia, hypoglycemia, or emphysema on arrival at the Seward Center. Depending on the medical evaluation, sea otters were washed within 2 to $24 \mathrm{~h}$ after arriving at the rehabilitation centers. As reported in previous studies, a 1:16 solution of dishwashing detergent and fresh water was effective in removing crude oil from the fur. The recovery period for otters was contingent on physical and physiological factors that permitted grooming activity. Ongoing research indicates that the replacement of natural oils in washed fur may speed coat recovery in washed sea otters.
\end{abstract}

The food preferences, behavior, and fur insulation of the sea otter make this marine mammal especially vulnerable to the effects of crude oil. While pinnipeds and cetaceans use subcutaneous blubber layers to keep warm in water, the sea otter relies on dense fur for thermoregulation. Soiling of the sea otter's specialized fur can lead to loss of body heat in cold water, and death as a result of hypothermia (Costa and Kooyman 1982; Davis et al. 1988). Other routes of exposure include inhalation of petroleum hydrocarbon vapors, and ingestion of contaminated prey. All three routes contribute to systemic hydrocarbon toxicity.

We describe the initial clinical assessment and care of sea otters affected by the T/V Exxon Valdez oil spill. Criteria for establishing an emergency evaluation system for large numbers of animals and for assessing petroleum hydrocarbon toxicity are presented. We also describe three major medical problems of oiled sea otters: hypothermia, hypoglycemia, and emphysema.

\section{Demographics of Oiled Sea Otters at the Rescue Centers}

From 30 March to 21 August 1989, 339 sea otters were received at the Valdez and Seward centers and the Homer Temporary Care Facility (HTCF) (Appendix). In addition, 18 pups were born in captivity. Almost $75 \%$ of the 154 sea otters that were captured and sent to the Valdez Otter Rehabilitation Center (VORC) arrived within the first 3 weeks of the spill (24 March to 11 April); the remainder arrived within 6 weeks of the spill. In comparison, $69 \%$ of the 175 otters that were captured and sent to the Seward Otter Rehabilitation Center (SORC) arrived from 1-25 May. The temporary care facility in Homer received 15 adults and 3 pup otters directly from the wild between 25 April-7 May.

Most otters at the rehabilitation centers were females; $55 \%$ of the otters at Valdez and $77 \%$ of the otters at Seward were female (Fig. 1). This sex ratio reflects the movement of oil into areas occupied predominantly by females (DeGange and Lensink 1990). Forty-six female otters (21\%) were recognized as pregnant (by palpation) when they arrived at the rehabilitation centers (Fig. 2). Of these, 3 female otters in Valdez, 11 in Seward, and 4 in Homer gave birth to live pups while in captivity. Fourteen of the pregnant animals died before giving birth, and 10 pregnancies ended in abortion or stillbirth. Further analyses of toxicological and histopathological samples are necessary to determine whether oil contamination, stress, or other factors contributed to these deaths.

Mortality was high in captive-born otters. Of the 18 animals born, only 1 pup from VORC, 3 from SORC, and 3 from HTCF survived. The percentage survival (39\%) for these animals is lower than the $57 \%$ survival reported for California sea otters born in the wild (Siniff and Ralls 1988). Survival was higher for orphaned pups retrieved during capture operations than for those born at the rebabilitation centers (Fig. 2). Of the 11 orphaned pups 
Fig. 1. Number of sea otters (Enhydra lutris) received at the Valdez and Seward Otter Rehabilitation centers and the Homer Temporary Care Facility in relation to sex of the animal and date denotes total number of otters received. of admission. The height of the bar

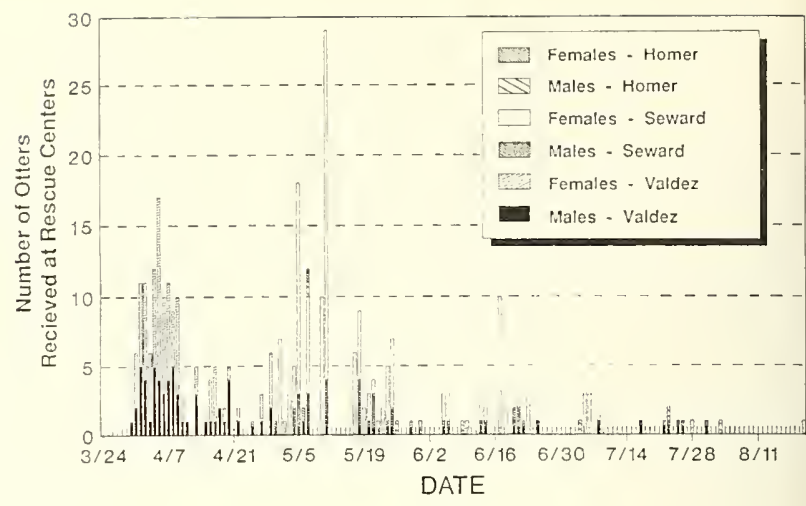

received by SORC, only one died. Two abandoned pups from Prince William Sound were brought to VORC, and both survived. Nine mother-pup pairs were captured along the Kenai Peninsula. Of these, four pairs were eventually released, three pups were raised in the nursery at SORC and later sent to Point Defiance Aquarium in Tacoma, Washington, and two pups died.

\section{Clinical Evaluation of Oiled Sea Otters}

With many sea otters arriving simultaneously at the rehabilitation centers, it was necessary to develop a quick, straightforward system for evaluating the overall condition of an animal. Unfortunately, the condition of each otter depended on many unknown factors, such as the age (fresh or weathered) of oil encountered, duration of exposure to oil, and general health of the animal before the oil spill. Our initial evaluation was limited to activity level, physiological indices, degree of oiling, and blood chemistry of the otters.

\section{Activity Level}

Sea otters arriving at the centers varied in responsiveness. Activity level of heavily oiled animals ranged from agitated to lethargic, and depended on the duration of exposure to oil. In severe cases of oil on the head, the otters had scratched the cornea and membranes surrounding their eyes. Damaged fur on the abdomen and the exposure of cartilage on the edge of the ears resulted from excessive grooming in at least two

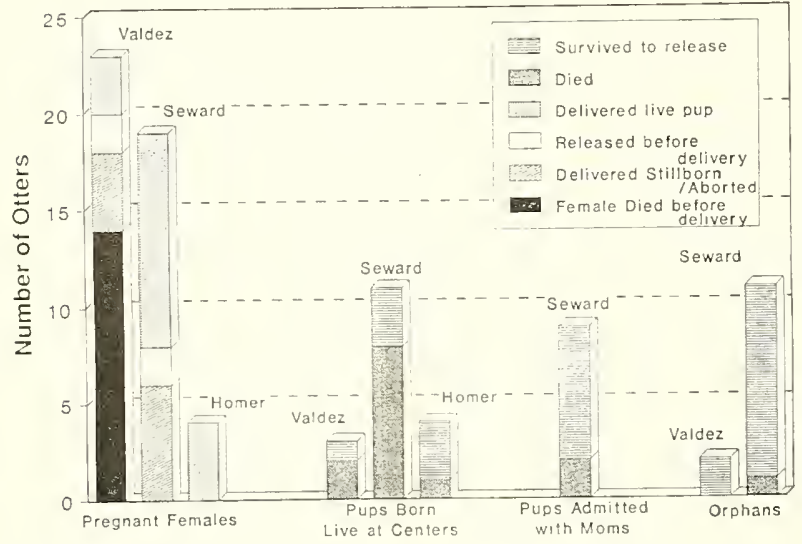

Fig. 2. Perinatal sea otter (Enhydra lutris) survival at the Valdez and Seward Otter Rehabilitation centers and the Homer Temporary Care Facility. Note the increased survival of orphaned pups in comparison with pups born at the rehabilitation facilities. 
heavily oiled otters. Moderately oiled and lightly oiled animals were usually alert, groomed, and accepted food. Normal grooming included rubbing the ears, muzzle, and forearms, as well as licking and nuzzling the abdomen.

\section{Physiological Indices}

Center staffs assessed respiratory rate, signs of pulmonary distress and shock, hydration, coat condition, degree of emaciation, and body temperature of the otters. Except for core body temperature, all indices were determined visually or by palpation. We made an initial, qualitative assessment of core body temperature by feeling the hind flippers. These appendages are important areas for heat loss in sea otters, and their temperature is a good indicator of hyperthermia or hypothermia. Shivering and panting were also useful indicators of general thermal status. In addition, the core body temperature of each otter was measured periodically with a rectal thermometer during washing and rehabilitation.

\section{Degree of Oiling}

Both internal (inhalation and ingestion) and external (pelage and dermal) exposure to petroleum hydrocarbons occurred in the sea otters. Initial assessment of oil contamination was by examination of the pelage. Some animals were lightly sprayed with water to remove the feces and dirt that complicated this assessment. The following four classifications were used: heavily oiled (>60\% body coverage), mod rately oiled (30-60\% body coverage), lightly oiled ( $<30 \%$ body coverage or light sheen on fur), and unoiled (no visual evidence of oiling).
Based on this ranking, 78 (50\%) of the animals that came into VORC were heavily or moderately oiled, 51 (33\%) were lightly oiled, and 11 (7\%) were unoiled (Fig. 3). The degree of oiling was not documented in $16(10 \%)$ otters at VORC. In comparison, only 19 otters $(10 \%)$ at SORC arrived heavily or moderately oiled, 72 (39\%) were lightly oiled, and $44(23 \%)$ were unoiled. The degree of oiling was not documented in $52(28 \%)$ of the otters at SORC because of the difficulty of detecting oil on animals captured late in the spill. Six otters taken to the Homer Temporary Care Facility were unoiled.

We also developed a blood-testing program to determine the degree of systemic absorption of oil. Blood samples were taken from sea otters on arrival at the rehabilitation centers; these samples were analyzed for total petroleum hydrocarbon concentration. Preliminary results indicate a positive correlation between total petroleum hydrocarbon concentration and mortality in the otters. Although further research is needed to determine the lethal thresholds of hydrocarbons for otters, total petroleum hydrocarbon concentration may be a useful diagnostic indicator for animals affected by oil spills.

\section{Blood Variables}

Blood samples were taken from the femoral, jugular, or popliteal vein of every animal on admission, as needed during rehabilitation, and before release. Basic hematological and blood chemical constituents (Table 1) were determined at the rehabilitation centers and provided diagnostic information for the veterinary staff. A more complete analysis of duplicate samples was provided within 7 days by the Physicians Medical Laboratories in Portland, Oregon.

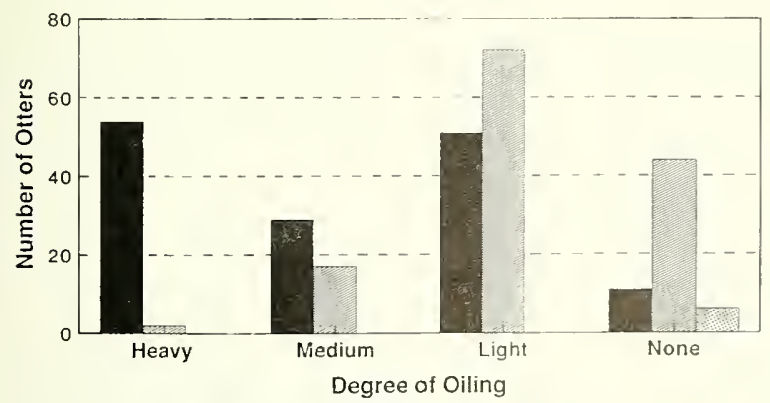

Valdez
Fig. 3. Degree of oiling on the fur of sea otters (Enhydra lutris) admitted to the Valdez and Seward Otter Rehabilitation centers and the Homer Temporary Care Facility. Note that Jakolof Pre-Release Facility, near Homer, received a few unoiled otters. 
Table 1. Blood variables examined in sea otters (Enhydra lutris) at the Valdez and Seward Otter Rehabilitation centers and the Homer Temporary Care Facility. Some parameters (indicated by ${ }^{*}$ ) were measured at the centers to provide immediate information for treatment of the otters. In addition, all parameters were examined by contracted clinical laboratories.

\begin{tabular}{cll} 
Hematology & \multicolumn{2}{c}{ Chemistry } \\
\hline $\begin{aligned} \text { Hematocrit } \\
\text { Hemoglobin }\end{aligned}$ & $\begin{array}{l}\text { Glucose }^{*} \\
\text { Creatinine }\end{array}$ & $\begin{array}{l}\text { Total bilirubin } \\
\text { Total protein }\end{array}$ \\
$\begin{array}{r}\text { White blood } \\
\text { cell count }\end{array}$ & $\begin{array}{c}\text { Blood urea } \\
\text { nitrogen }\end{array}$ & $\begin{array}{l}\text { Sodium } \\
\text { Albumin }\end{array}$ \\
Red blood cell & Uric acid & Globulin \\
count & Cholesterol & Thyroxine \\
Buffy coat & Lipase & Amylase \\
Sedimentation & Triglycerides & Potassium \\
rate & Liver enzymes & Chloride \\
Platelets & Kidney & Iron \\
Differential & enzymes & Calcium \\
count & & Phosphorus \\
& &
\end{tabular}

The hematocrit (HCT) of blood taken from sea otters on arrival at VORC showed no correlation with degree of oiling or survival (Tables 2 and 3). However, heavily and moderately oiled sea otters often developed anemia after several weeks of captivity. Plasma glucose concentration was below normal values in the heavily oiled otters that subsequently died. Indices of kidney and liver damage (i.e., blood urea nitrogen or BUN, serum glutamic pyruvic transaminase or SGPT, and serum glutamic oxaloacetic transaminase or SGOT) were highly variable in the otters. Blood urea nitrogen was about two-fold greater than normal in otters that died, and was elevated in beavily oiled animals that survived. In general, liver enzymes were elevated in otters that did not survive, but were only loosely correlated with visual assessments of external degree of oiling. Serum creatinine was two-fold greater in otters that died, but was still within the normal range for this species. Further researcb is needed to differentiate between the effects of oil exposure, hypothermia, dehydration, starvation, and the stress of capture on these blood variables.

\section{Medical Disorders of Oiled Sea Otters}

Heavily oiled animals arriving at VORC during the first 3 weeks of the spill had the severest medical problems, and consequently the highest mortality. When the otters encountered less oil or oil that had weathered, the incidence and severity of many medical disorders declined. Three disorders commonly diagnosed in oiled sea otters were hypothermia or hyperthermia, hypoglycemia, and emphysema.

\section{Hypothermia or Hyperthermia}

Previous studies have shown that body temperature is unstable in oiled sea otters (Davis et al. 1988). In healthy otters resting in water, core body temperature ranges from 37.0 to $37.8^{\circ} \mathrm{C}$ (Costa and Kooyman 1982). At the rehabilitation centers, we found that rectal temperature of oiled otters was variable during transport from the capture boats, during sedation and washing, and during the initial recuperation period of heavily or moderately oiled otters. More than $36 \%$ of the sea otters received at VORC were hypothermic on arrival. Many of these animals were heavily oiled, lethargic, and captured early in the spill when ambient air temperatures were $6.7-1.1^{\circ} \mathrm{C}$. The lowest core body temperature $\left(29.4^{\circ} \mathrm{C}\right)$ was recorded on an otter that arrived cyanotic and unconscious. The condition of this animal improved after gradual rewarming by immersion in warm water and intravenous administration of warm saline. This animal experienced no further complications and was eventually released.

By contrast, $27 \%$ of the otters received at VORC were hyperthermic on arrival. These animals were usually moderately oiled or lightly oiled. High body temperatures were coincident with excessive grooming of oiled fur, inadequate ventilation in transport cages, and hyperactivity associated with bandling. 'To mitigate this problem, capture teams often placed a layer of ice in the bottom of the transport cage. This was especially important for active otters, on warm days, and during prolonged transport.

Because of the lethal consequences of either hypothermia or hyperthermia, it is critical to determine the nature of the thermoregulatory imbalance in oiled sea otters. Core body temperature should be monitored during cleaning and the period of critical care. Such information allows veterinarians and busbandry personnel to take appropriate corrective action. 
Table 2. Blood variables for sea otters (Enhydra lutris) at the Valdez Otter Rehabilitation Center. Samples were drawn immediately upon arrival. The top portion of the table refers to animals that survived and were released. The lower portion presents values for otters that died in the center. Means $\pm 1 S D$ are shown. Numbers in parentheses denote the number of animals in each category.

\begin{tabular}{|c|c|c|c|c|c|c|c|c|}
\hline \multicolumn{9}{|c|}{ Blood Variables $^{\mathrm{A}}$} \\
\hline $\begin{array}{c}\text { Degree of } \\
\text { oiling } \\
\end{array}$ & $\begin{array}{c}\mathrm{HCT} \\
\% \\
\end{array}$ & $\begin{array}{c}\text { GLU } \\
\mathrm{mg} / \mathrm{dL}\end{array}$ & $\begin{array}{r}\text { BUN } \\
\mathrm{mg} / \mathrm{dL}\end{array}$ & $\begin{array}{c}\text { SGPT } \\
\mu \mathrm{g} / \mathrm{L}\end{array}$ & $\begin{array}{c}\text { SGOT } \\
\text { IU/L }\end{array}$ & $\begin{array}{l}\mathrm{LDH} \\
\mathrm{IU} / \mathrm{L}\end{array}$ & $\begin{array}{c}\text { CPK } \\
\mu \mathrm{g} / \mathrm{L}\end{array}$ & $\begin{array}{l}\text { CREA } \\
\mathrm{mg} / \mathrm{dL}\end{array}$ \\
\hline \multicolumn{9}{|c|}{ Released Otters } \\
\hline Heavy & 52.5 & 105.7 & 72.2 & 329.5 & 574.6 & 746.6 & - & 0.6 \\
\hline $\mathrm{SD}$ & 9.4 & 14.9 & 19.1 & 120.9 & 272.8 & 296.6 & & 0.2 \\
\hline $\mathbf{n}$ & (7) & (6) & (5) & (2) & (5) & (5) & & (5) \\
\hline Medium & 48.2 & 110.7 & 70.6 & 251.5 & 484.3 & 629.0 & 1283 & 0.5 \\
\hline SD & 7.9 & 44.6 & 23.7 & 145.1 & 305.5 & 509.6 & 1262 & 0.2 \\
\hline $\mathbf{n}$ & (7) & (7) & (7) & (6) & (7) & (7) & (5) & (7) \\
\hline Light & 48.0 & 155.9 & 48.8 & 420.4 & 738.0 & 538.7 & 746 & 0.8 \\
\hline $\mathrm{SD}$ & 5.9 & 50.8 & 8.4 & 213.9 & 445.5 & 259.3 & 291 & 0.1 \\
\hline $\mathrm{n}$ & (8) & (8) & (8) & (8) & (8) & (7) & (8) & (8) \\
\hline \multicolumn{9}{|c|}{ Dead Otters } \\
\hline Heavy & 60.3 & 53.2 & 189.6 & 287.3 & 960.8 & 1332 & 6654 & 1.2 \\
\hline $\mathrm{SD}$ & 12.5 & 36.1 & 143.3 & 52.3 & 563.5 & 594 & 5234 & 0.5 \\
\hline $\mathbf{n}$ & (6) & (6) & (7) & (4) & (6) & (5) & (5) & (6) \\
\hline Medium & 59.2 & 101.8 & 144.5 & 1384 & 3917 & 2194 & 2469 & 1.1 \\
\hline SD & 8.3 & 77.2 & 54.9 & 1374 & 4322 & 1804 & 1823 & 0.6 \\
\hline $\mathrm{n}$ & (11) & (7) & (10) & (7) & (8) & (7) & (6) & (9) \\
\hline Light & 49.3 & 119.4 & 108.2 & 610.1 & 1009 & 1798 & 4902 & 0.8 \\
\hline SD & 11.9 & 91.7 & 61.7 & 554.4 & 781 & 1345 & 3624 & 0.6 \\
\hline $\mathrm{n}$ & (8) & (11) & (11) & (10) & (10) & (10) & (9) & (9) \\
\hline
\end{tabular}

${ }^{\mathrm{a}} \mathrm{HCT}=$ hematocrit, GLU = glucose concentration, BUN = blood urea nitrogen, SGPT = serum glutamic pyruvic transaminase (also AGT), SGOT = serum glutamic oxaloacetic transaminase (also ALT), LDH = lactate dehydrogenase, CPK = creatinine phosphokinase, and CREA = creatinine.

Table 3. Normal ranges of blood variables for unoiled sea otters (Enhydra lutris) in captivity (after T. D. Williams, Monterey Bay Aquarium, Monterey, California, personal communication).

\begin{tabular}{|c|c|c|c|c|c|c|c|c|}
\hline \multicolumn{9}{|c|}{ Blood variables $^{a}$} \\
\hline $\begin{array}{l}\text { Degree of } \\
\text { oiling }\end{array}$ & $\begin{array}{c}\mathrm{HCT} \\
\%\end{array}$ & $\begin{array}{c}\text { GLU } \\
\mathrm{mg} / \mathrm{dL}\end{array}$ & $\begin{array}{r}\mathrm{BUN} \\
\mathrm{mg} / \mathrm{dL}\end{array}$ & $\begin{array}{c}\text { SGPT } \\
\mu \mathrm{g} / \mathrm{L}\end{array}$ & $\begin{array}{c}\text { SGOT } \\
\text { IU/L }\end{array}$ & $\begin{array}{l}\mathrm{LDH} \\
\mathrm{IU} / \mathrm{L}\end{array}$ & $\begin{array}{c}\mathrm{CPK} \\
\mu \mathrm{g} / \mathrm{L}\end{array}$ & $\begin{array}{l}\text { CREA } \\
\mathrm{mg} / \mathrm{dL}\end{array}$ \\
\hline \multicolumn{9}{|c|}{ Normal Ranges for Unoiled Otters } \\
\hline Low & 50.3 & 87.6 & 34.3 & 96.4 & 87.0 & 94.7 & 169.8 & 0.5 \\
\hline High & 62.1 & 150.2 & 63.6 & 240.0 & 511.0 & 419.3 & 490.3 & 1.4 \\
\hline
\end{tabular}




\section{Hypoglycemia}

Hypoglycemia (abnormally low blood glucose) was a common problem in animals admitted to the rehabilitation centers during the initial days of the oil spill. During this period, more than $45 \%$ of the sea otters tested showed blood glucose concentrations below the normal range (87.6 $150.2 \mathrm{mg} / \mathrm{dL}$; T. D. Williams, Monterey Bay Aquarium, Monterey, California, personal communication). These low glucose concentrations may have resulted from inability of the wild otter to feed before capture, impaired liver function or intestinal absorption, fasting during capture and transport, and stress or shock.

Hypoglycemia undoubtedly contributed to the thermoregulatory and metabolic problems of heavily oiled sea otters that subsequently died. Therefore, blood glucose concentration became an important diagnostic variable in the rehabilitation centers. Initially, Glucostix (Ames Laboratories) were used as a qualitative indicator of the blood glucose concentration. The donation of blood chemistry analyzers by Eastman Kodak (for VORC) and Abbot Laboratories (for SORC) permitted more quantitative and rapid analyses. As soon as hypoglycemia was diagnosed, $5 \%$ dextrose was administered intravenously or subcutaneously until normal blood glucose concentrations were reestablished. Comatose animals also received a dextrose bolus, either intravenously or through a feeding tube introduced into the stomach.

\section{Emphysema}

Pulmonary distress occurred frequently in sea otters arriving at the rehabilitation centers during the first 3 weeks of the spill. This condition was often associated with subcutaneous or pulmonary emphysema. Subcutaneous emphysema was characterized by pockets of air that could be felt below the skin. Small bubbles were first noted in the axillary region. In severe cases, air pockets could be felt beneath the skin along both sides of the neck and thorax, and along the spine. Postmortem examination showed that the subcutaneous emphysema arose from ruptured membranes in the lungs. Air escaping from the lungs moved along the mediastinum, through the thoracic inlet, and accumulated in subcutaneous tissues.

We recorded subcutaneous emphysema in 27 of the 154 sea otters admitted to VORC. Twenty-five of these cases occurred within 14 days of the oil spill. The actual incidence of subcutaneous emphysema during this period may have been higher because this condition was not diagnosed until the first necropsies were performed on 2 April. After that date we included palpation of the axillary region as part of the clinical examination.

We identified mild to severe pulmonary emphysema in $\mathbf{4 5}$ sea otters during postmortem examinations at the Valdez and Seward centers. More than half of the cases were recorded within 2 weeks of the spill. During this period nearly $70 \%$ of the otters that died exhibited some form of pulmonary emphysema.

The high incidence of emphysema during the first weeks of the spill suggests that the inhalation of volatile petroleum hydrocarbons may have been responsible. Depending on environmental conditions, lighter aromatic hydrocarbons (e.g., benzene, toluene, and xylene) will evaporate within several days of an oil spill. These compounds are considered the most toxic of the major classes of compounds in crude oil and are known to cause damage to the lungs and mucous membranes of the airways (Geraci and St. Aubin 1988).

\section{Cleaning Oiled Sea Otters}

After initial examinations, we weighed sea otters and either washed them immediately, placed them in a holding pen if cleaning was not required, or stabilized them with fluid therapy and fed them before washing. We cleaned oiled sea otters using methods from Minerals Management Service Report 86-0009 as modified by Williams et al. (1988) and Davis et al. (1988). Animals that were heavily oiled were washed immediately. This prevented further petroleum hydrocarbon exposure by absorption or by ingestion during grooming. Sea otters with light or patchy oil on their fur were fed, given fluids subcutaneously if dehydration was recognized, and cleaned within 12-24 h. Delaying the cleaning process for several hours permitted otters exposed to less toxic forms of oil to recover from the stress of capture before washing. Four otters at SORC and two otters at VORC did not appear to be oiled and were observed for several days to determine if washing was necessary.

Each oiled otter was placed on a cleaning basin and washed with a solution (1:16 in water) of Dawn dishwashing detergent. The detergent was gently massaged into the oiled fur and immediately rinsed out with fresh water. Applications were repeated for at least $\mathbf{4 0} \mathrm{min}$ or until there 
was no indication of oil on the fur or in the rinse water. Heavy oiling, weathered oil, or the presence of tar balls on the fur prolonged the cleaning process. An additional $40 \mathrm{~min}$ of rinsing with spray nozzles was necessary to thoroughly remove the detergent and help restore the water repellency of the fur (Williams et al. 1988).

After rinsing, the otters were dried with towels and pet dryers. Drying results were improved at SORC with the addition of a drying room that was separate from the high-humidity environment of the washing room. Drying time was $1 \mathrm{~h}$ when using three hand-held dryers. After drying, the sea otters were placed in cages to recover from sedation.

One result of cleaning oiled sea otters with detergent is that their fur does not immediately regain its water-repellent quality. This may result from mechanical disruption of the underfur so that the hairs no longer form an interlocking mat that entraps air, depletion of natural oils in the fur and skin (Davis et al. 1988), or a monolayer of detergent molecules that remains on the hairs and makes them hydrophilic.

As a result, sea otters that were washed in the rehabilitation centers could not be placed immediately into water. Normal grooming and a gradual reintroduction into water usually resulted in full restoration of the fur in 7-10 days. However, if the otter failed to groom, restoration of the fur was prolonged.

In an attempt to accelerate the restoration of the fur, L. Hunter (Redken Laboratories) developed a synthetic sebum (squalene in volatile silicon or ethanol carrier) that could be applied to the otter's fur after cleaning and drying. The ethanol was comiscible with water and penetrated the wetted fur. Both solvents were at least as volatile as water, and therefore helped complete drying of the fur in addition to coating the fur with artifi-cial sebum.

Initial testing was conducted on sea otter pelts. Squalene was applied to the fur of seven otters and their coat condition was compared with untreated controls. Preliminary results indicated that the fur of treated otters dried faster than untreated fur. Consequently, rehabilitation time may be shortened in otters whose fur has been treated with a natural oil substitute after washing.

\section{Further Research}

Research in several important areas is needed to improve the treatment of sea otters affected by the oil spill. The most important of these is a study of the short- and long-term toxicological effects of petroleum hydrocarbons on sea otters. Because of the high incidence of abortion and stillbirths, research concerning the effects of crude oil exposure on pregnant, lactating, and young animals is warranted. A standardized test for quickly assessing petroleum hydrocarbons in blood samples would help assess systemic exposure. This information would be especially important in developing suitable treatments for animals in rehabilitation centers.

The cleaning methods for oiled fur need to be refined. Although otters can be successfully cleaned with the present cleaning method, this method does not result in the immediate restoration of the water-repellent quality of the fur. Preliminary tests have demonstrated the effectiveness of applying a synthetic sebum to the fur of cleaned otters. Further tests of cleaning agents and fur conditioners may provide data that could reduce the length of the rehabilitation process for sea otters and decrease the time they spend in captivity.

\section{Acknowledgments}

Parts of this manuscript were presented previously in an Exxon report entitled, "Sea Otter Rehabilitation Program: 1990 T/N Exxon Valdez Oil Spill." We thank the many people and organizations who contributed to this work. Exxon Company U.S.A. provided continuous support for the rehabilitation centers and the analysis of the data. The dedicated staffs of VORC, SORC, and HTCF were invaluable in recording the behavior and medical progress of the animals. We also thank K. Bayha, D. Casper, A. Maki, D. J. St. Aubin, S. Shane, G. VanBlaricom, and T. D. Williams for useful discussions and insightful comments on the manuscript.

\section{References}

Costa, D. P, and G. L. Kooyman. 1982. Oxygen consumption, thermoregulation, and the effect of fur oiling and washing on the sea otter, Enhydra lutris. Can J. Zool. 60: 2761-2767.

Davis, R. W., T. M. Williams, J. A. Thomas, R. A. Kastelein, and L. H. Cornell. 1988. The effects of oil contamination and cleaning on sea otters (Enhydra lutris). 
II. Metabolism, thermoregulation, and behavior. Can. J. Zool. 66: 2782-2790.

DeGange, A. R., and C. J. Lensink. 1990. Distribution, age, and sex composition of sea otter carcasses recovered during the response to the T/N Exxon Valdez oil spill. Pages 124-129 in K. Bayha and J. Kormendy, tech. coords. Sea Otter Symposium: Proceedings of a symposium to evaluate the response effort on behalf of sea otters after the T/N Exxon Valdez oil spill into Prince William Sound, Anchorage, Alaska, 17-19 April 1990. U.S. Fish Wildl. Serv. Rep., Biol Rep. 90(12).
Geraci, J., and D. J. St. Aubin. 1988. Synthesis of effects of oil on marine mammals. U.S. Dep. Inter., Minerals Manage. Serv. Rep. 292 pp.

Siniff, D. B., and K. Ralls. 1988. Population status of the California sea otter. U.S. Dep. Inter., Minerals Manage. Serv. Rep. 368 pp.

Williams, T. M., R. A. Kastelein, R. W. Davis, and J. A. Thomas. 1988. The effects of oil contamination and cleaning on sea otters (Enhydra lutris). I. Thermoregulatory implications based on pelt studies. Can. J. Zool. 66: 2776-2781. 


\section{Appendix. Biosummary Data Base for Sea Otters at the Valdez and Seward Otter Rehabilitation Centers and the Homer Temporary Care Facility.}

Key to biosummary data base

Otter no. Sequential identification number given to each otter when it arrived at the particular rehabilitation center. Letters before the number identify the center: $\mathrm{H}=$ Homer; $\mathrm{SW}=$ Seward; $\mathrm{VA}=$ Valdez; $\mathrm{P}=$ pup; $\mathrm{V}=$ otter voluntarily entered pen

Tag

The number on the plastic tag attached to the hind flipper of each otter

Sex

Sex of each otter: $F=$ female; $M=$ male

Adm date

Date of arrival at the rehabilitation center

Adm wt

Weight (pounds) at the time of admission to the rehabilitation center. $0.00=$ no weight data at admission

Cap loc

Capture location: KP = Kenai Peninsula; $\mathrm{AP}=$ Alaska Peninsula; $\mathrm{PWS}=$ Prince William Sound; Kodiak $=$ Kodiak Island; UNK $=$ unknown. Date in parenthesis refers to capture date when different from admission date

Cap boat Name of capture boat. Asterisk means that the capture location and/or boat is based on sources other than capture forms. Number behind boat denotes the otter capture sequence for that boat

Comment Comment field. $\mathrm{H}=$ Homer. Names in (“") are pet names given by staff at centers

Oil

Status

Degree of oiling: $\mathrm{N}=$ no oil; $\mathrm{L}=$ lightly oiled; $\mathrm{M}=$ moderately oiled; $\mathrm{H}=$ heavily oiled; $\mathrm{U}=$ unknown

This field shows whether each otter was released, transferred to an aquarium, died or was euthanized. Also shown is the release location: $J$ = Little Jakolof Cove; KHI = Kenai Peninsula, Herring islands, Kachemak Bay; KJL = Kenai Peninsula, James Lagoon, McCarty Fjord; KNB = Kenai Peninsula, west arm of Nuka Bay; KTP = Kenai Peninsula, Taylor Bay; KPH = Kenai Peninsula, Picnic Harbor; $\mathrm{KHB}=$ Kenai Peninsula, Harris Bay; PWS = Prince William Sound (generally Sheep Bay for females and Nelson Bay for males); SB = Simpson Bay in Prince William Sound

Wash date Date that oiled otters were washed

Preg Shows whether the female was pregnant: $\mathrm{F}=$ false; $\mathrm{T}=$ true; $\mathrm{U}=$ unknown

Final disp Date that the otter was released, transferred to an aquarium, died, or was euthanized 


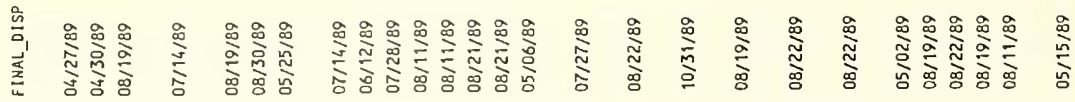
总

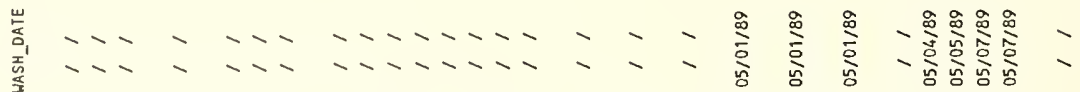

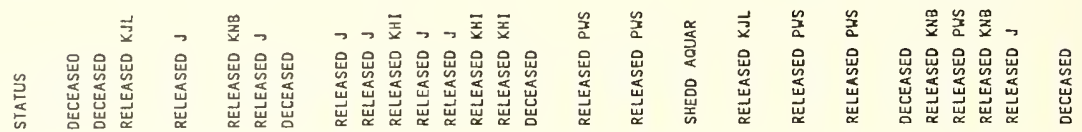

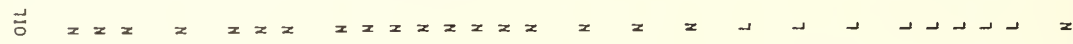

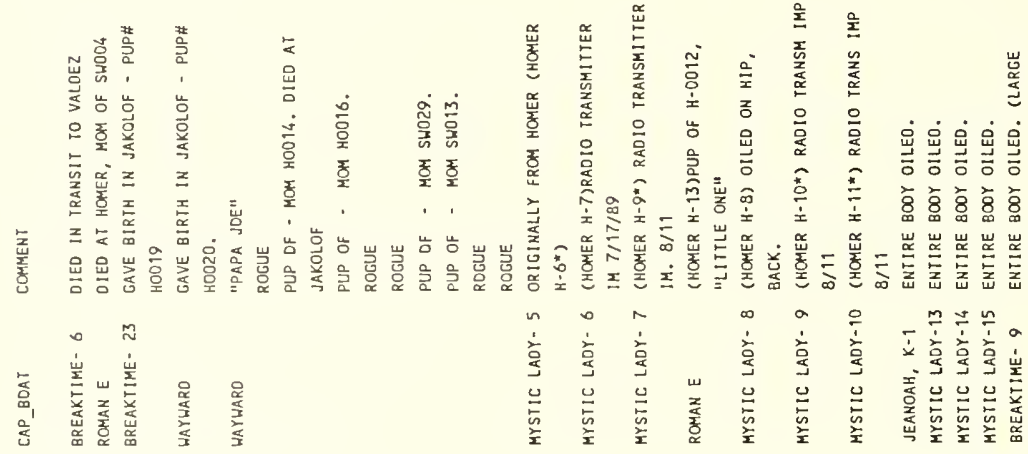

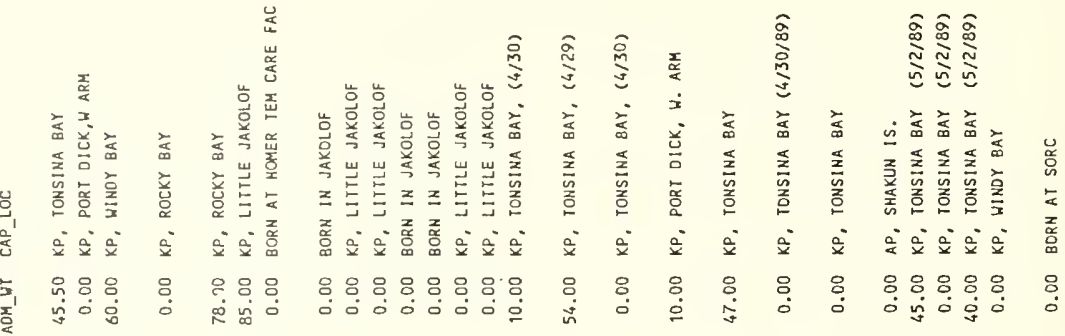

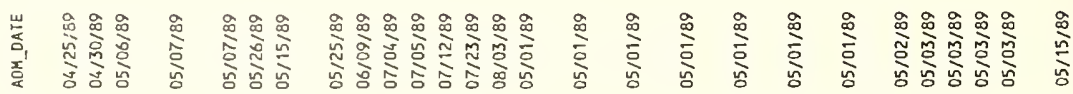

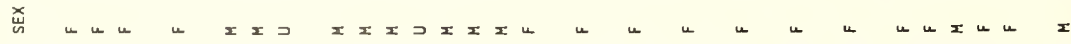

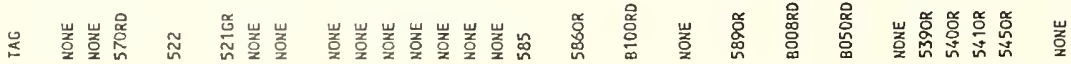

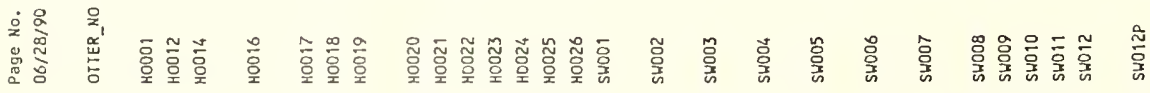




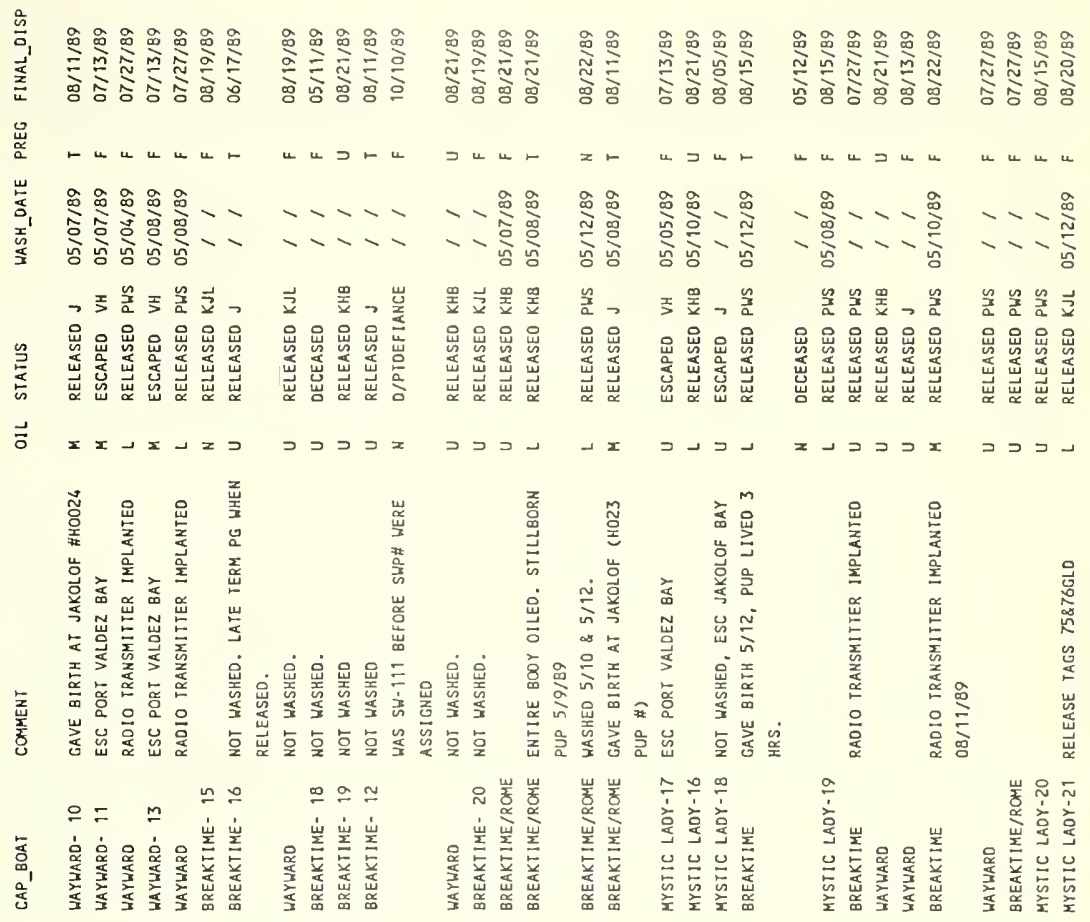

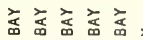

等

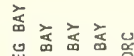

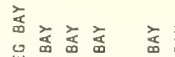

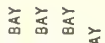

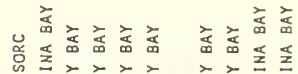

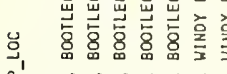
岁毫产 훌

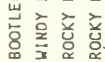

范

我希希

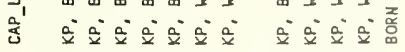

aे aे aे aे

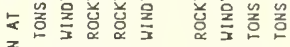

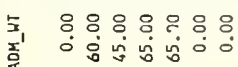

웅ㅇㅇㅇㅠ

888 웅

요

这这

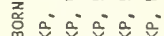

高安

वं जิ

ผ่

8웅요

용요

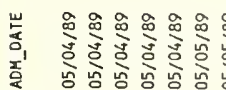

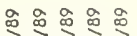

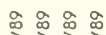

$\stackrel{\infty}{0}$

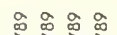

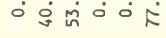

的昆合

觉

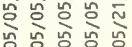

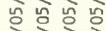

แิ้ ผั

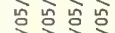

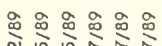

잃 잉

出出望望

资络经

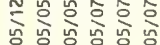

농응잉

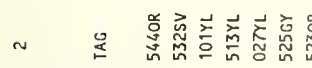

品总哭品宸

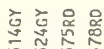

훙

똫

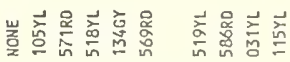

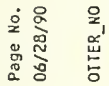

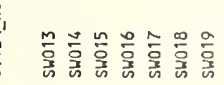

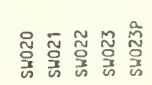

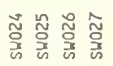

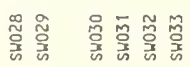

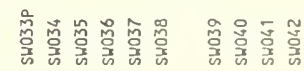




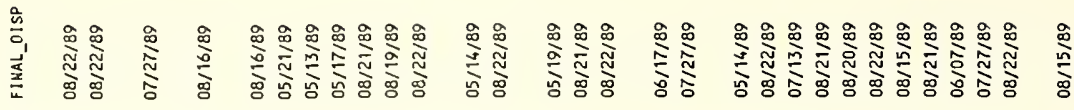

然

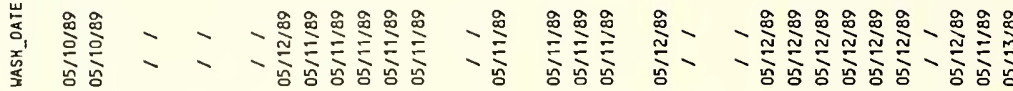

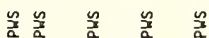

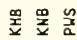

놈

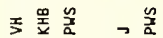

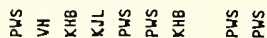

总总

品岕岕

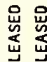

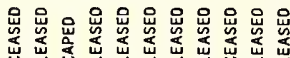

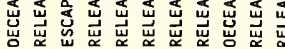

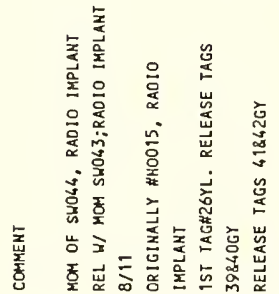

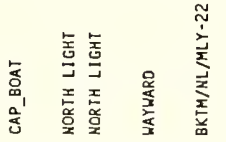

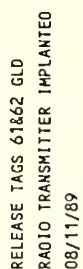

พับ

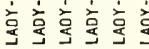

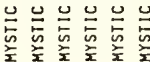

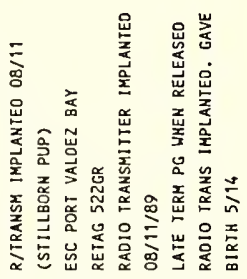

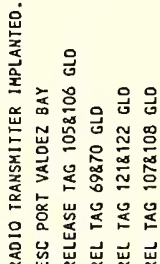

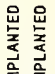

롤 줄

㗊总 훈

品<smiles>[Al]=NC=[W]</smiles>

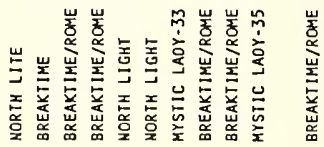

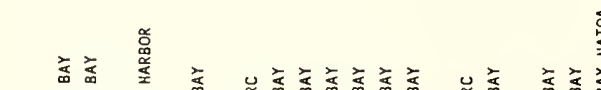

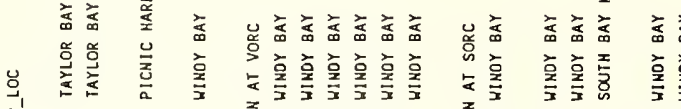

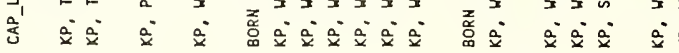

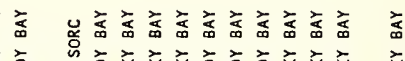

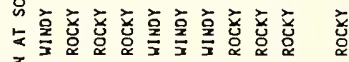

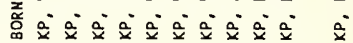

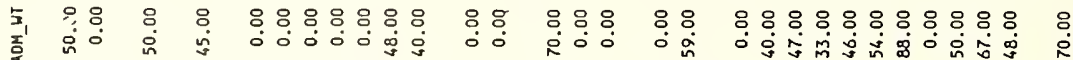
产

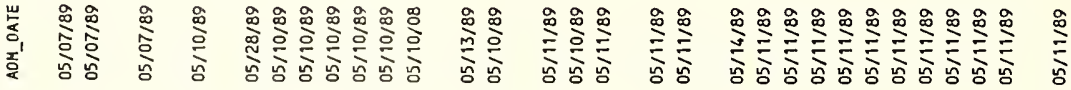

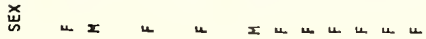

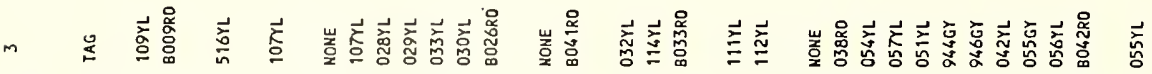

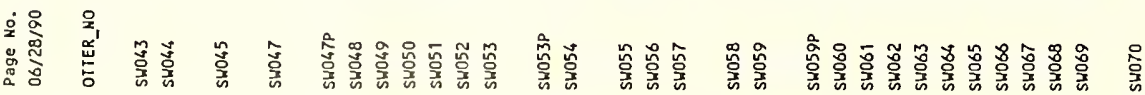




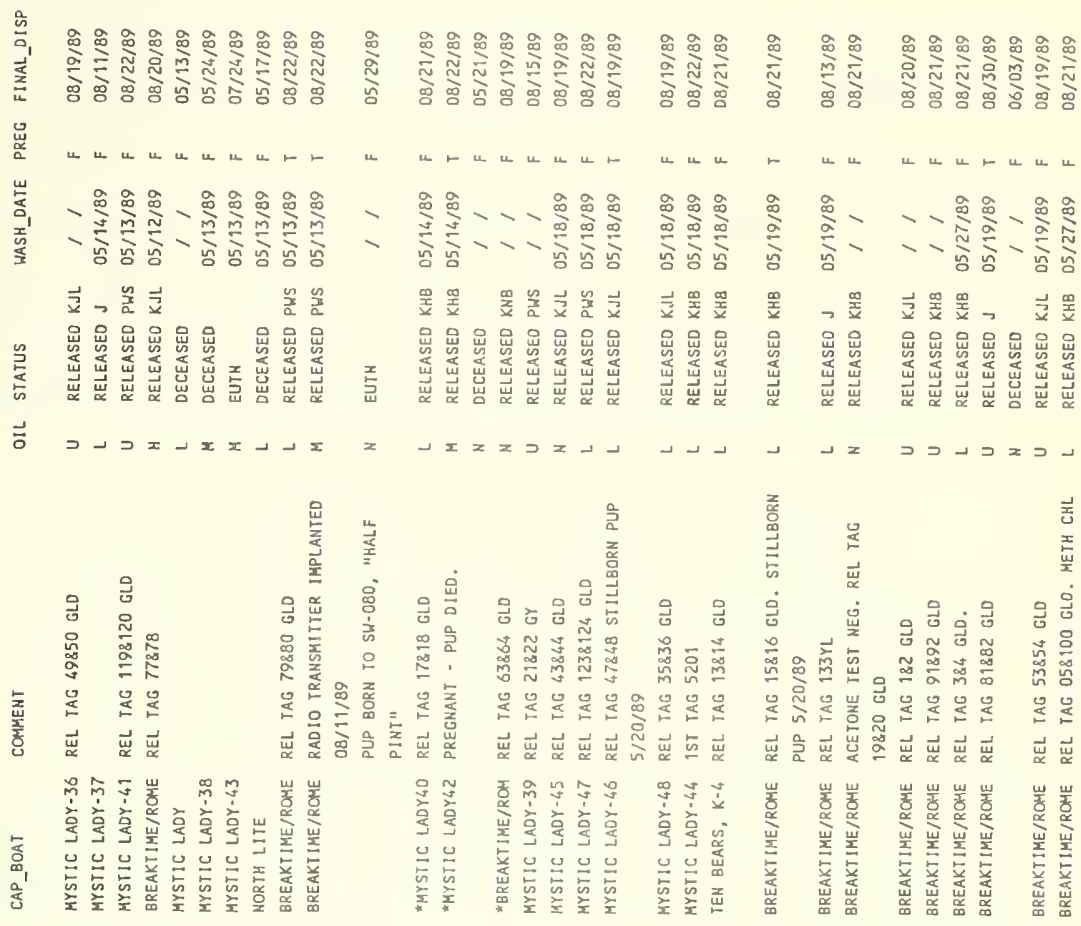




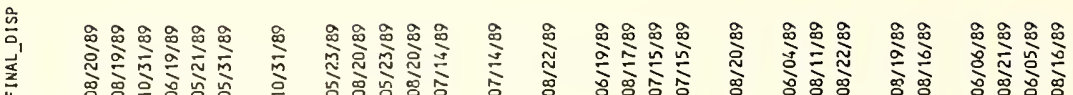

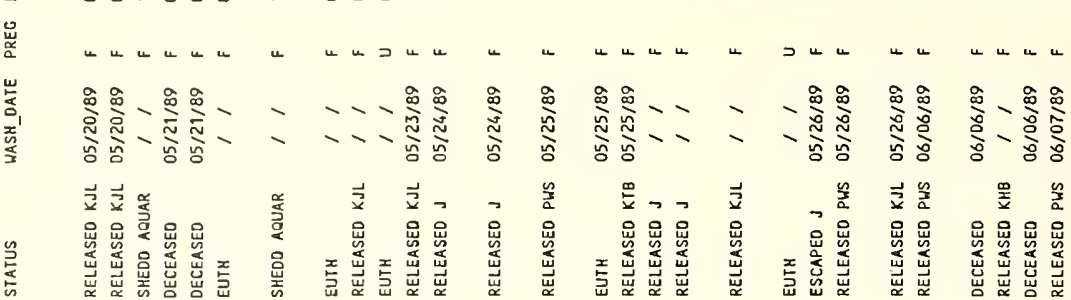

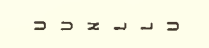

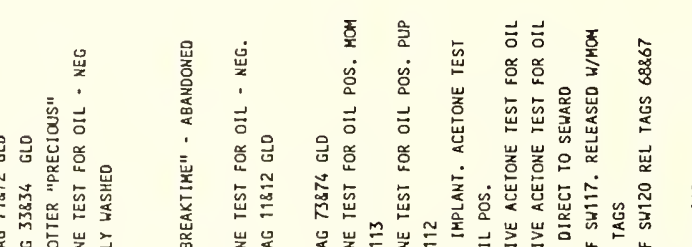

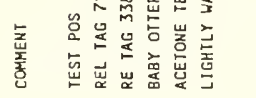

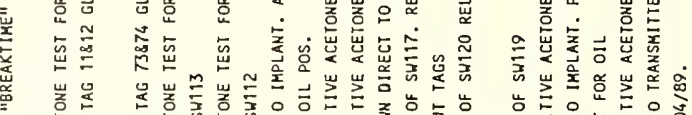

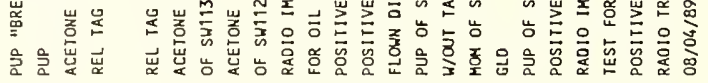

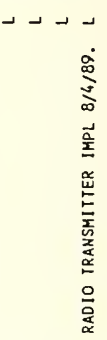

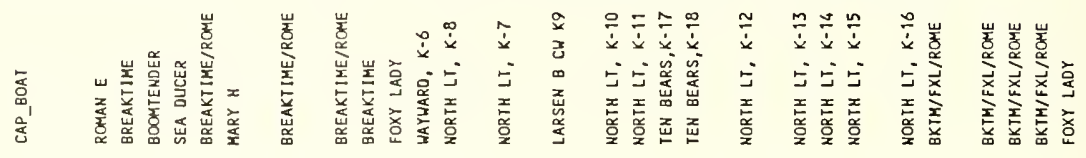

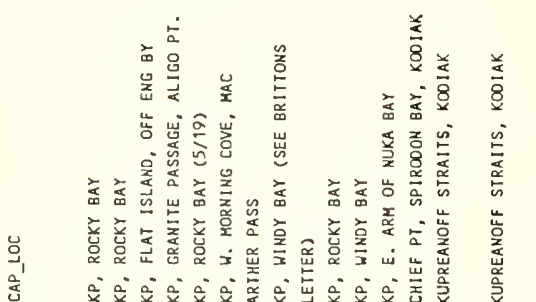

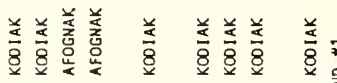

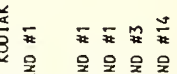

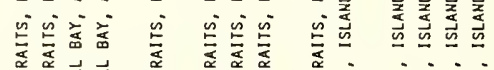

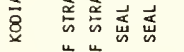

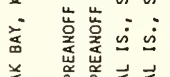

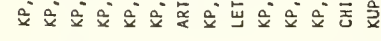

产密跑出

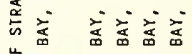

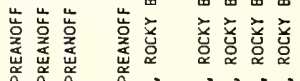

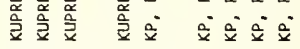

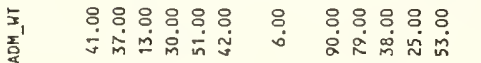

๑. 8

용ㅇㅇ

웅요움

요우

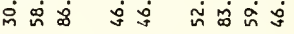

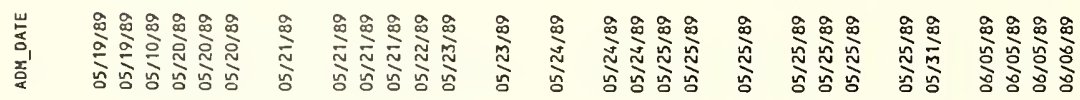
屁

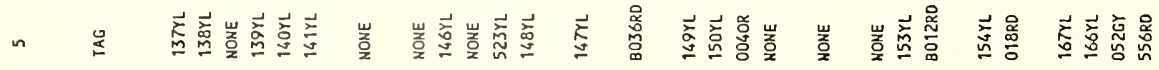

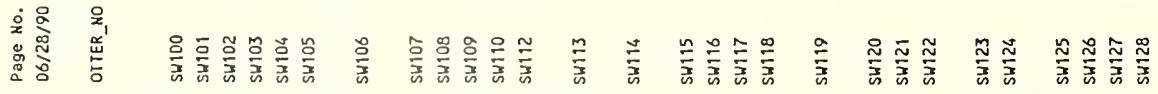




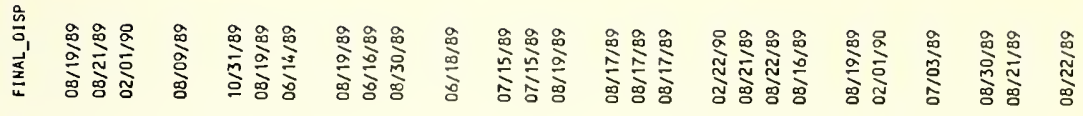

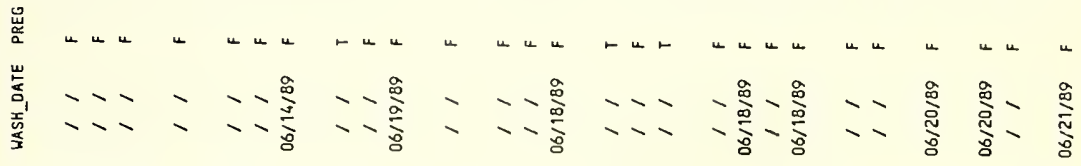

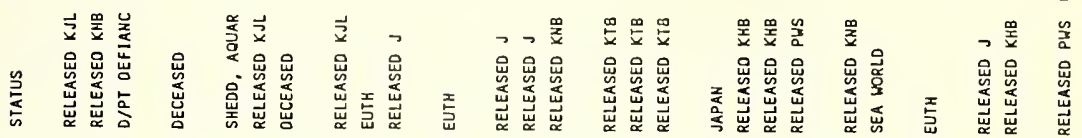
$\vec{\partial}+\supset x=x\lrcorner$

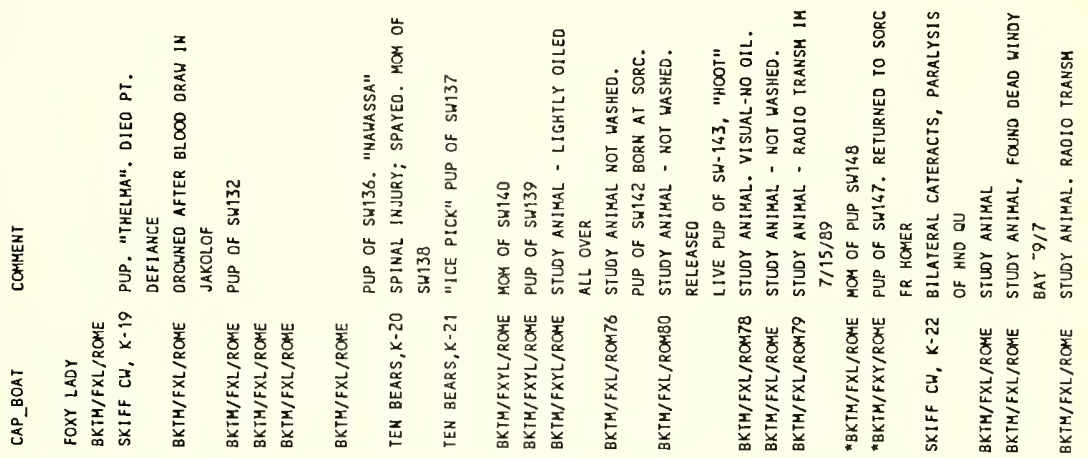

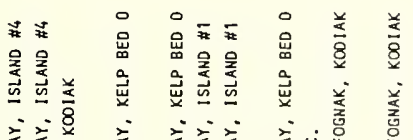

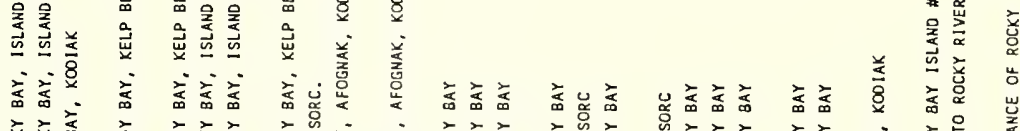

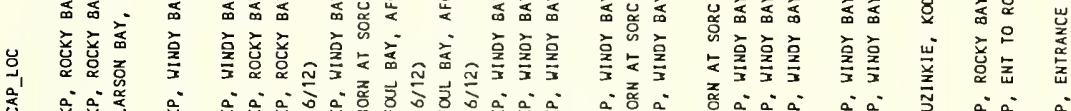

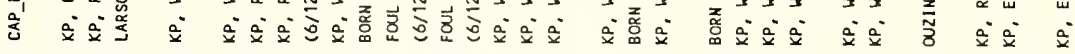

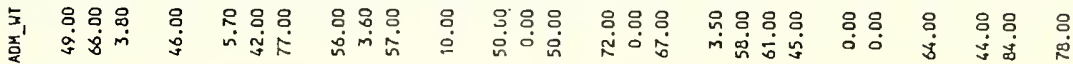

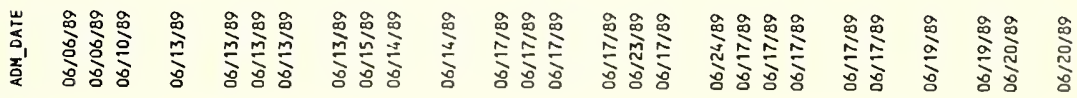

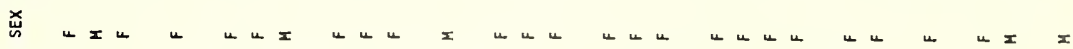

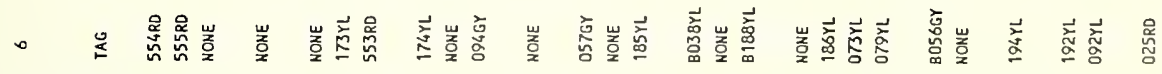
定总䄈 


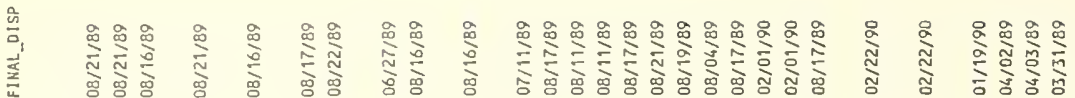
㟒

崖

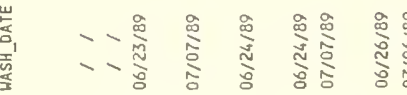

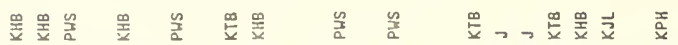

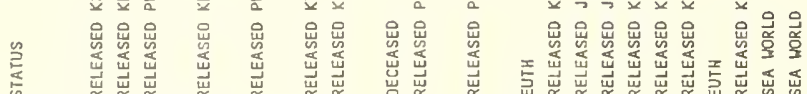

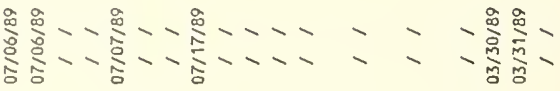

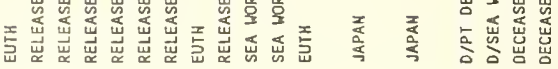
$\vec{a}$

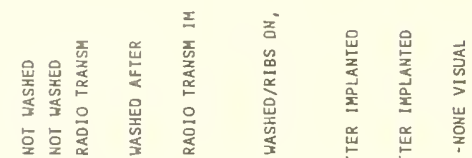

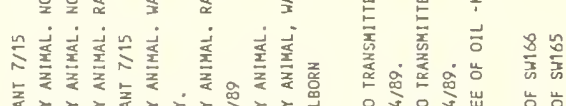

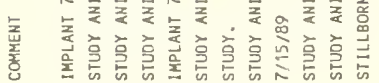

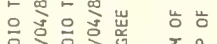

졸 $\frac{a}{a}$

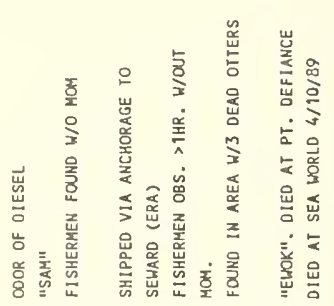

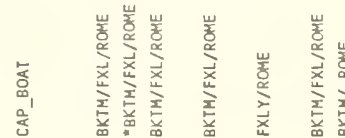

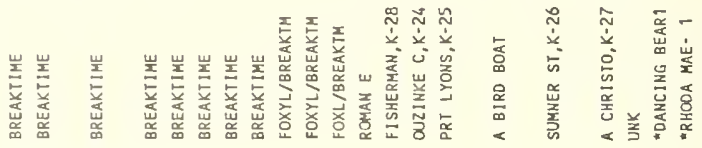

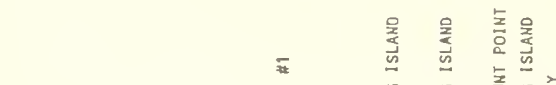

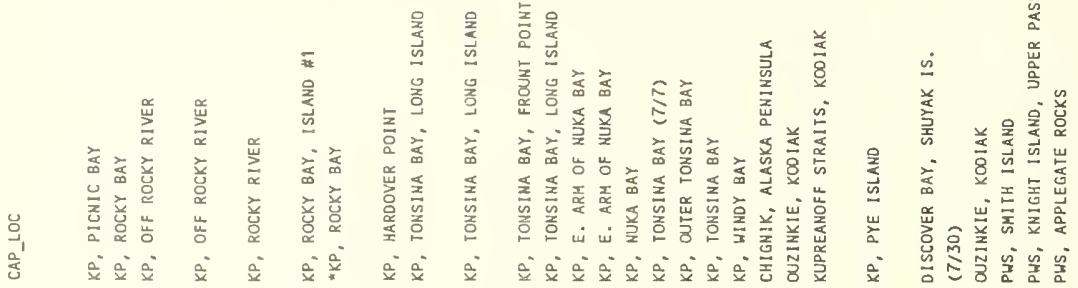

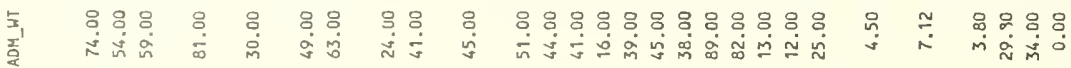

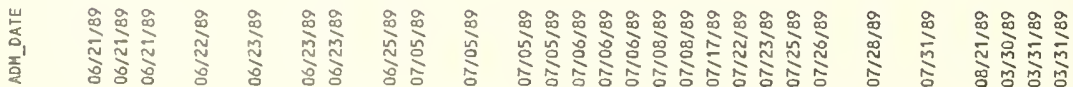

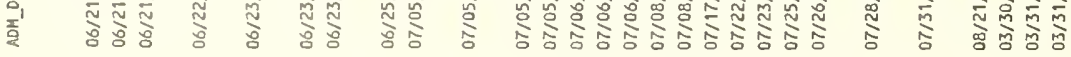
蛋

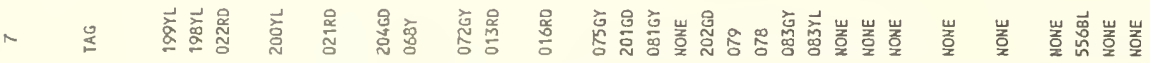

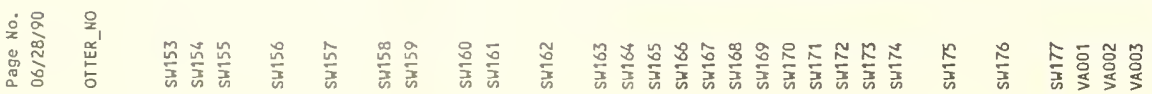




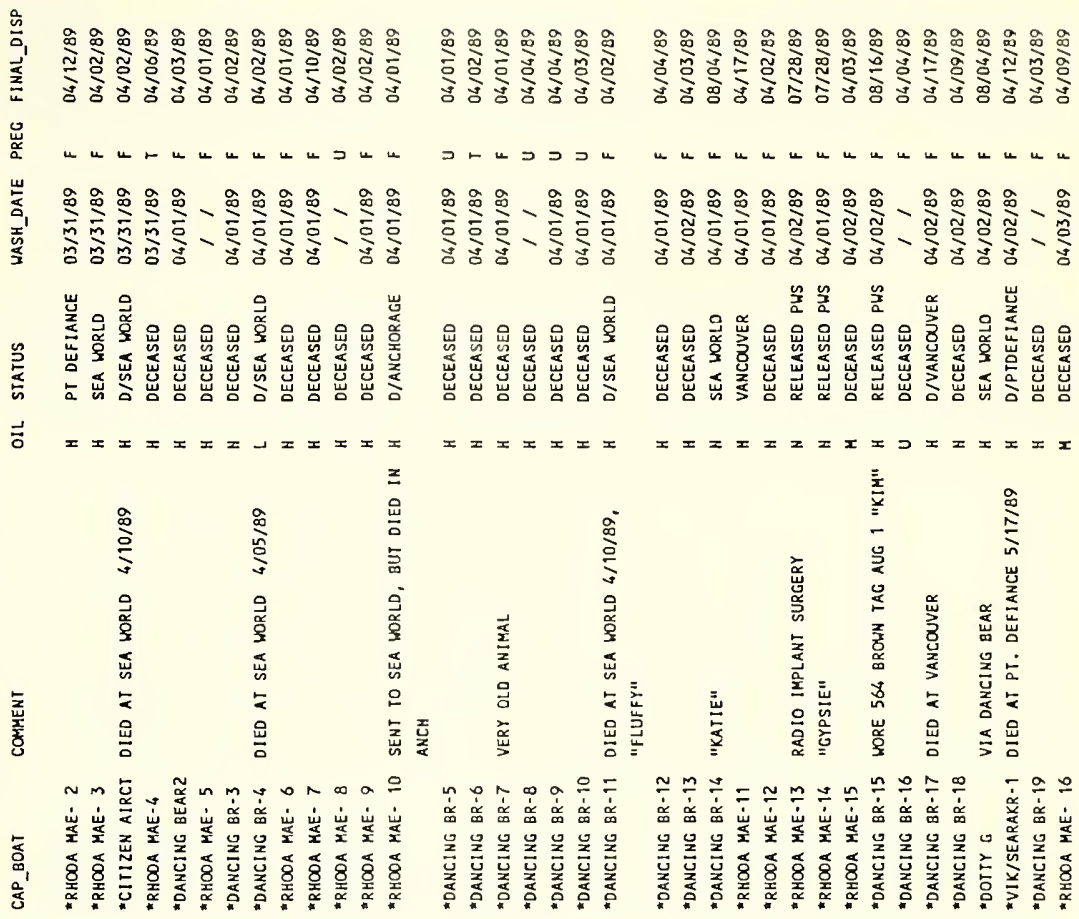

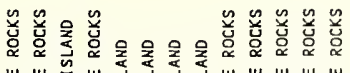

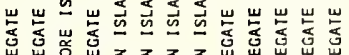

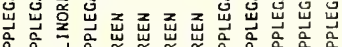

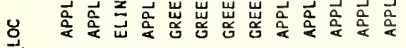

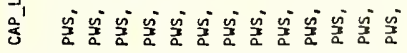

두요

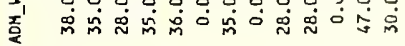

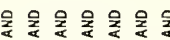

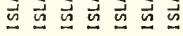

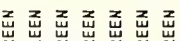

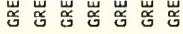

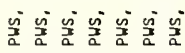

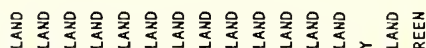

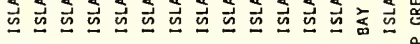

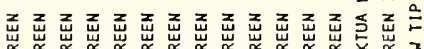

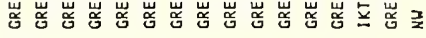

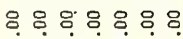

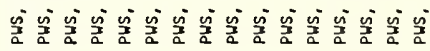
งิ

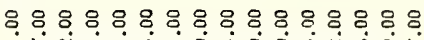

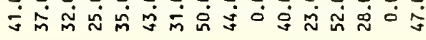

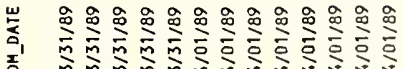

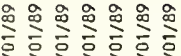

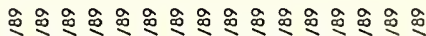

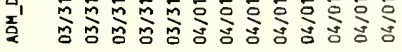

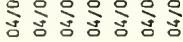

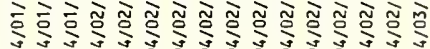
层

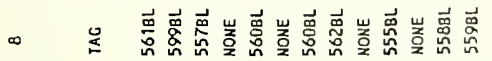

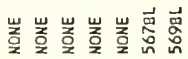

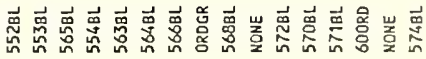




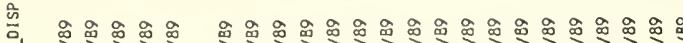

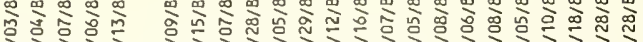

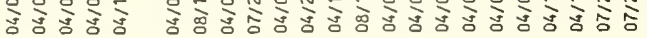

a $a$ a

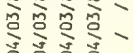

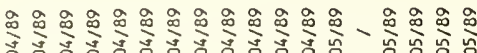

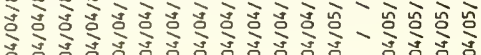

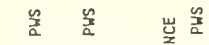

出岕出出亩

$\overrightarrow{0}$

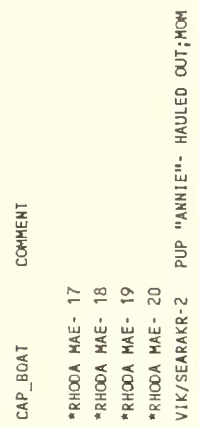

产管

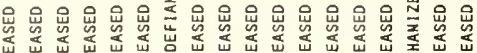

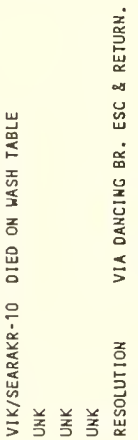

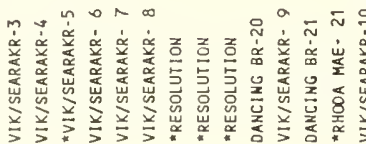

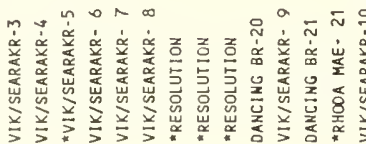

a

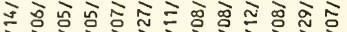

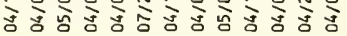

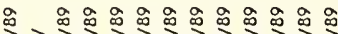

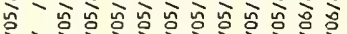

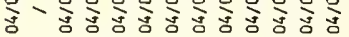

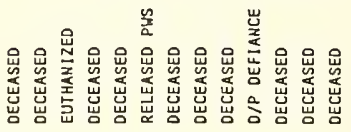
$\supset x x \supset I x I \supset x \supset-H$

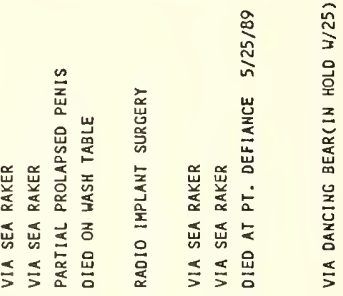

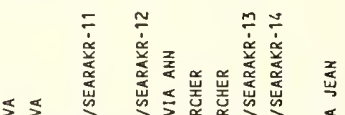

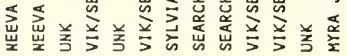

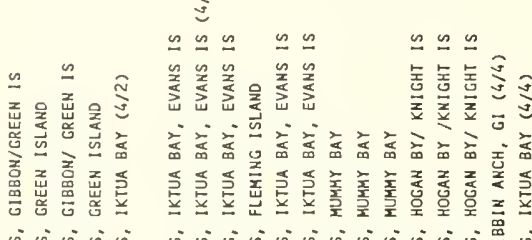

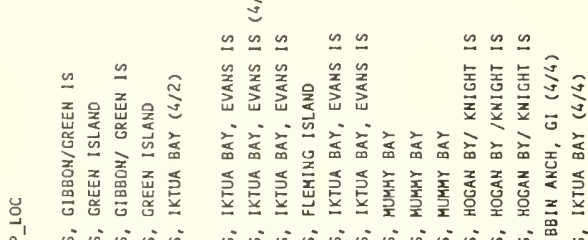
รู่

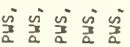

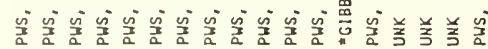

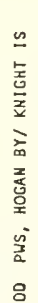

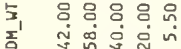

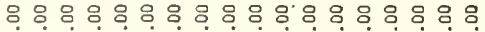

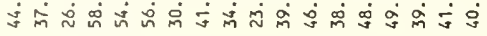

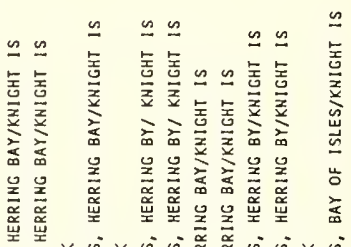

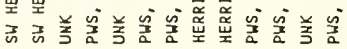

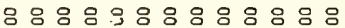

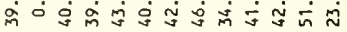

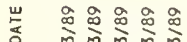

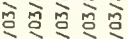

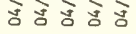

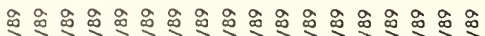

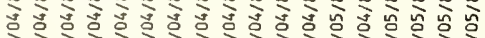

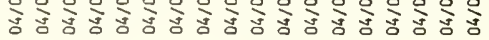

a a a a a a a a a a a

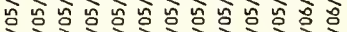

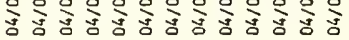
垒

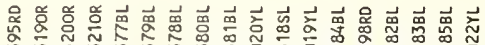

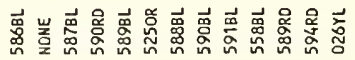

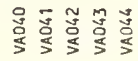

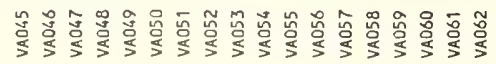

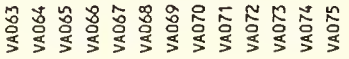




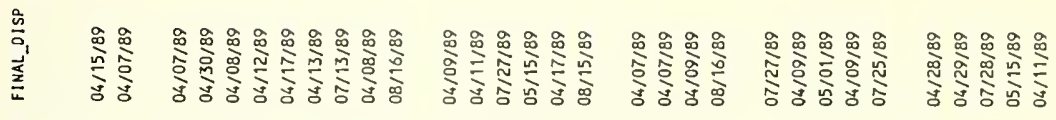

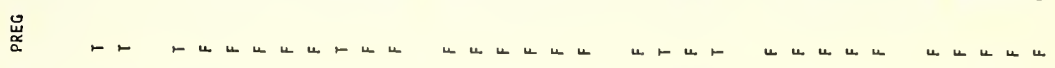

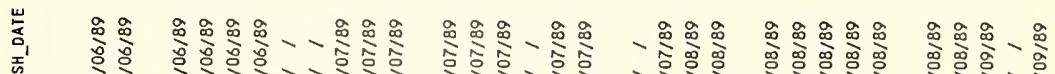

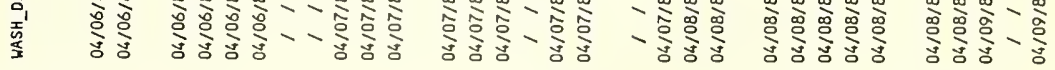

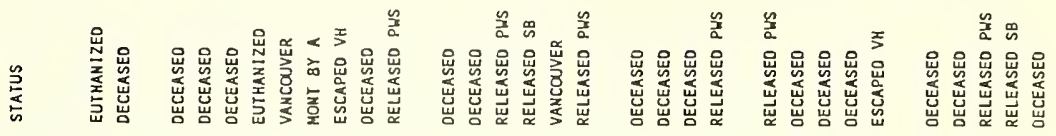
$\bar{\partial}$
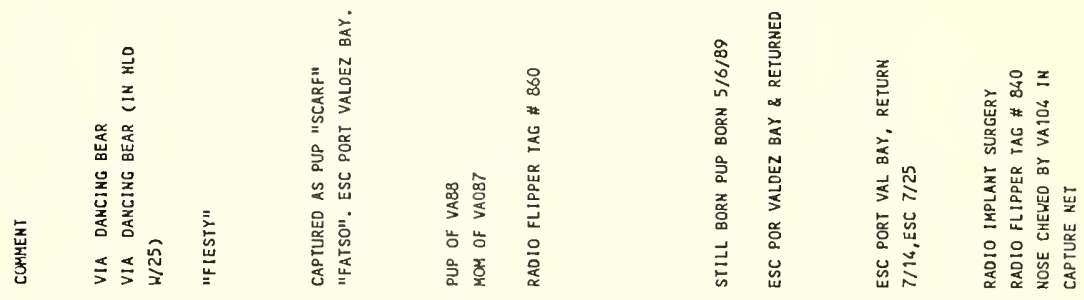

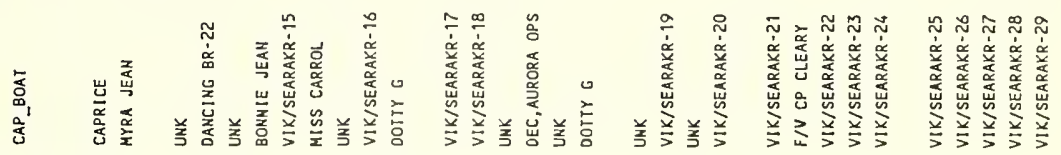

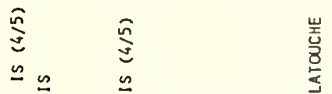

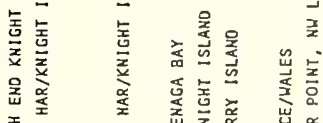

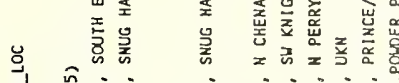

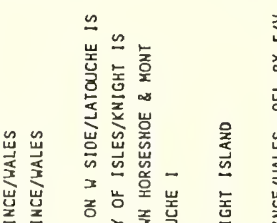

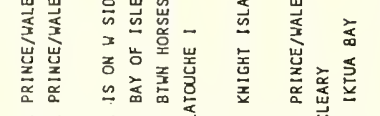

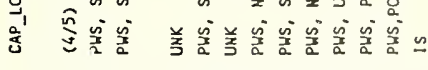

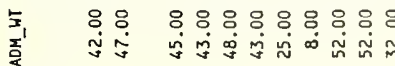

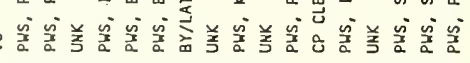

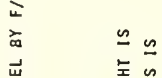

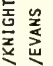

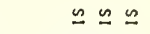

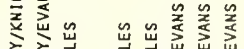

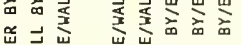

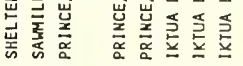

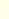

$\omega$
L a

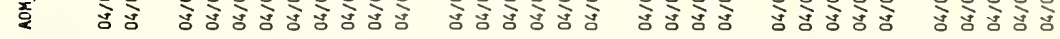

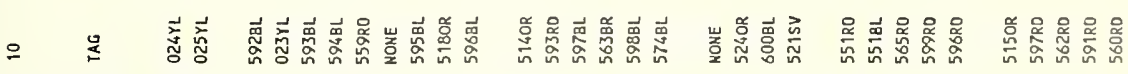

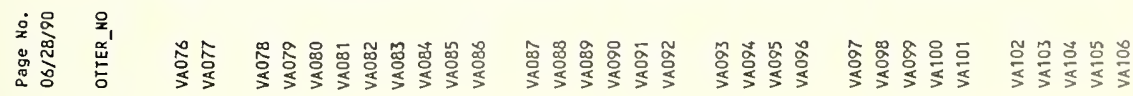




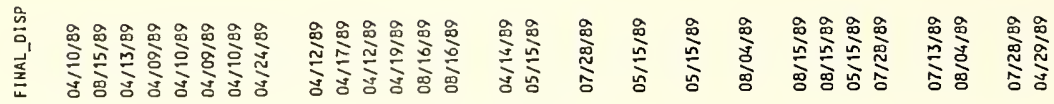
냄

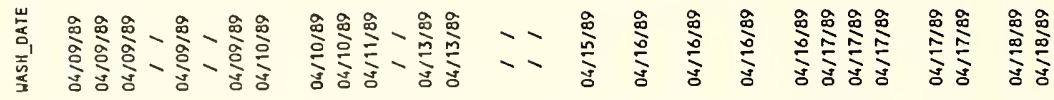

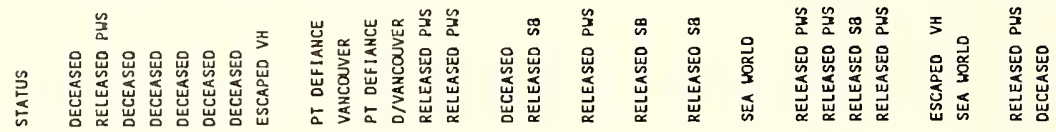
$\bar{z}$
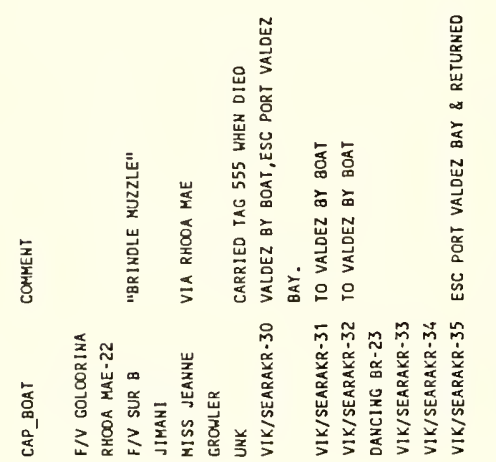

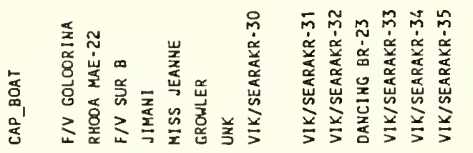

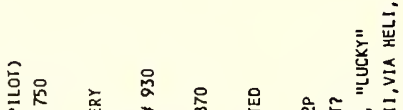

$\lesssim$

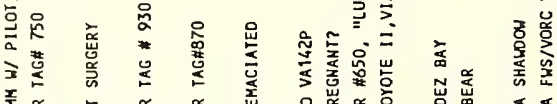

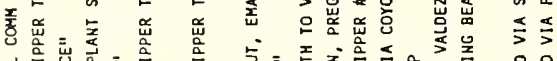

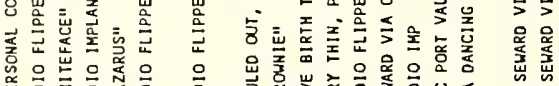

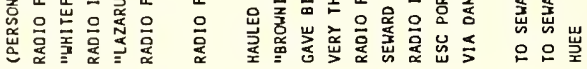

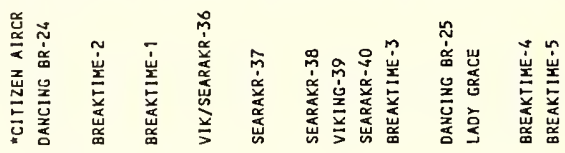

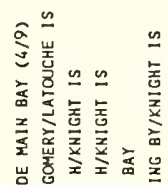

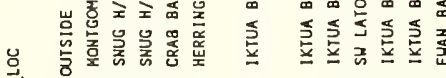

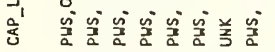

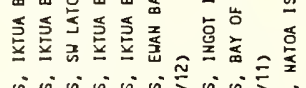

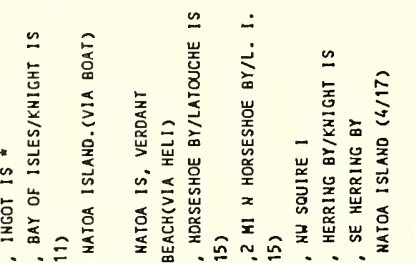

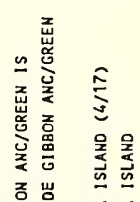

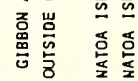

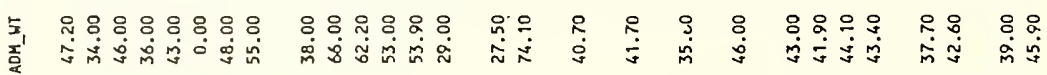

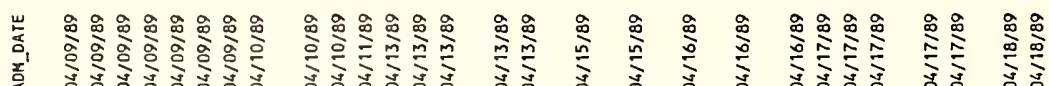
崫

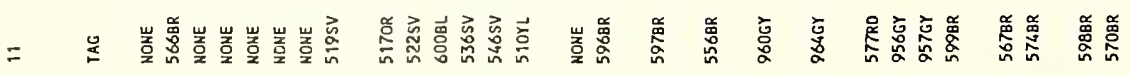

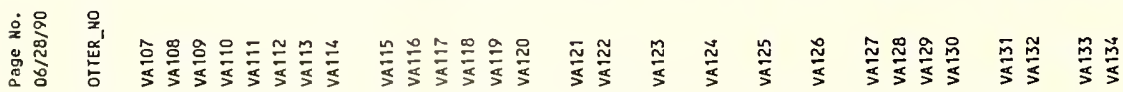




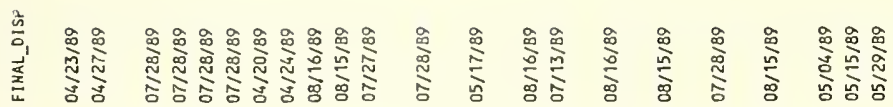

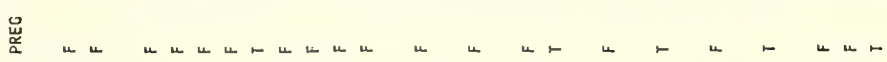

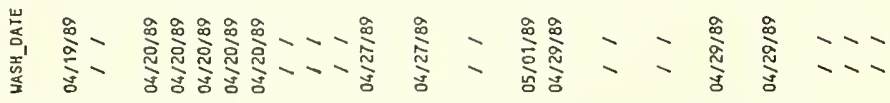

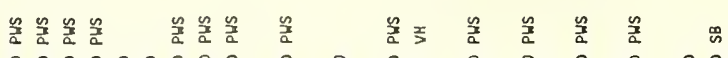

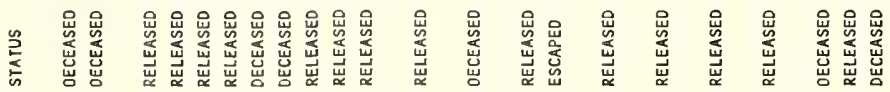

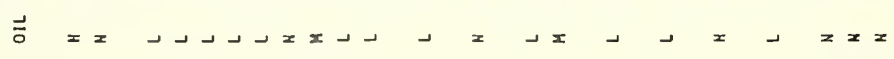

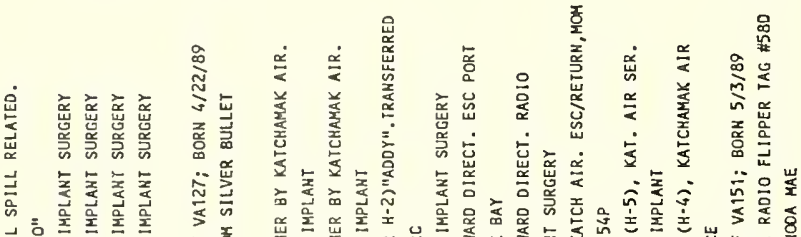

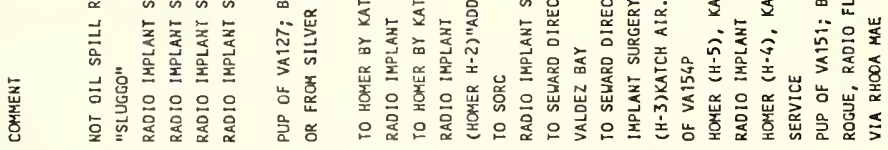

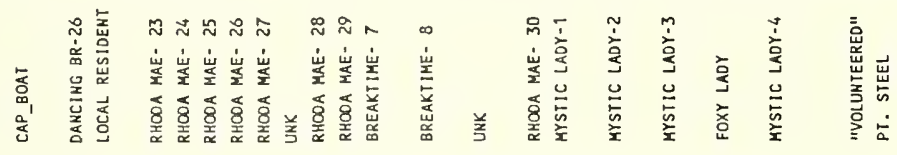

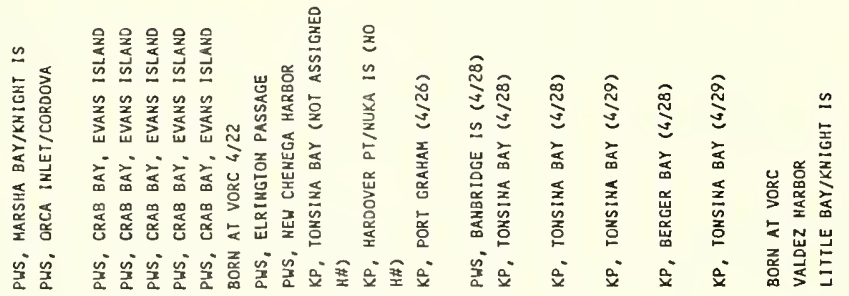

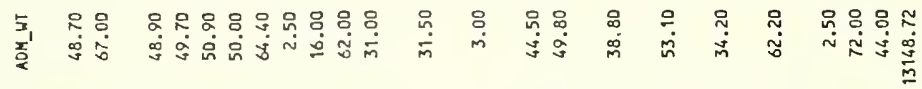

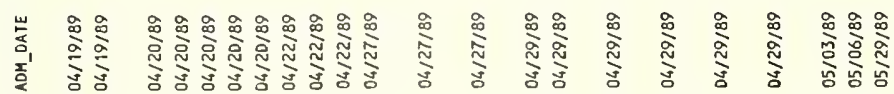

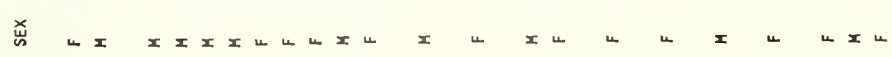

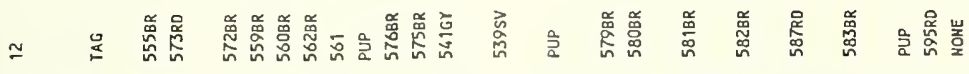

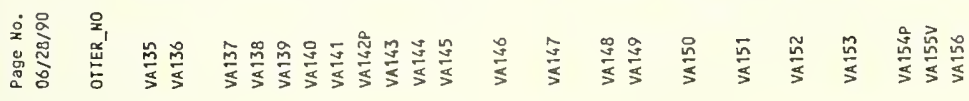




\title{
Coat Gradation and Conditioning of Sea Otters at the Seward Otter Rehabilitation Center
}

\author{
by \\ J. A. Rash, R. Alexander, S. J. Nichol, and D. C. Perrollaz \\ Marine Animal Resource Center \\ 220134 th Avenue West \\ Seattle, Washington 98199
}

and

C. R. McCormick

15536 Husky Street

Eagle River, Alaska 99577

\begin{abstract}
The Seward Otter Rehabilitation Center received more than 150 sea otters (Enhydra lutris) from May to September 1989. During the rehabilitation period, the sea otters proceeded through a series of pool systems. These systems provided an environment for the otters to stimulate their natural oils and recondition their coats before being returned to their natural habitat. We developed criteria to "grade" coat condition and provide valuable behavioral information in relation to coat condition. We found that with a study of grooming behavior, amount of time spent in the water, and a chemical analysis of hair samples, we could correlate the grade of the coat to the degree of oiling. We also show the relation between medical condition and coat condition at specific times during the rehabilitation process.
\end{abstract}

On 24 March 1989, the T/N Exxon Valdez ran aground on Bligh Reef in Prince William Sound, Alaska, spilling more than 11 million gallons of Prudhoe Bay crude oil into the surrounding waters. During the next few months many organisms, including sea otters (Enhydra lutris), were affected. Contamination of the sea otter's pelage by crude oil destroys the integrity of the natural oil coat and its protective air layer and allows water to penetrate to the otter's skin (Davis et al. 1988; K.W. Kenyon, U.S. Fish and Wildlife Service [retired], Seattle, Washington, personal communication). Once the otter feels this effect of coat degradation, it automatically begins to groom in an effort to provide an air layer between the guard hair and skin. As the otter grooms, it not only spreads contamination to other areas of its coat, but also begins ingesting oil, which lessens its chance of survival. Some otters were so affected by the crude oil that they died within days.

Many environmental factors are crucial for the rehabilitation of sea otters after crude oil contamination. Water temperature, humidity of air just above the water, pool space, feeding regime, and haul-out availability play important roles (Gornall 1983; M. Nakajima, Sea Paradise Aquarium, Isu Mitu, Japan, personal communication). The pool system established in Seward, Alaska, made the best use of many of these factors. This system also allowed staff members and volunteers to compile behavioral information about recovering otters. Hair samples from oiled, washed, and unwashed otters were collected for future determination of oil contamination. Behavioral observations and hair 
samples provide valuable information regarding the sea otter's ability to recover from an oil spill.

\section{Methods}

\section{Animals}

One hundred sixty-three sea otters were brought into the Seward Otter Rehabilitation Center (SORC). Upon arrival, they were examined by the veterinary and husbandry staff to determine general health and extent of oil contamination. Three hair samples were obtained from each of 86 otters. These samples were taken from the neck, xiphoid, and hip regions. Each otter was then tagged and placed in a slide-top cage to await further evaluation.

Otters of all ages and both sexes were brought into the center. In the study group there were 137 female and 39 male adults. The rehabilitation center also treated 14 otter pups, 4 of which were born at the center.

\section{Pool System Design}

Otter behavior was observed during confinement in a five-stage pool system at SORC:

(1) intensive care unit-directly after admitting or washing,

(2) single haul-out tote $(1.2 \times 1.2 \times 0.6 \mathrm{~m})$,

(3) double haul-out tote $(1.2 \times 1.2 \times 0.6 \mathrm{~m})$,

(4) large pool with a haul-out area $(3.4 \times 1.5 \mathrm{~m})$, and

(5) pond facility with haul-out $(3.7 \times 2.4 \times 4.3 \mathrm{~m})$.

Each of these pool stages had varying water capacity and allowed the staff and volunteers to closely monitor the otters. These stages also provided a flow system corresponding to the individual otter's behavior. The intensive care unit allowed recovery from anesthetic without access to water. The single haul-out tote allowed observation of the beginning of coat recovery, even though this type of tote did not promote normal grooming behavior (Gornall 1983). The otters were allowed access to haul-out areas and circulating salt water $24 \mathrm{~h}$ a day, but were indoors because monitoring of health status was top priority at this stage. The double haul-out tote provided exposure to the outdoors and to other otters and allowed a more intensive study of grooming and coat condition. Neither of the above systems provided sufficient depth or proper humidity of air above the water surface. Otters were placed in pools according to behavior, health status, and coat condition. The pond stage provided greater depth and lower humidity in the air above the water surface, both of which are essential to otter coat recovery (Gornall 1983).

\section{Behavioral Observations}

The behavior of each otter was recorded at 15 min intervals for $18 \mathrm{~h}$ per day. These observations were used to determine the percentage of time spent autogrooming (self-grooming), allogrooming (grooming another otter), swimming, diving, nursing, resting, and sleeping. Behavioral observations for several individual otters are shown in Appendixes A-F. Behavior was divided into "in water" and "hauled out". The sum of percentages of time spent in each behavior equals $100 \%$. Behaviors such as net biting (related to stress), shivering, and aggression were also recorded in a written comments section of each animal's chart (Appendix G).

\section{Grooming Gradation}

The following gradations are specific for SORC. These gradations were developed during 1982 and 1983 in conjunction with sea otter captures in Cordova, Alaska (Nakajima, personal communication). Percentages for grooming behaviors differ for captive and wild otters (Packard and Ribic 1982).

Otters were assigned a grooming grade of 1 (poor), 2 (average), or 3 (good) based on the following criteria:

(1) Poor grooming-The otter grooms less than $15 \%$ of the day. When an otter grooms on the haul-out area, it concentrates on the muzzle, face, and neck region. If in the water, the otter grooms only the face, slowly, with no pinwheeling (lateral roll) or augering (anterior or poste. rior roll);

(2) Average grooming-The otter grooms 15-25\% of the day. The animal starts to groom chest and shoulder area. When on the haul-out area, the otter grooms chest and arm by blowing air into that region. If in the water, the animal shows vigorous grooming behavior by augering, then pinwheeling and blowing air into the chest; and

(3) Good grooming-The otter grooms $25-60 \%$ of the day. It grooms the hindquarters and back area and when hauled out, it grooms its entire body. Coat hairs spike or point over entire body (depending if otter is wet or dry). When in the water, the otter vigorously grooms its back by periscoping (vertical axial roll) and pinwheel- 
ing. Vigorous swimming and augering also occur.

\section{Coat Gradation}

Otters were assigned a coat grade of 1 (poor), 2 (average), or 3 (good) based on the following criteria:

(1) Poor coat-Wet coat guard hairs only point from the head to the base of the neck. The coat on the rest of the body is matted and damp. The coat stays damp for more than $\mathbf{4 5} \mathrm{min}$ when otter is hauled out. When the otter is swimming, no beading or rolling of water occur on any portion of the coat below the base of the neck;

(2) Average coat-Wet coat guard hairs only point from the head to mid-back and mid-abdominal regions. The dry coat spikes at $40^{\circ}$. Coat lofts in spiked areas because of the presence of an air layer. When the otter is swimming, the water rolls and beads off the otter's coat in the pointed areas; and

(3) Good coat-Entire coat points when the otter shakes after getting out of the water. When dry, the coat spikes at $75-90^{\circ}$ angles and entire coat lofts. Coat dries in 10-20 min. When the otter is grooming and swimming, water rolls off the entire coat. When sleeping in the water, the otter is floating $50 \%$ above the waterline. The otter is able to roll horizontally and keep front paws, hind legs, and tail out of the water.

\section{Movement Through Pool System}

To ensure consistent grading of otters in the rehabilitation center, we conducted a seminar for the administrative, veterinary, and husbandry staffs. Supervisors were required to submit daily reports on each animal. Otters then moved through the pool system based on these daily reports (Appendix $\mathrm{H}$ ).

Veterinary reports were also considered in the progression or regression of otters through the pool system. Weight gain or loss, medication, blood chemistry, and injury were among the variables monitored during the rehabilitation process.

\section{Results}

\section{Time Budgets}

More than $20,000 \mathrm{~h}$ of behavioral observations were tabulated about 117 otters between 15 June and 15 August 1989. Behavior varied from otter to otter and showed individual patterns (Figure). A final average of the group behavior cannot be accurately determined and is best reported as a range (Table.)

\section{Allogrooming}

During the observation period, four motherpup pairs were at the center. Allogrooming occurred between mother and pup $95 \%$ of the total time observed. The remaining $5 \%$ of the allogrooming budget occurred between bonded otter pairs. These otters remained in the same pools throughout their rehabilitation. Because many of the otters were moved quickly through the pool system, bonding was infrequent. An example of the occurrence of allogrooming as it related to coat and grooming grade is shown in Appendix A.

\section{Autogrooming}

The highest percentage of autogrooming took place in the early stages of coat rehabilitation, decreasing as coat condition improved (Figure). The majority of the otters were in circulating saltwater pools within $48 \mathrm{~h}$ of washing and complete drying. Autogrooming occurred more frequently in the SORC otters than in other captive or wild populations (Table). The high incidence of autogrooming was an integral part of the recovery process of the damaged coat and allowed almost immediate stimulation of natural oil secretion to begin coat recovery (Appendix B).

\section{Swimming}

Swimming behavior was not observed until otters reached the pool and pond stage. Single and double haul-out totes did not allow the otter adequate space to swim. Swimming primarily took place after feeding and as part of grooming (Appendix C).

\section{Diving}

Diving was observed directly after feeding at the pond stage. The depth of the pond $(4.3 \mathrm{~m})$ allowed otters to dive for food on the pool bottom and provided air pressure to compress and expand the air layer between coat and skin to aid grooming (Appendixes C and D).

\section{Eating}

Feeding schedules were set to give otters the optimal amount of caloric intake during early 

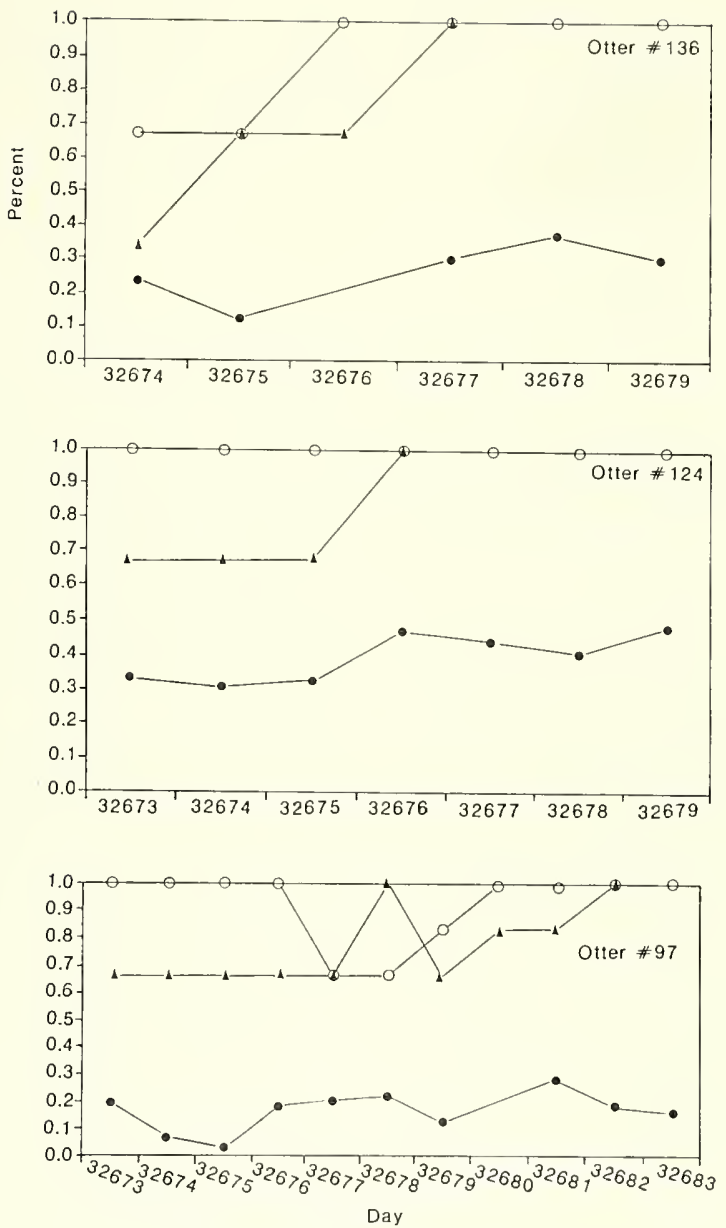

-Autogroom \Coat grade OGroom grade

Figure. Behavior versus coat and groom grades. 
Table. Comparison of otter behavior ranges at the Seward Otter Rehabilitation Center with captive and wild behavior average percentages.

\begin{tabular}{llccc}
\hline & $\begin{array}{c}\text { In Water } \\
\text { (Seward) }\end{array}$ & $\begin{array}{c}\text { Out of Water } \\
\text { (Seward) }\end{array}$ & $\begin{array}{c}\text { Captive } \\
\text { (Rash, personal } \\
\text { observations, 1987) }\end{array}$ & $\begin{array}{c}\text { Wild } \\
\text { (Estes 1982) }\end{array}$ \\
\hline Allogroom & $0.0-41.4 \%$ & $0.0-27.1 \%$ & $0.05 \%$ & - \\
Autogroom & $0.0-76.0$ & $0.0-68.3$ & 26.0 & $11.35 \%$ \\
Swim & $0.0-41.7$ & - & 30.3 & - \\
Dive & $0.0-38.3$ & - & 22.9 & - \\
Eat & $0.0-41.7$ & $0.0-25.0$ & 4.05 & 33.3 \\
Rest & $0.0-41.7$ & $0.0-63.3$ & 2.1 & 44.5 \\
Sleep & $0.0-46.6$ & $0.0-63.3$ & 10.0 & - \\
\hline
\end{tabular}

stages of coat recovery. As health and coat condition improved, food intake decreased. The primary foods given included squid, whitefish, pollack, clams, and crab. Most of the food offered was not ingested during the initial rehabilitation period.

\section{Coat and Grooming Gradation}

Coat and grooming grades were taken independent of behavioral observations. Husbandry volunteers recorded behavior, and husbandry supervisors evaluated coat and grooming grades.

Coat and grooming grades usually improved simultaneously (Figure). Coat condition depended on time spent grooming, along with area groomed. The more time an otter spent grooming, the more quickly the coat returned to its precontaminated condition (Figure).

The grade system gave the staff a quantifiable indication of the otter's overall condition. The grade also provided a way to evaluate coat condition and initiate movement through the pool system (Appendix E). The coat and grooming grade allowed for determination of when the animal could be transferred to the prerelease facility near Homer, Alaska.

\section{Discussion}

Each of the recorded and tabulated behaviors is important to the otter's general health. Autogrooming and sleeping, both in and out of water, were chosen as the best correlates of the progression of coat rehabilitation from oil damage. Autogrooming is vital to the recovery of an otter's pelage after oil contamination. This behavior helps provide an air layer near the skin to insulate the otter.
Sleeping behavior was another indicator of the progress of the air layer in the otter's pelage. Our data show that high percentages of autogrooming were associated with increased sleeping in the water. A larger surface area of coat protected by an air layer increases the time the otter spends in the water. The percentage of time spent autogrooming and sleeping was positively correlated with an improvement in coat grade and grooming behavior (Appendix F).

During the compilation of behavioral data at SORC, many variables existed that caused unusual behavior in the otters. The main body of data must be interpreted as a special situation and not normalized to otter behavior in wild or captive populations. Factors such as the amount of oiling, capture, water quality at the center, human influence, weather, and medical variables all contributed to the otter's initial behavior and subsequent rehabilitation. The coat grade and grooming behavior observations were key to understanding the otter's behavior and coat progression during rehabilitation.

The gradation system was introduced as a means of quantifying both grooming and coat condition. This system was first used to determine the behavior and overall health of the otters captured in Prince William Sound for transport to Japanese aquariums in 1983. During the transport, an increased water temperature caused sea otter coat degradation (Rash, personal observation). The gradation system was established at Valdez Otter Rehabilitation Center between 7 April and 1 May 1989. Implementation proved difficult because of a lack of organization, materials, a proper pool system, and failure to follow established protocol. The Seward Center implemented the system on 
15 May 1989 after 2 weeks of trial observations by staff members.

The pool system was established to allow the otters to flow through subsequent pool stages as their condition improved. Both coat and grooming gradations were used to determine progression through the system. The grading was specific to SORC. Each otter was considered as an individual case, not as part of a whole. Each grade had specific behavioral and physical criteria. As the behavioral observations were compiled on forms (Appendix G), patterns could be seen for each otter at any time.

The veterinary and husbandry staffs were the most familiar with the otters and were trained to detect problems. Any sign of stress or need for medical attention was quickly evaluated by the staff member in charge of each otter. A pattern of rehabilitative grooming in salt water became evident: The otter would begin at the top of its head and within 6 days would complete the rehabilitative process by grooming at the base of its tail. A recovery time of 3-7 days was necessary for a washed otter to recover its natural oils. Most washed otters developed a grade 3 coat within 7 days. During the initial 2 days, grooming behavior was observed $50-73 \%$ of the day. Grooming decreased to $17-20 \%$ once grade 3 was achieved. Otters that were not washed developed a grade 3 coat within 4 days. At that time, grooming behavior was observed $20 \%$ of the day, the otters were eating $10-13 \%$ of their weight each day, and they were in the pool or duck pond. The otter's sleeping time in the water increased as the coat improved. An otter in the first stages of coat recovery would not sleep in the water. Low metabolic energy is expended during sleep (Costa 1985), and an otter relies on air insulation to stay warm during sleeping periods. Sleeping time in the water increased as the otter's insulatory integrity improved simultaneously with coat condition.

Several variables influenced the reported recovery of coat grade. First, the assessment of oiling was made subjectively and without comparison standards. No quantitative test existed for measuring the degree of oil on the otter pelage, and inconsistent assessments of oiling by each staff member were possible. The time between washing and release are not as significant without an accurate measure of how much oil (and coat) damage actually occurred. Oil measurements also depend on location of hair sample, physiology of the hair, and behavior of the otter (Perrollaz and Rash, unpublished report). A method to provide a quick and accurate field assessment of pelage oiling is being developed by D. Perrollaz at the Marine Animal Resource Center in Seattle, Washington.

Second, the otters entered the pool system protocol under different circumstances. Some otters were washed, and others entered the system without initial washing. Progression through the pool system was influenced by coat and grooming grade as well as individual health needs such as preg. nancy and age (i.e., pups). Variations in behavior cannot be compared statistically because of the lack of a common baseline. Each individual otter must serve as its own control.

Third, grooming grades often changed in opposite or disproportional directions relative to coat grade. Each grade was recorded separately, and variations in grooming grade were observed in most otters on a day-to-day basis. Supervisors were trained to grade the otter's grooming behavior, but initially there was no quantifiable system to determine the percentage of time the otter spent grooming. Between 15 May and 15 June, the progression of otter grooming behavior was determined by written reports from staff and personal observation.

The principal needs for sea otter coat conditioning are cold, circulating salt water, and a low percentage of humidity directly above the water's surface (Gornall 1983). Limited tote size did not provide adequate space for proper grooming behavior. The tote was supplied with cold, circulating salt water, but depth and humidity were not always adequate. The main benefit of totes was to encourage autogrooming, decrease overheating, and relieve stress problems. The humidity above each section of the pool system fluctuated with the ambient temperature because $85 \%$ of the rehabilitation pools were outdoors. Humidity above single and double haul-out totes was higher $(85 \%)$ than humidity above the pools and pond (50\%) during the warm summer months. The tote humidity factor could be avoided by placing the otters directly into pool or pond systems.

The behavioral patterns and rehabilitation of SORC otters are unique to oil-affected otters. $\mathrm{Ob}$ servations have been made on both captive (Rash, personal observations) and wild otters (Kenyon, personal observations), although these reports are clearly not comparable with the situation at SORC. Both the number of otters observed and the environments that the otters occupied are markedly different. Each SORC otter must be looked at individually. The health, age, sex, degree of oiling, and capture status all played vital roles in rehabilitation. If otters need to be rehabilitated again in 
Prince William Sound, these observations can be used as baseline behavioral patterns. Direct comparison with otters in an oil spill elsewhere (e.g., California) would be inappropriate because of different environmental conditions.

Field observations should be made on all otters, especially those released from rehabilitation centers. This information could be used to evaluate the progression of rehabilitation and assess whether otters were returning to their precontamination status. We could then incorporate changes to improve the rehabilitation protocol (see Monnett et al. 1990).

\section{Recommendations}

Although SORC was hastily established during an emergency, it exceeded many expectations. The working relationships among staff members were exceptional, and morale was high. However, several changes could easily be made to improve the system and the subsequent process of sea otter rehabilitation. These changes include:

1. A field test should be developed for measurement of oil contamination. No accurate or reliable field test exists to measure the amount of crude oil on otter pelage. Such a test, combined with benthic sampling, water column testing, and careful monitoring of tagged otters and their food source, would allow an easier assessment of oil damage and improve the rate of otter recovery.

2. Rehabilitation pools should be enlarged. A deeper pool would stimulate coat recovery because of water pressure working to enhance air layer development in the pelage. Grooming increases in deeper, larger pools as well. If health permits, the otter should be placed either in a pool or pond immediately after washing and drying.

3. Tabulation of daily behavior reports should be expedited. Rapid tabulation of behavioral observations would allow a more complete description of overall otter condition. This system would allow staff members to evaluate patterns in otter behavior and detect problems earlier.

4. Stress factors should be reduced. Capture, transport, and medical examinations are stressors that cannot be completely alleviated. Human contact, handling, noise, and disruptive feeding regimes at the rehabilitation centers are factors that can be reduced. Human contact and handling could be reduced by decreasing the stages the otter must move through. The otters should be fed on demand once their coat condition improves.

5. Mother-pup recovery should be improved. Separate pools for pregnant females and motherpup pairs should be considered. Efforts should be made to immediately introduce orphaned pups to another female or surrogate mother. A reintroduction program would increase the chance that Prince William Sound otters would reestablish themselves in their native environment and decrease the stress encountered in finding a new home environment for the otter. The transport and subsequent care of orphaned otter pups taken to aquariums to await placement in new homes must be supervised by personnel knowledgeable in otter health care. The rehabilitation of Exxon Valdez oil-affected otter pups at Point Defiance Aquarium in Tacoma, Washington, lacked staff trained in otter care, and as a result only 10 of 14 pups survived.

6. The feeding regime should be improved. Otters should be fed often during the early phases of coat recovery. When the coat is in good condition, food quantity should decrease and otters should be fed on demand as their behavior dictates. This regime would decrease wasted food and improve pool water quality as well.

7. Common protocols and improved staff communication should be established. The top priority is otter rehabilitation. To compromise the health of otters in any way during this process was not necessary, but compromise did occur. If communication between individuals breaks down, then personality conflicts interfere with common sense, and the otter suffers. A feeling of cooperation and concern existed at SORC, which helped overcome personality differences, and the otter was the winner.

\section{Acknowledgments}

We thank R. Davis and T. M. Williams for allowing us to participate in this project; K. Kenyon and T. Gornall for their otter teachings; the volunteers for their willingness; and the husbandry supervisors, veterinarians, and vet technicians for their perseverance. In addition, we thank the Breaktime crew, the office staff, and G. VanBlaricom. Finally, we thank J. B. Wiles and N. Utkov; these two aided us in placing the first otter in saltwater holding pens at the Valdez boat harbor-it worked! 


\section{References}

Costa, D. P, and G. L. Kooyman. 1985. Contribution of specific dynamic action to heat balance and thermoregulation in the sea otter, Enhydra lutris. Physiol. Zool. 57(2):199-203.

Davis, R. W., T. M. Williams, J. A. Thomas, R. A. Kastelein, and L. H. Cornell. 1988. The effects of oil contamination and cleaning of sea otters (Enhydra lutris). II. Metabolism, thermoregulation and behavior. Can. J. Zool. 66(12):2782-2790.

Gornall, T. A. 1983. Letter to the U.S. Fish and Wildlife Service. February.

Monnett, C. W., L. M. Rotterman, C. Stack, and D. Monson. 1990. Postrelease monitoring of radio-instrumented sea otters in Prince William Sound. Pages $400-420$ in K. Bayha and J. Kormendy, tech. coords. Sea Otter Symposium: Proceedings of a sym- posium to evaluate the response effort on behalf of sea otters after the T/N Exxon Valdez oil spill into Prince William Sound, Anchorage, Alaska, 17-19 April 1990. U.S. Fish Wildl. Serv., Biol. Rep. 90(12).

Nakajima, M. 1983. Letter to the Federal Wildlife Permit Office, Washington, D. C. May.

Packard, J. M., and C. A. Ribic. 1982. Classification of the behavior of sea otter (Enhydra lutris). Can. J. Zool. 60:1362-1373.

Perrollaz, D. C., and J. A. Rash. 1990. Analysis of sea otter fur for crude oil contamination. Page 123 in K. Bayha and J. Kormendy, tech. coords. Sea Otter Symposium: Proceedings of a symposium to evaluate the response effort on behalf of sea otters after the T/V Exxon Valdez oil spill into Prince William Sound, Anchorage, Alaska, 17-19 April 1990. U.S. Fish Wildl. Serv., Biol. Rep. 90(12). [abstract] 


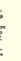

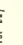

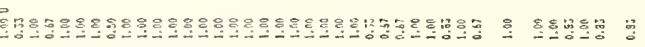

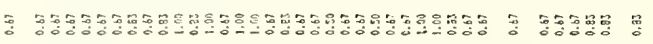

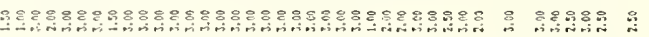

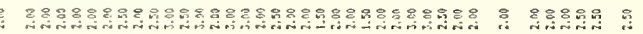

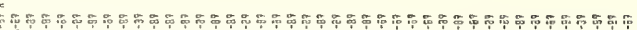

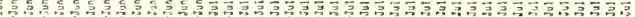

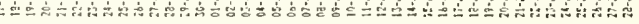

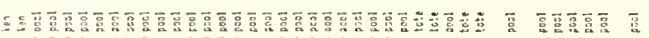

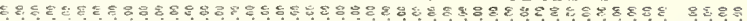

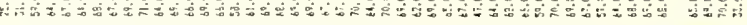

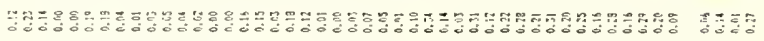

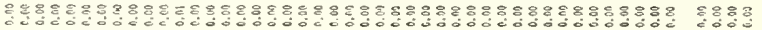

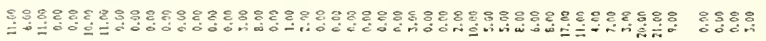

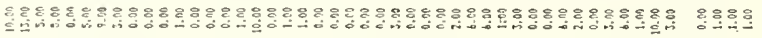

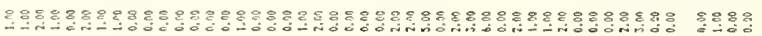

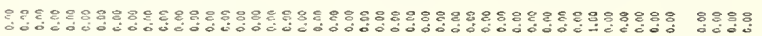

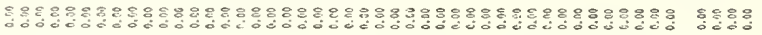

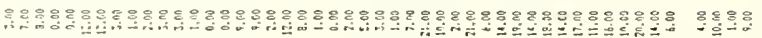

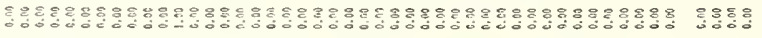

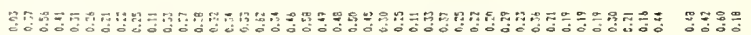

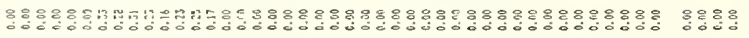

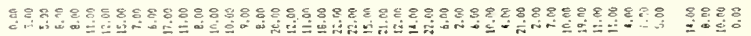

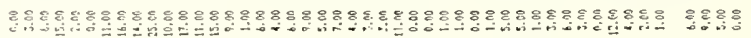
훙영연

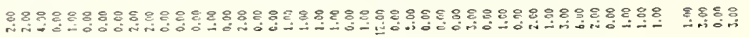

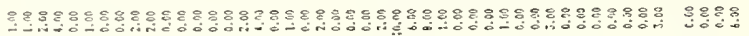

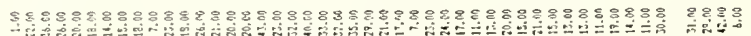

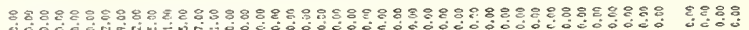

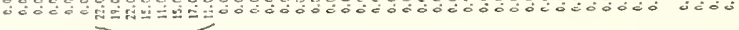

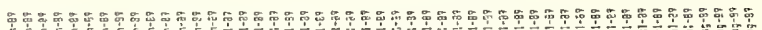

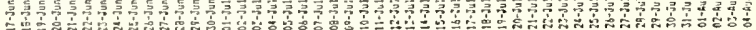




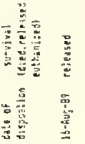

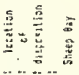

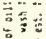

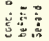




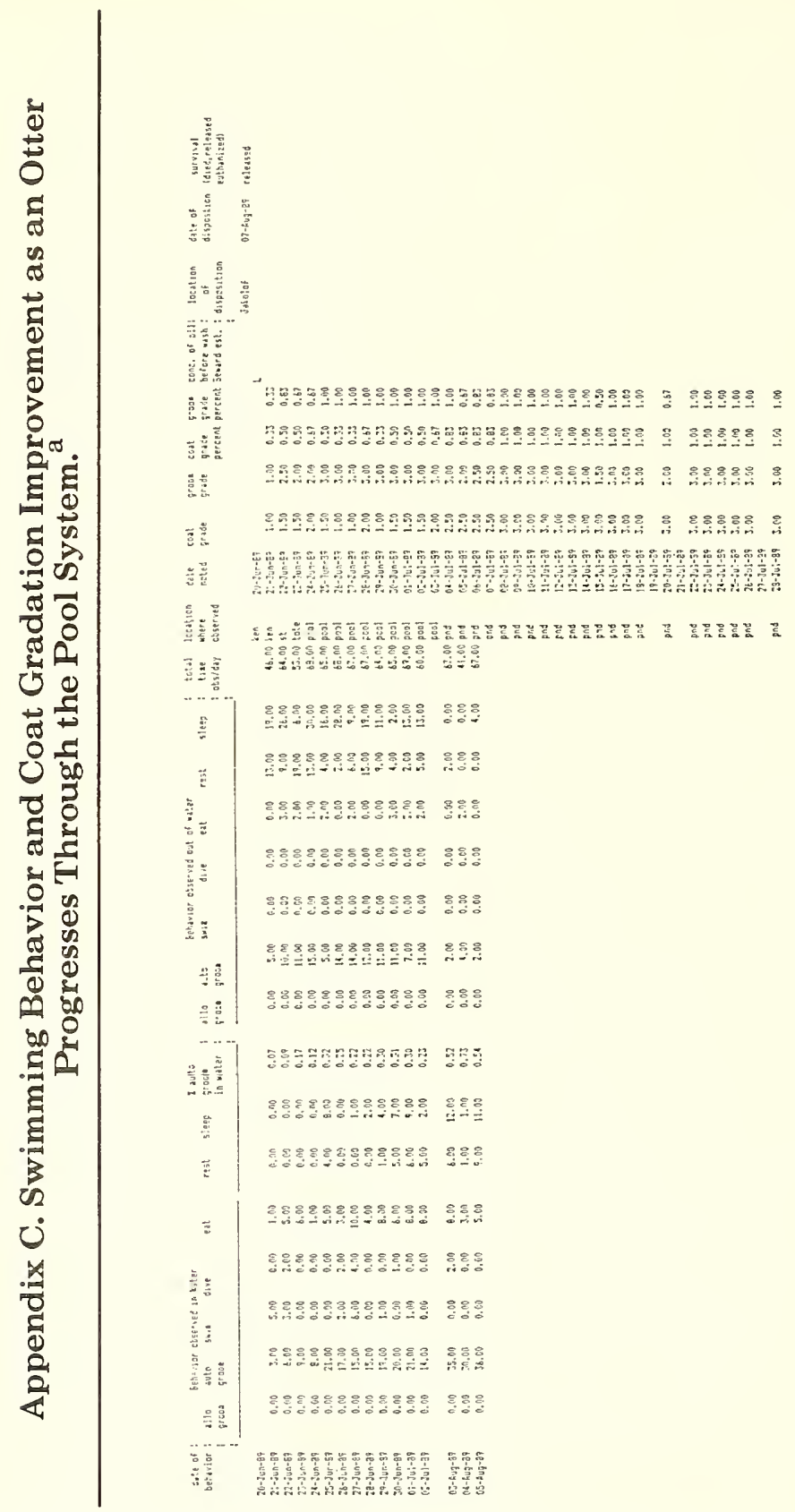


$\sigma$

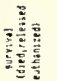

告高

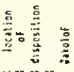

請

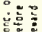

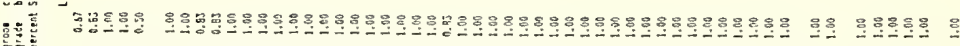

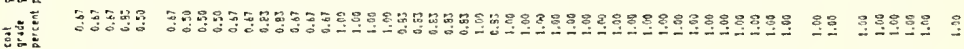

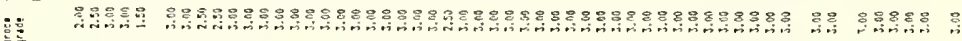

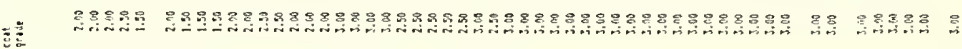

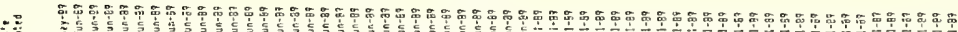

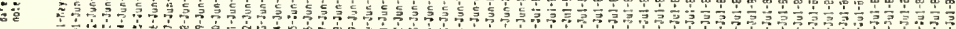

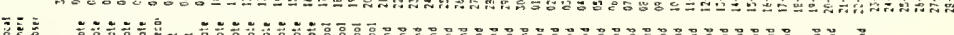

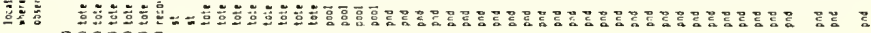

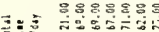

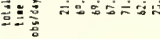

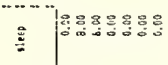

Е

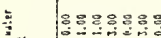

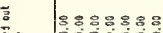

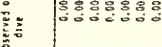

苟

$\div$ ล

옹영영옹영영

영영영용영영

을

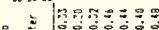

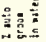

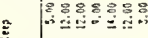

눈

1989888

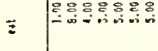

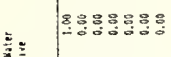

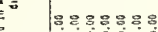

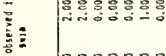

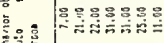

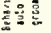

을

웅온 8398909

年

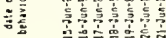




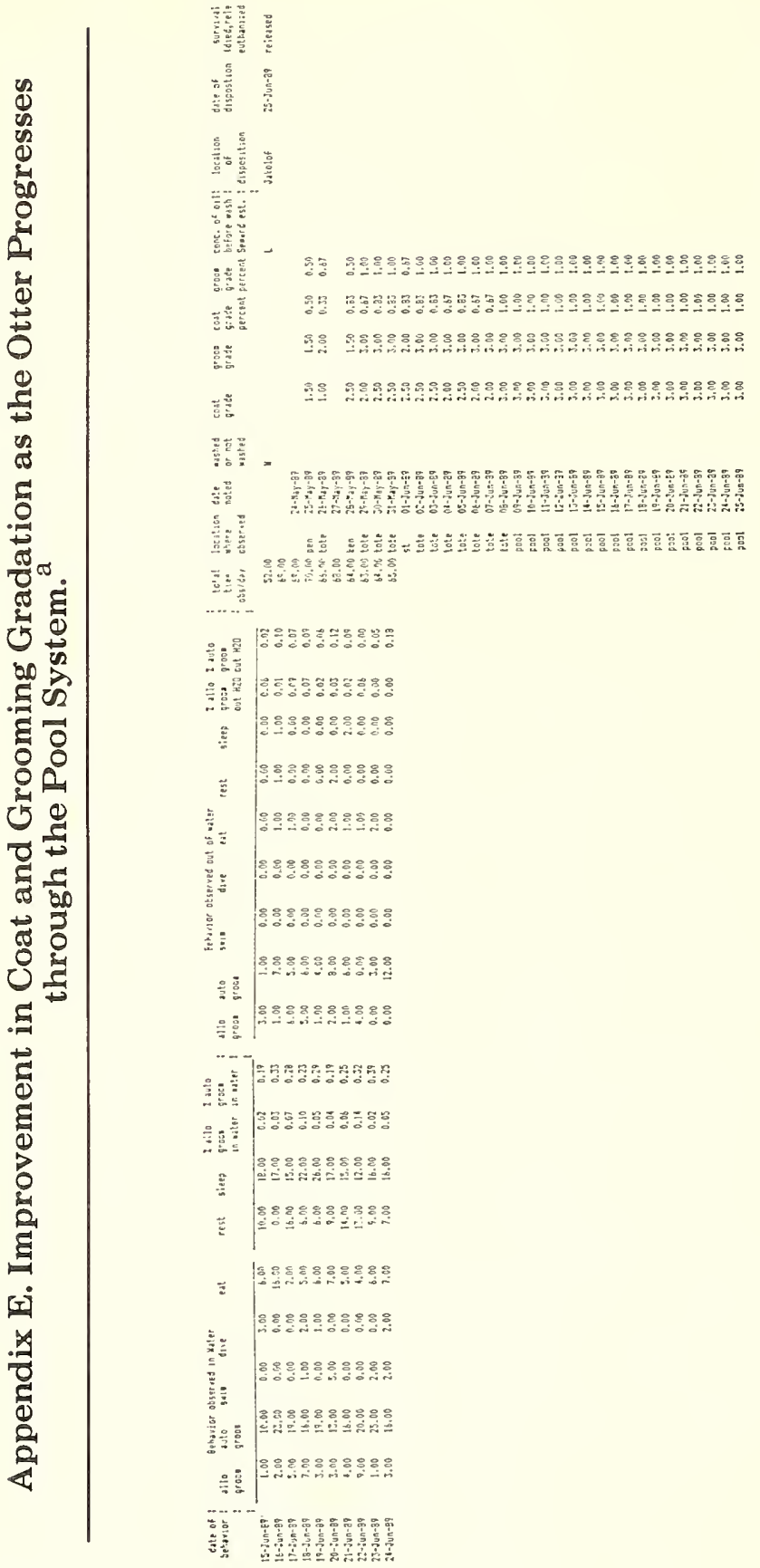




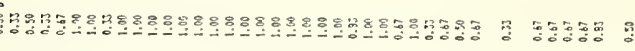

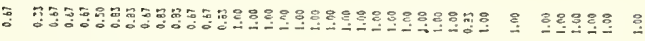

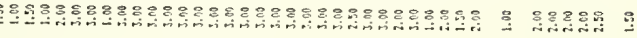

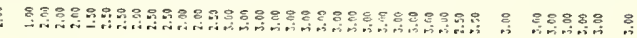

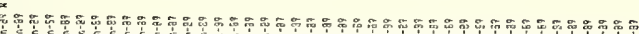

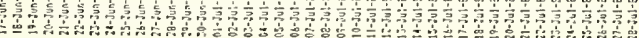
G..............

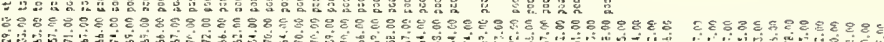

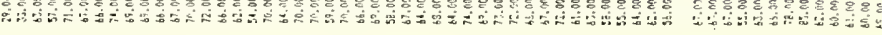

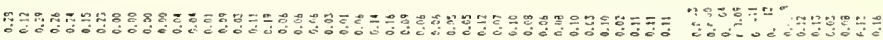

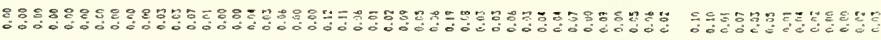

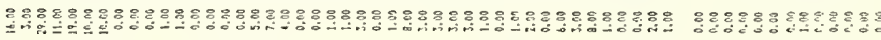

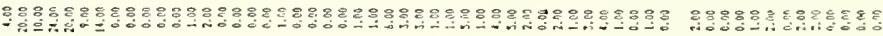

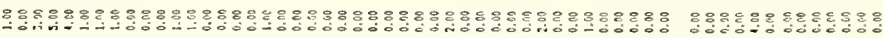

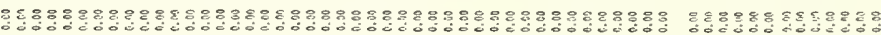

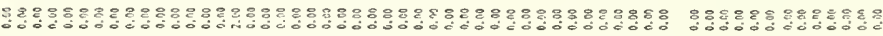

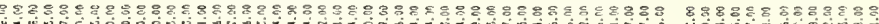

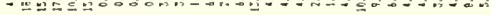

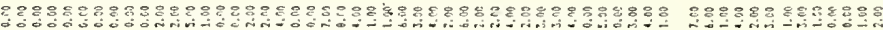

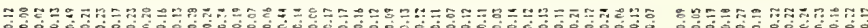

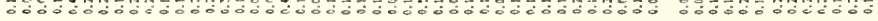

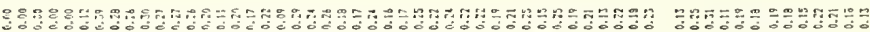

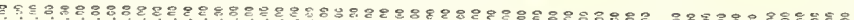

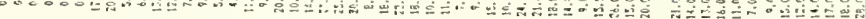

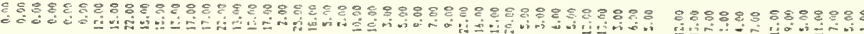

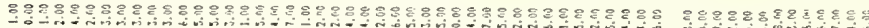

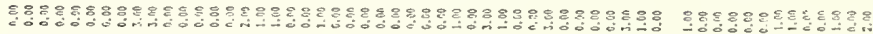

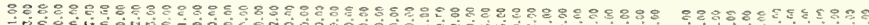

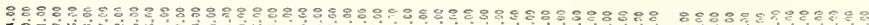
-

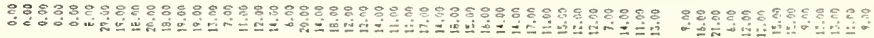




\section{Appendix G. Sample Observational Chart Used at the Seward Otter Rehabilitation Center.}

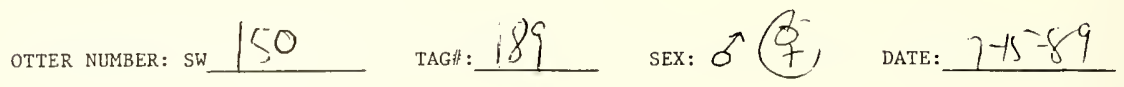

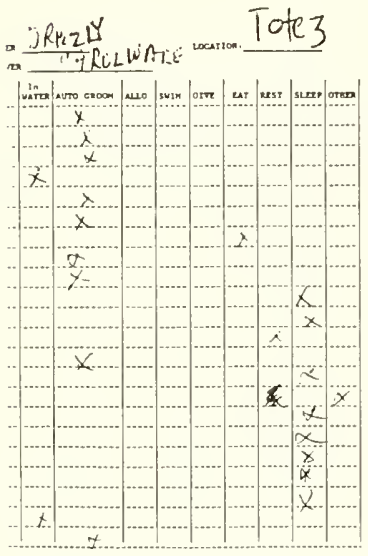

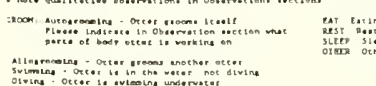
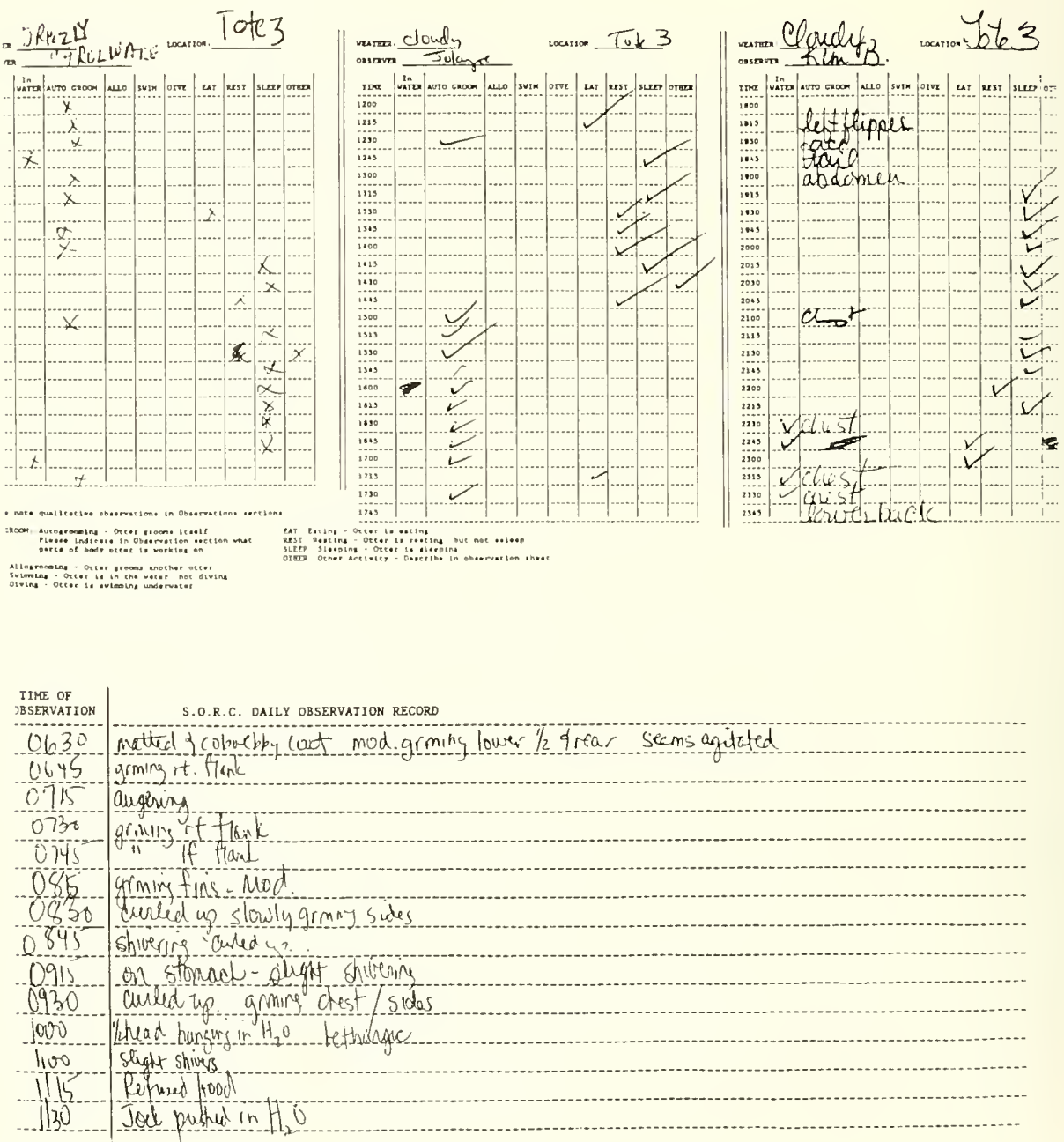


\section{Appendix H. Sample of Seward Otter Rehabilitation Center Summary Report.}

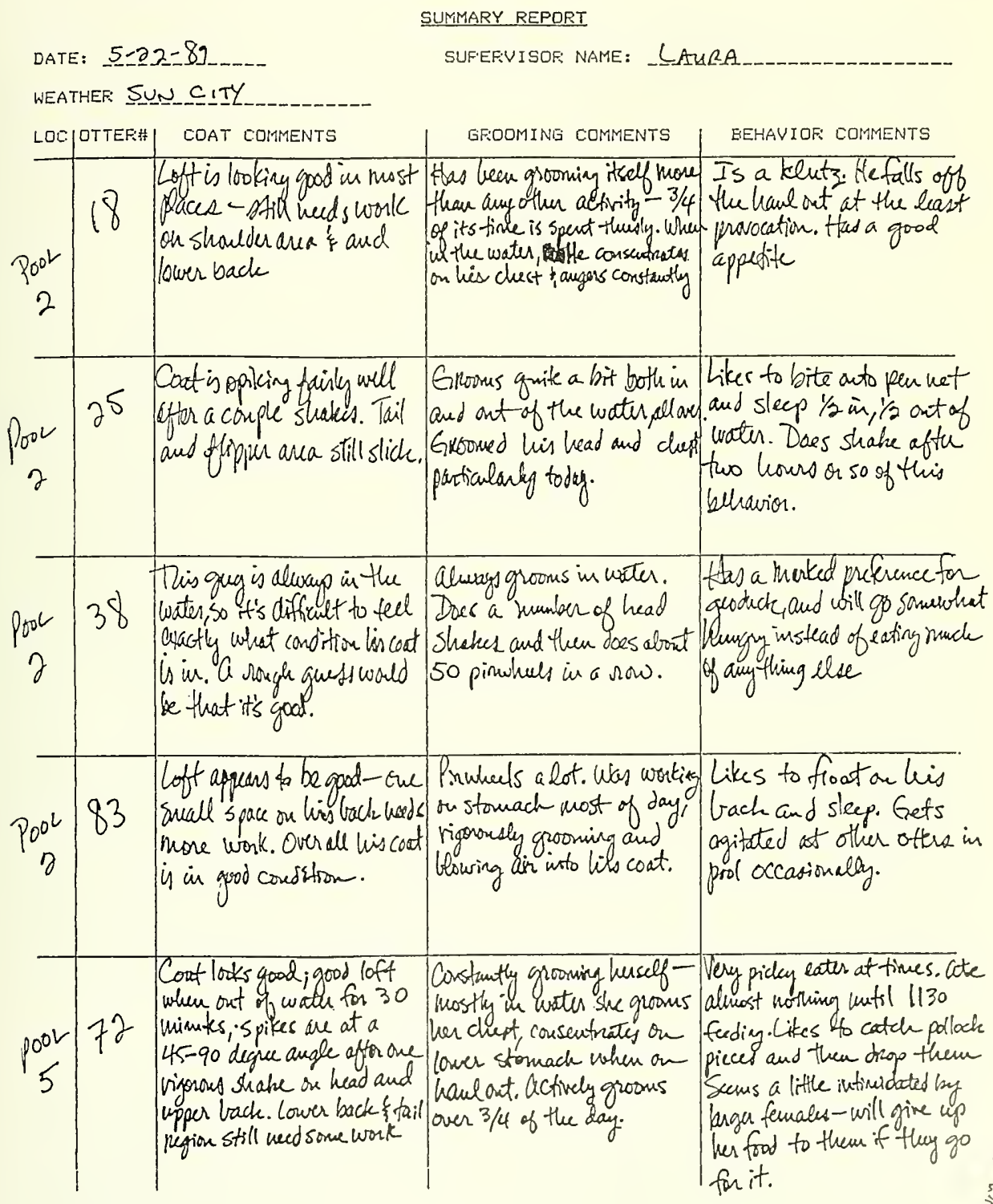




\title{
Husbandry at the Valdez Otter Rehabilitation Center
}

by

\author{
P. A. Tuomi \\ 2036 E. Northern Lights Boulevard \\ Anchorage, Alaska 99508
}

\begin{abstract}
Large numbers of sea otters (Enhydra lutris) were contaminated with crude oil after the 24 March 1989 oil spill from the T/V Exxon Valdez. Between 30 March and 16 August 1989, 178 sea otters were housed at the Valdez Otter Rehabilitation Center (154 admitted and treated directly from the wild, 21 transferred after treatment from the Seward Otter Rehabilitation Center, and 3 live-born pups). This was the first effort to treat and rehabilitate large numbers of wild oil-contaminated sea otters. The evolution of the center from critical care to long-term holding resulted in many innovations and improvements over time. I discuss short- and long-term care of sea otters debilitated by oil contamination, including attempts to provide an environment where otters could maintain body temperature and restore coat condition, nutritional support, maintaining sanitary and disease-free facilities, training of personnel in husbandry and handling procedures, and dealing with natural and capture-related stresses.
\end{abstract}

The high metabolic rate and insulating properties of sea otter (Enhydra lutris) fur normally enable the animals to maintain body temperatures of $36.7-38.1^{\circ} \mathrm{C}$ (Costa 1981) during immersion in seawater at temperatures as low as $-1.9^{\circ} \mathrm{C}$. Otters arriving at the Valdez Otter Rehabilitation Center's (VORC) washing areas typically had lost the insulating properties of their fur because of crude oil contamination and may not have been able to forage normally for several days before capture. They were often underweight and dehydrated, and their fur was wet to the skin over large areas of their bodies. The washing process removed the oil but could not immediately restore the fur to its normal water-repellent condition. A large percentage of the otters also exhibited signs of systemic toxicity from exposure to multiple hydrocarbon fractions present in the Prudhoe Bay crude oil, which further compromised their thermoregulatory ability and delayed recovery of coat condition.

VORC began operating under winter weather conditions, with ambient air temperatures of -5 to $0^{\circ} \mathrm{C}$ and periodic snowfall for the first 2 weeks. More than half of the total number of otters were received during this period. Most of these otters were heavily oiled and showed severe signs of oil toxicity. Transportation of equipment and supplies into Valdez was limited and frequently delayed because of adverse weather conditions during April.

Sea otter husbandry after washing at VORC was roughly divided into three stages-critical care, rehabilitation, and long-term holding. The staff attempted to combine the results of basic research on oil contamination of sea otters with established field and seaquaria techniques for housing captive sea otters, and to adapt these ideas along with the suggestions of many professionals and volunteers, to meet the real-life conditions after the oil spill.

\section{Housing}

A detailed description of the various pens and pools used at VORC and their physical placement is discussed by R. Davis and T. M. Williams (1990). I deal with how these various units were used.

The Valdez Center in the Copper Basin Hall at the Prince William Sound Community College was 
designed as an interim facility for holding 10-20 otters for 2-3 weeks. Otters would arrive, usually in plastic airline kennels of the type used to ship large dogs, and would be evaluated, sedated, and washed as necessary, and then placed in indoor dry pens for initial recovery. Hoses supplied hot and cold fresh water to rinse away excrement and assist in warming or cooling otter flippers. Plywood resting platforms were padded with clean towels that were changed when soiled. Otters were allowed to swim and groom for short periods in freshwater baths built from plastic totes. As soon as signs of chilling appeared (e.g., shivering, unsuccessful attempts to haul-out, lethargy), the otters were returned to the dry pens. Swimming duration was gradually increased as the otters regained their coat condition. When they could remain without assistance for unlimited periods in water, they were transferred to a saltwater holding pen in the small boat harbor to await release.

Unfortunately, the limited space in the Copper Basin Hall, which VORC shared with the bird rescue group, was rapidly overfilled after 81 otters were admitted during the first week (30 March through 6 April). Construction of indoor pens at the Growden-Harrison Complex increased the capacity of the critical care facility to 120 otters on 6 April. While indoor housing was being completed, efforts were begun to move otters outdoors to cages and pools, where the animals could begin to rehabilitate. Although completion of outdoor pens was delayed because of the unavailability of some materials, several cage designs and different types of wire and fabric netting were tried from 8-22 April. As soon as cages were available, otters that were eating well and able to maintain their normal core body temperature at ambient air temperatures (about $0^{\circ} \mathrm{C}$ ) were moved outdoors to dry cages or pens with tote pools that contained fresh water or seawater. The appetite and behavior of most otters improved when they were held outdoors. Some animals recovered rapidly and were moved to the seawater pens in the small boat harbor within 1-3 weeks after washing, but others continued to require constant monitoring and assistance for up to 8 weeks. A few otters had to be returned from the harbor to the outdoor pens when they became chilled.

The indoor housing at VORC was a first attempt to provide protection from winter weather for otters that were unable to thermoregulate properly. The indoor housing did temporarily house many severely debilitated animals, and allowed staff to supply basic food, safety, and medical require- ments. However, many problems were observed in the indoor housing, including overcrowding, inadequate ventilation, lack of adequate water flow and seawater supply, high noise levels from construction activities, and the necessity to frequently handle otters. During April and early May, many of the otters exhibited abrasions and pressure sores on their hocks and flippers from lying on cage floors of wire mesh, plywood, or resin grating (Chemgrate); several otters also developed a mild dermatitis over larger areas of skin. Other medical problems that may have been due to both oil toxicity and captivity were observed including diarrhea, myopathy, loss of appetite, and shock.

On 22 April, the first rehabilitated otters were transferred from the pens in the harbor to longterm holding in the seawater raceways at the Solomon Gulch Salmon Hatchery. The raceways were divided into sections with partitions constructed of herring net and wood; each section could hold 6 to 10 otters. Floating platforms provided haul-out space. Otters in this facility could be easily observed and netted as necessary for weighing, treatments, or placement in dry pens when chilled. The previously observed sores and dermatitis healed in all but two of the otters after they were moved to the seawater pens and raceways. One otter continued to groom excessively and seemed to have rubbed the fur from its abdomen and chest, which resulted in large bald patches without visible redness or inflammation of the skin. This animal's hair loss reversed after about 3 weeks, and its coat returned to normal density without specific treatment.

Between 1-11 May, 21 rehabilitated otters were transferred from the Seward Otter Rehabilitation Center (SORC) to VORC for long-term holding. These animals were held for short periods for observation at the Growden-Harrison Complex, but most were placed in the saltwater pens within the first few days after their arrival.

Beginning on 22 May, otters were moved to an octagonal, offshore salmon pen ("the octagon"). This pen system enabled the otters to complete their recovery by diving for food that was thrown into the enclosures, swimming and grooming in the large spaces, and socializing in groups of as many as 20 animals. Mature otters were generally kept segregated by sex to avoid injuries typically inflicted by mating behaviors, but several juveniles (male and female) were penned with older females who seemed to adopt them.

On 30 June, the last two otters (a mother and her center-born pup) were moved from the hatchery 
raceways, and all of the remaining otters were then held at the octagon until their release was arranged by the U.S. Fish and Wildlife Service.

\section{Maintenance of Body Temperature}

The need to regulate environmental air temperatures varied with the health of the otters. Overheating and chilling were both potential risks. Indoor housing was usually not heated, but ventilation was essential. Windbreaks and roofs were fashioned around outdoor pens as needed to reduce wind chill and wetting from rain and snowfall, and eventually to provide shade during the warm days of summer. During the coldest days in April and May, electric heating lamps were occasionally used to warm individual otters or the haul-out areas adjacent to the pens.

Until the cleaned otters had regained the waterrepellent quality of their fur, hypothermia was a potential problem whenever the otters entered the water in the tote pools.

Shivering alone was not a reliable sign of true hypothermia. Some otters seemed to shiver as a normal thermoregulatory behavior when they were sleeping or while floating with flippers extended flat on the surface of the water. In California translocation studies (VanBlaricom 1989; Williams and VanBlaricom 1989), observers reported that shivering seemed to be an early and reliable sign of captive stress syndrome.

Violent shivering, especially while the otter was awake and moving, extreme lethargy, excessive vocalization, unsuccessful attempts to haul out, lack of reaction to handling, and palpably cold flippers were the most easily recognized signs of hypothermia. Otters with these signs were moved to dry pens, and often their fur was dried with pet dryers. The dryers normally delivered unheated air but they could be adjusted to warm the flippers in severely chilled animals. Frequently, the use of dryers would stimulate grooming behavior. In some instances the flippers were placed in warm water. Otters were offered food as soon as possible during these episodes, and veterinary assistance was sought if the animal did not seem to respond.

Hyperthermia (overheating) most frequently occurred when the fur was dry and otters were indoors without access to water or ice. Otters would at first become quite agitated and vocalize loudly, then became stuporous, and finally comatose, with agonal seizures if their condition was not discovered and corrected in time. Sedated otters were especially at risk of hyperthermia; their body temperatures needed to be monitored with a rectal thermometer. Mild temperature rises could be corrected by running cold water across the hind flippers or placing ice on them. Immersing the otter in cold water or placing the animal on chipped ice while wetting it with hoses was effective in more severe cases.

\section{Coat Condition and Grooming}

Grooming in large amounts of clean seawater is essential for a washed otter to recover normal coat condition. Soiling of the fur by food, bodily wastes, or other debris causes matting and loss of water repellency (Kenyon 1969). Grooming behavior in sea otters consists of a large number of swimming maneuvers accompanied by vigorous rubbing movements with the forepaws and flippers. Wild otters typically groom 5-15\% of the time (Kenyon 1969; Packard and Ribic 1981). Grooming is thought to align the hairshafts and trap air in the fur, creating an insulating layer above the skin. The secretion of sebum at the base of the hairshaft may be important in keeping the hair healthy and may also make the fur hydrophobic. When properly groomed, the surface of the fur sheds water rapidly when the otter hauls out, and the entire pelt dries quickly (Rash et al. 1990; L. Hunter, Redken Laboratories, Thousand Oaks, California, personal communication). Although salt water should always have been used in the pools, adequate supplies were not available during the 3 weeks at Valdez, and lightly chlorinated (0.1 ppm) tap water was used. Warming the baths seemed to increase the time that the otters would tolerate being in the water, but this practice was discontinued because of the possibility that warm water might remove natural oils from the fur. Later reports on rehabilitated sea otters housed at Sea World in San Diego indicated no pelt or grooming problems when otters were kept in pools at ambient temperatures of $18^{\circ} \mathrm{C}$ (J. McBain, Sea World San Diego, California, personal communication). Eventually, seawater was hauled in tanker trucks to fill a large reservoir pool at the GrowdenHarrison Complex, and then it was pumped through hoses to provide continuous water flow to the outdoor tote pools.

During the rehabilitation period, some otters would spend up to $60 \%$ of their day grooming. This increased grooming most probably resulted from 
the need to restore their damaged fur and to generate extra metabolic heat to keep warm during the period of poor insulation (Costa and Kooyman 1981). Lack of grooming has been described as a symptom of captive stress (VanBlaricom 1989; Williams and VanBlaricom 1989), but several observers at VORC and SORC reported that intense grooming frequently followed periods of stress from handling or separation from other animals and, in the instance of the "bald" otter at the hatchery raceway, excessive grooming may have been an obsessive behavior possibly associated with confinement.

A newly cleaned otter with free access to seawater pools would usually complete grooming of the head and shoulders first, and then finish the abdomen and back over several days (Rash et al. 1990). Otters were able to perform grooming maneuvers within the confines of the plastic totes when the water depth was at least $0.6 \mathrm{~m}$ but larger seawater enclosures improved the efficacy of grooming efforts. Not surprisingly, severely debilitated otters were not able to groom effectively and sustained their poor coat conditions for longer periods.

\section{Nutrition}

Sea otters in the wild eat a variety of foods depending on locality, availability, and season. Normal daily food intake has been recorded as $20-33 \%$ of body weight (Kenyon 1969; Costa 1978, 1985). Sea otters have a high metabolic rate when compared with other mammals (Costa and Kooyman 1982), and have little body fat. Inadequate food intake results in rapid weight loss and may cause a stress-induced hemorrhagic enteritis (Stullken and Kirkpatrick 1955).

For oiled otters, these problems were exacerbated by the loss of the insulating properties of the pelt, which required a further increase in metabolic rate to maintain core body temperature (Costa and Kooyman 1981) or caused the animal to go ashore to decrease heat loss. Otters have only rarely been observed to feed onshore (Harrold and Hardin 1986; VanBlaricom 1988b), and if they do not maintain food intake, they begin to lose weight. Initial necropsy findings indicated the toxic effects of crude oil exposure, such as liver damage, gastrointestinal inflammation, depression of the immune system, and anemia, may have further compromised an animal's ability to thermoregulate and feed.

When otters arrived at VORC, they were offered squid, geoduck (Panomya ampla) fillets, scallops, peeled shrimp, pollack fillets, or other whitefish. The figure shows the proportions of foods provided over the first 3 months of operation at VORC. The April figures represent food types offered to animals in the critical care unit during the early stages of rehabilitation; May and June figures illustrate a progressive shift toward more natural diets (Calkins 1972, 1978; Estes et al. 1981) during long-term holding.

The food was handed (with metal kitchen tongs) directly to otters or was thrown onto their chests while animals were in the critical care facilities. In the seawater pens, food was thrown into the water, and otters would catch it or dive for it. Some animals seemed to have definite preferences for one or two types of food (especially geoduck), but

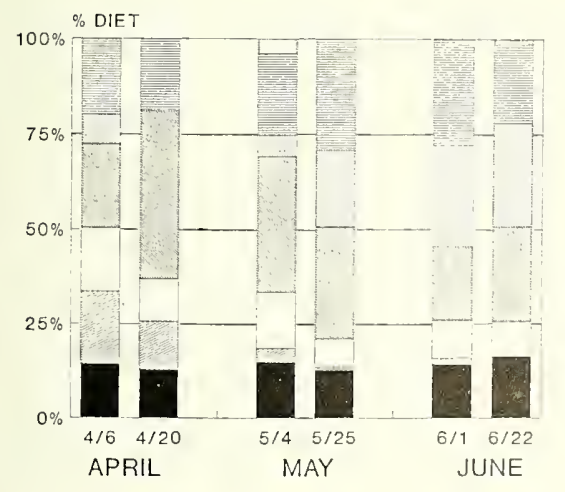

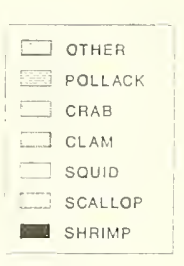

Figure. Food types as a percent of sea otter (Enhydra lutris) diet-Valdez Otter Rehabilitation Center. 
all otters were offered a variety at each meal. Frequently, otters were noted to change food preference from one meal to the next (e.g., all geoduck one meal, mostly shrimp the next).

Initially, shells, bones, and spines were removed before feeding to avoid physical irritation to already inflamed intestines (and because the center plumbing system at VORC would become obstructed by solid debris).

As otters were moved outside into tote pools and the incidence of hemorrhagic enteritis decreased (Wilson et al. 1990), small amounts of roughage (shrimp carapaces and whole squid) were added to the diet. The semisoft shrimp carapace was passed in the stools, resulting in a more solid stool form, but stool color and consistency continued to vary widely. Whole squid contain an ink sac that produces a tar-colored stool that is difficult to distinguish from the digested blood of hemorraghic enteritis, so this sac was removed whenever possible. Hard-shelled foods such as clams, mussels, and crabs were not offered in the critical care facility at the Growden-Harrison Complex, primarily because of the sewage flow difficulty. This was not a problem in the hatchery raceways and the seawater pens, and whole crabs, razor clams, cherry clams, and mussels were included in the diet regularly, with otter stool consistency continually improving. Crabs and mussels were consumed with the shell, whereas larger hard-shelled clams were opened by the otters and only the soft portions eaten. Salmon and black cod fillets were offered on several occasions but were not readily accepted by the otters.

Most otter food was obtained in bulk quantities from commercial seafood processors. Freezing is believed to destroy most parasite larvae (Sweeny 1965; Kenyon 1969), therefore fresh-frozen tablequality products were preferred. After the seafood was thawed, it was kept on crushed ice or refrigerated until it was delivered to husbandry staff.

At first, small quantities of a variety of foods were kept on ice in open buckets next to each otter's pen so that the observers could offer pieces whenever an animal would accept them. As the otters recovered, regular feeding times were established, and food was generally offered to the otters about every $4 \mathrm{~h}$ from $0700 \mathrm{~h}$ to $2300 \mathrm{~h}$.

After mid-May, prepared food was weighed and placed in plastic bags, which were then kept chilled. Each bag was marked with food type and weight (to aid in recording food intake) and with the date and time of preparation to ensure proper rotation of packages. We discarded food that had been thawed more than $24 \mathrm{~h}$, or that was warm or unsanitary. A more complete description of otter food procurement and handling is included elsewhere in these proceedings (Ferrante 1990).

Recorded daily intakes varied from $0-52 \%$ of body weight for individual otters, with an average of about one-third of body weight offered each day to otters in the rehabilitation and long-term holding facilities, which amounted to about $71.2 \mathrm{~kg}$ of seafood purchased for each otter every week. It was not always possible to determine the exact amount of food that was actually consumed by each otter, especially after the otters were transferred to saltwater pens.

The increased food consumption by surviving otters in VORC may have resulted from their need to regain the weight lost immediately after the spill, as well as from increased metabolic requirements for thermoregulation and increased grooming activity.

Chipped ice or pieces of block ice were regularly placed in cages and pens. Most otters seemed to enjoy drinking from water hoses as well as chewing the ice blocks and rolling in or eating the chipped ice. Snowballs of chipped ice (sprinkled with table salt or soaked with glucose solutions and seafood juices) were accepted by some otters that had refused other foods. At one point, thawed foods were soaked in a saltwater brine for otters that were kept in dry pens, but no additional attempt was made to provide additional salt- or fresh water to otters that were in seawater pools and pens.

Vitamin supplementation was attempted by a number of methods. Multivitamin-mineral tablets, wrapped in pieces of seafood, were usually rejected, even when the pieces were refrozen to mask the texture. Occasionally, individuals would accept food that contained smaller vitamin capsules, but if the otter bit into the vitamin once, it seemed to be able to detect the smell or taste and would refuse any further pieces. Vitamin liquids injected into food were also rejected, apparently for the same reason.

\section{Sanitation}

When soiled, dry pens and haul-out areas were rinsed with water to remove food and fecal debris. Clean, dry terry-cloth towels were used for bedding and were replaced as they became soiled. Each day, as otters were moved, the empty pens were disinfected with dilute chlorine bleach (1 part bleach to 30 parts water) and rinsed well. Tote 
pools were drained and scrubbed with dilute chlorine at least every third day. Plastic shipping kennels were rinsed and then sanitized with dilute chlorine and rinsed again before use. Food containers and utensils were washed with Dawn dishwashing detergent, rinsed with fresh water, then rinsed with dilute chlorine or chlorhexadine (Nolvasan) and rinsed again. Staff members were trained in proper seafood sanitation and were required to wear rubber gloves and to use proper utensils when handling food.

Uneaten food and shells were regularly removed from the dry pens and pools. Seawater pens were cleaned by scooping out debris with longhandled nets. A marine pump was used to power a vacuum system that suctioned food debris from the bottom of the hatchery and octagon through a 4 -inch corrugated plastic hose. Wastewater from the pens and tote pools was filtered to remove solid debris; the wastewater was either pumped into a sewage line or tanker trucks for treatment.

Minimum water quality standards have been established for housing of marine mammals (U.S. Department of Agriculture 1979). Because of the emergency nature of much of the housing during the first 4 weeks at VORC, these standards were not routinely monitored. Bacterial disease is always a prominent risk in marine mammals held under circumstances of inadequate water treatment or exchange (Howard 1983). Initially, totes filled with fresh- or salt water at VORC quickly became contaminated with feces and had to be changed frequently. Continuous flow provided by hoses in the outdoor pools kept the water cleaner, but the otters still had to be removed daily to allow thorough cleaning. Unacceptably high coliform counts have been described in sea otter holding pools and in the outfall water at Monterey Bay Aquarium during periods when more than 10 or 12 otters were being held at that facility (Van Blaricom 1988a).

Because of tidal action, the seawater pens had the best water quality. However, algal growth that occurred on the upper $15-20 \mathrm{~cm}$ of the nets in the silty glacial water in Valdez Harbor was a potential problem because it restricted water flow through the nets. This situation was controlled by periodically scrubbing the nets.

Visitors to VORC were restricted, and domestic pets were excluded at all times. Staff were instructed on the risk of infection and told to wash their hands regularly with povidone iodine hand soap or chlorhexadine solution, especially before and after handling otter food, and after cleaning pens.

A quarantine was instituted at VORC for a brief period after four otters died with somewhat similar gross pathological findings, including hemorrhagic enteritis. Tissue and serum samples from the dead otters, and serum from several otters that had been housed with these animals, were analyzed for evidence of canine distemper, parvo, corona and herpesvirus by the Washington Animal Disease Diagnostic Laboratory in Pullman, Washington. None of the samples showed evidence of any of these common domestic canine diseases, but the incident demonstrated the need to adopt sanitation procedures designed to prevent the introduction or spread of contagious disease within a sea otter rehabilitation center. Additional disease concerns and suggestions have been addressed elsewhere in these proceedings (Spraker 1990).

\section{Handling and Restraint}

Unnecessary handling of the otters was discouraged, but the cleaning and rehabilitation process often required that otters be handled and restrained for movement within the facilities, and for medical examination and treatments. All procedures were performed as quietly and rapidly as possible by designated otter handlers or professional staff members.

Heavy leather welding gloves with long cuffs were worn by otter handlers to prevent scratches and bites. Otters were transferred between pens with a large salmon hoop net, often with the handle removed. The typical salmon netting often caused cuts and abrasions to otters, so it was removed and replaced with a larger bag made of herring net. Otters were weighed during these transfers by suspending the net from the hook of a hanging spring scale, but accurate weights were difficult to obtain because the otters were constantly moving, and water content of the fur varied from day to day. Long-handled dip nets were required to capture otters in the seawater pens. When capture was required at the octagon, a large weighted seine net was pulled across the enclosure to encircle the otters.

Otters were placed in net-enclosed wooden cages (crab boxes or slide tops) for short-distance movement by truck or boat. Plastic dog kennels were used for transport in aircraft. Ice was placed in the cages to prevent hyperthermia and as a source of water. Block ice, broken into 6- to 10-inch 
chunks, was preferable because it lasted longer and provided the otters with something to chew on or manipulate with their paws. In warm weather or enclosed spaces, water was sprayed on the animals with hoses or spray bottles.

Injections, blood samples, and rectal temperature measurements were done while the otters were restrained with stuff bags (burlap sacks or nylon gear bags filled with foam rubber or dry towels). The bag was pressed against the otter's head, chest, and forelegs, thereby pinning the animal against the floor and leaving its hindquarters free to be grasped for treatment or examination. For more complete restraint, the otter was placed in a squeeze box built with a narrow floor, sloping sides, and a sliding door or small opening at one end. The otter was held on its back in the squeeze box with a stuff bag while the rear legs were pulled through the opening at the other end. In this device, the rear legs could be handled for taking blood samples, and the abdomen could be reached for palpation, cystocentesis, or fluid therapy.

Occasionally, very lethargic or lightly sedated animals were held on the washing tables for treatment. These otters were restrained by holding a fold of skin at the back of the head with both hands or by placing a figure-eight rubber pull toy (made for dogs) over the forelegs and chest and holding the free ends tightly behind the otter's shoulders. An assistant held the rear legs, and a third person performed the medical procedures.

Tube feeding was accomplished by holding a plastic or wooden dowel firmly between the premolars and passing a stomach tube over the dorsal aspect of the dowel and tongue into the esophagus to a premeasured length. The tube could usually be seen or felt to pass on the left side of the trachea. Proper placement of the tube in the stomach was tested by listening for bubbling sounds when air was blown into the tube. Liquified food or medication (antibiotics, Toxiban, or STAT - a high caloric lipodextrose paste) were quickly injected with syringes through the tube. The tube was sealed while it was withdrawn to prevent leakage of residual fluids into the pharynx.

\section{Staffing}

Staff members were assigned to observe otters $24 \mathrm{~h}$ a day. In the critical care facilities, one observer was assigned to one to four otters and was responsible for feeding, recording behavior, keeping the cage and otters clean, and advising the veterinary staff of unusual behavior. Each shift included a supervisor, otter monitors, food preparation staff, a pen-cleaning crew, otter handlers, an on-site veterinarian, and one or two veterinary technicians. Otter washing crews were assembled from among off-duty personnel and community volunteers as needed. Otters in long-term holding in seawater pens required much less supervision. Generally, one observer was assigned to a group of as many as 20 otters. Record notations were made less frequently, usually only to note the amount of food offered per pen and any abnormal behavior or activity. At intervals during the shift, maintenance chores, such as pen cleaning, repairs, and care of food containers, would be performed by the observers.

For the first 2 months, the professional staff and supervisors held daily meetings to discuss the status of the otters, evaluate ongoing procedures, and review suggestions for changes and improvements. Eventually, written protocols were prepared for new staff to review as they began work at the centers.

Most of the nonprofessional staff at VORC began as volunteers, many with little or no experience in handling wild animals. Initial training was provided one-on-one by VORC directors and veterinarians, and by professional marine mammal husbandry personnel on loan from the Marine Mammal Resource Center; the Monterey Bay Aquarium in Monterey, California; the Point Defiance Zoo in Tacoma, Washington; Sea World in San Diego, California, and San Antonio, Texas; and the Vancouver Aquarium. We prominently posted written instructions and held periodic meetings with staff from each shift to explain or reinforce protocols. Safety, sanitation, and creating a low. stress environment were emphasized at all times. A training film on cleaning oiled sea otters was produced by Proctor and Gamble, and made available to the staff in May. After mid-April, most of the personnel were placed on payroll at VORC to ensure that a stable and well-trained staff would continue to be available to care for the otters during the entire rehabilitation effort.

\section{Special Problems}

\section{Stress}

Otters were subject to stress from oiling, parasitism, disease, old age, and pregnancy. The handling necessary during capture, sedation or anesthesia, treatment, and confinement compounded these stresses. 
Overcrowding and the necessity of building or improving facilities during rehabilitation made it impossible to provide a quiet environment for the otters during the first month at Valdez. The severity of such stresses was decreased when the otters could be moved to outdoor pens, but handlers still had to be aware that these wild animals were unaccustomed to close human presence. Quiet periods were established at night, and unusual or loud noises were kept to a minimum.

When we observed such stress behaviors as chewing on the pens, the otter was offered food or ice to chew. Sometimes placing an object (towel, rope, clamshell, rock, rubber chew toy, or bucket) in the pen would provide the otter with something to manipulate; this seemed to relieve its distress. Movement of animals into the water for swimming and grooming was the most effective stressreduction method; stress behaviors were less common when otters had free access to pools.

\section{Injuries Due to Captivity}

Pressure sores and abrasions on the feet and legs were common in many of the otters held in dry pens for more than 1 or 2 days. A variety of surfaces were tested to prevent or lessen this problem, including the use of clean dry toweling, wire mesh, indooroutdoor carpeting, and Chemgrate. None of these products proved totally satisfactory. No such problems were noted with the plywood haul-out surfaces provided at the long-term holding pens.

One otter broke its upper canine teeth chewing on a wire cage enclosure. Although this did not seem to cause the animal any difficulty with eating (the otter was eventually released into the wild), fabric netting was used whenever possible, and the pens were constructed so that the otters could not wedge their teeth between boards or braces.

Several otters developed facial abscesses that may have been caused from splinters imbedding in their oral cavities during wood chewing. Similar facial abscesses have been observed in wild otters and were theorized to have been the result of punctures by sharp pieces of shells (Kenyon 1969). However, in the Seward Center, pens were built with polyvinyl chloride (PVC) pipe instead of wood frames (Styers and McCloskey 1990).

\section{Social Interactions}

In the wild, sea otters frequently gather in large "rafts" around favorable feeding or resting areas. Although the importance of social activity within these natural groups is unknown, it seemed that social contact was beneficial within the centers. Otters that were visually isolated from each other often vocalized intensely and ate less. Placing two otters together in a pen frequently reduced these problems. Female otters sleeping on haul-out platforms in the saltwater pens would often lie together, even when there was sufficient room to avoid physical contact. Males would sometimes group in this manner, but seemed to have a social hierarchy, and occasional threat displays would be noted when a large male was put in a pen. Fighting was rare but did occur once when a wild territorial male from the local area climbed into the hatchery raceway where there were captive male otters. This male had to be captured and penned as a result of the encounter. Other behaviors, such as food sharing, playing, holding of paws and flippers, neck hugging, and allogrooming, were observed.

Social bonding seemed to occur among a number of otters. These otters would seek each other's company, frequently touching while sleeping, swimming, and playing together. Similar behaviors have been observed in captive wild otters involved in translocation projects in Califormia (G.R. VanBlaricom, U.S. Fish and Wildlife Service, University of California, Santa Cruz, personal communication). In several instances, juvenile otters seemed to be adopted by older females. The adults in these pairs would groom the younger otter, hold it with both paws around the neck, and share food with it.

Additional observations on the behavior of sea otters within the rehabilitation facilities are presented by Michaelson (1990).

\section{Pregnancy and Birth}

Pregnant females and newborn pups had a high incidence of mortality. Pregnancy was terminated with the death of the mother, abortion of a nearterm fetus, stillbirth, or death of the newborn pup in 20 of 23 females diagnosed pregnant at admission (1 female was released without delivering a pup, and another died in labor after her transfer to Vancouver Aquarium). Further analysis of toxicological and histopathological samples from admission and necropsy will be required before any comments can be made regarding the effects of oil, the stress of handling, or other factors that might have contributed to these deaths. A more complete discussion of pregnancy and birth in rehabilitated sea otters is included in Wilson et al. (1990). 
Contrary to early suggestions, most females were able to deliver their pups out of the water. However, these pups usually were stillborn or died within a short time after birth. It may be that females that completed their labor on the haul-out areas were too ill to swim normally and were not able to stay in the water long enough to complete labor and care for their pups; the pups would be debilitated in utero by the same factors that affected their mothers.

Two live-born pups had to be taken from their mothers within hours after delivery because their fur was soaked with water. They became chilled, nearly drowned, and did not appear able to nurse successfully. Both of these pups died shortly after being transferred to the nursery.

At VORC, a pup was born in May to one of the females that SORC had transferred into longterm holding. This female was able to properly care for her pup; the mother and pup were eventually released into the wild.

The decision to leave a pup with its mother or move it to the nursery is always subjective, but from our experience, only females that had recovered sufficiently to maintain coat condition seemed able to support newborn pups.

\section{Conclusions and Recommendations}

Valdez Otter Rehabilitation Center proved to be adaptable and innovative, even with many needs and conditions. Obvious early shortcomings were in sanitation and ventilation, along with noise and other environmental stress-control problems. The basic tote and herring net system of pens and pools that evolved could be used to meet the basic needs of housing sea otters in an emergency situation. Water supply refinements (seawater source, flow rate, temperature control, and sanitation) still need to be perfected for the critical care and rehabilitation phases of husbandry. The octagon system for long-term holding was close to ideal. Pen size (especially depth), tidal flow, otter observation locations, ease in handling animals, and adaptability of the octagon facility were all excellent.

Otter food supplies were always plentiful, with good variety and quality. Otter acceptance of nearly all food products was reasonably good, with geoduck fillets and crabs being most favored. Providing the widest possible food variety at all times seems desirable to ensure balanced nutrition in otter diets. The inclusion of shells and carapaces in the diet seems to have a beneficial effect on the appearance and consistency of bowel movements, but further study is needed to determine if such items are harmful to damaged digestive systems or vital to normal digestion and nutrition.

None of the haul-out surfaces in the critical care and rehabilitation cages were entirely satisfactory, and the use of wooden building material in particular was a problem. Sharp, constant pressure from the flat surface resulted in severe pressure sores and other otter injuries. Chemgrate was also too sharp-edged and abrasive, and it appeared to break down and chip easily. Further attempts should be made with captive otters to investigate other possible materials for haul-out surfaces, including racks of PVC pipe, hard rubber grid-type floor mats, solid plastic or rubber sheets (which would be softer but not invite chewing), or simple racks covered with smooth, clean beach rocks.

Otters could not begin to regain coat condition until they had regular access to large amounts of clean seawater for grooming. Because many of the otters were unable to thermoregulate sufficiently to tolerate ambient water temperature for more than a few minutes, it would seem that in a critical care facility, warming the water slightly (4.4$12.8^{\circ} \mathrm{C}$ ) would be advisable. This would increase the amount of time an otter could spend in the water, thereby avoiding further coat damage, decreasing the time needed to regain coat condition, and conserving metabolic energy during a period of high stress. Gradual decreases in the pool water temperature should be possible, with return to ambient water temperature as soon as the otter is recovered sufficiently to haul out and thermoregulate without assistance. Extra care must be taken when attempting research on the efficacy of warmwater baths to ensure adequate ventilation and to avoid the accumulation of high humidity, which would prevent the otter's coat from drying properly when out of water.

The adaptations to outdoor housing and longterm holding were made as spring and summer arrived. The particularly mild weather in Valdez during this period eased some husbandry problems. However, a fall or early winter oil spill would present much greater challenges. Consideration must be given to the advisability or even possibility of using similar husbandry techniques in areas where temperatures and wind chill may fall well below $-17.8^{\circ} \mathrm{C}$ for several weeks at a time.

Sanitation and waste disposal were always problems, even with the assistance of the local utilities. In the future, some sort of internal pro- 
cessing of wastes should be considered, including filtering of solid wastes. Also, monitoring or decreasing the effects of facility byproducts on the local environment should be considered.

Similarly, disease-control and quarantine measures need to be reevaluated and strengthened. The constant need to move otters between cages and cagemates definitely increases the chance of spread of a contagious disease (had one occurred). Use of materials that were difficult to disinfect, especially wood and net fabrics, and lack of simple sanitary facilities (e.g., footbaths, scrub sinks, and steam cleaners) during the early weeks of center operation should be addressed in future plans (Spraker 1990). Evaluation of final necropsy data and further testing of banked tissue and serum from sea otters handled at all the centers should be completed to identify potential bacterial, viral, and parasitic disease problems.

Methods to alleviate capture stress will continue to be needed. In general, sea otters seem to be comparatively intelligent and adaptable animals, and most were surprisingly capable of tolerating the extreme confinement. For some of the animals, the toxicity and thermoregulatory damage caused by the effects of oil may have had synergistic effects, and death occurred. Because all of the otters were exposed to varying degrees of hydrocarbons (internal and external), differing natural stressors (parasites, pregnancy, nutritional state), and possibly previous human contact situations, it is difficult to define the exact effects of capture, confinement, and handling on survivability.

\section{Acknowledgments}

Many of the techniques and innovations at the Valdez Otter Rehabilitation Center were suggested by organizations and persons knowledgeable in marine mammal husbandry and sea otter fieldwork. It would be impossible to list all of the contributions made by the hundreds of persons who worked at the center or offered advice, but special thanks should be given to J. Antrim, M. Bressler, M. Dudley, and veterinarian J. McBain, and Sea World San Diego; T. Howe, P. Sassic, D. Wigdahl, and Sea World San Antonio (Texas); J. Fitz-Gibbon and the Vancouver Aquarium; veterinarian M. Jones and the Point Defiance Zoo in Tacoma, Washington; J. Hymer and veterinarian T. Williams, and the Monterey Bay Aquarium in California; veterinarians T. A. Gornall and P. Schraeder, and the Marine Mammal Resource
Center. The Prince William Sound Community College, Salmon Exchange, Solomon Gulch Hatchery, and the Valdez Harbormaster are acknowledged for their generous permission to use and extensively modify their existing facilities in Valdez, Alaska.

For cooperation in handling laboratory specimens and for advice and suggestions throughout the project I thank the staffs at Valdez Community Hospital; Providence Hospital, Anchorage; Physician's Medical Laboratories, Anchorage and Portland; and the State of Alaska Department of Seafood and Animal Health.

\section{References}

Calkins, D. G. 1972. Some aspects of the behavior and ecology of the sea otter (Enhydra lutris), in Montague Strait, Prince William Sound, Alaska. M.S. thesis, University of Alaska, Fairbanks. 52 pp.

Calkins, D. G. 1978. Feeding behavior and major prey species of the sea otter (Enhyrda lutris), in Montague Strait, Prince William Sound, Alaska. U.S. Natl. Oceanic Atmos. Admin. Fish Bull. 76:125-131.

Costa, D. P. 1978. The ecological energetics, water and electrolyte balance of the California sea otter (Enhydra lutris). Ph.D. thesis, University of California, Santa Cruz.

Costa, D. P. 1985. The ecological energetics of sea otters. Fourth international sea otter symposium, Santa Cruz, California. [unpublished report]

Costa, D. P., and G. L. Kooyman. 1981. Effects of oil contamination in the sea otter (Enhydra lutris). Pages 65-107 in Environmental assessment of the Alaskan continental shelf. Final reports of principal investigators. Vol 10. Biological studies.

Costa, D. P., and G. L. Kooyman. 1982. Oxygen consumption, thermoregulation, and the effect of fur oiling and washing on the sea otter, Enhydra lutris. Can. J. Zool. 60:2761-2767.

Davis, R. W., and T. M. Williams. 1990. Valdez Otter Rehabilitation Center. Pages 158-166 in K. Bayha and J. Kormendy, tech. coords. Sea Otter Symposium: Proceedings of a symposium to evaluate the response effort on behalf of sea otters after the T/V Exxon Valdez oil spill into Prince William Sound, Anchorage, Alaska, 17-19 April 1990. U.S. Fish Wildl. Serv, Biol. Rep. 90(12).

Estes, J. A. Jameson, and A. M. Johnson. 1981. Food selection and some foraging tactics of sea otters. Pages 606-641 in J. A. Chapman and D. Pursley, eds. Proceedings of the worldwide furbearer conference, August 1980, Frostburg, Md.

Ferrante, P. 1990. Food procurement and feeding of sea otters during the Exxon Valdez oil spill. Pages 321-322 in K. Bayha and J. Kormendy, tech. coords. Sea Otter Symposium: Proceedings of a symposium to evaluate 
the response effort on behalf of sea otters after the $\mathrm{T} / \mathrm{N}$ Exxon Valdez oil spill into Prince William Sound, Anchorage, Alaska, 17-19 April 1990. U.S. Fish Wildl. Serv., Biol. Rep. 90(12).

Harrold, C., and D. Hardin. 1986. Foraging on land by the California sea otter (Enhydra lutris). Mar. Mamm. Sci. 2:309-313.

Howard, E. B., J. O. Britt, G. K. Matsumoto, R. Itahara, and C. N. Nagano. 1983. Bacterial diseases. Vol. I. The pathobiology of marine mammals. CRC Press, Inc., Boca Raton, Fla. 232 pp.

Kenyon, K. W. 1969. The sea otter in the eastern Pacific Ocean. U.S. Fish Wildl. Serv., N. Am. Fauna 68. 325 pp.

Michaelson, N. E. 1990. Behavioral observations of rehabilitating sea otters in prerelease holding pens. Pages 313-320 in K. Bayha and J. Kormendy, tech. coords. Sea Otter Symposium: Proceedings of a symposium to evaluate the response effort on behalf of sea otters after the T/V Exxon Valdez oil spill into Prince William Sound, Anchorage, Alaska, 17-19 April 1990. U.S. Fish Wildl. Serv., Biol. Rep. 90(12).

Packard, J. M., and C. A. Ribic. 1981. Classification of the behavior of sea otters (Enhydra lutris). Can. J. Zool. 60:1362-1373.

Rash, J. A., C. R. McCormick, R. Alexander, S. J. Nichol, and D. C. Perrollaz. 1990. Coat gradation and conditioning of sea otters at the Seward Otter Rehabilitation Center. Pages 258-273 in K. Bayha and J. Kormendy, tech. coords. Sea Otter Symposium: Proceedings of a symposium to evaluate the response effort on behalf of sea otters after the T/V Exxon Valdez oil spill into Prince William Sound, Anchorage, Alaska, 17-19 April 1990. U.S. Fish Wildl. Serv., Biol. Rep. 90(12).

Spraker, T. 1990. Hazards of releasing rehabilitated animals with emphasis on sea otters and the T/N Exxon Valdez oil spill. Pages $385-389$ in K. Bayha and J. Kormendy, tech. coords. Sea Otter Symposium: Proceedings of a symposium to evaluate the response effort on behalf of sea otters after the T/N Exxon Valdez oil spill into Prince William Sound, Anchorage, Alaska, 17-19 April 1990. U.S. Fish Wildl. Serv., Biol. Rep. 90(12).

Stullken, D. E., and C. M. Kirkpatrick. 1955. Physiological investigations of captivity mortality in the sea otter (Enhydra lutris). Pages 476-493 in Proceedings of the twentieth North American wildlife conference.

Styers, J., and T. McCloskey. 1990. Seward Otter Rehabilitation Center. Pages 167-171 in K. Bayha and J. Kormendy, tech. coords. Sea Otter Symposium: Proceedings of a symposium to evaluate the response effort on behalf of sea otters after the T/V Exxon Valdez oil spill into Prince William Sound, Anchorage, Alaska, 17-19 April 1990. U.S. Fish Wildl. Serv., Biol. Rep. 90(12).

Sweeney, J. C. 1965. Common diseases of pinnipeds. J. Am. Vet. Med. Assoc. 147:1090.

U.S. Department of Agriculture. 1979. Marine mammals regulations. Fed. Regist. 44:33868.

VanBlaricom, G. R. 1988a. Concentrations of fecal coliform bacteria associated with the housing of wild sea otters at the Monterey Bay Aquarium, summer and fall 1987. U.S. Fish and Wildlife Service, Santa Cruz, Calif. [unpublished report]

VanBlaricom, G. R. 1988b. Effects of foraging by sea otters on mussel-dominated intertidal communities. Pages 48-91 in G. R. VanBlaricom and J. A. Estes, eds. The community ecology of sea otters. Springer-Verlag, New York.

VanBlaricom, G. R. 1989. Pattern of captive stress during translocation of sea otters. Presentation to the Committee of Scientific Advisors, U.S. Marine Mammal Commission. Monterey, Calif. [unpublished report]

Williams, T. D., and G. R. VanBlaricom. 1989. Rates of capture myopathy in translocated sea otters with implications for management of sea otter rescue following oil spills. Presentation to the eighth biennial conference on the biology of marine mammals. Pacific Grove, Calif. [unpublished report]

Wilson, R. K., C. R. McCormick, T. D. Williams, and P.A. Tuomi. 1990. Clinical treatment and rehabilitation of sea otters. Pages 326-337 in K. Bayha and J. Kormendy, tech. coords. Sea Otter Symposium: Proceedings of a symposium to evaluate the response effort on behalf of sea otters after the T/V Exxon Valdez oil spill into Prince William Sound, Anchorage, Alaska, 17-19 April 1990. U.S. Fish Wildl. Serv., Biol. Rep. 90(12). 


\title{
Husbandry at the Seward Otter Rehabilitation Center
}

by

\author{
J. Otten \\ Point Defiance Zoo \\ 2801 106th Street Northwest \\ Gig Harbor, Washington 98335
}

\begin{abstract}
In the establishment of the Seward Otter Rehabilitation Center, the staff attempted to design a system where the sea otters (Enhydra lutris) were provided with everything they would need for the quickest possible rehabilitation, movement to a prerelease facility, and release back into the wild. In designing this system, the staff used techniques learned at the Valdez Otter Rehabilitation Center and elsewhere in the field. The goal of the husbandry staff was to minimize human contact and its effects on oiled otters as much as possible. As the husbandry staff worked with the SORC system, it was able to define more clearly what worked and what did not work in regard to staffing requirements, feeding (e.g., amount, variety, and method), and housing (e.g., ways to eliminate abrasions, social stress, and to improve coat condition). In addition, the staff learned how to minimize many stress-induced problems, care for the needs of special groups, and improve general husbandry procedures. The staff hopes that what was learned will help set standards for future sea otter care in a rehabilitation center.
\end{abstract}

The Seward Otter Rehabilitation Center (SORC) was opened as the T/V Exxon Valdez oil spill affected regions of the Kenai Peninsula. We had the benefit of the rescue experience already gained at the Valdez Otter Rescue Center (VORC). As otter rehabilitation continued in Seward, an additional 4 1/2 months of concentrated husbandry experience were added to the cumulative knowledge of sea otter (Enhydra lutris) care and rehabilitation gained during this environmental disaster. I summarize the husbandry practices that were most effective (based on experience with more than 340 sea otters that underwent rehabilitation) and recommend priorities in setting up future otter care centers.

The teamwork at SORC between husbandry and veterinary departments worked well. The functions of the husbandry department were to:

- provide an environment where rehabilitating oiled sea otters could regain coat condition with minimal effects from humans, yet provide human intervention when necessary for the quickest possible progressive rehabilitation and ultimate release to the wild.
Through behavioral observations, housing, handling protocols, feeding procedures, and daily assessment of the progress of each otter, husbandry staff attempted to minimize stress on the otters, avoid the development of medical conditions that could be brought on by stress, aid in early detection of conditions requiring medical treatment, and notify and work with veterinarians on the best solutions to problems;

- provide for the nutritional needs of each otter;

- maintain detailed behavioral observations, feeding records, and records of location and progression of otters through the center, providing documentation for future reference;

- develop and revise, as necessary, protocols for the training of care personnel for otters, in a system of preventive husbandry; and

- ensure optimal sanitation procedures for disease prevention.

The primary goal of the husbandry staff was the quickest possible rehabilitation of each otter (the least time required under ideal conditions was 10 
days) with minimal human effect on the otter. We attempted to handle the otters as little as possible, and not to tame them. The protocols and systems developed through the experience with 163 adult otters treated at SORC are recommendations based on that experience, which included countless hours of behavioral observations now being compiled. Operating under varying circumstances at SORC and subjective assessment of each otter's needs often required staff to vary from strict protocols.

\section{Providing a Rehabilitation Environment}

\section{Otter Housing at the Seward Otter Rehabilitation Center}

The Seward Otter Rehabilitation Center was designed to meet different needs at different stages of otter rehabilitation. Upon admission, otters were allowed to settle down in a quiet spot, either in a dry quarantine slide-top cage or, if available, in a tote pool enclosure. Otters were fed, given ice (for dehydration), stabilized, and observed at least overnight. After being washed and fully dried, they were housed in a clean, dry cage until recovery from sedation. Once otters were released by the veterinarian, and if space permitted, they were allowed 24 -h access to cold (ambient) salt water pumped into their enclosures from Resurrection Bay.

Although the 24-h access to salt water was advantageous to quick rehabilitation in many ways, it required close monitoring of the otters as they were susceptible to hypothermia. If any indication of chilling was seen, timely intervention was necessary. Although moves to a different type of enclosure were generally made on the basis of coat condition, otters were moved on a priority basis for reduction of stress. If otters exhibited stress symptoms that seemed to be caused by confinement or isolation, a different enclosure or social arrangement could often help calm them.

In SORC's plan, after washing and recovery the otters were placed in an indoor tote pool enclosure, a 1.2- $\times 1.2-\mathrm{m}$ tote pool with a single haul-out area inside a trailer. These pools were designed to house one otter at a time in isolation (4 tote pens in each trailer for a total of 16 inside pens) where the animal could be observed and could concentrate on its initial grooming. After 1 or 2 days, otters were moved to an outside double tote (1.2$\times 1.2$-m tote with two haul-out areas). The otter was alone or with a compatible otter. Once an otter had attained a coat condition of $2+$, it was moved to an outdoor $3.4-\mathrm{m}$ round fiberglass pool, with one or two haul-out areas, and a slightly larger social group (two, three, or sometimes four otters). Once an otter attained a coat condition of 3 (i.e., fully rehabilitated) it was assessed for prerelease at the interim prerelease facility-two net enclosures $(3.7 \times 7.3 \times 4.3 \mathrm{~m}$ deep $)$ in a saltwater pond at the Marine Science Center near SORC, where little human intervention occurred except feeding, and where larger groups of otters were possible. If an otter did well at the interim prerelease center for a minimum stay of 2 days, and if its blood test results were satisfactory, it was transported to the prerelease center at Little Jakolof Bay (a similar pool and social situation as described above), where the animal stayed until release.

At any time during rehabilitation, if an otter experienced hypothermia or other medical problems in the enclosure, it could be moved to dry slide-top cages or back to isolation in tote pool enclosures (usually outside enclosures) as alternative critical care housing. These cages were equipped with handles so handlers could move the otters with minimal handling.

\section{Recommendations}

I recommend that rehabilitation centers set up more of the larger pools, as larger pools allow otters room for better grooming, and perhaps decrease the number of smaller enclosures, using them more for isolation. Otter stress seemed to decrease measurably when larger spaces were provided. However, more than three otters in one space is not recommended, even in the 3.4-m round pools.

Chempruf or similar pools should be modified from the designs used at SORC in the following ways:

- paint pools blue, not olive green, for better cleaning visibility;

- water flow should allow complete turnover in the entire pool every hour; and

- there should be adjustable incoming water flow on the surface to adequately skim the surface. Skimmer boxes should be at least $0.3 \mathrm{~m}$ wide to allow for excellent skimming. Surface water should be kept uncontaminated by food and feces (design can be seen in the pools designed for Point Defiance Zoo and Aquarium). 
Pools should be placed so that worker access to one pool for feeding or cleaning does not affect otters in other pools by walking by them. Similarly, observation posts should be placed in "blind" situations. Trailers with windows and binoculars worked well. If otters cannot see people, they groom more naturally. Otters should be shielded from noisy or high-traffic areas; these would include drying, delivery, staff, and observation areas. Noise should be kept to a minimum.

Indoor otter areas were not necessary in the Exxon Valdez spill, although some sheltering from extreme weather was required. We used plywood on roofs of enclosures for temporary shelter because it did not flap like tarps, which made the otters nervous. At SORC we did not experience harsh winter conditions as did VORC, but I would recommend adequate ventilation and wind if possible, despite cold temperatures.

Haul-out areas should be made of smooth plastic or polyvinylchloride (PVC), with some nonabrasive provision for a nonslip surface. Chemgrate was not suitable because it caused abrasions on otters' feet. If the haul-out areas were on the outside of the pool, it would make more critical surface water area available for optimal otter grooming. Ramps could be provided for emerging from the water to the haul out. The haul-out areas should provide a dry place that could be closed off from the pool for instances of hypothermia or for medical treatment.

The use of wood in enclosures should be avoided whenever possible. Problems with wood included difficulty in disinfecting the enclosures, and otters chewing on and possibly ingesting the wood. For the wooden slide-top cages, PVC capping over any exposed wood alleviates chewing of the wood, and bottoms made of PVC piping work better than wood slats, which otters often chewed.

The use of disinfectant foot baths at the center's entrances and exits, and a sink and disinfectant hand cleaner at the entrance of the center, is recommended.

Rain slickers worn by staff should be a muted color, such as dark green. Otters often seemed to be startled when staff walked by wearing bright orange or shiny yellow rain gear.

Once an otter has obtained a coat rating of 3 , it should be moved to a prerelease situation as soon as possible. Prerelease centers should be available even at the beginning of a rehabilitation effort, as otters develop problems associated with long-term holding in rehabilitation centers.

\section{Importance of Maintaining Body Temperature}

Hypothermia (chilling) and hyperthermia (overheating) occur in otters with compromised coat condition and health. Both conditions must be addressed immediately. If not caught in time, both can quickly result in seizures, unconsciousness, or death.

In hypothermia, otters exhibit differing degrees of shivering, inactivity, frantic activity, loud vocalizations, or other signs of stress. Variable weather and air temperature required frequent alterations in otter treatment (for hypothermia and hyperthermia) by husbandry staff in the same day. Shelter for the pens was provided during hard rain, snow, or hail, especially when the otters' coats were in the 1 or 2 category. Otters with hyperthermia exhibit panting and agitated or lethargic behavior; hyperthermia was usually seen only when an otter was hauled out or in a dry cage during warm weather.

\section{Treatment for Hypothermia}

On a cold or rainy day, otters were often offered food more frequently to replace the calories they expended maintaining body temperature. The protocol for handling shivering otters occurred in the following order: (1) otters were offered food, (2) stimulated to become more active, (3) helped from water and stimulated to groom by a handler using a towel or blow dryer, and (4) removed to a dry cage until they groomed on their own, and were calm and stable.

\section{Treatment for hyperthermia}

On sunny or warm days, otters were observed for signs of hyperthermia. Otters in dry cages were always given crushed ice, and inactive otters on haul-out areas for long periods were encouraged to get into the water to cool off by lightly splashing them.

\section{Charting Progress in Grooming and Coat Condition}

Drying the otter fully after washing was the most important criterion for successfully restoring coat condition.

A system was developed to evaluate coat condition and grooming behavior as the otter progressed through rehabilitation; this system was used as a quantitative measurement by all husbandry and veterinary staff at SORC. It entailed a 1-3 num- 
bering system ( 1 being the starting point, and graduating to 3 at the end of rehabilitation in both grooming stages and coat condition). Coat and grooming response were graded on daily supervisor summaries. The system is covered in detail in Rash et al. (1990).

\section{Stress Management}

Most of the warning signs indicating problems with stress were subtle and required urgent attention. Different situations we noticed contributing to signs of stress were hypothermia or hyperthermia, ineffective grooming, environmental noise, closeness of humans, other frantic (especially vocal) otters nearby, small enclosures (e.g., dry cages), placement of too many otters in an enclosure, placement of an otter with a dominant otter, and being alone (especially for smaller otters).

We watched for signs of stress-shivering, rigid posture, frantic swimming, panting, chewing on a cage or enclosure netting, hyperactivity or agitated behavior, lethargic behavior, refusing food for more than $4 \mathrm{~h}$, vomiting, vocalizing, abnormal feces (especially diarrhea or black, tarry stools), nasal discharge, heavy breathing, frantic or ineffective grooming, and in severe instances, seizures or unconsciousness. Stress symptoms could often develop into medical problems requiring treatment if not corrected quickly. For example, diarrhea could result in rectal prolapse. Stress could also result in fighting, with possible bleeding and later abscesses. Stress increased the risk involved with naturally existing problems, such as old age, pregnancy, disease, and parasitism.

Stress-related conditions were addressed quickly by both husbandry and veterinary staff. Signs of stress were addressed by dealing with possible hypothermia or hyperthermia (obtaining a core temperature reading if necessary), moving an animal to a different situation or location (in instances of noise or too much surrounding activity and other environmental or social problems causing stress), or trying different foods or feeding methods. The goal was to determine the cause of stress for an individual otter and to eliminate it.

Social bonding between otters seemed to reduce stress, so whenever possible, otters that had bonded were kept together.

\section{Social Interaction}

Overcrowding-more than three adults or two large adults in a $3.4-\mathrm{m}$ pool-seemed to result in fighting or other stress-related problems. Sometimes, moving the otters to more open pens (such as the prerelease pens) or in with a different animal improved these problems.

Generally, adults of the same size and sex were housed together. One male could be housed with adult females when necessary without creating any critical problems. At the prerelease pens, where the swimming areas were much larger, groups of 8 to 12 females and up to 6 males seemed socially compatible. In compatible groups, social bonding seemed to occur between groups of 2 or 3 otters, who would raft together (holding each other's forepaws while sleeping in the water), share food, groom each other, seek each other's company, and frequently hum when interacting.

Adolescent otters (particularly females), dominant males, pregnant females, mother-pup combinations, and critical care otters had specific housing requirements. Recommendations for special housing or social treatment, based on our experience at SORC, are as follows:

Adolescent otters-These otters seemed highly prone to stress-induced symptoms and problems, including rectal prolapse brought on by diarrhea, frantic but ineffective grooming, hypothermia, onset of clinical shock, and vocalizations. They had a higher-than-average mortality. They seemed less prone to stress if housed with other females or even males of the same size (or slightly larger) and weight. Generally, much larger females tended to dominate them and make them very nervous. Frequently, adolescent otters would bond with a subdominant adult female, who would tend to adopt the younger adolescent. Bonding with another otter seemed to reduce problems, but young females and, to a lesser extent, males were a highrisk group and were closely supervised.

Adult males-Generally, dominance would be established by one male, creating stress for older, subdominant, or ailing males. Adult males were more likely to tear through the wood in transport boxes or exhibit extreme lethargy in small areas. They had difficulty grooming in tote pools.

Pregnant otters-Some pregnancies were determined by the attending veterinarian at the time of washing and physical examination. Palpation was routinely performed on all females of breeding age. Pregnant otters were not given steroids. Quite often, pregnancy was not confirmed upon palpation, but was indicated by prenatal behavior. Pregnant otters tended to be lethargic and appeared uncomfortable 1 week before delivering, and seemed to prefer to be by themselves in a quiet 
area. Placing them in the same pool area with a more active otter seemed to make movement, grooming, and so forth more difficult. Whenever possible, pregnant otters were held in larger pools with one or two compatible females or, if at all possible, by themselves; pregnant otters were more prone to fighting. Some required assistance getting out of the water in totes and pools and had to be watched carefully. In some instances, special ramps or steps were installed to make hauling out easier for pregnant otters, but usually they were assisted with nets or paddles. Haul-out areas were adjusted to touch water level so pups, when born, could not float under or become trapped beneath the haul out.

Mothers with pups-As little interference as possible is best regarding mothers with pups. Problems often occurred as a result of movement or handling, so any elective handling should be kept to an absolute minimum. When mothers arrived with pups, they were observed from a distance for normal grooming and nursing behavior in a pool, or at least a tote enclosure, for 12-24 h. If the pup was vigorously nursing it was handled only if it required immediate washing. If no nursing was observed (mothers would sometimes abandon or stop caring for pups under the stress of the new situation) and the pup was visibly weak, veterinarians would quickly examine and weigh the pup and administer prophylactic injections of antibiotics and $\mathrm{B}$ complex intramuscularly and Lactated Ringers subcutaneously. The pup would then be tube-fed either pup formula or a Pedialyte and STAT (a high caloric lipodextrose paste) mixture. The pup was then returned to the mother with this nutritional support continued as needed for $24-48 \mathrm{~h}$. A pup was left with its mother as long as there was any hope that the mother would care for it. Pups were taken to the nursery for care based on veterinarians' assessments of their critical medical condition. If washing was required, mother and pup were reunited after the effects of sedation were no longer visible, and they were watched from a distance for normal behavior to resume. Whenever mothers and pups were transported, the kennels were placed so the door grates faced each other to provide visual contact at all times. This method seemed more successful than trying to move them together in the same kennel. Ideal housing for mothers and pups was a 3.4-m pool with at most two mother-pup pairs. At times, in all two-pair combinations we tried, there was some handling of the wrong pup by the wrong mother, with an ensuing fight, so whenever possible, I recommend that each mother-pup pair have its own pool. Larger pups seemingly could not nurse adequately in the $1.2-\times 1.2-\mathrm{m}$ pool totes; they required the space of a larger pool.

A special Daily Observation Form was developed (Appendix) to record frequency and length of all nursing occurrences.

\section{Providing Adequate Nutrition}

Otters were generally fed four times per day at $0700,1100,1700$, and $2200 \mathrm{~h}$. This schedule was a reduction from an original five feedings to reduce human traffic in the otter areas and to provide more quiet time in the afternoon. Daily food consumption proved to be equivalent. Otters that required more food (e.g., otters that were losing weight, pregnant, nursing, old, or sick) had records and cages marked for feeding more frequently than usual to meet additional caloric requirements. Sleeping otters were not disturbed for feeding, but we made every effort to feed these otters at the next feeding. The maximum amount of food given at each feeding was $2.77 \mathrm{~kg}$. Larger feedings made the otters lethargic, caused difficulty in grooming, and increased the possibility of diarrhea. Methods of feeding were varied, depending on the location of the otter. Food was offered on haul-out areas in the tote pool enclosures and served in stainless steel pans to disassociate the food from the handlers. On sunny days, food in dishes was offered on a bed of crushed ice, which also made ice available to otters in tote pools. Feeding by hand with long barbecue tongs was used in special instances to stimulate eating in distressed otters. Often, offering otters food in the water rather than placing it on haul-out areas would stimulate food consumption. Although food amounts varied from 10 to $40 \%$ of the otter's body weight (the greater amounts during early stages of rehabilitation), an average of about $25 \%$ was usual during the final rehabilitation stages. As otters recovered their coat condition, they preferred eating in the water, putting their food on their chests. Otters in pools (near the final stages of rehabilitation) were fed on demand more than on a rigid schedule (when they showed interest in eating by diving for food). Otters in pools and prerelease centers were fed in the water, with food thrown (using clean surgical gloves) to individual otters and apportioned for accurate records of food eaten. Any waste on the bottom was retrieved with a net to avoid adding to the bacteria load in the pool. 
To best meet nutritional requirements, a variety of food (usually four to five different items each day) was offered, including at least one item that provided shell roughage for $15 \%$ of total food weight. The shells gave more form to the otters' feces, decreasing the incidence of runny stools. Whole foods, such as crab, were preferred because they provided nutrients available to otters in their natural habitat. Reliable sources of local live foods were not readily available because of oil contamination. Frozen food (fit for human consumption) was ordered in advance, with enough in frozen storage for 2 weeks at a time. Each day's requirements were air-thawed or thawed quickly in cold water, then refrigerated immediately. No food was kept for more than $24 \mathrm{~h}$ after thawing. Food preparation staff followed rigid sanitation and preparation standards for handling seafood, then set the food out at feeding time in premeasured amounts or in special orders according to individual otter needs. Any food offered to an otter but refused was discarded. Small amounts, usually $1.4-1.8 \mathrm{~kg}$, were offered at a feeding; an otter's preferred food was offered last. More food was offered if an otter ate the first portion quickly. Food was left in the enclosures for no more than $1 / 2 \mathrm{~h}$, unless it was on ice or in cold water, when it could be left for $1 \mathrm{~h}$. Preferred foods were geoduck (Panope generosa), whole crab, shrimp (with shells on but heads removed because spines on shrimp heads punctured otters' forepaws and faces), mussels, pollack, squid, scallops, razor clams, and butter clams. When an otter first arrived, it was offered whole food similar to that in the environment, rather than fillets, to encourage eating.

Food supplements and vitamins were part of the nutritional program. Because frozen food was being fed, and because many of the otters suffered from anemia, supplements were used as much as possible. Pet vitamins and Nutrical could not be easily administered because the otters chewed off bite-sized pieces of food and easily detected anything unusual in their food. Sea World Marine Vitamins, designed in high dosages for pinnipeds and cetaceans, were soft enough to break into four pieces, which could be inserted into bite-sized pieces of food (usually shrimp, geoduck, or pollack); these vitamins were used most successfully.

At the prerelease center, handlers threw food in the water to the otters from a float between the pens, apportioning the amounts to make sure each otter received about the same quantity.

Kelp was provided at least once a week when it was available; it was left in the enclosures $24 \mathrm{~h}$ before removal. Otters would often roll in the kelp then fall asleep in it. Sometimes they would seem to hide in it. If they had abrasions, occasionally they would rub the kelp into their wound. They also chewed kelp and seemed to eat it.

Crushed ice (or when available, glacial snow) was always available in large quantities to otters in dry cages. Otters seemed very familiar with the snow, and would roll in it and chew it. Giving the otters ice made fluids readily available to them and helped prevent hyperthermia. Block ice was offered on hot days to otters in pools, but it was generally ignored.

For critical care otters who were not eating enough, hypoglycemia was a potential problem. To provide needed calories, snowballs made with crushed ice and soaked in STAT or dextrose were offered. Seafood that had been pureed in a blender and then frozen was also offered.

\section{Otter Husbandry Personnel}

The organization chart for husbandry, veterinary, and cleaning staff was arranged in this way:

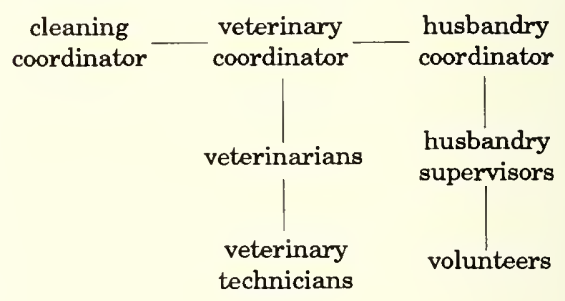

\section{Husbandry Staff}

Because of the emergency situation, trained otter husbandry personnel were not readily available. Help in initially setting up SORC was provided by Monterey Bay Aquarium, California Marine Mammal Center personnel, T. D. Williams, T. A. Gornall, J. A. Rash, and SORC staff. We began with protocols developed through the experience at VORC, adapting and revising them as necessary. J. A. Rash provided valuable ongoing training in grooming behavior and coat condition, and he designed the forms for husbandry record keeping (Appendix). Most of the staff were recruited from dedicated, although previously inexperienced, volunteers. As we learned what worked best and refined our procedures accordingly, minimum necessary staffing numbers 
became clear. Depending on the amount of care required (from intensive care for otters in critical condition to minimal care for prerelease otters), husbandry needs were one staff member for every 2-10 otters per shift; this covered all requirements. An average of one staff person was required for every four otters per shift during rehabilitation, whereas one staff person per 20 otters per shift was sufficient in a prerelease situation. We used a system of 12 -h shifts, 7 days a week. Fewer shift changes provided greater familiarity with each otter's needs and worked well from a husbandry standpoint.

Through most of the operation of the center we were short of staff, having a maximum of 36 paid staff (including 15 husbandry staff, at the maximum) supplemented with volunteers. When SORC first opened, volunteers could only stay for a few days at a time, and sometimes just the weekend. An average of 200 (6-h each) volunteer shifts were required each week.

Problems with using available volunteers in a remote location were that volunteers drained the staff's energy because of the constant training and supervision of new and inexperienced volunteers (pretrained or experienced volunteers would be preferred); the time involved in training volunteers to recognize the subtleties in otter behavior and care (by the time training was completed, most volunteers had to leave-husbandry is best provided by consistent personnel); and a lack of flexibility in volunteer numbers. Because of the need to preschedule volunteers well in advance for ticket reservations and housing (not knowing how our needs would change at the last minute), we often had either too few or too many people.

However, because of the staffing restrictions at SORC, volunteers were necessary and much appreciated, despite the problems. I recommend that for future centers a full staff should be hired using the minimum number guidelines outlined in this paper; this staff should be prepared and pretrained to work with otters, and committed to at least a month-long stay at an otter rehabilitation center. Untrained or inexperienced volunteers could be used to wash and dry otters, wash towels, and clean cages.

\section{Otter Handling and Restraint}

All husbandry staff were trained in safe handling of otters. Methods and frequency of handling were determined by choosing the least stressful alternative for the otter, and the safest method to protect handlers and veterinarians. Salmon dip nets with metal rims and short or long removable poles were preferred. The poles were used when catching the otters, then generally removed when moving the otters from one location to the next. The netting in the dip nets was replaced with softer, smaller meshed shrimp or herring netting, which was less abrasive than the original salmon netting and did not seem to disturb an otter's fur quite as much. When handling otters, leather welding gloves were always worn to prevent injury to the handlers. Otters were also moved in dry, slide-top transport cages. When removing food (or in some instances, towels) from the dry cages, long-handled grabbers were used to prevent injury to handlers. When restraint of an otter was required for treatment, a salmon net was locked over the otter, then a stuff bag (a gunny sack filled with large foam pieces) was held firmly against the animal's chest, forepaws, and head to pin it against the net sides of a transport cage or enclosure for quick treatment by the veterinarian. For most treatments requiring prolonged handling of the otter (e.g., blood drawing and physical examinations), light sedation was used rather than physical restraint. We found the otters were much less likely to overheat when chemically restrained, and they returned to normal behavior immediately after reversal of the sedative. Usually, otters were back in the water 10-15 min after light sedation.

\section{Record Keeping}

Husbandry staff were responsible for filling out complete records for everything pertaining to otter rehabilitation. Forms to be filled out included:

- An Otter Diet Chart (also see Appendix)—Records of the food actually consumed at each feeding, and related eliminations. When totaling food weight, the total weight, including, shell weight, was entered, which the computer would then subtract (based on averages) to estimate weight of food, calories, and roughage consumed. Foods preferred or refused were noted on the diet chart. Also, occurrences and condition (e.g., color, consistency, and odor) of feces and urine were noted. Staff were to notify the husbandry coordinator or a veterinarian about extreme diarrhea or dark-colored urine (which could indicate dehydration), and about black, tarry feces on the second occurrence in a row (often 
an indication of hemorrhagic enteritis, which might require treatment).

- A Daily Observation Record (also see Appendix)-Behavioral observations were made every $15 \mathrm{~min}$ or as needed, from 0630 to $2345 \mathrm{~h}$, indicating grooming (noting location of body being groomed, whether the animal was vigorous or lethargic, and allogrooming or autogrooming), swimming (including time spent in water), resting, diving, eating, or other activity. Time of observation and explanation, if unusual or noteworthy, were entered in more detail. The 15-min sheet gave a format to gauge time otters spent in each activity; this information could then be coordinated with coat-grooming gradation.

- Supervisor Summaries (also see Appendix)These were filled out for each shift (there were two 12-h shifts per day); they summarized the most important observations noted on each otter in each supervisor's area of responsibility, including coat and grooming condition (labeled 1-3). These observations were again summarized, along with daily food total and location of otter, on the Daily Otter Behavior Summary. This summary was provided daily to the director of SORC so the most current information could be given to the appropriate agencies.

- A Weight Chart-A weight chart was filled out each time an otter was weighed.

- A Location Board-The location board was updated each time an otter was moved.

\section{A System for Preventative Husbandry}

Daily rounds by both husbandry and veterinary staff began at the 0600 shift change. Areas of concern were identified, to be coordinated and handled as a team by veterinary and husbandry staff. Maintaining calm conditions at the center and minimizing stress to otters and staff were priorities. Because there were as many as 89 otters at one time, tracking each one, identifying potential problems before they became life threatening, and ensuring the best possible progress in health and coat condition were critical.

The system developed at SORC for preventative husbandry worked well in handling large numbers of rehabilitating otters. At $0600 \mathrm{~h}$, in order of priority, the husbandry coordinator would address these items:

\section{Priority I-Communication Between Shifts}

The otter areas were divided into duty areas, usually with one type of enclosure in each area (i.e., indoor or outdoor tote pens, pools, dry cages, or intensive care). Night shift supervisors would communicate any concerns (especially of an emergency nature) to the day shift supervisors coming into their duty area at $0600 \mathrm{~h}$, and the same would be done at $1800 \mathrm{~h}$, when the night shift came on duty.

\section{Priority II-Evaluation of Food Consumption}

Hypoglycemia could be a serious, life-threatening condition. As an early warning system, a comparative food consumption chart showed each otter's food consumption in pounds of actual food eaten (shell weight subtracted from the total) compared with daily food consumption for at least the previous 2 weeks. This chart was updated daily after midnight. Any otter that had consumed $1 / 2$ or less of its usual average food intake the day before was immediately flagged for medical or husbandry attention. Reduced food consumption was a warning sign, sometimes the only sign, before an otter presented a medical emergency due to hypoglycemia or other problems. Printouts were also available on histories of each otter (these histories were relative to food consumption based on percentage of body weight); these histories were checked periodically. We found the otters usually consumed larger amounts, up to $40 \%$ of body weight, during the initial stages of grooming and coat conditioning, but that their consumption generally decreased to about $25 \%$ of body weight once rehabilitation was complete.

Dietetic variety and roughage amount were monitored by reviewing the previous day's diet charts and checking to make sure that each otter was getting at least two or three varieties of food, at least one of which contained shell roughage. As necessary, adjustments were made daily to individual otter diets to achieve that goal, and pens were marked with special feeding instructions.

Adequate food amounts were indicated by otter weight gain or loss. Otter weights were recorded every 4 days. This was one method of determining an otter's progress toward rehabilitation and ensuring that the staff was meeting an individual's nutritional needs. A chart was kept on the scale and reviewed daily. Otters that had not been weighed for more than 3 days were weighed that day, and their numbers were listed on the communication board or noted with appropriate supervisors, who would weigh them at a conve- 
nient time that day. To reduce otter handling, weighing was timed for when animals were being moved for another reason (i.e., location move, move for pool cleaning, or medical treatment).

Protocol for weighing was to wait until $2 \mathrm{~h}$ after the otter had eaten and, if possible, to weigh the otter dry. Wet otter weights were marked by a "w" to indicate the possibility of water weight being included in the total. To weigh the otters, we used modified salmon nets (refitted with softer, smaller netting to avoid irritation of otters' front feet or noses). Otters were transported to an open dry cage (tare weight $22.7 \mathrm{~kg}$ ) on the platform scale. The otter was placed in the dry cage in the net (with the net held to avoid influencing the weight), and $22.7 \mathrm{~kg}$ was subtracted from the indicated weight. This number was added to the weight sheet as soon as the otter was returned to its area.

If an otter was not gaining or maintaining weight its diet was adjusted, and additional veterinary assessment was made.

\section{Priority III-Identifying Critical Problems}

At the end of each shift, the supervisor in each area filled out a Supervisor Summary of each otter's behavior in his or her care for that day. The summary included daily assessment of coat condition and grooming behavior plus comments indicating concerns about or progress with each otter. These reports were summarized on a computer printout (Daily Behavior Summary) each morning, with things to watch for marked with an asterisk next to the otter number. The asterisk served as a flag, marking priority issues to be addressed first by husbandry staff. Some causes for flagging an individual otter included medical treatment in progress, stress symptoms noticed, unusual amount of time spent hauled out, and difficulties with grooming or social interaction. When an otter was flagged, a Progress Summary (a 4-day printout of summaries, food consumption, and medical treatment) was printed by the computer. Copies were issued to the veterinarian and the husbandry coordinator, and one copy was attached to the otter's clipboard, indicating the cause for concern. The husbandry coordinator, husbandry supervisor, and veterinarian assessed the best course of action for flagged otters during that day.

\section{Priority IV-Treatment Coordination}

Night shift and day shift veterinarians conferred on medical rounds at shift changes. Veterinary and husbandry staffs then coordinated treatments. Any treatments given by husbandry staff (e.g., oral medications, eye medications, and vitamins) were logged on the Veterinary Treatment Sheet in the veterinary clinic, and also on the otter's record. If injections were required, the supervisor in charge of that otter would restrain the otter for the veterinarian. Any otters that had been flagged from a husbandry standpoint were discussed by the husbandry coordinator and veterinarian for further progress and medical assessment.

\section{Priority V-Priority Moves}

The veterinary coordinator and husbandry coordinator would rank by priority (based on progress report printout, medical priorities, and available space at the prerelease centers) daily moves requiring special handling of otters, including the following:

- new arrivals to be washed that day, requiring enclosures to be marked "do not feed in a.m." in preparation for sedation and coordination of cleaning staff, veterinary staff, and otter handlers,

- moves to the interim prerelease area (requiring final blood test), and moves to the Jakolof Pre-Release Facility. These moves required coordination with the transportation coordinator, ensuring availability of a helicopter and appropriate weather conditions for flying; and coordination with the duck pond supervisor to double-check an otter's eligibility to move and to change its feeding schedule (when they were to be moved, otters were generally fed earlier so that food was digested before they were handled for transport). To minimize stress, otters that had formed a social bond were moved together whenever possible. The move to the prerelease center also had to be coordinated with veterinary staff for administration of prophylactic injections, and retagging if necessary. We also had to arrange for several otter handlers to catch, restrain, crate (with appropriate ice for transport), mark cages, weigh, and accompany otters during transport (one handler per trip). Finally, for such a move record keepers were asked for an additional copy of all records to accompany otters to their new location.

Otter numbers in these special categories were then entered on the central communication board, and the supervisors in their areas were notified. 


\section{Priority VI-Location Update}

A map on the central communication board was checked for accuracy. The correct number of each otter in each area was crucial for everyone concerned, and whenever an otter was moved to another area, the move was marked immediately on the map. Pool cleanings were also dated and marked on that map to adhere to a proper sanitation schedule in each location.

\section{Sanitation and Disease Prevention}

Strict sanitation protocols were followed by all husbandry staff. One employee's position was devoted to sanitation procedures. Dry cages and transport kennels were disinfected between uses; equipment, such as nets and gloves used on otters, was disinfected daily; rain gear worm by staff and volunteers was disinfected every few days; and all walkways in and around SORC were also disinfected.

Husbandry staff were responsible for cleaning and disinfecting otter holding pens, totes, and pools in their assigned areas. Soiled haul-out areas were immediately rinsed (away from the pool water if possible) to avoid soiling the otters' fur as they hauled out. Totes and pools were cleaned and disinfected, preferably as otters were moved out of them, or on a rotating schedule, generally at 3-day intervals (in addition to regular removal of debris from pool bottoms). We used Nolvasan, a chlorhexadine disinfectant (diluted to 3 tablespoons per gallon of water, or 1:42), for most of our sanitation. Chlorine bleach (1:30) was used in a few instances. Whenever disinfectant was used in an otter enclosure, great care was taken to rinse thoroughly before filling pools and to avoid contamination of an otter's fur by contact with disinfectant.

Between feedings, all food dishes were washed in a dishwashing detergent and soaked in a
Nolvasan solution (1:42) for $15 \mathrm{~min}$. They were again rinsed carefully (at least twice) in fresh water and air-dried before the next use.

Husbandry staff used Betadine and Nolvasan to wash their hands when entering the center. Surgical gloves were worn whenever a person could come in contact with otter food or feces. Hands were washed regularly during shifts. Disinfectant foot baths were used for the intensive care unit and quarantine areas to prevent transmission of disease. Visitor traffic was limited whenever possible, and all domestic pets were excluded from the center.

\section{Acknowledgments}

I thank C. McCormick, veterinary coordinator, who made teamwork and some great strides forward possible; J. A. Rash, husbandry supervisor, who provided valuable systems and training in assessing grooming behavior and coat condition, and who designed the forms for husbandry record keeping; and F. Wilson, who continued as husbandry coordinator in August and September. I thank J. Kurihara, husbandry supervisor, for arranging to have critically necessary computer and blood analyzer equipment donated to the rescue effort at SORC. The staff and volunteers at SORC put forth unlimited effort and time-I thank them all.

\section{References}

Rash, J. A., C. R. McCormick, R. Alexander, S. J. Nichol, and D. C. Perrollaz. 1990. Coat gradation and conditioning of sea otters at the Seward Otter Rehabilitation Center. Pages 258-273 in K. Bayha and J. Kormendy, tech. coords. Sea Otter Symposium: Proceedings of a symposium to evaluate the response effort on behalf of sea otters after the $T / N$ Exxon Valdez oil spill into Prince William Sound, Anchorage, Alaska, 17-19 April 1990. U.S. Fish Wildl. Serv., Biol. Rep. 90(12). 


\title{
Appendix. Husbandry Forms Used at the Seward Otter Rehabilitation Center.
}

\author{
$\underline{\text { PUP }}$
}

OTIER NUMBER: SW

TAGit:

SEx:

DATE:

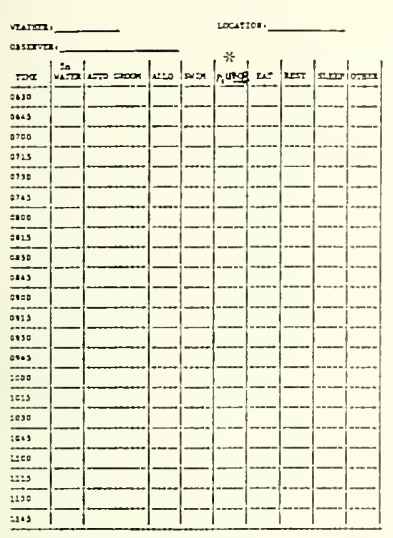

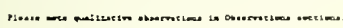

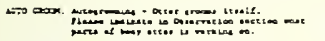

.

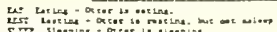
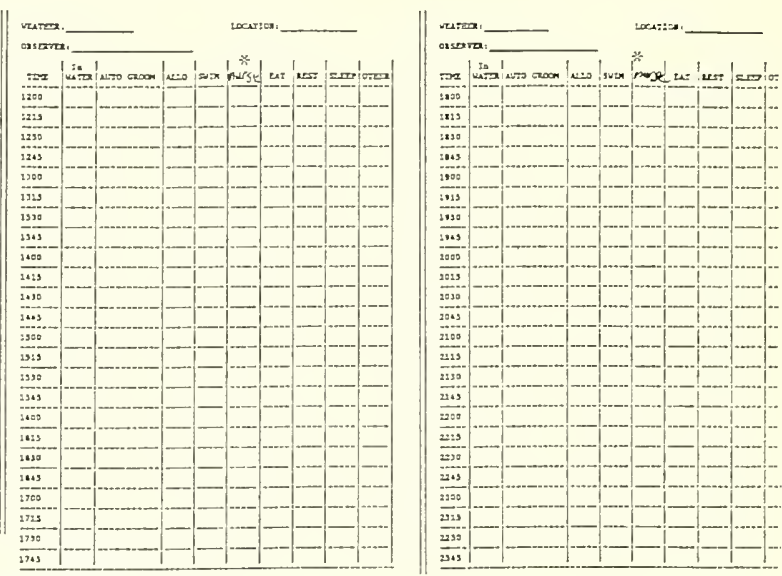

NURSING--PLEASE ENTER NUMBER OF MINUTES PER OCCURENCE.

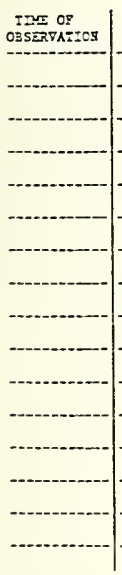

O.R.C. DAILY OBSERTAIEON RECORD 
DATE

DTTER DIET CiTART

OTTER S\#

TAG \#

SEX

LOCATION

ARRI VED (DATE)

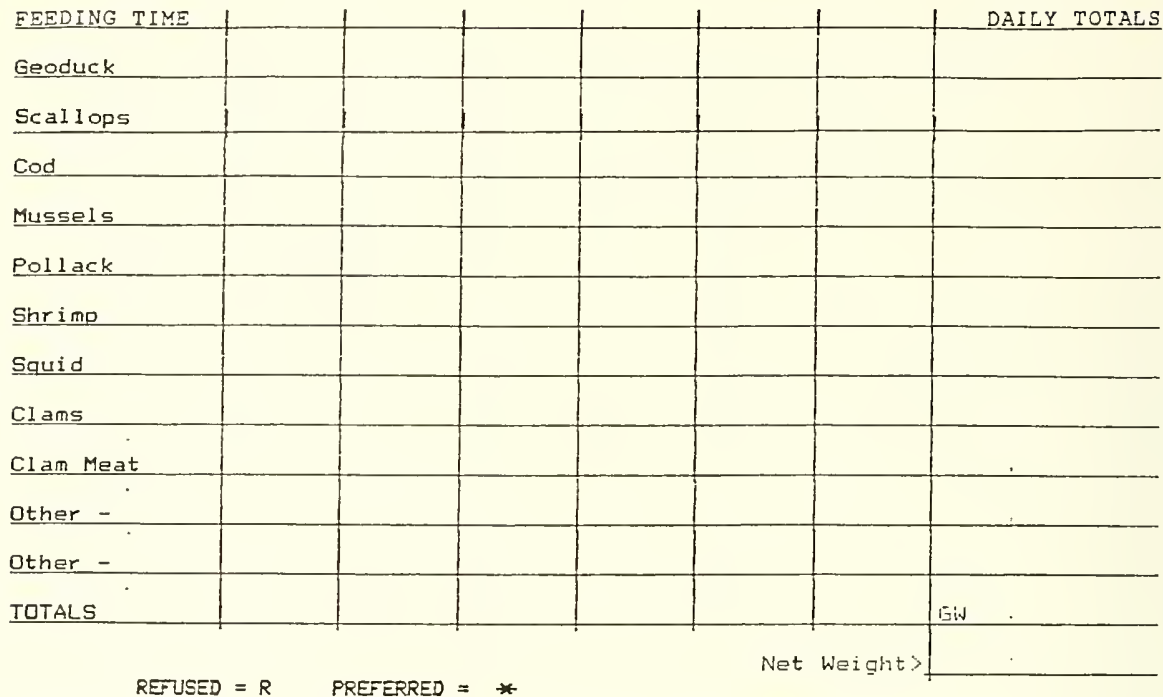

REMARKS :

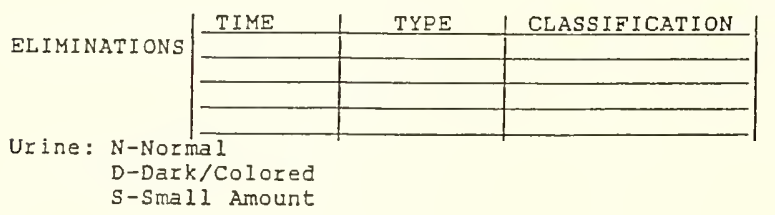

Feces: N-Normal, form L-Loose

$L / M-L o o s e ~ w / m u c o u s$

L/F-Loose, Eoamy

D-Diarrhea

B-Black, TarIy *t*

(Notify Supervisor)

o-other (specify)

REMARKS :

MEDICATIONS GIVEN :

VETERINARIAN COMMENTS: 
OTTER NUMBER: SW

TAG 击 :

SEX: 万 9 DATE:

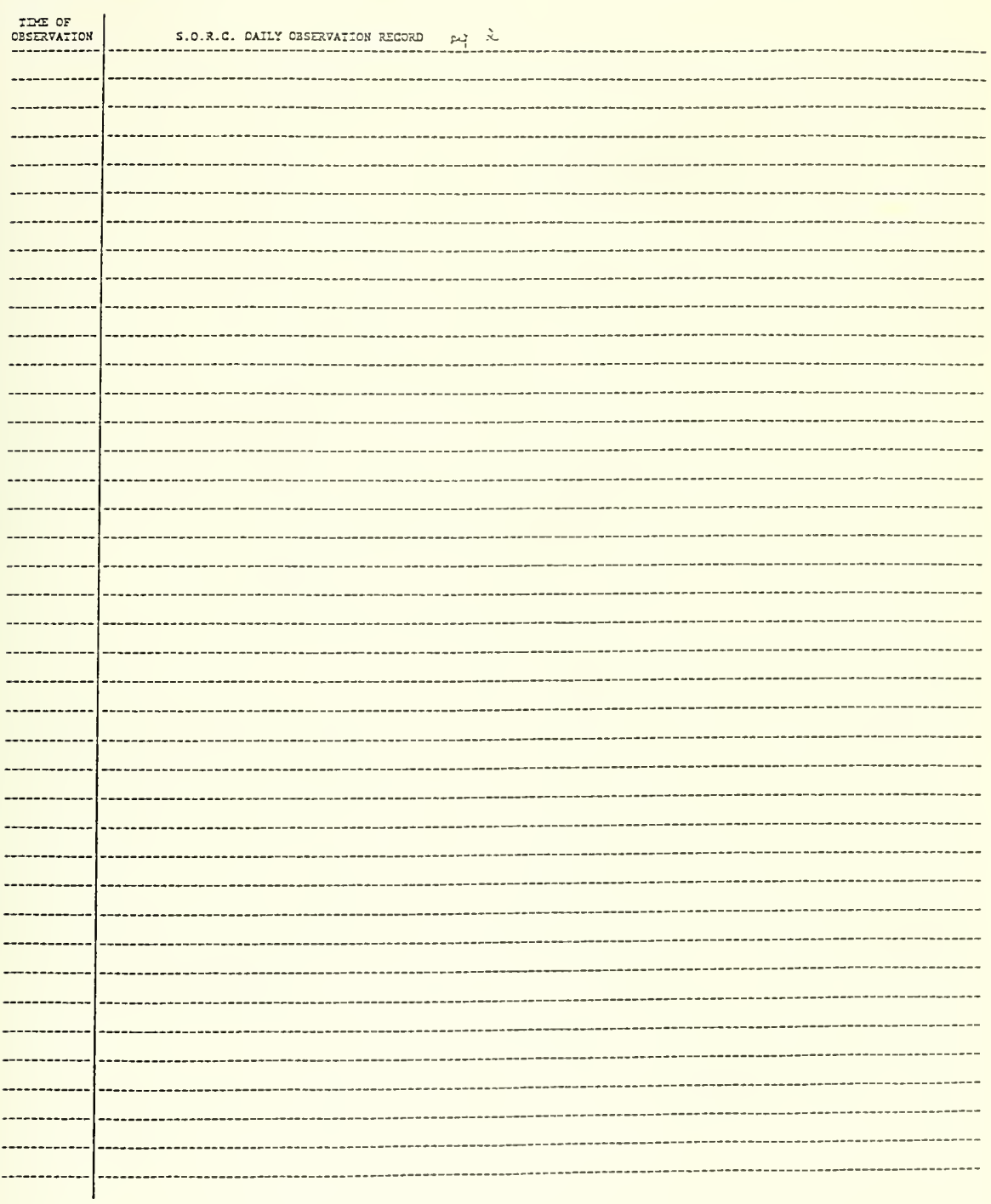


OTIER NUMBER: SW

TAGA :

SEx: $\sigma q$

DATE:

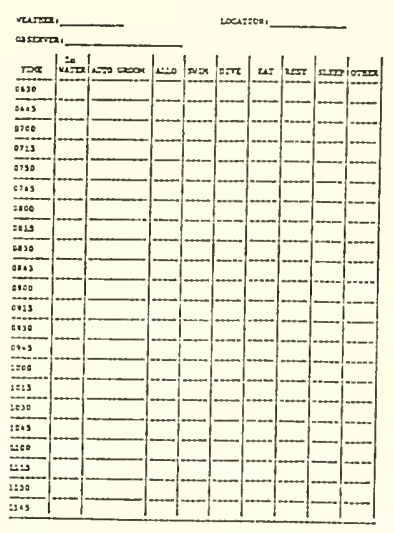

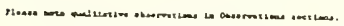

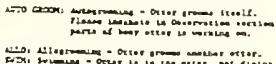

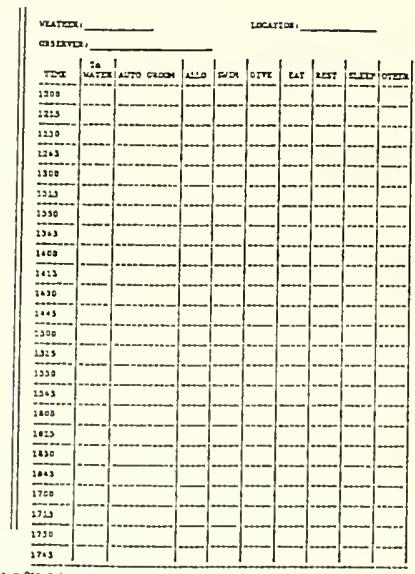

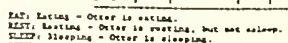

Sn:

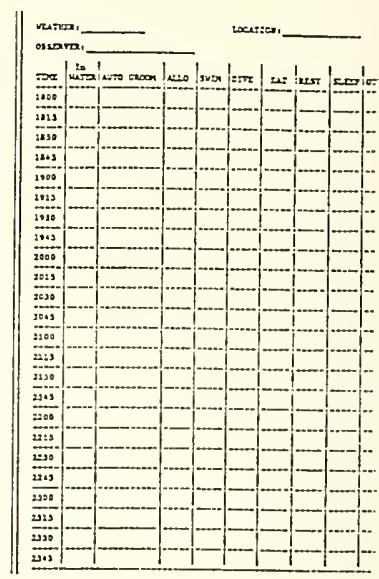

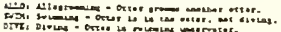

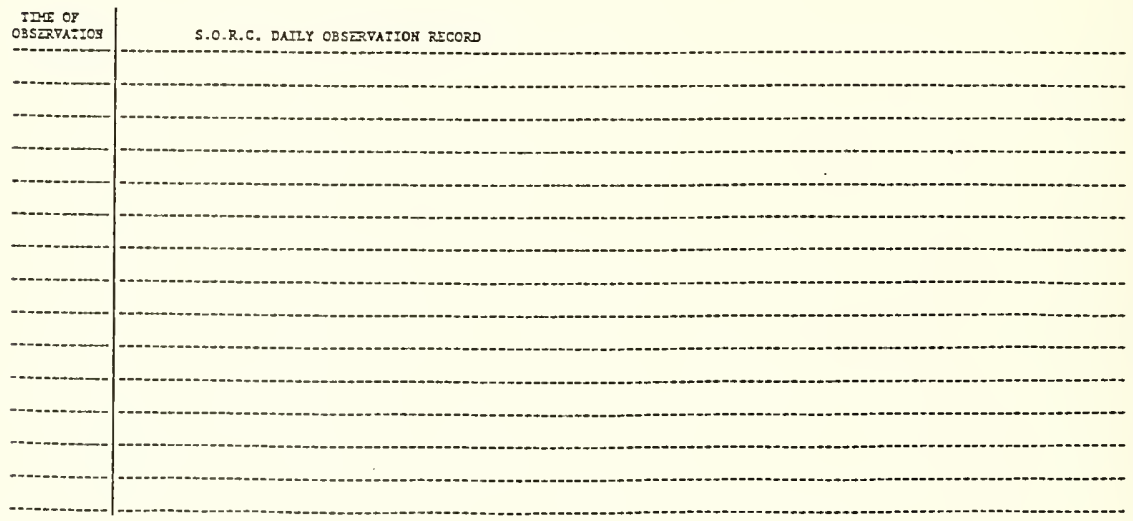


PROGRESS SUMMARY for SW-082 (Female) as of $07 / 16 / 89$ TAG\# 073

Admit Wt:

Admit Date: $05 / 11 / 89$

Oiled?: Moderately

Wash Date: 05/14/89
Most Recent Weight: 51 .

Weigh Date: $07 / 14 / 89$

Captured at windy Bay

BEHAVIOR SUMMARY fOr OTTER SW-082

EVALUATION NET WT

DATE COAT GROOM Eaten BEHAVIORAL COMENTARY

$07 / 12 / 89|2-| 2+|16.1 \mathrm{lb}|$ good appetite in AM, in h2o 108 of the day

$07 / 12 / 89 \mathrm{l} \mathrm{pm} \mathrm{|} \mathrm{|} 16.1 \mathrm{lb}$ | great appetite, 408 in h2o, upper body grooming

$07 / 13 / 89$ | $2-|3| 13.8$ lb | some trouble h/o, good appetite, on h/o most of day

$07 / 13 / 89$ | pm | | $13.8 \mathrm{lb} \mid$ grooms on h/o, appetite good, little h2o time

$07 / 14 / 89$ | $2-\mid 2$ | $13.51 \mathrm{~b}$ | good appetite, 158 of time grooming, coat needs work

$07 / 14 / 89$ | pm | 13.5 lb | good grooming, appetite good, 708 of time in h2o

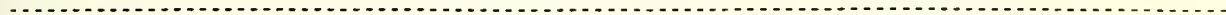

$07 / 15 / 89|2-| 2$ | $16.2 \mathrm{lb} \mid$ screaming off and on all day, fair to good appetite

$07 / 15 / 89$ | pm ] | $16.2 \mathrm{lb} \mid$ screaming a lot, good appetite, little h2o time, leth. grooming .....

$07 / 16 / 89|2| 2+\mid 11.7$ lb | moderate appetite, bottom feeds, in h2o $35 \%$ of the time

$07 / 16 / 89 \mathrm{pm} \mathrm{|} \mathrm{|} 11.7 \mathrm{lb}$ | appetite seems off, good h2o time but grooming could improve

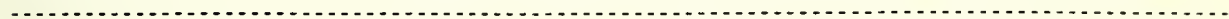

TREATMENTS SUMMARY for Otter SW-082

DATE TREATMENT COMMENTARY

$\begin{array}{ll}07 / 12 / 89 \text { Nutrical } 1^{n} \text { P.0. } & \text { received once } \\ \text { w/ ea meal } & \end{array}$

$07 / 13 / 89$ Nutrical $1^{n}$ P.O.

w/ea meal

$07 / 14 / 89$ Nutrical 2" P.0.

w/ea meal

$07 / 15 / 89$ Nutrical 2" P.O.

w/ea meal

w/ea meal

$07 / 16 / 89$ Nutrical $2^{n}$ P.O.

$07 / 16 / 89$ Nutrical $2^{n}$ P.O.
w/ea meal

I received once

I

| did not receive

I

| received 1 time

I 
300

Biological REPORT 90(12)

SUMMARY REPORT

DATE:

SUPERVISOR NAME:

WEATHER

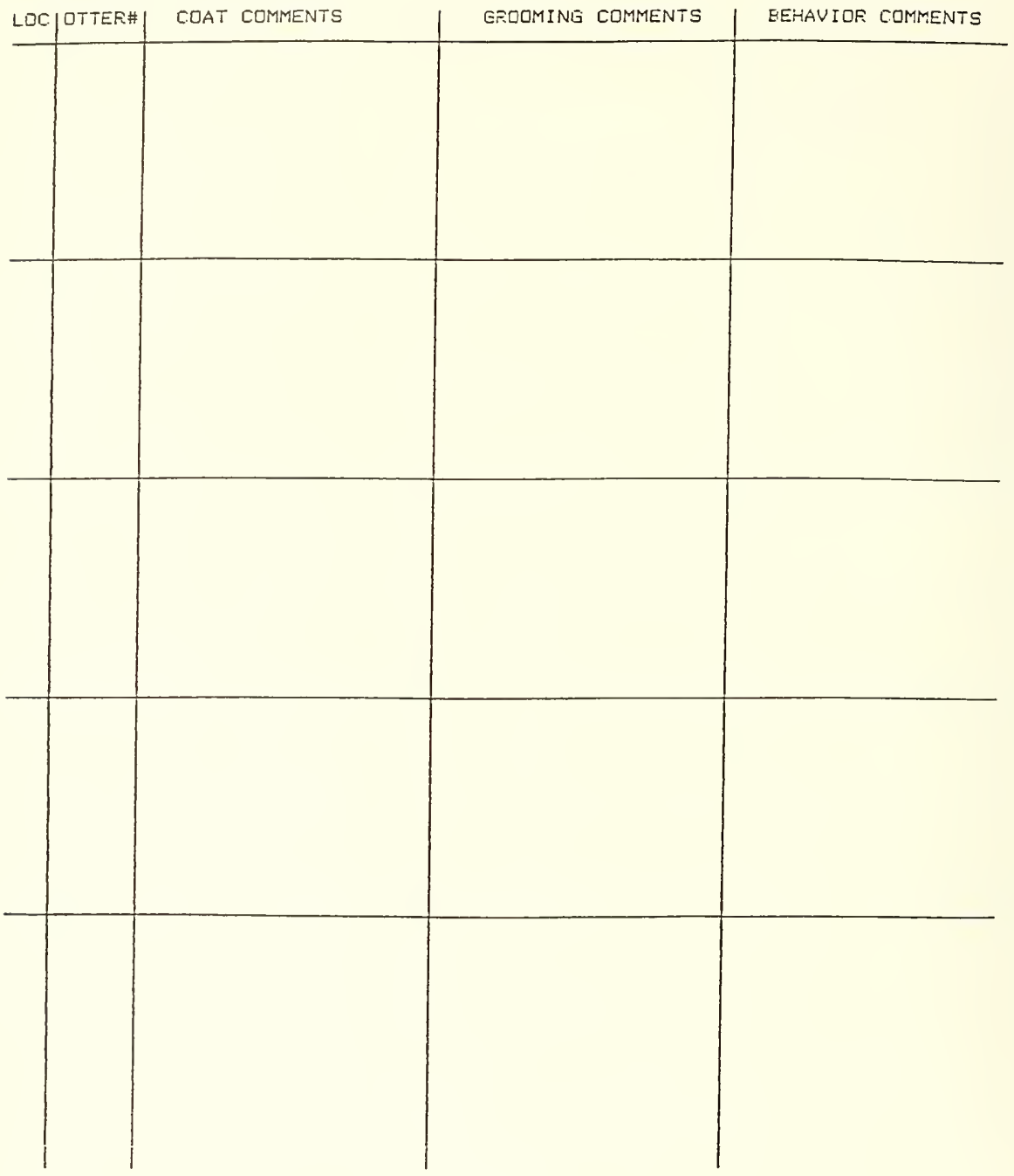




\title{
Pup Nursery at the Seward Otter Rehabilitation Center
}

\author{
by \\ A. Styers \\ Wildlife Rapid Response Team, Inc. \\ 9302 164th Avenue \\ Longbranch, Washington 98351 \\ and \\ C. McCormick \\ 15536 Husky Street \\ Eagle River, Alaska 99577
}

\begin{abstract}
Staff at the Seward Otter Rehabilitation Center cared for 21 sea otter (Enhydra lutris) pups that were born at the center, abandoned by their mothers, taken from their mothers for health reasons, or found orphaned in the Kenai or Kodiak areas. A nursery was set up to handle these pups. Although little had been previously known about raising sea otters, all knowledge was put to use. Several new techniques emerged, from formula and medical treatments to water and playtime requirements. We discuss all aspects of the pup nursery, including medical problems, building design, and the eventual shipment of 13 surviving pups to their final destination-aquariums in the lower 48 States.
\end{abstract}

The pup nursery was an integral part of the Seward Otter Rehabilitation Center (SORC). We anticipated that many sea otter (Enhydra lutris) pups might be brought to the rehabilitation center because the oil spill occurred during pupping season. Raising otter pups is labor intensive. To provide consistent care, four staff members and a few volunteers worked 12 -h shifts. As the number of pups increased, additional husbandry staff and a few experienced volunteers helped with the pups.

In total, 21 otter pups were cared for in the SORC nursery. They were born at the center, abandoned by their mothers, taken from their mothers for health reasons, or found orphaned in the Kenai or Kodiak areas. The practice of raising otter pups is far from being an exact science. We developed protocols (Appendix A)as new techniques were developed and experience warranted. We also revised the milk formula on the basis of our experience and the net weight requirements of the Alaskan otter pups.

\section{Husbandry}

\section{Design and Equipment}

Half of a 15.3-m-long trailer was used as the nursery. The nursery in the trailer was $7.6 \mathrm{~m}$ long by $3.1 \mathrm{~m}$ wide. Linoleum was used for flooring because it was waterproof and easy to clean and keep sanitary. The main equipment consisted of two large sinks (one for bathing the pups, the other for food preparation), counter space ( $2.4 \mathrm{~m}$ long), refrigerator, cabinets, and a double-sized waterbed. The waterbed was placed on the floor and surrounded by a $96.5-\mathrm{cm}$-high frame. This arrangement kept the pups contained as well as dirt and 
debris out. The waterbed gave the pups the sensation of floating. Other equipment included a blender, food scale, cutting boards, knives, measuring cups, bowls, pet driers (nonheating), cleaning materials, and an FM radio. The radio was kept on to block out the noise and cries from the adult otters, which would upset the pups whose cries would, in turn, upset the adult otters even more.

\section{Admission}

Pups arriving from the wild were separated from the other pups for the first 4-5 days. Blood samples were taken and the chemistry and hematology results analyzed. Every effort was made to ensure that disease was not passed on to the other pups. After the short quarantine period, the pups were introduced to the group.

\section{Bonding}

Because otters are social animals, association with the other pups was important. The pups rapidly bonded with one another. The bonds often superseded those with the staff; at times it was difficult to separate two animals that were bonded. The vocalization that resulted when bonded pups were separated upset the other pups in the nursery, as well as the adult otters. Occasionally a stressed pup attempted to bite a staff member. The nursery staff kept this problem to a minimum by keeping bonded pairs together when transferring them.

\section{Daily Care}

At the end of each shift (12 h), the staff exchanged information on the pups before leaving for the day. Food and formula were prepared by the previous shift for the first feeding of the next shift. Pups swam in regular saitwater husbandry totes. Newborn pups were put in the water for $5 \mathrm{~min}$ at a time. As they reached 3-4 weeks of age, they became more active in the water (i.e., swimming and putting their faces and heads under water). At this stage, they were left in the water $30 \mathrm{~min}$ or more, depending on the individual animal. All pups were put into the water after each feeding and after defecation or urination. When possible, salt water was used in the pools. In the beginning, when we did not have access to salt water, we used fresh water. However, fresh water tends to dry out the coat and skin. The pups that swam only in salt water seemed to have better coat condition. The pups were completely dried and brushed at least twice a day to prevent matting of the fur and possible skin problems from being damp all the time.

Visitation to the nursery was kept to a minimum. During V.I.P. tours, one or two pups were shown outside the nursery. Volunteers were allowed to brush or blow dry the pups, as this was time-consuming work.

\section{Hygiene}

The nursery was completely cleaned and disinfected with a Nolvasan solution at the end of each shift. A foot bath, which was used by everyone entering, was placed outside the nursery door. Nolvasan was diluted with water according to the label. All utensils were washed in hot, soapy water and rinsed thoroughly 3-4 times after each use.

\section{Milk Formula}

The basic milk formula was given to us by the Monterey Bay Aquarium (Appendix B). Two and one-half tablespoons of Kelloggs All Bran were added to each batch of the original formula to prevent diarrhea. Whipping cream was substituted for the Half and Half to provide a higher caloric content (Appendix C).

\section{Feeding}

Initially, bottle and syringe feeding were tried, but the pups' intake was small, and there was a greater risk of aspiration. Consequently, tube feeding was used to ensure the intake of 25 to $30 \%$ of the pup's body weight (which was adjusted as the pups grew). Rob-Nel catheters (size 12-FP, 16-inch) and 60-cc syringes were used for tube feeding. Tube feeding saved a great deal of time for the staff and gave the pups more time to sleep and play. Within 2-3 days, the pups became accustomed to the tube and in most cases slept through the feeding. Consistency of staff was important for tube feeding of the pups, as they felt safe and secure with the same caregiver. It is important to have an experienced person train staff to tube feed. Incorrect insertion can cause vomiting or aspiration.

When a pup first arrived, it was fed every $2 \mathrm{~h}$. The feeding schedule was changed as the pup's weight and intake improved. The schedule was gradually changed to every $3 \mathrm{~h}$, then $4 \mathrm{~h}$, per day.

\section{Transfer to Tacoma}

In late August, when it became apparent that the center would be closing, the Point Defiance Zoo 
and Aquarium in Tacoma, Washington, was chosen by the U.S. Fish and Wildlife Service as the relocation site for pups that could not be released. The director of the Seward Otter Rehabilitation Center assisted the director of the zoo and aquarium in designing and building the facilities to house the pups. On 11 September 1989, we accompanied the transfer of 13 otter pups from Seward to Tacoma. All pups arrived safely and remained at Point Defiance until placed in aquariums.

During their stay at the Point Defiance Aquarium, three of the younger pups died. The cause of death has not been determined.

Four pups were sent to the John G. Shedd Aquarium in Chicago, three to Sea World in San Diego, and three to Japan in late February.

\section{Conclusions}

Of the 21 pups that were cared for in the nursery, 13 survived and were transported to Point Defiance. Most of the pups that died at the rehabilitation center had been born prematurely. Others were rejected by the mothers. It is possible that if a pup did not have the opportunity to nurse at least once and receive its mother's colostrum, its chances of survival were reduced. No pup survived that had not nursed from its mother. Of the 13 surviving pups, two were born at the SORC and rejected by their mothers.

At 3-5 months of age, pups experienced teething problems at Point Defiance, which had not been seen in Seward. We noticed a drastic drop in food intake, rubbing of the mouth area, much stress, and much vocalization. We began to tube feed these animals again when they would not eat on their own and saw an immediate improvement. Teething would last between 4 and 8 weeks, and not all pups experienced this problem.

\section{Recommendations}

All efforts must be made to keep the pup with its mother. Pregnant females should be moved to a quiet but large tank, with no more than two females per tank. When the pup is born, 24-h observations must be made to ensure that it is nursing. If the pup does not nurse within $12 \mathrm{~h}$, or if the mother totally rejects or harms the pup, it should be taken to the nursery. Experienced staff members are absolutely necessary to give the pup the best chance of survival. Materials, food, and medical requirements need to be planned well in advance.
Maintain several areas for keeping pairs of pups, and move pups around often to lessen the bonding process, which can cause problems.

\section{Medical Concerns}

Pups placed in the nursery were orphaned either before or after their arrival at the Seward center. Every attempt was made to keep mothers and pups together; however, problems such as low birth weights, maternal neglect, and stress precluded this in all but one SORC birth. The following protocol was used with mother-pup pairs:

1. Near-term pregnant females were grouped together in pools if available.

2. A newborn pup remained with its mother for 12-24 h under close observation.

- If mother totally abandoned the pup, the pup was placed in the nursery.

- If the pup was vigorous and nursing, it was left alone.

- If the mother was grooming and caring for the pup, but no nursing was observed and the pup was visibly weakening, it was taken and treated as follows:

a. The pup was weighed and examined (handler should wear gloves).

b. The following were administered

- B Complex 0.2 cc I.M.

- Penicillin Procaine 0.2 cc I.M.

- DiTrim $48 \% 0.1$ cc S.Q.

- Lactated Ringers 30-50 cc S.Q.

c. The pup was tube fed either pup formula or a Pedialyte and STAT mixture.

d. The pup was returned to its mother.

e. During the next $24-48 \mathrm{~h}$, medical and nutritional support was continued. Then a decision was made to either place the pup in the nursery or leave it with its mother according to the pup's medical condition and the mother's ability to care for it.

Upon arrival at the nursery, pups from the wild were weighed and examined. Immediate problems, such as dehydration and hypothermia, were corrected. Prophylactic antibiotics (according to the preceding regimen) were administered for the first 5-7 days. If the mother was available, colostrum was milked from her during the first $48 \mathrm{~h}$ and administered to the pup. Pups not receiving colostrum seemed to have a poor chance of survival. 


\section{Thermoregulation}

Young pups' thermoregulatory abilities were limited. Rectal temperatures were checked every 1-2 h until body temperatures stabilized. Generally within 4-5 days after admission adequate thermoregulation had developed.

\section{Respiratory Problems}

Several pups suffered from respiratory compromise on arrival at the nursery. Pups born at the SORC and subsequently orphaned had frequently aspirated water. If the pups' coats were not being groomed they floated dangerously low in the water and were at risk of aspiration. If on auscultation upper airway sounds were present or if aspiration was suspected, the prophylactic use of broad spectrum antibiotics (Penicillin and Tribrissin) was considered sufficient treatment. Bottle feeding was avoided, and pups were tube fed to prevent further aspiration of fluids.

More severe respiratory compromise was seen in a few pups. Clinical signs manifested as fever, lethargy, and respiratory distress. These pups were treated with cidal antibiotics (Gentamicin) or Aminophylline. In one extreme case (pup SW138), oxygen was administered to alleviate the dyspnea.

\section{Diarrhea}

Loose stools were commonplace while pups were on the original Monterey Bay Aquarium formula. The diarrhea itself was not a problem, but it did soak into the perianal area, matting the fur and creating a perianal dermatitis. Two approaches to rectify the loose stools were tried: oral antibiotics (Neomycin), and replacing the natural enteric flora (Probiacin). Ultimately, the addition of bran to the formula alleviated the diarrhea.

\section{Perianal Dermatitis}

The perianal area needed to be cleaned after each urination or defecation. This resulted in a hind end that was damp most of the time. Many of the pups developed a reddened, pustular dermatitis around the base of the tail. Needle aspirates of the pustules yielded mixtures of rod and cocci bacteria, which were treated with limited success with antibiotics (Clavamox and Cephalexin). Daily shampooing with benzoyl peroxide also made some modest improvements in the dermatitis. The best method of addressing this problem was to avoid it with husbandry practices-washing the soiled area only with salt water and then blow drying until the area was completely dry.

\section{Hypoglycemia}

Both young pups and juveniles were prone to hypoglycemic seizures after relatively short periods of anorexia. Pups SW106 and SWP23 each had hypoglycemic seizures after missing only one meal. Concurrent underlying problems such as sepsis or stress exacerbated the tendency for hypoglycemia. Hypoglycemic seizures were treated with I.V. $50 \%$ dextrose. If the intravenous route was not available, Lactated Ringer's solution with $5 \%$ dextrose was administered intraperitoneally. Precautions were taken to make sure the pup received some oral glucose every $2-3 \mathrm{~h}$ until we were confident the problem had passed.

\section{Weight Gain}

The rate of weight gain varied among the pups. On the average, pups gained $0.45 \mathrm{~kg}$ every 8 days. However, weight gains slowed when pups reached $5.4-6.8 \mathrm{~kg}$. In some pups, this plateau persisted for at least 1 month (pup SW102 weighed between 5.0 and $6.4 \mathrm{~kg}$ for 8 weeks.) The best weight gains were seen in some of the pups arriving at Seward later in the season. This can be attributed partly to ensuring that each pup consumed at least $30 \%$ of its body weight a day in either formula or solid food, and a formula ingredient change from Half and Half to whipping cream. The formula change increased the caloric intake from $1.0 \mathrm{cal}$. per milliliter of formula to $1.6 \mathrm{cal}$. per milliliter.

The poorest weight gain was that of pup SWP23, which gained only $6.8 \mathrm{~kg}$ in the 3.5 months after his birth. The early poor gains were attributed to his low birth weight of $1.0 \mathrm{~kg}$ and his initial respiratory problems. Pup SWP23 survived his first month, yet remained a frail animal. His appetite was good-he frequently consumed $35-50 \%$ of his body weight per day. He did not develop swimming and other skills at the same rate as the other pups, and he had two hypoglycemic seizures, one in July and one shortly before his death in November 1989.

\section{Acknowledgments}

We thank M. Della Roca, T. Holonko, M. Olsen, and F. Wilson for traveling to Tacoma and taking care of these pups much longer than anyone had anticipated; T. Holonko and F. Wilson for helping 
devise the nursery protocol; T. Otten, for enabling us to transfer pups to the Point Defiance Zoo and Aquarium in Tacoma, Washington; and J. Jacoby, a Tacoma volunteer whose help proved invaluable. Exxon, Inc., funded the rehabilitation centers in Seward and Tacoma. We are grateful to personnel at the Monterey Bay Aquarium for basic information concerning otter pup care, and to J. Hymer and T. D. Williams for their assistance and expertise. Finally, we offer special thanks to the nursery staff in Seward, who dealt with the sea otter pups through good times and bad. 


\section{Appendix A. Nursery Protocol.}

This protocol represents some of the information that we learned in operating a sea otter pup nursery in Seward, Alaska, after the 1989 oil spill from the T/V Exxon Valdez. This information should be treated as a starting point onto which additional information may be added. The key ingredients to raising sea otter pups-stress reduction, proper nutrition, veterinary supervision, coat development, and social development-are necessary in any situation. How these are attained will differ as funding, pup health, staffing, and other factors dictate. We first present background information on what otter pups do and what their special requirements are before we describe how to operate an otter nursery.

\section{Background}

\section{General Development}

In the wild, sea otter pups are totally dependent on their mothers for food, grooming, and social development. As they grow they go through the following general stages:

1-week-pup nurses, is groomed by the mother, and spends most of the time sleeping in the water; 2-3 weeks-begins grooming groin and abdominal area, more interaction with mother, begins to be able to hold its head up, still sleeping most of the time;

3-4 weeks-more active, playing, begins lifting upper body, more grooming; and

4-5 weeks--better swimming ability, shows more interest in diving, will accept solid food from mother.

In a nursery setting, the ideal situation is to allow pups to follow this general development pattern. As the pups grow and develop, they will instinctively move toward solid foods and begin to groom themselves.

For the purposes of this paper, we define three categories of development based on age, weight, and dentition:

1. Pup

- birth to 3 months

- 1.1 to $5.4 \mathrm{~kg}$

- pup teeth appear

2. Juvenile

- 3 to 8 months

- 5.4 to $11.4 \mathrm{~kg}$
- pup teeth are replaced by adult teeth during this stage

3. Adult

- 8 months or older

- more than $11.4 \mathrm{~kg}$

- teeth become broken or worn

\section{Bonding}

The pup will develop a strong bond with the caregiver, or with other pups if they are around. We found at the Seward Center that these strong pup-pup bonds could be detrimental in that any separation led to severe stress behavior, which made veterinary treatment, tube feedings, and general handling a problem. In an ideal situation, pup-pup bonds should be avoided until after the pup is weaned from formula.

\section{Grooming}

During the first weeks of an otter's life, it is groomed by its mother about $30 \%$ of the time. The pup coat is fluffy, buoyant, and keeps the pup dry and afloat. It also requires much grooming, which in a nursery setting must be provided by the nursery staff.

\section{Diet}

A formula is used as a replacement for the mother's milk. After $3-5$ weeks in the wild, pups begin to show some interest in the solid food that the mother is eating. Although pups continue to nurse to some extent until they reach the juvenile stage, solid food is more and more a part of their diets. In a nursery setting, formula is gradually replaced by solid foods as the pup grows.

\section{Nursery Guidelines and Procedures}

\section{General Guidelines}

Some general rules regarding the nursery should be established: (1) Only authorized personnel are allowed into the nursery area. All exceptions must be approved by the center director or nursery coordinator. (2) Communication with the press should be consistent with guidelines set up by the center as a whole. Otters inspire strong emotions in many people and the potential for 
misinformation is high. (3) Veterinarians and nuxsery personnel should work as a team-both have important viewpoints to be considered, and both should be involved in decision making. (4) When screening staff and volunteers for the nursery, care should be taken to exclude individuals without a sincere interest in rehabilitating the otters.

\section{Nursery Environment}

A clean and quiet environment is crucial to success. One of the primary objectives should be maintaining a quiet area for the pups. The nursery should be located away from the area where adults are being rehabilitated, as otter noises can be much more disquieting to a pup than human noises.

Otter pups require close temperature monitoring-they can become hypothermic if exposed to water when coat condition is poor or food consumption is low; they may become hyperthermic if room temperature rises too high or if they are held too long. Room temperature should be kept between 12 and $14^{\circ} \mathrm{C}$ and definitely no bigher than $17^{\circ} \mathrm{C}$. Unheated waterbeds should be provided for the pups to sleep and play on. This gives a cool support that mimics a water environment.

Clean salt water is a key ingredient to coat development and grooming. Ideally, the pups should have pool areas separate from the adults. Because otter coat condition is affected by humidity, outdoor pools are preferable to indoor pools. A roof over the pools may keep out strong sun and rain (direct sun may overheat pups on the haul out, and fresh water is detrimental to coat condition). Water quality should be in accordance with government standards for marine mammal holding facilities.

\section{Sanitation}

Nursery staff should follow the same procedures for limiting disease transmission as the other staff of the center. Suggestions include shower-in procedures before coming to work, wearing coveralls over street clothing (or maintaining separate work clothing), taking foot baths between work areas, limiting contact between staff and domestic animals (even off the work site), and not allowing staff members to work when sick. While each center has its own unique problems and solutions, full consideration of the possibility of disease transmission from domestic to wild animals must be a priority.

Nursery staff should work only in the nursery, avoiding any contact with the adult otters or adult otter areas. Conversely, staff working with the adult otters should not be allowed in to the nursery area without following full sanitation procedures as given previously. Twice daily all areas in the nursery should be disinfected (we used a Nolvasan solution-2 tbsp per gal of water), including waterbeds, sinks, counter tops, and floor. The foot baths should also be changed regularly, trash emptied, and contaminated towels removed. All towels that are used with the pups should first be washed in a dilute bleach solution to disinfect them. Soaps, water conditioners, and fabric softeners should be avoided, as the chemicals they contain may harm the otters' coats. Staff training should emphasize sanitation.

After each feeding, all tube feeding and food preparation equipment must be washed thoroughly in hot, soapy water and rinsed well. No soap residues may be left on any equipment. In addition, all equipment should be disinfected by using a Nolvasan solution on a regular basis.

\section{Record Keeping}

A record-keeping system should be established before the first pup arrives. The data system should be compatible with the general husbandry system of the center, with data being entered into a central computer on a daily basis. This central data base allows veterinarians and others to quickly examine older records or compare trends between groups of otters-an important ability in an emergency situation. Information about the pups should include food (amount, type, times of feedings, preferred foods, rejected foods), medical (medications administered, temperature, odd behavior), behavior (feeding, sleeping, grooming, playing, swimming, interaction), feces (consistency, color, amount, time, urination), grooming (by the staff, self-grooming), coat condition (pup versus adult coat, matting, buoyancy, water repellency, what areas need work), and swimming (frequency, duration, diving, and swimming behavior). We found that differentiating between medical and husbandry notes was important.

In addition to the records described above, it is important to devise a good system of communication between shifts. In Seward, we used both oral review of the shift's events and a written "turnover" sheet. This informal written record ensured that small details thought of in the middle of a shift were not missed at shift change. This sheet included policy information, informal sugges- 
tions, and any other communication thought to be important.

\section{Stress Reduction}

Keeping stress to a minimum is vital to a pup's health. Therefore it is essential for staff to be able to recognize stress and eliminate its cause. A pup may vocalize when stressed. It may be hungry, frightened (by sound or sight), uncomfortable or in pain, overheated, chilled, or soiled and in need of cleaning. (In emergency cases, a sick pup may not be able to vocalize; it should be watched carefully for any changes that indicate an unstable situation.) Identifying and eliminating the problem should satisfy the pup and quiet it down. Stress can easily be induced by medical treatment, especially frequent injections. If this seems to occur, nursery staff should discuss this with the veterinarian, who may not be aware of the stress the treatment is causing.

\section{Admission Procedures}

For each pup entering the nursery, certain ad. mission procedures should be followed: (1) Physical exam by veterinarian. This will determine if the pup needs immediate emergency care or is stable and healthy enough to be monitored by nursery staff. (At the Seward Center, veterinarians generally would administer B-complex vitamins, Tribrissen, and an antibiotic. Subcutaneous fluids would be given if the pup seemed dehydrated). (2) Measure core body temperature. This will indicate how well the pup is thermoregulating and help staff determine whether the pup needs a cooler or warmer environment. Body temperature should be taken every half hour for the first $4 \mathrm{~h}$ to ensure that it has stabilized. (3) Check hydration. The veterinarian will probably do this upon initial exam. If dehydration is suspected, check with a veterinarian immediately. (4) Measure accurate body weight. (5) Feed the pup. Upon arrival, the pup should be given a small amount of formula every $2 \mathrm{~h}$ (10-20 cc Pedialyte and 15-20 cc formula) by tube feeding. (6) Take a blood sample. (7) Take a stool sample. (8) Keep the pup quarantined from any other pups for 5 days. (9) Assign an identification number. (10) Monitor the pup carefully during the first $24 \mathrm{~h}$, focusing attention on food intake, defecation and urination (especially lack of), temperature, regular breathing, and excessive vocalization.

\section{Feeding}

Pups under the age of 1 month are tube fed formula until they begin gaining weight; after 1 month, solid foods can be offered. The amount of formula the pup requires in a 24 -h period in order to grow is $30 \%$ of its body weight. The following formula is used: (pup weight in ounces $\times 0.3$ ) 6 . This value is the amount of solid food in ounces the pup should be eating at each meal, given six feedings in $24 \mathrm{~h}$. This value is multiplied by 30 ( $30 \mathrm{cc}=1$ ounce) to get the number of cubic centimeters of formula the pup needs at each of six feedings in $24 \mathrm{~h}$. As mentioned earlier, newly arrived pups should be fed smaller amounts of formula more often until they adjust to the food. Very young pups may be fed every $3 \mathrm{~h}$ for the first 1-2 weeks.

To tube feed a pup, use a catheter tube long enough to reach the stomach (measure from the throat to the bottom of the rib cage), yet small enough in diameter to easily slip down the pup's throat. Pups should be tube fed while on their stomachs to prevent aspiration of formula. Formula should be warmed to near body temperature before use.

When the pup reaches 1 month, it should be offered solid food gradually, beginning with small pieces of seafood such as scallops, shelled shrimp, geoduck, pollack, or squid. For the first few days, only small amounts (2-3 ounces at a meal) of solid food should be offered. If the pup does not eat the required amount of solid food at a meal, the rest of the meal should be formula, fed to the pup 3060 min after it has eaten solid food. By 3 months, the pup should be eating solid food exclusively.

We found that some pups had problems when teething. By the time the adult teeth were coming in, the pups were usually spending all their time in the pools. In the pups that had teething problems, we observed rubbing of faces, lowered appetites, and less grooming. In some severe cases, we had to revert to tube feeding for a short while, as the pups stopped accepting solid foods, even when offered small pieces of soft food. Most pups, however, had little problem with teething.

\section{Grooming}

Swimming in clean salt water is important for maintaining a healthy coat. Even pups only days old need regular exposure to salt water. Pups should swim in clean salt water (no chlorine or fresh water) as frequently as possible - at least at 
each feeding and after defecating or urinating (wait at least $15 \mathrm{~min}$ after tube feeding before a swim to avoid vomiting). Water will induce the pup to urinate and defecate, especially if some is splashed on the genital area. After the swim, the pup should be blotted dry with a towel, brushed, and blown dry (cool air dryer only). The pup should be dried completely to prevent skin irritation. The anal and genital areas should be kept clean and dry.

As the pups grow, they should spend more time in the water to encourage their own grooming skills. As the pups' grooming skills develop, they will lose their pup coat and gain their normal adult pelage. As the pup coat is being shed, special care must be taken to brush the coat carefully to prevent matting of the fur. When a pup can dive, groom, and haul itself, it can stay in a pool with a haul out full time.

\section{Medical Considerations}

One of the most important duties of the nursery staff is to monitor and help regulate the pup's temperature. Normal otter pup temperature is between 33.5 and $34.0^{\circ} \mathrm{C}$. Temperatures below $32.5^{\circ} \mathrm{C}$ or above $35.0^{\circ} \mathrm{C}$ require immediate attention. Treatment of extreme hypothermia or hyperthermia should be under the direction of a veterinarian, as rapid temperature changes can lead to shock. To warm a pup, first try warming the general environment; remove the pup from a cool waterbed or put insulating blankets or towels down between the pup and the waterbed. For more extreme cases of hypothermia, place warm water bottles on the flippers, or administer warmed subcutaneous fluids. For hyperthermia, place ice or cold water packs on the flippers. Again, environmental temperature regulation is preferable-in many cases of hyperthermia, the pup just needs to swim. Also, handling the pups-too much time on a warm lap during feeding, struggling during treatment, or tube feeding-can raise temperatures.

Urine and stools are important indicators of a pup's health. Stools should be of firm to pudding consistency. A veterinarian should examine any pup with watery stools or diarrhea. Stool color and consistency will vary with diet, but black tarry stools are an indication of blood in the digestive tract. Some foods (e.g., squid) can cause blackish stools, but a normal diet will not produce the tarry stools characteristic of blood. Urine should be yel. low or clear. Lack of urination is a sign of kidney malfunction, and a veterinarian should be notified.
Pups usually urinate while swimming, so a lack of urine will only be noticed in very young pups or sick otters whose water contact is limited.

There are three general ways to determine if the pup is well hydrated. First, the skin test should be given. If, upon grabbing the fold of skin at the back of the neck, the skin seems to hold its shape for a few seconds, like a tent, this could indicate dehy. dration. Second, the gums should appear wet. Upon depressing the normal pink gums, they should regain a pink color (from white) within a second. Third, the eyes should appear wet, almost teary. Pups that have just arrived, appear sick, or are acting abnormally should be checked frequently to see if they need fluids. If fluids are needed, pups will usually eat ice balls made from crushed ice (dextrose or food supplements may be added to the ice balls if the pups' nutrition levels are low). Fluids may also be tube fed or, under veterinary direction, administered intravenously or subcutaneously.

Other signs to watch for are vomiting, lethargy, breathing difficulty, or changes from normal behavior. Lethargy, vocalization, lack of appetite, and poor or compulsive grooming behavior can be signs of stress.

Several emergency situations may develop quickly in sick or stressed otter pups. When toxic oil effects or other causes lead to low food intake or improper digestion, hypoglycemia may result. When low blood sugar reaches a critical level, the otter may suddenly become lethargic, body temperature will drop quickly, and seizures may occur. For this reason, any otter with a history of hypoglycemia, any sick otter, or any otter whose food intake has been below normal should be watched carefully for abnormal behavior.

If hypoglycemia occurs, the primary objectives are to increase blood sugar and temperature as quickly as possible. Nursery staff can use emergency hypothermia procedures described previously, as well as administer oral dextrose (50\%) either by tube feeding or oral administration-it can be absorbed from under the tongue without swallowing. Veterinary support will usually include dextrose or possibly warm fluids intravenously or subcutaneously.

Aspiration of seawater or formula can be another potential emergency situation. If this happens, positioning the pup in a head-down orientation and clearing the mouth will usually be sufficient. For extreme aspiration, immediate veterinary care is required. 


\section{Socialization}

The ideal situation for a pup born in captivity or that is brought in with its mother is to keep them together through the rehabilitation process. To this end, keeping mother-pup pairs in pools by themselves in a quiet area is necessary. Any other otters in the same pool can stress the mother and lessen the chances that she will form a strong bond with the pup. The pair should be watched $24 \mathrm{~h}$ per day for the first few weeks, recording frequency and duration of nursing bouts. Observation should be made from a blind where the mother is not aware of the observer. All human contact, including veterinary intervention, should be kept to a minimum.

Even in the wild, pups are sometimes abandoned by their mothers. In a captive situation, there will also be times when pups will have to be separated from their mothers. We recommend that guidelines be developed ahead of time so that decisions regarding the future of the pup will not be made under pressure.

In a nursery with more than one pup, decisions regarding pup-pup bonding will have to be made. Pups destined to be released will, of course, be treated differently from those destined for captive display, so knowing the eventual disposition of the pups is a necessary first step in considering how to treat pup-pup bonds. We recommend that pups not be introduced to each other until the bond to the caregiver is well established. If pups are put together, we recommend that pups be grouped by sex, mimicking the sex-segregated groupings seen in the wild, and that initial exposures be for short periods only. 


\title{
Appendix B. Monterey Bay Aquarium Sea Otter (Enhydra lutris) Pup Milk Formula.
}

\author{
Make fresh daily: \\ $4 \mathrm{oz}$ clams (Manila or butter) \\ $4 \mathrm{oz}$ squid (skins, guts, and head removed), if no clams, double squid \\ $100 \mathrm{~mL} \mathrm{5 \%} \mathrm{dextrose}$ \\ $200 \mathrm{~mL}$ Lactate Ringers \\ $200 \mathrm{~mL} \mathrm{Half}$ and Half \\ $2 \mathrm{~mL} \mathrm{Hi-Vite} \mathrm{(two} \mathrm{droppers} \mathrm{full)}$ \\ 1 tsp D-Ca-Fos \\ 1 capful cod liver oil \\ Blend thoroughly: \\ Squid, clams, fluids, Hi Vite, D-Ca-Fos, and cod liver oil for 3 min, add Half and Half last, blending \\ for $30 \mathrm{~s}$; put in container \\ Label container (date-time-initials) \\ Keep refrigerated at all times \\ Dispose of after $24 \mathrm{~h}$
}




\section{Appendix C. Seward Otter Rehabilitation Center Sea Otter (Enhydra lutris) Pup Milk Formula.}

\footnotetext{
Make fresh daily:

$4 \mathrm{oz}$ clams (Manila or butter); if no clams, double squid or use shrimp or tender geoduck instead $4 \mathrm{oz}$ squid (skins, guts, and head removed)

$100 \mathrm{~mL} \mathrm{5 \%} \mathrm{dextrose*}$

$200 \mathrm{~mL}$ Lactate Ringers*

$200 \mathrm{~mL}$ whipping cream

1 tsp D-Ca-Fos

1 capful cod liver oil

2 1/2 tbsp Kelloggs All Bran

$2 \mathrm{~mL} \mathrm{Hi}$-Vite (two droppers full)

$1 \mathrm{Sea} \mathrm{Tab}$

Blend thoroughly:

Squid, clams, fluids, Hi Vite, D-Ca-Fos, cod liver oil, and bran for 3 min; add whipping cream last, blending for $30 \mathrm{~s}$; put in container

Label container (date-time-initials)

Keep refrigerated at all times

Dispose of after $24 \mathrm{~h}$
} 


\title{
Behavioral Observations of Rehabilitating Sea Otters in Prerelease Holding Pens
}

by

\author{
N. E. Michaelson \\ HC01 Box $6916 F$ \\ Palmer, Alaska 99645
}

\begin{abstract}
I summarize techniques and charts used and behavioral observations made of sea otters (Enhydra lutris) rehabilitating in prerelease holding pens in the Valdez and Seward Otter Rehabilitation centers, Alaska, after the T/N Exxon Valdez oil spill. Correct and informative observations by handlers, and careful review of their notations by the husbandry and veterinary staff, are requisite to ensuring successful rehabilitation or early detection of health problems in otters. Sleeping, eating, grooming, and hauling-out patterns along with shivering, net hanging, repetitive diving or porpoising, lethargy, aggression, vocalization, social interactions, and individual activity levels were affected by age, stress, health, boredom, sex, personality of individual, and captivity. Documented information about these behaviors or factors affecting them was not general knowledge among the husbandry staff on location daily. In the event of a future sea otter rehabilitation effort, more background knowledge in these areas is needed to improve the ability of the husbandry staff to identify which behavioral patterns indicate possible health problems or the return to health and normal behavior, thereby alerting caregivers to the need for veterinary care or providing a sound basis for release recommendations.
\end{abstract}

After the T/ Exxon Valdez oil spill and the establishment of the Valdez and Seward Otter Rehabilitation centers and the Jakolof Pre-Release Facility, more opportunities existed than ever before for behavioral observations of captive wild sea otters (Enhydra lutris). Except for a short-term program developed on-site at the Seward Center by Rash et al. (1990), which was not successfully completed at the holding pens, no behavioral research projects existed at any of the facilities. As part of routine husbandry duties, however, exact diet and basic behavioral patterns of each sea otter were recorded and collected daily. The purposes of these observations were to note anything that might indicate health problems, track progress in restoring fur to original condition, and record general activity levels.

My opportunity to work with the Valdez Otter Rehabilitation Center began on 7 April 1989 and lasted until 24 May, at which time I went to the Seward Otter Rehabilitation Center and worked until the last adult otters were released back to the wild on 24 August. After 3 weeks of monitoring otters in dry cages, the rest of my experience at each center was working at the prerelease holding pens.

I present only the basic behavioral observations of sea otters in the prerelease holding pens. In almost all instances, these areas held sea otters that had been washed clean of oil, had finished passing oil or tar through their systems, retained what appeared to be a normal level of alertness, and did not need any further intensive medical care. With sea otters oiled early in the spill, this process lasted 1 to 2 weeks. After the first 4 weeks of the spill, and when the facilities had space for the otters to move through to the holding pens as soon as they were ready, the process lasted 4 to 7 days.

\section{Observations}

Each sea otter at a rehabilitation center was assigned a number on arrival. In the holding pens, individual behavioral observations were made after specific otter numbers were learned, and the otters were identified by flipper tag numbers, natural 
scars, coloring, or other recognizable characteristics. I recorded and studied notes to distinguish between, and get to know, otters (Appendix A). My observations were made while I performed basic husbandry staff duties, some of which were to order and provide food (and medicine if necessary), note general health and coat condition, watch for medical problems and alert the veterinarian or director, and keep proper records of these activities. Appendix B shows a sample Daily Otter Behavioral Summary produced by staff at the Seward Otter Rehabilitation Center.

During the otter rehabilitation effort, captive sea otters were usually segregated by sex. There was concern that mixing of sexes in pens would cause fighting among males and harassment of females by males.

The sea otter behaviors I observed fell into five classic, broadly defined activity states: grooming, feeding, interacting, resting, and moving (Packard and Ribic 1981).

\section{Grooming}

Sea otter grooming patterns have been described by Packard and Ribic (1981; Table 1). These patterns were observed in the holding pens at both the Valdez and Seward centers, and many of them also occurred while the sea otters were kept in dry pens.

When oiled sea otters are cleaned, detergent used in the washing process strips their fur of its natural oils and water repellency, thereby impeding the ability of the fur to insulate. Rehabilitating sea otters expend increased time grooming to stimulate the distribution of natural oils back into their fur (Davis et al. 1988).

On arrival in holding pens, otters often groomed continuously for extended periods, from a few hours to as long as $32 \mathrm{~h}$. Grooming was most lengthy and intensive in otters with poor coat condition. Grooming became more normal as coats improved. In many instances coats were fully restored within a week of arrival in holding pens.

Table 1. Description of action patterns of sea otters (Enhydra lutris) observed in prerelease holding pens. Definitions are from Packard and Ribic (1981).

Action

General description

Floating

Hanging

Logrolling

Looking

Nibbling

Rocking

Rubbing

Shaking

Somersaulting (pinwheeling)

Stroking

Tuckrolling (augering)
Otter floats belly-up on the surface, rear feet up; no sculling feeding, or grooming movements

Belly-down with both rear and head submerged; the arched back remains visible at the surface, motionless for a few seconds as the otter apparently grooms its belly

From a belly-up position, the otter rotates to the side like a rolling log; differs from rocking in that feet and paws are submerged

Belly-up or on its side, the otter turns its head in various directions

Mouth contact is made with some part of the otter's own body, in a nibbling or licking movement; commonly directed toward paws, belly, feet, or tail

From a belly-up position, the otter does a side roll with torso arched such that the feet and paws remain out of the water

Rear feet rub some area of otter's own body

The head is rotated rapidly from side to side in a typical shaking movement; the muzzle may be outstretched

Full $360^{\circ}$ forward roll with the head tucked close to the belly; often only the curved back is visible until the head reappears at the end of the roll

Front paws repeatedly stroke some area of the otter's own body; may vary in intensity (rapidity of strokes); commonly directed toward chest, head, rear feet, belly, tail, flank, or back

Head is brought toward chest but bent over to side while otter does a $360^{\circ}$ side roll; intermediate between a somersault and a logroll 
Newly rehabilitated otters in the holding pens seemed to enjoy their ability to move freely in the larger pens. They spent the majority of their grooming time performing tuckrolls, or as we called it, augering. The animals were able to get into a rhythm while augering and continued at it tirelessly. This grooming technique allowed the sea otters to thoroughly clean and blow air into the fur on the belly and midsides. Somersaulting, or as we called it, pinwheeling, distributed bubbles into the fur the length of the back. The lower belly and back seemed to be groomed most often with a hanging technique or by hauling out and nibbling on these areas.

Sometimes one sea otter could be seen groom. ing another, or allogrooming. This occurred mainly between pairs of bonded otters (those that spent a large percentage of time in contact or close to one another).

\section{Feeding}

Sea otters with damaged fur require increased energy from food to survive (Siniff et al. 1982). Free-ranging adults may consume food equivalent to $23-33 \%$ of their body weight daily (Riedman and Estes 1988), and captive otters require at least as much (Kenyon 1969; Rotterman and Simon-Jackson 1988).

At the Valdez Center, no set feeding times were established. Observations of feeding were made constantly, and notes were made of the observations at least once an hour. This allowed the husbandry staff to begin feedings as soon as the sea otters showed signs of hunger. Characteristic behavior at those times was a medium level of activity, lethargic grooming, and diving in search of any food items that may have been left on the net bottom from the last feeding. Food was thrown into the pens by handlers hidden from the otters' field of vision. The intent was to minimize the direct association of food with handlers' presence. Care was taken to throw the food into the water between the sea otters, and not to them, so as to make them dive for food.

At the Seward Center, set feeding times were established. Food was thrown to the sea otters while the handler kept low at one end of the holding pens. There were no solid sides of the pens, and the handler was always in view. Concern existed about the amount of food that might lie uneaten on the bottom of the pens, so the handlers were instructed to toss the food directly to the sea otters. Observations were made many times of the same postrest, prefeeding behavior that had been seen at the Val- dez Center. However, in contrast with Valdez, sea otters would then swim to the nearest end of the pens and either periscope or haul out in apparent search for the handler. Begging occurred regularly.

Stealing of food occurred occasionally. Larger adults were observed robbing smaller adults or juveniles. Juveniles and subordinate males usually offered no resistance, but aggressive males might snap at robbing males (Kenyon 1969). This was, in my experience, the major cause of fighting among the sea otters. The fights were generally brief, typically less than $1 \mathrm{~min}$.

Use of tools by sea otters during feeding was observed. Rocks were not usually available on the bottoms of the nets in the holding pens. The sea otters used them when they could, otherwise they hit crabs or mussels together. They sometimes also hit the whole bunch of mussels on their own chests.

From time to time sea otters shivered while sleeping after a feeding. These occurrences did not seem to be signs of a medical problem for most of the sea otters in the prerelease holding pens, because the shivering was sporadic and occurred in apparently healthy otters. The degree of shivering seemed to be low enough to not disturb the affected sea otters. Data from my observations showed a significant correlation between shivering in specific animals and their consumption of a large amount of food within the previous hour. Although any frozen food had been thawed before delivery to the holding pens, it was kept packed in ice and was fed to the sea otters in a near-frozen condition.

\section{Vocalizing}

A summary of the vocalizations I observed, in the terms and definitions established by Kenyon (1969), is shown in Table 2.

At the Seward Otter Rehabilitation Center, otter number SW 155 became easily identifiable by, and gained quite a bit of notoriety for, her whines. Otter SW 155 produced loud whines when the staff approached the deck for feedings, when the staff moved the totes of food from the outside area to the storage area at the water's edge or from the water's edge out onto the dock, upon eye contact with a familiar handler, or upon entry into the fenced area by a familiar handler. At certain times it seemed that she also whined if she believed a staff member could hear her. Coos from the otters in general were also heard during feeding times.

Sea otter screams are as unforgettable as they are shrill. These screams were heard in the critical care areas of the otter rehabilitation centers. At the Valdez Center, the distance from the main 
Table 2. Definitions of vocalizations of sea otters (Enhydra lutris) from Kenyon (1969).

Screaming

Whistling

(whining)

Cooing

Snarling

Hissing
Severe distress-as when held in unsatisfactory captive conditions, or when a female loses her young; earsplitting at close quarters and can be heard 0.4 to $0.8 \mathrm{~km}$ away.

Denotes frustration or mild distress. Captive sea otters whistle when the feeding schedule is delayed or when they are transported; high-pitched vocal sound-loud enough to be heard 200 m away.

Females coo when satisfied and content or when eating if their food is particularly pleasing; can be heard as far as $30 \mathrm{~m}$ away.

Originates deep in the throat and is often uttered by newly captured otters.

Characteristic of females and juveniles, this sound is uttered during or after capture or before becoming tame. center precluded the screams being heard at the holding pens. At the Seward Center, the proximity of the main center to the holding pens meant that screams uttered by distressed sea otters were heard by the sea otters in the holding pens. The sea otters were sometimes bothered enough by the screams to respond, especially if pups were screaming. Otherwise, this kind of vocalization did not occur in the holding pen area.

Snarling and hissing were heard in the main rehabilitation centers from newly arrived, agitated, uncomfortable, or ill sea otters, but was not experienced at the holding pens.

One other vocalization heard at the Seward Center was from a mature male (SW 153). He stayed more than a week by the side of the male pen that was separated from the female pen by only the narrow dock. During that time he periscoped and stared at the female pen continuously, uttering strong, low moans.

\section{Interacting}

Observed sea otter interactions included nosing, or muzzle contact made with another otter, many times one behind another; pawing, the reaching out with one forepaw to contact, shove, or pat a partner; shoving, when a sea otter forcefully pushes another otter away with forepaws; splashing, when a sea otter moves partly submerged paws away from its body toward another animal, making water splash; and giving, when an otter holds out something to another otter that takes it.

Fighting was uncommon among sea otters that I observed. Fights almost always involved a quick lunge of one otter toward another. In extreme instances, lunges might include biting (Packard and Ribic 1981), but the otters usually finished their dispute quickly. The fights were usually over food items.

Bonding was observed among $35-40 \%$ of the sea otters in holding pens. Bonded sea otters spent most of their time with one another; they played, groomed, and ate together, and slept next to each other.

\section{Moving}

Swimming as locomotion occurred only in short spurts because of the restrictive size of the holding pens. Another swimming pattern observed was porpoising. A sea otter would swim beneath the surface and then emerge, arching its back tightly to dive directly back into the water. My notes indicate that $10-12 \%$ of the sea otters in Seward were observed porpoising. This was generally a solitary activity that occurred only a small percentage of the time; however, exceptions did occur.

A juvenile female (SW 157) was often seen playfully darting around other females in an apparent attempt to invite them to play. When she finally found a playmate, she would often begin a game of chase that included much porpoising. Perhaps some of what ensued was also racing; porpoising in unison sometimes resulted from these interactions.

Porpoising might be a symptom of extreme stress or depression, rather than play. Most of the time porpoising appeared to be a form of playfulness or athletic endeavor. At the Seward Center, a young adult male (SW 154) spent time every day in a routine of porpoising that made use of the entire length and depth of the holding pens. At one end of the pool, he dove to the bottom, swam to the other end, returned the length of the pool under- 
water, and porpoised up in a tight arch to once again dive in the same spot where he began. The routine was of such a perfectly repetitive manner that I was able to time the rounds, which occurred every 10.5 s. Kenyon (1969) observed a sea otter that, like many zoo animals, developed an exercise routine during which she circled the pool.

Walking was observed, but only for short distances on the haul outs. The body of the sea otter is long and heavy, making movement on land clumsy and slow (Kenyon 1969).

\section{Resting}

Sea otters rest, or sleep, either in the water or hauled out on land. On the land they sleep in many positions, from lying on their backs as they would in the water to stretching out flat on their bellies or curling up nose to tail (Kenyon 1969). In my experience, the older sea otters with fur that had not quite regained its full loft hauled out more often than the other sea otters. In the water, they float on their backs, flippers either up or folded on their bellies (Packard and Ribic 1981). They float individually or join together with others, forming a raft.

Garshelis (1983) observed that more nocturnal than diurnal resting occurred in female groups and that they were somewhat more distant from each other in resting than otters in male groups, where the otters were often touching. At both the Valdez and Seward centers my observations concurred with those findings, although at times the nocturnal resting patterns in the female pens seemed to reverse themselves. During a 4-day period the week of 7 May in the Valdez harbor holding pens, the sea otters showed a marked loss of appetite during the days. The change may have been due to the absence of the day-shift handler, to whom the female sea otters had become accustomed. They slept much less at night for those few days, and they ate enough fish at night to make up for what they had refused during the day. Upon the return of the regular day-shift handler the animals immediately returned to their original patterns of behavior. In general, sea otters seemed to acclimate to particular handlers within a few days of arrival.

Kelp, although not found in all sea otter environments, is an important part of resting and sleeping for sea otters. Wild sea otters often use surface kelp canopies for resting and foraging. Kelp may be used as an anchor to keep from drifting with tidal currents or wind (Kenyon 1969). Captive sea otters seemed to develop a number of techniques for anchoring while sleeping.
At the harbor holding pens in Valdez, yellow line was used to attach some flashing to the nets at water level. Occasionally, an extra length of the line would work itself free, sometimes aided by adroit handling by the sea otters. Sea otters were then seen playing with the line, even trying to unbraid it sometimes, but mainly rolling themselves up in it and going to sleep. At the same location, the pens had been constructed with the support posts on the inside of the nets. Otters were often seen squeezing their bodies between the posts and the nets just above water level. They would curl around the posts a bit and fall asleep, presumably thereby attaining a comfortable level of security and stability. One juvenile in particular (V 97) even found a corner of the pen where she crawled up into and curled up on a floating net stretched awkwardly between two edges of the pen support. All of these instances seemed to reflect the frequent use of kelp in the sea otter's natural sleeping habits.

In Seward, where the holding pens were constructed with the support posts on the outside of the nets, opportunities for similar sleep patterns did not exist. However, the sea otters anchored themselves by grabbing onto the net with their teeth, or, as it came to be called, nei hanging.

Net hanging was seen at the Valdez and Seward centers in cages, totes, pools, and holding pens. Net hanging was often viewed as a sign that the sea otter was stressed. Indeed, sea otters portraying this behavior were often not well. Net hanging could have been a sign of uncomfortable boredom. An alternative view is that it was simply anchoring behavior. One female (SW 124) with good coat condition and activity level continually slept in the water while net hanging. Three other females that she seemed to be bonded with (SW 146, SW 155, and SW 157) habitually held onto her as if to anchor themselves through her.

Whether it was done because of depression or stress, or as anchoring behavior, occurrence of this behavior had a negative effect on evaluations of the health of more than a few sea otters, and recommendations for movement from pool-to-pond or from pond-to-release were affected.

This behavior raises some questions: Does kelp produce any chemically induced comfort to the teeth, gums, or system? Does it perhaps produce an anesthetic or cooling affect? Could data on its composition provide us any added information on how beneficial the relation is between sea otters and kelp? 


\section{Recommendations}

The recommendation of marine mammal biologists has been that more research is necessary to determine discrete action patterns in sea otters to develop criteria for gathering action patterns into functional categories (Packard and Ribic 1981). My recommendations are that any future sea otter rehabilitation center management use as much information as is presently available, while remembering the distinction between wild, captive, and captive-wild otters. The information should then be consolidated into behavioral guides that could be presented to and discussed with all veterinarian and husbandry staff, made available to all staff upon request, and formulated into a valid set of release recommendation criteria.

Guides to sea otter behavior would improve the understanding of what is really happening to sea otters in the rehabilitation centers. For example, each husbandry member differed in his or her belief of what stressors for the sea otters were. This confusion suggests the importance of keeping observations and records objective and descriptive. At the same time, husbandry observations demonstrated how any hint that could have helped identify which behavior patterns indicated possible health problems or the return to health and normal behavior of the sea otters would have been invaluable.

Bonding in sea otters should be researched further. No research data exist to support the occurrence of significant bonding among sea otters. Commonly accepted knowledge of release information suggests that sea otters that appear to be bonded during captivity separate quickly and willingly upon release back to the wild. This seems to be so even when care has been taken to keep bonded otters together during release efforts. However, my observations of numerous gregarious interactions among otters that had returned to a fairly normal level of health suggested that further research is warranted. Because of logistics of release or transfer between or within facilities after the T/V Exxon Valdez oil spill, sea otters were held long enough in one holding-pen facility to become accustomed to it and become acquainted with each other. It is my belief that additional research would provide the data necessary to support a new understanding of the behavior of wild sea otters in captivity, while providing a different realization of the importance of their bonding.

Research should be undertaken to establish the cause of net hanging in captive-wild sea otters.
This behavior is significant in that a misunderstanding of it on the part of the husbandry staff affected the care and handling of many otters on a daily basis.

My final recommendation is that low-impact treatment, feeding, and observational methods continue to be a well-publicized, high-priority operational routine for any sea otter rehabilitation effort. My observations of sea otters' reactions to known handlers (no reaction) and to unknown photographers, press, or other handlers (frightened and skittish) indicated that when employed, serious efforts taken toward this end at the Valdez and Seward centers proved successful in providing environments that sea otters could become accustomed to.

\section{References}

Davis, R. W., T. M. Williams, J. A. Thomas, R. A. Kastelein, and L. H. Cornell. 1988. The effects of oil contamination and cleaning on sea otters (Enhydra lutris). II. Metabolism, thermoregulation, and behavior. Can. J. Zool. 66:2776-2781.

Garshelis, D. L. 1983. Ecology of sea otters in Prince William Sound, Alaska. Ph.D. thesis, University of Minnesota, Minneapolis. 321 pp.

Kenyon, K. W. 1969. The sea otter in the eastern Pacific Ocean. Dover Publications, Inc., New York. 352 pp.

Packard, J. M., and C. A. Ribic. 1981. Classification of the behavior of sea otters (Enhydra lutris). Can. J. Zool. 60:1362-1373.

Rash, J. A., C. R. McCormick, R. Alexander, S. J. Nichol, and D. C. Perrollaz. 1990. Coat gradation and conditioning of sea otters at the Seward Otter Rehabilitation Center. Pages 258-273 in K. Bayha and J. Kormendy, tech. coords. Sea Otter Symposium: Proceedings of a symposium to evaluate the response effort on behalf of sea otters after the T/ $\mathrm{V}$ Exxon Valdez oil spill into Prince William Sound, Anchorage, Alaska, 17-19 April 1990. U.S. Fish Wildl. Serv., Biol. Rep. 90(12).

Riedman, M. L., and J. A. Estes. 1988. A review of the history, distribution and foraging ecology of sea otters. Pages 4-21 in G. R. VanBlaricom and J. A. Estes, eds. The community ecology of sea otters. Springer-Verlag, New York.

Rotterman, L. M., and T. Simon-Jackson. 1988. Sea otter. Pages 237-275 in J. W. Lentfer, ed. Selected marine mammals of Alaska: species accounts with research and management recommendations. Marine Mammal Commission, Washington, D.C.

Siniff, D. B., T. D. Williams, A. M. Johnson, and D. L. Garshelis. 1982. Experiments on the response of sea otters, Enhydra lutris, to oil contamination. Biol. Conserv. 23:261-272. 


\section{Appendix A. Notes and Characteristics for Identifying Otters (Enhydra lutris) in Holding Pens at the Seward Otter Rehabilitation Center.}

Listed here are the notes I made on 15 July 1989 of the otters in the holding pens. The numbers in parentheses refer to the printed numbers on the flipper tag, tag color, which flipper the tag was attached to, and whether printed side of tag was on the belly side or back side, in that order. The most distinctive traits were underlined.

Males

Weight (kg)

151 (092 gray R belly) Into pond 7/2, rear $1 / 2$ slick, yellow head

152 (025, $038 \mathrm{red})$

Into pond 6/3, net hangs, darkest face of males, slick coat

153 (199 yel. $R$ belly)

Into pond 6/27, silver head, chest, belly, small spot on nose, good coat, moans at female pen

154 (198 yel. $\mathrm{R}$ belly) Into pond $6 / 27$, dark face but mottled, porpoises a lot

\section{Females}

43 (109 yel. L back)

Into pond 6/21, light head and base of arms, light pink stripe down nose

$60(020,038$ red $)$

Into pond 6/21, yellow head and chest, beats chest and splashes, raw nose (red), sticks rear end out of water and shakes

124 (061 yel. L belly)

Into pond 6/21, dark fur, light whiskers, net hanger

137 (094 gray L)

Into pond 6/30, silver head and chest, small

144 (186 yel. L belly)

Into pond $6 / 25$, light head, pretty

146 (079 yel. L back)

Into pond $6 / 27$, dark face, nose and whiskers are lighter, bonded w/\#157, good coat

155 -no tag-

Into pond $6 / 30$, face just a little bit lighter than the rest of fur, talks, all groomed out except base of tail

157 (089 yel. L belly)

Into pond 6/29, dark face (whiskers lighter), good coat, bonded w/\#146, quick and little 


\section{Appendix B. Sample of a Daily Sea Otter (Enhydra lutris) Behavior Summary From the Seward Otter Rehabilitation Center.}

\begin{tabular}{|c|c|c|c|c|c|}
\hline Otter & Location $^{1}$ & Coat $^{2}$ & $\mathrm{GRM}^{3}$ & $\begin{array}{c}\text { Food } \\
\text { (pounds) }\end{array}$ & Behavioral comment \\
\hline SW-004 & $\mathrm{T} 1$ & 3 & $2+$ & 3.4 & $\begin{array}{l}\text { moderate appetite, not much grooming in a.m., bet- } \\
\text { ter in p.m. }\end{array}$ \\
\hline SW-043 & Pnd & 3 & 3 & 17.0 & all time in $\mathrm{H}_{2} \mathrm{O}$, grooming has improved her coat \\
\hline SW-060 & Pnd & 3 & 3 & 17.0 & rafting $w / 124+144$, good grooming \\
\hline SW-077 & $\mathrm{T} 4$ & 1 & 1 & & no appetite, screaming all day \\
\hline SW-077 & $\mathrm{Dt}$ & (eve) & & & glucose crash at $1900 \mathrm{~h}$, euthanized \\
\hline SW-082 & $\mathrm{Dt}$ & p.m. & & 12.4 & difficulty hauling out, screams before defecating \\
\hline SW-089 & T 8 & 2 & 3 & 16.0 & good appetite, likes shrimp \\
\hline SW-106 & Nur & 3 & & & good grooming, irritable in pm \\
\hline SW-116 & Ken & 2 & 3 & 18.8 & MOVED TO KENNEL TO BE NEAR 82 \\
\hline SW-124 & Pnd & 3 & 3 & 15.5 & most of time in $\mathrm{H}_{2} \mathrm{O}$ net hanging \\
\hline SW-128 & P 6 & 2 & $2+$ & 17.0 & $25 \%$ of time in $\mathrm{H}_{2} \mathrm{O}$, mod. appetite \\
\hline SW-137 & Pnd & 2 & 2 & 15.0 & hauls out to groom after feeding \\
\hline SW-144 & Pnd & 3 & 3 & 16.0 & net hung for $45 \mathrm{~min} w / 146$ \\
\hline SW-144 & Pnd & $\mathrm{pm}$ & & 16.0 & rafting $w / 60+124$, good grooming \\
\hline SW-146 & Pnd & 3 & 3 & 16.3 & refused pollack, holding 144 \\
\hline SW-153 & Pnd & 3 & 3 & 24.3 & refused pollack, likes geoduck \\
\hline SW-154 & Pnd & 3 & 3 & 26.8 & allogrooming 153 , less porpoising \\
\hline SW-157 & Pnd & 3 & 3 & & plays w/155, allogrooming 155 \\
\hline
\end{tabular}




\title{
Food Procurement and Feeding of Sea Otters During the T/V Exxon Valdez Oil Spill
}

by

\author{
P. Ferrante \\ Monterey Bay Aquarium \\ 886 Cannery Row \\ Monterey, California 93940
}

\begin{abstract}
The T/N Exxon Valdez spilled 11 million gallons of crude oil in Prince William Sound on 24 March 1989. During spring and summer 1989, 339 sea otters (Enhydra lutris) were captured and taken to otter rehabilitation facilitites for treatment of various medical problems. These sea otters were severely stressed by oil contamination and removal from their natural environment. Adequate nutrition was an important factor in their recovery.

I discuss requirements and duties concerning food preparation and handling. In addition, I discuss food procurement from distributors, food types, expense, transportation, food storage, refrigerators, freezers, ice, methods of thawing frozen food, and equipment used in providing food for the rescue operation. Because of its high metabolic rate, a captive sea otter consumes about $15 \%$ of its body weight each day. As the exact nutrient requirement of the sea otter is not known, a variety of food was offered. Otter pups require special food, and preparation of pup food requires intensive labor. The facilities were staffed on a 24 -h basis.
\end{abstract}

In Valdez, food was obtained through local wholesale suppliers-Sea Hawk Seafoods through FAVCO of Anchorage. Procurement was complicated because fresh fish from the area was contaminated by the oil spill. The suppliers, however, were very cooperative. To compensate initially, local community members donated frozen fish from their home freezers. Once supply lines were secured each day, otters were fed geoduck (Panomya ampla), fish (cod, pollack), scallops, clams, squid, mussels, shrimp, and crabs. Frozen geoduck had to be flown in from Canada. At first, the geoduck sat for days in the freezer at Sea Hawk Seafoods because the boxes were labeled sea cucumber, and nobody wanted to touch it, let alone feed it to an otter.

The frozen food was ordered and picked up daily from the supplier, about $10 \mathrm{~min}$ from the Valdez Otter Rehabilitation Center (VORC). The food was stored at the center in two 27-cubic-foot freezers. The Seward Otter Rehabilitation Center (SORC) also used FAVCO, which delivered at SORC three times a week.
Initially, food was thawed in warm (sometimes hot) water, but this procedure was determined to be unsafe because of the danger of bacterial growth. Cold-water thawing helped prevent spoilage. Frozen food was also placed in refrigerators for slow thawing. Thawing under refrigeration leaches fewer vitamins than water soaking but requires a longer thawing period.

Thawed food was then prepared for feeding. Food was rinsed, and fish were filleted and cut into strips or chunks. At first, diets consisted in part of whole shrimp, crabs, and clams. However, because of clogged drains in the holding pens at VORC, shrimp had to be peeled, clams shelled, and squid "penned" (the ink removed). When otters were moved to outside pens or holding tanks, whole crab, mussels, and clams in the shell were added to the otters' diet.

Prepared food was placed in plastic bags in 1-, 2-, and 5-pound portions, then placed on large covered trays and stored on ice until needed by animal handlers. However, food was initially put 
directly on food trays without being put in plastic bags, which was not as sanitary, and the food became water-saturated. Shaved ice and block ice were provided daily by the suppliers. As many as 30 blocks of ice, specially formed into $4-\times 12-\times$ 18-inch blocks, were used daily. Ice was used for food storage and also given to otters. As an animal handler arrived to collect food for feeding, food in plastic bags was placed on ice in buckets and taken directly to the otters.

Otter preference for food items changed, and orders were adjusted to reflect food acceptance. Greycod, halibut, and herring were not eaten by the otters and were discontinued. Otters vigorously consumed scallops at first, but acceptance decreased, so the orders were adjusted. Squid was consumed intermittently throughout rehabilitation. Food consumption varied, depending on the number of otters (e.g., on 16 June 1989, the otters consumed $21.8 \mathrm{~kg}$ of food, on 29 May 1989 , they consumed $628 \mathrm{~kg}$ ).

Food items were purchased at surprisingly competitive market prices, with a total cost for all centers of $\$ 900,000$.

\section{Personnel}

One person was in charge of food procurement for each otter rehabilitation center. This person made all the food room staff assignments (day and night 12 -h shifts). Six people worked each shift at VORC, with one acting as supervisor. The Seward Center had four people on each shift, with one acting as supervisor. In addition to food preparation procedures, staff members continually kept the food rooms clean and sanitary.

\section{Food Preparation Area}

The Valdez Center was initially shared with the Prince William Sound Community College lunch room; often the food was prepared outside. In the gymnasium, the food preparation room was about $3 \times 3 \mathrm{~m}$, with two sinks, $7.6 \mathrm{~m}$ of wooden counter space, two 27-cubic-foot freezers and a $363.2-\mathrm{kg}$ capacity refrigerator just outside the food room.

The Seward Center's food preparation room was $3.3 \times 7.9 \mathrm{~m}$ with $9.1 \mathrm{~m}$ of stainless counter space and two sinks; it had three 27-cubic-foot freezers and three 27-cubic-foot refrigerators.

\section{Recommendations}

The following items are recommended to provide adequate, easily accessible, nutritious, and uncontaminated food for about 100 sea otters:

1. A mobile facility consisting of one 40-foot freezer truck and one 20-foot refrigerator truck, with an additional truck to handle deliveries.

2. A space of 37.2 square meters for food preparation, with windows and fans for ventilation. The area should have six sinks and at least $9.1 \mathrm{~m}$ of counter space.

3. An ample supply of plastic buckets, several sizes of plastic bags, sharp knives-four 12-inch butcher, four 8-inch butcher, and four 8-inch fillet-four blenders, six 2- $\times 3$-foot plastic cutting boards, eight garbage cans, 12 rubber aprons, 12 pairs of rubber gloves, two scales (0-16 ounces), four scales ( $1-5$ pounds), various sizes of plastic storage containers with lids, 25 large plastic-covered trays $(12 \times 18 \times$ 22 inches), two water hoses, knife sharpeners (two stones and two steels), tools for shelling, and so forth.

4. A list of which fish and shellfish to include in each diet should be available to food preparers, with approximate proportions per poundweight of otters. Feeding schedules and diets should be used for procurement to prevent ordering large amounts of unneeded food.

5. A manual or video explaining techniques of food preparation should be available for each staff member. A trained supervisor from a previous spill or from an aquarium should be available to train new employees. 


\title{
Veterinary Procedures Session
}

\author{
Chair: Jon F. Thomas, Chester Valley Veterinary Hospital, Anchorage, \\ Alaska.
}

Editors: Romona J. Haebler and Thomas D. Williams.

\section{Postcapture Supportive Care of Oil-contaminated Sea Otters}

\author{
by
}

\author{
J. F. Thomas \\ Chester Valley Veterinary Hospital \\ 1571 Muldoon Road \\ Anchorage, Alaska 99504
}

\begin{abstract}
Experience aboard capture boats soon after the T/V Exxon Valdez oil spill produced clinical data and observations on oiled otters. Signs observed in newly captured sea otters (Enhydra lutris) included shivering, weakness, coma, blindness, loose stools, diarrhea, eye irritation, and subcutaneous emphysema. Subtle behavioral characteristics in precapture oiled otters were head and neck shaking and intense grooming. Captured otters were often unable to maintain body temperature in kennels on deck, and precautions were necessary to prevent hypothermia. Survival was low in otters captured in areas where relatively unweathered oil was present.
\end{abstract}

Before the T/N Exxon Valdez oil spill there was much concern about the vulnerability of the sea otter (Enhydra lutris) to a crude oil spill. I discuss the condition of otters observed aboard otter capture boats beginning 2 April 1989, and concentrate on the early days of the spill when acute signs of toxicity were observed. Treatment and handling of newly captured, oil-contaminated otters are discussed. Sea otters may be vulnerable to other negative aspects of a capture and rehabilitation program, such as stress of capture, handling, and presentation of unfamiliar food.

\section{Symptoms of Oil Toxicity}

Captured otters were restrained in nets and restraint boxes so they could be examined for general condition (including pregnancy) and flipper-tagged. They were then either put into canine flight kennels on deck or lowered into pens below deck. Overt signs of oil toxicity in recently captured otters were not common but if present were usually manifested in a soft, watery stool. Stool color varied from green to black and tarry.

The postmortem analyses of five European otters that died in an oil spill indicated that the cause 
of death was hemorrhagic gastroenteropathy. In addition to gastrointestinal lesions, significant liver lesions were found, and one otter had mild kidney pathology. All five otters had ingested considerable oil (Baker 1981). There is little question that petroleum hydrocarbons can be absorbed from the gastrointestinal tract and distributed to various tissues (Engelhardt 1987).

On 2 April 1989 an otter was captured in lktua Bay, Prince William Sound, and assessed as lightly oiled. On 6 April 1989 it had a blood total petroIeum hydrocarbon concentration of about $170 \mathrm{ppm}$ $(17 \mathrm{mg} / \mathrm{mL})$. This level is apparently capable of contributing to death. The otter died on 17 April 1989 at the Valdez Otter Rehabilitation Center.

Ingestion of oil was assumed to result from grooming and from a contaminated food supply. Oiled otters spent much of their time grooming and probably swallowed oil in the process. The spraint (stool) of newly caught otters in Iktua Bay, Evans Island, contained $90 \%$ mussels and $10 \%$ clams. The sea otter is an opportunistic feeder (Calkins 1978). The blue mussel, Mytilus edulis, is the primary food source for otters in Iktua Bay, and two otters in Iktua Bay were observed feeding on them. Estes et al. (1981) reported that sea otters at nearby Green Island selected mussels as prey in their diets $39.7 \%$ of the time. Fossato and Canzonier (1976) found that mussels are capable of concentrating hydrocarbons in excess of 1,000 times above exposure levels. Thus the food supply of the otters may have been highly contaminated and may have been a major source of toxic hydrocarbons. Surprisingly, newly caught otters had an appetite and often would readily eat as many as six small herrings or squids.

Respiratory problems were nearly absent in newly caught otters, but an occasional single cough was noted. As oil weathers at the sea surface, there is rapid liberation of the volatile and soluble components, with major losses occurring in less than a day (Engelhardt 1987). This spill occurred in early spring when air and water temperatures were low, delaying the release of volatiles (benzene, toluene, and xylene). The main concern for sea otters was the content of the volatiles in the oil at the air-water interface. Inhalation of hydrocarbons was probably a source of intoxication in the first 3 weeks of the spill. Respiratory exposure could be expected to cause irritation of the respiratory system. Baker (1981) noted congestion and edema in the lung tissue of five European otters that died of oil intoxication in an oil spill. Two of these otters had tracheitis on necropsy. It was assumed that the content of volatiles decreased rapidly after $24 \mathrm{March}$, and at some time became negligible. Inhalation probably contributes directly to blood hydrocarbon levels. A respiratory-related illness, subcutaneous emphysema (air under the skin), was observed in an otter 6 days after the spill. Its chest appeared to be bulging as it lay in the water (K. Hill, Prince William Sound Science Center, Cordova, Alaska, personal communication).

Central nervous system signs, although rare, were observed. They included depression, mild convulsions, and coma, and were considered serious. Blindness was believed to be evident in an otter on 5 April. A capture crew netted an otter in shallow water that did not avoid the dip net because of apparent blindness (C. Donohoe, Sea World, San Diego, California, personal communication).

\section{Behaviors Associated With Oiling}

Because signs of intoxication in captured otters were usually mild except for occasional gastroenteric signs, it was considered important to note unusual precapture behaviors that might be linked to a degree of oiling.

The one behavior most consistently associated with oiling was persistent head and neck shaking. This seemed consistent with the observation that the head and neck usually receive the heaviest oiling. Another behavior after oiling was intensive grooming. It was assumed that if an otter is oiled it will feel cold in the areas of fur affected and will begin grooming those areas. If the oiling is significant the otter will frantically groom those areas in an attempt to restore insulating properties of the fur. Oil was observed collecting on the free ends of the pelage. Because otters swim mainly on their backs, they were heavily oiled on the back of the head and neck and the front paws. Grooming then spread oil to other parts of the body. A spiked appearance of the pelage was associated with oiling as groups of hairs matted together. Often the spiked appearance could be observed from a distance before capturing, and because of preoccupation with grooming, oiled otters were easily spotted by an experienced observer. Oiled otters often rolled, scooted, and rubbed themselves in snow on beaches and on ice floes. Other otters were seen rising halfway out of the water and shaking in an apparent attempt to remove oil. Also reported was excessive chest beating. On 4 April 1989, an unac- 
companied heavily oiled otter (VA055) was captured while hauled out near Point Helen on Knight Island, Prince William Sound. Otters usually haul out in groups, and this individual's behavior was attributed to the effects of oiling.

Signs of toxic effects to the skin and other parts of the integument were generally visually absent, with the exception of occasional mild conjunctivitis.

\section{Hypothermia}

Hypothermia may not be present in all newly captured, oiled otters, but there is little doubt that oiling of the fur increases heat loss, thereby stressing the otter. Some otters appeared to be hypothermic when captured. Two otters caught 9 April 1989 were shivering in the tangle net. One was assessed as lightly oiled; oiling was not obvious on the other. Both survived rehabilitation and were released. Signs of hypothermia included excessive shivering, slow movement, and tolerance of close approach by capture boats. Hypothermia was observed more often several hours postcapture. Apparently otters unable to groom in water cannot maintain the insulating ability of the fur and are prone to hypothermia, especially in cold, drafty environments. Two otters were held in cages on deck for more than $36 \mathrm{~h}$ awaiting helicopter transport. One died at the end of this time, and the other was near death, although it survived another 2 days. Hypothermia probably contributed to their deaths. The oil spill occurred when the weather was generally mild in the areas affected. daylight was usually warm and sunny, but at night temperatures often dropped below freezing; wind was rarely a factor. Hypothermia would probably have been more commonly observed in the adverse weather conditions that often exist in Prince William Sound.

\section{Recommendations}

On the first 2 days that the F/V Sea Raker and F/ Viking capture teams were operating, eight live otters were caught in Iktua Bay. All were described as having light oiling, but five died within 15 days. The Iktua Bay survival rates indicate that if relatively unweathered oil is present in an area that sea otters inhabit, regardless of whether otters appear affected by the oil, it is reasonable to begin prophylactic (preventive) supportive care immediately after capture.

No prophylactic veterinary treatment was initiated on captured otters by crews aboard the F/V Sea Raker and F/ Viking on 1-6 April 1989. Otters were relatively asymptomatic postcapture, and immediate treatment was deemed unnecessary. Therefore the U.S. Fish and Wildlife Service in Anchorage decided to drop the requirement to have veterinarians on capture boats.

After receiving medical records of otters captured by these crews, it became clear that otters may have benefited from onboard treatment. Therefore, any future oil spill capture crew should include a veterinarian prepared to administer prophylactic treatment.

I recommend that newly captured, oil-exposed otters be given a broad-spectrum antibiotic or sulfa (Amoxicillin or Ditrim), B-complex vitamin, vitamin $\mathrm{E}$ and selenium (Seletoc), and a corticosteroid (dexamethasone). In addition, to reduce postcapture mortality it would be beneficial to minimize time otters spend onboard vessels by timely transport by aircraft, minimize exposure to drafts, lower otters into holds rather than keep them on deck overnight, provide drainage so that otters are not forced to lie in water, and provide otters with acceptable foods so that energy stores are replaced.

\section{References}

Baker, J. R., A. M. Jones, T. P. Jones, and H. C. Watson. 1981. Otter Lutra lutra L., mortality and marine oil pollution. Biol. Conserv. 20:311-321.

Calkins, D. G. 1978. Feeding behavior and major prey species of the sea otter, Enhydra lutris, in Montague Strait, Prince William Sound, Alaska. Fish. Bull. 76:125-131.

Engelhardt, F. R. 1987. Assessment of vulnerability of marine animals to oil pollution. Pages 101-115 in J. Kuiper et al., eds. Fate and effect of oil in marine ecosystems. Martines Nijhoff, Amsterdam.

Estes, J. A., R. J. Jameson, and A. M. Johnson. 1981. Food selection and some foraging tactics of sea otters. Pages 606-641 in J. A. Chapman and D. Pursley, eds. Proceedings of the Worldwide Furbearer Conference, 3-11 August 1980, Frostburg, Md.

Fossato, V. U., and W. J. Canzonier. 1976. Hydrocarbon uptake and loss by the mussel Mytilus edulis. Mar. Biol. 36:243-250. 


\title{
Clinical Treatment and Rehabilitation of Sea Otters
}

by

\author{
R. K. Wilson \\ Arctic Animal Hospital \\ 1600 E. Tudor Road \\ Anchorage, Alaska 99507 \\ C. R. McCormick \\ 15536 Husky Street \\ Eagle River, Alaska 99577 \\ T. D. Williams \\ Monterey Aquarium \\ 886 Cannery Row \\ Monterey, California 93940-1085
}

and

P. A. Tuomi

2036 E. Northern Lights Boulevard

Anchorage, Alaska 99508

\begin{abstract}
Sea otters (Enhydra lutris) were brought to rehabilitation centers with varying degrees of oiling and general health; body conditions ranged from emaciated, comatose, and severely oiled to excellent with little or no oiling. Treatment during the washing process followed a standard protocol-while the otters were being washed under sedation they received fluids, steroids, antibiotics, and vitamin E-selenium. Blood was drawn for diagnostics. Immediately after washing, attention was given to the problems of hypothermia, hyperthermia, seizures, and shock. Throughout the rehabilitation program many medical problems were treated including those associated with skin, gastrointestinal and respiratory disorders, ophthalmic conditions, pregnancy, and several miscellaneous disorders. Treatment regimes and levels of success for each problem are discussed.
\end{abstract}

In the 5 months after the T/V Exxon Valdez oil spill, 358 sea otters (Enhydra lutris) were treated at the Valdez Otter Rehabilitation Center
(VORC), the Seward Otter Rehabilitation Center (SORC), and the Homer Temporary Care Facility. The condition of the animals varied widely in 
degree of oiling and general health, from emaciated, comatose, severely oiled otters to ones that were in excellent body condition with light or no oiling. We describe the veterinary care and treatment of these animals during the cleaning and rehabilitation process. Many treatment protocols changed during the course of the oil spill as new techniques were implemented.

\section{Initial Clinical Evaluation}

After admission, otters were evaluated and treated according to a standard medical protocol (Appendix A). The weight, body condition, and degree of oiling of each otter was recorded, and physical condition was assessed. The parameters monitored were temperature (normal, $37.5-38.7^{\circ} \mathrm{C}$ ), respiration (normal, 17 to 20 breaths per minute), and heart rate (normal, 144 to 159 beats per minute). The animals were weighed so that an accurate anesthetic dose could be computed, and weight gain throughout the rehabilitation process could be determined. General health was evaluated by body condition (good, fair, or emaciated), degree of awareness (alert, depressed, or comatose), and degree of oiling. Treatment was based on the results of these assessments. If there was no oiling, the otter was placed directly into saltwater holding with minimal handling. If the otter was heavily oiled and comatose, no sedatives were used; however, the otter was physically restrained during washing and received more intensive care.

\section{Acute Clinical Problems}

\section{Toxicity}

During the first 3 weeks after the spill, many otters exhibited symptoms associated with ingestion of petroleum hydrocarbons (e.g., disorientation, gastrointestinal distress, and seizures). In an attempt to neutralize the effects of such ingestion, $60 \mathrm{cc}$ of an activated charcoal solution (Toxiban) was given orally to heavily and moderately oiled sea otters. Activated charcoal is routinely used to counteract the ingestion of poisonous materials, but is of questionable benefit to animals that have been chronically exposed to petroleum hydrocarbons. This product absorbs large quantities of toxic materials and binds them so that they pass harmlessly in the stool. The solution was administered to sedated otters through a stomach tube. Because of the risk of aspiration, fully anesthetized otters were not intubated. Activated charcoal also darkens the stool, making immediate detection of blood or oil difficult. Despite these problems, this treatment may be effective in removing recently ingested oil so that it can pass through the gastrointestinal system. Therefore, this treatment should be considered for use early in an oil spill. As the oil weathered, severe toxic effects of crude oil diminished, and use of Toxiban was discontinued 4 weeks after the spill.

\section{Dehydration}

Many otters arrived at the rehabilitation centers with some degree of dehydration. Fluids were administered to all otters while they were being washed to correct possible dehydration and to prevent or treat shock. Staff administered $500 \mathrm{~mL}$ of a buffered electrolyte solution (Lactated Ringer's solution) subcutaneously or intraperitoneally. Later in May, recently captured otters were allowed 12 to $24 \mathrm{~h}$ to stabilize before washing. During this stabilization period otters had access to fresh water, food, and ice to correct dehydration, and the routine administration of fluids during washing was discontinued.

Dehydration was also a problem in debilitated otters that were anorectic for prolonged periods. Hydration in these otters was maintained with parenteral fluid administration three times per day; however, problems occurred with both long-term subcutaneous and intraperitoneal fluid administration routes. With the subcutaneous route even isotonic solutions were very slowly absorbed and frequently resulted in severe subcu. taneous edema in the otter. Some otters, after long-term intraperitoneal fluid administration, were found to have fibrinous peritonitis on postmortem examination.

\section{Hypothermia}

Hypothermia was one of the most frequent clinical disorders treated in the rehabilitation centers. In early rescue efforts, otters frequently were hy. pothermic because of low ambient temperatures and exposure to cold seawater after losing the insulating quality of their fur. A damp undercoat after washing also seemed to hamper an otter's ability to maintain its body temperature, regardless of ambient temperature. Hypothermia was also observed when otters were trapped in water 
and unable to haul out, in conjunction with hypoglycemia, and in otters in poor physical condition.

When under the effects of sedation or anesthesia, otters had difficulty thermoregulating. Otters were sedated for the wash process and several other routine procedures (e.g., blood drawing, wound care, and radiography). Monitoring an otter's temperature during anesthesia proved to be critical. The rear flippers, which are normally cool, were palpated for a rough body temperature estimate. Rectal temperatures were checked every $30 \mathrm{~min}$ during washing to determine if the washwater temperature should be adjusted. Many otters responded to warmed washwater. Hypothermia as a result of renarcotization was also a concern. Close monitoring during anesthetic recovery for signs of listlessness, sleeping in the water, and lack of arousal with provocation was essential.

\section{Hypoglycemia}

Hypoglycemia was associated with most otter crises observed at SORC, and was frequently observed at VORC. Subadults and pups were especially prone to hypoglycemic seizures; however, seizures also occurred in several adults. A period of anorexia generally preceded hypoglycemia. The duration of anorexia ranged from $6 \mathrm{~h}$ to more than 4 days. One pup (SW104) had a seizure after refusing to eat for $6 \mathrm{~h}$. Sea otters seem to deplete their body supply of glucose quickly, especially when in a stressful environment. Other factors contributing to a hypoglycemic state included sepsis and hypothermia.

Treatment of Hypothermic and Hypoglycemic Crises

At body temperatures below $32.2^{\circ} \mathrm{C}$ otters were usually comatose. An initial blood sample was taken and a blood glucose was determined. Many hypothermic otters were also hypoglycemic. In such an instance, the otter was placed on a warmwater "bed" (garbage bags filled with warm water). Bags filled with warm water were placed over flippers, and the otter was dried with a blow dryer on a warm setting. Warmed isotonic fluids were administered intraperitoneally, and a $50 \%$ dextrose solution was administered intravenously if the otter was hypoglycemic. Hypoglycemic seizures were treated with $50 \%$ dextrose administered intravenously, and Lactated Ringer's with $5 \%$ dextrose administered intraperitoneally. Additional Naloxone was given if renarcotization was a possible contributing factor.
As body temperatures rose above $32.2^{\circ} \mathrm{C}$ the otters became aware and active, necessitating the removal of the warmwater bags. Blow drying the otter through the cage netting was continued. Otters were enticed to eat food saturated with dextrose or STAT (a high caloric lipodextrose paste) to maintain blood glucose in the normal range. If it was believed that anorexia was going to be a continuing problem, the otter was tube-fed a mixture including STAT, Pedialyte, Lactated Ringer's, and ground seafood.

A frequent sequela of a hypothermic and hypoglycemic crash was melena. Otter SW176, a $10.9-\mathrm{kg}$ male that underwent numerous hypothermic and hypoglycemic crises over a 2 -week period, was anorectic and was supported by tube feeding. His temperature and blood glucose would plum. met as soon as $4 \mathrm{~h}$ after his last meal. Occult blood was consistently found in his stools. (The creamy color of "formula stool" obscured gross observation of melena). SW176's packed cell volume (PCV) dropped to 13 before his death. On necropsy, several segments of the small intestine were hemorrhagic, suggesting the gastrointestinal (GI) tract was the source of blood loss. We postulate that the GI tract, especially the small intestine, serves as a shock organ and experiences severe ischemia and damage during hypothermic and hypoglycemic crises.

\section{Hyperthermia}

Hyperthermia was a potential problem any time otters were out of water or agitated. To alleviate hyperthermia when in cages or in transport kennels, otters were routinely given ice. Additionally, their flippers could be cooled with salt water.

Acute fatal hyperthermia was seen in the heat of summer during the recovery of three otters from anesthesia. In July, two otters (SW125 and SW127) died $2.5 \mathrm{~h}$ after narcotic reversal had been administered. A third otter (SW135) had a rectal temperature of $42.2^{\circ} \mathrm{C} 2 \mathrm{~h}$ after narcotic reversal, when emergency procedures were initiated. This animal had a seizure and died within the next $15 \mathrm{~min}$. To prevent acute fatal hyperthermia on hot days, otters were given access to seawater totes during anesthetic recovery and then observed closely for renarcotization or hypothermia.

\section{Seizures of unknown etiology}

During the first 2 weeks of the otter rescue effort many otters had seizures. Ten heavily oiled 
otters had seizures within $48 \mathrm{~h}$ of arriving at VORC, and subsequently died. The cause of these seizures is unknown. However, hypoglycemia, hepatic encephalopathy, hyperthermia, hypothermia, electrolyte imbalance, stress, reaction to fentanyl anesthesia, and exposure to petroleum hydrocarbons may have been contributing factors. In some instances, periodic seizures persisted for several weeks. One animal exhibited multiple seizures lasting 3 to $5 \mathrm{~min}$ at intervals of $1-4$ days for about a week. Depending on the severity of the seizure, otters were given supportive care, which ranged from observation to intravenous diazepam and fluids.

\section{Shock}

The principal goal of shock treatment was to restore blood volume and pressure and to reduce the effects of toxic factors of bacteria. This was most easily accomplished by rapid infusion of fluids, administration of broad-spectrum antibiotics, and the use of steroids such as dexamethasone. To treat shock, $500 \mathrm{~mL}$ of Lactated Ringer's, injections of broad-spectrum antibiotics (Penicillin and Gentocin), and dexamethasone were administered. Initially, dexamethasone was given to all animals. This treatment seemed effective but may have compromised the pregnancies of some females. Because of the high incidence of unexplained stillbirths, this treatment was limited to male otters beginning in May. If an otter remained in a state of shock, a large-bore IV catheter was placed in the jugular vein, allowing continuous fluid therapy. Otters were kept warm to maintain normal body temperature.

\section{Capture Myopathy, Gastrointestinal, Respiratory, and Other Conditions}

\section{Capture Myopathy}

Capture myopathy is a potentially fatal condition associated with capture or transport of sea otters and other animals. Chalmers and Barrett (1982) also referred to capture myopathy as capture stress syndrome (CSS). Pursuit, capture, transport, and chemical immobilization of otters can result in CSS. Clinical manifestations of CSS include hyperthermia, myoglobinuria, stiffness, incoordination, weakness, respiratory and metabolic acidosis, depression, and collapse. Signs of CSS in sea otters include refusal of food, shivering, absence of grooming or grooming restricted to the muzzle and upper chest, matted pelage, rigid posture, floating motionless on back, rear limbs elevated, rear limbs crossed or folded tightly across lower abdomen, forelimbs in rigid "praying hands" posture, lack of responsiveness to other otters, and continuous vocalization. Gastric ulceration, gastroenteritis, and hemorrhagic adrenal cortex are evident at necropsy or through histopathology. Knowing the signs of CSS helps staff differentiate between stress, hypothermia, and toxic effects of oil. Capture stress syndrome signs were apparent only after otters had been held for at least $1 \mathrm{~h}$ and were not apparent to capture or transport teams. It does not seem possible to anticipate CSS, or to diagnose it before the holding phase.

Treatment was started immediately after recognition of signs of stress. Restraint cages were used to hold the animals securely, decreasing the stress to the handler and the animal. Otters were treated with cimetadine, vitamins, antibiotics, dexamethasone, and subcutaneous fluids and intraperitoneal fluids.

Thorough planning and preparation of transportation and rehabilitation centers can reduce the importance of capture myopathy as a cause of death in sea otters. The following husbandry techniques can be used to decrease CSS: place otters in a clean holding cage upon arrival, give food and water, allow 12 to $24 \mathrm{~h}$ rest before washing, maintain bonded pairs through release, vary foods to induce otters to begin eating, decrease the holding time of otters as much as possible by moving the animals through the facilities in 10 to 14 days, and house otters outdoors with access to seawater. Good husbandry means limiting involvement with humans. At the rehabilitation centers observations were made from a distance, feeding by hand was minimized, and no flash cameras were allowed. Access to husbandry areas was restricted, creating a hospital intensive care atmosphere. A separate quiet room was established for otters under anesthesia as a neuroleptanalgesic agent was used; the recovery room was also isolated.

\section{Conditions of the Gastrointestinal Tract}

Diarrhea, melena, parasites, and infrequently, intussusception and rectal prolapse were evident in otters undergoing rehabilitation. Diarrhea can be a sign of many underlying medical problems, such as liver disease, pancreatitis, malabsorption and maldigestion syndrome, parasites, stress, and 
dietary change. Stress and dietary change were considered the most likely causes of diarrhea in rehabilitated otters. At the onset of diarrhea, the color, frequency, and consistency of feces were carefully documented. Roughage plays an important role in maintaining normal bowel function in sea otters. Food without shells or bones, such as fish fillets, may result in diarrhea. Simple diarrhea was treated with increased roughage, and most otters recovered uneventfully.

Hemorrhagic enteritis, evidenced by black tarlike feces, occurred in many otters during the first days after the spill or after periods of severe stress. This condition is commonly associated with gastrointestinal bleeding. Intestinal ulcers, gastric ulcers, and hemorrhagic enteritis were observed in many of the otters during postmortem examinations. Although the etiology is unclear, stress and the toxicity of ingested oil could have been responsible for these problems. Treatment of hemorrhagic enteritis included a reduction in environmental stressors and cimetidine therapy (Appendix B). Hemorrhagic enteritis was difficult to distinguish from black feces resulting from ingestion of oil or squid ink.

Parasites recorded in sea otters included trematodes, ascarids, cestodes, nematodes, and acanthocephalids. Normally, in captive otters, parasites are not readily observed. However, many of the otters in the rehabilitation centers passed parasites in their feces. We suggest that ingested oil was toxic to the parasites and, as a result, they would detach from the intestinal wall. The acanthocephalids were seen only when feces were dark and mucoid. Otters passed cestodes intermittently often in large quantities. No parasitological studies have been performed to determine which antihelminthics are effective in sea otters. Attempts were made to use praziquantel to treat cestodes and fenbendazole to treat the acanthocephalids in selected cases. Otters with severe cestode infestations were given additional vitamin $\mathrm{B}$ complex because cestodes can lead to vitamin $B$ deficiency.

\section{Conditions of the Respiratory System}

Subcutaneous emphysema was one of the first indications that otters were suffering from severe pulmonary problems. Subcutaneous emphysema was created by the presence of bulus emphysema within the lungs. These buli would rupture and the air would extend up through the connective tissue of the mediastinum, through the thoracic inlet, and out into the subcutaneous tissues. Mild emphysema cases involved air primarily in the axillary region, whereas severe cases would have air pockets up to the top of the head and in the caudal lumbar region. Bulus emphysema was clear in postmortem examination of many otters. It was initially feared that all otters with bulus emphysema would die. However, some survived and were ultimately released. The cause of the emphysema is unknown although a similar condition has been reported in humans exposed to volatile hydrocarbons. Bulus emphysema occurred more frequently in otters captured early in the disaster than in those captured later, suggesting that the volatile hydrocarbons had a direct effect on the pulmonary parenchyma.

Labored breathing was frequently reported by handlers. In most instances, breathing disturbance was felt to be the normal apneustic respiration of a diving marine mammal. In some instances, however, abnormal respiration did precede death in severely debilitated otters.

Nasal discharge was present in many otters. Postmortem examination revealed a severe form of hemorrhagic necrotizing sinusitis in several otters. Sinusitis could have resulted from the volatile hydrocarbons acting as a strong contact irritant, nasal mite infestation, or secondary infection exacerbated by immunosuppression. One otter (VA026) developed a severe chronic sinusitis manifested by epistaxis and purulent nasal discharge. Culture and sensitivity tests were performed in which Escheria coli and Proteus were among multiple organisms that were sensitive to and successfully treated with ciprofloxicin and cephalexin.

\section{Other Conditions}

Several cases of abdominal distension occurred because of uterine torsion, volvulus, intussusception, hernia, or accumulation of fluids or air. One otter pup had an umbilical hernia that was surgically corrected; the pup's recovery was uncomplicated. Several otters had intussusceptions and torsions noted on their postmortem exams; these conditions could have been caused by agonal distress.

Rectal prolapse occurred as a result of straining from bowel irritation due to diarrhea. Minor prolapse associated with severe straining during defecation did not require treatment. One case of severe prolapse was successfully treated with a purse-string suture. In a second case, purse-string sutures failed, and an intra-abdominal tieback was 
performed. This otter died 3 weeks after the tieback surgery from a peritonitis believed to be secondary to a heavy acanthocephalid infestation, not surgical failure.

Several otters developed severe paraphimosis; the penis and prepuce were severely edematous, with areas of mucosal sloughing. A concentrated sugar solution was applied to the area, paraphimosis was reduced and a purse-string suture was placed to reduce the chance of reoccurrence. The prepuce was flushed alternately with betadine or hydrogen peroxide solution and dimethyl sulfioxide (DMSO). The suture was removed after 3 days with no reoccurrence in any otter so treated.

All otters were examined and treated with ophthalmic ointment during the washing process. Mild corneal ulcers were evident in several otters; other animals showed more chronic corneal scarring or protrusion of the third eyelid gland. Treatment and diagnosis of eye problems was difficult because otters are difficult to safely restrain for examination. Otters close their eyes tightly, making ointment applications difficult. Otters with severe cases were treated by attempting to squirt ophthalmic antibiotic solutions into the eyes from a distance. It was felt that most of the ulcers were created by contact with oil; other corneal lesions may have occurred naturally.

A female otter (SW150) had a protruding mass, which was noted on admission, arising from the vaginal floor. The tissue appeared to be an enlarged clitoris, which was subject to abrasion and irritation as the otter moved on the haul outs. This animal exhibited poor appetite, poor grooming, and reluctance to leave the haul out throughout the captive period.

\section{Medical Problems Encountered During Long-term Holding}

Because many of the sea otters were in captivity for as long as 4 months after their capture and washing, a number of incidental and sometimes secondary medical problems were encountered. In addition, some otters with no apparent oiling were received at the centers and subsequently died, probably from the conditions that had made them appear ill to the capture teams.

\section{Mortality in Unoiled Otters}

At VORC, a male (VA136) from an unoiled location and a pregnant female (VA156) were extremely debilitated upon arrival. The male seemed to have chronic multiple organ failure, with polyuria, congestive heart failure, kidney and liver abnormalities, and badly worn and infected teeth. He died 8 days after admission. The female died within $12 \mathrm{~h}$ of capture and at necropsy was found to have severe chronic pneumonia, with collapsed lungs and fibrinous pleuritis.

At SORC, a young male (SW160) died $24 \mathrm{~h}$ after admission, with peritonitis secondary to perforation of the intestine by an acanthocephalid parasite. A female (SW149) was euthanized after suffering progressive disorientation and blindness from a chronic sinusitis that resulted in encephalitis after the infection penetrated the cribriform plate of the skull. An older male (SW170) that was lethargic and whose fur had a peculiar pungent odor when washed died 17 days after admission. Hair samples from this otter's coat were tested by staff from the National Oceanic Atmospheric Administration. The animal was found to be contaminated with weathered fuel oil (not crude oil) possibly from one of the many boats working on cleanup and capture in the waters near his home territory; how this contamination contributed to his illness is unclear.

\section{Problems Related to Captivity}

Most sea otters held for more than 1 or 2 days out of water developed abrasions, pressure sores, and skin inflammation, especially on the hind legs and flippers. These lesions would initially appear as hairless reddened areas on the ventral parts of the distal digits, but in some cases they extended deeper, sometimes exposing the bone and joint spaces of the affected toes. Reddened skin and hair loss extended up the rear legs and flanks of several animals.

These lesions were probably influenced by several factors, including (1) hard and sometimes sharp floor surfaces (plywood, wire mesh, Chemgrate, and some types of nylon netting), (2) inability to wash away excrement and urine adequately, (3) decreased resistance to infection and poor healing secondary to oil toxicity and multiple stressors, (4) accentuated grooming responses resulting in constant rubbing and scratching and (5) possible direct toxicity to the skin, hair follicles, and sebaceous glands from contact with oil and detergent. 
One otter (VA108) in saltwater holding rubbed the hair from its chest and abdomen, resulting in severe alopecia that resolved without treatment within a month. Histopathological examination of skin biopsies from two very lightly oiled otters, one washed (SW158) and one unwashed (SW159), showed mild acanthosis, moderate follicular hyperkeratosis, and mild mixed mononuclear perivascular dermatitis, which was thought to be the result of a disruption of the normal keratinization process (W. Rosenkrantz, Animal Dermatology Clinic, Garden Grove, California, personal communication).

The most severe lesions were seen in the heavily and moderately oiled otters housed indoors at VORC's critical care facilities. Many of these animals eventually died with severe toxicity problems. However, varying degrees of these wounds continued to be a problem in the tote pool pens at VORC and SORC. All otters were transferred as rapidly as possible into larger seawater pens, and those with severe lesions were treated with oral or injectable antibiotics (Appendix B). Lesions had resolved in all but two otters by the final release date. One of these animals, an otter (VA126) with multiple open digital joints, was shipped to Sea World San Diego, where further treatment resulted in complete healing after several more months (J. McBain, Sea World San Diego, personal communication).

A few of the rehabilitated otters transported by air to long-term holding in Jakolof Pre-Release Facility exhibited head shaking, depression, and reluctance to dive for several days after their flight. It is possible that these otters suffered middle ear trauma as a result of altitude changes or motor noise while en route. All made seemingly complete recovery without treatment.

Oral injuries occurred when the otters chewed on wood or wire materials in the pens. One otter (VA128) fractured both upper canine teeth, but seemed to have no difficulty eating or apparent distress during the subsequent 10 weeks before release. Older otters frequently were admitted with severe dental pathology. Fractured and avulsed teeth, deep caries, and abscessed roots were observed, but no attempt was made to treat these problems except in one animal where loose root fragments were removed during sedation at admission. Some facial abscesses may have been related to dental problems, but this correlation was not definitely established.

Oral ulcerations were seen in a large number of otters in SORC and the Jakolof facility, and a herpesvirus-like inclusion body was found associated with these lesions.

Several otters developed facial abscesses that required sedation and surgical drainage. The wounds were then flushed thoroughly with a povidone iodine and hydrogen peroxide mixture daily for several days, and oral or injectable antibiotics were administered until the area was completely healed. It was suspected that these infections may have been the result of wood splinters in the mouth and gums, but no foreign material was found in the wounds. Abscesses were occasionally seen in other locations (dorsal lumbar, rear leg, and forepaw) and may have been the result of bite wounds, infected toenails, or possibly contaminated injection sites. These infections were also treated after sedation with surgical drainage followed by 5 to 7 days of oral or injectable antibiotics. Aerobic bacterial culture of material from facial and paw abscesses produced a variety of organisms, including Staphylococcus, Streptococcus, Proteus, and Pseudomonas species.

Minor lacerations of the lips, nose, or feet were occasionally noted but usually resolved without treatment. Deep lacerations were seen on the flippers and rear hocks of several animals; some of these were debrided and sutured under local anesthesia or sedation using mattress sutures of absorbable material. The wounds reopened in two otters but eventually healed in all of the animals.

\section{Orthopedic Problems}

One young male (VA052) with a swollen tibial tarsal joint was radiographed in May and again in July. An extensive calcifying arthritis and synovitis was seen in the July radiograph. No obvious bite wounds were noticed in the area of the swelling, and routine cultures of joint fluid demonstrated no growth. Oral antibiotics were administered for 2 weeks after the swelling was first noted but did not appear to affect the progress of the condition. The otter appeared to swim and dive normally despite the decreased range of motion in the hock, and he was released to the wild.

A female (SW137) with a young pup was captured near Kodiak and appeared paralyzed in the rear legs. Both otters were severely malnourished, and the pup died. The female gradually resumed near-normal mobility in the water but had an obvious deviation of the lumbar spine. Radiographs taken 2 weeks after capture showed an old, healed compression fracture of the second and third lumbar vertebrae with severe displacement. 
This otter also recovered sufficiently to be released, although an ovariohysterectomy was first performed to ensure that she would not have to attempt to support another pup.

\section{Pregnancy and Perinatal Problems}

Perinatal mortality was extremely high in both VORC and SORC during April and May (Figure). Nearly half of the females necropsied were pregnant or showed signs of recent delivery. Ten additional females that survived delivered stillborn or aborted fetuses. Of 18 pups born alive at all the centers, 5 were raised by their mothers, two died shortly after birth while with their mothers, and 11 were treated in the nurseries. Nine of these died while at the centers and the remaining two died after transfer to Point Defiance Aquarium in Tacoma, Washington. In contrast, 10 of 12 orphans brought to the center nurseries from the wild survived until transfer to Point Defiance and Monterey Bay aquariums; eight are still alive. Seven of nine pups brought to the centers with their mothers survived; four were released with their mothers, and three were raised in the nursery and transferred to Point Defiance.

Most of the live pups born at the centers were never able to nurse their mothers and had become hypothermic because of the mothers' inability to keep the pups' fur properly groomed. In several cases, small amounts ( 1 to $10 \mathrm{~mL}$ ) of colostrum were successfully collected from the mothers and given to debilitated newborns. Females that were rehabilitated sufficiently to swim and groom properly before delivery seemed to be successful in keeping and raising a pup. Pups were taken briefly from their mothers for weighing, transfer to other pens, or medical treatments; the mothers and pups vocalized loudly while separated but resumed normal activity as soon as the pups were returned. The five pups born in this category survived and were released with their mothers back to the wild.

Two females died with uterine torsion. It was suggested that the weight of the gravid uterus was not properly supported during transport when the otter was out of water for long periods and struggling. This may have contributed to torsion.

To combat shock, injections of dexamethasone were routinely given to all otters at VORC and for the first month at SORC. Similar products have been noted to stimulate abortion in the last trimester of pregnancy in bovines (Barth 1986), but have not been demonstrated to interrupt the pregnancy of canines or felines. Use of dexamethasone in females was discontinued after late May at SORC. Further investigation is needed to establish if corticosteriods contributed to the high abortion and stillborn rates at the centers.

Most otters delivered their pups after relatively short periods of obvious labor, regardless of whether they were in the water or on a dry surface. Some females with free access to water chose to

\section{\# OF OTTERS}

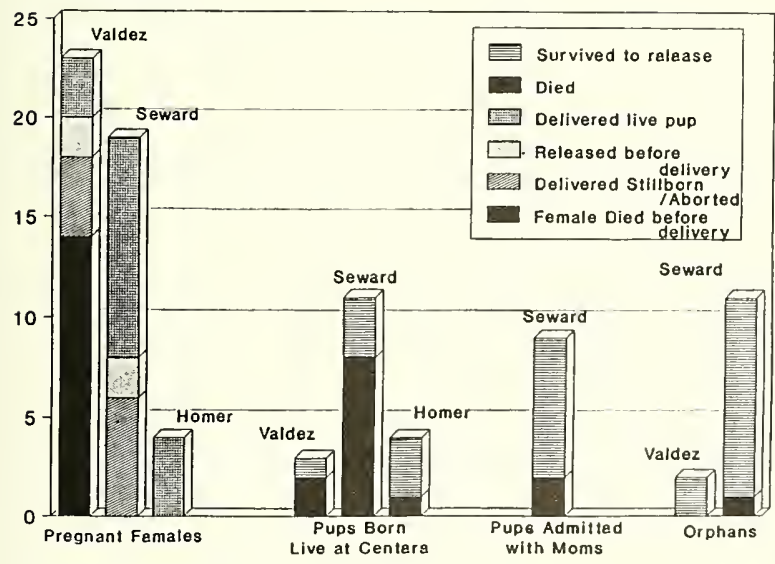

Figure. Mortality of pregnant sea otters (Enhydra lutris) and pups at Valdez and Seward centers, and the Homer Temporary Care Facility. 
complete their labor on the haul-out area. Two females (VA149 and SW159) experienced delayed delivery. One was treated with oxytocin and calcium injections in an effort to strengthen contractions, with questionable results. Both otters eventually delivered very large stillborn pups after more than $24 \mathrm{~h}$ of labor. The untreated female subsequently developed a purulent vaginal discharge and was treated with antibiotics for several days before making a seemingly complete recovery.

One otter (VA127) developed mastitis after losing her newborn pup. Her mammary glands became swollen and hard. This otter had a decreased appetite and was lethargic for several days. The gland was lanced and flushed, and oral antibiotics and $B$ vitamin supplements were administered until the condition subsided.
The poor viability of females stressed by pregnancy, and of pups born to debilitated otters at the centers is not surprising, but the exact relation of oil toxicity, capture stress, medical treatments, husbandry techniques, and natural "mothering" abilities is difficult to establish.

\section{References}

Barth, A. P. 1986. Induced abortion in cattle. Page 205 in Current therapy in theriogeneology. W. B. Saunders Company, Philadelphia.

Chalmers, G. A., and M. W. Barrett. 1982. Pages 84-94 in G. L. Hoff and J. W. Davis (eds.). Capture myopathy in non-infectious diseases of wildlife. Iowa State University Press. Ames. 


\section{Appendix A. Sea Otter Admission Medical Protocol.}

A. Assessment

1. Weight

2. General condition

3. Degree of external oiling

B. Triage-Determine if otter is to be:

1. Treated or washed immediately

2. Held overnight to stabilize, then treated or washed

3. Held for observation and reevaluated as needed

C. Sedation or anesthesia. Dose of best anesthesia:

1. Fentanyl -0.09 to $0.12 \mathrm{mg} / \mathrm{kg}$

2. Azaperone- $0.55 \mathrm{mg} / \mathrm{kg}$ or Acepromazine $0.09 \mathrm{mg} / \mathrm{kg}$

3. Diazepam-0.1 to $0.2 \mathrm{mg} / \mathrm{kg}$

D. Eye examination

1. Flush with eye wash

2. Fluorescein stain as indicated

3. Eye ointment

E. Rectal temperature

1. Record at $15-30 \mathrm{~min}$ intervals

F. Blood sample collection

1. Jugular or femoral venipuncture

2. 1-2 mL in ethylenediamine tetraacetic acidor (purple top)-invert slowly to mix *

3. $6-8 \mathrm{~mL}$ in each of two clot tubes (red top)*

4. 2-4 mL in toxicology tube (gray top) ${ }^{*}$

5. Use finger pressure at puncture site for several minutes to prevent hematoma

6. Glucostix-1 min blood glucose determination

* It is best to uncap tubes, remove needle from syringe, fill tube, and mix gently as sea otter blood may hemolyze easily

G. Fecal and hair sample collection

1. Place in clean aluminum foil

2. Freeze for toxicology

H. Palpate abdomen-pregnancy determination

I. Urine sample collection-whenever possible

1. Through cystocentesis

2. $6-8 \mathrm{~mL}$ in red top tube

3. Dipstick urinalysis-hold refrigerated for laboratory

J. Medication* *

1. Benzathine Penicillin-1 mL/20 pounds; intramuscularly (IM)

2. Trimethoprim sulfa (Tribrissen $48 \%$ )-1 mL/40 pounds; subcutaneously (SQ)

3. Vitamin B complex-1 mL/20 pounds; IM

4. Vitamin E-selenium (Seletoc) $-0.5 \mathrm{~mL} / 50$ pounds

5. Dexamethasone $(2 \mathrm{mg} / \mathrm{mL})-1 \mathrm{~mL} / 10$ pounds

6. Fluids-Lactated Ringer's or $5 \%$ dextrose

** Only as indicated by condition of otter

K. Oral intubation

1. As indicated by condition of otter 
2. Activated charcoal (Toxiban) $-60 \mathrm{~mL}$ diluted with $30 \mathrm{~mL}$ warm saline

3. Nutritional support (STAT-a high caloric lipodextrose paste)- $60 \mathrm{~mL}$ diluted with $30 \mathrm{~mL}$ warm saline

L. Place temple tag in flipper if needed

M. Monitor heart rate and respiration through examination, washing, and drying

N. Repeat eye flush; use ointment

O. Reverse sedation

1. Narcan $0.4 \mathrm{mg} / \mathrm{mL}-0.05 \mathrm{mg} / \mathrm{kg}$ given $1 / 2$ subcutaneously, then $1 / 2$ intravenously 


\section{Appendix B. Formulary. ${ }^{a}$}

\begin{tabular}{|c|c|c|}
\hline Drug & Dosage & ministration \\
\hline Aminophylline & $5 \mathrm{mg} /$ pounds TID & $\mathrm{IM}$ or $\mathrm{PO}$ \\
\hline Amoxicillin & $\begin{array}{r}\text { 5-10 mg/pounds BID } \\
(200 \mathrm{mg} / 40 \text { pounds) }\end{array}$ & $\mathrm{SQ}$ or $\mathrm{PO}$ \\
\hline Ascorbic acid & $1 \mathrm{~mL}$ & IV or IM \\
\hline Atropine & $0.5 \mathrm{mg} / 20$ pounds $\mathrm{PRN}$ & IM or SQ \\
\hline B-cocktail & $2 \mathrm{~mL} \mathrm{B12}+1 \mathrm{~mL} \mathrm{~B}$ complex & IM \\
\hline Banamine & $25 \mathrm{mg} / 50$ pounds single dose & IM \\
\hline Cephalexin & $\begin{array}{l}10 \mathrm{mg} / \text { pounds BID or } \\
\mathrm{TID}(500 \mathrm{mg} / 50 \text { pounds })\end{array}$ & $\mathrm{PO}$ \\
\hline Cimetidine & $5 \mathrm{mg} /$ pounds TID (150 mg/30 pounds) & IM or PO \\
\hline Ciprofloxin & $10 \mathrm{mg} /$ pounds BID or TID & $\mathrm{PO}$ \\
\hline Dexamethasone & $0.2 \mathrm{mg} /$ pounds $\operatorname{SID}(1 \mathrm{~mL} / 10$ pounds $)$ & IV or IM \\
\hline Diazepam & $0.25 \mathrm{mg} /$ pounds PRN ( $5 \mathrm{mg} / 20$ pounds) & IV or PO \\
\hline \multirow[t]{3}{*}{ Dipyrone } & $500 \mathrm{mg}(1 \mathrm{~mL}) / 40$ pounds $P R N$ & IM or SQ \\
\hline & $1 \mathrm{~mL} / 40$ pounds (48\%) SID or BID & $\mathrm{SQ}$ \\
\hline & $480 \mathrm{mg} / 40$ pounds SID & $\mathrm{PO}$ \\
\hline Fenbendazole & $\begin{array}{l}50 \mathrm{mg} / 2.2 \text { pounds }(50 \mathrm{mg} / \mathrm{kg}) \\
\mathrm{SID} \times 3 \text { days }\end{array}$ & $\mathrm{PO}$ \\
\hline Fluids (LRS or D5W) & $10-20 \mathrm{~mL} /$ pounds & SQ,IP or IV \\
\hline Gentamycin & $2 \mathrm{mg} /$ pounds or $1 \mathrm{~mL} / 10$ pounds BID & $\mathrm{IM}$ \\
\hline Ivermectin (Eqvalan paste 1.87\%) & $90 \mu \mathrm{g} /$ pounds & $\mathrm{PO}$ \\
\hline Neomycin & $10 \mathrm{mg} / 2.2$ pounds $(10 \mathrm{mg} / \mathrm{kg}) \mathrm{BID}$ & $\mathrm{PO}$ \\
\hline Oxytocin & $1 \mathrm{~mL} / 50$ pounds & $\mathrm{IM}$ \\
\hline Penicillin benzathine & $1 \mathrm{~mL} / 20$ pounds BID & $\mathrm{IM}$ \\
\hline Trimethoprim/sulfa (DiTrim) & $1 \mathrm{~mL} / 20$ pounds (24\%) SID or BID & $\mathrm{SQ}$ \\
\hline Praziquantel (Droncit) & $3 \mathrm{mg} /$ pounds & $\mathrm{PO}$ \\
\hline Vitamin $A$ and D & $1 / 2-1 \mathrm{~mL}$ & IM or $\mathrm{SQ}$ \\
\hline Vitamin $\mathrm{K}$ & $1 \mathrm{mg} /$ pounds SID & $\mathrm{PO}$ or $\mathrm{SQ}$ \\
\hline Winstrol & $24-50 \mathrm{mg} / 40$ pounds for 7 days & IM \\
\hline
\end{tabular}

${ }^{a} \mathrm{TID}=$ three times a day, $\mathrm{BID}=$ twice a day, $\mathrm{SID}=$ once daily, $\mathrm{PRN}=$ as needed, $\mathrm{IM}=$ intramuscularly, $\mathrm{PO}=$ by mouth, $\mathrm{SQ}=$ subcutaneously, IV = intraveneously, and IP = intraperitoneally. 


\title{
Perspectives of Veterinary Technicians
}

\author{
by
}

L. L. Kelly

1061 N. Leatherleaf Loop

Wasilla, Alaska 99687

A. M. Green

P.O. Box 972

Seward, Alaska 99664

and

B. W. Miller

6037 Bass Lake Road

Maple City, Michigan 49664

\begin{abstract}
In response to the T/N Exxon Valdez oil spill, veterinary technicians were called on to assist veterinarians and sea mammal experts in emergency rescue work with sea otters (Enhydra lutris). Technicians provided veterinarians with technical assistance in clinical pathology, surgery, daily treatments, record keeping, and archiving of laboratory samples. Technicians also established and maintained the pharmacy, laboratory, and animal washing and receiving areas. We outline the duties performed by veterinary technicians as a reference for veterinary medical staff involved in wildlife rescue.
\end{abstract}

\section{Technical Support Services}

\section{Pharmacy}

In setting up and maintaining a pharmacy it is important to keep the supplies well stocked and readily available. For the initial pharmacy supplies, the reference Sea Otter Oil Spill Mitigation Study by Davis et al. (1986) was used. Until ordering procedures were established, the sea otter (Enhydra lutris) rescue centers were fortunate to have veterinary medical supplies donated or loaned by various hospitals and veterinary clinics. Many pharmaceutical companies were happy to assist in the rescue effort and donated drugs and supplies.
The inventories underwent several revisions as needs became clear. A sample inventory list is provided that reflects the products used in this rescue effort for treatment of about 50 otters for 10 days (Appendix A).

The task of ordering and stocking supplies is difficult. Accounts must be established and proper ordering protocols defined as early as possible to ensure timely delivery of items (Appendix B). It is important to have a person with a medical background responsible for ordering. Problems arose when untrained personnel became involved in ordering. It is also important to have open communication with all medical staff to keep necessary supplies on hand. Many times a procedure was 
planned (such as drawing prerelease blood samples from 50 otters) and the plan was not conveyed to the inventory control person. To maintain a tight inventory, given the time involved to obtain necessary items, it is imperative to have long-range plans.

To maintain an adequate, but not excessive, inventory, it would be beneficial to have a weekly meeting of the medical staff to further define pharmaceutical needs and planned procedures. A weekly drug inventory (Appendix C) should be made available to the medical staff to assist them in assessing needs. Because medical supplies are usually urgently needed, it would be helpful to have supplies sent directly to the medical center without going through a processing warehouse. This intermediate step resulted in unnecessary delays and confusion in obtaining the proper products.

Organizing drugs according to their general class (e.g., antibiotics, steroids, gastrointestinal agents, emergency drugs, and nutritional supplements) made the products easier to locate in the pharmacy.

Controlled drugs were kept in locked cabinets with limited access. Existing quantities were inventoried biweekly by the technician and head veterinarian and compared with narcotic log sheets (Appendix D). Because of the large number of injections given, residual amounts had to be taken into account and incorporated into the logs (Appendix E). Because of liability concerns, needles were kept in locked cabinets. This made retrieval of vital supplies difficult in emergency situations.

\section{Medical Waste Disposal}

It is important to establish proper disposal methods for medical waste immediately. Sharps (e.g., needle points, scalpel blades) were disposed of in a marked container, which was sealed and taken to a disposal area. Other medical waste was collected in color-coded bags to assist cleanup crews in proper disposal.

\section{Laboratory}

Veterinary technicians assisted in the collection, handling, and processing of laboratory specimens. All samples were processed through the laboratory, where inhouse testing was performed. Certain tests were processed at outside laboratories.

Veterinary technicians helped to provide rapid results for the following inhouse tests:

Complete blood count (WBC, PCV, TP, and differentials)
Urinalysis (reagent test strip, specific gravity, and microscopic examination)

Fecals (flotation and direct)

Occult blood test

BUN and blood glucose reagent test strips

Initial blood chemistries

Blood chemistries were performed on a donated Kodak Ektachem Blood Analyzer (at the Valdez Otter Rehabilitation Center) and an Abbott Vision Blood Analyzer (at the Seward Otter Rehabilitation Center). This equipment enabled rapid assessment of an otter's health. The Kodak analyzer was the more time consuming of the two, but results correlated closely with outside diagnostic laboratory val. ues (Appendix F).

Several outside laboratories were used for testing. A log tracked samples sent to the following laboratories:

PML Microbiologicals, Anchorage, Alaska-Chemistry panels, CBC's, and bacterial cultures; turnaround time, 2-3 days.

Veterinary Reference Labs, Dallas, Texas-Parvovirus tests for harbor seals; turnaround time, 10-14 days.

Animal Dermatology Clinic, Garden Grove, California-Skin biopsy; turnaround time, 7-10 days.

Armed Forces Institute of Pathology-Histopathology.

Initially, there were no uniform protocols for collection, processing, and analysis of specimens. As a result, valuable data were lost. It is important to have proper procedures documented to ensure that proper handling and testing requirements are met. To ensure the quality of blood samples, centrifuging within an hour of collection and proper storage are imperative.

A number of problems resulted in invalid laboratory results: (1) lipemic samples resulted from feeding otters before drawing blood, (2) hemolysis due to venipuncture performed in struggling otters, (3) clotting in collection tubes, and (4) invalid serum chemistry results due to delayed centrifugation and hemolysis.

It was important to determine blood glucose levels quickly in critically ill sea otters. A blood-glucose monitor, such as the Boehringer-Mannheim Chemstrip Accu-check II, would have been helpful.

Results of blood chemistries and CBC's were transcribed onto hematology and serum chemistry forms so that they could be easily compared 
(Appendix G). Abnormal results were highlighted and brought to the veterinarian's attention.

Blood and serum samples were archived upon request of various researchers. As the laboratory protocol (Appendix $\mathrm{H}$ ) indicates, a small amount of serum from each sample was requested for specific destinations. The method of storing the samples differed, depending on the study being performed. For instance, glass vials with teflon caps were required for toxicology samples. Each container was labeled with the sea otter's center, number, date, and place of collection. Correct record keeping and archiving was an important task.

\section{Otter Care and Treatment}

\section{Admission of Sea Otters}

When the sea otters arrived at the center, they were assigned numbers chronologically. Capture information, which was taped to the cages, was transferred to the more permanent admission record (Appendix I) along with other pertinent information, such as the date and the otter's weight, sex, and tag number.

\section{Washing and Drying}

Oiled otters were anesthetized and transferred to a wash table, where an initial examination was performed. Technicians assisted the veterinarians in the administration of anesthetic agents. Many times it was necessary to give multiple anesthetic doses, and maintaining detailed records was of utmost importance. Calculators were used to prevent errors due to interruptions and confusion. It was the technician's responsibility to monitor the otter's vital signs, including temperature, heart rate, and respiration, during the washing procedure. All anesthetized otters had their eyes irrigated with an ophthalmic solution and protected with an antibiotic ointment. Blood drawn at this time was processed by the technician. A protocol was followed for giving antibiotics, steroids, and vitamins, and for preparing a mixture for gastric tubing (Appendix J).

During the drying process the technician was available if any complications arose. At the conclusion of the drying procedure, a veterinarian administered an anesthetic antagonist, and the otter was transferred to the recovery room. The technician cleaned the treatment area and recorded anesthetic doses on the appropriate form (Appendix K).

\section{Medical Assistance}

Technicians joined veterinarians on rounds twice daily to assist with record keeping and medical treatments. The technician then carried out the prescribed treatments throughout the day. An efficient system, easy for different shifts to follow, used day/duration/dosage notation, (e.g., 3/6/250 mg amoxicillin indicated the 3rd day of a 6-day treatment of a prescribed dose and drug; Appendix L). Because many drugs are available in different strengths, it is imperative that dosage be clearly marked.

Notations on vital information, such as coat condition, medication, and amount of food consumed, were taken from the husbandry forms and summa. rized on progress reports.

Surgeries were performed at the otter centers, including ovariohysterectomy, wound suturing, and transmitter implantation. Technicians assisted the veterinarians by organizing all necessary supplies and preparing the surgical area, which in most instances was in a remote location. Fishing vests with multiple pockets were used for carrying necessary supplies such as syringes, drugs, and other miscellaneous items to the surgery sites. Technicians assisted in prepping for surgery, administering and documenting all drugs used (Appendix M), and monitoring vital signs throughout the procedures.

\section{Conclusion}

Veterinary technicians played a primary role in animal care, treatment, monitoring, anesthesia, surgical assistance, and record keeping. For the technicians, it was a privilege to use our skills to work with the veterinarians, biologists, and marine mammal experts during the sea otter rehabilitation effort.

\section{Acknowledgment}

Special thanks to C. Harms for helpful comments on this paper.

\section{Reference}

Davis, R. W., J. A. Thomas, T. M. Williams, and R. A. Kastelein. 1986. Sea otter oil spill mitigation study. Minerals Management Service report OCS 86-0009. 219 pp. 


\section{Appendix A. Inventory or Stock Required for About 50 Sea Otters (Enhydra lutris) for 10 Days.}

\begin{tabular}{|c|c|c|}
\hline Product & Size & Amount \\
\hline \multicolumn{3}{|l|}{ Antibiotics } \\
\hline Amoxicillin $50 \mathrm{mg}$ tablet & $500 \mathrm{ct}$ & 1 bottle \\
\hline Amoxicillin $100 \mathrm{mg}$ tablet & $500 \mathrm{ct}$ & 1 bottle \\
\hline Amoxicillin $200 \mathrm{mg}$ tablet & $500 \mathrm{ct}$ & 1 bottle \\
\hline Amoxicillin $400 \mathrm{mg}$ tablet & $250 \mathrm{ct}$ & 1 bottle \\
\hline Amoxicillin inj. $3 \mathrm{~g}$ & $9 \mathrm{~mL}$ & 6 vials \\
\hline Amoxi-drops liquid & $15 \mathrm{~mL}$ & 12 bottles \\
\hline Clavamox drops liquid & $15 \mathrm{~mL}$ & 12 bottles \\
\hline Keflex $500 \mathrm{mg}$ capsules & $100 \mathrm{ct}$ & 1 bottle \\
\hline Keflex drops liquid & $10 \mathrm{~mL}$ & 6 bottles \\
\hline Penicillin G inj. & $100 \mathrm{~mL}$ & 6 vials \\
\hline Tribrissen $480 \mathrm{mg}$ tablet & $100 \mathrm{ct}$ & 1 bottle \\
\hline Tribrissen inj. $48 \%$ & $100 \mathrm{~mL}$ & 6 vials \\
\hline \multicolumn{3}{|l|}{ Emergency drugs } \\
\hline Aminophylline $250 \mathrm{mg} / 10 \mathrm{~mL}$ inj. & $10 \mathrm{~mL}$ & 20 vials \\
\hline Aminophylline tablet & $100 \mathrm{ct}$ & 1 bottle \\
\hline Atropine $1 / 120 \mathrm{gr}$ inj. & $100 \mathrm{~mL}$ & 3 vials \\
\hline Dexamethasone $2 \mathrm{mg} / \mathrm{mL}$ inj. & $100 \mathrm{~mL}$ & 3 vials \\
\hline Dopram $20 \mathrm{mg} / \mathrm{mL}$ inj. & $30 \mathrm{~mL}$ & 3 vials \\
\hline Epinephrine 1:1000 inj. & $30 \mathrm{~mL}$ & 3 vials \\
\hline KCL $20 \mathrm{mEq}$ inj. & $10 \mathrm{~mL}$ & 10 vials \\
\hline Lasix $50 \mathrm{mg} / \mathrm{mL}$ inj. & $50 \mathrm{~mL}$ & 3 vials \\
\hline Lidocaine HCL $2 \%$ inj. & $50 \mathrm{~mL}$ & 3 vials \\
\hline Sodium Bicarb. inate $8.4 \%$ inj. & $50 \mathrm{~mL}$ & 3 vials \\
\hline \multicolumn{3}{|l|}{ Ophthalmic medications } \\
\hline Gentocin Durafilm Ophthalmic sol. & $5 \mathrm{~mL}$ & 12 bottles \\
\hline Gentocin Ophthalmic sol. & $5 \mathrm{~mL}$ & 12 bottles \\
\hline \multicolumn{3}{|l|}{ Gastrointestinal agents } \\
\hline Carafate l gr & $100 \mathrm{ct}$ & 1 bottle \\
\hline Reglan $5 \mathrm{mg} / \mathrm{mL}$ inj. & $30 \mathrm{~mL}$ & 3 vials \\
\hline Tagamet $300 \mathrm{mg}$ tablet & $100 \mathrm{ct}$ & 4 bottles \\
\hline Tagamet $150 \mathrm{mg} / \mathrm{mL}$ inj. & $10 \mathrm{~mL}$ & 30 vials \\
\hline Toxiban liquid & $240 \mathrm{~mL}$ & 24 bottles \\
\hline \multicolumn{3}{|l|}{ IV fluids } \\
\hline Lactated Ringers Sol. inj. & liter & 48 bottles \\
\hline Lactated Ringers $5 \%$ Dextrose inj. & liter & 48 bottles \\
\hline Saline sol. inj. & liter & 48 bottles \\
\hline \multicolumn{3}{|l|}{ Nutritional supplements } \\
\hline Dextrose $50 \%$ inj. & pint & 24 bottles \\
\hline Multivitamin (marine mammal) & $500 \mathrm{ct}$ & 2 bottles \\
\hline Petcal tablets & $60 \mathrm{ct}$ & 6 bottles \\
\hline STAT liquid & quart & 24 bottles \\
\hline Vitamin B Complex inj. & $100 \mathrm{~mL}$ & 6 vials \\
\hline Vitamin B12 inj. & $100 \mathrm{~mL}$ & 6 vials \\
\hline Vitamin C $250 \mathrm{mg} / \mathrm{mL}$ inj. & $100 \mathrm{~mL}$ & 6 vials \\
\hline
\end{tabular}




\section{Steroids}

Prednisolone $5 \mathrm{mg}$ tablets

$1000 \mathrm{ct}$

1 bottle

Winstrol-V $50 \mathrm{mg} / \mathrm{mL}$ inj.

$30 \mathrm{~mL}$

10 vials

Winstrol-V 2 mg tablet

\section{Anesthetics}

Acepromazine $10 \mathrm{mg} / \mathrm{mL}$ inj.

$50 \mathrm{ct}$

1 bottle

Azaperone $40 \mathrm{mg} / \mathrm{mL}$ inj.

$50 \mathrm{~mL}$

1 vial

$30 \mathrm{~mL}$

1 vial

Fentanyl $50 \mathrm{mg}$ powder

Meperidine HCL $50 \mathrm{mg} / \mathrm{mL}$ inj.

$50 \mathrm{mg} / \mathrm{vial}$

20 vials

$30 \mathrm{~mL}$

1 vial

Narcan $1 \mathrm{mg} / \mathrm{mL}$ inj.

Oxymorphone HCL $1.5 \mathrm{mg} / \mathrm{mL}$ inj.

$10 \mathrm{~mL}$

30 vials

Telazol $100 \mathrm{mg} / \mathrm{mL}$ inj.

Valium $5 \mathrm{mg}$ tablet

Valium $5 \mathrm{mg} / \mathrm{mL}$ inj.

$10 \mathrm{~mL}$

10 vials

$5 \mathrm{~mL}$

5 vials

$100 \mathrm{ct}$

$10 \mathrm{~mL}$

1 bottle

Miscellaneous drugs

Droncit $34 \mathrm{mg}$ tablets

$50 \mathrm{ct}$

$10 \mathrm{~mL}$

Droncit $56.8 \mathrm{mg} / \mathrm{mL}$ inj.

Euthanasia solution $5 \mathrm{gr}$

$100 \mathrm{~mL}$

Saline for injection

Vials, sterile empty

$100 \mathrm{~mL}$

$30 \mathrm{~mL}$

20 vials

Syringes and needles

Syringe, $1 \mathrm{cc}$

100 ct

1 bottle

2 vials

3 vials

3 vials

24 vials

Syringe, 3 cc Luer slip tip

100 ct

10 boxes

Syringe, $3 \mathrm{cc}$ Luer lock 20GA 1-inch needle

100 ct

10 boxes

5 boxes

$100 \mathrm{ct}$

10 boxes

Syringe, $6 \mathrm{cc}$

$50 \mathrm{ct}$

5 boxes

50 ct

5 boxes

$20 \mathrm{ct}$

5 boxes

Syringe, $20 \mathrm{cc}$, eccentric tip

20 ct

$20 \mathrm{ct}$

Syringe, $60 \mathrm{cc}$, nozzle tip

$100 \mathrm{ct}$

Needles, 22GA 1 inch

Needles, 22GA 1-1/2 inch

Needles, 20GA 1 inch

100 ct

$100 \mathrm{ct}$

Needles, 20GA 1-1/2 inch

$100 \mathrm{ct}$

Needles, 19GA 1 inch

$100 \mathrm{ct}$

Needles, 19GA 1-1/2 inch

100 ct

Needles, 16GA 1 inch

$100 \mathrm{ct}$

5 boxes

5 boxes

1 box

1 .box

15 boxes

5 boxes

5 boxes

5 boxes

3 boxes

Laboratory supplies

Blood chemistry analyzer and equipment needed to operate

Blood glucose reagent test strips

Blood Glucose Accucheck II Monitor

BUN reagent test strips

5 vials

Centrifuge for hematocrits and urines

25 ct

1

Centrifuge for $9 \mathrm{~mL}$ red top tubes

5 vials

Clay, hematocrit

Hematocrit tubes

100 ct

Hemacytometer

I-Chem jars, toxicology studies-as needed

Microscope, good quality with oil lens

Misc. labels, sharpies, scotch tape, pens, calculator

Plastic storage vials, $1 \mathrm{cc}$

1

1

3

Refractometer

Refrigerator

3 packages

1

72 jars

1 
Slides, microscope, cover slips

10 boxes

Stain, Gram

Stain, new methylene blue

1 set

Stain, urine sedistain

1 set

Stain, Wrights

1 set

Test tubes, glass

2 sets

Test tube racks

3 boxes

100 ct

6 racks

Tubes, gray top, $5 \mathrm{~mL}$ draw

$100 \mathrm{ct}$

3 boxes

Tubes, green top, $9 \mathrm{~mL}$ draw

$100 \mathrm{ct}$

3 boxes

Tubes, lavender top, $3 \mathrm{~mL}$ draw

100 ct

5 boxes

Tubes, red top, $9 \mathrm{~mL}$ draw

$100 \mathrm{ct}$

10 boxes

Unopettes for WBC's

100 ct

2 jars

Urine reagent test strips

$100 \mathrm{ct}$

1 container

\section{Surgery supplies}

Autoclave

Betadine scrub

Betadine solution

Blades, sterile surgery, sizes 10, 11, 20

Cold pack container

Gloves, nonsterile exam type

Gloves, sterile surgery, various sizes

Emergency kits (fishing boxes)

Endotracheal tubes, sizes 4-8

Fishing vests, (for anesthetic procedures)

Instrucal

Instruments, basic for surgery, wrapped

Nolvasan scrub

1

gallon

1

gallon

1 gallon

1 gallon

1 box each

1

100

8 boxes

12 each

3 boxes

1 each size

2 vests

gallon 1 gallon

3 packs

gallon 1 gallon

gallon 1 gallon

Nolvasan solution

Oxygen, tank and respirator setup

Stomach tubing

2 tanks

Suture, gut, various sizes

5 feet

10

6 each

Suture, vicryl, 2-0, 3-0, cutting reverse

12 each size

6 each size

Thermometer, glass hypothermia

Thermometer, glass regular 


\section{Appendix B. Outline of Needs for Future Wildlife Rescue.}

\section{Setting Up the Pharmacy}

1. Organize list of suppliers

Open up accounts

Define ordering protocol

Including:

Procedures

Purchase order numbers

Approvals needed

2. Acquire list of medications that will be needed Including:

Emergency

Prophylactic

Maintenance

Anesthesia

Surgical

3. Inventory control

Coordinate supplies needed from all areas

Including:

Husbandry

Nursery

Laboratory

Special Studies

Anesthesia

Surgery

4. Keep all areas of hospital stocked

Including:

Emergency kits

Medical supplies

5. Keep updated medical protocols from doctors Including:

Treatment

Emergency procedures

Anesthesia

Formularies

Special Procedures

Specimen handling

6. Controlled drug documentation

Detailed records logs

Locked and limited access to controlled drugs

Define ordering and handling protocol

\section{Setting Up the Laboratory}

1. Consult with specific areas of recovery centers to determine information and samples desired.
Including:

Blood

Urine

Feces

Toxicology

Virology

Bacteriology

Electrophoresis

Special studies

Pathology

Histology

2. Maintain updated protocols

Including:

Sample collection

Sample Storage

Archiving

3. Establish laboratory logs

Including:

Documentation of all specimens

Cross-reference data

4. Order appropriate equipment, consider donation sources, such as:

Abbott Labs and Kodak donated Blood Chemistry Analyzers (consult major university pathologists as to the best analyzer available).

PmL Labs donated a centrifuge

Hewlett-Packard donated a computer system.

5. Maintain inventory of supplies

Including:

Slides

Stains

Specimen collection containers

6. Define and establish protocols for inhouse testing

Hematology

Blood chemistry

Fecals

Urine

Bacteriology

7. Define and establish protocols for outside laboratory testing

Including:

Name of laboratory

Specimens desired and handling requirements 
Assisting in Medical Care

1. Assist veterinarians:

Including:

Animal care

Treatments

Observation and monitoring

Anesthesia

Surgical assistance

Maintaining detailed records
Communication with other staff members and volunteers

2. Keep all protocols current

Including:

Treatment

Emergency

Anesthesia

Formularies

Specimen collection

Special procedures

3. Keep hospital clean and organized. 


\section{Appendix C. Existing Inventory.}

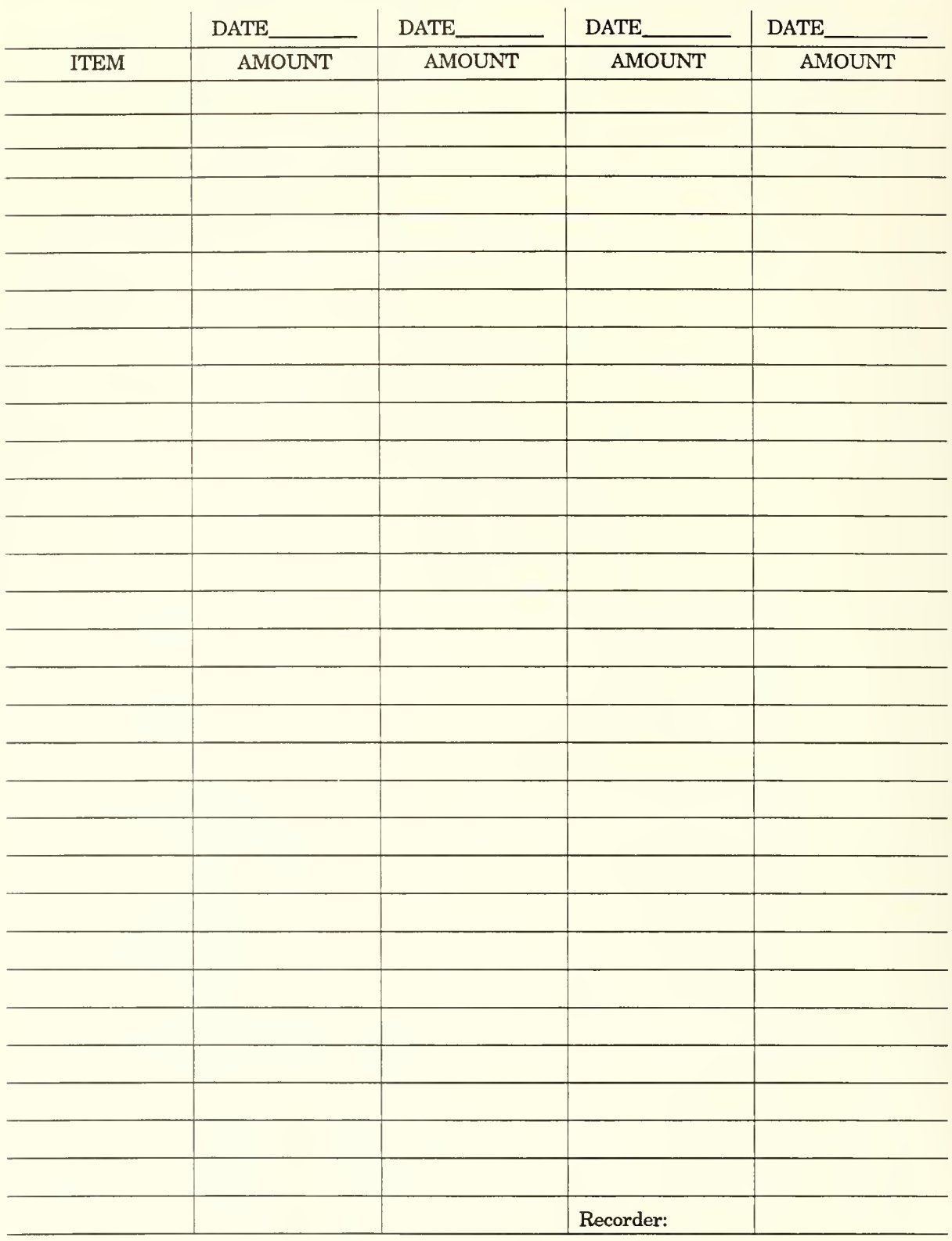




\section{Appendix D. Narcotics Log.}

Drug

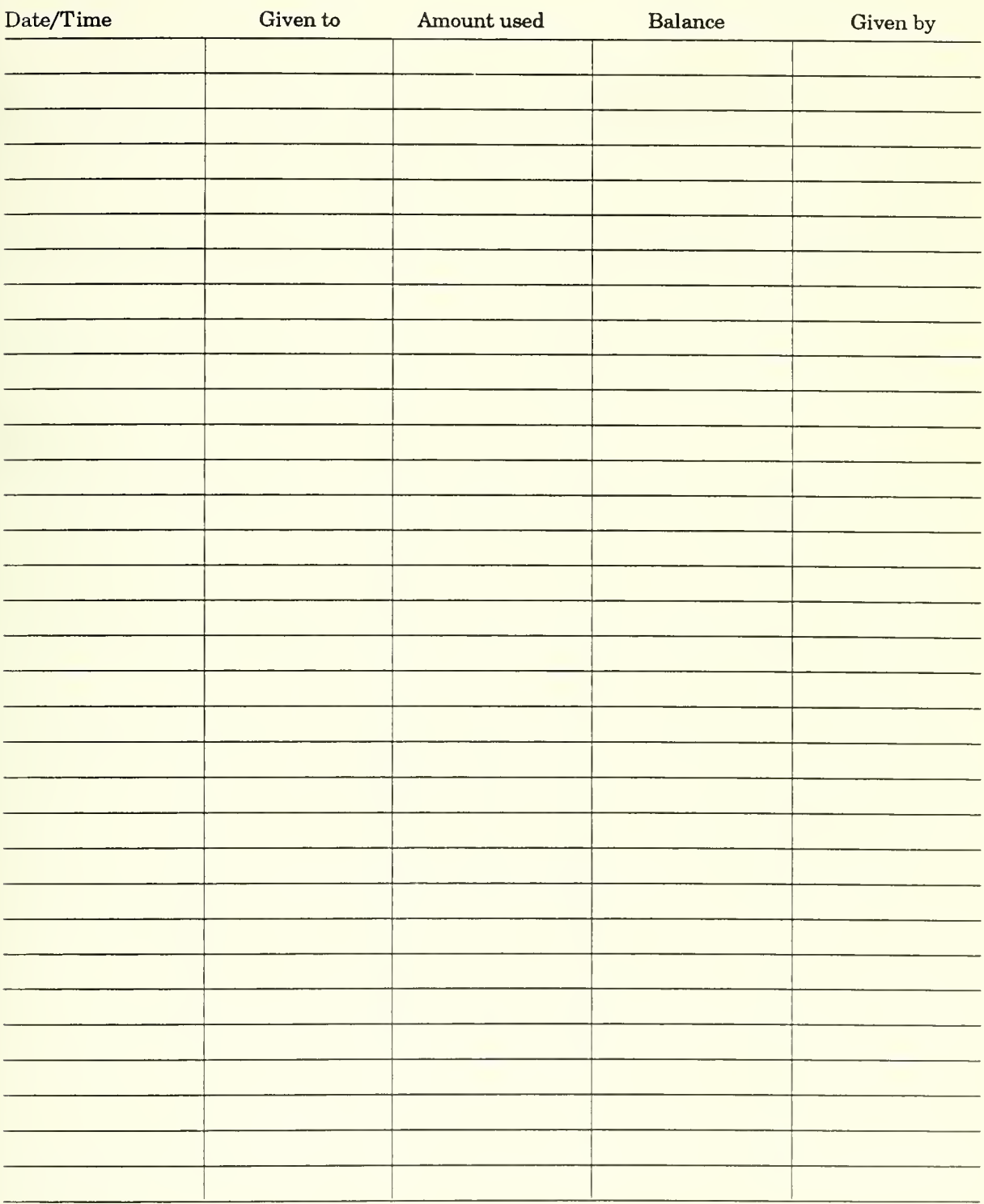




\section{Appendix E. Memorandum.}

To: $\quad$ All Vets and Vet Techs.

From: Laura Kelly, Vet Tech.

Date: July 25, 1989

Each time a drug is drawn up, we lose about $0.07 \mathrm{cc}$ to residual. We need to subtract this amount each time we draw up a drug. Some otters receive 2 or 3 injections of the same drug during an anesthetic procedure. It adds up! For ease of calculating and an average of times a drug is drawn up, $0.1 \mathrm{cc}$ will be allowed per otter. This can be subtracted about every 10 otters or when volume is measured and corrected. (For example, 10 otters anesthetized with fentanyl, subtract $1.0 \mathrm{cc}$ ).

The Valium and fentanyl quantities need to be checked more often (don't forget we lose 0.07 cc every time we check volume). Ideally, this should be done every shift. REALISTICALLY, we can shoot for once every other day or more often depending on quantities of drugs used.

Overall, we have fairly accurate, but messy, controlled drug records. Our biggest problem has been not accounting for the residual amounts.

Thank you,

Laura L. Kelly

Veterinary Technician 


\section{Appendix F. Blood Chemistry Analyzer Comparison.}

Comparison of the blood chemistry analyzers used at the Valdez Otter Rehabilitation Center and the Seward Otter Rehabilitation Center on sea otter blood as viewed by the technicians who operated them. This may not reflect the views, claims, or recommendations of the manufacturers.

Vision

Sample required

Hemolyzed/lipemic sample

Difficulty in use

Time to run controls

Time to run basic chemistry panel on one sea otter

Cost to Exxon and reagent storage

Accuracy of values

Tests available serum or heparinized plasma
best-whole blood if HCT
was below $50 \%$
would not calculate a value-
dilute and rerun

simple, no pipetting required

about $40 \mathrm{~min}$

about $40 \mathrm{~min}-15$ of these are hands-on time

donated use of analyzer and donated reagents-required $3 \times$ more room than the

Ektachem

good

albumin, alk. phos., Ca, amylase, c-react prot, $\mathrm{LDL}$, BUN, chol., G-GTP, creatinine, $\mathrm{LDH}$, glucose, hemoglobin, theo, HDL, prothrombin, SGOT, SGPT, $\mathrm{K}+$, T4, T.B., T.P., trig, CPK, U.A.
Ektachem

serum or heparinized plasma

appeared to calculate elevated value dilute and rerun

need experienced personnel-requires careful pipetting

about $2 \mathrm{~h}$

about $11 / 2 \mathrm{~h}$ of hands-on time
donated use of analyzer-needed to purchase reagents

good-it was felt this analyzer more closely correlated with PmL's values but no scientific study was done

SGPT, SGOT, $\mathrm{CO}_{2}$, alk. phos., amylase, $\mathrm{NH}_{3}, \mathrm{Ca}, \mathrm{Cl}-, \mathrm{CPK}$, chol., creatinine, GGT, crsc, glucose, hemoglobin, $\mathrm{LDH}$, $\mathrm{Mg}$, phos, $\mathrm{Na}+, \mathrm{T} . \mathrm{B} . \mathrm{BUN}$, trig, U.A., KT, Hb 


\section{Appendix G. Blood Data.}

\section{OTTER \#}

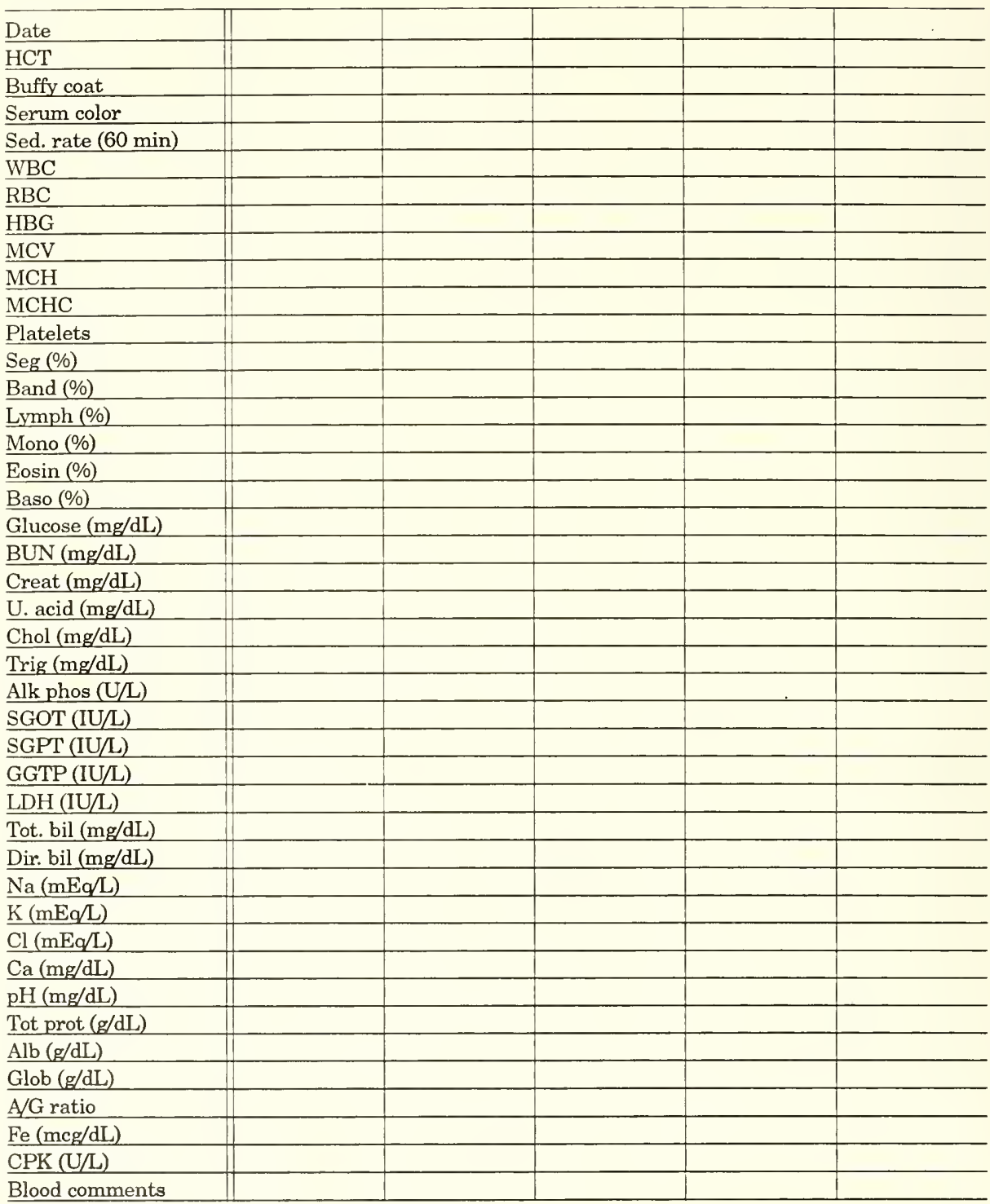




\section{Appendix H. Veterinary Laboratory Protocol.}

Labeling: Put the animal's number, date, and time of day on all tubes and specimen containers. The status of the animal should also be included, such as TOH (to the harbor); deceased, sick, new arrival, sample designation (e.g., serology), and origination (e.g., VORC) should be on each label.

Lavender-top tube: Remove needle and rubber caps and then gently squirt $2 \mathrm{cc}$ of fresh sample into the tube, hold at a slant. ROTATE SLOWLY for $30 \mathrm{~s}$ (about four rotations).

This will be used for STAT panel: HCT, WBC, blood glucose, BUN, T.P., sed. rate (1 mL), serum color, and serum for special tests.

C.B.C.: Return sed. rate tube blood to the LTT. Refrigerate remaining blood for the hospital. This tube should be at least half full due to the dilution factor of the tube.

Red-top tube: Use nonseparator type. Collect two tubes, do not rotate. Centrifuge within $1 \mathrm{~h}$ of collection for $20 \mathrm{~m}$. Decant serum into another tube, label, and refrigerate. Use a tuberculin syringe to measure $0.2 \mathrm{cc}$ samples. The tuberculin syringe can be used as a sample container if the small plastic vials are not available.

SERUM: DESTINATION/PRIORITY AMOUNT OF SERUM

$\begin{array}{ll}\text { Hospital for SMAC } & 1.25 \mathrm{~mL} \\ \text { Toxicology-glass vials with Teflon cap } \times 2 & 0.5 \mathrm{~mL} / \mathrm{vial} \\ \text { Serology } & 0.2 \mathrm{~mL} \\ \text { Distemper titers } & 0.2 \mathrm{~mL} \\ \text { Electrophoresis } & 0.2 \mathrm{~mL}\end{array}$

Extra-label and save in freezer

Clots: Save for pathology in freezer. This can be saved in the original RTT with the top wrapped in aluminum foil and frozen in an upright position.

Gray-top tubes: 3 to $4 \mathrm{cc}$ whole blood in gray-top tube at in-processing and out-processing only. After SMAC.

Draw heart blood on deceased animals immediately after death when possible. Save gray top tube for toxicology plus LTT and RTT as above, plus blood slides (six) for pathology.

Log samples on form provided inside Ziploc collecting bag in the refrigerator/freezer. Note otter number, date, time, and medical condition.

The person removing samples should sign and date the log sheet and indicate where samples are going. 


\section{Appendix I. Sea Otter (Enhydra lutris) Admission Record.}

Date Collected:

Tag Position \& Color: R

\section{$\mathrm{L}$}

Area Collected:

Collected by:

Method of Capture:

Time of Capture: Time Transported:

Condition (Good, Fair, or Poor):

Degree of oiling at time of capture:

Weight (otter + trap): Trap only: Otter wt:

Injections:

Ditrim Penicillin

Dexamethasone B Complex

Other

Remarks:

Final Disposition:

Expired ( ) Euthanized ( )

Date

Released ( )

Date Release Site:

Animal \#

Tag \#

Sex 


\section{Appendix J. Washing Protocol.}

Treatment Sequence

A) Assessment

1. Weight

2. Condition

3. Degree of oiling

4. Hair sample

B) Sedation

C) Eye ointment-flush and check corneas with flourescein dye.

D) Temperature-repeat every half hour.

E) Tube with Toxiban $60 \mathrm{cc}$ diluted with $30 \mathrm{cc}$ saline/40 pounds.

F) Medication

1. Dexamethasone $1 \mathrm{cc} / 20$ pounds IM

2. Penicillin $1 \mathrm{cc} / 20$ pounds with B-Complex $1 \mathrm{cc} / 20$ pounds IM

3. Ditrim or Tribrissen (48\%) $1 \mathrm{cc} / 40$ pounds SQ

4. Vitamin E-Selenium $1 / 2 \mathrm{cc} / 50$ pounds

G) Fecal sample-label with date, time, animal number. Freeze-not in plastic.

H) Blood collection-Label all tubes.

1. LTT-For CBC, must be half full and gently mixed.

2. RTT-For SMA, best if more than one tube.

3. GTT-For toxicology, mix gently at least half full, must be frozen.

I) Tube with STAT $60 \mathrm{cc}$ diluted with saline $30 \mathrm{cc}$ (at end of procedure).

J) Fluids, $5 \%$ dextrose $500 \mathrm{cc} \mathrm{SQ}$.

K) Repeat eye flush.

L) Toe tag.

Paperwork

1. Complete record log-sea otter received and assign numbers.

2. Copy admission records and attach copies to clipboard.

3. Log controlled drugs on narcotic log sheet. 


\section{Appendix K. Anesthesia and Cleaning Record.}

Animal Number

Weight

Date

Tag Number/Color

Sex

Physical Assessment

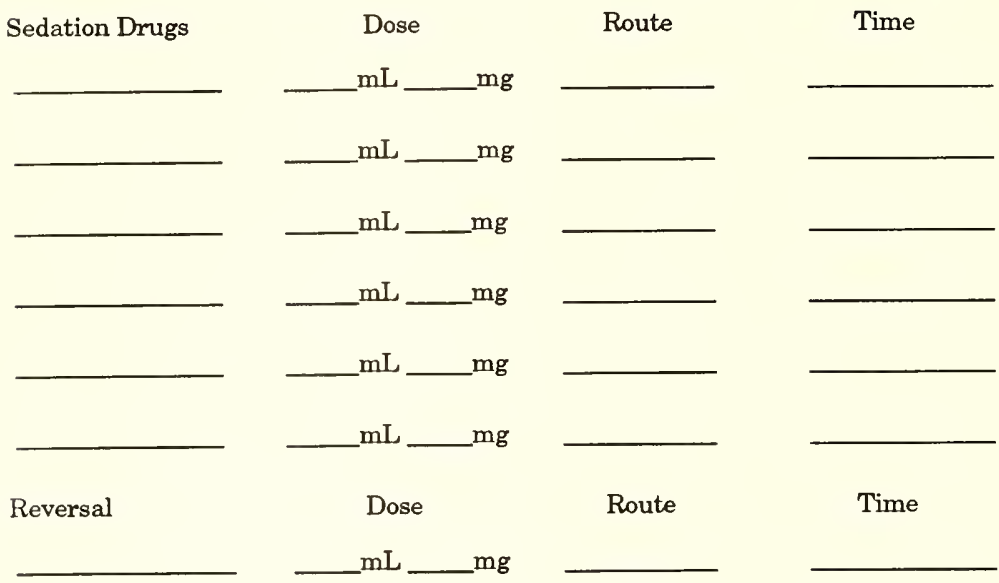

Time Moved to Cleaning Room

Time Moved to Drying Room

Time Finished

Temperature and Time

Additional Medications

Remarks 


\section{Appendix L. Treatment Schedulle.}

\begin{tabular}{|c|c|c|c|c|c|}
\hline Date & $\begin{array}{c}\text { Otter } \\
\text { number }\end{array}$ & $\begin{array}{c}\text { Tag } \\
\text { number }\end{array}$ & Treatment & $\begin{array}{l}\text { Duration } \\
\text { Day/time }\end{array}$ & $\begin{array}{l}\text { Times to } \\
\text { be given } \\
\text { a.m. p.m. }\end{array}$ \\
\hline & & & & & \\
\hline & & & & & \\
\hline & & & & & \\
\hline & & & & & \\
\hline & & & & & \\
\hline & & & & & \\
\hline & & & & & \\
\hline & & & & & \\
\hline & & & & & \\
\hline & & & & & \\
\hline & & & & & \\
\hline & & & & & \\
\hline & & & & & \\
\hline & & & & & \\
\hline & & & & & \\
\hline & & & & & \\
\hline & & & & & \\
\hline & & & & & \\
\hline & & & & & \\
\hline & & & & & \\
\hline & & & & & \\
\hline & & & & & \\
\hline & & & & & \\
\hline & & & & & \\
\hline & & & & & \\
\hline & & & & & \\
\hline & & & & & \\
\hline & & & & & \\
\hline & & & & & \\
\hline & & & & & \\
\hline & & & & & \\
\hline & & & & & \\
\hline & & & & & \\
\hline & & & & & \\
\hline & & & & Recorder: & \\
\hline
\end{tabular}




\section{Appendix M. Sea Otter (Enhydra lutris) Anesthesia for Implants.}

Otter Number

Date

Sex

Weight

Body Condition

Anesthetic:

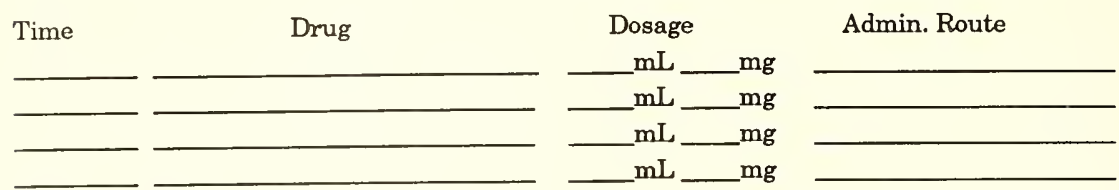

Time to surgical plane of anesthesia:

Time surgery began: completed:

Surgeon

Clinical Observations:

Time

Temperature

Heart Rate

Respiratory Rate

Complications:

Anesthetic Reversal: Narcan

Time Dosage Admin. Route

SURGERY: Routine Notes 


\title{
Chemical Restraint and Anesthesia of Sea Otters Affected by the Oil Spill in Prince William Sound, Alaska
}

\author{
by \\ D. C. Sawyer \\ Departments of Small Animal Clinical Sciences and Pharmacology and Toxicology \\ College of Veterinary Medicine \\ Michigan State University \\ East Lansing, Michigan 48864
}

and

T. D. Williams

Monterey Bay Aquarium

886 Cannery Row

Monterey, California 93940

\begin{abstract}
Most of the sea otters (Enhydra lutris) affected by the oil spill in Prince William Sound and brought to the rehabilitation centers in Valdez and Seward, Alaska, for cleaning and rehabilitation required chemical restraint for the 2-h cleaning process. Various combinations of opioid agonists, a dissociative agent, and tranquilizers were used, and a small number of otters were anesthetized with isoflurane. Varying numbers of otters were given combinations that included butorphanol-diazepam, meperidine-diazepam, fentanyl-azaperone-diazepam, fentanyl-acetylpromazine-diazepam (Telazol). We discuss problems in handling and administering the drugs, induction time, duration of effect, variables monitored during anesthesia, recovery time, complications, morbidity, and mortality. Advantages, disadvantages, and acceptability of each group are presented not only for the effectiveness of chemical restraint provided for the cleaning and therapeutic procedures but also for the potential risk and abuse potential to personnel working at the rehabilitation centers. The most effective combination was fentanyl $(0.1 \mathrm{mg} / \mathrm{kg})$ combined with either phenothiazine tranquilizer or diazepam $(0.22 \mathrm{mg} / \mathrm{kg})$ and given intramuscularly.
\end{abstract}

North America experienced its worst oil spill disaster in history on 24 March 1989, and thousands of wild animals were affected in Prince William Sound, Alaska. Three hundred thirtynine live sea otters were brought to rehabilitation centers in Valdez and Seward for cleaning and rehabilitation. Of those, 214 required chemical restraint and anesthesia for the more than $2-h$ washing and treatment procedure. The use of injectable agents was necessitated by the lack of anesthetic equipment, small working space in the washing stations, and potentially harmful effects of inhaled oil vapors by the otters early in the exposure period after the spill. Fifteen different drug procedures were used from 29 March to about 15 August 1989. The volatile liquid anes- 
thetic isoflurane was used on two otters after chemical sedation, and 16 other agents were given by intramuscular (IM) injection.

Availability and security of the narcotic drugs were problems early in the rescue process because veterinarians could only use drugs they brought to the Valdez Otter Rehabilitation Center (VORC), or drugs that could be obtained from a local medical hospital.

The opioids butorphanol, fentanyl, meperidine, and oxymorphone were used alone or in various combinations with the tranquilizers acepromazine, azaperone, and diazepam (Appendix). Butorphanol is classified as an agonist-antagonist analgesic, whereas fentanyl, meperidine, and oxymorphone are considered $\mu$ opioid agonist analgesics. In most of the procedures, the antagonist naloxone was given at the end of the procedure by IM injection to ensure recovery from the narcotic drugs. Acepromazine is a phenothiazine tranquilizer, whereas azaperone is classified as a butyrophenone, and diazepam is the most commonly used benzodiazepine. Telazol, used on only two animals, is a combination of teletamine, a dissociative agent, and zolazepam, a diazepinone tranquilizer.

Various reports in the literature indicate the usefulness of neuroleptanalgesia in sea otters. The neurolepsis is provided by phenothiazine and butyrophenone tranquilizers with analgesia induced by the opioid drugs. Etorphine, a highly potent opioid, was previously tested by Williams and Kocher (1978) in 16 otters. Induction occurred in 5 to $15 \mathrm{~min}$ at $0.01-0.02 \mathrm{mg} / \mathrm{kg}$. At doses of $0.05-0.13 \mathrm{mg} / \mathrm{kg}$, anesthesia was induced in 3 to $20 \mathrm{~min}$, with an average of $5 \mathrm{~min}$. Recovery time depended on when an antagonist was given. Convulsions occurred in three of the otters, and three others experienced slight cyanosis caused by drug-induced apnea. Flaccid muscle tone was apparent in each of the otters given etorphine. Diazepam $(0.04-0.11 \mathrm{mg} / \mathrm{kg}$ ) was reported by Williams and Kocher (1978) to aid induction with etorphine in all but three otters that exhibited convulsions. One otter given $0.21 \mathrm{mg} / \mathrm{kg}$ of diazepam to treat seizures required more than $3 \mathrm{~h}$ to recover. Etorphine was not available at the rehabilitation centers in Alaska.

Fentanyl has been used in sea otters for more than 10 years. Williams and Kocher (1978) administered the opioid alone six times to three otters, with unsatisfactory immobilization in each situation. Doses of $0.003-0.01 \mathrm{mg} / \mathrm{kg}$ IM had no effect.
At $0.02 \mathrm{mg} / \mathrm{kg}$, a slight degree of immobilization was evident after $7 \mathrm{~min}$. A dose of $0.04 \mathrm{mg} / \mathrm{kg}$ resulted in better restraint in about $20 \mathrm{~min}$. These effects were rapidly reversed by an IM injection of agonist-antagonist nalorphine or diprenorphine. Williams et al. (1981) used fentanyl effectively with azaperone to produce neuroleptanalgesia. Fentanyl was given at doses of $0.05-0.11 \mathrm{mg} / \mathrm{kg}$ IM in combination with azaperone at $0.11-0.45 \mathrm{mg} / \mathrm{kg}$.

Meperidine was reported by Joseph et al. (1987) to produce only slight sedation at doses up to $5 \mathrm{mg} / \mathrm{kg}$, but slight to moderate effects were achieved with 5 to $7 \mathrm{mg} / \mathrm{kg}$. Combinations of meperidine $(11-13 \mathrm{mg} / \mathrm{kg}$ ) with diazepam at 0.22 , 0.33 , or $0.55 \mathrm{mg} / \mathrm{kg}$ provided fair sedation. Duration of effect was not indicated.

Acepromazine was used by Williams and Kocher (1978) at $0.1 \mathrm{mg} / \mathrm{kg}$ to aid induction of anesthesia with etorphine but resulted in prolonged recovery. The otter could be aroused but became tranquilized again several times before total recovery. Azaperone has been used extensively for neuroleptanalgesia in sea otters (Williams et al. 1981). It was believed that the safety margin of fentanyl was higher when given with azaperone because the respiratory depression caused by fentanyl seemed to be impeded by the tranquilizer. Azaperone did not reduce body temperature at low doses, seemed to have no adverse cardiovascular effects, and provided smooth induction and recovery with less anxiety than when fentanyl was used alone.

In seven trials with Telazol, induction occurred in 0.5-6 min (Williams and Kocher 1978). A dose of $9.3 \mathrm{mg} / \mathrm{kg}$ produced safe immobilization for $30-45$ min. Results of four tests in three otters using ketamine from $0.89-1.17 \mathrm{mg} / \mathrm{kg}$ IM were unsatisfactory. Otters were immobilized in 10-15 min; they experienced severe tremors that continued even after recovery.

Joseph et al. (1987) reported that xylazine, an alpha-2 agonist $(0.11 \mathrm{mg} / \mathrm{kg})$, used alone and in combination with diazepam produced only slight sedation, during which otters seemed somewhat somnolent but were responsive when handling was attempted. Xylazine in conjunction with meperidine produced excellent sedation and immobilization. When xylazine was used as the sole agent or in combination, it produced residual lethargy lasting as long as $8 \mathrm{~h}$.

Halothane has been used successfully by one of us on sea otters for more than 15 years. Maintenance was easily maintained at $1.5 \%$, with recovery in $4.5 \mathrm{~min}$. Isoflurane also provided safe and 
rapid anesthesia in sea otters and is recommended for use in a hospital setting. Otters were wrapped in a net, induced by mask isoflurane delivered in $2-5 \mathrm{~L} / \mathrm{min}$ oxygen, intubated with a $5-6-\mathrm{mm}$ ID endotracheal tube, and maintained with $2.5 \%$ in $500-750 \mathrm{~mL} / \mathrm{min}$ of oxygen. Recovery occurred within $5 \mathrm{~min}$.

Williams and Kocher (1978) reported that the most effective opioid antagonists for sea otters were naloxone and diprenorphine. They recommended that naloxone be given at a dose of $1 \mathrm{mg}$ per $\mathrm{kg}$ of fentanyl, with a suggested range of $0.05-1 \mathrm{mg} / \mathrm{kg}$.

\section{Methods}

Animals brought to VORC were immediately taken to the wash station, removed from transport cages, and if cleaning was needed, given drugs by deep IM injection in the hind leg. A soft bag was placed over the face of the animal to keep it restrained during the injection process. When sea otters were brought to VORC during the first 2 weeks of rescue in April 1989, five different chemical immobilization procedures were used in 73 otters. Thirty-eight otters were anesthetized for washing the second 2 weeks, and four animals were treated the rest of the month.

Starting 29 April, otters were taken to Seward, and a slightly different procedure was used. Instead of anesthetizing otters immediately on arrival, they were allowed to recover from the capture and transport process, usually overnight. They were then given the anesthetics before washing and treatment.

\section{Results}

At VORC, butorphanol, butorphanol. acepromazine, butorphanol-meperidine-diazepam, butorphanol-diazepam, and meperidine-diazepam, were used on 73 otters. The combination of meperidine and diazepam was used on 51 otters, but 42 of those did not survive the rescue procedures. The use of combinations of butorphanol and meperidine with acepromazine and diazepam early in the process was not just by choice; they were the only drugs available, and veterinarians did the best they could with what they had. These animals were severely oiled and in much worse condition than those VORC received later. Although more animals died when meperidine and diazepam were used, there is no way to attribute the cause of death to the use of these drugs. The duration of anesthesia was not recorded on the animals in VORC, but one can assume that the procedures lasted about $2 \mathrm{~h}$. Repeat doses of meperidine were given to $41 \%$ of the otters that died, compared with $40 \%$ of those that survived. In contrast, diazepam was given to $24 \%$ that died and $27 \%$ that lived. The dosage rate for meperidine was about 1.6 doses per otter, and the repeat dose of meperidine was $12.3 \mathrm{mg} / \mathrm{kg}$ compared with the induction dose of $13 \mathrm{mg} / \mathrm{kg}$, the same dose as reported in the literature. Butorphanol and diazepam were used on 15 otters, with $40 \%$ of those surviving. Again, repeat doses of butorphanol were needed in $56 \%$ of those that did not survive, at a rate of 1.4 doses per otter, compared with $83 \%$ for the survivors (at the same dosage rate). The dose of butorphanol used for induction was $0.3-0.4 \mathrm{mg} / \mathrm{kg}$ combined with diazepam at $0.2 \mathrm{mg} / \mathrm{kg}$. The repeat dose of butorphanol was $0.22-0.26 \mathrm{mg} / \mathrm{kg}$ but the repeat dose of diazepam was the same as the induction dose. During week 3 at VORC, fentanyl was used in combinations with acepromazine, azaperone, and diazepam. Butorphanol and meperidine were not used after week 3 , mostly because of the short duration of effect and lack of adequate immobilization. Based on previous reports of the high doses of fentanyl and either azaperone or acepromazine required for immobilization, diazepam had to be used to counteract the seizures most likely induced by the rapid uptake of fentanyl after IM injection. Skeletal muscle in sea otters has a rich vascular supply, which most likely helps the uptake. Uptake is also augmented by the high lipid solubility of fentanyl. The combination of fentanyl $(0.09-0.12 \mathrm{mg} / \mathrm{kg})$, azaperone $(0.55 \mathrm{mg} / \mathrm{kg})$, or acepromazine $(0.09 \mathrm{mg} / \mathrm{kg})$ and diazepam $(0.1-$ $0.2 \mathrm{mg} / \mathrm{kg}$ ) provided effective immobilization, with repeat doses of fentanyl needed in only $5 \%$ of the animals. Repeat diazepam was given to $15 \%$ of the otters. The biggest advantage with fentanyl was that it could be obtained in $50-\mathrm{mg}$ quantities in powder form, whereas all other opioids were available only in liquid form in low concentrations, with the exception of butorphanol, which is $10 \mathrm{mg} / \mathrm{mL}$. Oxymorphone was used in five animals in VORC, but at an average dose of $0.3 \mathrm{mg} / \mathrm{kg}$, a $25-\mathrm{kg}$ otter would require $5 \mathrm{~mL}$ of the opioid for IM injection, compared with only $0.3 \mathrm{~mL}$ of fentanyl. The dose of oxymorphone used in five animals in Seward Otter Rehabilitation Center (SORC) was $0.5 \mathrm{mg} / \mathrm{kg}$.

Telazol was used on two animals in VORC with marginal success. One animal did well while anesthetized but died about $8 \mathrm{~h}$ later of toxic hepatitis and uterine torsion. The second otter required re- 
peated injections and did not have good muscle relaxation.

In SORC the most common combination used for the washing procedures was fentanyl-diazepam ( 49 otters); this combination was also used in 8 of the 34 animals receiving transponder implants. Perhaps because the animals were in better condition, a higher dose of fentanyl was used $(0.16 \pm 0.01 \mathrm{mg} / \mathrm{kg})$, with a repeat dose of $0.12 \pm 0.01 \mathrm{mg} / \mathrm{kg}$ in $84 \%$ of the otters, at a rate of 1.7 doses per otter. The induction dose of diazepam was $0.21 \pm 0.01 \mathrm{mg} / \mathrm{kg}$. On the other hand, perhaps a higher dose of fentanyl was needed because a neuroleptic tranquilizer was not used. When fentanyl $(0.14 \pm 0.01 \mathrm{mg} / \mathrm{kg})$ was given with azaperone $(0.6 \pm 0.05 \mathrm{mg} / \mathrm{kg})$ and diazepam $(0.23 \pm 0.04 \mathrm{mg} / \mathrm{kg})$ to 16 otters, a repeat dose of fentanyl was needed in $63 \%$ of the animals, and diazepam in $56 \%$. When acepromazine $(0.15 \pm 0.01 \mathrm{mg} / \mathrm{kg})$ with fentanyl and diazepam was used on 27 otters, the dose of fentanyl was $0.15 \mathrm{mg} / \mathrm{kg}$, and repeat doses of fentanyl were used only in $33 \%$ of the animals at $0.06 \pm$ $0.01 \mathrm{mg} / \mathrm{kg}$. However, the induction dose of diazepam was $0.24 \pm 0.01 \mathrm{mg} / \mathrm{kg}$, and repeat doses were given to $89 \%$ of the animals at $0.25 \pm 0.02 \mathrm{mg} / \mathrm{kg}$. No repeat doses of azaperone or acepromazine were used.

The dose of acepromazine with fentanyl and diazepam used in SORC was almost twice that used in VORC, which would result in longer recoveries. However, the dose of azaperone was the same at both centers. The frequency of use of fentanyl-diazepam in SORC increased from late May through August, and one must speculate that veterinarians were not willing to accept the longer recoveries most likely induced when a higher dose of acepromazine was used. This might not have been a problem had $0.05-0.07 \mathrm{mg} / \mathrm{kg}$ of acepromazine been used with fentanyl and diazepam.

The number of anesthetic procedures used on all of the sea otters in VORC and SORC was 496.
Although there was not a problem with the use of such a high concentration of fentanyl $(10 \mathrm{mg} / \mathrm{mL})$ at the rehabilitation centers, the potential existed for an accidental injection of the opioid in a human. If this drug had been sprayed into the ocular mucosa or accidently injected in a person working with the drug, profound sedation or unconsciousness, bradycardia, and respiratory depression could occur. It would be wise to have emergency procedures developed to reverse the depressant effects of fentanyl with naloxone, and equipment available for intubation and ventilation. In addition, a strict drug security system must be in effect to avoid potential abuse of controlled drugs.

From the experiences at VORC and SORC a great deal of knowledge was gained on the effects of various analgesics and tranquilizers in sea otters. Fentanyl $(0.09-0.22 \mathrm{mg} / \mathrm{kg})$ was the opioid of choice to produce the $2.5 \mathrm{~h}$ of neuroleptanalgesia needed for rehabilitation when combined with either azaperone $(0.5 \mathrm{mg} / \mathrm{kg})$ or acepromazine $(0.05 \mathrm{mg} / \mathrm{kg})$ with diazepam $(0.2-0.5 \mathrm{mg} / \mathrm{kg})$.

\section{Acknowledgments}

We thank Exxon Company, U.S.A., for funding, and M. Langham and E. Striler for their technical assistance in the statistical analysis of the data and manuscript preparation.

\section{References}

Joseph, B. E., L. H. Cornell, and T. D. Williams. 1987. Chemical sedation of sea otters, Enhydra lutris. J. Zoo Anim. Med. 18:7-13.

Williams, T. D., and F. H. Kocher. 1978. Comparison of anesthetic agents in the sea otter. J. Am. Vet. Med. Assoc. 173:1127-1130.

Williams, T. D., A. L. Williams, and D. B. Siniff. 1981. Fentanyl and azaperone produced neuroleptanalgesia in the sea otter (Enhydra lutris). J. Wildl. Dis. $17: 337-342$. 


\section{Appendix. Sources of Drugs Needed for Chemical Restraint and Anesthesia of Sea Otters.}

The drugs referred to in this paper may be obtained from the following sources:

Azaperone-Pitman Moore, Inc., Mundelein, Illinois

Acepromazine-Fort Dodge Laboratories, Fort Dodge, Iowa

Butorphanol-Fort Dodge Laboratories, Fort Dodge, Iowa

Diazepam-Roche Laboratories, Autley, New Jersey

Fentanyl-Sigma Chemicals, St. Louis, Missouri

Halothane-Fort Dodge Laboratories, New York, New York

Isoflurane (Aerrane)-Anaquest, Madison, Wisconsin

Meperidine-Winthrop Laboratories, New York, New York

Naloxone-Pitman Moore, Inc., Mundelein, Illinois

Oxymorphone--Pitman Moore, Inc., Mundelein, Illinois

Telazol-A. H. Robbins, Richmond, Virginia 


\title{
Blood Collection and Analysis During the T/V Exxon Valdez Oil Spill
}

\author{
T. D. Williams \\ Monterey Bay Aquarium \\ 886 Cannery Row \\ Monterey, California 93940 \\ and \\ R. Wilson \\ Arctic Animal Hospital \\ 1600 E. Tudor Road \\ Anchorage, Alaska 99507
}

\begin{abstract}
Large numbers of sea otters (Enhydra lutris) were contaminated with crude oil after the 24 March 1989 oil spill from the T/V Exxon Valdez. Three hundred fifty-seven sea otters (including pups born in captivity) were captured and taken to otter rehabilitation centers for treatment for various medical problems and rehabilitation in spring and summer 1989. Hematology and biochemical profiling was a major diagnostic aid providing valuable information regarding the health status of the sea otters. Samples taken for hematology, blood chemistry, and for hydrocarbon toxicity were compared with normals established on California sea otters involved in the U.S. Fish and Wildlife Service (California) translocation program and others under the care of the Monterey Bay Aquarium. Significant disease problems were identified and treatment protocols established.
\end{abstract}

Hematology and biochemical profiling provided valuable information about the health status of 357 sea otters (Enhydra lutris) captured after the 24 March 1989 oil spill from the T/N Exxon Valdez. Blood was routinely drawn upon admission, to help determine the overall health of the otter; during treatment, to monitor the animal's progress; at presurgery, to select healthy animals for surgical implantation of transmitters; and at prerelease, to ensure otters were healthy before release into the wild population. Blood was drawn from the femoral vein, the popliteal vein, or if the animal was anesthetized, from the jugular vein. Samples were taken for hematology, blood chemistry, and hydrocarbon levels.

Hematology and blood chemistry results were compared with normals established on California sea otters involved in the California sea otter translocation program and otters under the care of the Monterey Bay Aquarium. The sea otter's adaptation to its marine environment results in hematologic and blood chemistry values that are similar to those of pinnipeds and cetaceans, rather than domestic mammals. Abnormal values reflected the involvement of many organ systems, including renal, hepatic, bone marrow, and musculoskeletal.

\section{Materials and Methods}

One hundred fifty-six otters were treated at the Valdez Otter Rehabilitation Center (VORC), 177 were treated at the Seward Otter Rehabilitation Center (SORC), and 15 were treated at the Homer 
Temporary Care Facility. Shortly after the spill, most of the otters treated were captured in Prince William Sound. Later, animals were brought in from the Kenai Peninsula and Kodiak Island. Otters were held in an otter restraint device (Williams et al. 1990) or anesthetized with fentanyl $(0.1 \mathrm{mg} / \mathrm{kg})$ combined with either phenothiazine tranquilizer (acepromazine, $0.025-0.05 \mathrm{mg} / \mathrm{kg}$ ) or butyrophenone (azaperone, $0.4 \mathrm{mg} / \mathrm{kg}$; and diazepam, $0.22 \mathrm{mg} / \mathrm{kg}$ ) given intramuscularly (Sawyer and Williams 1990).

About $12-20 \mathrm{~mL}$ of blood were drawn from either the jugular, popliteal, or femoral veins. The jugular vein was accessible only while an otter was sedated or anesthetized. Blood can be obtained from the femoral vein either proximally, at the femoral triangle, or distally, about $5.1 \mathrm{~cm}$ cranial to the stifle in a caudo-medial direction. Digital pressure was applied after venipuncture to reduce the possibility of hematoma formation.

Blood samples were taken routinely on admission, during the rehabilitation process at the discretion of the attending veterinarian for diagnostic purposes, when otters were moved from the rehabilitation center to prerelease holding facilities, before surgery, and before release. Blood tubes were labeled with the otter number, time of sample, and date.

Immediately after collection, the blood was transferred into evacuated tubes containing ethylenediaminetetraacetic acid for hematology determinations, plain evacuated tubes for clinical chemistry determinations, and evacuated tubes containing sodium fluoride for glucose determinations and toxicological studies. Immediate glucose level was determined from blood with Glucostix. The blood was refrigerated before shipment to the laboratory.

A Technicon H-1 Analyzer (Technicon Inc., Tarryton, New York) was used for the following hematological determinations: white blood cell (WBC) count, red blood cell (RBC) count, hemoglobin (HGB), hematocrit (HCT), and mean corpuscular hemoglobin concentration (MCHC). Differential cell counts were determined on Wright-Giemsastained blood smears, counting at least 100 nucleated cells. The WBC count was made with light scatter-absorbance tungsten halogen lamp and laser. The RBC count was made with light scatter-absorbance laser. The HGB was determined by cyanmethemoglobin. The HCT was calculated by the formula $\mathrm{RBC} \times$ mean corpuscular volume [MCV]/10. The MCV was made by direct measure light scatter laser. The $\mathrm{MCH}$ was calculated by the formula $\mathrm{HGB} / \mathrm{RBC} \times 10$. The MCHC was calculated by the formula HGB/HCT $\times 100$ and confirmed by comparison with directly measured laser light scatter. The red cell distribution width was calculated from directly measured RBC volumes, and platelets by light scatter laser.

The following clinical chemistry tests were performed on a Technicon SMAC II (Technicon Corporation, Tarrytown, New York): glucose (Hexokinase), blood urea nitrogen, BUN (Diacetyl Monoxime), creatinine (Alkaline piclate without Lloyds), uric acid (enzymatic), cholesterol (enzymatic), triglyceride (enzymatic with blank), alkaline phosphatase (PNPP), serum glutamic oxaloacetic transaminase-SGOT, also known as aspartate amino transferase-AST (MDH/LDHNADH), GGT (GNA), LD (NAD), total bilirubin (Diazo J-G with blank), direct bilirubin (diazo J-G with blank), sodium (I.S.E.), potassium (I.S.E.), chloride (mercuric thiocyanate), calcium (cresolphthalein complexone), inorganic phosphorus (phosphomolybdate UV), total protein (Biuret), albumin (BCG), and total iron (Ferrozine). The following clinical chemistry tests were performed on a Roche Cobas.Bio: $\mathrm{CO}_{2}$ (enzymatic endpoint), serum glutamic pyruvic transaminase-SGPT, also known as alanine amino transferase-ALT (Gilford $37^{\circ}$ ), and creatine phosphokinase-CPK (Sigma $37^{\circ}$ ).

\section{Results}

Almost $50 \%$ of the animals that came into the Valdez Center were heavily to moderately oiled. In the early stages of the spill, they were also exposed to volatile hydrocarbons. In contrast, only two otters at the Seward Center arrived heavily oiled; 20 animals were moderately oiled. Almost $60 \%$ of the otters arriving at the Seward Center and all of the otters treated at the Homer Facility were lightly oiled or unoiled. The hematocrit of otters that arrived at the centers showed no correlation with degree of oiling or survival. However, anemia often developed in heavily oiled sea otters after several weeks of captivity. Anemia was determined by the packed cell volume (PCV), hemoglobin concentration, and red blood cells $(\mathrm{RBC} \times$ 1000). Otters that died within the first few days had elevated PCV levels, which is suggestive of dehydration. In otters that survived, the PCV returned to normal, on the average, in 3 months; this is an approximation, as blood was not drawn 
on all animals on the same dates, which makes correlation difficult.

Evaluation of blood smears failed to demonstrate the presence of Heinz bodies, which are pieces of hemoglobin on the red blood cell. Heinz bodies are often seen in hydrocarbon toxicosis of birds.

In the early phases of the program, many otters had markedly elevated liver enzymes, indicating hepatocellular damage. Otters that died had extremely high ALT(SGPT) and AST(SGOT).

Indices for renal function included BUN, serum creatinine, and urine specific gravity. Otters that died in the centers had extremely elevated BUN values. Some BUN values remained high for extended periods (at least a twofold increase). Serum creatinine was at least twofold greater in otters that died, but was still within the normal range for this species.

Blood glucose levels in sea otters were extremely variable. Plasma glucose concentration was consistently lower in heavily oiled otters. Many otters that died had lower glucose levels than those that survived; some had extremely low levels, which could be an indication of decreased food consumption and possibly impaired liver function. Some otters, however, had extremely high blood glucose levels.

There was concern throughout the rehabilitation process about the effects of capture stress syndrome (capture myopathy). Pursuit, capture, transport, and chemical immobilization can lead to capture stress syndrome. Elevated CPK may be a result of capture stress syndrome. Levels of CPK varied at times during captivity and may be partly explained by capture stress. Other possible explanations for CPK elevations include muscle hypoxia as a result of severe dehydration or direct toxic effects of the oil.

\section{Discussion}

During the first several days of the rescue minimal diagnostic procedures were performed at the VORC. Supplies were scarce, and no veterinary diagnostic laboratory was available in Valdez. Several days elapsed before a system was developed to get blood quickly from the Valdez Center to laboratories in Anchorage. As the otter center expanded, a functional on-site laboratory was developed. Unfortunately, these systems took time to implement, therefore many otters did not have blood drawn when they arrived at the center.
Analysis and interpretation of the blood test results is complex and difficult for several reasons. There were many different laboratories used, and results were not standardized. This is apparent when comparing PCV on blood drawn on the same day and analyzed by two different labs. The most likely cause for the variation is technique. Initially, blood was stored for variable times before analysis. Storage time and conditions had an effect on certain values, especially blood glucose. Otter blood hemolyzes easily, and certain values, such as serum potassium and $\mathrm{LDH}$, can be falsely elevated. Extreme care must be taken in assigning the cause for any abnormalities. Oil exposure could explain many of the changes seen in the blood results; however, other factors must be considered. Stress of capture and captivity, dehydration, anorexia, and the administration of pharmaceutical agents such as steroids can affect the hemogram and serum chemistries. Finally, the volume of results to be analyzed increases the difficulty of the task.

Because anemia was not initially present in most otters, it is difficult to determine the etiology without histological evaluation of the bone marrow from each otter. The frequency of anemia at the Valdez Center compared with that at the Seward Center may indicate whether the anemia was due to stress of capture and captivity or to bone marrow suppression as a result of oil exposure. In addition, steroids given at the time of admission may result in transient anemia.

The cause for the elevation of liver enzymes may be multifactorial, including hypoxia as a result of shock, thereby resulting in decreased blood flow to the liver, resulting in hepatocyte degeneration; fatty liver degeneration, as a result of anorexia (this situation is commonly seen in feline species); and direct toxic effects of oil ingestion and absorption.

Urinalysis provides valuable information concerning general health status and state of hydration. The renal (BUN and creatinine) are difficult to interpret without accompanying urinalysis data. Few urine samples were obtained because of the danger to handlers and stress to the otters. Therefore, it is difficult to determine if the elevation of BUN was prerenal or due to renal dysfunction. Elevation in BUN could be due to severe dehydration or from true renal impairment due to oil toxicosis.

Because otters groom almost constantly, a lightly oiled otter that was not captured for several days could potentially have a higher hydrocarbon level 
than a heavily oiled otter that was picked up within a few hours of contact with the oil. As the oil weathered, many of the toxic volatile hydrocarbons evaporated; therefore, the otters exposed to oil on the Kenai Peninsula or Kodiak Island did not show the same toxicity as the otters exposed to the fresh oil in Prince William Sound. Comparison of the blood work in Valdez and Seward will be helpful in this respect and is being undertaken.

Further study is needed to differentiate between the effects of oil exposure, hypothermia, dehydration, starvation, pathology, varying levels of hydrocarbons, and the stress of capture on the blood variables discussed.

\section{References}

Sawyer, D. C., and T. D. Williams. 1990. Chemical restraint and anesthesia of sea otters affected by the oil spill in Prince William Sound, Alaska. Pages 357-361 in K. Bayha and J. Kormendy, tech. coords. Sea Otter Symposium: Proceedings of a symposium to evaluate the response effort on behalf of sea otters after the T/V Exxon Valdez oil spill into Prince William Sound, Anchorage, Alaska, 17-19 April 1990. U.S. Fish Wildl. Serv., Biol Rep. 90(12).

Williams, T. D., A. H. Rebar, P. Yoos, and R. Teclaw. 1990. A comparison of hematology and blood chemistry in captive and wild sea otters. [unpublished manuscript] 


\section{Identification of a Herpes-like Virus in Sea Otters During Rehabilitation After the T/V Exxon Valdez Oil Spill}

by

R. K. Harris, R. B. Moeller, T. P. Lipscomb, and J. M. Pletcher

Department of Veterinary Pathology

Armed Forces Institute of Pathology

Washington, D.C. 20306

R. J. Haebler

Ecosystems Branch

Environmental Research Laboratory

Environmental Protection Agency

Narragansett, Rhode Island 02882

P. A. Tuomi

Veterinary Associates, P.C.,

2036 East Northern Lights Boulevard

Anchorage, Alaska 99508

C. R. McCormick

15536 Husky Street

Eagle River, Alaska 99577

A. R. DeGange and D. Mulcahy

Alaska Fish and Wildlife Research Center

1011 East Tudor Road

Anchorage, Alaska 99503

and

T. D. Williams

Monterey Bay Aquarium

886 Cannery Row

Monterey, California 93940 


\begin{abstract}
During implantation of radiotelemetry devices in sea otters (Enhydra lutris) at the Seward Otter Rehabilitation Center, surgical team members noted ulcers in the oral cavity of each of five animals examined. Oral lesions were identified in 25 of 27 otters examined at the center. Histological evaluation of the lesions revealed focal areas of mucosal epithelial necrosis with associated intranuclear viral inclusion bodies. A herpes-like virus was subsequently identified ultrastructurally. The concern of releasing a virus of unknown origin and virulence into a naive wild otter population prompted management decisions restricting the movement of otters and jeopardizing the scheduled release of the otters on 27 July 1989. A team of veterinarians and otter capture personnel captured and examined 12 free-living adult otters off the coast of the southern Kenai Peninsula. Viral-induced oral lesions were identified in many of these animals establishing that the virus was indigenous to sea otters living in Alaskan waters; rehabilitated otters were released back into the wild.
\end{abstract}

On 15 July 1989, during implantation of radiotelemetry devices in sea otters (Enhydra lutris) maintained at the Seward Otter Rehabilitation Center (SORC), surgical team members observed ulcers in the oral cavity of each of five animals examined. Lesions consisted of variably sized, irregular white plaques and deep, often bilaterally symmetrical ulcers. In severely affected animals, the lesions coalesced to cover extensive areas of the labial, buccal, gingival, and glossal mucosa. Ultimately, oral lesions were identified in 25 of 27 otters examined at the SORC.

Although the oral lesions were often severe, the animals exhibited no noticeable changes in behavior or appetite. Nor were there notable changes in their clinical-pathologic values.

The primary concern after identifying a disease in such a high percentage of animals was the possibility that an infectious agent of unknown origin and virulence was involved. The potential exposure of the rescued otters to a pathogen, particularly a virus, originating either in domestic animals (such as canine distemper in the dog) or from other captured wild animals (such as the distemper-like virus in seals), was considered from the early days of the rehabilitation efforts. Because of this possible hazard, the question of rehabilitation and release back to the wild had been debated by parties involved in the rehabilitation process. Of paramount concern was the potential of releasing a pathogenic agent into a native population of sea otters. It was decided that the cause of the oral lesions should be identified before release of the otters from the rehabilitation centers. In addition, if the cause was determined to be an infectious agent, then proof that the infection was indigenous to wild otters was necessary. On 16 July, the day after the initial discovery of the oral ulcers, biopsy specimens of the lesions were shipped to the Armed Forces Institute of Pathology (AFIP) in Washington, D.C., for histopathological evaluation.

On 17 July, while awaiting results of the histological examination, a pathologist familiar with the oral lesions at the Seward Center joined the radiotelemetry team in Valdez to examine the mouths of 12 sea otters to be implanted with radiotelemetry devices at the Valdez Otter Rehabilitation Center (VORC). No significant lesions were observed in these VORC otters.

On 19 July, results of the histopathologic evaluation were received from the AFIP, examination of the lesions revealed chronic ulcers with associated superficial bacterial colonies, as was expected. However, in the adjacent mucosal epithelium were separate foci of ballooning degeneration and necrosis with numerous Cowdry type $\mathrm{A}$ intranuclear inclusion bodies. The inclusions were morphologically consistent with those caused by herpesviruses in other species.

A tentative causative agent had now been identified in association with the lesions, but proof that the organism was a virus indigenous to sea otters still eluded investigators. On 19 July, a team composed of a clinical veterinarian and a veterinary pathologist was sent to an otter capture area off the southern Kenai Peninsula to join a capture team already in place. The purpose was to evaluate 12 otters in the wild with the hope of identifying oral lesions identical to those observed in otters at the SORC. Twelve otters were captured and examined between 19 and 23 July. Results of the clinical examinations were equivocal; small lesions were observed in the mouths of several otters, but none were bilateral (as many in Seward had been) and none were as severe as observed in Seward. Biopsies of the lesions were made and specimens sent to the AFIP. During this time, the AFIP reported that viral particles consistent with a herpesvirus 
had been identified ultrastructurally in biopsy specimens from SORC otters.

While the team was in the field looking for evidence of the virus, a group composed of wildlife biologists and a virologist was in Anchorage examining the oral cavities of sea otters found dead immediately after the oil spill. These otters had been frozen and stored pending future scientific use or litigation. A few suspect ulcers were identified in two animals, and specimens were collected.

On 25 July, oral lesions similar to those seen at the SORC were identified in a sea otter pup transferred from the Jakolof Pre-Release Facility to Seward, suggesting that the virus was also causing disease in the otters maintained at Jakolof (subsequent evaluation revealed a number of affected animals at this facility).

It had now been established that a pathogenic virus was responsible for the oral lesions observed in otters at the SORC. Because the lesions were apparently confined to the oral cavity and did not cause a clinically significant disease, it was believed that the virus was probably indigenous to sea otters in Alaskan waters and of minimal health significance. However, because of the lack of unequivocal evidence of the organism in the wild otter population, it was decided that the animals could not be released. The planned release date was 27 July, and for logistical and political reasons it was important to meet this deadline. The virus had also created a management problem at the otter rehabilitation centers because movement of animals between the centers and to the Jakolof Facility had been suspended to prevent spread of the disease. Whether or not to bring additional oiled otters in from the wild was also a dilemma because of the risk of exposing the animals to the virus. Most important, the lesions in the Seward animals were worsening; this was attributed primarily to the otters' close confinement, which resulted in stress and subsequent immunosuppression. In addition, high coliform counts in the tank water plagued the SORC.

On the morning of 27 July notification was received from the AFIP that viral inclusion bodies had been identified in biopsy specimens taken from the otters captured off the southern Kenai Peninsula. As a result of this information, the rehabilitated sea otters were released according to the established schedule.

Presently, lesions caused by this herpes-like virus have been identified in the oral cavity, on the lips and, in one case, in the cornea of an eye. We speculate that the viral lesions were secondarily infected by bacteria and then progressed to chronic ulcers. Generally, lesions in animals at the Seward and Jakolof centers-particularly at the former, were more severe than those observed in animals in the wild. This is attributed to the close confinement of animals at the SORC and to the high bacteria counts in the water at the center. Attempts to isolate the virus have thus far been unsuccessful.

The efforts involved in this investigation demonstrate the type of team approach and cooperation required to successfully evaluate the cause and significance of a disease process like that observed at Seward. Government and nongovernment scientists, managers, administrators, and technicians cooperated extremely well; this cooperation was largely responsible for the timely resolutions of the problem. 


\title{
Pathological Examination and Collection of Toxicological Samples From Sea Otters
}

by

\author{
R. J. Haebler \\ U.S. Environmental Protection Agency \\ South Ferry Road \\ Narragansett, Rhode Island 02882
}

R. K. Harris, J. M. Pletcher, R. B. Moeller, and T. P. Lipscomb

Armed Forces Institute of Pathology

Washington, D.C. 20306

M. Bates

5012 Tierra Baja Way

San Diego, California 92115

and

C. Armitstead

19432 First Street

Eagle River, Alaska 99577

\begin{abstract}
In an environmental disaster that affects wildlife, such as the oil spill of the T/N Exxon Valdez, it is critical that rigorous pathological examinations of carcasses be performed to provide medical information to guide and improve clinical treatment of living animals, document pathological processes to increase scientific understanding of mechanisms associated with exposure to toxic chemicals, and provide scientific documentation required for legal purposes. Field laboratories were created, stocked, and staffed in two places. Gross necropsies were performed on all sea otters (Enhydra lutris) that died in sea otter rehabilitation centers and on all recently dead otters recovered from the field. Protocols were established for record keeping, tissue collection, disposition of samples, and chain of custody. Written necropsy reports were recorded on a standardized form. Tissue samples were collected for histopathology, chemical residue analysis, and other tests as indicated. Information from the pathological examinations and data generated from chemical residue analyses is now being integrated with the clinical record and histopathology to fully characterize the pathological processes that caused death in sea otters after the oil spill of T/N Exxon Valdez.
\end{abstract}


After the T/V Exxon Valdez oil spill, postmortem examinations were performed on all sea otters (Enhydra lutris) that died during rehabilitation and on fresh carcasses found in the wild. During an environmental disaster such as this, it is important to conduct thorough examinations to provide scientific information to guide and improve clinical treatment of living animals, document pathological processes to increase scientific understanding of mechanisms of toxicity in an indicator species associated with exposure to crude oil, provide scientific documentation required for litigation, and build on the data base of background pathological changes in that particular species.

\section{Standardized Protocols and Methods}

An essential element for a meaningful pathological investigation of a group of animals is standardization of protocols and methodology. In an environmental event that adversely affects wildlife, the goal of the necropsy is twofold: to identify the cause of death and to characterize the pathological pro- cesses in the individual animal, and to collect the samples and information necessary for the scientific investigation concerning the entire population of animals within that ecological niche. To do this, sound protocols must be instituted from the beginning, including gross necropsy procedures and forms, methods for tissue collection and storage (e.g., samples for histopathology, chemical residue analysis), and appropriate labeling and chain of custody on all collected specimens.

Ideally, a manual describing procedures, required supplies, lists of scientific experts available for consultation, and so forth, should be prepared and updated periodically. It is important to have this information available before a field response effort because much valuable data can be lost in the early days of an environmental disaster. We recommend that such a manual be used governmentwide.

Proper record keeping is critical to ensure the reliability of the samples collected. Without the ability to show that a given sample originated from a certain carcass, the information becomes useless. Ideally, the primary responsibility for record keeping and sample labeling should be assigned to a specific person. A trained pathology

NECROPSY REFERENCE KEY

\begin{tabular}{c|c|c|c|c|c|c|c}
\hline $\begin{array}{c}\text { Specimen \#/ } \\
\text { Path }\end{array}$ & Tag \# & $\begin{array}{c}\text { Date of } \\
\text { Necropsy }\end{array}$ & Sex & Age & Pathologist & $\begin{array}{c}\text { Weight } \\
\mathrm{kg}\end{array}$ & $\begin{array}{c}\text { Length } \\
\mathrm{cm}\end{array}$ \\
\hline & & & & & & & \\
\hline & & & & & & & \\
\hline & & & & & & & \\
\hline
\end{tabular}

Fig. 1. Necropsy reference key.

GENERAL NECROPSY RECORDS

\begin{tabular}{|c|c|c|c|c|c|}
\hline $\begin{array}{c}\text { Species/ } \\
\text { Specimen \# }\end{array}$ & Necropsy & Collection & Condition & Samples & Comments \\
\hline & $\begin{array}{l}\text { Date: } \\
\text { Person: } \\
\text { Place: }\end{array}$ & $\begin{array}{l}\text { Date: } \\
\text { Location: } \\
\text { Collector: } \\
\text { Transported by: } \\
\text { Received by: } \\
\text { Disposition: }\end{array}$ & & & \\
\hline
\end{tabular}

Fig. 2. General necropsy records. 
technician is recommended. To ensure the integrity of data, we suggest that several standardized forms be used to track the collection and disposition of samples.

A Necropsy Reference Key (Fig. 1) lists only the pertinent information required to log the carcass identification and vital statistics, and identify the necropsy date and examining pathologist. A General Necropsy Record (Fig. 2) provides a brief description of the origin and disposition of an individual animal. This record can be used to identify where, when, and by whom a particular carcass was examined; collection information regarding removal of the animal or carcass from the wild, including date, location, person responsible,

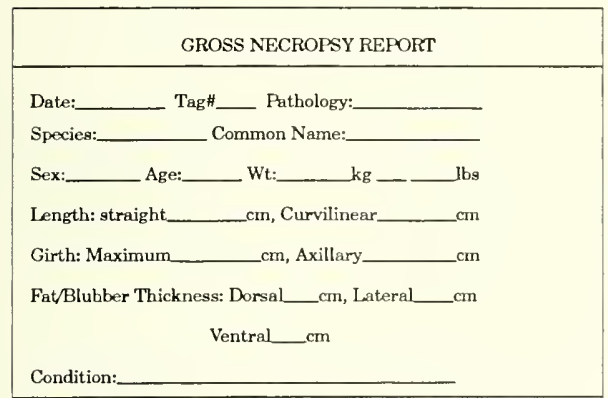

Clinical abstract:

Integument:

Nutrition:

Muscoloskeletal System:

Fat Distribution:

Abdominal Cavity:

Liver

Gallbladder

Digestive system:

Esophague

Suall intestine

Large intestine

Pancreas:

Endocrines:

Thyroid

Parathyroid and mode of transportation; general condition of the carcass (e.g., fresh or autolyzed); samples collected (e.g., histopathology, toxicology, and virology); and summary of necropsy findings.

During the necropsy, a detailed anatomical description should be recorded on a Gross Necropsy Report (Fig. 3), and an attached Tissue Checklist (Fig. 4) should be used to identify which samples were collected. In addition, a Tissue Storage Specimen Log (Fig. 5) is needed for each type of sample collected (e.g., histopathology, toxicology). The purpose is to track their existence and disposition. Proper record keeping is critical to ensure the reliability of data that will be generated from each sample.

\section{Hemolymphatic syatem: \\ Bone marrow \\ Lymph nodes \\ Thymus \\ Spleen \\ Candiovascular syatem: \\ Respiratory system: \\ Lung \\ Tracbea \\ Nasal passage \\ Urinary system: \\ Kidneyg \\ Bladder \\ Genital ayatem: \\ Testes/ovaries and uterua \\ Nervous вystem: \\ Special senses: \\ Eyes \\ Ears}

Parasitism:

Differential diagnoais:

Remarks:

Tissues saved for histo:

Tissues saved for tox:

Fig. 3. Gross necropsy report. 
TISSUE CHECKLIST

\section{HISTOLOGY}

\begin{tabular}{|c|c|c|}
\hline Abdomen: & $\begin{array}{l}\text { liver } \\
\text { gallbladder } \\
\text { adrenals } \\
\text { adneys } \\
\text { kidneys } \\
\text { urinary bladder } \\
\text { spleen }\end{array}$ & $\begin{array}{l}\text { pancreas } \\
\text { stomach } \\
\text { small intestine } \\
\text { large intestine } \\
\text { lamph nodes }\end{array}$ \\
\hline Thorax: & $\begin{array}{l}\text { tongue } \\
\text { _thyroid/parathyroid } \\
\text { _ } \text { traches } \\
\text { _eaophagus }\end{array}$ & $\begin{array}{l}\text { _hymus } \\
\text { _ heart } \\
\text { lung } \\
\text { diaphragm }\end{array}$ \\
\hline Other: & $\begin{array}{l}\text { brain } \\
\text { eyes } \\
\text { epinal cord } \\
\text { nasal turbinates } \\
\text { parasites }\end{array}$ & $\begin{array}{l}\text { muacle } \\
\text { _ blubber/fat } \\
\text { __akin } \\
\text { _ gonads }\end{array}$ \\
\hline
\end{tabular}

\section{TOXICOLOGY}

\begin{tabular}{|c|c|}
\hline $\begin{array}{l}\text { liver } \\
\text { _ bile } \\
\text { _ Iung } \\
\text { _ kidney } \\
\text { fat//lubber } \\
\text { _ brain } \\
\text { muscle } \\
\text { _ akin }\end{array}$ & $\begin{array}{l}\text { _atomach contents } \\
\text { intestinal contents } \\
\text { placenta } \\
\text { amniotic fluid } \\
\text { ascites } \\
\text { _ cardiac blood } \\
\text { thoracic fluid } \\
\text { other }\end{array}$ \\
\hline \multicolumn{2}{|l|}{ FOOD HABIT } \\
\hline __ stomach & _ intestinal contents \\
\hline \multicolumn{2}{|l|}{ MEASUREMENTS } \\
\hline $\begin{array}{r}\text { teeth } \\
\text { skull }\end{array}$ & $\begin{array}{l}\text { baculum } \\
\text { other }\end{array}$ \\
\hline
\end{tabular}

Fig. 4. Tissue checklist.

\section{Laboratory Requirements}

Appropriate laboratory facilities are necessary to perform rigorous gross necropsies and store collected samples. The physical requirements in. clude an examination table with a nonporous surface (preferably metal), proper lighting, running water with appropriate drainage, sufficient counter space to store supplies and process tissue, refrigeration for carcass storage, freezer space for tissue sample storage, ventilation (toxic chemi- cals such as formalin are used), a large scale to weigh carcasses, a small scale to weigh organs and tissue samples, sinks to clean equipment, and proper containers for refuse disposal (e.g., hazardous chemicals, biological material, needles, scalpel blades).

\section{Supplies}

A wide variety of supplies are needed to stock the laboratory (Table 1). Without these supplies, the

IISTOPATHOLOGY SPECIMEN STORAGE LOG

\begin{tabular}{l|l|l|l}
\hline ACCESSION NO. & TISSUES STORED & DATE STORED & DATE REMOVED \\
\hline & & & \\
& & & \\
\hline
\end{tabular}

FROZEN TISSUE SPECIMEN STORAGE LOG

\begin{tabular}{l|c|c|c|c|c}
\hline ACCESSION NO. & $\begin{array}{c}\text { TISSUES STORED } \\
\text { Identify Tissue \& Analysis Required }\end{array}$ & $\begin{array}{c}\text { DATE } \\
\text { STORED }\end{array}$ & \\
\hline
\end{tabular}

Fig. 5. Histopathology specimen storage log and frozen tissue specimen log. 
Table 1. Supplies.

A. General

1. Medical Supplies

Syringes (various)

Capillary tubes

Needles (various)

Hematocrit clay

Vacutainers ( $f$ )

Microscope slides

Whirlpacks (various)

Sterile swabs

Microcassettes' tissue bags (and sponges)

Instruments Scalpel handle and blades

Needle holders

Fillet knives

Sharpening stone

Thumb forceps

Stryker autopsy saw

2. Nonmedical supplies

Ziploc bags

Paper towels

Permanent markers

Large, heavy-duty garbage bags

Waterproof notebooks

Cleaner and disinfectant

Pencils

5-gallon buckets with lids (for cleaning and as large formalin containers)

Sealable formalin containers

B. Oil Spill Supplies

1. Chemically cleaned jars and vials for toxicology analysis

1-CHEM RESEARCH 1-800-443-1689, outside California; 1-800-443-5006 in California

2. Neutral buffered formalin (10\%)

Sigma Corporation 19 L (5-gallon) boxes with

handles, 1-800-325-3424

recipes: $1.9 \mathrm{~L} 37 \%$ (full-strength) formaldehyde $76 \mathrm{~g}$ monobasic sodium phosphate $123 \mathrm{~g}$ dibasic sodium phosphate

$16.9 \mathrm{~L}$ distilled $\mathrm{H}_{2} \mathrm{O}$ (heat small amount to dissolve buffer)

-or-

1 part formaldehyde

$6-8$ parts seawater (depends on salinity) tissue samples cannot be appropriately collected or preserved. These supplies should be assembled ahead of time and stored in an accessible location.

\section{Necropsy Procedures}

In an environmental disaster such as the oil spill, it is important to determine whether the cause of death in wildlife was associated with exposure to toxic chemicals. Therefore, it is critical that tissues be properly collected for chemical residue analysis during the necropsy procedure.

The order of events should proceed as follows: (1) external examination of carcass, (2) collection of toxicology samples, (3) collection of microbiology and virology samples, (4) internal examination, and (5) collection of histopathology samples.

\section{Toxicology Samples}

Tissues for chemical residue analyses must be collected and stored properly to prevent contamination and ensure viability of the sample. These samples should be removed immediately upon opening the body cavity. Fluid samples such as bile should be placed in chemically cleaned amber-colored vials (the coloration prevents photodegradation). Tissue samples should be excised with instruments cleaned and rinsed with a solvent such as dichloromethane. Sample size should be about $20 \mathrm{~g}$. Tissue should be placed in a preweighed, chemically cleaned jar (e.g., I-Chem) and tissue weight recorded. Air space in the jar should be minimal to prevent desiccation of tissue. If chemically cleaned jars are not available, tissue should be wrapped in aluminum foil that has been wiped clean with acetone. All samples should be collected in triplicate.

Organs recommended for chemical residue analysis are listed in Table 2 . All samples must be clearly labeled with the pathology identification number, date of necropsy, type of tissue (e.g., liver, kidney), weight, and pathologist's name.

Table 2. Samples for hydrocarbon toxicology.

\begin{tabular}{ll}
\hline Liver & Stomach contents \\
Bile & Intestinal contents \\
Lung & Placenta \\
Kidney & Amniotic fluid \\
Fat/Blubber & Ascites \\
Brain & Cardiac blood \\
Muscle & Thoracic fluid \\
Skin & Other \\
\hline
\end{tabular}


Tissue samples should be frozen as soon as possible. It is important to store them in the freezer in an organized way, so any given sample can be easily located and retrieved. When transporting these samples to the analytical laboratory, they must remain frozen. Therefore, dry ice or hand transport by a responsible party is recommended.

\section{Pathological Examination and Specimens}

Necropsies should be conducted by a veterinary pathologist whenever possible. The necropsy report form, including the list of tissues to be collected, should be clear enough to guide a nonpathologist, such as a veterinarian or paraprofessional, through the postmortem examination. Routine procedures for gross examination and collection of samples for histopathology, parasitology, microbiology, and virology are recommended.

Persons with expertise in various biomedical fields should be identified and listed along with their phone numbers and addresses, including pathologists, toxicologists or chemists, virologists, microbiologists, veterinarians, individuals with expertise in particular species (e.g., marine mammals, birds, reptiles), and contacts at appropriate government agencies.

\section{Chain of Custody}

As samples are collected, the name of the pathologist and where the samples are stored should be recorded. As the samples are sent to laboratories for analysis, it is critical to track where the samples are at all times and to identify the person who has responsibility. This chain of custody procedure will protect and ensure the integrity of the samples and data, which is important for both scientific and legal purposes.

A central repository is necessary for assembly and storage of all materials and data to ensure consistency between animals, between laboratories, and between investigators.

\section{Data Interpretation}

Information from the pathological examinations and data generated from chemical residue analyses must be integrated with the clinical record and histopathology. To fully characterize the pathological processes that cause death in animals exposed to environmental contaminants, synthesis of the complete data set on individual animals and the population as a whole is necessary.

\section{Conclusion}

The effects of environmental contaminants on the health of sea otters is poorly understood. We hope that the careful collection of samples and analysis of data from these sea otters will improve scientific understanding of the toxic effects of crude oil in sea otters. In future environmental events that adversely affect wildlife, we recom. mend that the above procedures be followed to ensure proper collection and preservation of samples and data. 


\title{
Release Session
}

\author{
Chair: Jon Nickles, U.S. Fish and Wildlife Service, Anchorage, Alaska. \\ Editors: Susan H. Shane and Mary E. Hogan.
}

\section{Development of the Release Strategy for Rehabilitated Sea Otters}

by

\author{
A. G. Rappoport, M. E. Hogan, and K. Bayha \\ U.S. Fish and Wildlife Service \\ 1011 E. Tudor Road \\ Anchorage, Alaska 99503
}

\begin{abstract}
After the capture, cleaning, and holding of sea otters (Enhydra lutris) contaminated by the 24 March 1989 oil spill from the T/N Exxon Valdez, the U.S. Fish and Wildlife Service's objective was to return as many healthy otters to the wild as possible. This objective included releasing otters in clean habitats where they could be monitored and where there would be minimal socioeconomic conflicts. Advantages and disadvantages of releasing otters in areas ranging from where they had been captured, to southeastern Alaska, the north side of the Alaska Peninsula, the Aleutian Islands, or Washington State were considered. Long-distance translocation was considered but then judged inappropriate because of the spill's effects, stresses to which captured animals were exposed, otter homing instincts, and high losses of animals in previous translocation efforts. Otter rehabilitation centers were initially established in Valdez and Seward. After strong recommendations from the Service, long-term holding facilities for monitoring and stabilizing rehabilitated otters before their release were established in Little Jakolof Bay, across from Homer, Alaska, and in a fish hatchery octagon (floating net enclosure) in Valdez Arm. The Service consulted with veterinarians, other otter experts, Service site representatives, and the State of Alaska in developing its 10 July 1989 release strategy. The strategy included a protocol for determining the health of otters. Seven otters with radios attached to their flippers were released into clean waters in eastern Prince William Sound on 15 May. Monitoring those otters and 21 radio-tagged otters released 27-28 July into clean waters in eastern Prince William Sound provided the basis for further releases. Releases back to the wild of 197 otters were completed by 30 August.
\end{abstract}

Recovery of the first oiled sea otter (Enhydra lutris) carcasses came 6 days after the T/N Exxon Valdez went "hard aground" on Bligh Reef,
24 March 1989, spilling 11 million gallons of Alaskan crude oil into Prince William Sound. With the capture of the first live but sick and oiled otter on 
30 March, the U.S. Fish and Wildlife Service was thrust into a decision-making and management role it had never before undertaken, and which had never been experienced by any other agency or private group. From the start, the Service's intentions were to minimize effects of the spill on sea otters-a formidable task given the reality of the developing situation: a huge spill, which proved uncontainable and impossible to swiftly clean up, compounded by the vagaries of weather and tides and the intricacy of the area's shoreline. Over the next 6 months, these factors resulted in oil spreading more than $1,100 \mathrm{~km}$ from the spill site (Data Management Division, Alaska Department of Environmental Conservation, personal communication), from Prince William Sound, southwest along the Kenai Peninsula, and then around Kodiak to the Alaska Peninsula. This resulted in the contamination of hundreds of otters and broad expanses of otter habitat.

Under the Marine Mammal Protection Act of 1972 (and accompanying regulations), the Service has management responsibility for sea otters. Under that authority, the Service authorized the capture, cleaning, and holding of sea otters by Exxon's contractors. The Service retained sole authority to direct the disposition of rehabilitated sea otters. From the outset, the Service's objective was to return as many healthy otters to the wild as possible. We describe the process undertaken by the Service in developing a strategy for the disposition of rehabilitated sea otters.

\section{Background}

The initial response by Exxon Company U.S.A. (Exxon) to the T/N Exxon Valdez oil spill called for use of booms, skimming, and other operations to contain and minimize effects of the spill. Because these activities failed to keep wildlife, such as otters, and their habitats from being contaminated by oil, the Service's policy was to provide for capture of otters in distress by qualified otter handlers. Those otters were to be cleaned and otherwise rehabilitated for eventual release. Rehabilitation centers for cleaning and caring for oiled otters were established in Valdez (the Valdez Otter Rehabilitation Center [VORC]) shortly after the spill, and in Seward (Seward Otter Rehabilitation Center [SORC]) by early May (Davis and Styers 1990). The Valdez Center was established to handle otters captured in Prince William Sound; the Seward Center served otters captured off the coasts of the Kenai Peninsula, Kodiak Archipelago, and Alaska Peninsula.

As early as 4 April, the Marine Mammal Commission (1989) wrote to the Alaska regional director of the Service urging that animals in danger of death because of contact with oil be found, cleaned, rehabilitated, and held until fit for release once the spill was cleaned up; these activities were already occurring. The commission also urged establishment of immediate and long-term studies regarding spill effects on otters and their rehabilitation. The commission was strongly supportive of surveys, radio-tagging studies, and bringing California sea otter experts to Alaska to assist with the spill response.

The Service responded with information about the ongoing otter rescue efforts. Information was then indicating that the rehabilitation process might be longer than the 1-2 weeks after cleaning and recovery that the commission mentioned. Moreover, some California experts were already assisting Service experts in Alaska, and there had been several meetings among the Service, Alaska Department of Fish and Game, and National Marine Fisheries Service on necessary studies.

At the same time, groups such as the California-based Friends of the Sea Otter (1989) were asking for protection of otters and their current habitat in Prince William Sound, suggesting that if such protection were not possible, then trans. locating sufficient numbers of otters to another location secure from the oil spill threat was necessary. Members of these groups asserted that rehabilitating thousands of otters was not possible, and that protecting otters before oil arrives was the only reasonable alternative.

Within the first weeks of the spill the Service was considering options for releasing cleaned and rehabilitated otters. Service objectives were to release sea otters in good habitats that had not been oiled and were not in danger of being oiled, and where there was an established otter population, areas where there would be minimal real or perceived human socioeconomic conflicts (e.g., shellfisheries, commercial fisheries, ongoing or planned research), and areas where the animals could be readily monitored. The advantages and disadvantages of four alternatives were considered: holding otters for future release in Prince William Sound, releasing them in southeastern Alaska, releasing them on the north side of the Alaska Peninsula (Cold Bay to Port Moller area), or translocating them to the State of Washington. 
By mid-April more than 50 live otters were at VORC, and several others had been shipped to long-term care centers in British Columbia, Washington, and California. It was clear that several VORC animals might not be releasable because of permanent health problems and inability to survive in the wild. However, several animals had recovered and were ready for release.

Within a month of the spill, the Service provided Exxon with a basic plan governing the release of sea otters (U.S. Fish and Wildlife Service 1989a). The Service requested that implementation of the plan be coordinated with Exxon's contractor. In a 28 April letter to Exxon, the Service indicated that construction of long-term holding centers should begin immediately so that they would be completed and available by the time rehabilitated otters were ready for release. All animals were to be held in a cold-water environment for monitoring and stabilization before release. In providing further details on the developing policy for releasing rehabilitated otters, the Service described its desire for interim holding near VORC or SORC, depending on capture location and planned release site. If long-term holding was required for animals treated in the Seward Center, the animals were to be held in the Seward area. Once healthy, most otters being held in aquariums (as a result of the spill) were then expected to be returned to Alaska and released in the wild when there was little risk of reoiling. Animals captured outside Prince William Sound were to be released as soon as they were healthy and the risk of reoiling was past. Healthy animals were to be released in the general area of capture.

The Service evaluated the possibility of trans. locating otters to clean waters far from the spill area by carefully reviewing the sea otter relocation effort in California, which began in 1987, and contacting involved and knowledgeable scientists for their input (Riedman 1987). Problems with the California translocation discouraged the Service from proceeding with a translocation in Alaska. One year after the California translocation of 69 otters, 11 otters had died of known causes, $12 \mathrm{had}$ emigrated up to $322 \mathrm{~km}$ back to Big Sur, another 26 were missing, and only 20 remained in the area in which they had been translocated (U.S. Fish and Wildlife Service 1988). By this time it was felt that any advantages of translocation would be offset by additional stress, high mortality, probable long movements from the release site, difficulty of monitoring, and unexplained loss of animals. Increasing knowledge of the spill's effects and consideration of the stresses to which captured animals would be exposed provided further reasons for considering translocation as a less desirable option.

Based on experience from previous otter translocations, the assumption was made that released otters emigrate away from the release sites back to the vicinity of their capture (Jameson et al. 1982). Thus the Service came to believe it would be better to release sea otters in clean waters adjacent to the spill area rather than to translocate them extremely long distances to the Alaska Peninsula, Aleutian Islands, southeastern Alaska, or State of Washington.

The plan submitted to Exxon by the Service on 28 April included the assumption that animals would be held in an enclosed portion of Sheep Bay in eastern Prince William Sound, or at an alternate long-term holding site approved by the Service. The premise was that those animals could be released in Prince William Sound as soon as the threat of significant reoiling was gone.

The Service also suggested to Exxon that, pending proper approvals, existing requests for otters for public display would be met using animals not able to be released to the wild (Gruber and Hogan 1990). Animals judged to be in poor health and unlikely to survive in the wild would be held in aquariums for follow-up monitoring and, if they died, necropsy.

In early May, the Service was working on the final release strategy, ensuring that the involved Service site representatives, veterinarians, and other otter experts provided review and input. University of Minnesota sea otter expert D. Siniff traveled to the otter centers and spill area to assist in developing a study plan to evaluate the success of the rehabilitation efforts. Surgically implanted radios in some of the animals would be needed to allow long-term monitoring of movement patterns, survival, and reproductive success of these otters.

By early June, veterinarians at VORC were reviewing the medical histories and current status of otters there to determine which otters were ready for release, which might be ready after further treatment and recovery, and which might not be releasable. Veterinarians worked on protocols for the health status of the captive otters and the release of near-term pregnant sea otters (Haebler et al. 1990).

After evaluating all female otters that were healthy enough to be captured and palpated, only two otters (both at the Jakolof Pre-Release Facil- 
ity) were thought to be near term. The veterinarians and husbandry staff decided those otters should not be released to another area in the immediate future because of several concerns. There was concern over stress that would be caused by separation from the social group and loss of close bonding relations established at the holding center; capture, handling, and transport; and release into an unfamiliar environment with an unknown population of otters. As a result, the Service decided to allow a "soft" release from the Jakolof Pre-Release Facility. A soft release involved opening the pen door and releasing the otter directly into the Little Jakolof lagoon where it was free to swim away. The two near-term pregnant animals were released in this manner on 17 June.

For pregnant otters whose health was such that release might jeopardize their survival, or otters who had given birth in captivity, a natural setting was available at Little Jakolof Bay. Here there were additional individual pens for pregnant females; several mothers and pups born in captivity were doing well in this area. The veterinarians began preparing a document with appropriate guidelines for release of mother-pup pairs.

As the otter release strategy and the study plan for the radio-implant study were completed, the Service consulted with the State regarding the release of captive animals. The State had strongly opposed releasing any seals to the wild and preferred that otters also not be released because of concerns over potential disease problems (Alaska Department of Fish and Game 1989). The State generally agreed that if distressed wild animals were captured and rehabilitated, the primary purpose should be for release back to the wild. However, the State did not believe that the otters had been captured, handled, and confined in a way to minimize the risk of introducing disease and parasites to wild, healthy populations.

A worldwide canvass of potential educationalpublic display recipients for the otters was urged by the State. If existing centers proved inadequate, the State suggested that Exxon fund a permanent educational center in Alaska, where some otters could be held. In summary, the State strongly recommended that there be no additional otter releases because unknown disease risks would threaten wild populations of sea otters and other species. If the Service did release otters, the state believed that before release the animals should be carefully screened.
The State opposed release of otters at their general areas of capture because it considered those sites to be at or near carrying capacity. Release site alternatives were suggested; these sites were in British Columbia, Washington, Oregon, and areas in Alaska, such as Cold Bay and Yakutat, where additional sea otters would not exacerbate local concerns regarding competition for shellfish, and where considerably more otters could be accommodated in relation to carrying capacity. Contending that the mortality factor associated with translocation was overemphasized, the State indicated that proper handling would minimize mortality.

The Service's prompt response to this 23 June 1989 letter attempted to alleviate the State's concerns, which had all been considered in developing the release strategy (U.S. Fish and Wildlife Service 1989 c). While no worldwide canvass was attempted, it was recognized that there would not be sufficient aquarium facility capacity to handle the many otters awaiting release. The Service assured the State that every effort had been made to ensure that capture, handling, and confinement of contaminated sea otters occurred in a manner minimizing the risk of disease and parasites to wild, healthy populations. The Service had attempted to restrict capture to boats and individuals authorized by the Service. Qualified veterinarians and specially designed centers were involved in every phase of treatment and confinement.

Because wild otters could (and did) approach the floating net pens at the Jakolof Pre-Release Facility and the octagon at VORC the State's concern that captured animals not contact wild subpopulations because of the disease risk had not been met. The Service agreed that careful screening had to be completed before releasing any animals and included a health protocol in the release strategy.

Given the known deaths of more than 800 otters by late June, and possible release of only some 150 otters at that time, the Service did not agree with the State that carrying capacity was a concern if animals were released in the general area of capture. Translocation to distant areas presented greater problems related to long-term survival and follow-up monitoring. Based on the State's concerns, the Service clarified the strategy to indicate that if early releases resulted in a strong preference by otters to move back to oiled habitats and become stressed, translocation would be reevaluated. 
The Service recognized the importance of obtaining all the scientific knowledge possible by monitoring the subsequent movements and longevity of released animals, as well as monitoring otters with poorer health that could not be returned to the wild, and those that were not treated but were potentially affected by the spill. If any good could result from the tragedy of this spill, it would be knowledge gained that could benefit future responses to such events or needs to rehabilitate wildlife.

In the latter half of June, the veterinarians were completing medical evaluations of otters at the Valdez and Seward centers as preparation for the otters' eventual release and as candidates for radio implants. Additional blood analyses were required for final verification of health status. After the health evaluation, it became clear that it would be necessary to use otters from both centers to obtain a scientifically adequate sample for the radio-implant and tracking study. It was recognized that the movement of otters from the Kenai Peninsula to eastern Prince William Sound could complicate findings from the follow-up monitoring of released otters.

\section{Service Release Strategy}

The Service release strategy was made available to the public on 10 July (U.S. Fish and Wildlife Service 1989d). Strategy objectives were to return rehabilitated otters to the wild as soon as possible, return otters to areas where they had the best chance of survival, and learn as much as possible about the success of the rehabilitation process. There was concern that holding otters in centers for longer times might increase their risk of disease, result in unhealthy levels of stress, and result in the animals acclimatizing to human care, which could affect their survival once they were returned to the wild.

The Service decided that otters would be released only in Alaska because any effort to expand the range of a species should not come as the result of an oil spill. This meant otters could be returned to the area where they were captured, returned to habitats generally uncontaminated by the oil spill and used by their subpopulation, or translocated to other areas of Alaska known to support sea otters. All options presented drawbacks. In the first option, the otters might become recontaminated if oil remained in the original capture area. In the second option, information from transloca- tion efforts aimed at reestablishing sea otter populations in Alaska, British Columbia, Oregon, and California showed that sea otters have a strong homing instinct (Jameson et al. 1982). Thus, otters released in clean areas might return to their point of capture. As in the first option, these animals could be at risk from reoiling or from eating contaminated foods. Movements of otters to the original site of capture, however, might occur within a month or take more than a year (G. VanBlaricom, U.S. Fish and Wildlife Service, personal communication). Some otters might remain in clean environments for a long period. Movement patterns had been found to be variable and individual. In the third option, the drawbacks were similar to those in the second option, with stress from transportation and emigration being of particular concern. Experience from past translocations had shown that translocated otter numbers decreased by at least $50 \%$ because of emigration and mortality. In any instance other than direct release from the holding pen, there would be stress from transporting otters and potential difficulty monitoring their fate.

The final release strategy contained criteria and a plan for releasing otters held in the octagon at VORC, SORC, and the Jakolof Pre-Release Facility. The Service began with the premise that otters would remain or linger in release sites such as eastern Prince William Sound, where the waters were oil-free. Before undertaking a large release, the Service had initially tested this premise by releasing three rehabilitated otters and four unwashed otters with flipper radio transmitters on 15 May in Simpson Bay near Cordova, Alaska. Only two of the animals were successfully tracked for the proposed 30 days, probably because of radio failure. As described by Monnett et al. (1990), these two animals remained in the clean waters of eastern Prince William Sound. The last known locations of the other animals were also in eastern Prince William Sound. Extensive searches in the fouled waters of southwestern Prince William Sound failed to locate any of the radio-tagged otters. Clean waters of the northern Sound and east to Controller Bay were also extensively searched, with no contacts. There was no evidence that the radio-tagged otters had moved out of the eastern Sound.

Information from this preliminary release as to the movement pattern and rate of movement of the animals, in conjunction with oil conditions in Prince William Sound, was critical to deciding about the release of all other animals. However, 
because results from this initial release were not conclusive, a second release of radio-implanted otters (captured in Prince William Sound and off the Kenai Peninsula and then held at the Valdez octagon) into the clean waters of eastern Prince William Sound was planned. These animals were to be tracked for 20 days before a decision would be made on releasing the remaining otters. If the otters remained in eastern Prince William Sound, the remaining otters in the octagon would also be released in that area. However, if monitoring of marked otters demonstrated a return to the original capture area, resulting in mortality, other otters would not be released until all uncontained free-floating oil had been picked up and the environment was declared safe. At that point the release decision would consider advantages of holding animals in a saltwater prerelease center versus the advantages of long-distance translocation. Criteria for such translocation were to include the critical factors discussed previously.

Release of otters from SORC was to be based on movements exhibited by the otters released in Prince William Sound. Healthy otters were to be first moved from Seward to Little Jakolof Bay near Homer. The strategy for releasing otters from the Jakolof Pre-Release Facility was to be based on movement behavior of the otters released near Cordova; the health, sex, and age of the rehabilitated otters; and suitability of the natural environment. Environments off the Kenai Peninsula and Kodiak Archipelago were not as heavily oiled as parts of Prince William Sound. Moreover, those areas were exposed to weathered oil, which was considered less toxic to sea otters. Therefore, otters from areas outside Prince William Sound were to be returned generally to within $80 \mathrm{~km}$ of the areas from which they were initially captured. Where health and age factors would make transportation particularly stressful (e.g., pregnancy, presence of a mother-pup pair, or old age), the Service agreed that a small number of animals might be released into Kachemak Bay directly from the Jakolof Pre-Release Facility. In response to the concerns of some local residents, that number was not to exceed the number of dead otters found in the Kachemak Bay area. A minimum number of rehabilitated otters captured outside Prince William Sound were to be released in the eastern sound for scientific purposes as part of the monitoring program.

\section{Implementing the Release}

On 14 July a soft release of two female otters and their pups was made from the Jakolof Pre-Release Facility. Two more mother-pup pairs were also soft-released on 15 July. The soft release was used to ensure that mothers would not abandon their pups after the stress of transportation to another release site.

As soon as the release strategy was made public, personnel began preparing to implant radios into 21 otters before their release into eastern Prince William Sound and tracking. But problems arose on two fronts. Eight otters escaped on 13 July from the octagon at VORC when some of the net pens were cut by persons presumably opposed to Service policies. Then, on 14 July, oral lesions were found in the course of implanting radios into SORC-held otters. Steps were taken to determine the cause of the lesions and whether they were due to a condition that already existed in free-ranging sea otters (Harris et al. 1990). The lesions were biopsied and sent to the Armed Forces Institute of Pathology for analysis. Additional animals at SORC were checked for lesions and also found to have them. After a meeting among otter veterinarians, managers, and Service representatives and otter biologists, a plan for determining the source and danger of the lesions was developed. It was decided to capture, anesthetize, examine, biopsy, and take blood from wild sea otters to determine whether the lesions were a naturally occurring phenomenon, or a problem at SORC only.

If the same lesions were discovered in the wild, then the release plans could proceed. If the lesions were not found in the wild, then the release would need to be delayed until a diagnosis of the cause of the lesions was completed. Evaluation of pathology, virology, and serology results would confirm whether the lesions were caused by trauma, and if so, the release could proceed. Positive results for disease that did not occur in the wild would indicate that SORC should be isolated until diagnosis was complete. The Service was concerned about the possible virulence of infectious agents and the detriment to the wild population if animals were released.

Subsequent capture and examination of 17 sea otters off the outer coast of the Kenai Peninsula resulted in the discovery of similar lesions in the mouths of the wild otters. Biopsy of those tissues confirmed that wild populations had similar intranuclear inclusions (Harris et al. 1990). Thus, pathogens causing the lesions in captive sea otters 
were probably present in the wild population. The Service decided to proceed with release plans.

Monitoring of the 21 radio-implanted otters released in eastern Prince William Sound on 27-28 July provided positive support for further releases (Monnett et al. 1990). During the 20-day monitoring period, radios were implanted in 10 otters at SORC, and in 12 otters at the Jakolof Pre-Release Facility. With two additional otters that had received radio implants earlier in July, but which were not part of the July release, this completed the study group of 45 animals to be monitored on a long-term basis. At the same time, the Service had implemented efforts to locate and evaluate release sites along the Kenai Peninsula (Sharpe 1990).

On 10 August, sea otter rescue coordinator, Valdez site representative, acting Homer site representative, and Service otter expert traveled to the Jakolof Pre-Release Facility to meet with the Service's otter biologist stationed at the Jakolof Facility and to brief the staff on the upcoming radio-implants and release. The night before, in the midst of blood sampling in accordance with the release health protocol, an otter had drowned. Seemingly the otter had lapsed back under anesthesia after being returned to its pen, and the pen monitors did not notice that it was in trouble. The cause of death, however, was not learned until an autopsy had been completed later the next day. Thus, Jakolof Pre-Release Facility workers were concerned that the blood-drawing procedure had caused the death and were angered with the Service for insisting on further drawing of blood. As a result, several members of the press were invited to the center at the same time that the Service planned to be there. The Service wished to avoid conflict and had set up the meeting specifically to promote better understanding among the Jakolof Pre-Release Facility staff members. The Service believed the Jakolof staff deserved greater information at the earliest opportunity when compared with the general public.

A service representative briefed the press on the proposed radio-implant study. Then Service representatives met with Jakolof staff to thoroughly explain the need to monitor released otters and procedures for the proposed implants, monitoring of otters after surgery, and subsequent release and monitoring in the wild. Some staff opposed the implants because of the stress to otters from surgery and extra handling. The Service and other groups believed it was critical to monitor the rehabilitated otters to learn whether rehabilitation efforts resulted in otters that could successfully live and reproduce in the wild again. Such information was essential to know how effective this response to the T/V Exxon Valdez spill had been and to learn what actions should or should not be taken in any future spills that might affect sea otters. Numerous issues were raised and questions answered during the wide-ranging 5 - $h$ meeting.

The next day, the veterinarians and Service biologists began implanting radios into 12 of the Jakolof otters. In the midst of surgery, a Service biologist noticed that two of the pen doors had been opened. Upon questioning, a Jakolof worker explained that those were the pens with the mothers, pups, and penmates that Sea Otter Rescue Coordinator Bayha had agreed could be released, contingent on completion of blood sampling and clearance by the veterinarians, tagging of both flippers, and absence of implant candidates in those pens. The Jakolof worker showed the Service representative a data sheet showing that those conditions had all been met. Because the veterinarian was in the midst of surgery, the Service representative could not further confirm the information. Later in the day, another Jakolof record keeper examined the records and indicated that blood had not yet been drawn from all otters in the two opened pens, and the veterinarians had not cleared the release.

A second unauthorized release occurred later that day when the Service representative noticed open doors on two other pens containing 13 otters. One otter escaped before the Service representative could shut the pen doors. Aside from those unfortunate incidents, the implant surgery and the animals' subsequent recovery proceeded well.

Release of the remaining otters at SORC and the Jakolof Pre-Release Facility (that were capable of release to the wild) occurred during the last 3 weeks of August. These began on 11 August with the soft release, described previously, of three mother-pup pairs and their three penmates from the Jakolof Facility. Other otters were released at sites in Sheep and Nelson bays in eastern Prince William Sound, along the outer coast of the Kenai Peninsula (James Lagoon in McCarty Fjord, Nuka Bay, Taylor Bay, Picnic Harbor, and Harris Bay), and by the Herring Islands in Kachemak Bay.

In summary, efforts leading to the releases had at one time included as many as 14 vessels dedicated to full-time sea otter recovery. Experienced biologists and veterinarians came from many parts of the country to assist in the rehabilitation to release program. Many volunteers and paid staff from other parts of the country, as well as Alaska, worked countless hours in those efforts. Starting 
with the May release of seven rehabilitated otters into the nonoiled portion of eastern Prince William Sound, to the last few otters released at the end of August, and including escapees, 197 otters were put back into the wild (Table). Thirty-seven otters were sent to aquariums in the lower 48 states for long-term care (Gruber and Hogan 1990).

The Service's experience in developing and implementing a release strategy for rehabilitated sea otters leads to recommendations for such efforts that may be needed in the future. These recommendations include:

1. The results of follow-up monitoring of released otters will provide critical information for developing and refining oil spill contingency plans, including sea otter management. Those results should be carefully evaluated in conjunction with the release strategy used in response to the T/V Exxon Valdez oil spill.

2. To aid later data analyses, there must be thorough record keeping from capture, rehabilitation, and the eventual release or other disposition of each otter concerned. This record keeping should include completion of prearranged release forms by the Service representative supervising the releases.

3. The specific circumstances of any future spills and probable effects on sea otters should be considered in developing appropriate capture, rehabilitation, and release strategies.

\section{Acknowledgments}

We thank A. R. DeGange for his helpful review of this manuscript.

\section{References}

Alaska Department of Fish and Game. 1989. Letter from D. Timm, regional supervisor, to R. Gould, assistant regional director, U.S. Fish and Wildlife Service, 23 June 1989. 2 pp.

Davis, R. W., and J. Styers. 1990. History of the sea otter rehabilitation centers. Pages 142-157 in K. Bayha and J. Kormendy, tech. coords. Sea Otter Symposium: Proceedings of a symposium to evaluate the response effort on behalf of sea otters after the T/V Exxon Valdez oil spill into Prince William Sound, Anchorage, Alaska, 17-19 April 1990. U.S. Fish Wildl. Serv., Biol. Rep. 90(12).

Friends of the Sea Otter. 1989. Letter from C. Fulton, executive director, to M. Lujan, secretary, Department of the Interior; W. Reilly, administrator, U.S.
Environmental Protection Agency; S. Cowper, governor of Alaska; W. Evans, assistant administrator for fisheries, National Oceanic and Atmospheric Administration; J. Twiss, executive director, U.S. Marine Mammal Commission; and F. Iarossi, president, Exxon Shipping, 31 March 1989. 3 pp.

Gruber, J., and M. E. Hogan 1990. Transfer and placement of nonreleasable sea otters in aquariums outside Alaska. Pages 428-431 in K. Bayha and J. Kormendy, tech. coords. Sea Otter Symposium: Proceedings of a symposium to evaluate the response effort on behalf of sea otters after the T/V Exxon Valdez oil spill into Prince William Sound, Anchorage, Alaska, 17-19 April 1990. U.S. Fish Wildl. Serv., Biol. Rep. 90(12).

Haebler, R., R. Wilson, and C. R. McCormick. 1990. Determining health status in rehabilitated sea otters before release. Pages 390-393 in K. Bayha and J. Kormendy, tech. coords. Sea Otter Symposium: Proceedings of a symposium to evaluate the response effort on behalf of sea otters after the T/V Exxon Valdez oil spill into Prince William Sound, Anchorage, Alaska, 17-19 April 1990. U.S. Fish Wildl. Serv., Biol. Rep. 90(12).

Harris, R. K., R. B. Moeller, T. P. Lipscomb, R. J. Haebler, P. A. Tuomi, C. R. McCormick, A. R. DeGange, D. Mulcahy, T. D. Williams, and J. M. Pletcher. 1990. Identification of a herpes-like virus in sea otters during rehabilitation after the T/V Exxon Valdez oil spill. Pages 366-368 in K. Bayha and J. Kormendy, tech. coords. Sea Otter Symposium: Proceedings of a symposium to evaluate the response effort on behalf of sea otters after the T/N Exxon Valdez oil spill into Prince William Sound, Anchorage, Alaska, 17-19 April 1990. U.S. Fish Wildl. Serv., Biol. Rep. 90(12).

Jameson, P. J., K. W. Kenyon, S. M. Johnson, and H. M. Wright. 1982. History and status of translocated sea otter populations in North America. Wildl. Soc. Bull. 10:100-107.

Marine Mammal Commission. 1989. Letter from J. Twiss, Jr., executive director, Marine Mammal Commission, to S. R. Lamson, U.S. Fish and Wildlife Service, 4 April 1989. 6 pp.

Monnett, C. W., L. M. Rotterman, C. Stack, and D. Monson. 1990. Postrelease monitoring of radio-instrumented sea otters in Prince William Sound. Pages 400-420 in K. Bayha and J. Kormendy, tech. coords. Sea Otter Symposium: Proceedings of a symposium to evaluate the response effort on behalf of sea otters after the T/V Exxon Valdez oil spill into Prince William Sound, Anchorage, Alaska, 17-19 April 1990. U.S. Fish Wildl. Serv., Biol. Rep. 90(12).

Reidman, M. L. 1987. Final environmental impact statement for translocation of southern sea otters. Vol. II. Technical support documents. U.S. Fish and Wildlife Service and University of California, Santa Cruz. $69 \mathrm{pp}$. 
Table. Releases of rehabilitated sea otters (Enhydra lutris) during 1989.

\begin{tabular}{|c|c|c|c|c|}
\hline Date & Location $^{\mathrm{a}}$ & Number & Comments & $\begin{array}{l}\text { Rehabilitation } \\
\text { Center }^{b}\end{array}$ \\
\hline 24 April & Valdez Harbor & 1 & Escaped & VORC \\
\hline 15 May & Simpson Bay & 7 & With flipper radio tags $s^{c}$ & VORC \\
\hline 19 May & Valdez Harbor & 1 & Escaped & VORC \\
\hline 12 June & Kachemak Bay & 1 & Rogue ${ }^{d}$ & JPRF \\
\hline 17 June & Jakolof Cove & 2 & Late-term pregnancy $^{\mathrm{e}}$ & JPRF \\
\hline 13 July & Valdez Bay & 7 & $\begin{array}{l}13 \text { escaped but } 6 \text { recaptured } \\
\text { (14 July) }\end{array}$ & Octagon \\
\hline 14 July & Jakolof Cove & 4 & 2 mother-pup pairs ${ }^{\mathrm{e}}$ & JPRF \\
\hline 15 July & Jakolof Cove & 4 & 2 mother-pup pairs ${ }^{e}$ & JPRF \\
\hline 25 July & Valdez Bay & 1 & $\begin{array}{l}1 \text { recaptured on } 14 \text { July escaped } \\
\text { again }\end{array}$ & Octagon \\
\hline \multirow[t]{2}{*}{27 July } & Sheep Bay & 9 & Radios were implanted & Octagon \\
\hline & Sheep Bay & 4 & & Octagon \\
\hline 28 July & Herring Islands & 1 & Rogue $^{d}$ & JPRF \\
\hline \multirow[t]{2}{*}{28 July } & Nelson Bay & 12 & Radios were implanted & Octagon \\
\hline & Nelson Bay & 3 & & Octagon \\
\hline 5 August & Jakolof Cove & 1 & Escaped & JPRF \\
\hline 11 August & Jakolof Cove & 9 & $\begin{array}{l}3 \text { mother-pup pairs and } \\
3 \text { penmates }\end{array}$ & JPRF \\
\hline 11 August & Jakolof Cove & 1 & Unauthorized release $e^{\mathbf{e}}$ & JPRF \\
\hline 13 August & Jakolof Cove & 2 & Late-term pregnancy ${ }^{e}$ & JPRF \\
\hline \multirow[t]{2}{*}{15 August } & Sheep Bay & 8 & & Octagon \\
\hline & Nelson Bay & 6 & & Octagon \\
\hline \multirow[t]{5}{*}{16 August } & Sheep Bay & 7 & Radios were implanted & SORC \\
\hline & Sheep Bay & 1 & Radio was implanted & Octagon \\
\hline & Sheep Bay & 7 & & Octagon \\
\hline & Nelson Bay & 1 & Radio was implanted & Octagon \\
\hline & Nelson Bay & 2 & & Octagon \\
\hline \multirow[t]{2}{*}{17 August } & Taylor Bay & 7 & & SORC \\
\hline & Picnic Harbor & 1 & & SORC \\
\hline \multirow[t]{2}{*}{19 August } & Nuka Bay & 7 & & JPRF \\
\hline & James Lagoon & 16 & & JPRF \\
\hline 20 August & James Lagoon & 8 & & JPRF \\
\hline 21 August & Harris Bay & 25 & & JPRF \\
\hline 21 August & Herring Islands & 2 & Rogue $^{d}$ & JPRF \\
\hline \multirow[t]{4}{*}{22 August } & Sheep Bay & 12 & Radios were implanted & JPRF \\
\hline & Sheep Bay & 6 & & JPRF \\
\hline & Nelson Bay & 3 & Radios were implanted & JPRF \\
\hline & Harris Bay & 4 & & SORC \\
\hline 30 August & Jakolof Cove & 4 & Includes 1 rogue ${ }^{\text {de }}$ & JPRF \\
\hline \multirow{3}{*}{\multicolumn{2}{|c|}{ Total rehabilitated otters }} & 180 & Released by design & \\
\hline & & 5 & Kenai rogues released & \\
\hline & & 12 & Escapees (10 Valdez; 2 Jakolof C & \\
\hline
\end{tabular}

Total returned to the wild

197

\footnotetext{
${ }^{a}$ For maps showing release locations, see Monnett et al. (1990) and Sharpe (1990).

${ }^{b}$ VORC = Valdez Sea Otter Rehabilitation Center, SORC $=$ Seward Sea Otter Rehsbilitation Center, JPRF = Jakolof Fre-release Facility, and Octagon $=$ holding pens at. VORC.

${ }^{c}$ Released in clean water habitats according to release strategy; includes Valdez Harbor rogue.

$\mathrm{d}$ Rogues are territorial male sea otters captured near holding facilities because of harassment of rehabilitated otters in net pens.

${ }^{\mathrm{e}}$ Soft releases from the Jakolof Pre-Release Facility in Kachemak Bsy.
} 
Sharpe, E. 1990. Sea otter release site selection and postrelease activities along the Kenai Peninsula, Alaska. Pages 421-427 in K. Bayha and J. Kormendy, tech. coords. Sea Otter Symposium: Proceedings of a symposium to evaluate the response effort on behalf of sea otters after the T/N Exxon Valdez oil spill into Prince William Sound, Anchorage, Alaska, 17-19 April 1990. U.S. Fish Wildl. Serv., Biol. Rep. 90(12).

U.S. Fish and Wildlife Service. 1988. Annual report. Southern sea otter translocation to San Nicolas Island, August 1987-July 1988. $13 \mathrm{pp}$.

U.S. Fish and Wildlife Service. 1989a. Prince William Sound oil spill, sea otter holding and release from rehabilitation centers. Attached to letter from W. Stieglitz, regional director, U.S. Fish and Wildlife
Service, to D. Cornett, Exxon Company U.S.A., 28 April 1989. 3 pp.

U.S. Fish and Wildlife Service. 1989b. Letter from J. G. Rogers, Jr., acting regional director, U.S. Fish and Wildlife Service, to O. Harrison, Exxon general manager, 12 May 1989. 2 pp.

U.S. Fish and Wildlife Service. 1989c. Letter from W. Stieglitz, regional director, to D. Collinsworth, commissioner, Alaska Department of Fish and Game, 26 June 1989. 3 pp.

U.S. Fish and Wildlife Service. 1989d. Release strategy for rehabilitated otters resulting from the Prince William Sound oil spill, 10 July 1989. Anchorage. $11 \mathrm{pp}$. 


\title{
Hazards of Releasing Rehabilitated Animals With Emphasis on Sea Otters and the T/N Exxon Valdez Oil Spill
}

by

\author{
T. R. Spraker \\ Department of Pathology \\ College of Veterinary Medicine \\ Colorado State University \\ Fort Collins, Colorado 80523
}

\begin{abstract}
When animals are removed from the wild for rehabilitation and then released into preexisting or new habitat, many problems can occur. Of particular concern is the transmission of disease to free-ranging animals from the released animals. These can be endemic diseases of the rehabilitated animals or diseases that were acquired during trapping, handling, and rehabilitation procedures. Numerous problems can result from such disease exposure, including death of an animal and the animal becoming a disease carrier, which could make the animal diseased in times of low nutrition or stress and allow it to transmit disease to its offspring or to other species. I discuss examples of these conditions as they relate to the sea otter (Enhydra lutris) release program after the T/ Exxon Valdez oil spill. The potential exposure to disease for the rehabilitated sea otters was overwhelming. I believe the decision to release rehabilitated sea otters into Prince William Sound and the Kenai Peninsula was probably not wise.
\end{abstract}

\section{Social and Habitat Effects of Transplanted Animals}

After transplantation, social alterations are created within resident animal populations in the area of transplant, and the population's food base is also affected. With bighorn sheep (Ovis canadensis) transplants, for example, biologists have to consider the interaction of the transplanted bighorns with mule deer (Odocoileus hemionus), elk (Cervus elaphus), mountain goats (Oreamnos americanus), mountain lions (Felis concolor), and domestic sheep (Ovis aries), cattle (Bos taurus), and llamas (Lama glama). The biologists must also consider such human conflicts as real estate, ranching, and oil and gas exploration endeavors. When the sea otters were released, were the social effects on the resident sea otters, mink (Mustela vison), river otters
(Lutra canadensis), seals, and so forth considered? Was the natural food supply for the sea otters examined? Were the commercial fisheries near the release sites considered? The release of animals into a new environment where the local people do not want them usually results in an unsuccessful transplant.

\section{Diseases}

The transmission of diseases by transplanted animals has the most effect on free-ranging populations. Transplanted animals may have endemic diseases or strains of a particular organism in their population that may not be present in the resident population of the release site. An example of this is the Pasteurella sp. pneumonia complex of bighorn sheep. If bighorn sheep are used as a supple- 
ment transplant into new range where a few bighorn sheep are presently living, several things can happen. First, the transplanted animals may do well and mix with the resident animals, or they may not mix, which can result in a reduction of size of each herd on the inhabited range. Second, the transplanted animals may avoid the resident animals and vice versa. Third, when a herd of bighorn sheep is supplemented with transplants, high mortality can occur in resident animals, but the transplanted animals survive. One theory for this phenomenon is that the transplanted animals are carrying a low pathogenic Pasteurella that when transmitted to native bighorn sheep becomes virulent and causes pneumonia (Schmidt, personal communication).

A similar example may be the herpesvirus that was found in the rehabilitated and free-ranging sea otters in Prince William Sound. The endemic disease was probably exacerbated by the stress of captivity and the increased human activity in Prince William Sound. Was this herpesvirus also present in the resident animals where the rehabilitated otters were released? What was the effect of mixing the sea otters from Homer with sea otters from Prince William Sound? Did one of these populations of sea otters carry an endemic disease that the other population did not have? Sea otters in Homer are reported to haul out on docks that are contaminated with dog feces. In my opinion, the intermixing of different animals from areas that far apart was not a judicious decision. Endemic disease not only poses a threat to the species being transplanted, but it could also affect other species that come in contact with these transplanted animals. Therefore, the question with the herpesvirus is not only how it affected sea otters in Prince William Sound, Kodiak, or the Kenai Peninsula, but also what is the effect of this herpesvirus on other mustelids, such as river otter and mink, which live in the intertidal zones of the release sites?

Rehabilitated animals could also be exposed to new diseases during handling and rehabilitation. These diseases could cause high mortality in rehabilitated animals during the handling and rehabilitation phase. The rehabilitated animals could also become disease carriers, transmitting diseases to free-ranging sea otters or other species after release. Some diseases may be sublethal to adults but lethal to neonates. Disease sources in the rehabilitation process include handlers or caretakers, domestic animals, vermin, food, and water. The transmission of human diseases to animals and vice versa should also be considered in rehabilitation programs. Little is known about infectious diseases of sea otters, especially those acquired from humans. For example, ferrets and steppe polecats (Mustela eversmannii) are susceptible to the human influenza orthomyxovirus (Bernard et al. 1984). Influenza virus causes a mild chronic bronchitis in these mustelids, which can predispose them to bacterial bronchopneumonia. Neonates seem to be especially susceptible to this condition. The susceptibility of sea otters to the orthomyxovirus of humans is not known. However, precautions such as wearing masks could help prevent the possible spread of this virus to rehabilitated sea otters. Serological testing of sea otters for this disease may prove helpful in understanding this potential problem.

Bacterial diseases of humans, such as Escherichia coli, Salmonella, Klebsiella, Streptococcus, Campylobacter, Staphylococcus, and Pseudomonas, may be transmitted to wild animals, including otters. Handlers or caretakers can be the transmission vehicle, enabling contaminants to gain access into the water or food supply of the sea otters. These diseases are fairly pathogenic in stressed animals, including otters.

Direct or indirect transmission of disease from domestic animals to wild animals is a potential problem in rehabilitation programs. The pathogenicity in sea otters of viral diseases of domestic animals is not known. Viral diseases that should be considered suspect, however, include the paramyxovirus of canine distemper (mustelids are extremely susceptible [Carpenter et al. 1976]) and the parvovirus of canids and felids (mustelids seem to have a relatively low susceptibility). Nothing is known about the susceptibility of sea otters to adenovirus (infectious canine hepatitis), calicivirus, coronavirus (feline infectious peritonitis), rotavirus and herpesvirus (infectious feline rhinotracheitis). Ferrets are susceptible to rotavirus and pseudorabies virus (Bernard et al. 1984).

Rabies seems to be an unlikely sea otter disease; however, rabies is an important disease of foxes in Alaska. Sea otters do haul out on areas where foxes could bite them, thereby transmitting rabies. Rabies should be considered as a possible disease in rehabilitated animals, and it may pose a serious risk to handlers. If a wild animal, including a sea otter, bites a human, the animal should be euthanized and checked for rabies.

Bacterial diseases of domestic animals, such as Bordetella spp., Pasteurella, Brucella, Campylobacter, and Salmonella, can be transmitted from 
domestic animals, especially dogs and cats, to other animals (e.g., sea otters) during a rehabilitation program. There is a possibility that rehabilitated sea otters (after the Exxon Valdez incident) could have acquired some of these bacterial infections, especially Bordetella and Pasteurella. These organisms can survive in nasal secretions for a short time; therefore, handlers that had contact with a dog or cat shedding these organisms could transmit organisms to sea otters. In turn, the otters then could become carriers and transmit these bacterial diseases to their offspring or to offspring of other animals in the release sites. These organisms are notorious for causing pneumonias, septicemias, and abscesses. Also, Pasteurella, Salmonella, and Brucella have been associated with abortions, and Salmonella and Pasteurella can result in enteritis.

The possibility of vermin (e.g., rats, mice, roaches) transmitting diseases to sea otters is low. These animals primarily transmit disease through parasites or contamination of food and bedding. In the Alaska rehabilitation effort, this mode of disease transmission probably had little effect because of the type of operation that was occurring within the sea otter rehabilitation program. However, efforts should be made to keep out vermin. Wild birds, especially sparrows, waterfowl and pigeons, are notorious for shedding Salmonella, Campylobacter, and Chlamydia.

Food can serve as a primary source of disease transmission. Many foods that were fed to the Alaskan sea otters were partly processed; these foods included fish, crab, shrimp, and clams. This food material came from various parts of the United States and other countries and could have been contaminated with numerous chemicals, bacteria, or viruses, or it could have carried parasites foreign to the rehabilitated otters. These agents may have infected the otters, causing them to die or to become disease carriers able to transmit organisms to other free-ranging animals. For example, these sea otters could have acquired the parasite Anisakis from eating raw fish. Numerous species of Anisakis exist, some of which are more pathogenic than others. Therefore, by feeding raw fish obtained from various parts of the country rehabilitated animals could have been targets for the transmission of new parasites. Once infected, these animals could then introduce the parasites to resident animals after release. Fish are also carriers of several bacterial diseases to which sea otters could be susceptible. These diseases include Aeromonas, Erysipelothrix, Vibrio, Mycobacte- rium, and Corynebacterium. Food can serve as an amplifier of water-borne or bacterial organisms. For example, the water used to wash sea otter food could have been contaminated with Salmonella. Salmonella grows rapidly in food and may be ingested in overwhelming doses. During rehabilitation programs, the animals are stressed; therefore, their immune systems are impaired. A stressed (immunologically compromised) animal could be fed an overwhelming dose of bacteria that under normal circumstances would not be harmful but in stressful situations could cause disease.

The coliform count of the water supply for rehabilitation centers should also be checked. High coliform counts suggest fecal or sewage contamination. Bacterial, chlamydial, protozoan, parasitic, and viral diseases could be transmitted through water. One particular virus that should be considered is Hepatitis B. Sea otters may be able to serve as a carrier host, which could eventually lead to infection of clams at the release site.

Some diseases have extremely long incubation periods; therefore, rehabilitated sea otters could have been exposed to and acquired certain diseases in captivity that would not cause clinical signs until several months later. These animals could then transmit diseases to their free-ranging counterparts or to other species in the release area. The long incubation periods of some diseases pose a problem for setting quarantine periods and conducting serologic tests to certify animals free of disease before release.

An estimated 8,000-10,000 sea otters naturally inhabit Prince William Sound, and about 200 rehabilitated animals have been released in Prince William Sound and the Kenai Peninsula area. Was it worth the risk to the rest of the free-ranging animals to release these few sea otters back into the wild? These rehabilitated animals could have been exposed to, and may later spread, many diseases about which little or nothing is known. Therefore, I find it questionable whether it was worth the risk. If a disease such as canine distemper or parainfluenza virus were introduced into the wild, several thousand animals could die before the disease would even be discovered. Treatment for such a disease in the wild would be futile.

\section{Preventive Measures}

Measures can be taken to help reduce the risk of transmitting diseases in rehabilitation centers. 
These procedures will help reduce disease transmission but are not $100 \%$ effective:

- Do not bring unoiled or lightly oiled animals into rehabilitation centers. This will reduce the number of animals exposed to disease

- Before handling rehabilitated animals, animal catchers and handlers must not be in contact with domestic animals for at least 3 weeks

- Those persons handling animals should wear masks

- Before handling animals or entering areas where animals are kept, people should shower (at the center) and put on clean clothes and boots provided by the center. The body and the head should be thoroughly washed, finger nails cleaned, the nose blown, and the respiratory tract expectorated

- All food should be acquired from local sources and handled properly, particularly fresh seafood

- People that are touring rehabilitation centers should be kept to a minimum and should undergo the same cleaning procedures as staff

- Animals entering the center should be given a complete examination, including collection of blood (for smears, complete blood count, and serum) and feces. Serum and feces should also be stored for future reference. Fecal, nasal, and pharyngeal bacterial cultures should be done. These same procedures should be carried out just before release of animals

- Reasonable quarantine periods should be established. Quarantine periods are usually set with regard to a specific disease in which the incubation period is known. Quarantine periods in domestic animals range from 10 days to 36 months depending on the disease in question. However, it is difficult to suggest a quarantine period when you do not know which diseases you might be dealing with

Some people may think these measures are absurd and nearly impossible to fulfill, yet when these suggested precautions are compared with procedures taken by poultry and porcine producers, they are minimal. It is extremely difficult to prevent disease transmission, therefore all available precautions should be taken to reduce the possibility of disease spread. When these precautions are not taken, the release of animals back into the wild means a great risk of disease introduction to free-ranging animals.

Before another massive rehabilitation and release program of sea otters is undertaken, these problems of social interaction and potential disease transmission between rehabilitated, released otters and the resident otter population and other species should be examined in great depth. Unanticipated disease problems may have already occurred in the released sea otters; these may not be discovered for several months or years. It is extremely difficult to foresee all the potential hazards that could occur in a rehabilitation program of this magnitude and complexity. Therefore, in my opinion, these animals should not have been released into the wild. The risks were too high.

\section{Fate of Rehabilitated Sea Otters}

If the sea otters should not have been released, what could have been done with them? The ideal situation would have been that only moderately to heavily oiled otters would have been captured and taken to rehabilitation centers. Lightly or unoiled otters should not have been removed from the wild. Otters that were oiled and who subsequently recovered should have been kept in captivity (funded by Exxon Company, U.S.A.) to study and monitor long-term effects of oil toxicity. A second alternative would have been to give the recovered otters to zoos and aquariums. However, in my opinion the reality of the situation was that most of the animals that were taken to rehabilitation centers at Seward and Homer were not oiled. The majority of oiled animals at the Valdez Otter Rehabilitation Center died, and at the end of the program about 200 sea otters were in captivity with no place to go. Another option would have been to transplant sea otters to historic habitat at the west end of the Aleutian Islands, an area that has a good food base and a low-to-nonexistent resident population of harbor seals (Phoca vitulina), Stellar sea lions (Eumetopias jubatus), northern fur seals (Callorhinus ursinus), mink, and river otters.

My objective is to help those involved in future rehabilitation programs save a few individual animals, while not jeopardizing the free-ranging animals at release sites. If a disease is introduced into the wild, it may kill more sea otters and other species by the disease than the number killed as 
a result of the oil spill. If the released otters introduce a new disease into the wild population, the release program will be just as guilty of injuring the sea otter population as was the oil spill. The releases in the T/V Exxon Valdez incident were not needed to save the sea otter in the wild. I believe the animals were released because of preconceived ideas and public opinion about how things were "supposed to be done."

\section{References}

Bernard, S. L., J. R. Gorham, and L. M. Ryland. 1984. Biology and disease of ferrets. Pages 386-397 in J. C. Fox, B. J. Cohen, and F. M. Loew, eds. Laboratory animal medicine. Academic Press, Inc., New York.

Carpenter, J. W., M. J. G. Appel, R. C. Erickson, and M. N. Novilla. 1976. Fatal vaccine-induced canine distemper virus infection in black-footed ferrets. J. Am. Vet. Med. Assoc. 169:961-964. 


\title{
Determining Health of Rehabilitated Sea Otters Before Release
}

by

\author{
R. J. Haebler \\ Environmental Protection Agency \\ Environmental Research Laboratory \\ South Ferry Road \\ Narragansett, Rhode Island 02882
}

R. K. Wilson

Arctic Animal Hospital

1600 E. Tudor Road

Anchorage, Alaska 99507

and

C. R. McCormick

15536 Husky Street

Eagle River, Alaska 99577

\begin{abstract}
After the accident of the TN Exxon Valdez, sea otters (Enhydra lutris) were exposed to oil that caused adverse health effects. Many of these animals were rescued and treated at rehabilitation centers in Valdez and Seward. The goal was to release rehabilitated animals back to their natural environment if it could be determined that the health of these animals was sound enough that they could be expected to survive in the wild. To ensure that minimal risk was associated with their release, protocols were established for determining the health of each animal. Several sources of information were used. First, the medical record provided information concerning the clinical history, medical treatment, and temporal change of clinical signs. Second, physical examination and visual observation of the animal provided information on the physical status of the animal, appearance of the hair coat, appetite, nutritional status, and activity level. Third, blood samples were collected and analyzed for hematology and clinical chemistry profiles. This blood analysis provided the "health profile" that allowed determination of how well the internal organs were functioning. Also, animals were examined for pregnancy. All of this information was integrated and weighed by the veterinarians to determine if an individual animal was ready for release to the natural environment.
\end{abstract}

A protocol was developed by a team of veterinarians representing the U.S. Fish and Wildlife Service and the otter rehabilitation centers to evaluate the health status of sea otters (Enhydra lutris) at rehabilitation centers before their re- lease. Sea otters treated at centers in Valdez and Seward exhibited a broad range of adverse health effects associated with contamination from crude oil, stress of capture and captivity, and natural disease processes. The severity of these conditions 
varied greatly, as did the animals' ability to recover completely.

Health status determination was needed to identify whether individual animals should be released. The ultimate goal of the rehabilitation effort was to return healthy otters to their natural environment. Evaluation of health status of individual animals was necessary to ensure that there was minimal risk to animal survival associated with release. Health status determination was also needed to identify surgical candidates. As part of a long-term followup study, radio transmitters were to be surgically implanted in the abdomens of 45 rehabilitated sea otters before their release. The health status determination protocol was used to identify which animals were the best surgical candidates.

\section{Clinical Methodology}

Several sources of information were used to evaluate the health of each animal. First, the medical record provided information concerning physical condition at time of capture, clinical history, medical treatment, and temporal change of clinical signs. Second, physical examination and observation allowed evaluation of coat, appetite, nutritional status, and activity level. Third, blood samples collected during rehabilitation and at the time of final examination were analyzed for hematology and clinical chemistry profiles. These data were the basis for a health profile that characterized the functional status of the internal organ systems.

Both the hematology and clinical chemistry analyses consisted of a battery of tests. Each test generated a piece of information about an organ system or critical biochemical mechanism. When data from all these tests were considered, they provided an understanding of most of the major organ systems and, therefore, the overall health of an animal.

These hematological and biochemical data were then integrated with the medical record and physical status at the time of final examination to characterize the overall state of health for each sea otter. On the basis of this information veterinarians were able to weigh the risks and express their best medical judgments regarding the suitability of each animal for release or surgery.

The hematology and clinical chemistry profile analyses included many different tests. The following is a brief description of these analyses and how they are used.
Hematology evaluates the circulating blood system and provides data on inflammatory processes, immune response to infectious or parasitic diseases, anemia, blood dyscrasia, shock, stress, dehydration, and cytotoxic bone disease. Several different tests are used separately and in combination. Though normal ranges have been established for the various indices, specific acceptable maximum or minimum values cannot always be set. Because many factors may effect a given process in different ways, it is necessary to consider test results as they relate to the overall data set. The difficulty of establishing absolute numbers that are "normal" is illustrated by the exam. ple of an immune-deficient animal with a bacterial infection. An infection of this type should trigger an elevation of the total white blood cell count (WBC). However, in an immune-deficient animal that is incapable of responding to the infectious challenge, its absolute WBC may fall within what is usually considered normal range. In this situation, a "normal" WBC would be extremely abnormal, clinically.

The clinical chemistry profile analyzes serum for several factors that provide information about the biochemical and metabolic status of the liver, muscle, urinary, digestive, endocrine, and immune systems and the fluid, electrolyte, and acid-base balance. Within a given system, certain tests provide information that allows detection of specific types of abnormalities. For example, a battery of tests can be used to characterize liver function. These include serum glutamic-pyruvic transaminase, serum glutamic-oxaloacetic transaminase, alkaline phosphatase, bilirubin, ammonia, total protein, albumin, globulin, albumin-globulin ratios, and so forth. The integration and interpretation of this information allows the differentiation of hepatic disease due to hepatocellular leakage, cholestasis, or reduced functional mass. As is the case with hematology, the normal range values provide guidelines for interpretation, but it is not always possible to set absolute limits. The integrated biochemical data must be interpreted in light of the overall knowledge from the medical record and physical examination.

\section{Rating System}

To facilitate decision making, a rating system was created that assigned a numerical classification for health status. The purpose for this rating was twofold. First, it was used to determine whether an animal could be released back to the 
natural environment (releasable, classed 1-5; nonreleasable, classed $5 \mathrm{~A}$ ). Second, it was used to identify which of the releasable animals would be the best surgical candidates. Descriptions of the classifications are as follows:

1. Excellent surgical candidate with no history of impaired health.

2. Good surgical candidate with history of slight abnormalities in blood variables that are presently resolved.

3. Fair surgical candidate with history of moderate health problems or abnormal blood variables.

4. Poor surgical candidate with history of severe health problems or abnormal blood variables.

5. Unacceptable surgical candidate due to history of severe medical problems that preclude anesthesia or surgery.

5 A. Unacceptable surgical candidate due to current medical condition; severity of health problems requires permanent captive care in aquariums.

This rating system was initially used to identify candidates for radio transmitter implant surgery. Review of the medical record provided information about specific medical problems that were noted throughout rehabilitation. For example, if an otter had a history of subcutaneous emphysema, it was considered a poor anesthetic risk and was therefore classified 5. One otter had severe coat loss on the chest and abdomen. This animal could not be considered for surgery because he would be at risk for further coat loss problems associated with grooming in the incision area. (With time, the coat condition improved sufficiently so this animal could be released.)

Otters that were anemic or had elevated liver enzymes or white blood cell counts were classified in a range from good to fair (2-3) depending on the severity of the problem. When an otter was classified 4 or 5 , no surgery was performed. If followup blood work indicated sufficient improvement, the animal could be reconsidered.

Classification was a dynamic process. An animal's rating could be changed up or down depending on subsequent blood analyses or behavior. At the time animals were first brought to the centers, most would not have been good surgical or release candidates. With time, proper feeding, and medical care, the health of most otters improved sufficiently that there was minimal risk associated with surgery or release.

\section{Evaluation for Surgery}

In Valdez, 63 sea otters held in the octagon (prerelease holding pens) were considered on 30 June for surgery. The animals were classified as follows:

\begin{tabular}{cccc} 
Rating & $\begin{array}{c}\text { Prince William } \\
\text { Sound otters }\end{array}$ & $\begin{array}{c}\text { Kenai } \\
\text { otters }\end{array}$ & Total \\
\hline 1 & 4 & 2 & 6 \\
2 & 4 & 17 & 21 \\
3 & 7 & 9 & 16 \\
4 & 3 & 2 & 5 \\
5 & 6 & 3 & 9 \\
$5 \mathrm{~A}$ & 6 & 0 & 6 \\
\hline
\end{tabular}

Of these otters, 23 were implanted with radio transmitters. All recovered without incident. Five implanted animals were assigned a rating of 1 , nine a rating of 2 , and nine a rating of 3 .

At the time of the surgical considerations, otters were still being admitted to the Seward Center. Most of the grade 2 and 3 otters were recent arrivals that either (1) had abnormalities on their admission blood work, or (2) needed more time to restore coat condition.

Rating Number of otters

\begin{tabular}{ll}
1 & 23 (including 2 female-pup pairs) \\
2 & 4 \\
3 & 6 \\
4 & 6 \\
5 & 11 (all juveniles or pups) \\
\hline
\end{tabular}

Of these animals, ten animals graded 1 were implanted with radio transmitters.

The Jakolof Pre-Release Facility was used as a prerelease site. All animals were graded 1 before transfer from Seward to Jakolof. Twelve animals at Jakolof received radio transmitters.

\section{Evaluation for Release}

Pregnant sea otters were given special consideration regarding release. Many of the affected animals were in various stages of pregnancy. Because of the high rate of abortion and early neonatal death at the rehabilitation centers and the poor pup survival at aquariums, it was decided that near-term pregnant females should be released to the wild as soon as possible. To best protect both the female and her unborn pup, it was critical that 
a sound procedure be developed for determining which females should be released. To do this, it was necessary to identify which females were pregnant, determine their approximate stage of pregnancy, and establish the health status of each individual. Pregnancy was determined by abdominal palpation performed by veterinarians. If a skeleton, particularly the skull, could be clearly identified, the animal was considered to be in the near-term stage of pregnancy. The health status was determined as described above. If the consensus of the veterinarians was that a female was near term and her health status was sufficient to expect the animal to survive in the wild, she was released immediately. If she was near term but her medical condition would likely jeopardize her chances for survival, it was recommended that she be provided with special housing and husbandry care in captivity to maximize the chance of survival of both the female and her newborn. Females were reexamined at regular intervals to determine if and when health had improved sufficiently so that release would entail minimal risk to survival.
In Valdez, five sea otters were classified $5 \mathrm{~A}$ and sent to aquariums. Three otters that had originally been classified as $5 \mathrm{~A}$ were upgraded and released after improvement in coat condition. Fifty-eight sea otters were returned to the natural environment from the Valdez Center.

Thirty-five otters were released from the Seward Center. Four of the grade 4 animals died before release, and 11 were transferred to aquariums.

One hundred eight sea otters were released from the Jakolof Facility.

\section{Conclusion}

We think that the approach described was a good way to determine health status. Many otters had severe medical problems when they arrived at the rehabilitation centers. With time, appropriate medical care, and good nutrition, their medical conditions usually improved dramatically. In future events, we recommend that this system be used as part of the medical record to track clinical progress from the time of admission through rehabilitation. 


\title{
Procedures and Rationale for Marking Sea Otters Captured and Treated During the T/V Exxon Valdez Oil Spill
}

by

\author{
A. R. DeGange \\ U.S. Fish and Wildlife Service \\ 1011 E. Tudor Road \\ Anchorage, Alaska 99503
}

and

T. D. Williams

Monterey Bay Aquarium

Monterey, California 93940

\begin{abstract}
Four methods were used for marking sea otters (Enhydra lutris) captured and treated during the response to the T/N Exxon Valdez oil spill. Colored and numbered flipper tags were placed on each sea otter that was brought to the otter treatment centers. These tags allowed individual recognition and permitted the tracking of individuals through the treatment and holding processes. Recovery of tagged carcasses may provide a crude measure of the fates of rehabilitated otters. Seven sea otters were instrumented with radio transmitters attached to flipper tags as part of a pilot release program. The results of that study were inconclusive. Forty-five sea otters were implanted with radio transmitters as part of a study to assess the fate of rehabilitated sea otters. Specific objectives of the study include estimating survival rates and monitoring the reproductive success of the sample of rehabilitated sea otters and comparing the results with similar variables in a control population. Transponder chips were injected in the perianal region of all but seven of the instrumented sea otters, and all were tagged with red flipper tags. The advantages and disadvantages of each type of tag are discussed.
\end{abstract}

More than 400 sea otters (Enhydra lutris) were captured during the response to the T/N Exxon Valdez oil spill; 358 of these otters were brought to otter rehabilitation centers in Valdez and Seward. The treatment and rehabilitation processes and the long-term postrelease monitoring efforts required different marking and tagging techniques. Four marking techniques, all in wide use on free- ranging sea otters in Alaska and California, were used in the otter rehabilitation centers: flipper tags, flipper-tag radio transmitters, implantable radio transmitters, and transponder chips. We describe the marking techniques used on sea otters during the oil spill response, describe the rationale behind using the various tags, and discuss the advantages and disadvantages of each tag. 


\section{Tag Description, Methodology, and Rationale}

\section{Flipper Tags}

The large numbers of sea otters that were captured, treated, and released from the otter centers necessitated a tagging system that permitted the tracking of individuals through the rehabilitation process. The tags also needed to be readily available and easy to apply. Flipper tags have been used on sea otters since the mid-1970's. The tag in common use on sea otters is a cattle ear tag manufactured by the Temple Tag Company in Temple, Texas. The tags, usually referred to as Temple tags, are made of durable plastic and come in many colors. They can be imprinted with unique combinations of letters and numbers.

Flipper tags are applied to the interdigital webbing of the hind flippers. The tags are applied by punching a hole in the webbing with a leather punch and inserting the tag through the hole. Predrilling the tag and affixing it with a brass screw through the top of the tag and the post may increase tag retention. By using a variety of colors and varying the placement of the tags between various digits, a large number of combinations are available to permit individual recognition from a distance (Jameson 1989). Because of the large numbers of sea otters that were captured and treated, it was not possible to release each otter with a unique color and placement combination. However, each sea otter was released with a uniquely numbered tag that was color-coded by otter center; gold for the Jakolof Pre-Release Facility (JPRF) and gray for the Valdez Otter Rehabilitation Center (VORC). Unfortunately, sea otters from the Seward Otter Rehabilitation Center (SORC) were released with a variety of colors. Gray and gold tags, although not ideal for viewing from a distance, were selected to avoid confusion with ongoing studies of free-ranging sea otters.

\section{Transponder Chips}

The transponder chip or PIT (passive integrated transponder) tag is a small, biologically inert, battery-free tag that is now in use as a permanent identifier for free-ranging sea otters (Thomas et al. 1987; R. J. Jameson, U.S. Fish and Wildlife Service, San Simeon, California, personal communication). All but seven of the sea otters that were implanted with radio transmitters were marked with transponder chips.
PIT tags are about $10 \times 2 \mathrm{~mm}$ and have a cylindrical glass casing. They consist of a transponder and an integrated circuit. The tag is powered by a $400-\mathrm{kHz}$ radio signal emitted from a hand-held transmitter. When activated by being passed close to the transmitter, the PIT tag transmits a 10-digit code at $50 \mathrm{kHz}$. The transmission is detected by the transmitter, which sends it through a cable to the reader, which is a self-contained unit that displays the code number of the tag on an LCD display. The PIT tag does not require an internal power source and has an unlimited lifespan.

Application of the PIT tag is relatively simple. The tag is inserted subcutaneously in the perianal region of a restrained sea otter with a sterile 12-gauge needle.

\section{Flipper Tag Transmitters}

Radio transmitters have been used on sea otters since the mid-1970's. Early radiotelemetry studies used transmitters attached to collars (Loughlin 1979), but collars caused several deaths or were removed by the otters. Garshelis and Garshelis (1984) and Ribic (1982a,b) used radio transmitters attached to the hind flippers, but these sometimes lead to tears in the interdigital webbing or even broken toes (Garshelis and Siniff 1983). In 1987, experiments in Alaska were undertaken using a new generation of transmitters for attachment to the interdigital webbing of the hind flippers (DeGange, unpublished data; C. W. Monnett and L. M. Rotterman, Prince William Sound Science Center, Cordova, Alaska, unpublished data). Those transmitters were small enough to cement to standard flipper tags and light enough not to cause the degree of trauma associated with earlier transmitters.

The flipper tag transmitters (manufactured by Advanced Telemetry Systems of Isanti, Minnesota) measure about $2.5 \times 1.3 \times 0.6 \mathrm{~cm}$. They are equipped with an internal, coiled antenna that is potted as a unit with the battery and circuitry. The transmitters are powered by a 3.5-V lithium battery that provides a maximum operating life of 60 days. The transmitter plus the flipper tag on which it is cemented weigh about $15 \mathrm{~g}$; they are attached to the sea otter in the same way as flipper tags.

The flipper tag transmitters were used as the principal marking device in a pilot release program for sea otters treated during the oil spill response. The primary objective of the study was to determine if sea otters released near Cordova in water 
unaffected by the oil spill remained there or returned to the affected habitats from which they were captured. The U.S. Fish and Wildlife Service was operating on the assumption that it was better to release sea otters in clean waters adjacent to the spill zone rather than translocate them extremely long distances. The operating plan was to track the sea otters for 30 days and use the information to guide the release of other rehabilitated sea otters.

One moderately oiled, three lightly oiled, and two unoiled sea otters, all captured after the oil spill and held at VORC, were instrumented and released near Cordova on 15-16 May. The release group was composed of three male and three female otters. A male sea otter from Port Valdez, who became a nuisance around the otter holding center, was also instrumented, moved to the Cordova area, and released as part of that effort. Only two of the sea otters were relocated throughout the 30-day monitoring period. Unfortunately, the results of the study were inconclusive, partly as a result of limitations in transmitter capabilities and performance (Monnett et al. 1990).

\section{Implanted Radio Transmitters}

One of the most controversial aspects of the response to the oil spill was the decision by Service personnel to implant radio transmitters in a sample of sea otters to monitor their fate after release into the wild. Implantation of radio transmitters is the preferred method of instrumentation for mustelids such as mink (Eagle et al. 1984), river otters (Melquist and Hornhocker 1983), and sea otters (Garshelis and Siniff 1983; Williams and Siniff 1983). Implanted transmitters do not restrict movements, are not manipulated by the animal, and in sea otters, do not limit the animals' ability to groom. Implantable transmitters were first used on sea otters in Alaska in 1982 (Garshelis and Siniff 1983; Williams and Siniff 1983). As long as the transmitters are implanted intraperitoneally, there seems to be no adverse effects (Ralls et al. 1989; Monnett and Rotterman, unpublished data).

Instrumentation of sea otters in this study was done as part of the natural resource damage assessment (Stieglitz 1990). The two principal objectives of the study were to monitor the movements of a sample of instrumented sea otters for 20 days after release and to use that information to guide later releases of sea otters and to determine the fate of sea otters that underwent oiling, treatment, holding, and release over a 2-year postrelease pe- riod. The specific hypotheses for the study were that survival of rehabilitated sea otters does not differ significantly from survival of free-ranging sea otters that were not affected by the oil spill, reproductive rates of rehabilitated sea otters do not differ significantly from reproductive rates of females that were not affected by the oil spill, and survival of rehabilitated sea otters that reenter oiled areas does not differ significantly from rehabilitated sea otters that remain in oil-free areas.

Forty-five sea otters were selected for instrumentation (Table). The sample size was the minimum allowable for statistical validity but still adequate to fill a balanced design of 15 animals from each center (Valdez, Seward, and Jakolof). The intention was to focus the study on females. As instrumentation proceeded, the design was modified in response to the changing availability of animals. Principal criteria for selection of sea otters included sex, capture or location, and degree of oiling; however, the otter's health became the ultimate criterion. The health of each candidate otter was evaluated by a team of 3 or 4 veterinarians, which included R. Haebler, the Federal on-scene veterinary pathologist; $\mathrm{T}$. $\mathrm{D}$. Williams, who developed the surgical protocol for transmitter implantation; C. R. McCormick, the chief veterinarian at SORC, and R. Wilson, the chief veterinarian at VORC. The appearance of the otters, their clinical histories, and their blood hematology and chemistry profiles were used to evaluate health. A number of candidate otters were rejected by the veterinary panel. Two other factors further eroded the original candidate list of sea otters: the unauthorized release of otters from VORC and JPRF, and the discovery of herpes-like oral lesions in sea otters, at SORC (see Harris et al. 1990). These factors contributed to the instrumentation of a group of rehabilitated sea otters that in terms of sex composition, otter treatment center from which they originated, and degree of oiling were different than originally intended.

Implantable transmitters were designed and constructed by Cedar Creek Bioelectronics Laboratory in Bethel, Minnesota. They measured about $7.6 \times 5 \times 2.5 \mathrm{~cm}$ and weighed about $120 \mathrm{~g}$. The lithium batteries were MIREL $T$ cells supplied by Promeon Division of MEDTRONIC Inc., in Haverhill, Massachusetts. These batteries are designed for long-life applications. The use of thionyl chloride as the cathode material provides the peak current capacity required of the transmitters. The transmitters were encapsulated in Scotchcast \#5 
Table. Capture location, capture date, degree of oiling, and sex of rehabilitated sea otters (Enhydra lutris) instrumented and released in Prince William Sound (PWS).

\begin{tabular}{|c|c|c|c|c|c|}
\hline $\begin{array}{l}\text { Otter } \\
\text { number }\end{array}$ & $\operatorname{Sex}^{\mathrm{a}}$ & $\begin{array}{c}\text { Capture } \\
\text { Region }\end{array}$ & $\begin{array}{l}\text { Capture } \\
\text { location }\end{array}$ & $\begin{array}{c}\text { Otter } \\
\text { center }\end{array}$ & $\begin{array}{c}\text { Degree } \\
\text { of } \\
\text { oiling }\end{array}$ \\
\hline V.029 & M & PWS & Green Island & VORC & High \\
\hline V-048 & M & PWS & Fleming Island & VORC & Low \\
\hline V-062 & M & PWS & Hogan Bay & VORC & Low \\
\hline V-068 & $F$ & PWS & Herring Bay & VORC & High \\
\hline V-104 & $\mathbf{M}$ & PWS & Iktua Bay & VORC & Low \\
\hline V-123 & M & Kenai Peninsula & Natoa lsland & VORC & Low \\
\hline$V-130$ & M & Kenai Peninsula & Natoa Island & VORC & Medium \\
\hline V-137 & $\mathrm{M}$ & PWS & Crab Bay & VORC & Low \\
\hline V-138 & M & PWS & Crab Bay & VORC & Low \\
\hline V-139 & $\mathbf{M}$ & PWS & Crab Bay & VORC & Low \\
\hline V-140 & M & PWS & Crab Bay & VORC & Low \\
\hline V-145 & $\mathbf{F}$ & Kenai Peninsula & Tonsina Bay & VORC & Low \\
\hline V-146 & $\mathrm{M}$ & Kenai Peninsula & Nuka Bay & VORC & Low \\
\hline V-148 & M & Kenai Peninsula & Windy Bay & VORC & Low \\
\hline V-150 & $\mathbf{F}$ & Kenai Peninsula & Tonsina Bay & VORC & Low \\
\hline V-152 & M & Kenai Peninsula & Berger Bay & VORC & High \\
\hline S-002 & $\mathrm{F}$ & Kenai Peninsula & Tonsina Bay & VORC & None \\
\hline S-003 & $\mathbf{F}$ & Kenai Peninsula & Tonsina Bay & JPRF & None \\
\hline S-006 & $\mathbf{F}$ & Kenai Peninsula & Tonsina Bay & JPRF & Low \\
\hline S-007 & $\mathrm{F}$ & Kenai Peninsula & Tonsina Bay & JPRF & Low \\
\hline S-015 & $\mathbf{F}$ & Kenai Peninsula & Bootleg Bay & VORC & Low \\
\hline S-017 & $\mathrm{F}$ & Kenai Peninsula & Bootleg Bay & VORC & Medium \\
\hline S-035 & $\mathbf{F}$ & Kenai Peninsula & Windy Bay & VORC & Unknown \\
\hline S-038 & M & Kenai Peninsula & Windy Bay & JPRF & Medium \\
\hline S-043 & $\mathrm{F}$ & Kenai Peninsula & Taylor Bay & SORC & Low \\
\hline S-044 & M & Kenai Peninsula & Taylor Bay & JPRF & Low \\
\hline S-045 & $\mathrm{F}$ & Kenai Peninsula & Picnic Harbor & VORC & None \\
\hline S-080 & $\mathrm{F}$ & Kenai Peninsula & Rocky Bay & JPRF & Medium \\
\hline S-053 & $\mathrm{F}$ & Kenai Peninsula & Windy Bay & JPRF & Low \\
\hline S-054 & $\mathrm{F}$ & Kenai Peninsula & Windy Bay & JPRF & Medium \\
\hline S-057 & $\mathrm{F}$ & Kenai Peninsula & Natoa Island & JPRF & Medium \\
\hline S-059 & $\mathrm{F}$ & Kenai Peninsula & Windy Bay & VORC & Unknown \\
\hline S-060 & $\mathrm{F}$ & Kenai Peninsula & Windy Bay & SORC & Low \\
\hline S-068 & $\mathrm{F}$ & Kenai Peninsula & Rocky Bay & VORC & Low \\
\hline S-069 & $\mathrm{F}$ & Kenai Peninsula & Rocky Bay & JPRF & Medium \\
\hline S-114 & M & Kodiak & Kodiak Island & JPRF & Medium \\
\hline S-122 & M & Kodiak & Kupreanof Strait & JPRF & Low \\
\hline S-124 & $\mathrm{F}$ & Kenai Peninsula & Rocky Bay & SORC & Low \\
\hline $\mathrm{S} \cdot 128$ & $\mathrm{~F}$ & Kenai Peninsula & Rocky Bay & SORC & Low \\
\hline S-146 & $\mathrm{F}$ & Kenai Peninsula & Windy Bay & SORC & Low \\
\hline S-152 & M & Kenai Peninsula & Windy Bay & SORC & Low \\
\hline S-155 & $\mathrm{F}$ & Kenai Peninsula & Rocky Bay & SORC & Medium \\
\hline S-157 & $\mathrm{F}$ & Kenai Peninsula & Rocky Bay & SORC & Low \\
\hline S-161 & $\mathrm{F}$ & Kenai Peninsula & Tonsina Bay & SORC & Low \\
\hline S-162 & $\mathrm{F}$ & Kenai Peninsula & Tonsina Bay & SORC & Low \\
\hline
\end{tabular}

\footnotetext{
${ }^{\mathrm{a}} \mathrm{M}=$ male and $\mathrm{F}=$ female.
}

${ }^{b}$ VORC $=$ Valdez Otter Rehabilitation Center, JPRF $=$ Jakolof Pre-Release Facility, and SORC $=$ Seward Otter Rehabilitation Center. 
and coated with Medadhere, a medical-grade urethane. All the transmitters were gas-sterilized and stored in sealed plastic bags until implanted.

Before surgery, the otters were immobilized with a combination of fentanyl citrate, valium, and azaperone (Williams et al. 1981). Surgeries were performed in a protected area adjacent to the otter holding areas by either T. D. Williams or C. R. McCormick. The surgical procedures have been described in detail elsewhere (Williams and Siniff 1983), with the exception that all transmitters were left free-floating in the body cavity. The surgical procedure lasted about $30 \mathrm{~min}$ for each sea otter. After the procedure was completed, chemical immobilization was reversed using naloxone hydrochloride. Otters were held a minimum of 6 days in the otter centers before release.

\section{Discussion}

The four marking methods used on sea otters captured during the response to the oil spill are useful depending on the goals and objectives for tagging. PIT tags are useful as a permanent marking device for sea otters; however, live sea otters must be restrained while the tags are implanted or read. The detection distance for the PIT tags is usually only inches. PIT tags are especially useful for identifying sea otter carcasses that have lost their flipper tags.

Flipper tags are widely used in studies of freeranging sea otters, but their usefulness is also limited. Generally, the observer must be close to distinguish the color and placement of tags on individuals. The imprinted numbers or letters are rarely readable except from extremely close distances, and tag loss does occur (Siniff and Ralls 1988). Color selection is important, as some colors are more prone to fading than others. Despite these limitations, several studies relying solely on this marking method have been successfully completed (Jameson 1989; K. Lyons, U.S. Fish and Wildlife Service, University of California, Santa Cruz, personal communication). Flipper tags proved to be of great usefulness in the otter rehabilitation centers by permitting the staffs to track individuals through the rehabilitation process. The ability to identify individual sea otters that die after release may help us understand the ultimate fate of some of the sea otters that survived the oil spill, and the results of our attempts to treat their injuries.

To date, flipper tag transmitters have been used with only limited success. The limitations of the transmitters themselves are part of the problem. They have a short operating life and a limited range. They are also susceptible to damage by the sea otter, and the radio signal is not audible when the otter has its flipper underwater. Loss of the signal is therefore difficult to interpret. Unfortunately, flipper tag transmitters have not been used in the types of studies for which they are probably best suited (i.e., studies of relatively sedentary animals over short periods). They are probably ideally suited for studies of dependent sea otter pups or those recently weaned from their mothers.

Implantable radio transmitters have proven very useful, despite their relatively high cost (\$500 each) and limited range when compared with transmitters attached externally to other kinds of animals. For studies of movements and home range, and for estimating rates of survival, reproduction, and tag loss, implantable transmitters are essential. Implantable transmitters are also essential for studies linking sea otter behavior to the distribution and abundance of their food supply through activity pattern and time budget analyses (Garshelis et al. 1986; Estes et al. 1987; Ralls and Siniff 1988; Ralls et al. 1989). The transmitters are highly reliable and have a 2.5-year lifespan that allows long-term monitoring. Implantable transmitters were the best option available for the long-term monitoring of rehabilitated sea otters.

\section{References}

Eagle, T. C., J. Choromanski-Norris, and V. B. Kuechle. 1984. Implanting radio transmitters in mink and Franklin's ground squirrels. Wildl. Soc. Bull. 12:180-184.

Estes, J. A., K. E. Underwood, and M. J. Karmann. 1987. Activity time budgets of sea otters in Califor. nia. J. Wildl. Manage. 50:626-636.

Garshelis, D. L., and J. A. Garshelis. 1984. Movements and management of sea otters in Alaska. J. Wildl. Manage. 48:456-463.

Garshelis, D. L., J. A. Garshelis, and A. T. Kimker. 1986. Sea otter time budgets and prey relationships in Alaska. J. Wildl. Manage. 50:637-647.

Garshelis, D. L., and D. B. Siniff. 1983. Evaluation of radio transmitter attachments for sea otters. Wildl. Soc. Bull. 11:378-383.

Harris, R. K., R. B. Moeller, T. P. Lipscomb, R. J. Haebler, P. A. Tuomi, C. R. McCormick, A. R. DeGange, D. Mulcahy, T. D. Williams, and J. M. Pletcher. 1990. Identification of a herpes-like virus in sea otters during rehabilitation after the T/V Exxon Valdez oil spill. Pages 366-368 in K. Bayha and J. Kormendy, tech. 
coords. Sea Otter Symposium: Proceedings of a symposium to evaluate the response effort on behalf of sea otters after the T/V Exxon Valdez oil spill into Prince William Sound, Anchorage, Alaska, 17-19 April 1990. U.S. Fish Wildl. Serv., Biol. Rep. 90(12).

Jameson, R. J. 1989. Movements, home range, and territories of male sea otters off central California. Mar. Mammal Sci. 5:159-172.

Loughlin, T. R. 1979. Radio-telemetric determination of the 24-hour feeding activities of sea otters, Enhydra lutris. Pages 717-723 in C. J. Amlaner, Jr. and D. W. McDonald, eds. A handbook on biotelemetry and radio tracking. Pergamon Press, Inc., New York.

Melquist, W. E., and M. G. Hornhocker. 1983. Ecology of river otters in west-central Idaho. Wildl. Monog. $83.60 \mathrm{pp}$.

Monnett, C. W., L. M. Rotterman, C. Stack, and D. Monson. 1990. Postrelease monitoring of radioinstrumented sea otters in Prince William Sound. Pages 400-420 in K. Bayha and J. Kormendy, tech. coords. Sea Otter Symposium: Proceedings of a symposium to evaluate the response effort on behalf of sea otters after the T/N Exxon Valdez oil spill into Prince William Sound, Anchorage, Alaska, 17-19 April 1990. U.S. Fish Wildl. Serv., Biol. Rep. 90(12).

Ralls, K., and D. B. Siniff. 1988. Time budgets and activity patterns of California sea otters. Pages 64-83 in D. B. Siniff and K. Ralls, eds. Population status of California sea otters. Outer Continental Shelf Study, Minerals Management Service 88-0021.
Ralls, K., D. B. Siniff, T. D. Williams, and V. B. Kuechle. 1989. An intraperitoneal radio transmitter for sea otters. Mar. Mammal Sci. 5:376-381.

Ribic, C. A. 1982a. Autumn movement and home range of sea otters in California. J. Wildl. Manage. 46:795-801.

Ribic, C. A. 1982b. Autumn activity of sea otters in California. J. Mammal. 63:702-706.

Siniff, D.B., and K. Ralls. 1988. Reproduction, survival and tag loss in California sea otters. Pages 13-32 in D. B. Siniff and K. Ralls, eds. Population status of California sea otters. Outer Continental Shelf Study, Minerals Management Service 88-0021.

Stieglitz, W. O. 1990. Opening address: boundaries of the symposium. Pages 1-3 in K. Bayha and J. Kormendy, tech. coords. Sea Otter Symposium: Proceedings of a symposium to evaluate the response effort on behalf of sea otters after the T/N Exxon Valdez oil spill into Prince William Sound, Anchorage, Alaska, 17-19 April 1990. U.S. Fish Wildl. Serv., Biol. Rep. 90(12).

Thomas, J. A., L. H. Cornell, B. E. Joseph, T. D. Williams, and S. Dreischman. 1987. An implantable transponder chip used as a tag for sea otters (Enhydra lutris). Mar. Mammal Sci. 3:271-274.

Williams, T. D., and D. B. Siniff. 1983. Surgical implantation of radiotelemetry devices in the sea otter. J. Am. Vet. Med. Assoc. 183:1290-1291.

Williams, T. D., A. L. Williams, and D. B. Siniff. 1981. Fentanyl and azaperone produced neuroleptanalgesia in the sea otter (Enhydra lutris). J. Wildl. Dis. 17:337-342. 


\title{
Postrelease Monitoring of Radio-instrumented Sea Otters in Prince William Sound
}

\author{
by \\ C. Monnett \\ Prince William Sound Science Center \\ P. O. Box 705 \\ Cordova, Alaska 99574 \\ L. M. Rotterman \\ University of Minnesota \\ Department of Ecology and Behavioral Biology \\ 318 Church St. S.E. \\ Minneapolis, Minnesota 55455 \\ C. Stack \\ Prince William Sound Science Center \\ P.O. Box 705 \\ Cordova, Alaska 99574 \\ and \\ D. Monson \\ U.S. Fish and Wildlife Service \\ Alaska Fish and Wildlife Research Center \\ 1011 E. Tudor Road \\ Anchorage, Alaska 99503
}

\begin{abstract}
Sea otters (Enhydra lutris) that were captured in western Prince William Sound (PWS) or the Gulf of Alaska, treated, and held in captivity at the temporary rehabilitation centers established in response to the T/N Exxon Valdez oil spill were instrumented with radio transmitters, released into eastern PWS, and monitored by radiotelemetry. We undertook the present study to gain information for guiding the release of the remaining captive otters and evaluating the efficacy of sea otter rehabilitation after exposure to crude oil. Radio transmitters were attached to the flippers of seven sea otters released in May 1989 and monitored for periods of a few hours to more than 60 days. However, little was learned about the fate of these animals because the radio transmitters used proved unreliable. Forty-five additional sea otters from the
\end{abstract}


rehabilitation centers were implanted with radio transmitters, released into northeastern PWS and monitored for 8 months. During the first 20 days after the first release of these implanted otters $(n=21)$, they were more mobile than wild-caught and released sea otters studied in PWS, from 1984 through 1990. All were alive and vigorous at the end of the 20-day period. Tracking of all 45 implanted sea otters during the 8 -month period showed that the otters remained highly mobile. Many (46.6\%) crossed into western PWS. However, by the end of the 8 months, 12 of the instrumented otters were dead and 9 were missing. One radio failed. These mortality and missing rates are much higher than those normally observed for adult sea otters in PWS. The death rate was highest in winter. These data suggest that, despite the tremendous amount of money and energy directed toward the treatment and care of these animals, the sea otters released from the centers were not completely rehabilitated, that is, not returned to a normal state. We recommend that future policies focus on preventing otters from becoming oiled, rather than attempting to treat them after oiling has occurred. This focus is especially recommended because of stress and disease risks associated with bringing wild animals into captivity.

The vulnerability of the sea otter (Enhydra lutris) to oil contamination was well established (Geraci 1988) before the oil spill resulting from the grounding of the T/V Exxon Valdez. Thus, in response to the spill, a large number of otters were captured in or adjacent to oiled areas and brought into centers that were hastily established for their temporary treatment and care.

Our major short-term goal was to provide information necessary to make decisions about whether sea otters should be released back into the wild, and if so, where such releases should occur. Thus, the short-term concerns were whether sea otters held for long periods in captivity and released into clean areas would resume basic activities necessary to survive in the wild, and whether they would immediately return to the areas where they were captured, and thus potentially come into contact with oil.

Our primary long-term goal was to gain insights into the efficacy of the rehabilitation strategy by providing data on survival, reproduction, and behavior of these sea otters.

We offer preliminary results on the behavior and survival of otters that were taken from the otter centers and released into northeastern Prince William Sound (PWS), and comparable data from two other studies of sea otters in PWS.

\section{Methods}

On 15 May 1989, seven sea otters (four males and three females) from the Valdez Otter Rehabilitation Center were equipped with small radio transmitters. The transmitters were affixed with epoxy to nylon cattle ear tags and attached through the interdigital webbing of their hind flippers by a procedure similar to that of Garshelis and Siniff (1983). The seven otters were transported by helicopter and released in Simpson Bay near Cordova, Alaska.

Forty-five sea otters (18 males and 27 females) were selected from otter centers during July and August 1989 and instrumented with surgically implanted radio transmitters (Garshelis and Siniff 1983; Monnett 1988; Monnett and Rotterman 1988). These otters were held for observation for at least 1 week after surgery. They were transported by helicopter in individual kennels and released in Sheep Bay (females) or Nelson Bay (males) in eastern PWS. Twenty-one otters were released on 27-28 July. Data from these individuals provided the basis for the release of the rest of the otters in mid-August. Otters were released $100-400 \mathrm{~km}$ from the site of capture into what was presumed to be unfamiliar and unoiled habitat. Figure 1 shows the capture sites of the otters selected for this study, which we refer to as treated otters.

Unpublished data from two other ongoing radiotelemetry studies of untreated sea otters are given for comparison. Fifty-eight sea otters (44 females and 14 males) were captured in eastern PWS from July to October 1987. Additionally, 30 females were captured in various parts of PWS in October and November 1989. Otters in both studies were placed in kennels and transported 1-10 $\mathrm{km}$ by boat to holding facilities. Because otters were captured at night, they were usually held in a floating pen until the following day. They were instrumented according to the same surgical protocol and with the same type of radio transmitters as those implanted in the otters from the rehabilitation centers. Otters were held for less than $24 \mathrm{~h}$ and were generally released within $1 \mathrm{~km}$ of the place at which they were captured. 


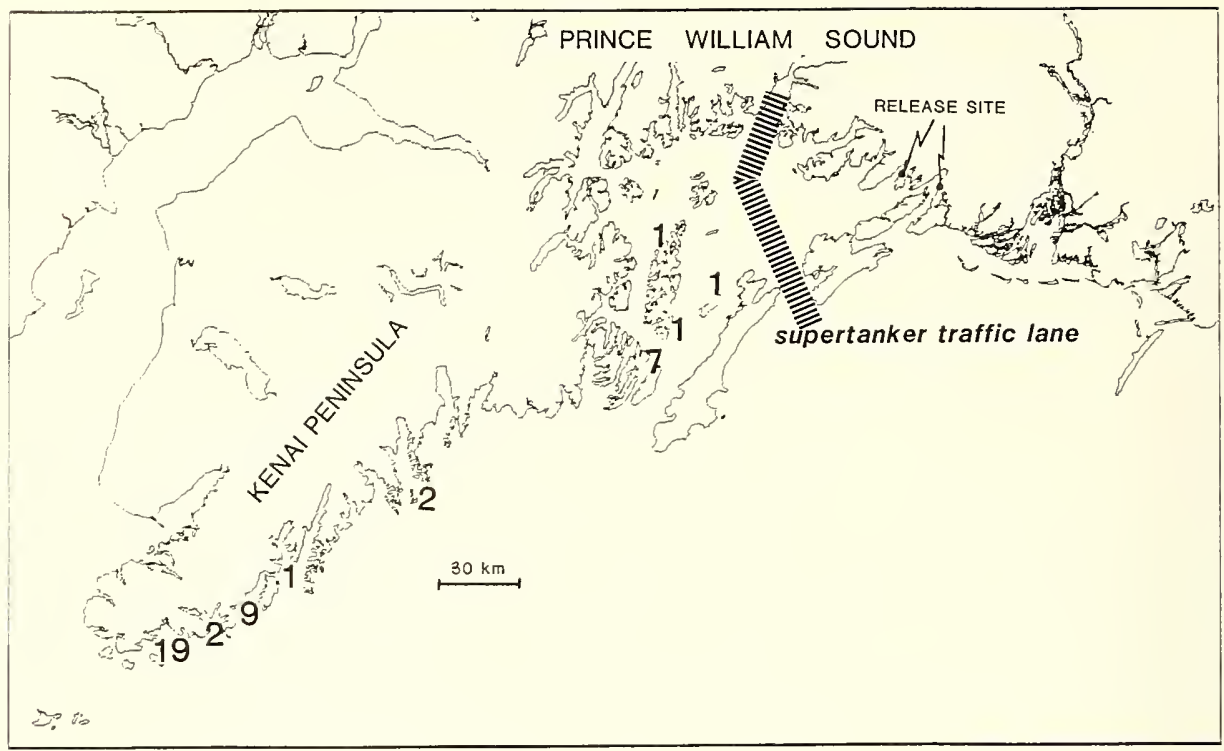

Fig. 1. Capture locations of sea otters (Enhydra lutris) treated in otter rehabilitation centers, implanted with radio transmitters, and released in eastern PWS for followup studies. Two otters that were captured in the Kodiak Archipelago are not shown on the figure.

In all studies, monitoring of radio-instrumented individuals was conducted from small skiffs and fixed-wing aircraft as described by Monnett (1988). Since the release of the first otters in May 1989, fixed-wing aircraft have been used about $1,000 \mathrm{~h}$ for radiotracking instrumented sea otters. Small boats have been used for an additional 1,500$2,000 \mathrm{~h}$. The search area included PWS, the coastline of the Gulf of Alaska between Kachemak Bay and Sitka, the Barren Islands, and some other areas of the Kodiak Archipelago. An attempt was made to locate and visually examine each otter every 7-14 days after instrumentation.

\section{Results}

\section{Observations on Otters With Flipper-tag Transmitters}

Seven otters with externally attached flipper radio transmitters were monitored over periods of a few hours to more than 60 days. One large male was seen only once after his release, a few kilome. ters from the release site. The radio transmitters of three otters failed prematurely ( 8 days of life or less) and when last heard, after 21 days, the strength of a fourth transmitter was substantially reduced. Thus, it is likely that at least four, and possibly five, radio transmitters either malfunctioned or were damaged by otters.

No mortalities were observed during the observation period. However, several females seemed to be relatively inactive, especially when compared with the treated otters that were instrumented and released in July. One female was hauled out during observations in a 2-day period. She was reluctant to enter the water when approached by observers in a skiff. Unfortunately, when she was last observed her radio transmitter was failing, and her fate was uncertain.

No otters were observed west of the supertanker traffic lanes (Fig. 1). Two males swam to Orca Inlet, $30-40 \mathrm{~km}$ from the release site, and entered male groups. A third male was last observed 12 days after release within $10 \mathrm{~km}$ of the release site. The maximum distances known to have been traveled from the site of release by three females were 2,10 , and $16 \mathrm{~km}$. 


\section{Early Observations of Radio-implanted Otters}

About 400 radiolocations were taken on 21 radio-implanted sea otters during the 20 -day observation period prescribed under the U.S. Fish and Wildlife Service's release plan. Most radiolocations were accompanied by a brief visual observation, sufficient to establish the status and behavior of the sea otter. No days were lost because of bad weather. Sighting locations for each of the 21 otters studied during the first 20 days after release are presented in the Appendix.

All 21 otters were alive at the end of the 20-day observation period. None exhibited prolonged periods of inactivity. However, during the first week or longer, many otters were swimming rapidly when observed, alternating short periods of swimming on the surface with longer periods of swimming underwater. Initially upon release, some of the otters swam continuously away from the release site for many hours. During the first week after release, travel rates of $20-40 \mathrm{~km} /$ day were not unusual. During the first 20 days, the median total distance traveled by males was $45 \mathrm{~km}$ (range, $10-280 \mathrm{~km}$ ), whereas that of females was $160 \mathrm{~km}$ (range $5-300 \mathrm{~km}$ ). Six of nine females traveled more than $150 \mathrm{~km}$, but only 3 of 12 males did so.

Two of 21 otters traveled into areas officially classified as being within the coverage of the T/V Exxon Valdez oil spill. However, only a single otter (ID no. 4098) remained within the oil spill area for more than a few days. Both otters were seen in the vicinity of beaches that were being subjected to Exxon's cleaning protocols. On the 14 th day of observation, one of the females (ID no. 4098) was seen hauled out near Eleanor Island on oil-contaminated rocks that were surrounded by oil sheen. However, both otters appeared vigorous during the entire 20 days of the study, and both swam in excess of $100 \mathrm{~km}$ after encountering oiled habitat.

\section{Later Observations of Radio-implanted Otters}

During the first 8 months after release from the otter rehabilitation centers, 21 of 45 instrumented otters were known to have traveled from their release sites into areas of western PWS affected by the oil spill. Six otters returned to waters adjacent to the Kenai Peninsula. One otter traveled about $90 \mathrm{~km}$ to Controller Bay, which is southeast of PWS. Several otters took up at least a temporary residence in the Gulf of Alaska, along the southern coast of Hinchinbrook Island or Montague Island. The maximum known distance traveled from the site of release was by a female that swam to English Bay on the Kenai Peninsula, a distance of about $400 \mathrm{~km}$.

As of 19 April 1990, 23 of 45 (54.5\%) radioinstrumented sea otters released from the otter centers were known to be alive (Table 1). Another otter experienced a radio transmitter malfunction, and its radio was no longer broadcasting. Twenty-one otters were either dead (12) or classified as missing (9). Not counting the otter with the malfunctioning radio transmitter or those that were missing, $65.7 \%$ of the radio-instrumented otters survived the first 8 months after release. Mortality increased strikingly during the winter season (January-April; Table 1). The proportion of otters known dead versus those classified as missing was higher after 1 January than in previous months (Table 1; August-December, 1 dead vs. 6 missing; January-April, 11 dead vs. 3 missing; $\chi^{2}=7.9,1 \mathrm{df}, P<0.01$ ).

The proportion of the radio-instrumented otters released that survived was less than that of the two groups of untreated otters (Fig. 2). Fifty. eight sea otters were radio-instrumented in 1987. After 8 months of monitoring, all 58 otters were alive (if individuals from otter centers classified as missing are excluded; $\chi^{2}=22.2,1 \mathrm{df}, P<0.001$ ). A single radio transmitter malfunctioned during the 1987 study. The otter, a female, was observed during the following summer, when she was identified by her flipper tag colors while swimming near a skiff on which her pup was being tagged. Moreover, proportionately more of the otters from the treatment centers were classified as missing (Table 2; $\chi^{2}=12.9,1 \mathrm{df}, P<0.01$ ).

A second group of untreated sea otters was radio-instrumented during October-November

Table 1. Fates of sea otters (Enhydra lutris) implanted with radio transmitters and released from otter centers, summarized by season.

\begin{tabular}{lrrrr}
\hline \multicolumn{1}{c}{ Status } & $\begin{array}{c}\text { Aug.- } \\
\text { Sept. }\end{array}$ & $\begin{array}{c}\text { Oct.- } \\
\text { Dec. }\end{array}$ & $\begin{array}{c}\text { Jan.- } \\
\text { April }\end{array}$ & Total \\
\hline Alive & 40 & 37 & 23 & 23 \\
Dead & 1 & 0 & 11 & 12 \\
Missing & 3 & 3 & 3 & 9 \\
$\begin{array}{l}\text { Transmitter } \\
\quad \text { failure }\end{array}$ & 1 & 0 & 0 & 1 \\
\hline
\end{tabular}




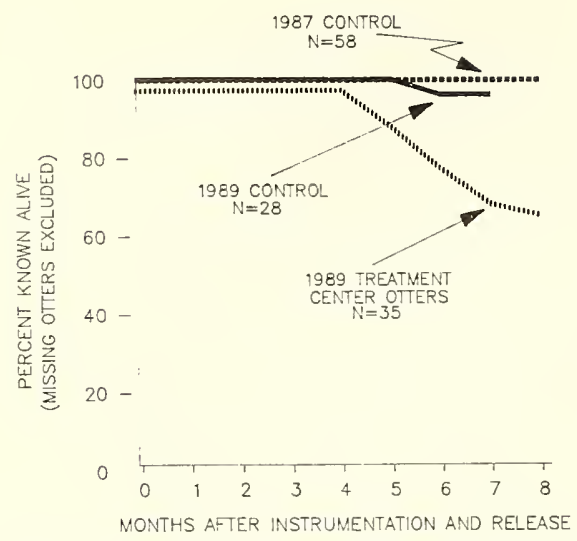

Fig. 2. Survival rates of sea otters (Enhydra lutris) implanted with radio transmitters in three studies during the first 8 months of observation. Otters classified as missing were not included in this analysis, as reflected in sample sizes given.

1989 and monitored, as of 3 June 1990, for $7-8$ months. During this period, one individual died, and two were classified as missing. When compared to the otters released from the otter centers, proportionately fewer of the untreated otters were dead (individuals classified as missing excluded; $\chi^{2}=9.0,1 \mathrm{df}, P<0.01$ ). However, the proportion of individuals classified as missing in the two studies was not significantly different $\left(\chi^{2}=2.7,1 \mathrm{df}, P>0.05\right)$.

The likelihood that an individual survived during the study period did not seem to be related to whether it reentered waters in the vicinity of the spilled oil trajectory. The proportion of dead or missing animals was similar between those that, at some point after release, crossed the super-

Table 2. Last known location of dead or missing sea otters (Enhydra lutris). Habitat east of the supertanker lanes was generally not oiled by the $T / V$ Exxon Valdez oil spill. Otters entering habitat west of the supertanker lanes would probably traverse oiled habitat.

\begin{tabular}{lcc}
\hline Status & $\begin{array}{c}\text { East of the } \\
\text { supertanker lanes }\end{array}$ & $\begin{array}{c}\text { West of the } \\
\text { supertanker lanes }\end{array}$ \\
\hline Dead & 10 & 2 \\
Missing & 7 & 2 \\
\hline
\end{tabular}

tanker traffic lanes into the western PWS and those that remained in the east. Eleven of the 21 otters that were known to have traveled into western PWS were missing or dead as of 1 April. A comparable proportion (10 missing or dead otters of 23) was observed for otters that remained in habitat east of the tanker lanes. Moreover, the vast majority of the dead or missing otters were, when last observed alive, in habitat located east of the tanker lanes (Table 2).

Whether an individual was dead or missing was apparently not related to whether the individual was captured in PWS versus along the Kenai Peninsula (Table $3 ; \chi^{2}=0.16,2 \mathrm{df}$, not significant).

\section{Discussion}

The sea otters that were captured, underwent treatment, and were selected for inclusion in this study seemed to be healthy and in good condition at the time of release into eastern PWS (Haebler 1990). Most of these animals seemed to remain vigorous in the first 20 days after release. More important, however, during the first 8 months after release the survival rates of the otters released from the rehabilitation centers seemed to have been relatively low. These findings are particularly sobering when one considers that by the time the seven individuals were selected for the first phase of this study (15 May 1989), $40.1 \%$ of the otters that had been admitted alive to the rehabilitation centers had already died (Williams et al., 1990; Appendix). Thus, all of the otters that were even considered for inclusion in this study were the "survivors" of the capture and treatment process, and as such, were a subset of those that entered the rehabilitation centers. Moreover, the sea otters included in this study (those that were selected for instrumentation) were among the healthiest of these survivors.

Table 3. Fates of sea otters (Enhydra lutris) captured and taken to otter centers and location of capture. Both otters captured within the Kodiak Archipelago are classified as missing.

\begin{tabular}{lcc}
\hline Status & $\begin{array}{c}\text { Prince William } \\
\text { Sound }\end{array}$ & $\begin{array}{c}\text { Kenai } \\
\text { Peninsula }\end{array}$ \\
\hline Alive & 6 & 17 \\
Dead & 3 & 9 \\
Missing & 1 & 6 \\
\hline
\end{tabular}


Our results emphasize the value and the necessity of long-term monitoring with reliable radio transmitters to assess the long-term fates of these animals. If only the flipper radio transmitter data were available, there would be insufficient information to reach any conclusion about the fates of these animals. If data for only the first 20 days after release were available (as was true when decisions about the release of the remaining captive otters had to be made), very different fates would be assumed for these animals than those that we now know or suspect occurred.

\section{Study of Otters With Flipper Radio Transmitters Not Informative}

The goals of the flipper radio transmitter study were to provide short-term information necessary for formulating policy about whether to release sea otters held in the centers back to the wild, and if so, where they should be released. Those who designed the study hoped that it would provide sufficient data to indicate whether animals initially captured in western PWS would remain in the clean northeastern PWS where they were released, and whether they would be able to survive in the wild after their experiences with oil, treatment, and captivity. However, because of the intrinsic limitations of flipper radio transmitters (e.g., if an animal dies in the water, its flippers are mostly underwater and the radio signal cannot be detected) and the poor performance of the transmitters in this study, little insight into these issues was gained.

\section{Insight From Study of Otters With Implanted Radios}

It is insightful to compare the findings obtained after the first 20 days of tracking the radio-implanted otters with those available after 8 months. The data on relative mobility tended to be similar over the two periods, whereas the data on fate of the otters were not.

As noted, otters released from the centers tended to be more mobile than normal sea otters in eastern PWS, both over the first 20-day period and over the first 8 months of monitoring. Some otters could be termed hyperactive, swimming almost constantly. During the 8 -month period, $46.6 \%$ of the instrumented otters from the centers entered western PWS one or more times. Conversely, of 75 normal adult females captured since 1984 in eastern PWS and studied using transmitters such as those in this study, only one old, morphologically aberrant female has ever been known to cross into western PWS. That sea otters are capable of making a movement of this magnitude is well documented (e.g., during the recolonization of the Aleutian Islands [Lensink 1962; Kenyon 1969]). However, Lensink (1962) noted that natural features, such as deep, wide bodies of water, can act as barriers or discouragements to sea otter movement unless otters are sufficiently motivated, such as by depletion of food resources.

The motivations underlying the movements of the otters released from the treatment centers are not readily apparent. However, the process of releasing animals caught in western PWS, or even farther west, into eastern PWS was essentially a translocation of those individuals. All information available from previous translocations (e.g., the translocations to Oregon, or the recent translocation of otters to San Nicolas Island) suggests that sea otters are unlikely to remain at the release site. However, the translocation made here differs from those attempted before in at least four important ways: animals were held for long periods in captivity between capture and translocation; the habitat from which they were captured, was, at least in some cases, one in which their recent experiences were likely to have been unpleasant; the habitat into which they were released contained large numbers of otters; and the release location was not isolated from other suitable habitat by many miles of open ocean, as was true in the recent San Nicolas Island translocation. Because of these differences, the behavior of the animals after release could not be predicted with any certainty.

Regarding the prognosis for future survival of the otters released from the centers, the shortterm results of this study were optimistic, as compared with those available after 8 months. At the end of the first 20 days of monitoring the first 21 animals in the long-term study, all appeared healthy and were obviously competent to care for themselves in the wild. However, mortality increased sharply as winter weather patterns developed. The mortality observed over the first 8 months of observation of these animals was much higher than that observed in the control groups.

On the basis of directly comparable data from previous studies in which adult sea otters from PWS were surgically implanted with radio transmitters, it is clear that survival rates of adult sea otters in normal, healthy populations tend to be high. For example, 8 months after instrumentation (the interval examined in this paper) all of the 
58 adult females implanted in 1987 in PWS were known to be alive (Fig. 2).

The number of treatment center animals that are categorized as missing is also high. While this study is ongoing, and hence, results are preliminary, it is likely that many or all of the sea otters now in the missing category are dead. Alternatively, they could be alive with functioning radios, but remain undetected, or their radios could have failed. Since a large area, including the entire PWS, the Kenai Peninsula, and the Gulf of Alaska to Controller Bay has been searched many times, we are confident that few or no "missing" animals with functional radios are alive within that area. Additionally, an even larger area, from PWS to the Barren Islands, and the nearshore areas of the Gulf of Alaska south to Sitka, has also been searched at least once. Some of the missing animals could be alive, with functional radios, if they traveled great distances (i.e., south of Sitka, west of the Barren Islands, or into Cook Inlet) or were living far offshore. While such distant travel is possible, we think it is unlikely to account for any significant portion of the missing animals, especially because many of the animals that became missing should have been detected at least once while en route to such locations. Regarding the possibility of radio failure, there is no reason to think that the performance of the radio transmitters would be different in the sea otters from the treatment centers than in any of the other otters that have undergone this type of instrumentation, either as controls for this study or in the past. Hence, radio failure is unsatisfactory as an explanation for the increased rate of missing animals in the group from the treatment centers versus otters in the control groups or in previous studies.

Radiotelemetry has become an effective and reliable tool for studies of sea otter natural history in recent years. Individuals are usually easily relocated and seldom remain undetected if living in an area that is overflown by a tracking flight more than one time. However, we suggest that it should not be expected that all dead sea otters would have been recovered during this study, for several reasons. The search area is bounded by thousands of miles of ocean. Certainly, some carcasses would be likely to drift out to sea. We have observed that, in PWS, otter carcasses are often scavenged within a few days. Once released from a carcass a radio may become submerged and go undetected indefinitely. Carcasses have been known to freeze into ice sheets that form in the backs of bays, where they may become submerged or destroyed, or they may drift away in ice floes. Radios may even be carried off by other wildlife and go undetected. For example, sea otter radios have been found in raptor nests and bear caches. In the case of raptors, we doubt that the radios were transported while still in the carcasses. The radios must have been selected and carried independently. Last, some carcasses may sink and remain undetected.

At this time, information and analyses are incomplete and insufficient to allow us to reach conclusions about the causes of the deaths of the sea otters studied. As noted, most of the mortality of the instrumented animals from the treatment cen. ters occurred during the winter. Apparently, the animals that died could not tolerate the winter weather conditions. Potential causes of the reduced survival rate of the animals that went through the capture and rehabilitation process include the following: chronic damage (e.g., organ or immune system damage) from initial exposure to oil or from stress of captivity, disease, translocation, and damage from chronic exposure to oil or contaminated prey following release.

These factors may be interactive. For example, a hypothetical sea otter with a damaged immune system due to exposure to toxic components of crude oil would be more susceptible to disease and stress associated with translocation and captivity. Geraci and Smith (1976) concluded that captivityrelated stress was probably the primary cause of death in seals experimentally contaminated with crude oil, and that the oil served as a trigger for the stress. St. Aubin (1988) suggested that the proximate cause of death in these seals may have been cardiac fibrillation resulting from high levels of epinephrine (due to stress) and hydrocarbons. Many or all of the sea otters examined in this study may have ingested, had their fur contaminated with, or inhaled components of Prudhoe Bay crude oil. Certain components and metabolites of crude oil are known to have pathogenic effects in mammals, including mutagenic, carcinogenic (Bingham et al. 1980), and embryopathic effects (Currie et al. 1970; Bui et al. 1986).

The case of the lesions at the Seward Center is a good model of the potential for disease transmission at an otter center and thus the risks inherent in captivity. Harris et al. (1990) pointed out that well-defined oral lesions, assumed to have been caused by a herpes-like virus, were common to otters housed at the Seward center. The presence of the viral-induced lesions, assumed to be benign (Harris et al. 1990), was correlated with the otters being held captive at the Seward Center. Similar, 
well-defined lesions were not observed at the Valdez Center or in wild sea otters in PWS. Presumably, if an ostensibly harmless virus can be transmitted so thoroughly through a captive population, so could a more harmful virus.

Further analyses, including evaluation of data from necropsy and histopathology studies, may permit better definition of the cause of death in these animals.

Several potential explanations for the increase in mortality are not supported by the data analyzed to date. There is no indication from necropsy results (R. Moeller, Armed Forces Institute of Pathology, Washington, D.C., and J. Blake, University of Alaska, Fairbanks, personal communication) or from previous or current studies of otters that were captured in the wild, instrumented, and immediately released that the radio implants were in any way related to the increased mortality of the sea otters released from the treatment centers. As noted previously, the untreated individuals are also carrying the same type of implanted radios. At present, the increased mortality observed in the otters from the centers does not seem to be directly related to the location inhabited postrelease. Thus, preliminary analyses indicate that otters that crossed into western PWS, at any point after release, were no more likely to die than those that did not make the crossing. The instrumented animals from the centers were not present in large numbers in western PWS during the periods of winter storms, when oil was coming off the beaches and recirculating, and when large slicks were observed. However, more detailed analyses are required to determine the relation (if any) between probability of death and time spent in the oil spill area after release.

\section{Failure to Rehabilitate Suggests Broadened Perspective}

The term rehabilitate means to restore to customary activity or to a former state. The findings presented and discussed in the present paper suggest that the combination of measures undertaken in an attempt to aid sea otters after the T/N Exxon Valdez oil spill did not result in the true rehabilitation of the surviving otters. This combination included capture (often by inexperienced personnel); treatment, which often involved frequent sedation; holding in a highly artificial situation with extensive exposure to humans and, in some instances, domesticated animals; and release in unfamiliar, but rich, habitat. It is not our pur- pose to attempt to determine why this combination of measures failed. However, the data presented here indicate that it failed to result in the rehabilitation of captured sea otters. Thus, because there are no data available that indicate that rehabilitation can be accomplished, we suggest that in future discussions the centers that were established be referred to as treatment centers rather than rehabilitation centers, and the released otters be referred to as treated otters, not rehabilitated otters. This distinction is not simply semantic; it is critical. The implication from the word rehabilitate is that if the otters in the rehabilitation centers were damaged, for whatever reason, the damage could be, and was, fixed. To imply such an ability, if no such ability exists, tends to mollify the public's and policymakers' concerns by providing a false sense of security about our ability to mend what we break.

We recommend that the entire strategy of focusing on oiled animals undergo careful reconsideration. Alternative strategies that are more likely to result in the long-term health and viability of sea otter populations include the following, listed in order of priority: (1) prevention of oil spills; (2) protection of critical habitats and areas of high population density, in the event of a spill, with concurrent minimization of disturbance in such areas; (3) preemptive capture of individuals in the path of a spill, with removal of the unoiled animals to natural, barricaded, remote habitats where natural food items are supplemented and in which human contact is minimal. All of these strategies emphasize preventing otters from becoming oiled, rather than trying to treat animals after oiling. All are feasible in certain situations. For example, it is clear from the success enjoyed by those involved in commercial fisheries in Cordova, Alaska, in their attempts to protect hatcheries and fish streams, that many of the critical sea otter habitat areas in western PWS could have been effectively protected with booms during the T/N Exxon Valdez spill. Additionally, these strategies keep sea otters out of highly captive situations and away from people.

Our viewpoint is that captivity, in and of itself, poses serious dangers to the specific otters brought in, to the population exposed to capture procedures during an oil spill, and to the population into which the otters are released. Factors contributing to captivity risk are (1) stress-during capture (particularly by inexperienced personnel, some of whom chased sea otters during "rescue efforts" for periods in excess of $1 \mathrm{~h}$, [M. DeVille, Cordova, 
Alaska, personal communication]), during captivity (e.g., Geraci and Smith [1976] documented a dramatic difference in the survival of oiled seals held indoors versus those in pens in a natural situation), and during translocation; (2) diseasecontracted from humans or domesticated animals, which risks the captive population and eventually, through release, the wild population (Spraker 1990); (3) separation of mother-pup pairs (Ames 1990); and (4) disruption of the natural learning processes of young animals.

Holding otters captive, then releasing them back into the wild, should be viewed as an option that may result in the death of many captive and wild individuals. Hence, such an action is a measure of last resort and should be taken only with extreme caution. Unless it can be demonstrated that treatment will be effective and that the risk of spreading disease to the wild population will be eliminated, capture and housing policies such as those after the T/V Exxon Valdez oil spill should not be repeated. Avoiding oiling and captivity are more promising strategies.

In conclusion, despite the tremendous amount of resources invested in the attempted rehabilitation of sea otters after the T/N Exxon Valdez oil spill, indications are that survival was reduced and behavior was, at least temporarily, abnormal-hence, rehabilitation did not occur.

\section{Acknowledgments}

We are grateful to K. Balog, A. Doroff, and S. Ranney for assistance with radiotelemetry. We thank K. Bayha, A. DeGange, J. Nickles, P. Oswalt, L. Pank, and G. Sonnevil for assistance with logistics and contract administration. We thank K. Bayha, J. Nickles, L. Pank, A. Rappoport, S. Shane, and G. VanBlaricom for reading and providing helpful comments on various drafts of the manuscript. We thank the Alaska Fish and Wildlife Research Center of the U.S. Fish and Wildlife Service, and the Alaska Department of Fish and Game for generously providing office space and other office-related support in Anchorage and Cordova, respectively.

This research was supported by funds from the U.S. Fish and Wildlife Service through cooperative agreements between the Alaska Fish and Wildlife Research Center and Alaska Pacific University (contract 14-16-0009-88-962) and the Prince William Sound Science Center (contract
14-16-0007-90-7717) and by personal funds lent by most of the authors.

\section{References}

Ames, J. 1990. Impetus for capturing, cleaning, and rehabilitating oiled or potentially oiled sea otters after the T/N Exxon Valdez oil spill. Pages 137-141 in K. Bayha and J. Kormendy, tech. coords. Sea Otter Symposium: Proceedings of a symposium to evaluate the response effort on behalf of sea otters after the T/N Exxon Valdez oil spill into Prince William Sound, Anchorage, Alaska, 17-19 April 1990. U.S. Fish Wildl. Serv., Biol. Rep. 90(12).

Bingham, E., R. P. Trosset, and D. Warshawky. 1980. Carcinogenic potential of petroleum hydrocarbons. A critical review of the literature. J. Environ. Pathol. Toxicol. 3:483-583.

Bui, Q.Q., M. B. Tran, and W. L. West. 1986. A comparative study of the reproductive effects of methadone and benzo[a]pyrene in the pregnant and pseudopreg. nant rat. Toxicology 42:195-204.

Currie, A. R., C.C. Bird, A. M. Crawford, and P. Sims. 1970. Embryopathic effects of 7,12-dimethylbenz[a]anthracene and its hydroxymethyl derivatives in the Sprague-Dawley rat. Nature 226:911 914.

Garshelis, D. L., and D. B. Siniff. 1983. Evaluation of radiotransmitter attachments for sea otters. Wildl. Soc. Bull. 11:378-383.

Geraci, J. R. 1988. Physiologic and toxicologic effects on sea otters. Pages 216-224 in J. R. Geraci and D. J. St. Aubin, eds. Synthesis of effects of oil on marine mammals. Department of Interior, Minerals Management Service, Atlantic OCS Region. vii + 292 pp.

Geraci, J. R., and T. G. Smith. 1976. Direct and indirect effects of oil on ringed seals (Phoca hispida), of the Beaufort Sea. J. Fish Res. Board Can. 33:1976-1984.

Harris, R. K., R. B. Moeller, T. P. Lipscomb, R. J. Haebler, P. A. Tuomi, C. R. McCormick, A. R. Degange, D. Mulcahy, T. D. Williams, and J. M. Pletcher. 1990. Identification of a herpes-like virus in sea otters during rehabilitation after the T/V Exxon Valdez oil spill. Pages 366-368 in K. Bayha and J. Kormendy, tech. coords. Sea Otter Symposium: Proceedings of a symposium to evaluate the response effort on behalf of sea otters after the T/N Exxon Valdez oil spill into Prince William Sound, Anchorage, Alaska, 17-19 April 1990. U.S. Fish Wildl. Serv., Biol. Rep. 90(12).

Haebler, R., R. Wilson, and C. R. McCormick. 1990. Determining health of rehabilitated sea otters before release. Pages 390-393 in K. Bayha and J. Kormendy, tech. coords. Sea Otter Symposium: Proceedings of a symposium to evaluate the response effort on behalf of sea otters after the T/N Exxon Valdez oil spill into Prince William Sound, Anchorage, Alaska, 17-19 April 1990. U.S. Fish Wildl. Serv., Biol. Rep. 90(12). 
Kenyon, K. W. 1969. The sea otter in the eastern Pacific Ocean. U.S. Fish Wildl. Serv., N. Am. Fauna 68. $352 \mathrm{pp}$.

Lensink, C. J. 1962. The history and status of sea otters in Alaska. Unpubl. Ph.D. thesis, Purdue University, Lafayette, Indiana. $186 \mathrm{pp}$.

Monnett, C. 1988. Patterns of movement, postnatal development and mortality of sea otters in Alaska. Ph.D. thesis, University of Minnesota, Minneapolis. ix +134 pp.

Monnett, C., and L. M. Rotterman. 1988. Movement patterns of adult female and weanling sea otters in Prince William Sound, Alaska. Pages 133-161 in D. B. Siniff and K. Ralls, eds. Population status of California sea otters. Department of Interior, Minerals Management Service, Pacific OCS Region. xxiv + $368 \mathrm{pp}$.

Spraker, T. 1990. Hazards of releasing rehabilitated animals with emphasis on sea otters and the $\mathrm{T} / \mathrm{V}$ Exxon Valdez oil spill. Pages 385-389 in K. Bayha and J. Kormendy, tech. coords. Sea Otter Symposium:
Proceedings of a symposium to evaluate the response effort on behalf of sea otters after the T/V Exxon Valdez oil spill into Prince William Sound, Anchorage, Alaska, 17-19 April 1990. U.S. Fish Wildl. Serv., Biol. Rep. 90(12).

St. Aubin, D. J. 1988. Physiologic and toxicologic effects on pinnipeds. Pages 120-142 in J. R. Geraci and D. J. St. Aubin, eds. Synthesis of effects of oil on marine mammals. Department of Interior, Minerals Management Service, Atlantic OCS Region. vii + 292 pp.

Williams, T. M., J. McBain, R. Wilson, and R. Davis. 1990. Clinical evaluation and cleaning of sea otters affected by the T/N Exxon Valdez oil spill. Pages 236-257 in K. Bayha and J. Kormendy, tech. coords. Sea Otter Symposium: Proceedings of a symposium to evaluate the response effort on behalf of sea otters after the T/N Exxon Valdez oil spill into Prince William Sound, Anchorage, Alaska, 17-19 April 1990. U.S. Fish Wildl. Serv., Biol. Rep. 90(12). 
Appendix. Locations of radio fixes taken over the first 20 days of observation on instrumented sea otters (Enhydra lutris) released into eastern Prince William Sound. Otters were captured, transported to, treated in, and held in treatment centers established in response to the 24 March $1989 \mathrm{~T} / \mathrm{V}$ Exxon

Valdez oil spill. Numerals on each map indicate the day the radiolocation was obtained after the day of release.

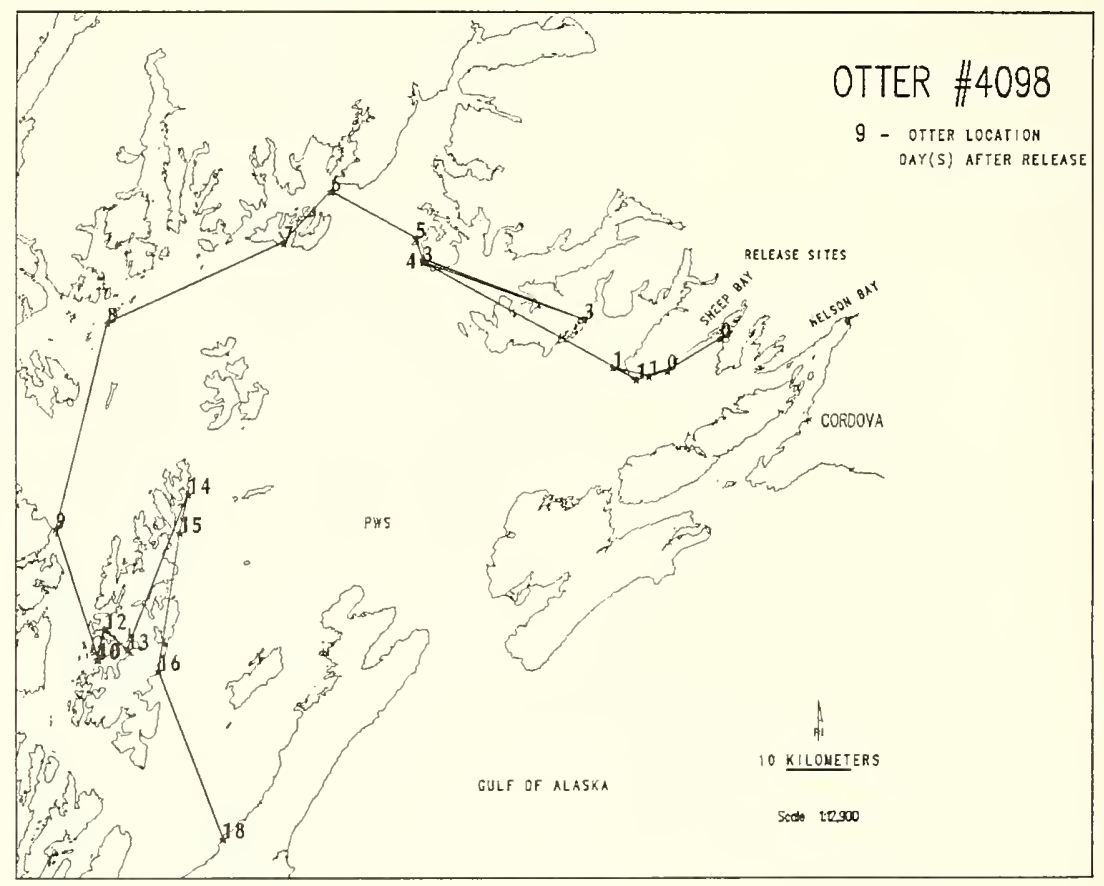


C. MONNETT ET AL

411
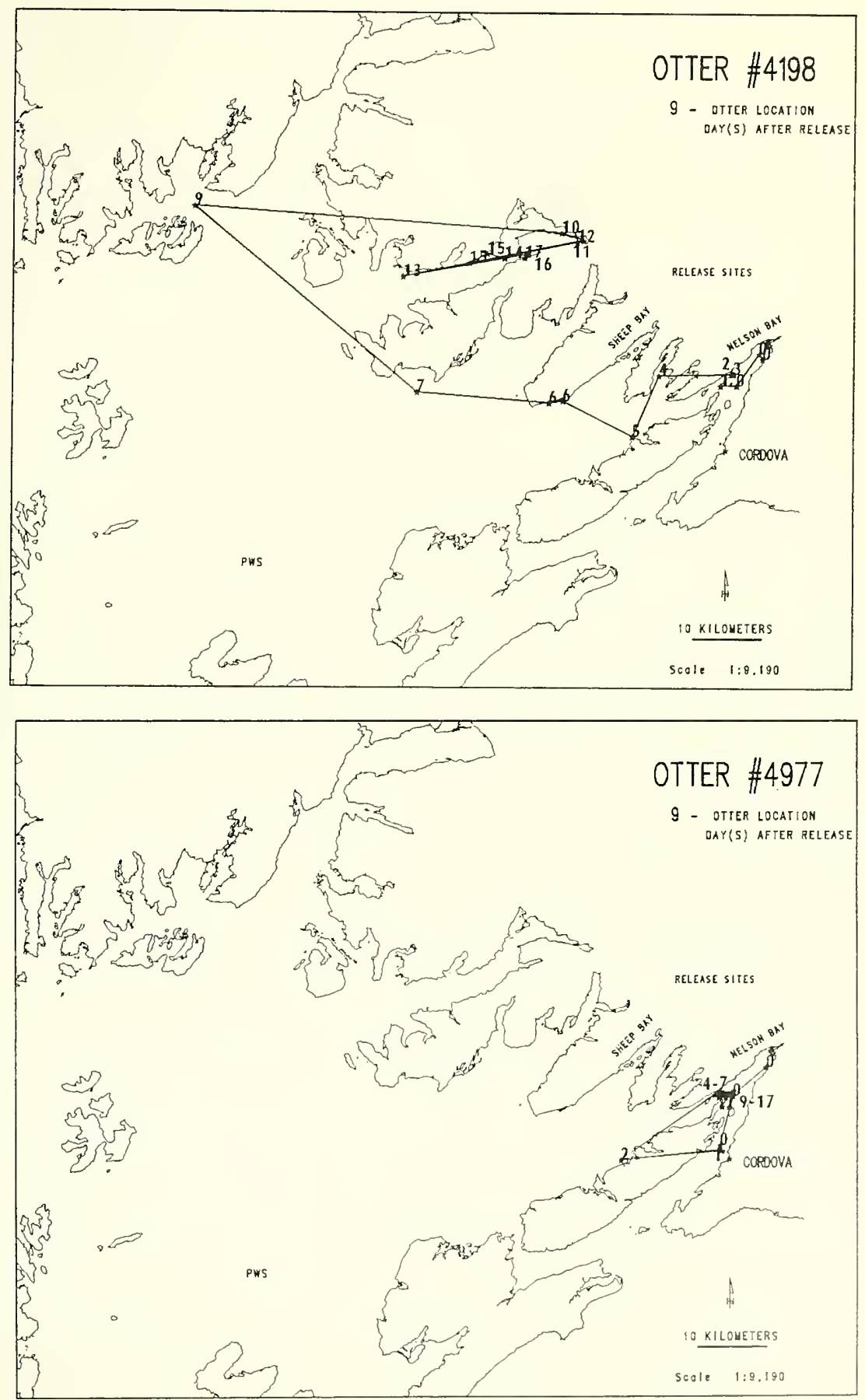

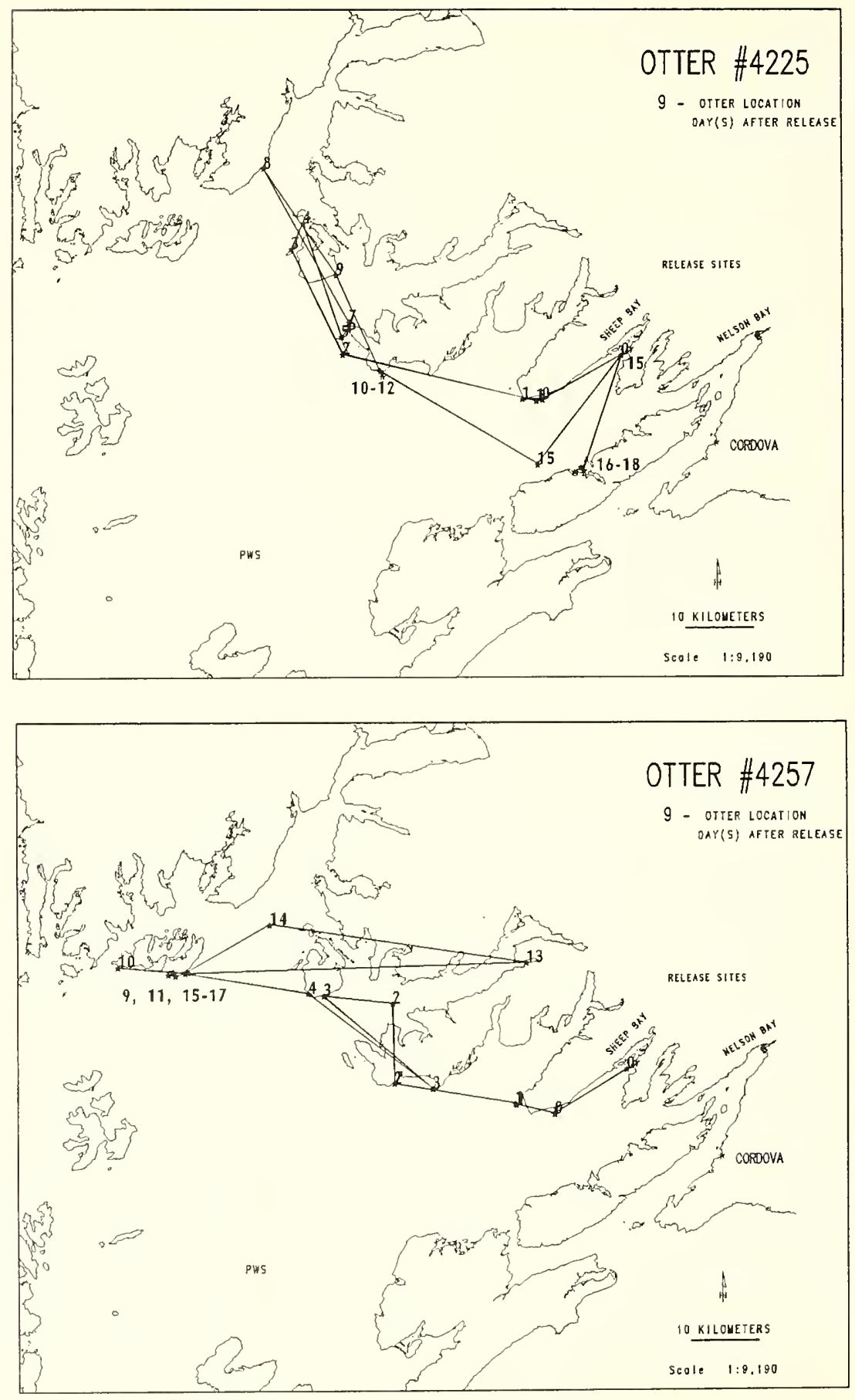
C. MONNETT ET AL

413
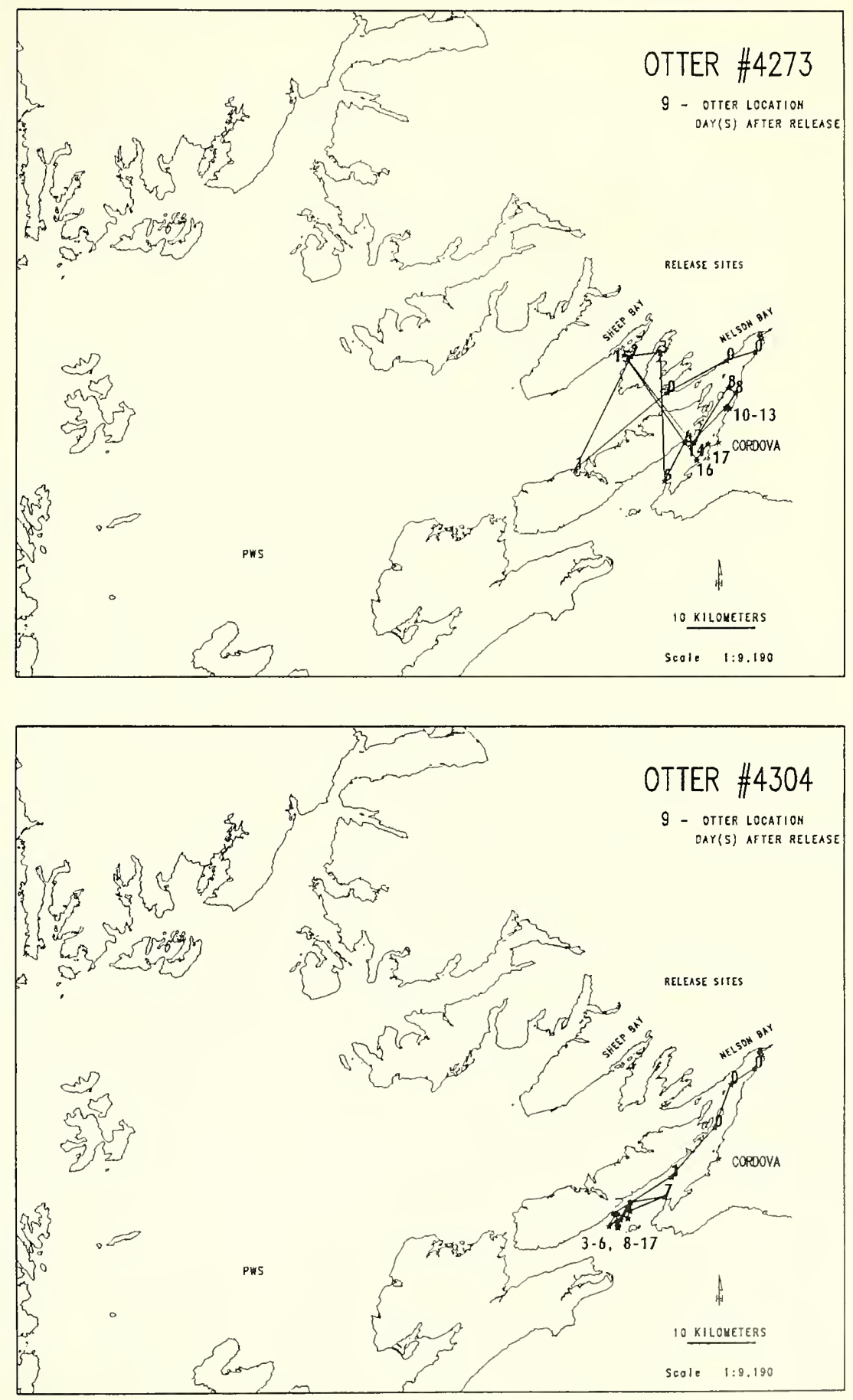

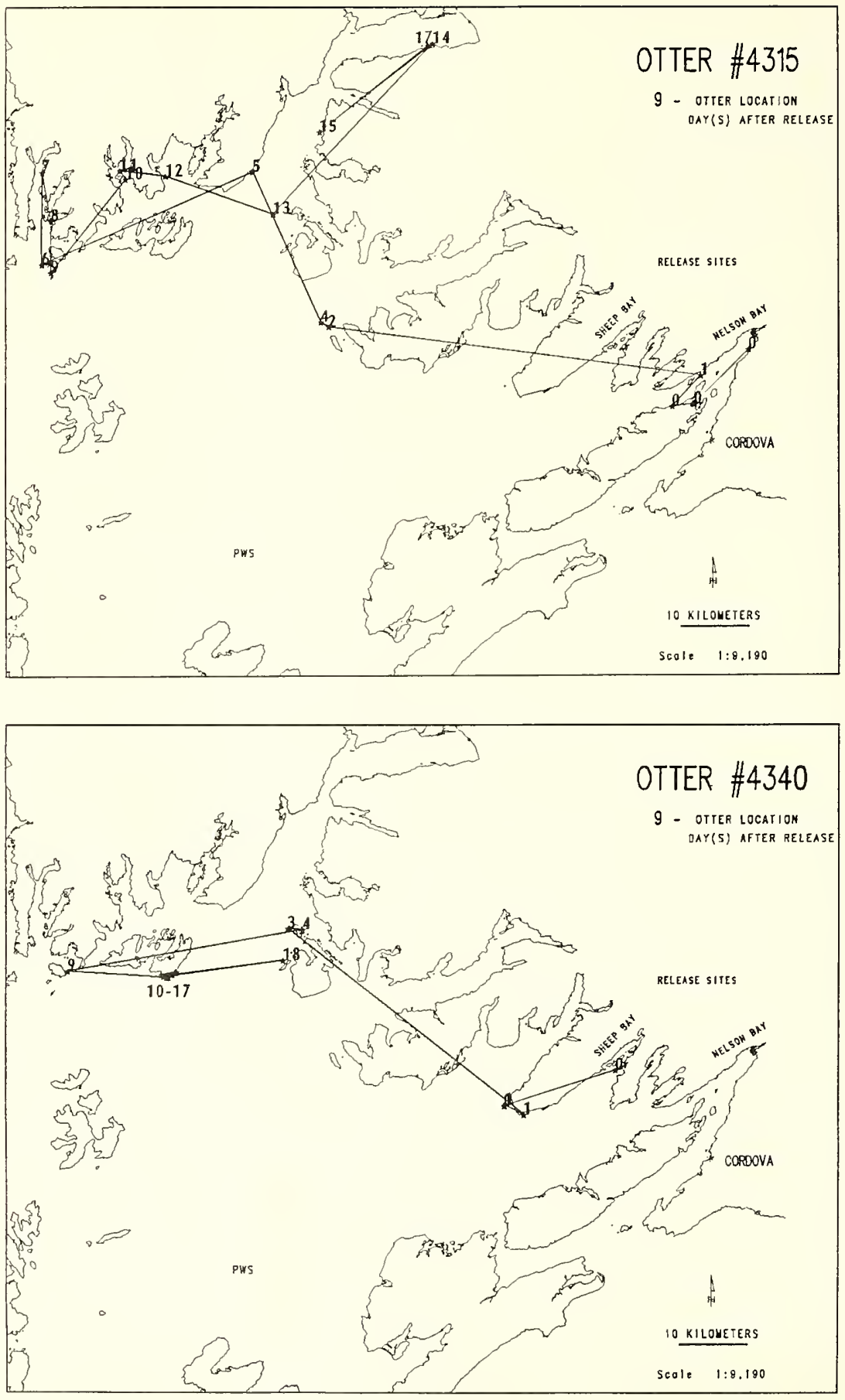

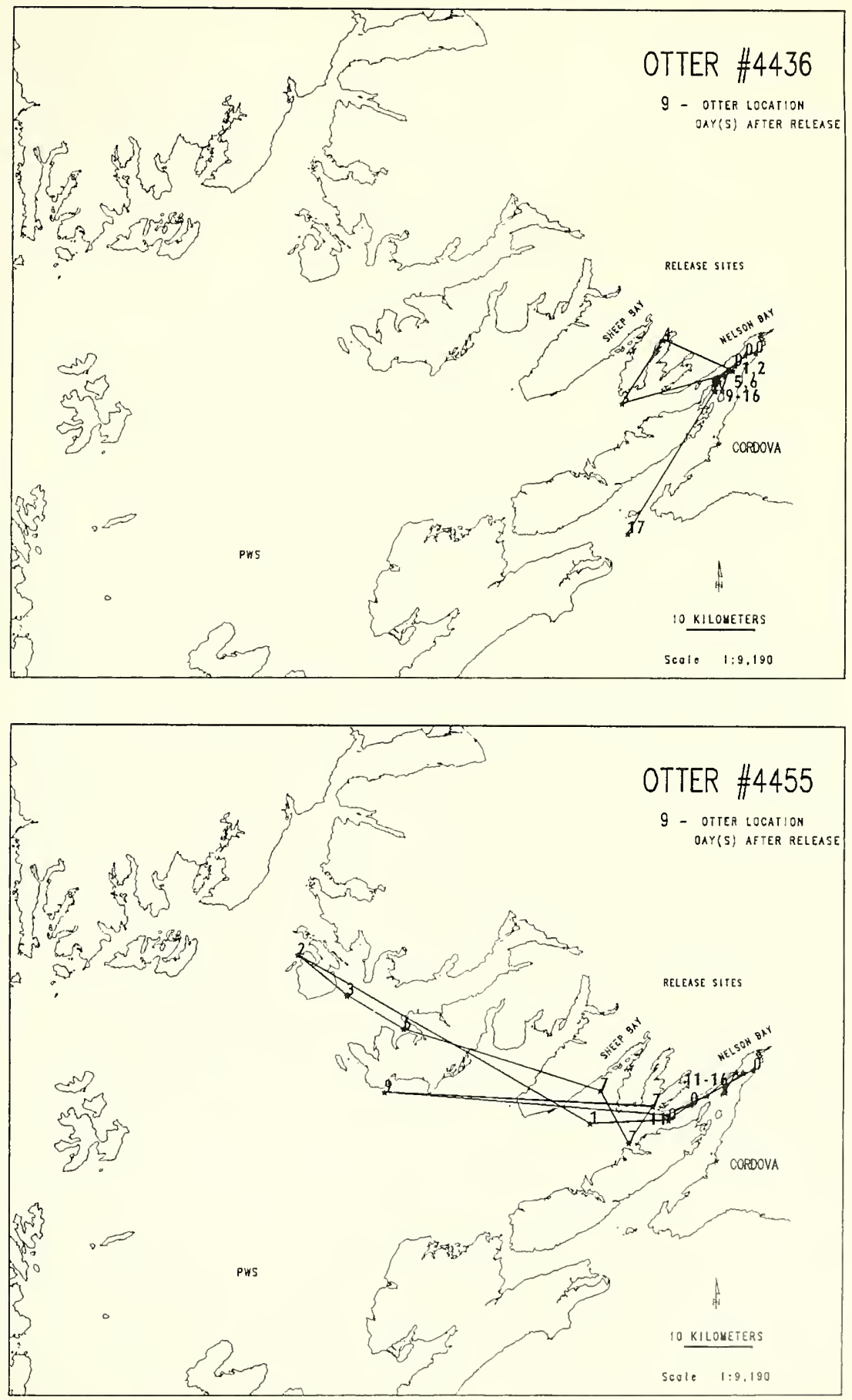

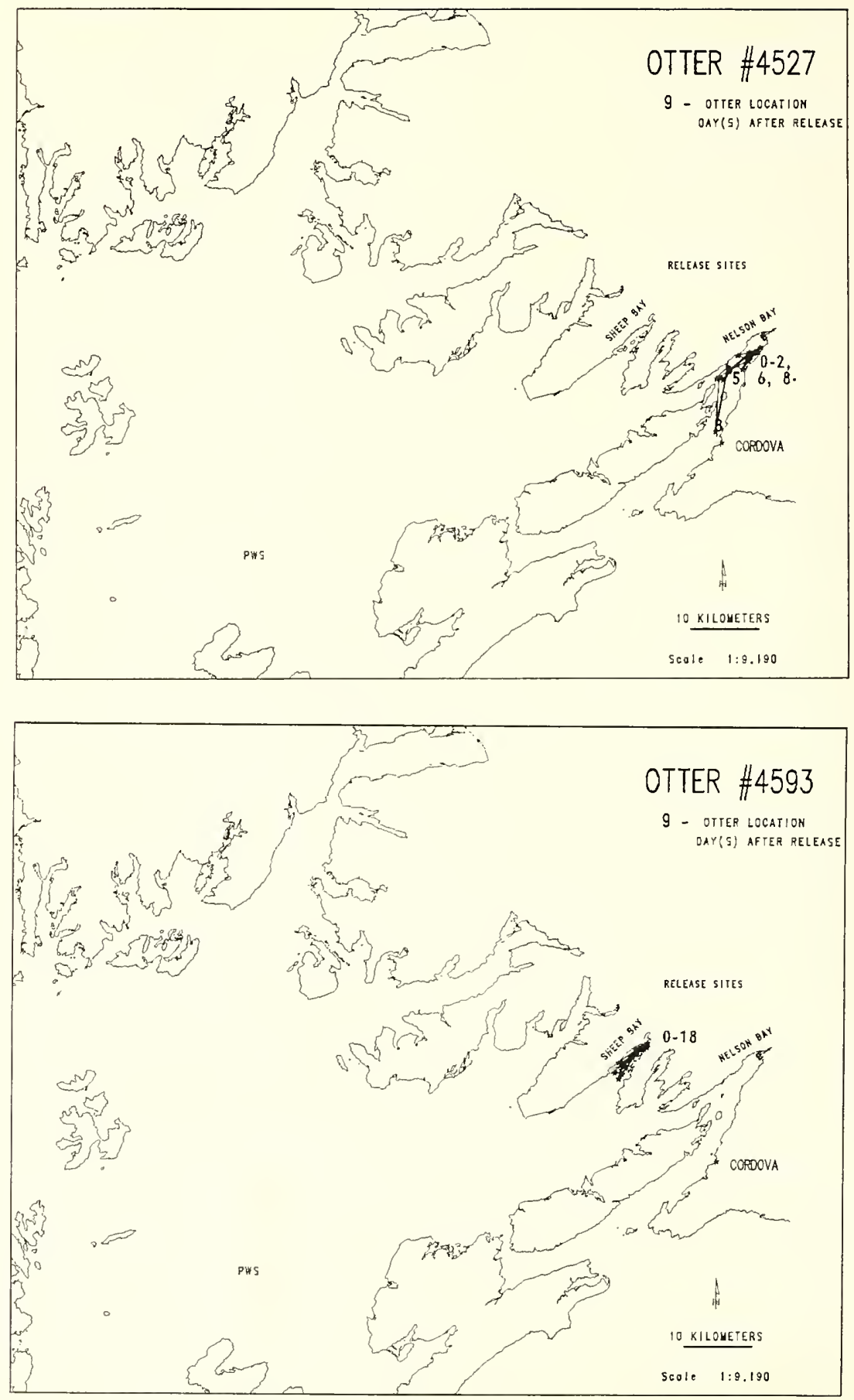

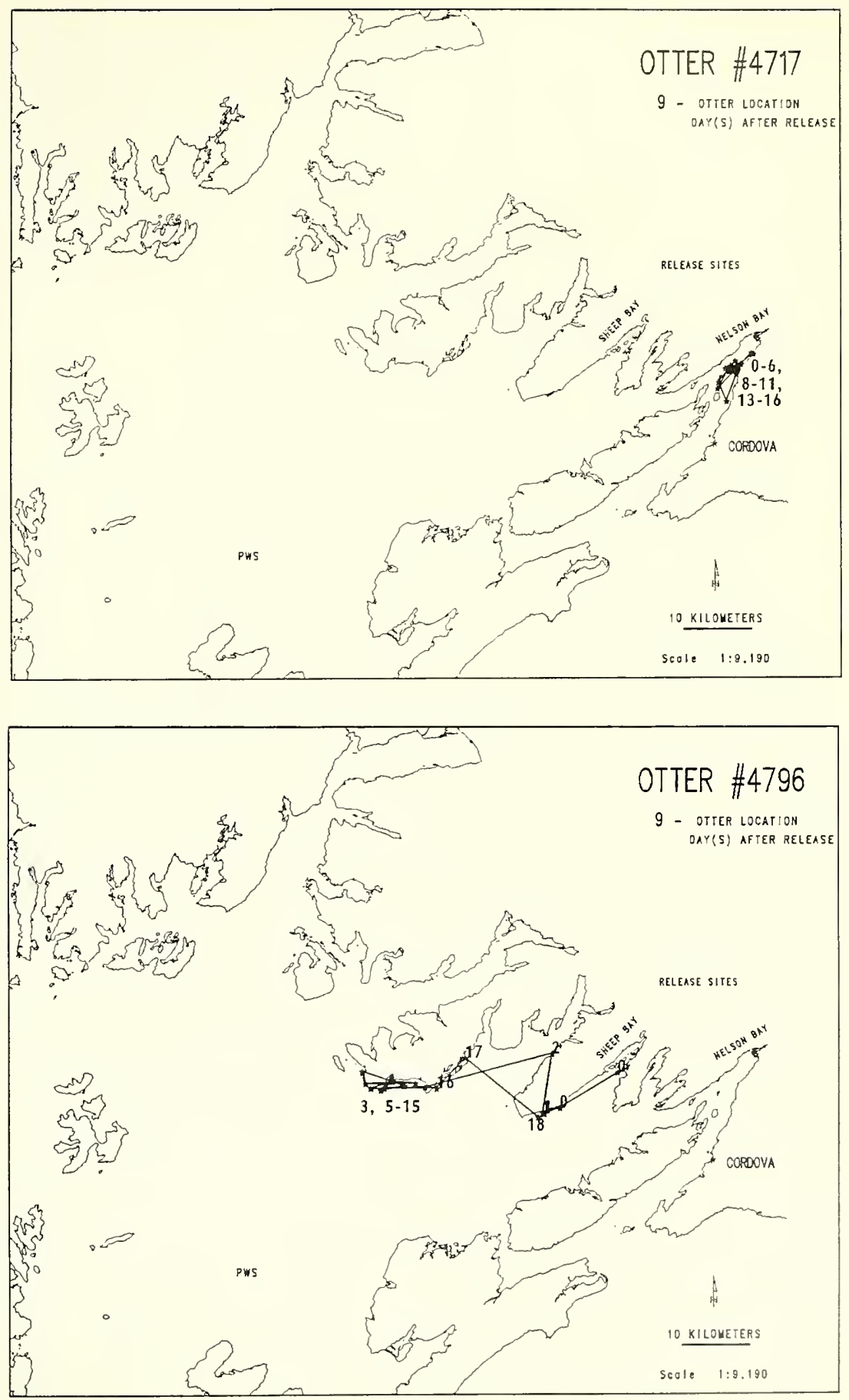

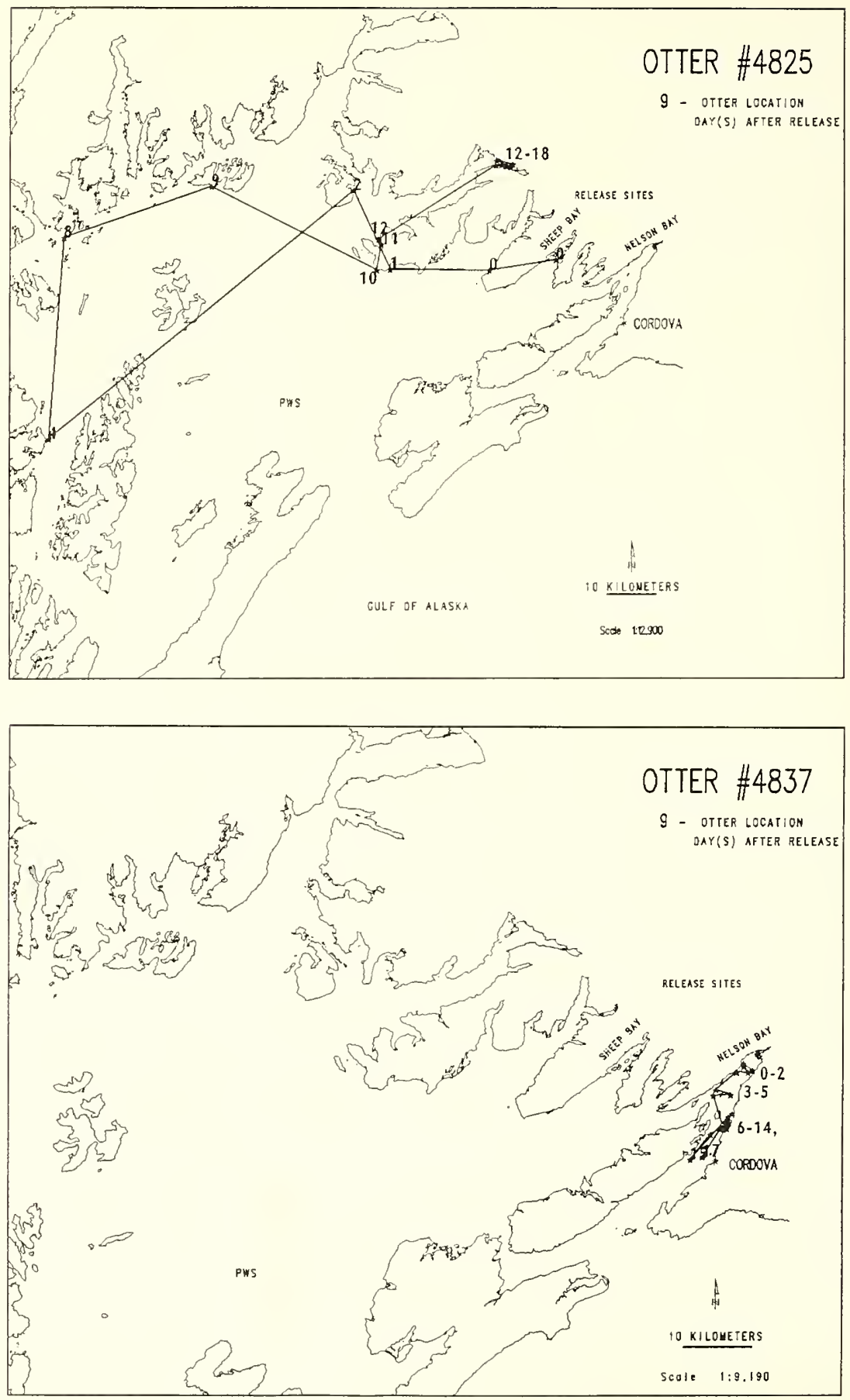

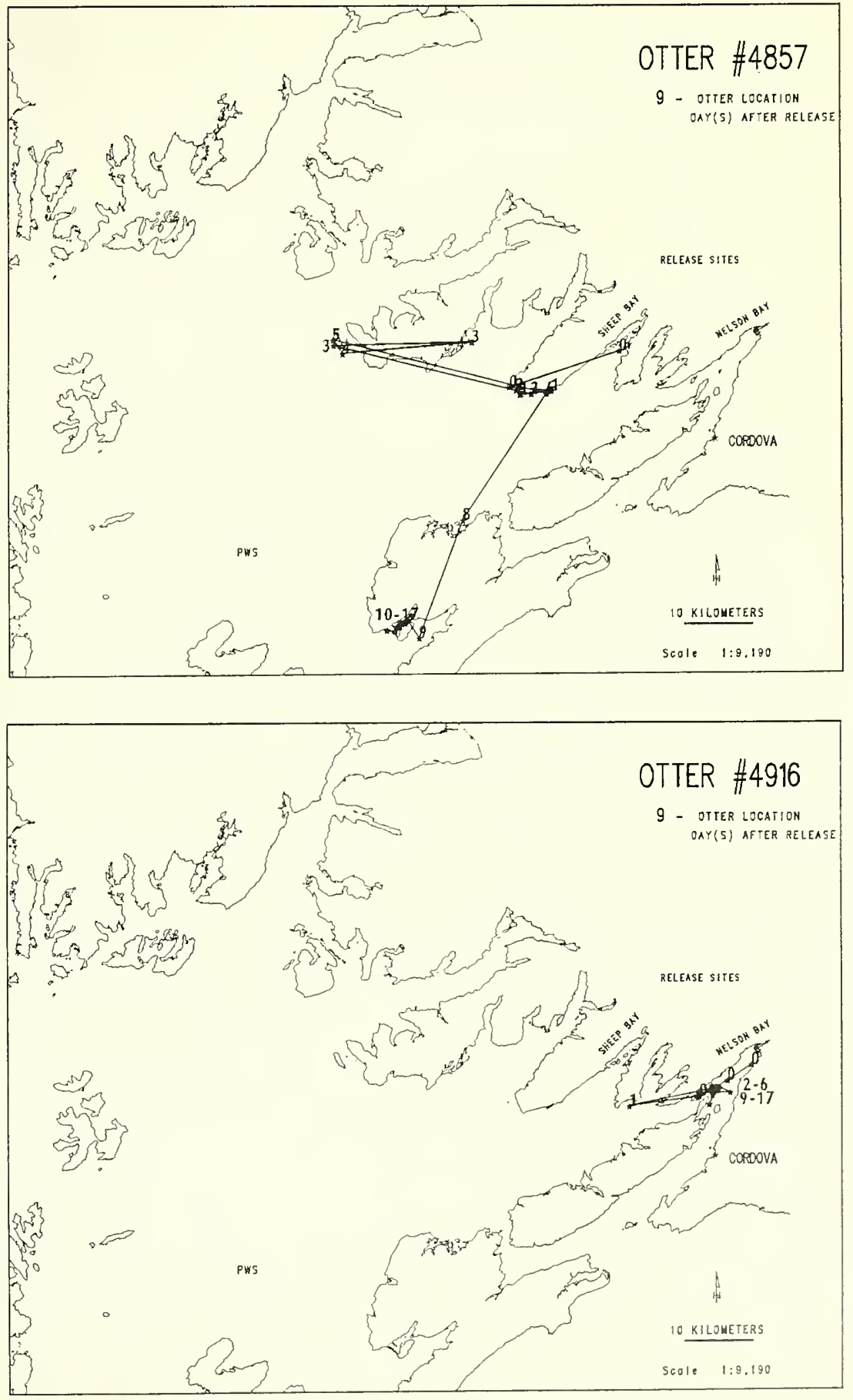
420 BIOLOGICAL REPORT 90(12)
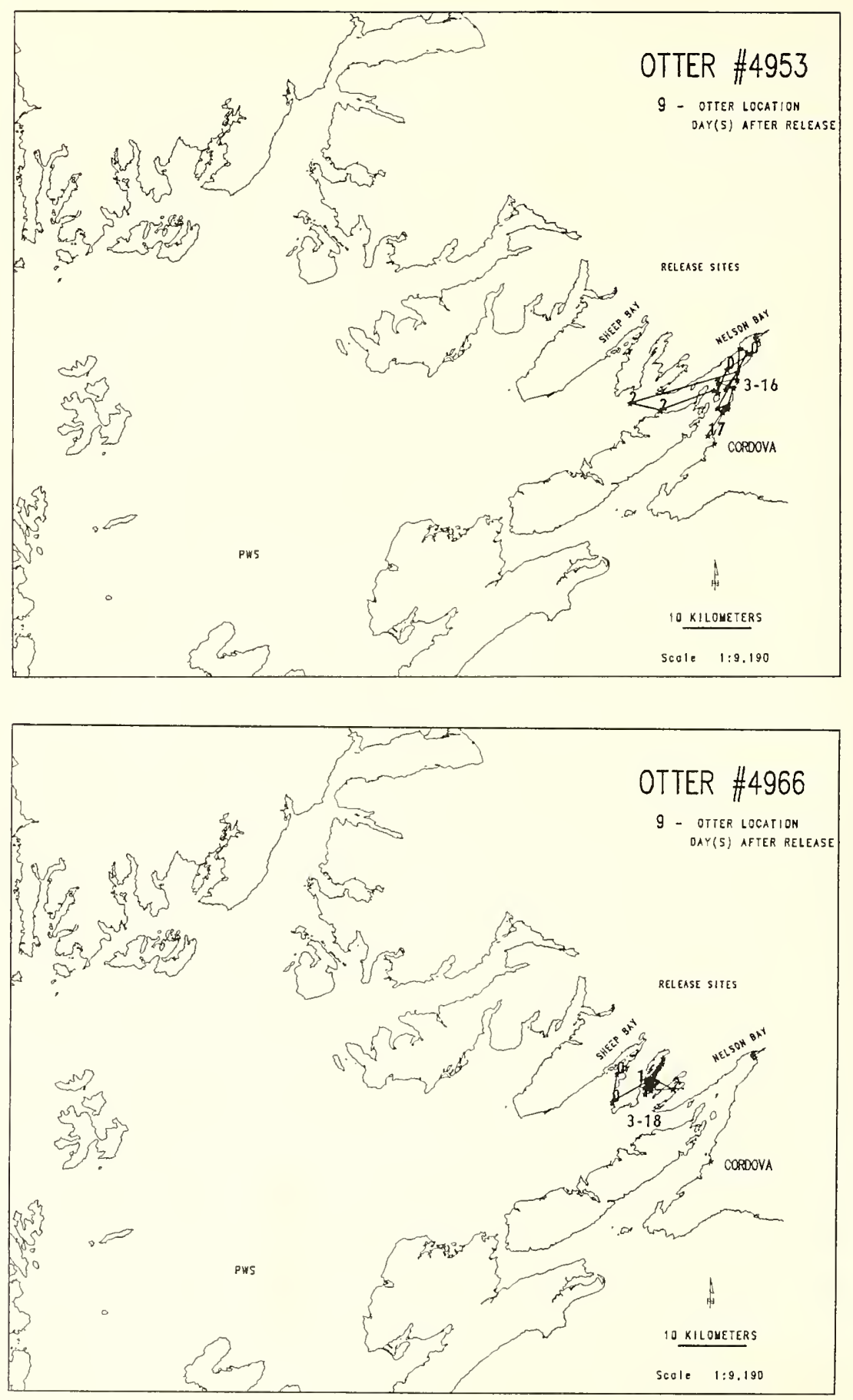


\title{
Sea Otter Release Site Selection and Postrelease Activities Along the Kenai Peninsula, Alaska
}

by

\author{
E. Sharpe \\ U.S. Fish and Wildlife Service \\ 1011 E. Tudor Road \\ Anchorage, Alaska 99503
}

\begin{abstract}
Consistent with the U.S. Fish and Wildlife Service's release policy, 99 sea otters (Enhydra lutris) affected by the T/V Exxon Valdez oil spill in Prince William Sound, Alaska, were released in clean-water habitats along the outer coast of the Kenai Peninsula. Several factors were used to select these release sites. After selecting release sites, flipper-tagged otters were released and observed for up to 2 weeks to determine if they remained at the release sites or relocated. The first week of monitoring was spent in the release areas to establish if the otters remained. Most of the second week was spent at the main capture sites to determine if the otters returned. Monitoring of flipper-tagged otters proved difficult because of the poor visibility of the tarnished brass-colored tags used.
\end{abstract}

Because of the T/V Exxon Valdez oil spill on 24 March 1989, 445 sea otters (Enhydra lutris) were captured from Prince William Sound westward to Chignik Village on the Alaska Peninsula. Of the 445,357 were processed through the rehabilitation centers. One hundred ninety-seven otters were released or escaped from rehabilitation centers; of these, 99 were released in waters off the Kenai Peninsula, and 98 were released in Prince William Sound. Most of the otters released along the Kenai Peninsula were captured in this area. The reasons for releasing the rehabilitated otters in the Kenai Peninsula and Prince William Sound areas are covered in papers by Rappoport et al. (1990) and Monnett and Rotterman (1990).

\section{Methods}

\section{Release Site Selection}

Two vessels were employed to survey and determine otter release sites. These two vessels were the F/ Roman E from Homer and the MN Breaktime from Seward. Potential release sites were surveyed from 10 to 15 August 1989 by the Roman $E$ and the Breaktime. The Roman $E$ surveyed the west side of the Kenai Peninsula from Flat Island to Gore Point. The Breaktime surveyed the east side of the Kenai Peninsula from Harris Bay to Gore Point (Fig. 1).

Selection factors applied in evaluating potential release sites were (1) areas free of oil contamination with water depths at least 20 fathoms, (2) sea otters present (establish whether male or female groups), (3) kelp beds or other indicators of food supply, (4) suitable helicopter landing sites, (5) weather security (resting and storm protection) of the area, (6) water quality, (7) suitable habitat adjacent to the release site to allow for movement out of sites, (8) greatest distance from significant oiled areas, (9) opportunity for postrelease observations, and (10) areas subject to least human contact and interference.

Surveys were conducted using a small Zodiak, a Traktor Jet skiff, and the main vessels. Observations were made with binoculars. A spotting scope was used when making observations from land. Each potential site was surveyed completely from offshore, and at most sites surveyors went ashore to check for presence of oil and to investigate potential helicopter landing areas. Number of otters using an area was determined by following the shoreline and counting each otter observed. 


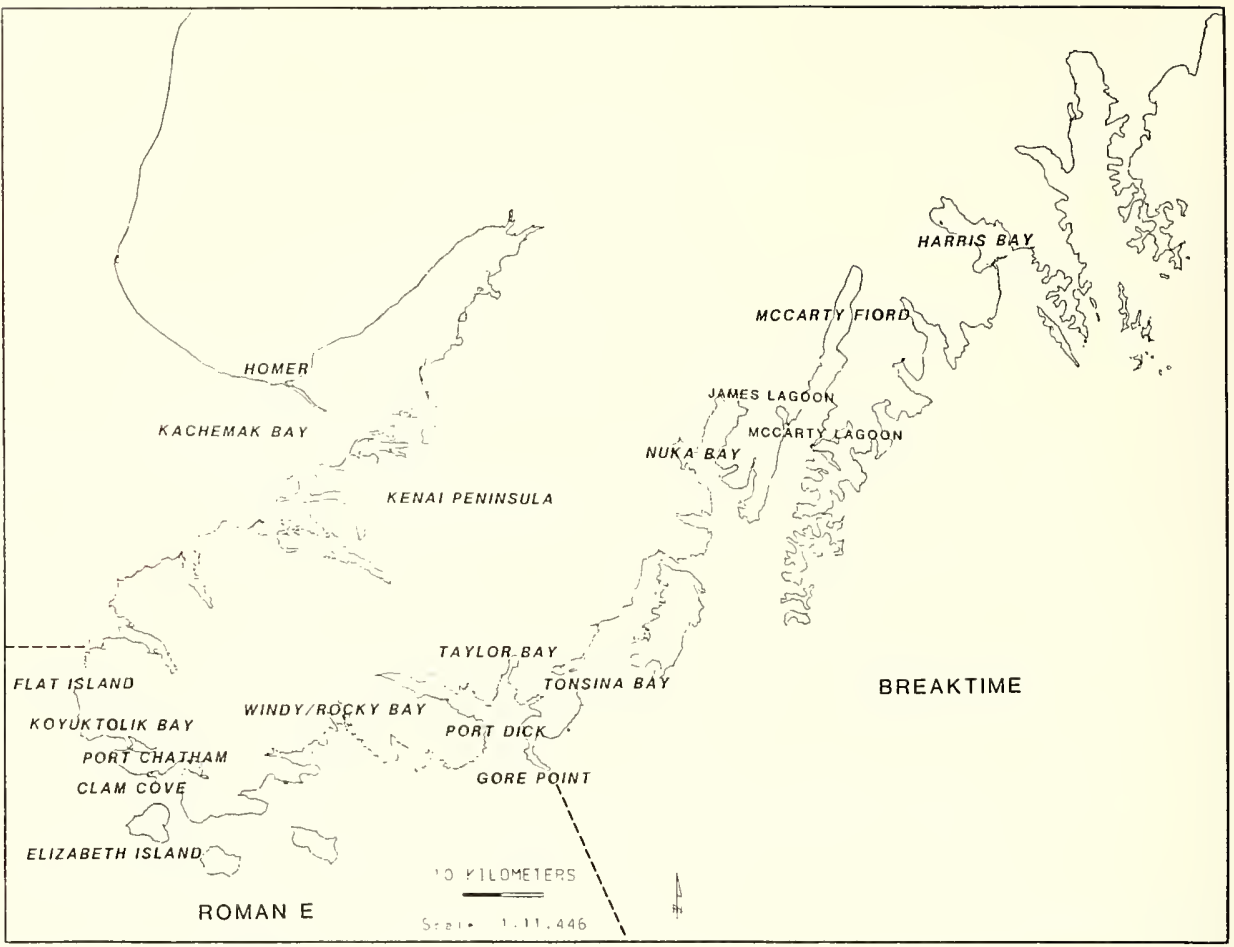

Fig. 1. Areas surveyed for release sites of sea otters (Enhydra lutris) by the crew of the M/V Breaktime.

On 16 August, crew leaders met with U.S. Fish and Wildlife Service personnel; five areas were chosen as release sites. The release of otters on the Kenai Peninsula was carried out from 17 August through 21 August. Most released otters received tarnished, brass-colored tags on both flippers; some received a tag only on the right flipper.

\section{Postrelease Observations}

After release, flipper-tagged otters were monitored for up to 2 weeks to establish if any mortality occurred, if they left the release site and, if so, if they return to the area where they were originally captured? Each otter observed was recorded as definitely having a tag, definitely not having a tag, or unable to determine whether it was tagged.

The F/ Roman $E$ was in Taylor Bay on $17 \mathrm{Au}$ gust for the release of the first group of otters. The crew observed the otters' movements from a dis- tance in order to not interfere with the animals' movements. The Roman $E$ stayed in Taylor Bay from 17 August to 19 August. On the evening of 19 August, the F/ Roman $E$ traveled around Gore Point, and on 20 and 21 August, surveyed the North Arm of Nuka Bay. On 22 August, Tonsina Bay was surveyed. The Roman $E$ then traveled west around Gore Point to the Windy-Rocky Bay area to estimate the number of flipper-tagged otters that might have returned. This area was surveyed from 23 August to 30 August. On 2 September, the F/N Roman $E$ returned to Homer.

The principal area monitored for tagged animals by the M/V Breaktime was James Lagoon, which was the most suitable site for shoreside observations, and the site where the rehabilitated otters were reintroduced to McCarty Arm. The McCarty Lagoon area was also monitored almost daily to locate any tagged animals that may have moved from James Lagoon. 
The M/V Breaktime crew remained in the James Lagoon and McCarty Lagoon areas to observe otters until 26 August; then the vessel traveled to Tonsina Bay to look for tagged sea otters and evidence of oil. The M/V Breaktime crew surveyed Harris Bay near the moraine and Northwestern Lagoon on 29 August 1989, en route to Seward.

The bird-monitoring boat Hasta assisted in monitoring the release of otters on 21-22 August. The areas covered in the postrelease observations for the M/N Breaktime, F/V Roman E, and Hasta are shown in Fig. 2.

\section{Results}

\section{Release Site Selection}

After inspection, the areas on the east side of the Kenai Peninsula that fulfilled the requirements of the main selection factors were the West and North arms of Nuka Bay, McCarty Arm of Nuka Bay, Harris Bay, and Aialik Bay. On the west side of the Kenai Peninsula, Dogfish Bay in Koyuktolik Bay, Clam Cove on the outside portion of Port Chatham, the cove in the back portion of Port Chatham, and Taylor Bay at the most northerly portion of Port Dick were chosen as the best-suited areas for otter release. The selection criteria and rankings of potential release sites for the east and west sides of the Kenai Peninsula are presented in Table 1.

Otter abundance was considered an indicator of good habitat conditions in general. The number and, when possible, the sex of otters in each potential release site were recorded (Table 2).

Service personnel used information gathered during prerelease surveys to develop a plan at a meeting in Homer. This plan established the final release sites, which otters would be released together, and the number of otters to be released at each site (Table 3). Based on recommendations

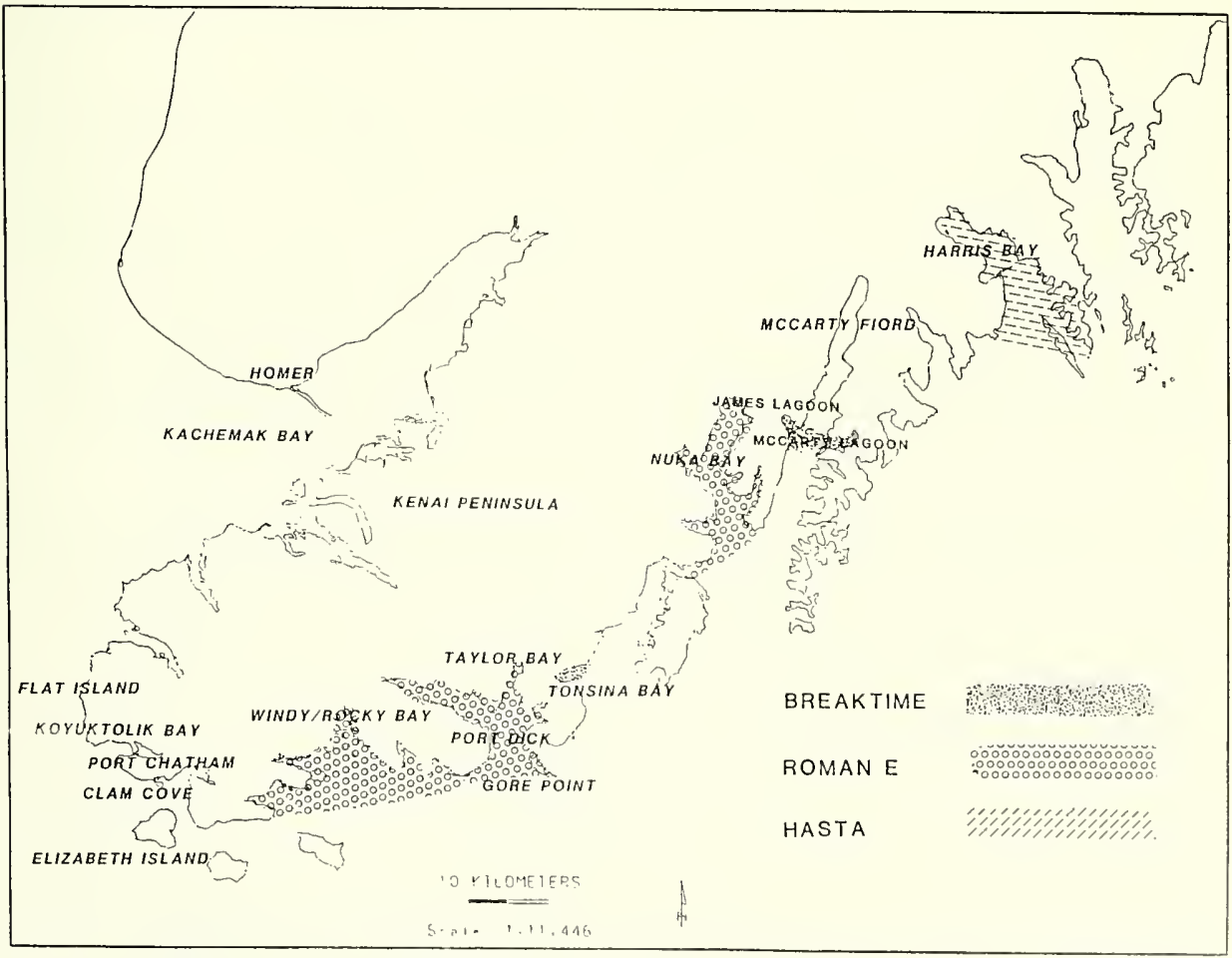

Fig. 2. Areas surveyed in postrelease monitoring of sea otters (Enhydra lutris) by the crews of the M/V Breaktime, F/N Hasta, and the F/ Roman E. 
Table 1. Comparison of potential sea otter (Enhydra lutris) release sites.

\begin{tabular}{|c|c|c|c|c|c|c|c|c|}
\hline $\begin{array}{l}\text { Criteria (Value: } \\
\text { 4=greatest, } \\
\text { 1=least) }\end{array}$ & $\begin{array}{l}\text { Nuka } \\
\text { Bay }\end{array}$ & $\begin{array}{l}\text { McCarty } \\
\text { Arm }\end{array}$ & $\begin{array}{c}\text { Harris } \\
\text { Bay }\end{array}$ & $\begin{array}{c}\text { Aialik } \\
\text { Bay }\end{array}$ & $\begin{array}{l}\text { Dogfish } \\
\text { Bay }\end{array}$ & $\begin{array}{l}\text { Clam } \\
\text { Cove }\end{array}$ & $\begin{array}{l}\text { Pt. Chatham } \\
\text { Cove }\end{array}$ & $\begin{array}{c}\text { Taylor } \\
\text { Bay }\end{array}$ \\
\hline $\begin{array}{l}\text { Amount of shoal and } \\
\text { areas of moderate } \\
\text { depth (0-20 fathoms) }\end{array}$ & 2 & 4 & 3 & 1 & 2 & 2 & 3 & 3 \\
\hline Amount of kelp ${ }^{a}$ & 3 & 4 & 2 & 1 & 1 & 2 & 1 & 1 \\
\hline $\begin{array}{l}\text { The most weather-se- } \\
\text { cure area (resting and } \\
\text { storm protection) }\end{array}$ & 2 & 4 & 3 & 1 & 3 & 1 & 3 & 3 \\
\hline $\begin{array}{l}\text { Apparent water qual- } \\
\text { ity (e.g., turbidity, gla- } \\
\text { cial inflow, and water } \\
\text { temperature) }\end{array}$ & 3 & 4 & 2 & 1 & 2 & 2 & 2 & 3 \\
\hline $\begin{array}{l}\text { Suitable habitat in } \\
\text { areas adjacent to re- } \\
\text { lease site }\end{array}$ & 3 & 4 & 2 & 1 & 2 & 2 & 2 & 3 \\
\hline $\begin{array}{l}\text { Distance from signifi- } \\
\text { cantly oiled areas }\end{array}$ & 1 & 2 & 4 & 3 & 3 & 2 & 2 & 2 \\
\hline $\begin{array}{l}\text { Opportunity for } \\
\text { postrelease observa- } \\
\text { tions }\end{array}$ & 2 & 4 & 3 & 1 & 3 & 2 & 3 & 3 \\
\hline $\begin{array}{l}\text { Area subject to least } \\
\text { human contact and in- } \\
\text { terference }\end{array}$ & 4 & 3 & 2 & 1 & 2 & 1 & 1 & 3 \\
\hline $\begin{array}{l}\text { Number of otters pres- } \\
\text { ently using areas }\end{array}$ & 2 & 4 & 3 & 1 & 1 & 1 & 1 & 2 \\
\hline $\begin{array}{l}\text { Suitable sites for heli- } \\
\text { copter landing }\end{array}$ & yes & yes & yes & yes & yes & yes & yes & yes \\
\hline Total & 22 & 33 & 24 & 11 & 19 & 15 & 18 & 23 \\
\hline
\end{tabular}

Kelp is considered both a resting place and an indicator of habitat productivity.

${ }^{\mathrm{b}}$ Otter abundance is considered an indicator of habitat condition in general. Seasonal variations in numbers do occur; thus these comparisons may only be appropriate as of this date. Otter numbers may reflect the effect of oil on populations of otters.

Table 2. Number of sea otters (Enhydra lutris) observed in each potential release site.

\begin{tabular}{lc}
\hline Potential release site & $\begin{array}{c}\text { Number of } \\
\text { otters observed }\end{array}$ \\
\hline West and North arms of Nuka Bay & 39 \\
McCarty Arm of Nuka Bay & 101 \\
Harris Bay & 86 \\
Aialik Bay & 15 \\
Dogfish Bay & 3 \\
Clam Cove & 8 \\
Pt. Chatham Cove & 1 \\
Taylor Bay & 9 \\
Sunday Harbor (in area) & 15 \\
Total & 277 \\
\hline
\end{tabular}

Table 3. Number of sea otters (Enhydra lutris) released along the Kenai Peninsula.

\begin{tabular}{lc}
\hline $\begin{array}{c}\text { Release } \\
\text { area }\end{array}$ & $\begin{array}{c}\text { Number of otters } \\
\text { released }\end{array}$ \\
\hline Taylor Bay & $7^{\mathrm{b}}$ \\
Picnic Harbor & $1^{\mathrm{b}}$ \\
North Arm of Nuka Bay & $7^{\mathrm{a}}$ \\
James Lagoon, McCarty Fiord & $24^{\mathrm{a}}$ \\
Harris Bay & $29^{\mathrm{a}, \mathrm{b}}$ \\
Little Jakolof & $27^{\mathrm{a}}$ \\
Kachemak Bay & $4^{\mathrm{a}}$ \\
Total & 99
\end{tabular}

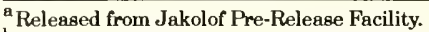

${ }^{b}$ Released from Seward Otter Rehabilitation Center. 
from the Jakolof Pre-Release Facility staff, an effort was made to release otters so that potentially bonded pairs or groups could remain together.

\section{Postrelease Observations}

The otters released on the west side of the Kenai Peninsula consisted of seven animals released in Taylor Bay and one released in Picnic Harbor. On 17 August seven animals, including one mother and pup pair, were released in Taylor Bay. The skiff and main vessel tried to keep track of the otters released while still staying far enough away not to affect their movement. In spite of inclement weather and difficulty in seeing tags, the observers recorded that one otter quickly left the area and moved out of the bay. Two other otters also left the bay, but at a slower pace. These otters could not be followed outside of the bay because of the stormy weather. Four otters, including the mother and pup, stayed behind in the bay. We could see only one tag, and it can only be assumed that the others were tagged animals.
On 18 August, only one otter was still in Taylor Bay. On 19 August, the weather improved, and all of Port Dick was surveyed. Only one flippertagged otter was still in the Port Dick area, and this otter was seen outside Taylor Bay. This otter was observed grooming and eating. The F/V Roman $E$ left Port Dick on the evening of 19 August, and on 20 August its crew surveyed the west and east side of the North Arm of Nuka Bay. On 21 August, the West Arm of Nuka Bay was surveyed. No tagged otters were seen in Nuka Bay. The F/N Roman $E$ traveled to Tonsina Bay on 22 August, and two tagged otters were seen when this area was surveyed. On 23 August, the Roman $E$ traveled to the Windy-Rocky Bay area and stayed until 2 September, when the vessel left the area to return to Homer. While in the WindyRocky Bay area, the crew saw two tagged otters on 24 August, and one tagged female with a pup on 26 August. The complete results of the postrelease surveys conducted by the crew on the F/ $N$ Roman $E$ are presented in Table 4.

Table 4. Roman E Postrelease sea otter (Enhydra lutris) observations.

\begin{tabular}{|c|c|c|c|c|c|c|c|}
\hline Date & Location & $\begin{array}{c}\text { Adult } \\
\text { Unknown }\end{array}$ & $\begin{array}{l}\text { Adult } \\
\text { No tag }\end{array}$ & $\begin{array}{c}\text { Adult } \\
\text { Tagged }\end{array}$ & $\begin{array}{l}\text { Female-pup } \\
\text { Unknown }\end{array}$ & $\begin{array}{c}\text { Female-pup } \\
\text { No tag }\end{array}$ & $\begin{array}{c}\text { Female-pup } \\
\text { Tagged }\end{array}$ \\
\hline 18 August & Taylor Bay & 3 & 2 & 1 & 0 & 0 & 0 \\
\hline \multirow[t]{3}{*}{19 August } & Taylor Bay & 2 & 10 & 1 & 0 & 3 & 0 \\
\hline & Sunday Harbor & 28 & 6 & 0 & 3 & 1 & 0 \\
\hline & $\begin{array}{l}\text { Takoma Bay, West } \\
\text { Arm of Port Dick }\end{array}$ & 0 & 1 & 0 & 0 & 0 & 0 \\
\hline \multirow[t]{2}{*}{20 August } & $\begin{array}{l}\text { West side of the } \\
\text { North Arm of } \\
\text { Nuka Bay and } \\
\text { Beauty Bay }\end{array}$ & 8 & 1 & 0 & 1 & 0 & 0 \\
\hline & $\begin{array}{l}\text { East side of the } \\
\text { North Arm of } \\
\text { Nuka Bay }\end{array}$ & 8 & 3 & 0 & 1 & 0 & 0 \\
\hline \multirow[t]{5}{*}{21 August } & Surprise Bay & 0 & 2 & 0 & 0 & 1 & 0 \\
\hline & $\begin{array}{l}\text { Palisade Lagoon in } \\
\text { Surpriae Bay }\end{array}$ & 0 & 1 & 0 & 0 & 1 & 0 \\
\hline & Quartz Island & 2 & 1 & 0 & 0 & 1 & 0 \\
\hline & Yallick Cove & 1 & 2 & 0 & 1 & 0 & 0 \\
\hline & $\begin{array}{l}\text { Suprise Bay to } \\
\text { Herrington Point }\end{array}$ & 6 & 0 & 0 & 0 & 3 & 0 \\
\hline 22 August & Tonsina Bay & 3 & 2 & 2 & 0 & 1 & 0 \\
\hline 23 August & Windy Bay & 0 & 0 & 0 & 0 & 0 & 0 \\
\hline 24 August & Rocky Bay & 2 & 2 & 2 & 0 & 0 & 0 \\
\hline 25 August & Windy Bay & 0 & 1 & 0 & 0 & 0 & 0 \\
\hline 26 August & Rocky Bay & 13 & 1 & 0 & 4 & 0 & 1 \\
\hline 27 August & Rocky Bay & 6 & 3 & 0 & 2 & 0 & 0 \\
\hline 28 August & Windy Bay & 0 & 1 & 0 & 0 & 0 & 0 \\
\hline \multirow[t]{2}{*}{29 August } & $\begin{array}{l}\text { Rocky Bay-Tele- } \\
\text { phone lsland }\end{array}$ & 5 & 1 & 0 & 1 & 1 & 0 \\
\hline & Windy Bay & 2 & 1 & $\mathbf{0}$ & 1 & 0 & 0 \\
\hline \multirow[t]{2}{*}{30 August } & Bootlegger's Cove & 1 & 1 & 0 & 0 & 0 & 0 \\
\hline & East of Rocky Bay & 1 & 0 & 0 & 2 & 0 & 0 \\
\hline
\end{tabular}


Because of the extreme difficulty in sighting tarnished brass-colored tags, only cursory surveys were conducted by the M/V Breaktime crew outside the James Lagoon and McCarty Lagoon areas. However, one tagged animal was observed across McCarty Arm near the Moonlight Bay entrance. This sighting tends to confirm some interchange of otters between the two lagoon areas, a distance of about $4.8 \mathrm{~km}$.

On 26 August, the Breaktime crew conducted a survey of Tonsina Bay at high tide that revealed six otters around the outside rocks and three within the bay. All appeared healthy; no tags were observed. However, an apparently healthy single animal with a red tag on its right flipper was seen near the head of the bay. This animal might have been tagged on 20 July in Tonsina Bay during a field check for oral ulcers, as reported by Harris et al. (1990). It was clear that no return of tagged otters had occurred from the recent releases.

On 29 August, the Breaktime crew surveyed Harris Bay near the moraine and Northwestern Lagoon. Forty-one sea otters were observed in Northwestern Lagoon and 35 in Harris Bay proper. One tagged otter was seen in Northwestern Lagoon.

\section{Discussion}

Flipper tags (especially a neutral or tarnished brass color) are one of the most nonintrusive means of identifying otters in the wild. Unfortunately, neutral-colored tags are almost impossible to see, even in ideal conditions. During the entire postmonitoring effort, observers were not able to read one tag number. Therefore, it was impossible to distinguish individual animals. It is evident from the lack of information that was gathered on tagged animals during the postrelease monitoring along the Kenai Peninsula that the use of neutral-colored flipper tags is a poor choice when data collection is the objective.

Surveyors from the Roman $E$ were able to distinguish the presence or absence of a tag on only $58(34 \%)$ of the 171 otters seen. Of these 58 , only $7(13 \%)$ were tagged, which is $5 \%$ of the total. It is estimated that at least one of the tagged otters was seen on two different days and, therefore, counted twice.

The otter seen in Taylor Bay had a tarnished brass-colored tag on the right flipper. Both otters in Rocky Bay had tarnished brass-colored tags; one otter was tagged on both flippers and the other on the right flipper only. Both tagged animals in Tonsina Bay had a yellow tag on at least one flipper. The mother seen in Rocky Bay had a yellow tag on the right flipper. It is the opinion of the Roman $E$ crew that only one otter stayed behind in the area of the Taylor Bay release site.

Because of the difficulty in identifying tagged animals in open water, the Breaktime crew attempted to establish an index of tagged-to-untagged animals from a number of certain observations (observer was $100 \%$ sure whether the animal was tagged or untagged) at the James Lagoon outlet (Table 5). By applying the results of this index to the number of animals using the James Lagoon

Table 5. Breaktime postrelease sightings of tagged and untagged sea otters (Enhydra lutris) at the James Lagoon outlet.

\begin{tabular}{|c|c|c|c|c|c|c|}
\hline \multirow{2}{*}{$\begin{array}{l}\text { Observation } \\
\text { data }^{\mathrm{a}}\end{array}$} & \multicolumn{6}{|c|}{ Date (August) } \\
\hline & 20 & 21 & 22 & 23 & 25 & 26 \\
\hline & \multicolumn{6}{|c|}{ Tagged } \\
\hline Inside lagoon & $29(6)^{b}$ & $16(2)^{b}$ & $25(2)^{b}$ & $26(2)^{b}$ & 37 & 36 \\
\hline Outside lagoon & $23(1)^{b}$ & 23 & 27 & 3 & 16 & 7 \\
\hline Total & 52 & 39 & 52 & 39 & 53 & 43 \\
\hline Tag sightings & 9 & 8 & 6 & 7 & 12 & 4 \\
\hline \multirow{2}{*}{$\begin{array}{l}\% \text { of observed animals that } \\
\text { were tagged }^{\mathrm{b}}\end{array}$} & 17 & 21 & 12 & 17 & 23 & 10 \\
\hline & \multicolumn{6}{|c|}{ Untagged } \\
\hline Inside lagoon & $30(6)^{b}$ & $18(2)^{b}$ & $31(3)^{b}$ & $31(5)^{b}$ & $42(4)^{b}$ & $38(8)^{\mathrm{b}}$ \\
\hline Outside lagoon & 0 & 8 & 4 & 4 & 4 & 2 \\
\hline Total & 30 & 26 & 35 & 35 & 46 & 40 \\
\hline Tag sightings & 0 & 0 & 0 & 0 & 0 & 1 \\
\hline
\end{tabular}

${ }^{a}$ Only observations used to establish percentage were those where the observers were $100 \%$ sure the animals were tagged or untagged.

${ }^{b}()=$ pups 
and McCarty Lagoon areas, some assumptions of total tagged animals remaining can be made.

Assuming that an average of $16 \%$ of James Lagoon animals were tagged (Table 5), then at least eight of the released animals were still present in the area. If we further assume that the McCarty Lagoon site had some of the tagged animals, as indicated by a single sighting, then we can account for a few more tagged animals.

It is the opinion of the crew of the Breaktime that at least half, and perhaps more, of the tagged otters were still in the general area of the release during the postrelease monitoring. Most certainly, some may have moved away from the release site, but the Breaktime crew questions whether any overwhelming migration occurred.

\section{Recommendations}

When postrelease data collection is the objective, the following recommendations should be considered by those designing the monitoring effort: (1) consider the use of implant radios if feasible; (2) use brightly colored tags or body markings; (3) use tags on both flippers; (4) if only flipper tags are used, provide more boats and personnel, and continue the monitoring effort for more than 2 weeks; and (5) conduct shoreline surveys for postrelease mortality in release areas.

\section{Acknowledgments}

Information for the M/V Breaktime observations was obtained from a memorandum by L. Heckart and E. Klinkhart, and personal communications with Klinkhart. Additional information on otter sightings for the few days the author was not pres- ent on the F/N Roman $E$ was obtained from trip reports by C. Keller and L. McShane. The crews of the M/V Breaktime and F/N Roman $E$, and VE Construction Company employee M. Kansteiner, all provided valuable assistance throughout the project.

\section{References}

Harris, R. K., R. B. Moeller, T. P. Lipscomb, R. J.Haebler, P. A. Tuomi, C. R. McCormick, A. R. DeGange, D. Mulcahy, T. D. Williams, and J. M. Pletcher. 1990. Identification of a herpeslike virus in sea otters during rehabilitation after the T/V Exxon Valdez oil spill. Pages 366-368 in K. Bayha and J. Kormendy, tech. coords. Sea Otter Symposium: Proceedings of a symposium to evaluate the response effort on behalf of sea otters after the T/N Exxon Valdez oil spill into Prince William Sound, Anchorage, Alaska, 17-19 April 1990. U.S. Fish Wildl. Serv., Biol. Rep. 90(12).

Monnett, C. W., and L. M. Rotterman. 1990. Postrelease monitoring of radio-instrumented sea otters in Prince William Sound. Pages 400-420 in K. Bayha and J. Kormendy, tech. coords. Sea Otter Symposium: Proceedings of a symposium to evaluate the response effort on behalf of sea otters after the T/N Exxon Valdez oil spill into Prince William Sound, Anchorage, Alaska, 17-19 April 1990. U.S. Fish Wildl. Serv., Biol. Rep. 90(12).

Rappoport, A. G., M. E. Hogan, and K. Bayha. 1990. Development of the release strategy for rehabilitated sea otters. Pages 375-384 in K. Bayha and J. Kormendy, tech. coords. Sea Otter Symposium: Proceedings of a symposium to evaluate the response effort on behalf of sea otters after the T/V Exxon Valdez oil spill into Prince William Sound, Anchorage, Alaska, 17-19 April 1990. U.S. Fish Wildl. Serv., Biol. Rep. 90(12). 


\title{
Transfer and Placement of Nonreleasable Sea Otters in Aquariums Outside Alaska
}

by

\author{
J. A. Gruber and M. E. Hogan \\ U.S. Fish and Wildlife Service \\ Marine Mammals Management \\ 1011 E. Tudor Road \\ Anchorage, Alaska 99503
}

\begin{abstract}
During the first 6 months after the T/N Exxon Valdez oil spill, 37 sea otters (Enhydra lutris) were transported from Alaska to aquariums in the United States and Canada. This number included 20 adult sea otters that were shipped in April 1989 from Valdez, Alaska to aquariums that provided immediate intensive care under emergency conditions set forth in the Marine Mammal Protection Act of 1972. An additional four adults, suffering from chronic long-term health problems, were sent to Sea World San Diego in August. In September 1989, 13 otter pups that were orphaned or abandoned by their mothers were transferred to Point Defiance Aquarium in Tacoma, Washington, for intensive care before permanent placement in other aquariums. The U.S. Fish and Wildlife Service is reviewing procedures for taking and rehabilitating marine mammals, particularly in emergency circumstances such as an oil spill. Consideration will be given to development of a network of preapproved placement centers that would be able to accommodate animals on short notice. The Service review may also consider measures to ensure an animal's return to the wild, when feasible, and requirements for permanent maintenance facilities.
\end{abstract}

The Marine Mammal Protection Act of 1972 delegated management authority for sea otters (Enhydra lutris) to the Fish and Wildlife Service, U.S. Department of the Interior. Under Section 109 (h) of the act, an appropriately designated Federal, State, or local government official may take a marine mammal with no permit required if such taking is for the protection or welfare of the mammal; the act also includes steps designed to ensure return of that mammal to its natural habitat. In addition, any such employee or official may possess and transport, but not sell or offer for sale, the marine mammal, and may use any port, harbor, or other place under the jurisdiction of the United States.

In response to the T/V Exxon Valdez oil spill, the Service exercised oversight of the capture, transfer, rehabilitation, and release of oil-affected otters under the authorities granted in Section 109(h) of the act and implementing regulations in 50 CFR
18.22 (taking by State and local government officials). The authority was originally intended as a limited, small-scale remedy. However, the rapidity with which otters were severely affected by the spill, and the absence of adequate cleaning, holding, or rehabilitation centers for oiled otters in Alaska when the spill occurred, necessitated the transport of several critically ill animals to aquariums outside the State.

The first sea otter rehabilitation center, established on 27 March 1989 at Prince William Sound Community College in Valdez, was limited to half of a dormitory; it consisted of 278.7 square meters. Few personnel were on the scene; little equipment and veterinary supplies were available; and no adequate system for rapid, accurate diagnostics existed. Bloodwork, for example, was initially sent to clinics in Anchorage and to out-of-state laboratories. Travel time, weather, and logistical constraints complicated the rapid return of laboratory 
test results crucial for optimum treatment of animals. Sea otters brought into the center suffered from hypothermia and severe problems associated with the ingestion, dermal absorption, and inhalation of volatile hydrocarbon compounds. The Valdez Otter Rehabilitation Center (VORC) was prepared to clean otters and to care for immediate problems, but at that early stage was unable to diagnose and treat the entire range of systemic disorders observed in the otters.

In April 1989, R. Davis, the director of the Sea Otter Rehabilitation Program, requested that 20 seriously ill otters be shipped to aquariums outside Alaska, which would relieve VORC's pressure of having exceeded its staff's capacity to attend to the animals. Also, such a transfer would provide the highest quality diagnostics, treatment, and expertise. Aquariums with veterinarians, toxicologists, and pathologists on staff could work directly with the animals and quickly forward important information that would improve the survival rate of oiled otters brought into Alaskan treatment centers.

Thus, on 2 April 1989, Davis recommended that six otters be transported to Sea World San Diego. One otter died at the Anchorage International Airport on 3 April, and four more ultimately died. An additional six otters were shipped to Point Defiance Aquarium in Tacoma, Washington, on 13 April. Two of these otters died and another was eventually transferred to Sea World San Diego. In addition, on 13 April, two otter pups that were not severely oiled, but were in need of specialized round-the-clock care, were sent to the Monterey Bay Aquarium in California. By June, however, this aquarium needed space for other animals and recommended that a permanent facility be identified for the pups. Vancouver Public Aquarium in British Columbia offered to take the pups on a permanent basis. Previously, on 17 April, six sea otters had been sent from VORC to Vancouver Public Aquarium. Two of those animals died, but with the addition (on 24 August) of the pups from Monterey, Vancouver again held six otters. Eleven of the original 20 otters transported out of Alaska in April 1989 were alive 1 year later.

After health evaluations of four additional adult female sea otters, Davis and attending veterinarians at VORC recommended that the four be shipped to Sea World San Diego in August 1989. One of these four otters suffered from serious sinusitis, another was blind, and all four had severe locomotive problems and difficulty feeding and diving. The veterinarians believed that the otters had little chance of surviving in the wild if ever released. These animals are still alive and their health is regularly monitored.

During July and August 1989, the Seward Otter Rehabilitation Center (SORC) acquired 13 pups that had been abandoned or orphaned. Eight of these pups were captured alone and assumed to be orphans, and three pups were born at the center. Two mother-pup pairs were brought to the center (Styers and McCormick 1990).

Center staff tried to keep pups together with their mothers; however, some mothers ignored or rejected their offspring. Several pups became highly susceptible to hypothermia when their mothers failed to adequately groom them. One mother abandoned her pup after being transported to the Jakolof Pre-Release Facility near Homer. This pup became hypothermic and was returned alone to SORC. In such instances mothers were ultimately released, and the pups were provided intensive, round-the-clock care. Most pups at SORC were newborn animals weighing $4.5 \mathrm{~kg}$ or less and fully dependent on human care. Their young age, inability to forage for themselves, and absence of mothers to teach them diving, foraging, and other basic survival skills precluded their release. However, SORC was being pressured by Exxon personnel to close by September because it was unsuitable for winter conditions and was losing personnel. Thus, the Service had to decide where to send the 13 abandoned or orphaned pups.

The Service had two options for determining the appropriate authority and permitting process for transfer and permanent placement of the pups. The Service's Alaska Region could assume responsibility for placement and permanently transfer the pups under the authority of Section 109(h) of the Marine Mammal Protection Act. Alternatively, the Service's Office of Management Authority in Washington, D.C., could require that the pups be held at an interim facility while recipient aquariums went through the permitting procedure for public display permits. Because the decision to place the pups was no longer being made in an emergency situation, the Office of Management Authority was deemed the appropriate office to issue public display permits to the aquariums in which the otters would be placed. The major advantage offered by this course of action was that the applications had to be reviewed by the public and Federal and State agencies, the Alaska Regional Office, and the Marine Mammal Commission before issuance of a public display permit. The permit also ensured that placement facilities were 
in compliance with U.S. Department of Agriculture Animal and Plant Health Inspection Service standards and that they provided an acceptable education or conservation program.

An important consideration in determining the best course of action for placement of the pups was based on the difficulty involved in raising sea otters to the juvenile stage. Otter pups need roundthe-clock intensive care and optimum environmental conditions for rearing. In August, the director of SORC reported that the pups raised by the center were progressing slower in natural behaviors, weight gain, and overall self-reliance than pups raised by their natural mothers. He recommended that the pups continue to receive care and handling by trained nursery staff until they were large enough for permanent placement. The director and SORC's staff developed criteria that they believed would help determine when a pup could most successfully be permanently transferred to an aquarium. To them, it was essential that a pup weigh $11.4-13.6 \mathrm{~kg}$, eat solid foods, and be self-sufficient before transfer to a permanent facility. In the instance of the 13 pups, adherence to these criteria would have prepared them for permanent placement 2-3 months after the proposed September closing of SORC. Therefore, Styers recommended that the pups be sent to Point Defiance Aquarium, which had offered to act as an interim intensive care placement facility. The Service concurred with Styers' recommendation. While additional facilities were constructed at Point Defiance, staff from SORC continued caring for the pups at Point Defiance, thereby providing some continuity for the animals. The expense of preparing additional pools, transporting the pups from Alaska to Point Defiance, the initial 2 weeks of handlers' salaries, and the care of the otters was borne by Exxon Company U.S.A. Subsequent costs were to be reimbursed by recipient aquariums.

Permanent placement options were limited. $\mathrm{Po}$ tential recipient aquariums were already saturated by earlier emergency placements. By August 1989, 24 otters had already been accepted by Sea World San Diego, Monterey Bay Aquarium, Point Defiance Aquarium, and Vancouver Public Aquarium. Several of these aquariums already cared for resident sea otters before the spill and had limited capacity to accept more animals. These facilities had virtually no time to prepare for additional otters received after the spill.

Few accredited zoos or aquariums in the world were prepared to accept otters because of the expense of maintaining both the hydrological systems and dietary needs required by the animals. Fortunately, three facilities had already requested permits to capture sea otters before the spill. The John G. Shedd Aquarium in Chicago had submitted an application for a permit to collect two male and four female otters from Prince William Sound in 1990. After the oil spill, the Office of Management Authority rescinded this facility's application and referred the aquarium to the Service's Alaska Region, advising aquarium staff to attempt to obtain otters rescued from the spill that might not be releasable. The Shedd Aquarium contacted the Service's Alaska Region and agreed to take four otter pups. Likewise, Marine World Umino-Nakamichi, in Fukuoka, Japan, also had a permit application under consideration to collect sea otters from Prince William Sound. After the oil spill, the Office of Management Authority withdrew this application from consideration, and staff were advised to contact the Alaska Region for nonreleasable animals. A third facility, Sea World San Diego, submitted a request after the spill for nine pups that would be divided between San Diego and the Orlando, Florida, facility. Because the Shedd Aquarium and Marine World Umino-Nakamichi had already initiated the permitting process to collect otters, they were given priority in placement of pups. Once their requests were filled, those pups that remained would be shipped to Sea World San Diego.

On 11 September, the 13 abandoned or orphaned otter pups, ( 6 males and 7 females), were transferred to Point Defiance. As of 1 April 1990, 9 of the 13 pups were still alive. The smallest pup, a male, died in October 1989, and two more pups, a male and a female, died in January 1990 and February 1990 at Point Defiance Aquarium. Four pups were eventually transported in October 1989 to Shedd Aquarium, and three pups were shipped to Sea World San Diego in January 1990. Three pups and a young female were transported to Japan in late February 1990. One of the pups sent to Japan died in March.

Conditions for transferring all sea otters to their permanent placements included (1) the transfer, care, and maintenance of the sea otters had to be in compliance with the U.S. Department of Agriculture Animal and Plant Health Inspection Service Specifications for the Humane Handling, Care, Treatment, and Transportation of Marine Mammals (9 CFR, Part 3, Subpart E); (2) the transferred sea otters could not be sold, donated, or transferred unless the recipient had first been issued authorization by the Office of Management Authority; (3) any deaths that occurred had to be 
reported to the Service's Marine Mammals Management Office in Alaska and to the Office of Management Authority within 1 week; (4) all dead animals had to be necropsied by a qualified veterinary pathologist and the report given to the Service; and (5) any births attributed to these transferred sea otters had to be reported to the Office of Management Authority.

\section{Recommendations}

The authors recommend that a worldwide inventory of permitted aquariums be maintained by the Office of Management Authority for all types of nonreleasable otters. Facilities that are approved to hold rehabilitated animals on a permanent basis should have a public display permit for those animals. The issuance of a public display permit would ensure that the facilities meet USDA standards, that a public review occurs, and that an education or conservation program concerning marine mammals exists. Foreign facilities should meet these criteria as well and supply annual reports to the Office of Management Authority. Guidelines are needed for determining the releasability of rehabilitated animals; the authors recommend that these guidelines be included in planning documents created for responding to future oil spills. Another policy question that needs attention pertains to rehabilitated animals that could be restored to the wild but that might be used instead as substitutes for additional marine mammals taken from the wild by permitted facilities.
Rehabilitated animals that are held permanently should be identified on aquarium inventories as rehabilitated animals so that aquariums are not jeopardized for taking animals that may not be as healthy or as long-lived as animals collected from the wild.

If another disaster occurred today that required the Service to place as many as the 37 animals that required permanent facilities in the Exxon Valdez spill, the authors believe the Service would encounter great difficulty in securing suitable placements. Some aquariums in Japan are interested in acquiring otters, but most U.S. aquariums have no facilities for more otters. Some aquariums are not interested in acquiring blind or otherwise disabled animals, and most aquariums are not prepared to raise pups. In such an event, other alternatives would have to be considered, including the release of animals in marginal condition, the use of surrogate mothers to reintroduce pups in the wild, construction of new facilities for long-term holding and display, and euthanasia.

\section{References}

Styers, D., and C. R. McCormick. 1990. Pup nursery at the Seward Otter Rehabilitation Center. Pages 301312 in K. Bayha and J. Kormendy, tech. coords. Sea Otter Symposium: Proceedings of a symposium to evaluate the response effort on behalf of sea otters after the T/V Exxon Valdez oil spill into Prince William Sound, Anchorage, Alaska, 17-19 April 1990. U.S. Fish Wildl. Serv., Biol. Rep. 90(12). 


\title{
Protecting Sea Otters From Oil Spills: Recommendations Based on the Alaska Experience
}

by

\author{
S. H. Shane \\ Friends of the Sea Otter \\ P.O. Box 221220 \\ Carmel, California 93922
}

\begin{abstract}
The 1989 Alaska oil spill provided valuable lessons about how to improve management of sea otters (Enhydra lutris) during a spill: The U.S. Fish and Wildlife Service, the Federal agency charged with responsibility for sea otters, must have clear authority and unlimited funds to respond immediately to otters affected or threatened by an oil spill. Decisions affecting otters cannot be left to the spiller. Once an oil spill occurs, the Service must direct protective booming efforts and preemptive captures to prevent sea otters from becoming oiled. To adequately treat oiled otters, sea otter rescue and holding facilities must be constructed and operational before an oil spill occurs. Trained staff and volunteers, otter care protocols, and record-keeping procedures must be in place before a spill occurs to ensure that otters receive the best care possible. Both short- and long-term research projects relating to the effects of oil spills on otters and their habitat should be designed in advance of an oil spill and implemented as soon as a spill occurs.
\end{abstract}

Opportunity often arises out of catastrophe. The March 1989 spill of 11 million gallons of crude oil from the T/N Exxon Valdez into Prince William Sound, Alaska, was a tragedy, but it provided a chance to revamp oil spill prevention and response measures in the United States. This accident caused the first oiling of sea otters (Enhydra lutris) by a spill in U.S. waters, and the attempt to respond appropriately to the affected otters taught us many lessons. I take a retrospective look at the conduct of the sea otter response effort in Alaska and present recommendations for improving that response and, thus, better protecting sea otters in future oil spills.

Sea otters are marine mammals long known to be vulnerable to oil spills because the insulating properties of their fur can be destroyed by contact with oil (Kenyon 1975). In 1977, the California sea otter population was listed as a threatened species under the Endangered Species Act of 1973, precisely because of the danger posed to the entire population by a major oil spill (Secretary of the Interior 1977; U.S. Fish and Wildlife Service 1984; U.S. Fish and Wildlife Service and Institute of
Marine Sciences 1987). The 1989 Alaska spill confirmed many of the worst fears about the effects of a major oil spill on sea otters. It also introduced us to the unpredicted degree of otter mortality and pathology caused by inhalation and ingestion of hydrocarbons. Many otters died, and long-term contamination of the sea otter's habitat may be present. The problems generated by the spill were compounded because, from the outset, Alaska was unprepared to manage sea otters affected by the oil. My purpose here is not to lay blame, but to point out failures in the system and to propose recommendations for improving it.

\section{Recommendations}

Recommendation 1: The U.S. Fish and Wildlife Service, the Federal agency charged with responsibility for sea otters, must have clear authority and sufficient funds to respond immediately to sea otters affected or threatened by an oil spill.

Decisions directly affecting otters cannot be left to the spiller. The Service is charged with sea otter 
protection under the Marine Mammal Protection Act and, in California, under the Endangered Species Act as well. Lack of federalization of an oil spill cannot excuse the agency from taking all steps necessary to protect sea otters.

One example of the unfortunate consequences of muddled lines of authority can be found in the delayed construction of the second Sea Otter Rehabilitation Center at Seward. This delay occurred, in large part, because the Service initially took an "oversight" role, as opposed to a command role, in the decision. In a 20 April 1989 letter to D. Cornett, Alaska coordinator for Exxon Company, U.S.A., Service Regional Director W. Stieglitz said that he had "... asked [Exxon] to construct an otter and bird cleaning and rehabilitation facility in Seward" on 7 April. Stieglitz continued, "We assumed things were proceeding as discussed...." In fact, no progress toward a Seward Center had been made in 2 weeks. In this instance, Exxon was given too much leeway to proceed as it saw fit. The Service finally abandoned its laissez-faire approach to this issue, when Stieglitz commanded in his 20 April letter to Exxon: "Immediately construct a full-care otter rehabilitation facility in Seward....Bring this facility on line by April 23, 1989." The Seward Otter Rehabilitation Center actually opened for full-time otter care on 8 May 1989. Had the authority of the Service been clearer, the Seward Otter Rehabilitation Center would probably have been operating several weeks earlier than it was, and might have provided care for more otters touched by the first onslaught of oil along the Kenai Peninsula.

A corollary to the Service's maintaining complete decision-making power regarding sea otters in oil spills is the need for sufficient funding to carry out the necessary activities. Although there is always the possibility that the Service will recover money spent on otter protection from the spiller, it is the proper role of the agency to expend Federal funds on this task. Because the costs of otter protection and rehabilitation during an oil spill can be high, there should be oil spill response funds created at both the Federal and State levels to handle these needs, among others. Such funds should be created from fees imposed on the oil industry. Contribution to these funds should be viewed as a necessary part of engaging in the profitable-yet risky-business of petroleum production and transport. In California, a $\$ 500 \mathrm{mil}$ lion oil spill prevention and response fund for the State, to be created by assessing a fee of $\$ 0.50$ per barrel, is one element of legislation (A.B. 2603) introduced in early 1990 . Surely such fees are a small price for the industry to pay for some degree of insurance against the exorbitant costs incurred by oil companies trying to make reparations for major oil spills (for instance, Exxon reportedly spent about $\$ 2$ billion on its response to the Prince William Sound spill).

One more vital component of the Service's leadership role in the response to sea otters affected by oil spills involves the delegation of responsibilities for specific roles. There must be a clear chain of command and a well-defined division of labor established in advance of a spill. If outside contractors are hired to perform some rescue and rehabilitation duties, the Service cannot abdicate its ultimate responsibility for the health and welfare of sea otters.

To formalize the Service's primary responsibility for sea otters in oil spills, laws and contingency plans may need to be revised. S. Robinson, deputy director of the U.S. Fish and Wildlife Service (1989), emphasized the "oversight roles" of State and Federal agencies during the Alaska spill. By taking an oversight role, the Service often followed, rather than led, Exxon in the sea otter response. Laws and contingency plans must reverse these roles, so that the director of the Service and all regional directors with sea otters in their regions take command roles with respect to otters affected by spills. The Service's leadership position must be made clear to State wildlife agencies, the U.S. Coast Guard, and oil industry representatives.

Recommendation 2: After an oil spill occurs, the Service must direct protective booming efforts and preemptive captures to prevent sea otters from becoming oiled.

The only certain way to prevent sea otter mortalities from oil spills is to stop the oil from contacting the otters. Where practicable, protective booming of bays containing aggregations of otters must be given at least as high a priority as was protective booming of fish hatcheries during the Prince William Sound spill. Booms provide far from foolproof protection from oil, yet some fish hatcheries in elongate, sheltered bays were saved by the setting of double and triple booms across their entrances. In some areas, such as most of the California coast, protective booming would be impossible. However, there must be a stated commitment to giving wildlife resources protection equal to that given to commercial resources wherever possible.

Another way of preventing otters from becoming oiled is to conduct preemptive captures of threatened otters. When large numbers of otters are 
clearly at risk from approaching oil in an area that cannot be effectively protected by booms, they should be captured and placed in seminatural, long-term holding facilities before the oil reaches them. Participants at a workshop on sea otters and oil spills in California in November 1989 agreed that preemptive captures would be given priority in areas where they were feasible (Smith 1990).

Recommendation 3: To adequately treat oiled otters, sea otter rescue and holding facilities must be constructed and operational before an oil spill occurs.

The devastatingly high mortality (74\%) of otters captured during the first week of the response effort in Alaska (Williams 1989) was partly because rescue workers had no place to wash, treat, and hold sea otters. Of course, the toxicity of the fresh oil and the heavy oiling of these first otters accounted for the other part of this high mortality. Grim stories of oiled otters lining the hallway of a school building in Valdez vividly illustrate the cost of being unprepared for handling otters during an oil spill (R. Davis, University of California, San Diego, personal communication). People and otters made do with less than optimum facilities and equipment during much of the Alaska spill. Lessons learned about the otter's needs were incorporated into each new facility built, and the quality of care improved greatly as time went on. With the knowledge gained in Alaska, it is now possible to design and build sea otter rescue facilities that will truly serve the needs of the animals.

One vital aspect of such facilities is that they must be already constructed and in operating condition before a spill occurs. The idea of mobile facilities that could be flown where needed at a moment's notice may be appealing, but it is not realistic. When the Exxon Company first discussed construction of the Seward Center with the Service, it predicted that the facility would take 3 to 4 days to build. In reality, the facility took closer to 3 weeks to build. When I was in Seward, I heard repeated predictions about when parts of the facility would be completed and open for business. Despite the best efforts of a diligent work crew, none of the deadlines that I heard were met. For example, an ostensibly simple project such as hooking up a seawater pipeline, projected to take one afternoon in Seward, ended up taking days. Because of the Seward experience, I am convinced that sea otter rescue facilities need to be permanent and operational in advance of a spill if they are to best serve the needs of oiled otters. The land must be purchased, buildings or trailers must be constructed and equipped, and seawater and sewage systems must be in actual use. Now that we know what composes an effective sea otter rescue facility, there is no excuse not to build one or more in every State where sea otters are threatened by oil.

Not only must the intensive care centers for otters be ready before the next spill, but also seminatural, long-term holding facilities, such as the Valdez octagon or the Jakolof Pre-Release Facility, need to be constructed and ready for immediate otter occupation. Because the first otters that come into captivity after a spill may be unoiled otters threatened by the approaching spill, they must be put directly into long-term holding areas so as to be minimally stressed.

Funding for permanent sea otter rescue and long-term holding facilities should come from the oil industry. The cost of providing such facilities in advance of a spill will be far less than the cost of the same facilities in the crisis atmosphere that prevails once a spill takes place. An appropriate analogy can be found in the fact that preventive human medicine is more cost-effective than is emergency medicine. Thus, the oil industry could view expenditures for the construction, operation, and maintenance of sea otter facilities as insurance. Should the industry decide not to voluntarily invest in sea otter rescue facilities, State or Federal legislation must be used to impose this funding requirement on the industry.

Recommendation 4: Trained staff and volunteers, otter care protocols, and record-keeping procedures must be in place before a spill occurs to ensure that otters receive the best care possible.

People are an integral part of the otter rescue equation, and advance planning for both people and otter management is crucial to a successful spill response. There must be a trained, experienced staff established with clearly defined roles and chains of command. Once the site for a sea otter rescue center is chosen, a corps of volunteers should be recruited from the local community and trained. In a large spill, additional volunteers will arrive from all over the country to assist. The local volunteers can act as an extension of the staff in helping train these newcomers. People and facilities should be subjected to at least one surprise drill each year to ensure that all systems are functioning as they should in the event of a real spill.

The T/N Exxon Valdez spill permitted us to experiment with a number of different protocols for capture, transport, admission, veterinary care, husbandry, sedation, washing and drying, pup 
care, necropsy, quarantine, long-term holding, tagging, and release. The various protocols should be completed and preserved together in the form of a handbook on responding to sea otters affected by an oil spill. Such a handbook could be revised as warranted, but it would provide for a consistency of response that was often lacking in Alaska.

Data sheets for use at every stage of the sea otter's time in captivity must be designed and included in the protocol handbook. One cost of the lack of preparedness in Alaska was chaotic record keeping. Basic information, such as the number of otters that survived at a particular facility, was often impossible to find in Alaska. There was no consistent method for evaluating the status of recovering otters; when I worked at Seward, methods for evaluating otter behavior and coat condition changed on a daily basis. With the benefit of hindsight, we can now create simple data sheets, accompanied by instructions for filling them out, and make them standard issue for staff and volunteers involved in every aspect of response. Accurate records are the key to learning what works and what doesn't work and ensuring that each otter receives appropriate, customized care.

Recommendation 5: Both short- and long-term research projects relating to the effects of oil spills on otters and their habitat should be designed in advance of a spill and implemented as soon as a spill occurs.

The purpose of conducting research on sea otters during and after an oil spill is not purely academic. Results of such studies clarify the magnitude and type of threats posed to otters by oil spills, while sometimes showing us the way to solutions. They also provide fuel for enacting stiffer oil spill prevention and response legislation.

On the basis of the Alaska experience, we can now identify research issues, and we can design projects aimed at resolving them. Such studies can be fine-tuned to fit the circumstances of a particular spill, but the groundwork can be completed before the crisis strikes. There should be a mechanism for speeding issuance of otter research permits during an oil spill. Conditional preapproval of research plans by the permit office before a spill, with final approval after the spill occurs, might be a viable means of dealing with this problem.

Short-term research questions include determining the number of otters killed by the spill, the immediate effects on otter prey items, changes in otter distribution as a result of the spill, and the behavioral response of otters to the oil. One of the crucial unanswered questions both before and, unfortunately, after the T/N Exxon Valdez spill was, "Do sea otters avoid spilled oil?" On 4 April 1989, J. Twiss (U.S. Marine Mammal Commission) wrote to the Service suggesting both research and response approaches toward sea otters. Among his suggestions was the proposal that a "representative sample of sea otters be radiotagged and followed in one or more areas where otters have not, but likely will be, contacted by oil to determine what otters do and where they go after they are oiled (e.g., do they haul out on remote beaches, do they ingest significant quantities of oil while grooming, do they remain at sea and sink or float after death, and are they eaten by eagles or killer whales)?" Unfortunately, the Service Regional (Alaska) Director, W. Stieglitz, vetoed such a study. While certain aspects of such a study might have been difficult to sell to the public (e.g., watching otters become oiled and then die), the central question of how sea otters respond to oil could have been answered without putting otters at extraordinary risk. Otters could be radio-tagged and observed to see whether they avoid oil or not. If they do consistently avoid oil, we might feel more confident about leaving some otters in parts of their habitat that are unoiled but adjacent to oiled areas. If they do not avoid oil and actually become oiled, they could be captured and brought to rescue centers almost immediately. Answering the question of what becomes of oiled otter carcasses-Do they sink, float, or get eaten?-could be accomplished by radio-tagging freshly dead carcasses and tracking them closely.

An important short-term research activity that was carried out in Alaska was aerial surveys of parts of Prince William Sound before and after the oil hit. Unfortunately, because the surveys covered a relatively circumscribed area, abundance changes could not be explained. It was not known whether an increase in the number of otters seen in some areas after oiling was a result of the spill or was a normal seasonal shift in distribution (C. Monnett, Prince William Sound Science Center, Cordova, Alaska, personal communication). In the future, surveys should cover an area far in excess of that affected by the spill to prevent such ambiguous results.

Integrating studies of the short- and long-term effects of the spill on otters with the effects on their prey are critical to fully understanding the effects of an oil spill. Prey studies can also be used to determine the suitability of habitat for release of rehabilitated otters. Analyzing hydrocarbon levels 
in the tissues of otters and their prey may provide insight into the ecosystem level effects of a spill.

There are many other short-term research questions, some of which were addressed during the Alaska spill. For instance, how can we determine if an otter is oiled in the field? Can lightly oiled otters survive in the wild? Is capture and rehabilitation more stressful and more likely to result in eventual mortality than light oiling?

Long-term research questions should focus on the fate of rehabilitated otters as well as that of otters that remain in oiled habitat. Only by study. ing otter movements, behavior, reproductive success, and survival are we to learn the effects of a major spill after $1,5,10$, and 20 years. Failing to conduct such studies means ignoring the long. term plight of otters whose habitat has been devastated by petroleum.

One of the most troubling aspects of the research being conducted on the effects of the T/V Exxon Valdez spill is the secrecy in which it continues to be shrouded more than a year after the spill. Most of the scientists involved have expressed frustration with the silence imposed on them about their data by the lawyers involved in spill litigation. As the National Academy of Sciences Committee on the Conduct of Science (1989) wrote, "The need for skeptical review of scientific results is one reason why free and open communication is so important in science. The free exchange of research results exposes hypotheses to different points of view fostering the development of a consensus view of a phenomenon." Law and science are at odds on this point, and efforts to resolve this conflict before the next major spill are needed.

\section{Conclusion}

As pointed out by the California Coastal Commission Energy and Ocean Resources Unit (1990), all major oil spills motivate reassessments of oil spill prevention and response measures and result in legislation or industry actions improving these variables. The T/V Exxon Valdez spill, the largest in U.S. history, shook the Nation out of its complacency about tanker transport. Unfortunately, the human attention span is short, and the outrage that prompted early proposals to change the system has waned in the year since the Alaska oil spill. Sea otters represent just one of the many entities affected by major oil spills, but they are our responsibility. We will be outrageously negligent if another major oil spill occurs in sea otter habitat and we are no better prepared to protect otters than we were in March 1989 in Prince William Sound. The Federal Government and the States of Alaska, California, and Washington, as well as the Province of British Columbia, must work together on oil spill prevention and on implementing the recommendations proposed here before the next oil spill occurs in sea otter habitat.

\section{References}

California Coastal Commission Energy and Ocean Resources Unit. 1990. Exxon Valdez spill: ramifications for California (discussion draft report). California Coastal Commission, 631 Howard Street, San Francisco, Calif.

Committee on the Conduct of Science-National Academy of Sciences 1989. On being a scientist. National Academy Press, Washington, D.C. 22 pp.

Kenyon, K. 1975. The sea otter in the eastern Pacific Ocean. Dover Publications, Inc., New York. 352 pp.

Robinson, S. (U.S. Fish and Wildlife Service deputy director). 1989. Letter to C. Fulton, executive director, Friends of the Sea Otter. 31 March 1989.

Secretary of the Interior. 1977. Determination of threatened status of the California sea otter (Enhydra lutris nereis). Fed. Regist. 42(10): 2965-2968.

Smith, R. 1990 . Synopsis of the November 20-22 meetings of the Sea Otter Task Force, 9 January 1990. [memorandum]

Williams, T. 1989. The impact to sea otters from oil and sea otter cleanup operation in Alaska-observations for California. California Coastal Commission Workshop on the Exxon Valdez-Prince William Sound, Alaska, March 1989 Oil Spill-Implications for the California coast, 12 June 1989. Monterey, Calif. [speech]

U.S. Fish and Wildlife Service-Acting Project Leader, Endangered Species Office, Sacramento, Calif. 1984. Assessment of significant points of concern relative to the southern sea otter (SSO) 5 year review, 9 April 1985. [memorandum]

U.S. Fish and Wildife Service and Institute of Marine Sciences. 1987. Final environmental impact statement: Translocation of southern sea otters. University of California, Santa Cruz. Vol. 1. var. pagings. 


\title{
Introduction to Workshops
}

\section{Workshops on Capture, Facilities, Husbandry, Veterinary Procedures, and Release}

\begin{abstract}
The five workshops provided an open forum for evaluating the information presented in the symposium papers, discussing the issues, and reaching a consensus on recommendations. A suggestion box was available during the first 2 days of the conference for persons to recommend issues they felt deserved attention at the workshop. The suggested issues were then routed to the appropriate workshops. These workshops played an important role in formulating recommendations for future sea otter (Enhydra lutris) rescue, rehabilitation, and release efforts. Because the workshops were offered concurrently, attendees were asked to choose the workshop in which they had the greatest knowledge, experience, input, or interest. Persons with a strong commitment to a particular workshop topic signed up as "participants" in that workshop. They attended the full workshop and served as a committed, responsible, and active player in the formulation of recommendations concerning issues addressed in the workshop. Persons with a general interest in several topics signed up as "observers." These people were able to move freely between workshops to get an overview of the various issues being discussed and the progress being made. However, direct involvement in the decision-making process was left to the participants. Observers were able to collaborate with participants before workshops to ensure that their concerns were aired. Participants with valuable input for more than one workshop were also encouraged to collaborate with participants of other workshops. A workshop challenge speaker provided an initial list of issues for discussion, in order of priority. The workshop facilitator allowed participants the opportunity to expand on this list and to reset priorities, if there was consensus. The facilitator guided discussion to ensure that all participants had the opportunity to make their points and to expedite formulation of consensus (where attainable) or recognition of nonconsensus. The end product from each workshop consisted of a set of recommendations for action by identified entities, either before or during the next sea otter response effort.
\end{abstract}




\title{
Workshop I. Capture
}

\author{
Facilitator: Jack Hicks \\ Recorder: Leslie Kerr \\ Challenge Speaker: Jack Ames \\ Synthesizers: Bob Hardy and Keith Bayha \\ Reporter: Tom McCloskey
}

\section{Participants:}

Jack Ames, John Anton, Keith Bayha, Pam Bergmann, Jim Blake, Bobby Candopolous, Dean Cramer, Jeff Foster, Ray Hander, Bob Hardy, Larry Heckart, Ken Hill, Ed Klinkhart, Tom McCloskey, Dean Perrollaz, Jeff Rash, Karl Schneider

\section{Issues Identified by the Challenge Speaker}

- How to determine which sea otters (Enhydra lutris) are to be captured-consider:

magnitude of oil spill

preemptive capture

lightly oiled-not obviously oiled

further research and field tests necessary

- Methods of capture

- Communications

- Overall coordination

- Holding and transport protocols

- Personnel and equipment

- Training

Twenty-two participants expanded this list and ranked the issues for discussion:

1. What criteria should apply in deciding to initiate a capture and rehabilitation program?

Consider:

basic reasons to capture preserve the population level enhance survival of individual animals reduce pain and suffering

satisfy human need to "do something"

variability of oil spills

amount of oil spilled

toxicity of oil

geography

weather

season

hazards of capture

safety of capture crew members

disease transmission from rehabilitated otters social disruption

increased pain and suffering (stress)

2. Methods of capture

tangle nets

dip nets

traps

breakaway nets

tranquilizer gun

net gun at haul outs

research on new methods

3. How to determine the degree of oiling of individual sea otters

external

internal

4. Communications (hardware)

5. Criteria for deciding when to capture and rehabilitate versus preemptive capture

6. Organization of capture personnel-overall coordination

7. Training:

capture techniques

record keeping

handling of sea otters

transport techniques

safety

field assessment of sea otter's condition

8. Criteria for decision on when to stop capture effort

9. Role of research during capture phase

10. Record keeping

11. Capture techniques

12. Postcapture handling before transport

13. Best way to transport sea otters

14. What to do when you don't know what to do

15. Need for criteria to judge an oiled habitatacceptable or unacceptable 
16. Survey procedures for relative abundance, while searching for otters in need of capture

17. Guidance on maximum pursuit time for individual otters

18. Independent animal capture (authorized versus unauthorized)

19. Set of field procedures for applying criteria

20. Timing of capture relative to development of rehabilitation facilities

21. Euthanizing on site of heavily oiled otters

\section{Workshop Discussion Results}

1. What criteria should apply in deciding to initiate a capture and rehabilitation program?

Discussion. The Alaska Regional Response Team presently uses the following checklist in deciding whether to recommend implementation of a sea otter capture and rehabilitation program:

- safety of capture team

- legal status of species

- population status (international, national, or regional significance)

- percentage of population affected

- logistical constraints

- anticipated success

- public concern

- use of species as subsistence resource

- projected cost and funding availability

- risks assessment

- welfare of individual animal (survival)

- humaneness

- research potential

They ask these questions:

- Does assessment of capture decision require threat at population level?

- Does rehabilitation make a difference to the individual animal?

- Is risk to the population from reintroducing rehabilitated otters too great?

- Does public opinion drive the decision?

One of the participants, K. Schneider (Alaska Department of Fish and Game, Anchorage), suggested that the Wildlife Protection Working Group consider rearranging its checklist as follows:

Decision to implement a rehabilitation program

A. Benefits

1. Enhance population recovery

a. status of population

b. percentage of population affected

c. special population values
d. anticipated success

2. Public concerns

a. individual animal survival

b. humaneness-degree of pain and suffering

3. Research options

a. to guide action in future spill

b. to answer other biological questions

B. Risks

1. Further injury to population

a. introduce or increase disease

b. increase mortality (from disturbance, handling, social disruption)

2. Further injury to individuals

a. increase injury due to the factors above

b. increase pain and suffering

3. Other
a. response team safety
b. costs (economic)

The workshop participants did not reach consensus on Schneider's suggestion. They did, however, reach consensus on the following recommendation.

Recommendation. The Wildlife Protection Working Group of the Alaska Regional Response Team should amend the Wildlife Guidelines by adding the following to the checklist of when to capture for rehabilitation:

Capture of otters for rehabilitation should only initiated when the following criteria are met:

A. Otters are at risk

B. Adequate facilities exist (i.e., facilities must maintain otters in an environment that has low risk of disease)

C. Survivorship of captured otters meets or exceeds survivorship of otters not captured

D. Capture and rehabilition program does not pose an undue risk to wild otter populations (i.e., disease, social dismuption, mortality)

E. Prerelease facility is in place

F. Facilities exist for keeping otters in captivity that cannot be released back into the wild

2. Methods of Capture

A. Tangle nets

1. Are effective for removal of large num. bers of animals

2. Are very effective at night

3. Are nonselective

4. Are the best technique for preemptive capture. 
5. Corkless tangle nets
a. Are effective in daylight
b. Can be set and retrieved rapidly
c. Are easy to untangle
d. Are nonselective
e. Require continual observation.

6. Drawbacks to tangle nets:
a. Fouled nets may inadvertently oil non- oiled animals
b. Will catch species other than otters
c. Human and animal safety jeopardized in rough weather
d. Possible drowning and injuries of cap- tured animals

\section{B. Dip nets}

1. Are effective for obviously distressed animals, especially for hauled out animals and for severely distressed otters in water

2. Are useful in heavily oiled areas where tangle nets are impractical

3. Are very selective

4. Require training by "dippers" to avoid excessive stress through prolonged pursuit

5. Are hazardous (if done improperly) to personnel and equipment.

C. Breakaway nets are limited to use for habituated animals in water

D. Net guns-the general consensus of the group was that this is not a viable option

E. Traps should be limited to those areas where diving is feasible

Recommendations. The guidelines in (1) above should be included in the capture handbook to be prepared by the U.S. Fish and Wildlife Service.

There should be research of new methods for rough water capture.

The oil industry should contract for design and construction of an optimal capture vessel. This vessel should be similar to the seine skiffs used in the Prince William Sound salmon purse seine fishery (e.g., Boston Whaler or Outrage, powered by outboard engines); equipped with an aluminum or fiberglass reel capable of holding two $91-\mathrm{m}$ nets; the hydraulic reel may be powered by the outboards or an auxiliary two-cycle engine; a removable fairlead attached to the bow; and portable floating holding pens to allow short-term holding in the field. All cleats, screws, and other protuberances should be removed from the vessel. The servicing vessel for the capture crews should have net-cleaning equipment available.

3. What constitutes a lightly oiled animal?
Discussion. The 1989 response effort revealed that detection of lightly oiled sea otters was one of the most difficult decisions capture personnel faced. While several techniques were employed and testing was attempted, there was not consensus that any were fully acceptable.

Recommendation. Further research of a field method for detecting oil in sea otter pelage is needed. The two tests presented by Perrollaz and Rash (unpublished report) and Hill and Tuomi (1990) in the symposium should be evaluated.

Possible statistical modeling, correlating sea otter behavior, concentration of oil in the pelage, and ultimate disposition of the sea otters may be revealing. Initiate a multipoint system of assessment using the following information:
A. Analytical determination of oil concentra- tion
B. Degree of oiling
C. Observed behavior in the wild
D. Observed contamination in area where caught

Researchers should consult the literature for specific information on chemical properties of degraded or oxidized crude oil, then relate specific properties of contaminant to possible ingestion.

\section{Communications hardware}

Discussion. The workshop participants concluded that communications limitations were a major constraint to timely transport of captured sea otters. Recommendation. Pursue improved communication systems through the Alaska Regional Response Team and include specific instructions concerning the selected communication system in a sea otter rescue training program before the next spill response.

\section{When to capture: preemptive}

Discussion. The workshop participants believed that preemptive capture might offer greater efficacy than capture of stressed sea otters, as was the priority in the recent spill.

Recommendation. The Wildlife Protection Working Group of the Alaska Regional Response Team should amend the Wildlife Guidelines by adding to the checklist for When to capture for rehabilitation:

Capture of otters preemptively should be initiated when the following criteria are met: 
A. Otters are at risk

B. Survival of preemptively captured otters meets or exceeds survival of otters not captured

D. Preemptive capture does not pose an undue risk to wild otter populations (i.e., disease, social disruption, mortality)

E. Prerelease facility is in place

6. Communications: chain of command for capture effort

Discussion. Participants identified receiving inconsistent instructions from several supervisors as a communications problem.

Recommendations. In implementing the next response effort, the Fish and Wildlife Service should establish a clear chain of command. The following is suggested:

A. Overall coordinator-otter capture effort

B. Geographic coordinator-maintains regular contact with overall coordinator and field coordinator

C. Field coordinator-person who maintains contact with the geographic coordinator and all boats and crews in their area. This person should have authority to make necessary decisions if impossible to contact the geographic coordinator for directions

7. Training (personnel and equipment)

Discussion. Participants reached consensus that training was an important part of preparation for a number of areas.

Recommendation. The Fish and Wildlife Service should prepare a handbook and appropriate video tapes for use in implementing a training program for local citizens and professionals before the next spill response. The training program should include:
A. Safety
B. Field assessment of sea otter's condition (dependent on criteria to be developed)
C. Capture technique
D. Handling technique
E. Transportation technique
F. Record keeping
G. Annual drilling of trained personnel

(See Wildlife Protection Guidelines for equipment and materials such as freezers, food, and other items to go on capture boats.)
Recommendation. Caches of capture equipment should be placed in strategic locations throughout the area of sea otter distribution in Alaska. The Service should be responsible for approval of materials needed for capture. Those responsible for transportation of oil should be responsible for (financial) support and maintenance of materials.

\section{When to stop capture}

Discussion. There was consensus that lack of criteria for deciding when to stop capture effort was a problem.

Recommendation. Use same checklist.

9. Role of research during the capture phase of response

Discussion. Participants agreed there are research needs that should be pursued before the next spill response and during the next spill response, but they did not take the time to identify specific research needs. Rather, they opted to investigate a parallel effort already under way in California. Recommendation. The Fish and Wildlife Service should develop or arrange for others to develop (1) preapproved study plans to be implemented in the event of spill, and (2) research that should be initiated as soon as possible. One source that merits consultation is VanBlaricom (1990).

10. Record keeping. (see 7 above)

11. Capture techniques. (see 2 and 7 above)

12. Postcapture handling. (see 7 above)

13. Transport of sea otters. (see 7 above)

14. What to do when you don't know what to do. (no consensus)

15. Need for criteria to judge an oiled habitat-acceptable or unacceptable, relative to capturing all otters present. (no consensus)

16. Survey procedures for relative sea otter abundance to focus the capture effort. (no consensus)

17. Guidance on maximum pursuit time for individual otters. (no consensus)

18. Independent animal capture-authorized versus unauthorized. (consensus that only Fish and Wildlife Service capture teams should capture sea otters)

19. Set of field procedures for applying criteria. (consensus that research is required)

20. Timing of capture relative to development of rehabilitation facilities. (no consensus)

21. Euthanizing on site of heavily oiled otters. (no consensus) 


\section{References}

Hill, K., and P. A. Tuomi. 1990. Field test for detecting crude oil on the fur of sea otters. Pages 95-122 in K. Bayha and J. Kormendy, tech. coords. Sea Otter Symposium: Proceedings of a symposium to evaluate the response effort on behalf of sea otters after the T/N Exxon Valdez oil spill into Prince William Sound,
Anchorage, Alaska, 17-19 April 1990. U.S. Fish Wildl. Serv., Biol. Rep. 90(12).

Perrollaz, D. C., and J. Rash. 1990. Analysis of sea otter fur for crude oil contamination. (unpublished report)

VanBlaricom, G. R. 1990. Draft subcomittee report. Research needs relating to oil spills in the habitat of the sea otter in California. Interagency working group on sea otters and oil spills in California. U.S. Fish and Wildlife Service, Santa Cruz, California. 


\title{
Workshop II. Facilities
}

\author{
Facilitator: Bob Hays \\ Recorders: Connie Hill and Carol Cook \\ Challenge speakers: Randy Davis and Jim Styers \\ Synthesizers: Ruthie Stough and Kirk Vasey \\ Reporter: Randy Davis
}

\author{
Participants: \\ Randy Davis, Linda Redman, Ruth Stough, Jim Styers, and Kirk Vasey
}

\section{Issues Identified by the Challenge Speaker}

Challenge speakers R. Davis and J. Styers opened the workshop by suggesting that the major objective be to produce a report containing facility recommendations including what should be done to prepare for or react to a future spill affecting sea otters (Enhydra lutris).

\section{Workshop Discussion Results}

\section{Relation Between the Spiller and Agencies}

Discussion. Some believed that the Department of the Interior has a conflict of interest between its role in promoting off-shore oil development and its role in wildlife and environmental protection.

Recommendation. The trustee for sea otters (U.S. Fish and Wildlife Service) should be accountable to a board of trustees. This board of trustees would be tentatively called the "Wildlife Protection Working Group" and would include representatives from industry, interest groups, and local, State, and Federal governments.

Recommendation. Enact legislation to establish a Federal trust fund to provide ongoing funding for preparation and response. The rationale is that a capacity for immediate response is needed; that is, a center, equipment, and other items must be in place beforehand. It was suggested that a minimum of $\$ 25$ million was needed for the fund and possibly double that figure if wildlife other than sea otters are included in the plan.

The trust fund would be managed by the board of trustees, thereby giving the board the power to build centers, hire staff, and operate and maintain the centers in a timely manner. The funds would be obtained through either donations from the oil industry or the taxing of petroleum products.

A consensus was reached that the spiller's involvement in setting up and operating the wildlife rescue-rehabilitation centers would be a conflict of interest. With this in mind, it was recommended that the spiller be billed for expenses after a spill or project completion. It was further recommended that the spiller be on-site and that the representative or auditor of the spiller have marine mammal expertise.

\section{Centers}

Discussion. Participants in the workshop were interested in overall center design, but did not address it in great detail.

R. Davis presented his plans for a 100-otter permanent center and for an expanded center. The 100 -otter center would accommodate 60 otters in tote pools and 40 otters in large pools, plus a nursery on a "flow-through" basis. The participants outlined the following as their recommendations. Both plans are intended to be flexible and to expand as needed.

Recommendation. For future rehabilitation of sea otters:

In Alaska, contingency planners should include provisions for three phases of rehabilitation-a permanent center, mobile triage units, and prere- 
lease areas. The whole system would operate on a "flow-through" basis, dependent on individual animal health.

\section{Permanent Center}

\section{Rationale}

1. It would be available for year-round operation.

2. It could provide immediate response.

3 . It would not require relocating people.

4. It would be a large center.

\section{Site criteria}

1. All-weather road and air access.

2. A natural, quiet setting, free from disturbances, such as heavy traffic and construction noises.

3. Clean seawater supply available.

4. Access to business and supply sources.

5. Controlled access to site.

6. Seafood supply and storage capabilities.

7. Staff housing (on- or off-site).

Design criteria

1. Interchangeability of components with the mobile triage units.

2. The center must be state of the art.

3. On-site warehousing of supplies.

4. Staff housing (on- or off-site).

5. Administrative center.

6. Critical care area.

7. Long-term care for nonreleasable animals.

8. Interpretive center for training, education, and media.

9. Controlled access (i.e., fencing).

10. Individual pools, not raceways.

11. Pens and pools should be isolated, or at least away from the main complex and main people area.

12. Design access to pens and pools so there is minimum disturbance from staff during feeding and observations.

13. The physical plant which houses pumps and maintenance shop should be away from the pen and pool area.

14. Pens and pools should be at eye level to reduce intimidation of otters during feeding and observations.

15. As much sound proofing as possible.

16. Limited climate control; that is, protection from wind, freezing, and humidity to accommodate for seasonal and climatic changes in weather.

17. Easily cleaned pools.
18. Isolated observation stations for staff observers.

19. Pen and pool design that promotes natural behavior and reduces stress associated with captivity.

20. Wastewater capacity and design adequate to

a. produce water quality that meets or exceeds U.S. Department of Agriculture standards for captive marine mammals.

b. meet State (Alaska Department of Environmental Conservation) and local or municipal wastewater regulations.

21. Animal food preparation and storage facility.

a. 400 square-foot walk-in freezer

b. 200 square-foot walk-in refrigerator

c. 400 square-foot food preparation room

d. 30 feet of counter space-stainless steel

e. six large deep-well sinks-stainless steel

f. hot and cold water supply

g. six hose and six faucet fixtures

h. four large exhaust fans

i. adequate lights, windows, skylights

j. waterproof floors and walls

k. floor drains

1. shelving and cabinets

m.ice machines

n. tools and equipment

Design criteria submitted from other workshops

1. Husbandry

a. pools and filters that are easily cleaned

b. arrangement for access to animals without having to pass other animals (blind access)

c. arrangement for nonintrusive observation

d. eye-level cages

e. separate facilities to ensure quiet (including salt-water supply)

i. for nursery-separate from adult otters

ii. for critical care

(See also recommendations on facilities in "Workshop IV. Veterinary Procedures," this volume.)

Mobile Triage Units

Rationale

1. Would be available whenever needed. 
2. Would have the ability to be taken anywhere.

3. Would lessen construction time, allowing for quick operation.

4. Immediate triage and stabilization

a. in the event the permanent center is hundreds of miles away, or

b. if transport to the permanent center is not possible because of bad weather, temporary care could be pro. vided

Site criteria

1. Flat ground.

2. Access by air transport (i.e., fixed-wing aircraft or industrial transport helicopter).

An alternative concept submitted by a nonparticipant called for the mobile triage unit to be placed on a large vessel and therefore able to move with the oil and the capture efforts.

Design criteria:

1. Must be fully self-contained, including power generator, wastewater management.

2. Storable at permanent center.

3. Dry pens.

4. Pool pens.

5. Oil spill containment booms.

If the triage site is such that floating pool pens are used, booms must be in place around them. Access to clean salt water is essential.

\section{Prerelease Areas}

Rationale

1. Designed to be stored and easily reassembled for fast response.

2. In the event of preemptive capture, they would be available within a couple of days.

Site criteria

1. Natural setting-lagoon area.

2. Minimum noise and visual disturbance.

3. Designed to withstand wind and strong currents.

4. Adequate water circulation to maintain good water quality.

Design criteria

1. The equipment must disassemble and be storable.

2. Stored at permanent center.

3. Large pens $\left(9.2 \times 30.5 \mathrm{~m}^{2}\right)$.

4. Staff housing at prerelease site.

5 . Must be fully self-contained.
6. Utilities-generator, communications, fresh water.

\section{Disease Problems}

Recommendation. To the U.S. Fish and Wildlife Service and directors of the otter rehabilitation centers:

Policies and protocols must be established to prevent disease transmission within rehabilitation centers.

Recommendations include

1. Complete controlled access of staff and visitors.

2. Exclusion of domestic animals from facilities.

3. Controlled viewing area to prevent contact between otters and visitors.

4. Regular screening of animals for domestic diseases.

5. Quarantine procedures.

6. Training in disease control for all personnel.

\section{Rehabilitation Center Management}

Discussion. The ability to preplan can prevent a crisis-induced lapse in management. Suggested organization would include

1. Director

2. Operations manager with subordinate supervisors for
a. veterinary medicine
b. food preparation
c. husbandry (including a behaviorist)
d. facilities maintenance
e. nursery
f. engineering

3. Logistics and communications manager

4. Personnel officer a. volunteer coordinator

5. Documentation and property inventory and control officer

6. Public relations officer

a. internal information office- to keep staff informed, and up to date

The rest of the staff would be determined by the director and operations manager. The number of staff depends on husbandry recommendations for the number of people needed per otter. Averages from the T/N Exxon Valdez oil spill response were:

Valdez Otter Rehabilitation Center, 0.5-3.5 persons per otter per day

Seward Otter Rehabilitation Center, 0.5 persons per otter per day 
Recommendations. The otter rehabilitation center director should adopt a management concept or style to ensure that

1. Management authority is clear.

a. someone is always in charge

b. management has no conflict of interest

(i.e., business-related interest)

2. The organization is interactive.

a. has a clear chain of command

b. delegates responsibilities

c. holds staff meetings regularly

d. has free flow of information up and down the chain of command.

3. New hires undergo a probationary period of 1-2 weeks.

4. Qualification and background of new hires are adequately researched to ensure appropriate expertise among the staff.

5. Everyone takes at least 6 days off per month.

6. 12-h shifts are provided for continuity and best animal health care.

7. Meals are provided on site so people do not wander off during food breaks.

8. Group events such as picnics are provided (.) keep up morale.

9. Volunteers
a. receive regular training
b. make long-term commitment
c. use a docent-type program
d. are assigned to wash animals and do "hands off" types of work

10. Adequate security is provided through

a. controlled access to the facility

b. a badge system with color coding for easier identification of administration, supervisors, volunteers, and others

c. personal lockers with locks in changing rooms

d. restricting access to controlled substances used by veterinarians to accountable individuals e. restricting access to documentation files to accountable individuals

\section{Media and Tours}

Discussion. There was substantial interest in the sea otter rehabilitation centers by both the general public and the press. This can be a problem as well as an opportunity. At the very least, this interest must be managed so as not to disrupt the primary work at the center with additional effort and response. This interest might be turned into an educational force of substantial weight.

Recommendation. The Fish and Wildlife Service contingency planners and the center director should consider the alternatives. If a proactive program is desired, these ideas emerged from the workshop:

1. Interpretive center

a. a live video in the center to view animals

b. educational displays/films/bookstore

2. Media and tour protocol to limit access; rationale for disease control and to reduce ani$\mathrm{mal}$ and staff stress

3. Review the possibility of display animals in the interpretive center

\section{Recommendations for Future Research}

1. Test long-term holding facility designs

2. Improve sea otter cleaning techniques

3 . Thermoregulatory studies for improving rehabilitation protocols (e.g., warmwater baths)

4. Additional research to analyze existing data collected during previous oil spills

\section{Recycling}

Recommendation. The Fish and Wildlife Service and rehabilitation center directors should adopt a policy that promotes ecological sensitivity at all centers. 


\title{
Workshop III. Husbandry
}

\author{
Facilitator: Joe Truett \\ Recorder: Rosa Meehan \\ Challenge Speaker: Terrie Williams \\ Synthesizer: Jill Otten \\ Reporter: Jill Otten
}

\begin{abstract}
Participants:
Peter Ferrante, Tanya Holonko, Julie Hymer, Nancy Michaelson, Jill Otten, Jeff Rash, Dale Styers, Pam Tuomi, Terrie Williams, Frank Wilson
\end{abstract}

\section{Issues Identified by the Challenge Speaker}

The challenge speaker, T. Williams, asked us to consider the following during our discussion:

1. A flexible system, that could handle heavily and lightly oiled sea otters (Enhydra lutris).

2. A system that could provide for the natural needs of otters.

3. A flow-through concept, tracking otters through arrival, washing, recovery, rehabilitation, and prerelease.

\section{Workshop Discussion Results}

\section{Communications}

Problems identified and discussed (the following statements outline the recommendations of the participants):

1. Improve external communications-trustee agency (U.S. Fish and Wildlife Service, Alaska Department of Environmental Conservation, National Oceanic and Atmospheric Administration) feedback and directives.

This was decidedly the responsibility of the directors of the rehabilitation centers, who should set guidelines for clear communication of agency directives to avoid confusion and conflict. The center directors should also communicate with the spiller and the press.

2. Improve communication between shifts in husbandry staff.
We addressed the morale problems that can often result from poor communication between shifts. This was the responsibility of husbandry coordinators. One suggestion was to have two husbandry coordinators, one to work from 0600 to $1800 \mathrm{~h}$, the other to work an overlapping shift, from 1200 to $2400 \mathrm{~h}$, and act as a shift liaison and decisionmaker during the major part of the night shift. Communication between husbandry staff on different shifts would occur at a set time each day, at shift changes.

3. Improve intrafacility communication-this was the responsibility of the center director, who defined the organization and responsibility of administration, veterinary, and husbandry staffs (Figure).

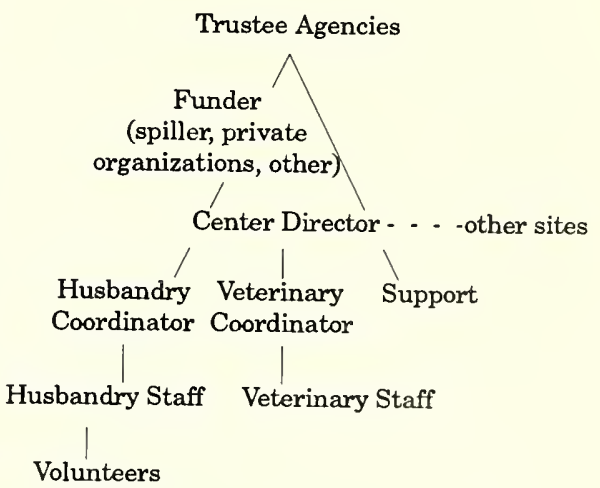

Fig. A proposed communication flowchart. 
The center director would be responsible for establishing a chain of command, and for developing a communication model that outlined agency responsibilities, the center's roles, and kept communications clear. This communication model should be set up in contingency plans so it can be functional at the time of a spill.

The use of a bulletin board similar to the one used at the Seward Otter Rehabilitation Center (SORC) was suggested, where personnel in charge could be listed, as well as what was happening that day (otters arriving, being washed, being moved).

Regular staff meetings were recommended.

4. Improve communication with funding source.

The trustee agencies would be responsible for setting guidelines in developing a communications manual, and easing cooperation from the funding source. Each rehabilitation center should be preequipped with this manual.

5. Improve communication between different sites (centers, capture crews, and prerelease sites). Examples used were

- Husbandry personnel would work with capture crews to minimize stress associated with capture and transport.

- Capture crews would fill out complete and informative capture records to help center staff when giving initial treatment on otters' arrival.

- A dedicated radio link should be established between the rehabilitation centers and the capture teams to ensure clear communications with the field.

- Daily conference calls should be scheduled between centers to ensure good communication.

6. Improve record keeping.

The importance of up-to-date copies of records and the need to establish staff for record keeping was discussed.

We decided that daily printouts from a computer data base were important for assessing problem areas. The computer data base developed by $D$. Swarthout for use at SORC was very effective. P. Tuomi also offered to research a wildlife rehabilitation record-keeping data base that was developed by M. Longo (Tufts University, Medford, Massachusetts, personal communication), to determine its usefulness in otter rehabilitation.

It was suggested that papers published in these proceedings (Loshbaugh 1990; Swarthout 1990; and Rash et al. 1990) on record keeping be referenced in detail when evaluating what is needed in a record-keeping system.

The behavioral observation system used at SORC was discussed. The consensus was that it was helpful during rehabilitation to get a thorough assessment ( $15 \mathrm{~min}$ observations, from a distance).

It was not necessary to monitor as closely in a prerelease or long-term holding facility, where observations could be more general and infrequent.

It was agreed that the same record-keeping system should be used by all sites, and that it should correspond with the computer data base for quick entry and reference.

\section{Stress Reduction}

Problems addressed with regard to stress reduction in a rehabilitation (hospital) setting were

1. Capture Stress Syndrome-it was suggested that material by T. D. Williams, D.V.M., on capture stress syndrome be referenced, and that recommendations be made on how to reduce stress related to capture.

2. Housing - suggestions were made to the facilities group. Recommendations taken into account were socialization requirements (ensuring sufficient housing units to separate groups according to natural social groups, and providing for special needs); and space requirements (allowing more space in enclosures to lessen problems arising from confinement during rehabilitation).

3. Human interaction-problems creating stress for otters were associated with capture, handling, medical treatments, movement, feeding methods, observation methods, effects of visitors, and physiologic stress.

The responsibility for reducing stress associated with human interaction falls on the husbandry coordinator.

The husbandry coordinator and veterinary coordinator should work together to reduce physiologic stress.

Some suggested steps to reduce stress were

- Reduce noise

- Reduce handling

- Schedule and consolidate movements and placement to reduce disruption

- Limit human contact

- Keep otters at eye level-don't look down on them 
- Have facilities ready to use immediately, since the first $3-5$ days in rehabilitation are critical for stabilizing otters and reducing stress for low-impact rehabilitation

- Coordinate with capture crews to have ice in transport, to increase comfort and avoid any additional thermoregulatory distress

- Ensure accurate capture records, to give rehabilitation crews an accurate first assessment of each otter's condition

- Observe otters' behavior from a distance, or from "blinds" set up for observations

- During rehabilitation, provide distraction with natural objects such as ice, kelp, rocks, or shells

- Provide areas of quiet isolation and necessary social options for stressed otters

\section{Provisions for Special Cases}

Responsibility for handling special needs in rehabilitation falls on the husbandry coordinator in collaboration with the nursery supervisor and veterinary coordinator. Problem groups requiring special handling were

1. Orphaned Pups-these pups need to be isolated physically from the adult otters, and from otter noises. They require intense human attention for feeding and grooming, and may need to be isolated even from the other pups. It was suggested that they have their own separate saltwater system. Protocols that cover in detail the special procedures and requirements necessary to raise orphaned pups, whether destined for human care or released to the wild, were written by Styers and McCormick (1990) and by J. Hymer (Monterey Bay Aquarium, Monterey, California). It was suggested that, in the case of an oil spill involving orphaned pups, all pups go to one center with specially trained personnel to work with them.

2. Normal (unoiled) otters - it was suggested that these, and all rehabilitated otters with good coat condition, be transferred out of the rehabilitation (hospital) setting to prerelease or long-term holding facilities after initial health assessment. This should take about 2 days to determine, and will depend on blood tests and observations. It is important to reduce human contact whenever possible.

3. Juvenile otters - this group tended to be particularly prone to signs of stress and were consid- ered a high-risk group-especially young females. One suggestion was to place them with a socially compatible group of females, where one of the adults could possibly "adopt," or form a social bond with the juvenile. Social isolation for young otters was not recommended, and copying natural social structure for wild otters is recommended whenever possible.

4. Pregnant females-it was recommended that every effort be made to facilitate the restoration of their coat condition before pupping, so they could take better care of a pup. Alternatively, these animals should be released as soon as possible, to allow pupping in the wild. Factors used to determine the release site should include: availability of sufficient prey, clean water, proximity to capture site, and presence of territorial males in the area. If release is not possible, a quiet location, preferably a prerelease site, and a pool for each mother-pup pair, if possible, is recommended, reducing distractions for the mother.

5. Mothers with pups-optimum spatial requirements are one mother-pup pair per pool, thus avoiding competition. It was also suggested that the pairs be moved to a quiet prerelease situation as soon as they were able. In Alaska, mothers were often oiled, while pups were not. It is possible that the mothers ingested the oil from the pups' fur while grooming them, and thus may have additional toxic problems. When the pups are larger, a larger pool is required to allow room for nursing. When pups are born at the center, policy outlining protocols for pulling pups when mothers reject them, or are unable to care for them, should be developed. It was believed that the welfare of the adult female should be given priority over that of the pup, because of her increased chances of survival and future participation in breeding. All efforts should be made to let the mother care for the pup naturally. If a pup is separated from the mother to be raised in the nursery (presumably a decision has been made that it is the pup's only chance for survival) it should be done in the least stressful way for the mother. The mother can be distracted, and only two staff members should be present.

6. Critical care-medical cases-a quiet, isolated area with its own saltwater system (for quarantine requirements) should be provided for critical-care otters. The use of warm water for swimming critical-care otters was discussed, since 
they developed abrasions and pressure sores on paws and flippers from prolonged periods lying on grating or plywood. Because they cannot thermoregulate, and have more difficulty grooming and waterproofing their coats, placing them in cold salt water was believed to risk hypothermic reaction. Use of warm water for swimming (above $9^{\circ} \mathrm{C}$ ) is thought to break down natural oils in skin and hair follicles. Suggestions such as raising and lowering water in the enclosure for short periods and using less abrasive materials on floors of haul outs were made. Use of warm water was also thought to cause high humidity, which further prevents good thermoregulation. Dry air and good ventilation (cool wind) are important for thermoregulation, even with critical care otters. It was concluded that further research was needed in this area.

\section{Staff Needs}

1. Recruiting - the support staff would organize the recruiting of staff. Decisions about hiring would be made by the husbandry coordinator, with final approval from the director.

It was suggested that the Service should keep lists of experts involved in the T/N Exxon Valdez oil spill to use, if possible, in another incident involving sea otters. Ongoing sources for current, up-to-date expert lists include

- Wildlife Rapid Response Team contact: J. Styers and T. McCloskey

- the Sea Otter Monograph contact: T. M. Williams and R. Davis

- American Veterinary Medical Association contact: T. D. Williams, P. Schraeder

- 1989 Otter Rehabilitation Centers mailing list contact: T. Monahan

2. Training-prespill training of potential husbandry personnel is optimal. Orientation onsite is also recommended for initial training of new staff. Topics in training should include preparation for incidents of otter death. The use of instructional video tapes for husbandry training, such as those planned by International Wildlife Research, would be helpful. It was suggested that R. Smith, in California, be contacted for training materials. Any prespill training materials should be archived by the Service. The Service should also archive copies of any postspill papers dealing with sea otters.
It was suggested that protocols for rehabilitating sea otters developed by Otten (1990) based on experiences at SORC be reviewed by a volunteer panel of the workshop participants, and used for general guidelines when treating sea otters in a rehabilitation setting. Recommendations are made in the protocols regarding minimum staffing requirements.

3. Safety-includes that of humans as well as animals.

- Regarding human safety, basic first aid should be available at the center, and at a local hospital prepared for quickly treating wounds and other potential human problems related to sea otter rehabilitation.

- Staff burnout and stress should be addressed as a safety precaution, and 1 day off each week is recommended to help prevent fatigue, stress, and burnout. Staffing should be increased to handle the necessary time off.

4. Volunteers-should be trained by experienced staff. Use of trained volunteers will vary depending on amount of skill and location of the center.

\section{Disease Control}

It is the responsibility of the center director, working with the husbandry and veterinary coordinators to ensure proper disease prevention standards. These standards should be rigidly enforced and be included in prespill and on-site training.

Problems discussed with regard to disease control were:

1. Water sanitation-incoming water used for otters' pools must be checked for contamination by nearby sewage outfalls. Water quality should be monitored periodically (weekly testing recommended) for coliform bacteria count. Pool water quality should be as good as possible, meeting at least minimum U.S. Department of Agriculture standards for otter health. High water turnover (at least once per hour) and inflow and outflow skimming should ensure low coliform counts. Bacteria in contact with otters from any source should be kept to a minimum.

2. Food handling-Ferrante et al. (1990) developed protocols for food handling in an otter rehabilitation facility, including recommendations for strict standards in sanitation and food quality.

To avoid introduction of exotic bacteria in the otters' food, it is recommended that, whenever possible, local sources for otter food be used. The 
highest quality food possible should be fed to the otters, fit for human consumption. Food should be inspected before feeding.

3. Equipment and building sanitation-to prevent fomite transfer, it is suggested that husbandry staff scrub down and suit up before entering rehabilitation areas. Rubber boots, overalls or raingear, and rubber gloves, all disinfected, should be used around the otters. It was not believed that wearing masks for the long shifts required was feasible, but strict hospital standards should be observed. Disinfecting foot baths should be used when entering and exiting the center and special quarantine areas.

\section{Visitors.}

Visitors should not be allowed into the hospital or rehabilitation areas, or to have contact with the otters. A viewing area for visitors, with a glass window, could be provided as an alternative to entering otter areas.

No domestic animals should be allowed into the centers.

5. Quarantine and Isolation.

- Critical-care or quarantined otters should be handled by dedicated personnel who do not handle other otters that shift. Clothing changes and disinfection are required for entering and exiting those isolated areas.

- It was suggested that newly admitted otters be kept in areas isolated from the others until assessment was made.

\section{Feeding and Diet}

Protocols (Otten 1990; Ferrante 1990) were developed for recommended nutrition, routine, schedules, and delivery:

- Minimal human interaction while feeding is recommended. In a prerelease holding situation, a feeding "blind" where otters will not see the feeder is recommended. As much as possible, duplicate natural otter feeding requirements.

- Food preparation and presentation, including appropriate thawing methods, should be provided in prespill and on-site training.

- Nutritional requirements should be decided and reviewed by the veterinary or husbandry coordinator. Food supplements and, if possible, kelp, should be provided.
- Ice should always be available to otters who do not have full-time access to water, to meet fluid requirements.

- Individual requirements due to age and medical condition should be addressed and provided.

- In a prerelease pool or other group setting, food consumed should be monitored as closely as possible, to make sure all otters are eating sufficient amounts.

- Suppliers should be local if possible. Food should be frozen to reduce introduction of parasites in food, and should be the safest available. When possible, whole foods containing all organs (e.g., crab, mussels, shrimp, clams, sea urchins) should be fed to supply nutrition normally in the otters' wild prey source.

- Shell roughage in amounts determined to match natural requirements should be provided.

\section{Coat Restoration}

Allowing the otters to groom normally, therefore restoring the insulating properties of their coats, is the major goal in rehabilitation. It is the husbandry coordinator's responsibility to provide everything the otters need to restore coat condition, within the restrictions of center design. Problems with coat restoration included:

1. Water quality - excellent surface skimming and clean salt water are vital to efficient grooming.

2. Improve otter cleaning methods-additional research testing other detergents (which may rinse more easily) is suggested.

- It is important to completely dry otters after washing.

- Drying rooms need to have low humidity and be cooled.

- Towels (3M), used for a short time at the Valdez Otter Rehabilitation Center (VORC) to dry the otters after washing, were very absorbent. P. Tuomi offered to further research their use, and to make sure there are no chemicals or additives on the towels that might contaminate otter fur.

- Otter fur conditioners, like the Redken artificial sebum product used at VORC, may speed coat restoration, or at least help provide necessary insulation during the first stages of grooming. Although the effectiveness of this product was not conclusive, further refinements are being made by L. Hunter (Redken Laboratories, Inc., Canoga Park, California, personal communication). 
3. Improve housing facilities-providing ideal housing is the responsibility of the facility designers and the husbandry coordinator.

- A cool area with low humidity and good ventilation (fans or direct wind) is best to stimulate grooming and to allow otters to thermoregulate on their own, as much as possible. Steps to take during cases of hypothermia or hyperthermia are discussed elsewhere.

- Warming the water for critical-care otters (to try to lessen body heat loss in the water) creates additional humidity, so it is not recommended. Rash et al. (1990) reported that water temperatures above $9^{\circ} \mathrm{C}$ can be detrimental to otters' coat restoration.

- Reducing stress and physical problems, then providing an optimal low-impact grooming environment, was recommended for most efficient coat restoration.

It is recommended that the grooming and coat gradation method of Rash et al. (1990) be used to evaluate progress in grooming and coatrestoration.

\section{Protocols}

Protocols on different subjects based on the experience gained are provided in the present symposium proceedings. The subjects and authors are sea otter rehabilitation (Otten 1990), sea otter pup rehabilitation (Styers and McCormick 1990), sea otter food preparation (Ferrante 1990), sea otter cleaning techniques (Williams et al. 1990), and grooming and coat gradation (Rash et al. 1990).

\section{Conclusion}

General recommendations made during the Husbandry Workshop were that, to ensure most effective rehabilitation of sea otters affected by an oil spill, it was necessary to be prepared. Preparations to be made in advance of a spill are

- Contingency plans

- Detailed protocols for most effective otter care

- A communications model

- A common record-keeping and computer system

- Training programs (qualified personnel should be pretrained)

- Rehabilitation facilities and equipment, and long-term holding pens, ready for immediate use

\section{References}

Ferrante, P. 1990. Food procurement and feeding of sea otters during the T/V Exxon Valdez oil spill. Pages 321-322 in K. Bayha and J. Kormendy, tech. coords. Sea Otter Symposium: Proceedings of a symposium to evaluate the response effort on behalf of sea otters after the T/V Exxon Valdez oil spill into Prince William Sound, Anchorage, Alaska, 17-19 April 1990. U.S. Fish Wildl. Serv., Biol. Rep. 90(12).

Loshbaugh, S. F. 1990. Record keeping for an otter rehabilitation center. Pages 182-223 in K. Bayha and J. Kormendy, tech. coords. Sea Otter Symposium: Proceedings of a symposium to evaluate the response effort on behalf of sea otters after the T/N Exxon Valdez oil spill into Prince William Sound, Anchorage, Alaska, 17-19 April 1990. U.S. Fish Wildl. Serv., Biol. Rep. 90(12).

Otten, J. 1990. Husbandry at the Seward Otter Rehabilitation Center. Pages 285-300 in K. Bayha and J. Kormendy, tech. coords. Sea Otter Symposium: Proceedings of a symposium to evaluate the response effort on behalf of sea otters after the T/N Exxon Valdez oil spill into Prince William Sound, Anchorage, Alaska, 17-19 April 1990. U.S. Fish Wildl. Serv., Biol. Rep. 90(12).

Rash, J. A., C. R. McCormick, R. Alexander, S. J. Nichol, and D. C. Perrollaz. 1990. Coat gradation and conditioning of sea otters at the Seward Otter Rehabilitation Center. Pages 258-273 in K. Bayha and J. Kormendy, tech. coords. Sea Otter Symposium: Proceedings of a symposium to evaluate the response effort on behalf of sea otters after the T/V Exxon Valdez oil spill into Prince William Sound, Anchorage, Alaska, 17-19 April 1990. U.S. Fish Wildl. Serv., Biol. Rep. 90(12).

Swarthout, D. J. 1990. Animal rehabilitation center data base. Pages 224-235 in K. Bayha and J. Kormendy, tech. coords. Sea Otter Symposium: Proceedings of a symposium to evaluate the response effort on behalf of sea otters after the T/N Exxon Valdez oil spill into Prince William Sound, Anchorage, Alaska, 17-19 April 1990. U.S. Fish Wildl. Serv., Biol. Rep. 90(12).

Styers, D., and C. R. McCormick. 1990. Pup nursery at the Seward Otter Rehabilitation Center. Pages 301312 in K. Bayha and J. Kormendy, tech. coords. Sea Otter Symposium: Proceedings of a symposium to evaluate the response effort on behalf of sea otters after the T/V Exxon Valdez oil spill into Prince William Sound, Anchorage, Alaska, 17-19 April 1990. U.S. Fish Wildl. Serv., Biol. Rep. 90(12).

Williams, T. M., J. McBain, R. K. Wilson, and R. W. Davis. 1990. Clinical evaluation and cleaning of sea otters affected by the T/V Exxon Valdez oil spill. Pages 236-257 in K. Bayha and J. Kormendy, tech. coords. Sea Otter Symposium: Proceedings of a symposium to evaluate the response effort on behalf of sea otters 
after the TN Exxon Valdez oil spill into Prince William Sound, Anchorage, Alaska, 17-19 April 1990. U.S. Fish Wildl. Serv., Biol. Rep. 90(12). 


\title{
Workshop IV. Veterinary Procedure
}

\author{
Facilitator: John Warden \\ Recorder: Bill Seitz \\ Challenge Speaker: Jim McBain \\ Synthesizers: Jim McBain and Jon Thomas \\ Reporter: Jim McBain
}

\section{Participants:}

Carolyn McCormick, Jim McBain, Jack Tuomi, John Blake, Riley Wilson, Jon Thomas, Harold Spaulding, Tom Williams, Laura Kelly, Keith Harris, and Chris Harvey-Clark

\section{Issues Identified by the Challenge Speaker}

Recommendation. To the U.S. Fish and Wildlife Service and contingency plan authors:

Acute treatment of sea otters (Enhydra lutris) should begin on a capture boat rather than after arrival at a rescue center.

Rapid initiation of treatment could make the difference between survival and death. Treatments should consist of a broad-spectrum antibiotic, administration of fluids, dexamethasone, selenium, vitamin $\mathrm{E}$, and vitamin $\mathrm{B}$-complex, as deemed appropriate by the attending veterinarian. Capture boat crews should attempt to minimize the physical stress of capture. Food and water should also be offered. A veterinarian should be aboard each mothership. Initial admission procedures and record keeping should be begun on the mothership.

\section{Workshop Discussion Results}

Based on the experience of the T/V Exxon Valdez oil spill we recommend the following treatments: Hypothermia: (Normal rectal temperature 99 to $100^{\circ} \mathrm{F}$ ). Warm fluids (intravenous or intraperitoneal) or lay the animal on a warm surface (garbage bags filled with warm water work well). Dry the coat if it is wet.

Hyperthermia: If temperature is above $104^{\circ} \mathrm{F}$ offer shaved ice or ice cubes for the otter to eat and lie on. Packing ice on the flippers is helpful.

Hypoglycemia: (Laboratory finding: serum glucose less than $85 \mathrm{mg} / 100 \mathrm{~mL}$; signs are depression, rapid chilling, and occasional seizures) Treatment should first aim at decreasing energy consumption by decreasing swim time and if possible warming the pool water to 60 to $65^{\circ} \mathrm{F}$ and drying the coat of very weak animals if they are also hypothermic. The next consideration is to make adequate calories available by feeding according to food preference to maintain maximum food intake. Ice containing glucose can be fed for a rapid response. Intravenous glucose or oral glucose via stomach tube can be used in otters that are extremely depressed or comatose.

Crude oil exposure: (Ingestion, inhalation, and cutaneous contact). We agree that the activated charcoal treatment is of questionable value and recommend that the U.S. Fish and Wildlife Service arrange for a group of veterinarians and toxicologists to investigate more effective treatments.

Capture Stress Syndrome: (Signs are screaming, shivering, muscle stiffness, anorexia, hyperthermia, and hypothermia). Physical stress should be minimized in all stages of capture, handling, and transport. The treatment recommended should be antibiotics, glucocorticoids, selenium, Vitamin E, and fluids including bicarbonate (which must be given intravenously). This condition was deemed serious enough to recommend to contingency planners that blood gas analyzers be part of the equipment available to monitor treatment. Further investigation into other medications, such as Dantrolene, should be initiated.

Pulmonary and subcutaneous emphysema: No treatment was used for these conditions. It is unclear if the emphysema itself was responsible for fatalities (there was a high correlation between emphysema and mortality). 
Corneal ulcers: Flush eyes before and after washing animal and instill antibiotic ointment. Continued treatment was generally unnecessary. Deep ulcers can be patched with surgical adhesive and animal can be maintained on systemic antibiotics.

\section{Recommendation. To veterinarians:}

The best sedation protocol for washing sea otters, on the basis of current experience, is fentanyl, acepromazine, and diazepam given in combination, as described in the Sea Otter Symposium proceedings.

A triage system can be helpful in deciding which animals are likely to have a chance of survival and which are unlikely to survive. This becomes most important when the case load exceeds the capacity of the medical staff. This system should be a multigrade system that takes into consideration the degree of oiling, the known toxicity of the oil at the time of exposure, activity level of the otter, physical examination findings (diarrhea, emphysema, hyperthermia, hypothermia), and serum hydrocarbon levels (animals with levels greater than 200 ppm usually died). Equipment should be available and capable of measuring blood hydrocarbon levels. This triage system cannot be completed until all of the spill-associated data regarding sea otters become available.

Recommendation. To the U.S. Fish and Wildlife Service and veterinarians:

There should not be a triage system for pups. Emotions of the public and care facility staff members dictate that all pups are treated regardless of circumstances.

Recommendation. To the U.S. Fish and Wildlife Service and contingency planners:

Because of the risk of capture, lightly oiled otters should probably not be picked up but, in the event that they are captured, they should be sent directly to a prerelease area after admission and examination. This recommendation is intended to decrease the case load in the rescue centers, leaving staff and space for animals requiring therapy. This recommendation obviates the need for construction of prerelease areas early in the spill response.

Recommendation. To the rehabilitation center director:

Otter rescue center pharmacies should be secured areas with access limited to designated persons.
Recommendations to U.S. Fish and Wildlife Service and contingency planners:

Modular laboratory and hospital facilities should be available to make rapid response available. The hospital should have a flow-through design to aid in preventing cross-contamination and disease spread. The laboratory should be in regular use at a place such as the University of Alaska so that its equipment is operating and upgraded over time. Stored areas are often vandalized or become unusable after years of storage. There should be a list of items needed to make the hospital and laboratory ready for operation.

Recommendation. To the U.S. Fish and Wildlife Service and veterinary medicine researchers:

The toxicity of crude oil requires a great deal more investigation; toxicologists seemed poorly equipped to explain the toxic effects of the crude oil ingestion by the sea otters.

The cause of the anemia seen in many of the oiled otters needs to be defined. Data from hematology and histopathology results should be made available to attempt to understand this medical problem.

Recommendation. To rehabilitation center directors:

Open communication between veterinarians and veterinary pathologist must exist.

Recommendation. To the U.S. Fish and Wildlife Service and contingency planners:

Clinical pathology and pathology data should be incorporated in data base.

An established computer record-keeping system should be in place before a spill occurs.

Rapid clinical pathology results are essential to effective treatment. The Service needs to ensure that pathology work is performed in a timely manner. The recommendations in the symposium paper of R. Haebler (1990) symposium paper should be considered by the Service.

Medical and husbandry forms should be designed and available in the event of a future environmental disaster.

These recommendations have been made to emphasize the need for adequate records and the timely availability of medically relevant information.

Recommendation. To the U.S. Fish and Wildlife Service and contingency planners:

A flow-through type hospital setting and the use of medical teams can functionally limit the potential spread of disease between newly arrived ani- 
mals and those that are completing their hospital stay.

No pets should be allowed anywhere on the grounds of hospitals and animal holding, handling, or transporting areas.

New staff on the hospital medical and husbandry teams should complete a 1-week probation to determine their ability to perform the tasks required and to participate in a positive manner with the other team members.

Recommendation. To the U.S. Fish and Wildlife Service:

If transmitter tagging is used on rehabilitated animals in the future, the program should have a control group to make the results scientifically useful and to reduce misinterpretation and misuse of the data.

Recommendation. To the U.S. Fish and Wildlife Service and rehabilitation center director:

All animals admitted for rehabilitation should be implanted with an identification microchip. These chips do not fall off and do not conflict with other tagging systems.

\section{Recommendation.}

A national wildlife contingency plan is needed. This plan should be administered by a Federal lead agency with the management of specific species problems falling under the agencies that currently have jurisdiction over those species. This plan would include organizational flow charts, data management, species-specific plans, and handbooks and plans for regional response teams.

This sort of plan is needed to allow the rapid integration of the agencies involved in a given event and to facilitate a rapid and effective response.

\section{Reference}

Haebler, R. J., R. K. Harris, J. M. Pletcher, R. B. Moeller, and T. P. Lipscomb. 1990. Pathological examination and collection of toxicological specimens from sea otters. Pages 369-374 in K. Bayha and J. Kormendy, tech. coords. Sea Otter Symposium: Proceedings of a symposium to evaluate the response effort on behalf of sea otters after the T/V Exxon Valdez oil spill into Prince William Sound, Anchorage, Alaska, 17-19 April 1990. U.S. Fish Wildl. Serv., Biol. Rep. 90(12). 


\title{
Workshop V. Release
}

\author{
Facilitator: Charlotte Benji \\ Recorder: Jill Anthony \\ Challenge Speaker: Lisa Mignon Rotterman \\ Synthesizers: Lisa Mignon Rotterman and Keith Bayha \\ Timekeeper: Susan Shane
}

\begin{abstract}
Participants:
Jill Anthony, Amy Christensen, Mary Hogan, Lloyd Lowry, Albert Manville, Jon Nickles, Ann Rappoport, Lisa Mignon Rotterman, Lloyd Rudd, Susan Shane, Elizabeth Sharpe, Terry Spraker, and Paul Wunnicke
\end{abstract}

\author{
Observers: \\ Ron Britton, Roman Haskins, and Jack Lentfer
}

\section{Issues Identified by the Challenge Speaker}

- Underlying goal of a release policy

- Linkage of capture and holding practices and release policy

- Whether release should occur

- Where release should occur

- Basis for decision making

The participants agreed that the issues identified by the challenge speaker were of high priority. They suggested additional major issues:

- Who should make decisions on release policy

- Information and research needs

- When to release

- Public education

The participants also identified several subissues under the first and fourth issues, which are discussed further.

\section{General Discussion}

The issues were not ranked in importance. However, by virtue of ensuing discussion, it was clear that the issues of greatest concern were the effect of disease risk to the wild population on release policy, the basic goal of the policy, and criteria for determining whether release should occur. Emphasis was on ensuring that all identified issues be addressed immediately, so that a detailed standing release policy exists before the occurrence of another major spill in the range of the sea otter (Enhydra lutris). Because of the close relation between capture and holding policy and release policy, and because we cannot presume to know what future capture and holding policy will be, the participants considered two separate capture and holding scenarios while discussing the release issues.

The first scenario considered was similar to the circumstances that followed the T/V Exxon Valdez oil spill at the Valdez and Seward Sea Otter Rehabilitation centers. In this scenario, animals considered for release were captured because they were assumed to be oiled, cleaned, and treated, and held in an artificial setting where contact with humans was relatively high. Although this was termed a "highly captive" scenario during discussion, it is termed "oiled/highly captive" in this synthesis for clarity. However, the scenario actually imagined by the participants assumes that many of the worst mistakes made after the last spill would be remedied in any future, highly captive setting (e.g., quarantine measures would be in effect).

The second capture and holding scenario assumed that sea otters would be preemptively captured (before they were oiled) and held in a barricaded but natural or seminatural setting in which human contact was minimal, domestic animal contact prohibited, and natural foods provided. This is termed a "preemptive/seminatural" scenario for this synthesis. 


\section{Discussion and Recommendations of Issues Raised}

\section{Issue 1. Underlying Goal of a Release Policy}

Discussion. The challenge speaker contended that the first issue in policy formulation was to determine the goal to be realized by the release policy. Alternate goals suggested were attainment of a positive balance sheet overall, that is, more individual sea otters being helped than harmed; and aiding individual sea otters, with no regard for the ramifications to the natural population.

L. Lowry said it was important to make clear whether the focus of the release policy was the individual or the population. J. Nickles suggested that if there were not assurances at every step that the population would benefit, then capture and release should not be attempted in Alaska where the sea otter numbers are high. L. Rudd suggested that it was important to think about helping individuals, as well as the effect on the population, especially because it was important to children that they see something being done. Other participants pointed out that wild populations are made up of individuals, and thus, that negative effects on the wild population meant that individuals were going to suffer.

Recommendation. The guiding principle of a release policy should be that more individual animals should be helped than harmed by implementing the policy. There should be a net benefit to the population of sea otters from which the animals were taken, those inhabiting the locations where release is proposed, and those taken into captivity.

\section{Issue 2. Linkage of Capture and Holding} Practices and Release Policy

Discussion. The challenge speaker said release policy is inextricably linked to capture and holding policy because

1. The release of individuals that have been held in captivity poses a considerable risk to wild populations of the same species, and perhaps to other species, due to the possible introduction of disease. Capture and holding policy in large part determine this risk because different policies have different levels of exposure associated with them.
2. Capture policy determines whether otters being dealt with are likely to have been oiled or not, and hence, may relate to their probability of survival after release.

Discussion of feedback between capture, holding, and release policy was focused on the effect that disease risk has on release policy and the effect that capture and holding conditions have on that risk. Additionally, there was discussion of other ways in which capture policy affects release policy, (e.g., through the separation of mother-pup pairs, the pups of which are usually nonreleasable).

Views on whether capture should occur if release was not possible were varied and included

- That capture should occur, but the animals should be held in captivity in highly visible settings so that the public is reminded of the ramifications of the oil spill,

- That capture should occur, but non-releasable animals should be euthanized, and

- That it was not ethical to capture individuals that could never be released.

Rotterman suggested the minimal level of capture (consistent with the identified goal) should occur and capture should be preemptive, with individuals held in barricaded, natural settings.

\section{Consensus Opinions of Participants}

Capture and holding policy to a large extent determines disease risk, and hence, the likelihood that an individual will ever be released to the wild. Thus, capture and holding policies must give serious consideration to disease risk.

It should be assumed that the oiled/highly captive scenario is associated with a degree of disease risk to the natural population, and that the risk associated with the preemptive/seminatural scenario is lower. The preemptive/seminatural scenario was favored by the participants of the workshop because of the lowered disease risk and reduced stress to the otters. Most participants believed that the prospects for eventual release were greatly increased over those of sea otters held in the highly captive situation.

At each step of capture, treatment, and holding activities, there should be a determination made of whether the specific action is likely to result in a net benefit to the natural population. If this answer is not clearly yes, the action should cease.

\section{Items on Which No Consensus Was Reached}

Although some participants believed that as few individuals as possible should be captured and 
that they should be captured on the basis of the degree of oiling, some believed that only preemptive capture was useful.

No consensus was reached on whether the riskbenefit ratio was ever low enough, after animals are held in the highly captive situation, to justify their release. Some participants believed that the risk was unacceptably high, whereas others believed that a hypothetical disease risk should not prevent release. It was believed that the decision to release must be decided according to the principles outlined above, on a case-by-case basis.

Recommendation. Because different capture and holding policies have different risks associated with them, integrated capture-holding-release policies are needed. Detailed capture and holding protocols should be developed and followed in the event of another spill. Emphasis on minimizing disease risk is imperative in capture and holding protocols because of the critical influence such risk has to release policy.

Extreme care should be taken during the capture and holding periods to minimize both direct and indirect contact of the sea otters with humans or other species of animals.

Release policy should be developed for two different scenarios: an oiled/highly captive situation (similar to that in centers after the T/N Exxon Valdez spill, but with better quarantine conditions), and a situation in which indiriduals are captured preemptively and held, preferably in a seminatural situation behind a barricade or in net pens (e.g., similar to the Octagon or Jakolof PreRelease Facilities).

\section{Issue 3. Whether Release Should Occur}

The challenge speaker identified three factors that provided the basis for release criteria:

1. Disease risk to natural populations of sea otters and other species.-Risks posed to the wild sea otter (and other) populations by the possible introduction of a new or modified disease need to be considered in the formulating release policy.

2. Ability of young sea otters to survive after release.-Objective criteria for assessing the developmental competency of individual pups to survive in the wild need to be developed.

3. Medical Condition.-Objective protocols for determining the medical condition of the animals, including condition of the fur, body condition, and physiology.
[Editor's note: Although not recognized in the foregoing, all three factors were considered in development of the release strategy employed by the Fish and Wildlife Service in 1989. Further, the Marine Mammal Protection Act, Section 109(h)(3) requires that steps be taken in any case feasible, to return animals taken under the welfare clause (Section (h)(1)(A) to the wild. Fish and Wildlife Service policy provides for two exceptions: where health of the individual requires continued long term care, or where the animal is behaviorally unfit for release. Thirty-seven sea otters were not released under these provisions.]

The participants identified two more factors:

4. Disease testing - the appropriate role that disease testing should play in the decision process may be limited given the limitations in such testing (a negative result does not mean there is not disease present).

5. Contribution to receiving population-the relative contribution of the released animals to the receiving population should be considered.

Discussion focused primarily on the disease issue, and implications from the telemetry study of the animals released from the treatment centers after the T/V Exxon Valdez oil spill. T. Spraker gave a review of the herpesvirus (Harris et al. 1990) and potential complications from that disease, including neonatal death. He pointed out that cross-specific disease transmission could occur and that when it does, a disease that has relatively mild effects in its regular host may be deadly in its new host (e.g., a herpesvirus that causes oral lesions in monkeys but is fatal in humans). He also discussed the policy of releasing animals with active lesions. He pointed out that when the lesions are active the animal is shedding large amounts of virus, and hence, is infective. He reminded the participants that they don't want to cause more death than that caused by the oil spill and that disease may do just that. In the discussion, the participants were frustrated that they could never be sure whether disease was present (because a negative test does not mean no disease), and hence, that there was always a potential for introduction of disease.

\section{Consensus Opinions}

The decision to release or not must be decided on a case-by-case basis. The basic questions to be addressed, in order of priority, are

- Will the release benefit the wild population?

- Is there an unacceptable risk to the wild population? 
- Will the release benefit the captive sea otters?

One should not automatically assume that individuals that are captured will be released. Individuals should not be released if the wildlife population will not benefit. Important factors to be considered are number, age, sex, condition of animals to be released, the likelihood of their survival, and the status of the receiving population.

Released individuals that have been held in captivity pose a risk of unknown magnitude to the recipient population. Every reasonable step should be taken to minimize the risk of introducing disease during capture and holding of sea otters.

In assessing risk, the following factors should be considered:

- Evidence of infectious disease-a negative test result does not mean that there is no disease present; the responsible agency should discuss tests used and results with many informed people (e.g., pathologists, epidemiologists, and virologists), and animals with active infectious disease should not be released under any circumstances; the release of animals held with infected otters should be decided on a case-bycase basis.

- Length of captivity-the probability of exposure to disease increases as length of time in captivity increases.

- Known potential exposure to infectious disease.

- Adequacy of procedures in capture, handling, and holding to prevent exposure to disease.

To gain information about disease risk, an appropriate sample (if the capture-housing scenario is preemptive/natural) or all (if it is oiled/highly captive) individuals should be tested for domestic animal diseases, any disease known to be present in sea otter populations when they are first brought into captivity, before decisions are made about their release.

If individuals show signs of active contagious disease, they should be isolated as long as they are likely to be contagious to other animals. These individuals should be studied so that the exact type and implications of the disease can be understood. If the disease is shown not to be endemic, they should be isolated permanently or euthanized.

\section{Items on Which No Consensus Was Reached}

No consensus was reached on whether the riskbenefit ratio was ever low enough after animals were held in the highly captive situation to justify their release.
No consensus was reached on whether asymptomatic individual sea otters (known to be infected with a disease that was definitively shown to be endemic within the population in which the individuals were to be released) should be released or should be isolated temporarily or permanently. The major reason for this lack of consensus was a lack of information about the risks associated with such a release.

No consensus was reached on whether individuals deemed "nonreleasable" should be held in captivity permanently or whether they should be euthanized. One participant suggested that such individuals be kept in a facility paid for by the spiller as a reminder to the public of the ramifications of oil spills, and thus, serve as an educational tool. Other participants believed that this would be cruel to the individual otters and that they should be euthanized. Thus, failure to reach agreement in this case stemmed mainly from philosophical or ethical differences among participants.

Recommendations. Clear guidelines containing the fundamental components of a decision-making process concerning the disease risk factor and the use of those components should be developed.

If it is decided that the release of individuals from captivity provides little or no benefit to the wild population, but that there is an unacceptable risk to it, then animals should be held in captivity for the foreseeable future, and not released.

If no suitable habitat is available (e.g., the food supply has been eliminated or is highly contaminated), individuals should not be released.

Objective criteria to determine developmental competency of individual sea otters to survive (e.g., weaning length-weight ratios, diving behavior, wild food recognition) should be developed. Those meeting the criteria would be released, if the other previously mentioned criteria are met.

\section{Issue 4. Where Release Should Occur}

Discussion. The challenge speaker outlined three factors to stimulate the discussion:

1. Location of population stocks.-Because of legal and biological concerns, population stock identity (as defined in the Marine Mammal Protection Act) should be taken into consideration in choosing release sites.

2. Translocation Stress.-Release policy should be developed in light of available information about the likely outcomes of particular types of translocation, including the likelihood that 
individuals will survive or stay at the site of release.

3. Socioeconomic considerations.-An issue that was considered in the Fish and Wildlife Service's 1989 Release Strategy was socioeconomic and political ramifications of releasing large numbers of otters in a particular area.

The group added a fourth factor:

4. Habitat quality at potential release sites.-The group sought guidelines for assessing habitat quality at potential release sites and for determining, on the basis of habitat quality information, whether the site is suitable for release. Specific issues for discussion include: prey abundance and distribution, hydrocarbon levels in prey, and the carrying capacity of the habitat relative to the sea otters already inhabiting the site.

One participant, in discussing translocation effects, referred to the San Nicolas Island, California, translocation project. Most participants believed that translocation should be avoided. However, M. Hogan questioned whether we wanted to be definitive on the issue of translocation. She believed that the term "translocation" was being used to broadly. [Editor's note: Translocation has been used to mean relocation outside the individual's home range, outside the subpopulation's range, and outside the population's range.] Discussion that followed revised "translocation," for purposes of this workshop discussion, to mean "release outside of the subpopulation," unless otherwise stated. The point the participants wanted to make was that it may be stressful and disadvantageous for sea otters to be released into unknown areas.

However, Hogan pointed out that in some instances this may be the only option other than permanent captivity. She asked, "If the wild population is not at great risk, is it better to lose some individuals after release due to translocation stress than to have all captured otters remain in captivity or be euthanized?"

Discussion ensued on the tradeoffs of permanent captivity versus disease risk, increasing the risk to individuals in the wild by mixing subpopulations, and on translocation effects. Discussion kept returning to overall risk-benefit analyses, which must be made on a case-by-case basis. Some participants questioned whether the risk to the wild population, and to other species, is ever justifiable. Many believed that permanent captivity and euthanasia were last choices.
Lowry pointed out that carrying capacity must also be considered. He noted that it should not automatically be assumed that an area already supporting a large number of residents (as in the previous release of sea otters into eastern Prince William Sound) can necessarily support a large number of additional residents. Part of the riskbenefit ratio to the natural population should include evaluation of what effect the release, particularly a translocation of individuals to an area that they did not previously inhabit, will likely have on the animals already resident in the area in terms of both disease risk and carrying capacity. The discussion of carrying capacity was broadened and it was noted that information should be available about prey availability and prey contamination levels before animals are released into an area.

Rotterman summarized that there were three distinct concerns with respect to translocation: 1) the disease issue, in which risk to natural populations increases as individuals are moved to a different subpopulation or population than that of which they were a part when captured; 2) the risk to the individual being translocated, due to the stress of being moved to unfamiliar habitat (in this case, moving an individual to an area outside the extant range may entail greater risk to the individual but less risk to natural populations of the same species); 3) the carrying capacity issue, with risks to the individuals being released and to the receiving population if the release causes an exceeding of the carrying capacity. Rotterman recommended animals from one population stock not be released within the range of another to avoid possible biological and legal problems.

\section{Items Without Consensus}

No consensus was reached on whether, as an only option for release to the wild, translocation to areas outside of the bounds of the subpopulation is recommended if there is no indication of disease.

Recommendations. The first preference is to release individuals in clean, supportive habitat (see below) within an average home range distance of the site at which they were captured. Unanimous. The second preference is for release within the approximate boundaries of the subpopulation of origin. Unanimous. The three other alternatives in order of preference were translocation and release, permanent captivity, and euthanasia.

- Before releasing individuals in an area, information should be collected about the ability of the habitat to support these animals. Data 
should be collected about the availability of prey, hydrocarbon levels in the prey (if it is proposed that animals will be released in or adjacent to areas affected by the oil spill prompting their capture), the carrying capacity of the habitat, and the number of otters already inhabiting the proposed release location. Unanimous. If there was no suitable clean habitat then longterm holding had to be considered.

- Sea otters should generally not be released in nonsupportive habitat or in areas where their release would result in the aggregate of otters in the area (the existing residents and the new releases) exceeding the carrying capacity of the area.

- Sea otters should not be translocated to distant locations. Three major reasons were agreed upon as forming the basis of this recommendation: Translocation causes stress and imparts a high degree of risk to the individual otter being released in a unfamiliar location; translocation increases the risk of spreading disease to more populations of sea otters and to other species; and the habitat carrying capacity issue. The first two reasons were unanimously supported.

- All females should be released in female areas, whereas adult males should be released in male areas. Young males should be released in the type of area in which they were captured.

- Stress and disturbance should be minimized at the release sites, particularly during the release of female-pup pairs and pregnant females.

\section{Issue 5. Basis for Decision Making}

The challenge speaker suggested that participants should provide explicit recommendations about the underlying basis for decision making (e.g., political versus biological considerations).

Recommendations. Biological considerations should override socioeconomic and political concerns in the formulation of release policy.

\section{Issue 6. Responsibility for Decision Making and Costs}

Participants wanted a consensus reached on who should make decisions about release policy and who should pay for such items as capture, housing, release, and research.

Discussion. Those participants offering opinions on these issues suggested that the decision-making process and lines of authority affecting sea otter release policy after the T/N Exxon Valdez spill were seriously flawed. Much of the criticism centered around the spiller's role in decision making. Participants believed that the spiller should have no role in decision making. Participants who had worked at the treatment centers cited lengthy delays in decision making. Other participants cited the decision to release sea otters with active oral lesions as the prime example of severe problems with the decision-making process. One individual informed the group that such a decision would have been illegal if sea ctters were domesticated animals. Most participants wanted a single entity in charge, but emphasized that there must be room for feedback from the public and scientific entities. Some participants acknowledged, however, that after the T/N Exxon Valdez oil spill, public pressure played too strong a role in decision-making. All participants agreed that this problem could only be addressed through public education, and that decisions should be biologically based, as discussed previously.

One participant informed the group that in nonfederalized spills the Service is in an advisory role to the spiller. (This needs clarification since, through provisions of the Marine Mammal Protection Act, the Service can limit possession and disposition of sea otters or parts of sea otters and can control other policy affecting them.)

Major suggestions offered as to who the responsible entity should be included: a) the Service, in federalized and nonfederalized spills, with the note that public review is very important; b) a nongovernmental scientific group; c) a commission, independent of the government, possibly composed of members of the scientific community, environmental groups, or representatives of the government. It was suggested that the Marine Mammal Commission could play an important role in providing scientific advice about release policy or that a committee, including virologists, be selected before a spill, possibly in conjunction with the National Academy of Sciences. It was pointed out that experts were consulted before the release of animals captured in response to the T/ Exxon Valdez, but another participant said that, because animals with active lesions were knowingly released, the responsible entity should consider getting advice from other "experts."

\section{Consensus Opinion}

Some single entity must have responsibility and decision-making authority in a spill. 


\section{Items on Which No Consensus Was Reached}

Agreement could not be reached on whether the U.S. Fish and Wildlife Service should have sole decision-making authority after a spill on issues related to sea otters. The major alternative suggestion was that an independent committee be appointed to make such decisions. There was deep concern raised over the decision made by the Service in the T/V Exxon Valdez oil spill to release sea otters with active lesions back into the wild. However, a majority felt that the Service should at least be involved in the decision-making process. Failure to reach a consensus stemmed mainly from differences among participants in the level of confidence they had in the Service.

\section{Recommendations.}

- The responsible entity should be decided on before the next spill. Additionally, this entity should develop criteria and a template for decision making before occurrence of the next spill.

- The spiller should have no decision-making role related to sea otters in any spill, including nonfederalized spills. Unanimous.

- The spiller should bear all costs associated with capture, holding, treatment, feeding, transport, release and (if necessary) permanent captive maintenance of sea otters affected by a spill. Unanimous.

\section{Issue 7. Information and Research Needs}

The group felt that it should provide recommendations for research needed now, before the next spill.

Discussion. The committee recognized that the current level of knowledge was insufficient in several areas relevant to release policy. Participants felt that it was important to provide guidelines for research priorities to those responsible for developing contingency plans.

\section{Consensus Opinions}

Participants agreed that results presented at this symposium of telemetry studies on the otters released from the treatment centers were valuable and emphasized the need to ensure that a comprehensive long-term research program was in place.

It was agreed that it was important to understand all of the ramifications of a spill, not just the immediate mortality.

With respect to the specifics of the research, there was also little disagreement. Participants agreed it was a good idea to mark individuals in more than one way. There was agreement on the need to stockpile flipper tags with numbers on both sides and an easily visible color.

\section{Items on Which No Consensus Was Reached}

The participants could not agree on whether healthy, wild-caught sea otters should be translocated within Prince William Sound to determine whether the low survival rate observed in the animals released from the treatment centers after the T/N Exxon Valdez spill was due to translocation stress.

No agreement was reached on which entity should be in charge of formulating and conducting research relevant to release policy, even though there was agreement that there should be peer review of the research proposals.

There was no agreement about the need for research on treating natural sea otter diseases.

\section{Recommendations.}

- The following research should be conducted on sea otters either before, during, or after the next major oil spill in sea otter habitat:

1. Research that should be conducted on the effects of the T/N Exxon Valdez spill

Postrelease survival, reproduction and movements of otters held in treatment centers constructed after the T/N Exxon Valdez oil spill.-Ongoing studies of released sea otters should be continued, with a monitoring effort sufficient to obtain valid estimates of mortality (including causes) and reproduction rates and to locate individuals that have made long-distance movements. In order to obtain information about cause of death, necropsies should be performed and samples collected for histopathological and toxicological analyses on recovered carcasses of sea otters that were held in these centers and on a suitable number of control individuals.

Habitat-prey studies relevant to the T/N Exxon Valdez oil spill.-Studies aimed at assessing the distribution and abundance of important sea otter prey species, and of the levels of hydrocarbon contamination of such species, need to be undertaken now in the area affected by oil from the T/V Exxon Valdez. These studies should be specifically integrated with ongoing studies of sea otters in the same area.

Necropsy studies.-Necropsies should be performed on all fresh carcasses of sea otters discovered in the oil spill zone and on any carcasses of otters released from the treatment centers. 
Beach walks.-Beach walks aimed at assessing levels of mortality and at recovery of fresh carcasses (to aid in determining cause of mortality through necropsies) should be conducted in the oil spill zone, including on the Kenai Peninsula.

2. Research that should be conducted before the next spill

Development of research protocols.-Research protocols should be developed immediately for research to be undertaken at the time of the next spill. Development of such protocols will enable researchers to focus on data-gathering immediately rather than scrambling to determine what needs to be done.

Development of release criteria.-Research needs to be done now to identify appropriate criteria for evaluating release sites (including health of sea otter food organisms), medical evaluation of the otters, developmental evaluation, and evaluation of disease risk.

Studies of diseases of natural populations of sea otters.-After the T/V Exxon Valdez oil spill, a herpes-like virus was identified in sea otters held at the SORC. One of the issues of greatest contention surrounding the release of these sea otters back to the wild (although not the only issue) was whether this virus was present in sea otters in the areas where these individuals were to be released (eastern PWS and coastal areas of the Kenai Peninsula) or whether a new virus was being introduced into wild populations by this release. In order to provide greater information about the occurrence of natural diseases in sea otter populations, studies aimed at documenting diseases and further investigating the herpes-like virus in natural sea otter populations should be carried out.

3. Recommendations for research after future oil spills

Postrelease survival, movements and reproduction.-After each major oil spill in which sea otters are affected, studies aimed at assessing the longterm health, movements, reproduction, and survival rates of released sea otters should be carried out over a period of at least three years (see first research recommendation). It was agreed that radio-implants were a necessary research tool in such studies. The number of animals to be im. planted in these studies should be large enough that results are statistically valid. Thus, statistics should be considered in research design and implementation. However, unreasonable replication should be avoided and other stresses minimized.
Every animal that is released should be tagged in the flippers with colored tags that are readily visible, but that differ in color from those carried by the individuals selected for the implant study. Each individual that is released should carry a transponder chip injected below its skin for permanent identification. Unanimous.

Habitat-Prey Studies.-If animals are to be released into either their previous home range area, or into another area, information is needed about the ability of the habitat to support them. Several related issues need to be addressed by such research: a) the current carrying capacity of the habitat in the proposed area of release; b) the size of the population inhabiting the area before the release occurs; c) contamination of the prey (when considering whether to release near the capture location); and d) the general suitability of the habitat for sea otters. It is recommended that, before release, prey surveys be conducted in proposed release sites, and determination of the hydrocarbon levels of prey at those same sites be made. Habitat studies should also be made after release, to understand the outcomes and behavior of the individuals released. Unanimous.

Other research needs identified include effect of captivity, chronic oil spill effects, and sublethal effects.

\section{Issue 8. When to Release}

Discussion. Participants from the treatment centers constructed after the T/ Exxon Valdez oil spill expressed the view that the length of captivity was a major problem that negatively affected the health of otters in those centers.

\section{Consensus Opinions of Participants}

Increasing the length of captivity increases disease risk and increases stress, all other things being equal.

Recommendations. If a decision is made to release a given animal, or group of animals, release should occur as soon as possible, given consideration of factors listed under "Whether and Where to Release Should Occur."

Females with pups and pregnant females are the highest priority animals for release, and consideration of their release status should be made first. These animals should be soft-released (as was done at Jakolof Pre-Release Facility) if possible. 


\section{Issue 9. Public Education}

Discussion. The importance of this issue became apparent in discussions of other issues. Discussion mainly centered on the need to educate the public about biological realities so that public pressure will not stem primarily from emotional responses and, hence, put pressure on policy makers to insert emotionally based elements in response policy. L. Lowry (who was concerned about risk of disease transmission to the wild populations) suggested that the oil companies responsible for the spill set up an educational facility with the rehabilitated otters as a constant reminder.

\section{Consensus Opinions}

A program is needed to educate the public about the research findings of ongoing effects of the $\mathrm{T} N$ Exxon Valdez oil spill on sea otters, the potential disease risks from releasing treated animals into the wild, and stress associated with captivity.

Recommendation. Such a program should be initiated immediately.

[Editor's note: This workshop did not define who was expected to act on the recommendations. A subsequent effort should be made to fix responsibility.] 



\section{Acknowledgments}

We thank the many persons whose collective efforts resulted in a successful symposium and these proceedings.

The steering committee members, identified on the inside cover, provided valuable advice and shared responsibility for the many difficult decisions involved in planning the symposium and these proceedings.

The session chairpersons and session editors are identified in these proceedings at the beginning of each session. These people played key roles in conducting the sessions and ensuring the quality of the papers. The authors are identified for each paper, and their roles in the response effort are also presented in Appendix B. Peer reviewers of the presented papers are listed in Appendix C.

The workshop challenge speakers, facilitators, recorders, authors, and reviewers are identified at the beginning of each workshop synthesis. They were directly responsible for the success of the workshops. Additionally, R. Meehan deserves credit for arranging for the workshop facilitators.

A. (Ayers) Storie assisted with manuscript typing and staffing the registration desk at the symposium.

The editorial staff at the U.S. Fish and Wildlife Service, Office of Information Transfer (OIT) in Fort Collins, Colorado, provided final editorial review of the proceedings. A. Storie and S. Loshbaugh reconciled the OIT comments; R. Gould provided the policy review for the Service; A. DeGange, J. Gruber, B. Grafel, T. Odenbaugh, N. Michaelson, and A. Storie assisted in the review of galley proofs.

The registered participants in the symposium are listed in Appendix D, to aid in continued communication.

A financial grant from the National Fish and Wildlife Foundation ensured publication of these proceedings. 



\section{Appendix A. Sea Otter Response: Chronology of Events, 1989}

24 March

25 March

27 March

29 March

30 March

31 March

1 April

2 April

6 April

7 April

11 April

12 April

13 April

14 April

14 April

15 April

17 April
The T/V Exxon Valdez runs aground on Bligh Reef in Prince William Sound, Alaska.

The Exxon Corporation contracts with Sea World (San Diego) to rescue oiled otters and establish an otter rehabilitation center in Valdez.

First rehabilitation center opens at Prince William Sound Community College in Valdez.

First otter capture boat, F/V Dancing Bear, leaves port.

Oil moves out of Prince William Sound and nears Resurrection Bay near Seward.

Second otter capture boat, F/V Rhoda Mae, leaves port.

First oiled otter arrives at Valdez Otter Rehabilitation Center (VORC).

U.S. Fish and Wildlife Service contracts with two more capture boats, SS Viking and Sea Raker, to begin picking up oiled otters the next day.

K. Weaverling launches first of 28 Cordova District Fishermen's Union boats over the next 3 days.

The Service asks Exxon to build an otter rehabilitation center in Seward.

VORC requests hold on captures. They are over capacity with 21 otters washed and 20 more on hand.

Construction begins on larger rehabilitation facility at Valdez.

Six critically ill otters are transported to Sea World, San Diego; one dies in Anchorage, and eventually four die in San Diego.

Oil hits the Chiswell Islands south of Seward.

VORC moves into expanded facility.

The Service issues a press release to halt unauthorized efforts to capture oiled otters.

Oil moves around the Kenai Peninsula off English Bay in Cook Inlet.

Six sea otters are sent to Point Defiance Aquarium, Washington; two eventually die and one is transferred to Sea World.

Two otter pups are sent to Monterey Aquarium, California.

The first rehabilitated otters are placed in floating pens in the Valdez small-boat harbor.

Service regional director approves new policy for capture crews to release unoiled otters at point of capture.

Temporary Care Facility is established in Homer.

First otter captured off the Kenai Peninsula and transported into VORC.

Six otters are sent to Vancouver Aquarium, British Columbia; two eventually die.

Ten Bears, the first capture boat in Kodiak zone, leaves port. 
18 April

21 April

22 April

25 April

30 April

1 May

2 May

5 May

7 May

8 May

10 May

15 May

17 May

22 May

23 May

28 May

17 June

13 July

14-15 July

13-27 July

25 July

27 July

28 July

Homer reports oil in the mouth of Kachemak Bay.

Ground breaking and construction begin on rehabilitation center in Seward.

Tar balls hit Uyak Bay, Kodiak Island.

Oil washes up on the west side of Kodiak Island.

Rehabilitated otters are transferred from floating pens to Solomon Gulch Hatchery.

Homer Temporary Care Facility receives first otter, which later dies in transit to VORC.

Oil hits the beaches of Katmai National Park, Alaska Peninsula.

More than 500 dead otters have been recovered from the path of the spill.

Hold order issued to capture boats in Kenai Peninsula zone.

First otter from Kodiak arrives in Seward.

The leading edge of the oil is 500 miles southwest of the spill site and oil is found along more beaches of the Alaska Peninsula.

First oiled sea otter is cleaned at Seward to test newly constructed equipment.

Another hold order issued to capture boats in the Kenai zone after the count reaches 43 otters in Seward.

The Seward Otter Rehabilitation Center is operational.

Construction begins on Jakolof Pre-Release Facility.

The Service releases six rehabilitated otters and one rogue with flipper radio tags in Simpson Bay, Prince William Sound, as part of the release plan to determine if they will return to oiled areas.

Restart of capture off the Kenai Penninsula.

Exxon reorganizes all otter centers under R. Davis.

The Service approves moving 21 otters from the overcrowded SORC to Valdez.

Otters held at the hatchery are transferred to a large floating salmon pen (octagon) in Port Valdez.

Homer Temporary Care Facility is closed; four remaining otters are transferred to the Jakolof Pre-Release Facility.

First transfer of otters from SORC to Jakolof.

Two late-term pregnant females are released in Little Jakolof Cove.

Thirteen rehabilitated otters escape after holding pens are slashed at Octagon PreRelease Facility; five are later recaptured.

Eight sea otters (four females with pups) are released in Little Jakolof Cove.

Twenty-six otters at the octagon holding pens and seven otters at SORC are implanted with abdominal radio transmitters. During surgery at SORC, oral ulcers (possible herpes-like virus) are discovered.

One of the captured otters from the 13 July group escaped again.

Thirteen rehabilitated otters (12 with abdominal radio transmitter implants) from VORC are released in Sheep Bay, Prince William Sound.

Receive confirmation that herpes-like virus is present in wild otters.

Fifteen rehabilitated otters (12 with radio transmitter implants) from VORC are released in Nelson Bay, Prince William Sound. 
4 August Four adult otters with chronic health problems are sent to Sea World, San Diego.

7-16 August Crews examine Kenai Peninsula for suitable release sites.

11 August Twelve otters from Jakolof are implanted with abdominal radio transmitters.

Ten otters (three mother-pup pairs, and 4 pen mates) without transmitters are released in Little Jakolof Cove.

13 August Two late-term pregnant females are released in Little Jakolof Cove.

15 August Six otters are released in Nelson Bay and eight in Sheep Bay, Prince William Sound.

16 August Eighteen otters are released in Nelson Bay (3) and Sheep Bay (15).

17 August Seven otters from SORC are released in Taylor Bay and one in Picnic Bay, Kenai Peninsula.

18 August Octagon and rehabilitation center at Salmon Exchange are closed; demobilization is completed on 25 August.

19-21 August Jakolof otters without radio transmitters are released in Nuka Bay (7), James Lagoon (24), and Harris Bay (25), along the Kenai Peninsula.

22 August Twelve Jakolof and three Seward otters with abdominal radio transmitters and six without transmitters are released in Sheep Bay and Nelson Bay, Prince William Sound.

Four SORC otters are released in Harris Bay.

30 August Last four otters from the Jakolof Facility are released; Jakolof Pre-Release Facility is closed.

11 September Thirteen sea otter pups are transferred from Seward to Point Defiance Aquarium, Tacoma, Washington.

13 September Otter rehabilitation centers are closed. 


\section{Appendix B. Index To Authors.}

Alexander, R. - Marine Animal Resource Center, Seattle, Washington.

Coat Gradation and Conditioning of Sea Otters at the Seward Otter Rehabilitation Center

Ames, Jack - California Department of Fish and Game, Monterey, California. Viking capture and survey crew; sea otter capture certification specialist for Kodiak zone; dimethyl chloride test study team.

Impetus for Capturing, Cleaning, and Rehabilitating Oiled or Potentially Oiled Sea Otters After the T/V Exxon Valdez Oil Spill

Armitstead, Clyde. - Eagle River, Alaska.

Pathological Examination and Collection of Toxicological Samples From Sea Otters

Bates, Melissa. - San Diego, California.

Pathological Examination and Collection of Toxicological Samples From Sea Otters

Batten, Bruce T. - Public affairs officer, U.S. Fish and Wildlife Service, Anchorage, Alaska.

Press Interest in the Sea Otters Affected by the T/V Exxon Valdez Oil Spill: A Star is Born

Bayha, Keith - Chief, Division of Technical Support, U.S. Fish and Wildlife Service, Anchorage, Alaska. Chief of Sea Otter Operations for the Service in the oil spill response; Sea Otter Symposium Chairman.

1. Role of the U.S. Fish and Wildlife Service in the Sea Otter Rescue

2. Overall Capture Strategy

3. Development of the Release Strategy for Rehabilitated Sea Otters

Benz, Carl. - U.S. Fish and Wildlife Service, Ventura, California.

Sea Otter Capture Along the Kenai Peninsula, Alaska.

Bodkin, James L. - U.S. Fish and Wildlife Service, Galena, Alaska. Sea Raker capture and survey crew.

Evaluation of Sea Otter Rehabilitation After the T/VExxon Valdez Oil Spill, Prince William Sound, Alaska

Britton, Ron - U.S. Fish and Wildlife Service, Ventura, California. Roman E capture and survey crew; Adviser, Jakolof Pre-Release Facility and Prince William Sound radio-tracking team.

Sea Otter Capture Along the Kenai Peninsula, Alaska

Cramer, Dean W. - U.S. Fish and Wildlife Service, Anchorage, Alaska. Seward-based otter transport.

Transportation of Sea Otters to Rehabilitation Centers

Davis, Randall W. - International Wildlife Research, Texas A\&M University, Galveston. Senior Director, Sea Otter Rehabilitation Program.

1. History of the Sea Otter Rehabilitation Centers

2. Valdez Sea Otter Rehabilitation Center

3. Clinical Evaluation and Cleaning of Sea Otters Affected by the T/VExxon Valdez Oil Spill 
DeGange, Anthony R. - U.S. Fish and Wildlife Research, Anchorage, Alaska. Project leader, sea otter research.

1. Distribution and Relative Abundance of Sea Otters in South-central and Southwestern Alaska Before or at the Time of the T/VExxon Valdez Oil Spill

2. Procedures and Rationale for Marking Sea Otters Captured and Treated During the T/V Exxon Valdez Oil Spill

3. Distribution, Age, and Sex Composition of Sea Otter Carcasses Recovered During the Response to the T/VExxon Valdez Oil Spill

4. Identification of A Herpes-like Virus in Sea Otters During Rehabilitation After the T/V Exxon Valdez Oil Spill

Douglas, David C. - U.S. Fish and Wildlife Service, Anchorage, Alaska.

Distribution and Relative Abundance of Sea Otters in South-central and Southwestern Alaska Before or at the Time of the T/VExxon Valdez Oil Spill

Ferrante, Peter - (Monterey Bay Aquarium, Monterey, California) Seward Otter Rehabilitation Center, food procurement and preparation.

Food Procurement and Feeding of Sea Otters During the T/V Exxon Valdez Oil Spill

Foster, Jeff - 2033 South 304, Federal Way, Washington.

Sea Otter Capture Along the Kenai Peninsula, Alaska

Galt, Jerry A. - National Oceanic and Atmospheric Administration, Seattle, Washington.

Movement of Oil Spilled From the T/VExxon Valdez

Green, Anne M. - (Seward, Alaska). Veterinary technician, Valdez Otter Rehabilitation Center.

Perspectives of Veterinary Technicians

Gruber, Jody. - (U.S. Fish and Wildlife Service, Anchorage, Alaska). Aquarium transfer monitor.

Transfer and Placement of Nonreleasable Sea Otters in Aquariums Outside Alaska

Haebler, Romona J. - (U.S. Environmental Protection Agency, Narragansett, Rhode Island). Pathologist, Valdez Otter Rehabilitation Center.

1. Identification of a Herpes-like Virus in Sea Otters During Rehabilitation After the T/V Exxon Valdez Oil Spill

2. Pathological Examination and Collection of Toxicological Samples From Sea Otters

3. Determining Health of Rehabilitated Sea Otters Before Release

Hander, Ray F. - U.S. Fish and Wildlife Service, Kodiak National Wildlife Refuge, Kodiak, Alaska. F/V Ten Bears capture and survey crew.

Sea Otter Survey and Capture Effort, Kodiak Island Island Archipelago and Alaska Peninsula

Harris, R. Keith - D.V.M., U.S. Fish and Wildlife Service pathologist, Seward Otter Rehabilitation Center, (Department of Veterinary Pathology, Armed Forces Institute of Pathology, Washington D.C.).

Identification of A Herpes-like Virus in Sea Otters During Rehabilitation After the T/V Exxon Valdez Oil Spill

Hill, Ken - (Prince William Sound Veterinary Clinic, Cordova, Alaska) F/V Dancing Bear capture and survey crew; Valdez-based otter transport.

Field Test for Detecting Crude Oil on the Fur of Sea Otters 
Hogan, Mary E. - ICE trainer, Jakolof release strategy representative, aquarium transfer monitor (U.S. Fish and Wildlife Service, Anchorage, Alaska).

1. Transfer and Placement of Nonreleasable Sea Otters in Aquariums Outside Alaska

2. Development of the Release Strategy for Rehabilitated Sea Otters

Irons, David B. - U.S. Fish and Wildlife Service, Anchorage, Alaska.

Distribution and Relative Abundance of Sea Otters in South-central and Southwestern Alaska Before or at the Time of the T/V Exxon Valdez Oil Spill.

Kelly, Laura L. - (Northern Lights Animal Clinic, Anchorage, Alaska) veterinary technician, Valdez and Seward Otter Rehabilitation Centers.

Perspectives of Veterinary Technicians

Lensink, Calvin J. - (U.S. Fish and Wildlife Service, Anchorage, Alaska)

Distribution, Age, and Sex Composition of Sea Otter Carcasses Recovered During the

Response to the T/VExxon Valdez Oil Spill

Lipscomb, T. P. - (Department of Veterinary Pathology, Armed Forces Institute of Pathology, Washington, D.C.)

Identification of a Herpes-like Virus in Sea Otters During Rehabilitation After the T/V

Exxon Valdez Oil Spill

Loshbaugh, Shana F. - Documentation supervisor, Valdez Otter Rehabilitation Center.

Record Keeping for an Otter Rescue Center

Lowry, Lloyd F. - Marine Mammals Coordinator, Alaska Department of Fish and Game, Fairbanks, Alaska.

Alaska's Role in Mitigating the Effects of the T/V Exxon Valdez Oil Spill on Sea Otters

McBain, Judy - D.V.M., Valdez Otter Rehabilitation Center (San Diego, California).

Clinical Evaluation and Cleaning of Sea Otters Affected by the T/V Exxon Valdez Oil Spill

McCloskey, Thomas - Operations manager, Seward Otter Rehabilitation Center.

Seward Otter Rehabilitation Center

McCormick, Carolyn R. - D.V.M., Eagle River, Alaska. Valdez and Seward Otter Rehabilitation Centers; Jakolof implant surgeon.

1. Coat Gradation and Conditioning of Sea Otters at the Seward Otter Rehabilitation Center

2. Clinical Treatment and Rehabilitation of Sea Otters

3. Pup Nursery at the Seward Otter Rehabilitation Center

Michaelson, Nancy E. - Husbandry.

Behavioral Observations of Rehabilitating Sea Otters in Prerelease Holding Pens

Miller, Bonnie W. - Veterinary technician, Seward Otter Rehabilitation Center; implants and surgery.

Perspectives of Veterinary Technicians

Moeller, R. B. - (Department of Veterinary Pathology, Armed Forces Institute of Pathology, Washington, D.C.)

Identification of a Herpes-like Virus in Sea Otters During Rehabilitation After the $T / V$

Exxon Valdez Oil Spill

Monnett, Charles W. - Prince William Sound Science Center, Cordova, Alaska. Otter census, release and radio tagging in Prince William Sound.

Postrelease Monitoring of Radio-instrumented Sea Otters in Prince William Sound 
Monson, Daniel H. - (U.S. Fish and Wildlife Service, Anchorage, Alaska) F/V Ten Bears capture and survey crew, census, radio tracking.

Postrelease Monitoring of Radio-instrumented Sea Otters in Prince William Sound

Mulcahy, Dan - (U.S. Fish and Wildlife Service, Anchorage, Alaska)

Identification of A Herpes-like Virus in Sea Otters During Rehabilitation After the T/V

Exxon Valdez Oil Spill

Nichol, S.J. - Marine Animal Resource Center, Seattle, Washington.

Coat Gradation and Conditioning of Sea Otters at the Seward Otter Rehabilitation Center

Otten, Jill - (Point Defiance Zoo, Tacoma, Washington) Husbandry Supervisor, Seward Otter Rehabilitation Center.

Husbandry at the Seward Otter Rehabilitation Center

Payton, Debbie L. - (National Oceanic and Atmospheric Administration, Seattle, Washington) Tracking movement of spilled oil.

Movement of Oil Spilled From the T/V Exxon Valdez

Perrollaz, Darin C. - Marine Animal Resource Center, Seattle, Washington.

1. Coat Gradation and Conditioning of Sea Otters at the Seward Otter Rehabilitation Center

2. Analysis of Sea Otter Fur for Crude Oil Contamination

Pletcher, J. M. - (Department of Veterinary Pathology, Armed Forces Institute of Pathology, Washington, D.C.)

Identification of a Herpes-like Virus in Sea Otters During Rehabilitation After the T/V Exxon Valdez Oil Spill

Rappoport, Ann G. - U.S. Fish and Wildlife Service, Anchorage, Alaska. Acting zone coordinator, Homer and Seward.

Development of the Release Strategy for Rehabilitated Sea Otters

Rash, Jeffery A. - (Marine Animal Resource Center, Seattle, Washington) M/N Breaktime capture and survey crew; husbandry, Seward and Valdez Otter Rehabilitation Centers.

1. Coat Gradation and Conditioning of Sea Otters at the Seward Otter Rehabilitation Center

2. Analysis of Sea Otter Fur for Crude Oil Contamination

Redman, Linda - Jakolof Pre-Release Facility.

Homer Temporary Care Facility and Jakolof Pre-Release Facility

Robbins, Christopher M. - (U.S. Fish and Wildlife Service, Anchorage, Alaska)

Distribution and Relative Abundance of Sea Otters in South-central and Southwestern Alaska Before or at the Time of the T/VExxon Valdez Oil Spill

Rotterman, Lisa M. - (University of Minnesota, Department of Ecology and Behavioral Biology, Minneapolis) Radio tracking, census.

Postrelease Monitoring of Radio-instrumented Sea Otters in Prince William Sound

Sawyer, D.C. - D.V.M., (Michigan State University, East Lansing) Valdez Otter Rehabilitation Center.

Chemical Restraint and Anesthesia of Sea Otters Affected by the Oil Spill in Prince

William Sound, Alaska

Shane, Susan H. - (Friends of the Sea Otter, Carmel, California) Seward Otter Rehabilitation Center. Protecting Sea Otters From Oil Spills: Recommendations Based on the Alaska Experience 
Sharpe, Elizabeth - (U.S. Fish and Wildlife Service, Anchorage, Alaska) Roman E capture and survey crew; Jakolof Pre-Release Facility adviser; Kenai otter release site evaluator and monitor.

Sea Otter Release Site Selection and Postrelease Activities Along the Kenai Peninsula, Alaska

Spraker, Terry - D.V.M., (College of Veterinary Medicine, Colorado State University, Fort Collins) Consultant to Alaska Department of Fish and Game for diseases of seals and sea otters.

Hazards of Releasing Rehabilitated Animals With Emphasis on Sea Otters and the T/V Exxon Valdez Oil Spill

Stack, Cece - (Prince William Sound Science Center, Cordova, Alaska)

Postrelease Monitoring of Radio-instrumented Sea Otters in Prince William Sound

Stieglitz, Walter O. - Regional Director, U.S. Fish and Wildlife Service, Anchorage, Alaska. Represented the U.S. Department of the Interior for the Trustee Council, which was formed to direct the damage assessment of the T/V Exxon Valdez Oil Spill.

Opening Address: Boundaries of the Symposium

Styers, Anadale - (Wildlife Rapid Response Team, Inc., Longbranch, Washington)

Pup Nursery at the Seward Otter Rehabilitation Center

Styers, James - (Wildlife Rapid Response Team, Inc., Longbranch, Washington) Director, Seward Otter Rehabilitation Center.

1. Seward Otter Rehabilitation Center

2. History of the Sea Otter Rehabilitation Centers

Swarthout, David J. - Data Manager, Seward Otter Rehabilitation Center.

Animal Rehabilitation Center Data Base

Thomas, Jon F. - D.V.M., (Chester Valley Veterinary Hospital, Anchorage, Alaska) F/V Sea Raker capture and survey crew.

Postcapture Supportive Care of Oil-contaminated Sea Otters

Tuomi, Pamela A. - (College Village Animal Clinic, Anchorage, Alaska) Valdez and Seward Otter Rehabilitation centers, Jakolof Pre-Release Facility.

1. Husbandry at the Valdez Otter Rehabilitation Center

2. Clinical Treatment and Rehabilitation of Sea Otters-Pregnancy and Musculo-skeletal Problems

3. Field Test for Crude Oil on the Fur of Sea Otters

VanBlaricom, Glenn R. - (U.S. Fish and Wildlife Service, National Ecology Research Center, University of California, Santa Cruz) U.S. Fish and Wildlife Service representative at the Seward Otter Rehabilitation Center; Breaktime capture and survey crew.

Capture of Lightly Oiled Sea Otters for Rehabilitation: A Review of Decisions and Issues

Weltz, Fred - Skipper, F/V Dancing Bear.

Evaluation of Sea Otter Rehabilitation After the T/V Exxon Valdez Oil Spill, Prince William Sound, Alaska

Williams, Terrie M. - Director, Valdez Otter Rehabilitation Center.

1. Clinical Evaluation and Cleaning of Sea Otters Affected by the T/V Exxon Valdez Oil Spill

2. Valdez Otter Rehabilitation Center 
Williams, Thomas D. - D.V.M., (Monterey Bay Aquarium, Monterey, California) Valdez and Seward Otter Rehabilitation centers.

1. Blood Collection and Analysis During the T/VExxon Valdez Oil Spill

2. Clinical Treatment and Rehabilitation of Sea Otters-Gastro-intestinal and Respiratory Problems

3. Chemical Restraint and Anesthesia of Sea Otters Affected by the Oil Spill in Prince William Sound, Alaska

Wilson, Riley K. - D.V.M., (Arctic Animal Hospital, Anchorage, Alaska) Valdez Otter Rehabilitation Center.

1. Clinical Treatment and Rehabilitation of Sea Otters-Initial Treatment

2. Blood Collection and Analysis During the T/V Exxon Valdez Oil Spill

3. Clinical Evaluation and Cleaning of Sea Otters Affected by the T/V Exxon Valdez Oil Spill 


\section{Appendix C. List of Peer Reviewers.}

Vic Barnes - U.S. Fish and Wildlife Service, Kodiak, Alaska

Melissa Bates - Eagle River, Alaska

John Bauer - Department of Environmental Conservation, Valdez, Alaska

Keith Bayha - U.S. Fish and Wildlife Service, Anchorage, Alaska

Carl Benz - U.S. Fish and Wildlife Service, Ventura, California

Edward Bowlby - Kirkland, Washington

Debbie Brigman - Bering Sea Animal Clinic, Anchorage, Alaska

Ron Britton - U.S. Fish and Wildlife Service, Ventura, California

Douglas Burn - U.S. Fish and Wildlife Service, Anchorage, Alaska

Don Calkins - Alaska Department of Fish and Game, Anchorage

David Casper - University of California, Santa Cruz

Tony Chatto - U.S. Fish and Wildlife Service, Kodiak National Wildlife Refuge, Kodiak, Alaska

Pattie Chen - California Marine Mammal Center, Sausalito

Amy Christiansen - Homer, Alaska

Randall Davis - Exxon Inc., Anchorage, Alaska

Tom Early - U.S. Fish and Wildlife Service, Kanuti National Wildlife Refuge, Fairbanks, Alaska

Jim Estes - U.S. Fish and Wildlife Service, Santa Cruz, California

Charles Farwell - Monterey Bay Aquarium, Monterey, California

Al Fransman - Alaska Department of Fish and Game (retired), Soldotna, Alaska

Kathy Frost - Alaska Department of Fish and Game, Fairbanks

Gerald Garner - U.S. Fish and Wildlife Service, Anchorage, Alaska

Paul Gates - U.S. Department of the Interior, Office of Environmental Affairs, Anchorage, Alaska

Ron Goodwin - ESSO Resources Canada Ltd., Calgary, Alberta

Tag Gornall - Marine Animal Resource Center, Seattle, Washington

Elaine Hander - Sunnyvale, California

Robert Hardy - California Department of Fish and Game, Morro Bay

Chris Harvey-Clark - Animal Care Center, University of British Columbia, Vancouver

Ken Hill - Cordova, Alaska

Joe Hunt - Anchorage Times, Alaska

Lee Hunter - Canoga Park, California

Julie Hymer - Monterey Bay Aquarium, Monterey, California

William Innskeep - Walter Reed Army Institute for Research, Washington, D.C.

Ancel Johnson - U.S. Fish and Wildlife Service (retired), Hecla, South Dakota

Susan Klopfer - Aquajito Veterinary Hospital, Monterey, California

James Lake - U.S. Environmental Protection Agency, Narragansett, Rhode Island

Calvin Lensink - U.S. Fish and Wildlife Service, Anchorage, Alaska

Lloyd Lowry - Alaska Department of Fish and Game, Fairbanks

Carolyn McCormick - Eagle River, Alaska

Tom Monahan - Exxon Inc., Anchorage, Alaska

Chuck Monnett - Prince William Sound Science Center, Cordova, Alaska

Jon Nickles - U.S. Fish and Wildlife Service, Anchorage, Alaska

Onnalee Ollestad - Edmonds, Washington

Jill Otten - Point Defiance Zoo and Aquarium, Tacoma, Washington

Allan Rebar - Purdue University, West Lafayette, Indiana 
Richard Rech - Michigan State University, East Lansing

Christine Ribic - University of Washington, Seattle

Marianne Riedman - Monterey Bay Aquarium, Monterey, California

John Robinson - National Oceanic and Atmospheric Administration, Seattle, Washington

Jan Roletto - California Marine Mammal Center, Fort Cronkhite

Tom Royer - Institute of Marine Science, University of Alaska, Fairbanks

Rachel T. Saunders - Center for Marine Conservation, Pacific Grove, California

Karl Schneider - Alaska Department of Fish and Game, Anchorage

Susan Shane - Friends of the Sea Otter, Carmel, California

Elizabeth Sharpe - U.S. Fish and Wildlife Service, Anchorage, Alaska

Jim Sikarski - Michigan State University, East Lansing

Claudia Slater - Alaska Department of Fish and Game, Anchorage

Michael Slayter - Armed Forces Institute of Pathology, Washington, D.C.

Dawn Smith - California Marine Mammal Center, Sausalito

Harold Spaulding - Pet Emergency Treatment, Inc., Fairbanks, Alaska

Jim Styers - Wildlife Rapid Response Team Inc., Longbranch, Washington

David Swarthout - Homer, Alaska

Carol Thomas - Hartnell College, Salinas, California

Tammy Thomas - Anchorage, Alaska

Pamela Tuomi - Animal Hospital, Anchorage, Alaska

Glenn VanBlaricom - U.S. Fish and Wildlife Service, Santa Cruz, California

Fred Weltz - Cordova, Alaska

Rob Whorter - Bureau of Land Management, Anchorage, Alaska

Thomas D. Williams - Monterey Bay Aquarium, Monterey, California

Terrie M. Williams - NOSC Hawaii Laboratories, Kailua, Hawaii

Riley Wilson - Arctic Animal Hospital, Anchorage, Alaska

Denny Zwiefelhofer - U.S. Fish and Wildlife Service, Kodiak, Alaska 


\section{Appendix D. Registered Participants.}

Tom Albert

Department of Wildlife Management

Barrow, Alaska 99723

Jack Ames

California Department of Fish and Game 2201 Garden Road

Monterey, California 93940

Jill Anthony

Institute of Marine Science

University of Alaska

Fairbanks, Alaska 99775

John and Nikki Anton

2531 Tradewind Drive

Anchorage, Alaska 99516

Clyde Armitstead

19432 First Street

Eagle River, Alaska 99577

Knut Atkinson

British Columbia Wildlife Branch

2569 Kenworth Road

Nanaimo, British Columbia V9T 4P7

Michael Baffrey

949 E. 36th Avenue

Anchorage, Alaska 99508

Brenda Ballachey

U.S. Fish and Wildlife Service

1011 E. Tudor Road

Anchorage, Alaska 99503

Mark Bartholomew

2820 Pelican Drive

Anchorage, Alaska 99515
Keith Bayha

U.S. Fish and Wildlife Service

1011 E. Tudor Road

Anchorage, Alaska 99503

Carl Benz

U.S. Fish and Wildlife Service

2140 Eastman Avenue

Ventura, California 93003

Pamela Bergmann

1689 C Street, Room 119

Anchorage, Alaska 99501-5126

David Berrey

3267 Laurance Road

North Pole, Alaska 99705

Jim Blake

2444 Galewood Street

Anchorage, Alaska 99508

John Blake

University of Alaska

Fairbanks, Alaska 99775

Jim Bodkin

U.S. Fish and Wildlife Service

P.O. Box 237

Galena, Alaska 99714

G. Thomas Braznell

ALFA Products Co.

5990 S.W. Ninth Street

Fort Lauderdale, Florida 33317

Ron Britton

U.S. Fish and Wildlife Service

2140 Eastman Avenue

Ventura, California 93003 
Doug Burn

U.S. Fish and Wildlife Service

1011 E. Tudor Road

Anchorage, Alaska 99503

Bobby Candopolus

P.O. Box 3458

Palmer, Alaska 99643

Mary Carr

HC 31, Box 5150

Wasilla, Alaska 99687

Amy Christiansen

P.O. Box 1804

Homer, Alaska 99603

Linda Comerci

U.S. Environmental Protection Agency

437 E. Street, Suite 301

Anchorage, Alaska 99501

Dean Cramer

1903 Stonegate Circle

Anchorage, Alaska 99515

Steve Curtis

P.O. Box 4231

Homer, Alaska 99603

Randy Davis

Department of Marine Biology

Texas A\&M University

Galveston, Texas 77553

Anthony DeGange

U.S. Fish and Wildlife Service

1011 E. Tudor Road

Anchorage, Alaska 99503

Angela Doroff

U.S. Fish and Wildlife Service

$1011 \mathrm{E}$. Tudor Road

Anchorage, Alaska 99503

David Duam

P.O. Box 81414

College, Alaska 99708

ENSR Consulting and Engineering

750 W. 2nd, Suite 100

Anchorage, Alaska 99501
Peter Ferrante

Monterey Bay Aquarium

886 Cannery Row

Monterey, California 93940

Jeremy Fitz-Gibbon

P.O. Box 3232

Vancouver, British Columbia V6B 3 X8

Jeff Foster

2033 South 304

Federal Way, Washington 78003

Darryl Fowler

1243 Crescent

Anchorage, Alaska 99508

Al Franzman

P.O. Box 666

Soldotna, Alaska 99669

Jerry Galt

7600 Sand Point Way, N.E.

Seattle, Washington 98115

Rowan Gould

U.S. Fish and Wildlife Service

1011 E. Tudor Road

Anchorage, Alaska 99503

Glen Grady

3315 Fairbanks

Anchorage, Alaska 99503

Linsay Graham

\#705 1483 Lamey's Mill Road

Vancouver, British Columbia V6H $3 Y 7$

Angie Grassano

HC78 Box 2366

Chugiak, Alaska 99567

Anne Green

P.O. Box 972

Seward, Alaska 99664

Paula Groundwater

HC31, Box 5150

Wasilla, Alaska 99687 
Romona Haebler

17 Anna Olivo

Narragansett, Rhode Island 02882

Ray Hander

U.S. Fish and Wildlife Service

Kodiak National Wildlife Refuge

1390 Buskin River Road

Kodiak, Alaska 99615

Bob Hardy

California Department of Fish and Game

213 Beach Street

Morro Bay, California 93442

Craig Harms

P.O. Box 770528

Eagle River, Alaska 99577

Keith Harris

Armed Forces Institute of Pathology

Department of Veterinary Pathology

Washington, D.C. 20306

Chris Harvey-Clark

Animal Care Center

6199 South Campus Road

Vancouver, British Columbia V6T 1W5

Larry Heckart

1510 Woo Blvd.

Anchorage, Alaska 99515

Ken Hill

P.O. Box 1290

Cordova, Alaska 99574

Tanya Holonko

P.O. Box 92057

Anchorage, Alaska 99509

David Huff

P.O. Box 3232

Vancouver, British Columbia V6B 3X8

Julie Hymer

Monterey Bay Aquarium

886 Cannery Row

Monterey, California 93940
David Irons

U.S. Fish and Wildlife Service

1011 E. Tudor Road

Anchorage, Alaska 99503

Laura Kelly

1061 North Leatherleaf Loop

Wasilla, Alaska 99687

Ed Klinkhart

11101 Snowline Drive

Anchorage, Alaska 99516

Rebecca Knight

P.O. Box 671974

Chugiak, Alaska 99567

Jennifer Kormendy

U.S. Fish and Wildlife Service

1011 E. Tudor Road

Anchorage, Alaska 99503

Jack Lentfer

P.O. Box 2617

Homer, Alaska 99603

Doug and Shana Loshbaugh

HCR 64770 Pitzman Avenue

Homer, Alaska 99603

Lloyd Lowry

Alaska Department of Fish and Game

1300 College Road

Fairbanks, Alaska 99701

Cindy Lowry

P.O. Box 104432

Anchorage, Alaska 99510

Jon Luoma

3910 First Avenue South

Minneapolis, Minnesota 55409

Al Manville

1244 19th Street N.W.

Washington, D.C. 20036

Marine Mammals Commmision 1825 Connecticut Avenue, N.W. Washington, D.C. 20009 
Jake Matulka

3641 Sandvik Street

Fairbanks, Alaska 99709

Jim McBain

Sea World of California

1720 South Shores Road

San Diego, California 92109

Tom McCloskey

18 Anacapa Street

Santa Barbara, California 93101

Carolyn McCormick

15536 Husky Street

Eagle River, Alaska 99577

Liza McCracken

1031 W. 4th Avenue, Suite 200

Anchorage, Alaska 99501

Rosa Meehan

U.S. Fish and Wildlife Service

1011 E. Tudor Road

Anchorage, Alaska 99503

Mary Miceli

P.O. Box 671289

Chugiak, Alaska 99567

Nancy Michaelson

HC01, Box 6916F

Palmer, Alaska 99645

Bonnie Miller

1161 Hastings

Traverse City, Michigan 49684

John Monarch

P.O. Box 7924

San Francisco, California 94120

Dan Monson

U.S. Fish and Wildlife Service 4257 Charing Cross Road

Anchorage, Alaska 99504

Kate Montgomery

1835 South Bragaw MS 578

Anchorage, Alaska 99512
Moss Landing Marine Laboratories

P.O. Box 450

Moss Landing, California 95039

Jon Nickles

U.S. Fish and Wildlife Service

1011 E. Tudor Road

Anchorage, Alaska 99503

Tina Odenbaugh

U.S. Fish and Wildlife Service

1011 E. Tudor Road

Anchorage, Alaska 99503

Onnolee Ollestad

P.O. Box 3166

Seward, Alaska 99664

Miriam Olsen

P.O. Box 1073

Seward, Alaska 99664

Bill Ostrand

P.O. Box 129

Girdwood, Alaska 99587

Jill Otten

2810 106th Street Court, N.W.

Gil Harbor, Washington 98335

Larry Pank

U.S. Fish and Wildlife Service

1011 E. Tudor Road

Anchorage, Alaska 99503

Pamela Pope

P.O. Box 196612

Anchorage, Alaska 99519

Ann Rappoport

U.S. Fish and Wildlife Service 1011 E. Tudor Road

Anchorage, Alaska 99503

Jeffery Rash

8332 Mary Avenue, N.W.

Seattle, Washington 98117

Linda Redman

P.O. Box 2731

Homer, Alaska 99603 
James Roderick

P.O. Box 916

Homer, Alaska 99603

Lisa M. Rotterman

University of Minnesota

318 Church Street, S. E.

Minneapolis, Minnesota 55455

Lloyd Rudd

P.O. Box 871864

Wasilla, Alaska 99687

Susie Shane

P.O. Box 221220

Carmel, California 93922

Elizabeth Sharpe

U.S. Fish and Wildlife Service

1011 E. Tudor Road

Anchorage, Alaska 99503

Dan Shelden

261 McCarrey, \#16B

Anchorage, Alaska 99508

Sherry Shiesl

1700 Kodiak Street

Anchorage, Alaska 99504

Casey and Kiki Smith

P.O. Box 991

Girdwood, Alaska 99587

Harold Spaulding

7005 Whitehall

Anchorage, Alaska 99502

Terry Spraker

Colorado State University

Fort Collins, Colorado 80523

Karen St. Jean

P.O. Box 141215

Anchorage, Alaska 99514

Wells Stephensen

U.S. Fish and Wildlife Service

1011 E. Tudor Road

Anchorage, Alaska 99503
Ruthie Stough

4030 Cosson

Anchorage, Alaska 99509

Jim and Dale Styers

5601 N. 37th Street, \#WW-2

Tacoma, Washington 98407

Dave Swarthout

P.O. Box 671

Homer, Alaska 99603

Jon Thomas

1571 Muldoon Road

Anchorage, Alaska 99504

Tami Thomas

P.O. Box 874311

Wasilla, Alaska 99687

Robert Truett

P.O. Box 74174

Fairbanks, Alaska 99707

Jack Tuomi

11650 Old Seward Highway

Anchorage, Alaska 99515

Pam Tuomi

2036 E. Northern Lights

Anchorage, Alaska 99508

Glenn VanBlaricom

U.S. Fish and Wildlife Service

272 Applied Sciences Building

University of California

Santa Cruz, California 95064

Kirk Vasey

P.O. Box 3095

Homer, Alaska 99603

Clyde Vicary

2158 Sunrise

Anchorage, Alaska 99508

Janet Warburten

2933 Lily Street, \#2

Anchorage, Alaska 99708 
Fred Weltz

P.O. Box 982

Cordova, Alaska 99574

Westy

P.O. Box HC 477

Gakona, Alaska 99586

Jan White

699 Potter Street

Berkley, California 94710

Dudley Wigdahl

Sea World of Texas

10500 Sea World Drive

San Antonio, Texas 78251

Barbara Wilkley

8120 Rabbit Creek Road

Anchorage, Alaska 99516
Terrie Williams

P.O. Box 997, Code 511

Kailua, Hawaii 96734

Tom Williams

Monterey Bay Aquarium

886 Cannery Row

Monterey, California 93940

Frank Wilson

207 Rhododendron

Black Mountain, North Carolina 28711

Riley and Cindy Wilson

2101 Tudor Hills Drive

Anchorage, Alaska 99507

Dave Wiswar

101 12th Avenue, Box 20

Fairbanks, Alaska 99701

Paul Wunnicke

4540 Snowcup Circle

Anchorage, Alaska 99516 

NOTE: The mention of trade names does not constitute endorsement or recommendation for use by the Federal Government. 

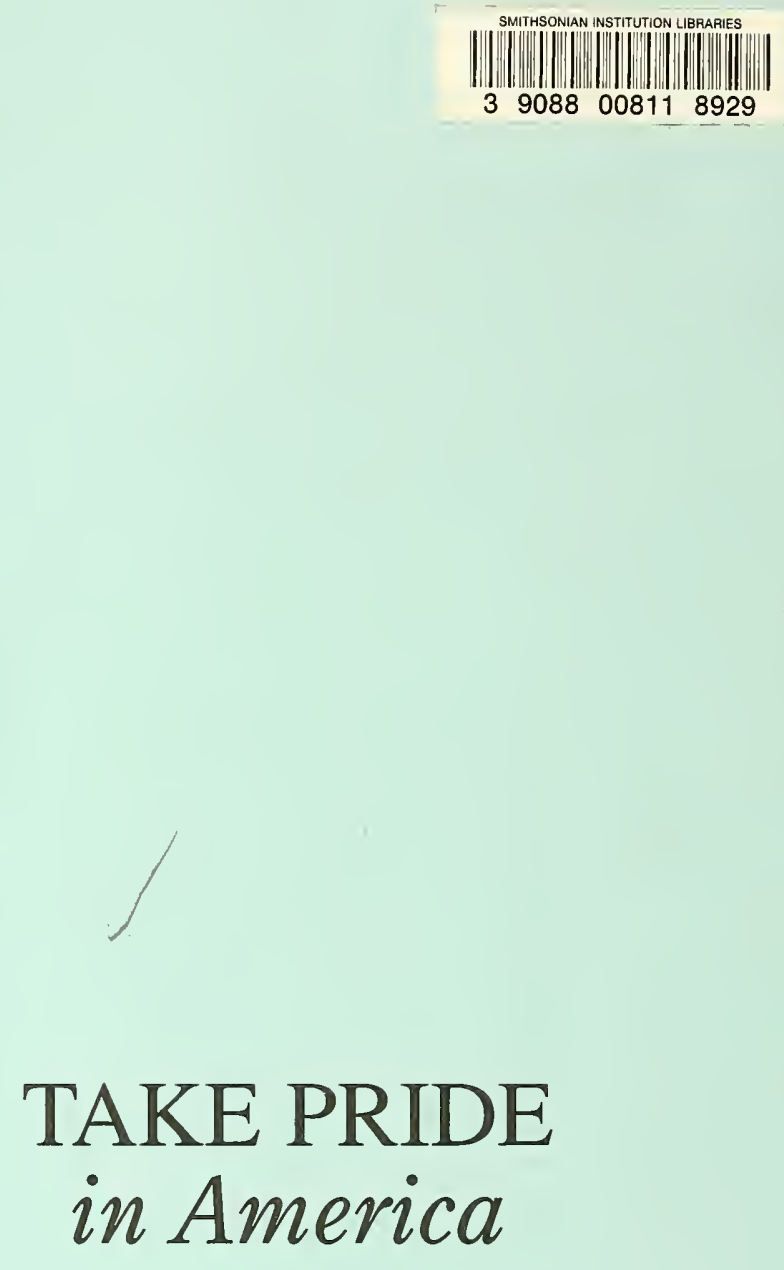

\section{U.S. DEPARTMENT OF THE INTERIOR FISH AND WILDLIFE SERVICE}

As the Nation's principal conservation agency, the Department of the Interior has responsibility for most of our nationally owned public lands and natural resources. This includes fostering the wisest use of our land and water resources, protecting our fish and wildlife, preserving the environmental and cultural values of our national parks and historical places, and providing for the enjoyment of life through outdoor recreation. The Department assesses our energy and mineral resources and works to assure that their development is in the best interests of all our people. The Department also has a major responsibility for American Indian reservation communities and for people who live in island territories under U.S. administration. 